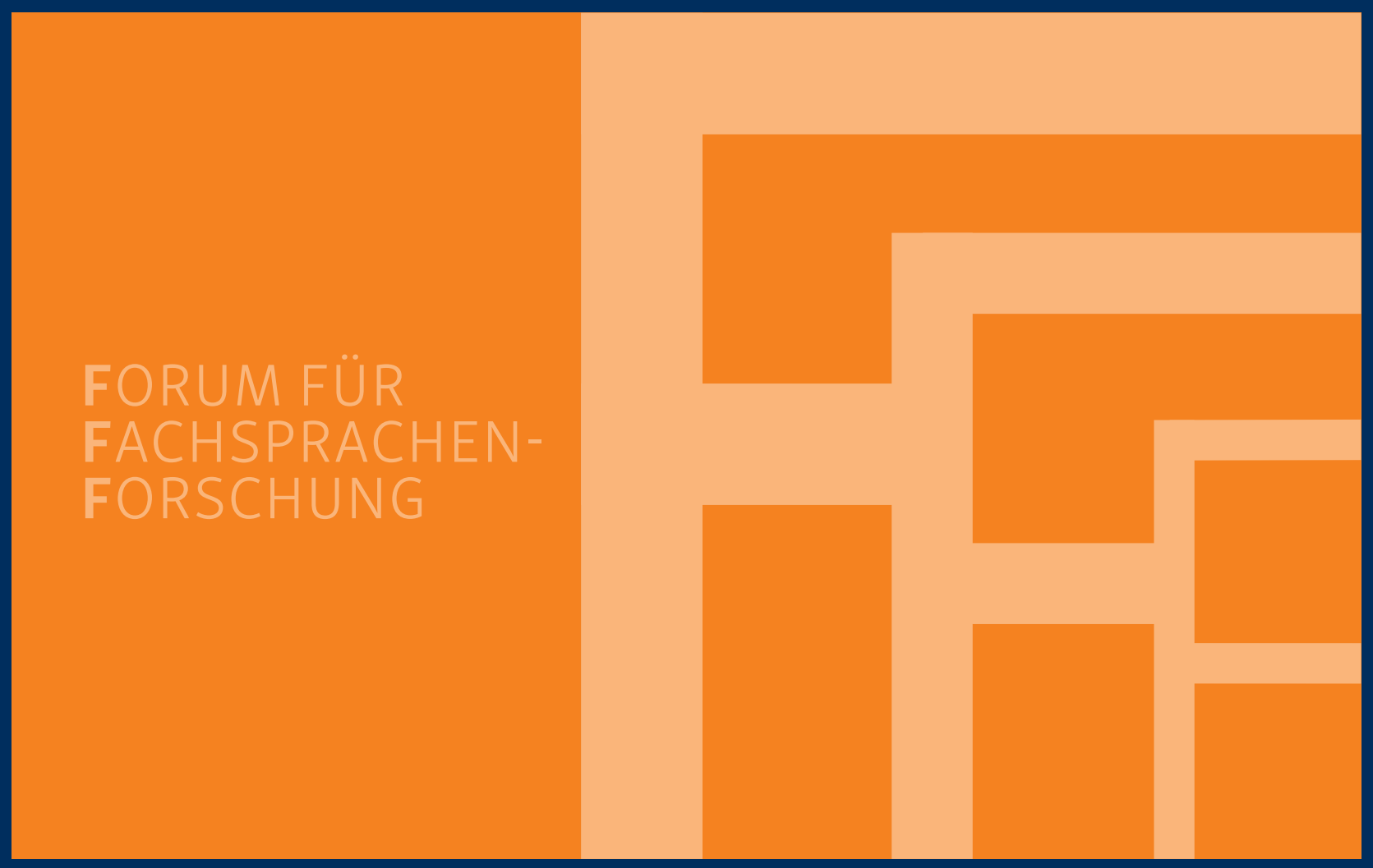

\title{
Semiotische Effizienz
} interfachlicher

Sprache-Bild-Textsorten

Schreibprozesse bei Pflichtenheften technischer Ausschreibungen

Alexander Holste 
Alexander Holste

Semiotische Effizienz interfachlicher Sprache-Bild-Textsorten 


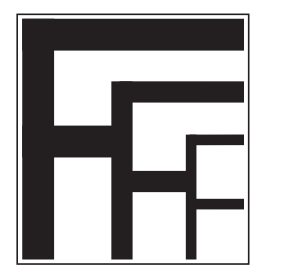

Forum für Fachsprachen-Forschung Hartwig Kalverkämper (Hg.)

in Zusammenarbeit mit Klaus-Dieter Baumann

Band 158 
Alexander Holste

\section{Semiotische Effizienz interfachlicher Sprache-Bild-Textsorten}

Schreibprozesse bei Pflichtenheften

technischer Ausschreibungen 


\section{(c) (1) (8) $\Theta$ \\ BY NC ND CC-BY-NC-ND}

ISBN 978-3-7329-9354-3

ISSN 0939-8945

(C) Frank \& Timme GmbH Verlag für wissenschaftliche Literatur Berlin 2019. Alle Rechte vorbehalten.

Das Werk einschließlich aller Teile ist urheberrechtlich geschützt. Jede Verwertung außerhalb der engen Grenzen des Urheberrechtsgesetzes ist ohne Zustimmung des Verlags unzulässig und strafbar. Das gilt insbesondere für Vervielfältigungen, Übersetzungen,

Mikroverfilmungen und die Einspeicherung und Verarbeitung in elektronischen Systemen.

Herstellung durch Frank \& Timme GmbH, Wittelsbacherstraße 27a, 10707 Berlin.

Printed in Germany.

Gedruckt auf säurefreiem, alterungsbeständigem Papier.

www.frank-timme.de

Zugl. Diss. Universität Duisburg-Essen, 2019 


\section{Inhaltsverzeichnis}

Abbildungsverzeichnis $\quad$ X

$\begin{array}{ll}\text { Tabellenverzeichnis } & \text { XIV }\end{array}$

$\begin{array}{ll}\text { Vorwort } & \text { XVII }\end{array}$

1 Einleitung 1

1.1 Zentrale Forschungsfrage und deren Relevanz 3

1.2 Praktisches Problem der erforschten Domäne und dessen Relevanz 6

1.3 Aufbau der Arbeit 12

2 Konzeption des Modells semiotischer Effizienz 25

2.1 Kommunikative Effizienz 28

2.1.1 Das Modell kommunikativer Effizienz 28

2.1.2 Erweiterungsmöglichkeiten für das

Modell kommunikativer Effizienz 33

2.1.3 Drei Modifikationsthesen zum

Modell kommunikativer Effizienz $\quad 38$

2.2 Kapazität der Fachkommunikanten als Textsortenkonventionen

und Erwartungen $\quad 40$

2.2.1 Der Einfluss gültiger Textsortenkonventionen auf die

Kommunikationsfähigkeit der Kommunikanten 41

2.2.2 Auflösung der Modellkategorie ,Kommunikationsbereitschaft zugunsten von Textsortenkonventionen und

fachkommunikativen Teilkompetenzen $\quad 54$

2.3 Komplexität des Kommunikats als multimodale Textsorten 64

2.3.1 Sprache-Bild-Textsorten und Textdesign 66

2.3.2 Eigenschaften von Sprache-Bild-Texten: Ähnlichkeit materieller (fachlicher) Bilder, Diagrammatik rekonfigurierender

Diagramme und Bildlichkeit von Metaphern 
2.3.3 Salienztheorie und Annahmen

zu Top-down-Rezeptionsprozessen $\quad 89$

2.4 Kontext 92

2.4.1 Interfachlichkeit in Domänen-, Organisationen- und Projektkommunikation $\quad 94$

2.4.2 Skalen interfachlicher Kommunikation 105

2.4.3 Asymmetrische Formularkommunikation zwischen Prozipienten 109

2.5 Zwischenfazit: Modell semiotischer Effizienz 114

3 Integriertes Analyseraster für interfachliche Sprache-Bild-Textsorten 119

$\begin{array}{lll}3.1 & \text { Textdesign } & 121\end{array}$

3.1.1 Design: Visuelle Variablen von Sprache-Bild-Texten 126

3.1.2 Layout: Positionierung in der Fläche und Rahmung 131

3.2 Funktionsstruktur 133

3.2.1 Bildakte einer multimodalen Funktionsstruktur 134

3.2.2 Textfunktionen-Typologie 142

3.3 Themenstruktur 150

3.3.1 Raumdeiktische Mittel zur Spezifikation von Technikkommunikation 152

3.3.2 Multimodale Mittel horizontaler Themenstruktur 157

3.3.3 Multimodale Mittel vertikal-modularisierter Themenstruktur 161

3.4 Logisch-semantische Sprache-Bild-Relationen 167

3.4.1 Konkurrenz (concurrence) 171

3.4.2 Erweiterung (extension) 172

3.4.3 Komplementarität (complement) 173

3.4.4 Verbesserung (enhancement) 173

3.4.5 Elaboration (elaboration) 175

3.5 Intertextualität: Verfahrensbedingte Textsortennetze 176 
3.5.1 Text-Text-Relationen in Gesetzgebungsverfahren vs.

Wissensbearbeitung in verwaltungsinstitutionsspezifischen Verfahren

3.5.2 Fachtextsortennetze in technisch-juristischen $\begin{array}{ll}\text { Harmonisierungsprozessen } & 180\end{array}$

3.6 Verknüpfungen zwischen Textgestaltung und Kontext 185

4 Datenerhebung, Korpus und Beschreibung des Forschungsfeldes

4.1 Feldzugang und Erhebungsmethodik

4.1.1 Teilnehmende Beobachtungen 195

4.1.2 Qualitative Interviews

4.1.3 Triangulation der Beobachtungs-, Interviewauswertung sowie der Analyse von Sprache-Bild-Textsortenexemplaren 198

4.2 Zusammensetzung und Umfang des Korpus

4.2.1 Umfang des Korpus

4.2.2 Das Textsortennetz Ausschreibungsverfahren als Grundlage für die Zusammensetzung des Korpus

4.2.3 Verdingungsunterlagen der Auftraggeber 214

4.2.4 Optimierungsvorschläge (OV) des Bieters 220

4.2.5 Pflichtenhefte des Bieters 222

4.2.6 Fahrpläne des Bieters 226

4.3 Beschreibung weiteren Materials und des interfachlichen Kontextes 228

4.3.1 Beschreibung der interfachlichen Projektstrukturen als Teil der erforschten Domäne und Organisationen 228

4.3.2 Durchgeführte Beobachtungen von gemeinsamen Textüberarbeitungen 240

4.3.3 Durchgeführte Interviews und Befragungen 241

4.4 Auswahl an Textsortenexemplaren für die Textanalyse 242

4.5 Überblick über das Textkorpus und weitere Material für die Analyse 245

4.5.1 Verdingungsunterlagen der Auftraggeber 246

4.5.2 Optimierungsvorschläge (OV) des Bieters 247 
4.5.3 Pflichtenhefte und Zeichnungen des Bieters

4.5.4 Fahrpläne des Bieters

4.5.5 Durchgeführte Beobachtungen von gemeinsamen Textüberarbeitungen

4.5.6 Durchgeführte Interviews und Befragungen

4.5.7 Praktikumszeugnisse, Genehmigungen und Vertraulichkeitserklärung

4.5.8 Weiteres

\section{Exemplarische Analyse ausgewählter Sprache-Bild-Textsorten}

5.1 Textsorte Optimierungsvorschlag (OV) 252

5.1.1 Textdesign 252

5.1.2 Funktionsstruktur 262

5.1.3 Themenstruktur 270

5.1.4 Logisch-semantische Sprache-Bild-Relationen 283

5.1.5 Verknüpfungen zwischen Textgestaltung und Kontext 288

5.2 Textsortenvarianten Lastenheftvordruck (LHV) und Pflichtenheft (PH) 291

5.2.1 Textdesign 294

5.2.2 Funktionsstruktur 314

5.2.3 Themenstruktur 324

5.2.4 Logisch-semantische Sprache-Bild-Relationen 349

5.2.5 Verknüpfungen zwischen Textgestaltung und Kontext 355

5.3 Überblick über Varianten der Textsorte Fahrplan 357

5.4 Zwischenfazit zur Textsortenanalyse 363

5.4.0 Intertextualität 363

5.4.1 Textdesign 364

5.4.2 Themenstruktur 367

5.4.3 Funktionsstruktur 369

5.4.4 Logisch-semantische Sprache-Bild-Relationen 371

5.4.5 Verknüpfungen zwischen Textgestaltung und Kontext 373 
$6 \mathrm{Zu}$ Aushandlungen semiotischer Effizienz bei Textüberarbeitungsprozessen

6.1 Die Kapazität der Kommunikanten 379

6.1.1 Beispiele zur Überarbeitung von Fahrplanvarianten 380

6.1.2 Beispiele zur Überarbeitung von Optimierungsvorschlägen 382

6.1.3 Beispiele zur Überarbeitung von Pflichtenheften 386

6.1.4 Zwischenfazit zur Interpretation von Kommunikantenkapazität

6.2 Semiotische Effizienz: Verhältnis zwischen Komplexität und Kapazität

7.1 Fazit

7.1.1 These 1

7.1.2 These 2

7.1.3 These 3

7.2 Ausblick

7.3 Empfehlungen zu semiotischer Effizienz

7.3.1 Optimierungsansätze für die Empfehlungen der BAG SPNV

7.3.2 Modularisierung von Lasten- und Pflichtenheften nach Funktionsdesign

Literaturverzeichnis

Normen und Regelwerke

Rechtsquellen 


\section{Abbildungsverzeichnis}

Abbildung 2-1: Elemente fachlicher Sprachkultiviertheit

(ENGBERG/JANICH, 2007, S. 223).

Abbildung 2-2: The page as a site of cooperation and integration of distinct semiotic modes (BATEMAN, 2008, S. 106).

Abbildung 2-3: Gleisvorfeld, Christof Meckel (1910 in SCHMIDT, 2006, S. 277).

Abbildung 2-4: Überfahrrampe für Rollstühle bei einem Doppelstockwagen JANICKI/REINHARD, 2013, S. 482).

Abbildung 2-5: Behindertengerechtes WC im Doppelstock-Steuerwagen (JANICKI/REINHARD, 2013, S. 456).

Abbildung 2-6: Einstiegssituation Mehrzweckraum (BAG SPNV, ${ }^{3} 2016$, S. 52).

Abbildung 2-7: Zugkraft-Widerstandskraft-Geschwindigkeitsdiagramm (JANICKI/REINHARD, 2013, S. 57).

Abbildung 2-8: Typen der Kommunikation zwischen Experten und Laien (ROELCKE, 2014, S. 164).

Abbildung 2-9: Kontextmodell des Aachener Forschungsansatzes (JAKOBS, 2011b, S. 82).

Abbildung 2-10: Dimensionen einer, gemeinsamen Sprache“ (JANICH/ZAKHAROVA, 2014, S. 23).

Abbildung 2-11: Fachsprachlichkeits- und Abstraktionsgrad aufgeführter Texte (OSTAPENKO, 2009, S. 237).

Abbildung 2-12: Kontextmodell zu B2G-Ausschreibungsverfahren (eigene Darstellung in Anlehnung an ADAMZIK, ${ }^{2} 2016$; KALVERKÄMPER, 1989; u. a.). 
Abbildung 3-1: Level of the retinal variables (BERTIN, ${ }^{22010, ~ S . ~ 96) . ~}$

Abbildung 3-2: Zusammenfassung zur Analysekategorie ,Textdesign“ (eigene Darstellung in Anlehnung an KRESS/VAN LEEUWEN, ${ }^{2} 2006$; BERTIN, ${ }^{2} 2010$; u. a).

Abbildung 3-3: Kommissive Textsorten (ROLF, 1993, S. 275).

Abbildung 3-4: Deiktische und intrinsische Perspektive

(DÜRR/SCHLOBINSKI, ${ }^{3} 2006$, S. 192).

Abbildung 3-5: Projektionsmodell mit schräger Projektionsebene und einem Gegenstand in beliebiger Lage zur Projektionsebene $\left(\beta>90^{\circ}\right)($ DIN EN ISO 5456-4, 2002, S. 9).

Abbildung 3-6: Toilettenzugänge für Rollstühle (TSI PRM, 2008, S. 119). 159

Abbildung 3-7: Schematische Darstellung der Struktur argumentativer Themenentfaltung (BRINKER/CÖLFEN/ PAPPERT, ${ }^{9} 2018$, S. 79).

Abbildung 3-8: Towards a framework of image-language relations in the construction of ideational meaning (UNSWORTH, 2007, S. 1175).

Abbildung 3-9: Overview of visual-verbal linking (VAN LEEUWEN, 2005a, S. 230).

Abbildung 3-10: Zusammenfassung zur Analysekategorie ,Logischsemantische Sprache-Bild-Relationen“ (eigene Darstellung in Anlehnung an UNSWORTH, 2007; u. a.). 175

Abbildung 3-11: Textsortennetz im Kommunikationsrahmen ,Harmonisierung im Bereich des Bauwesens (OSTAPENKO, 2009, S. 235).

Abbildung 4-1: Interfachliche Projektzusammensetzung bei Organisationen in der Domäne zu SPNVAusschreibungsverfahren. 
Abbildung 5-1: Beispiel eines prototypischen OV (eigene Darstellung basierend auf OV 2).

$\begin{array}{ll}\text { Abbildung 5-2: } & \text { Diagramm } 1 \text { (OV 7). }\end{array}$

Abbildung 5-3: Diagramm 2 (OV 7). 259

Abbildung 5-4: Struktur der Funktionsmodule (in Grün). 266

Abbildung 5-5: Themenstruktur mit Themenmodulen (Orange) im

Verhältnis zur Funktionsstruktur

(Grün; eigene Darstellung).

Abbildung 5-6: Analyse von OV 6 (Aus 1) entsprechend dem Schema argumentativer Themenentfaltung (eigene Darstellung). 278

Abbildung 5-7: Hyponym-Hyperonym-Relationen im Fachtextwortschatz (eigene Darstellung).

Abbildung 5-8: Erste Seite von Lastenheftvordruck 1 in Ansicht der digitalen Schreibumgebung des Bieters.

Abbildung 5-9: Anonymisierte erste Seite von Pflichtenheft 1 in Ansicht der digitalen Schreibumgebung für die Textüberarbeitung durch den Bieter.

Abbildung 5-10: Modellformular NedTrain (ABDULLAH/ HENZE, 2007, S. 193).

Abbildung 5-11: Anonymisiertes Pflichtenheft 2 in der ausgedruckten Ansicht.

Abbildung 5-12: Lastenheftvordruck, Schriftmodul Toilettenräume (LHV 1).

Abbildung 5-13: Pflichtenheft, Schriftmodul Toilettenräume (PH 1). 308

Abbildung 5-14: Vertikale Bildmodul-Gliederung (in Gelb), horizontale Formular-Gliederung mit Frage-AntwortmöglichkeitAntwort-Struktur (in Grün) im Themenmodul Toilettenräume ( $\mathrm{PH} 2)$.

Abbildung 5-15: Beispiel für zwei Subordinationsebenen (PH 1). 
Abbildung 5-16: CAD-Seitenansicht aus STADLER (o. J.c).

Abbildung 5-17: Themenentfaltung als Anordnung der Themenmodule in Pflichtenheft 1 (eigene Darstellung in Anlehnung an Tabelle 5-2).

Abbildung 5-18: Ausschnitt aus dem Grundriss in Pflichtenheft 3.

Abbildung 5-19: Zuordnung des Fachtextwortschatzes in SPNV-

Pflichtenheften zu beteiligten Organisationsbereichen (eigene Darstellung).

Abbildung 5-20: Zwangspunkte für die Konstruktion eines Taktfahrplans (PACHL, ${ }^{7} 2013$, S. 198).

Abbildung 7-1: Festlegungskategorien für jede Funktionale Einheit (MUTHIG/SCHÄFLEIN-ARMBRUSTER, 22014, S. 51). 


\section{Tabellenverzeichnis}

Tabelle 2-1: $\quad$ Elemente effizienter Kommunikation im Überblick (in Anlehnung an ROELCKE, 2002a, S. 70).

Tabelle 2-2: $\quad$ Modell semiotischer Effizienz unter Berücksichtigung einer Norm-/Textsorten-Ebene (eigene Darstellung in Anlehnung an BRINKER/CÖLFEN/PAPPERT, ${ }^{9} 2018$; u. a.).

Tabelle 3-1: Zusammenfassung zur Analysekategorie ,Funktionsstruktur' (eigene Darstellung).

Tabelle 3-2: $\quad$ Zusammenfassung zur Analysekategorie ,Themenstruktur' (eigene Darstellung).

Tabelle 3-3: Zusammenfassung zur Analysekategorie ,Verfahrensbedingte Textvernetzung' (eigene Darstellung).

Tabelle 3-4: Zusammenfassung der Analysekategorie, Verknüpfung von Textinterna und Textexterna' (eigene Darstellung).

Tabelle 4-1: $\quad$ Übersicht über Genehmigungen und weitere Dokumente des Feldzugangs.

Tabelle 4-2: Quantitative Angaben zum Gesamttextkorpus.

Tabelle 4-3: $\quad$ Gegenüberstellung von verfahrensbedingten

Textfunktionen am Beispiel von Texten in

SPNV-Ausschreibungs-verfahren.

Tabelle 4-4: Übersicht und quantitative Angaben zum Teilkorpus

Verdingungsunterlagen (eigene Darstellung).

Tabelle 4-5: $\quad$ Übersicht über das Teilkorpus Verdingungsunterlagen (eigene Darstellung).

Tabelle 4-6: $\quad$ Übersicht und quantitative Angaben zum Teilkorpus Optimierungsvorschläge (eigene Darstellung) 
Tabelle 4-7: $\quad$ Übersicht über vorliegende Optimierungsvorschläge (eigene Darstellung).

Tabelle 4-8: $\quad$ Übersicht und quantitative Angaben zum Teilkorpus

Pflichtenhefte (eigene Darstellung).

Tabelle 4-9: $\quad$ Übersicht über vorliegende Pflichtenhefte

(eigene Darstellung).

Tabelle 4-10: $\quad$ Übersicht und quantitative Angaben zum Teilkorpus

Fahrpläne (eigene Darstellung).

Tabelle 4-11: $\quad$ Übersicht Beobachtungsprotokolle (eigene Darstellung). 240

Tabelle 4-12: $\quad$ Übersicht über Interviews und Befragungen (eigene Darstellung).

Tabelle 4-13: Übersicht über ausgewählte Textsortenexemplare für die

Textanalyse (eigene Darstellung).

Tabelle 5-1: $\quad$ Übersicht über OV-Themen und deren Zuordnung zu

Organisationsbereichen (eigene Darstellung).

Tabelle 5-2: $\quad$ Gegenüberstellung der Kapitelstrukturen in LHV 1, LHV 2, LHV 3 und der Empfehlungen der BAG SPNV.

Tabelle 5-3: $\quad$ Zeile aus dem Themenmodul Technische Fahrzeugausstattung (PH 2).

Tabelle 5-4: $\quad$ Zeile aus dem Themenmodul Mehrzweckraum (PH 2). 336

Tabelle 5-5: $\quad$ Zeile aus dem Teilthemenmodul Generalklausel (PH 2). 336

Tabelle 6-1: $\quad$ Zeile aus der Vorversion von Pflichtenheft 3 zur Verteilung der Anteile an Sitzplätzen nach deren Ausrichtung.

Tabelle 6-2 Zeile aus Pflichtenheft 3 zur Verteilung der Anteile an Sitzplätzen nach deren Ausrichtung.

Tabelle 6-3: $\quad$ Zeile aus Pflichtenheft 1 mit der Angabe zu Elektrorollstühlen. 
Tabelle 6-4: Überblick über Anforderungen an Einstiegshilfen (TSI PRM, 2008, S. 126). 389

Tabelle 6-5: $\quad$ Zeile zu sogenannten Öhrchen an Kopfstützen (PH 1). 390

Tabelle 6-6: Zeile mit der Abweichung vom Terminus behindertengerecht durch behindertenfreundlich (PH 1). 


\section{Vorwort}

Diese Arbeit wurde im Rahmen meines Promotionsverfahrens von der Fakultät für Geisteswissenschaften an der Universität Duisburg-Essen unter dem Titel „Semiotische Effizienz von interfachlichen Sprache-Bild-Textsorten“ als Dissertation angenommen, am 5. Juni 2019 erfolgreich verteidigt und nur geringfügig zur vorliegenden Version überarbeitet. Um für alle erforschten Unternehmen, Verbände und Einzelpersonen die Anonymität zu gewährleisten, die juristisch notwendig ist, sind einige Beispiele im Analyseteil verändert oder getilgt worden.

Allen, die dieses Projekt ermöglichten, danke ich herzlich. Sehr herzlich danke ich meinem Doktorvater, Prof. em. Dr. Ulrich Schmitz, der meinen Forschungsprozess in Gesprächen sehr ausdauernd, äußerst fachkundig und herzlich begleitete. Die folgende Arbeit bildet einige Ideen dieser Gespräche ab. Prof. Dr. Ulrike Haß danke ich herzlich für die Zweitbegutachtung und auch Prof. Dr. Bernd Rüschoff dafür, den Vorsitz der Prüfungskommission bereitwillig übernommen zu haben. Ein besonderer Dank gilt Prof. Dr. Klaus Schubert der Universität Hildesheim, der mich in sein Doktorandenkolloquium aufnahm, in Gesprächen Anreize aus der Perspektive der Fachkommunikationswissenschaft - u. a. dem Modell kommunikativer Effizienz - gab und meine Forschungsergebnisse interessiert diskutierte. Auch Prof. Dr. Thorsten Roelcke der TU Berlin danke ich für ein ausführliches Gespräch, in dem ich sein Modell kommunikativer Effizienz besprechen konnte.

Als Linguistik und technischer Laie danke ich Prof. Dr.-Ing. Jörn Pachl, geschäftsführender Leiter des Instituts für Eisenbahnwesen und Verkehrssicherung an der TU Braunschweig, für zwei ausführliche Gespräche und den E-Mail-Kontakt zu Fragen, die sich im Bereich Schienenfahrzeugtechnik auftaten. In diesem Zusammenhang danke ich auch Prof. Dr.-Ing. Peter Köhler, Leiter des Instituts für Rechenreinsatz in der Konstruktion an der Universität Duisburg-Essen, für ein längeres Gespräch zu technischen Zeichnungen und CAD-Darstellungen.

PD Dr. Reiner Küpper und Dr. Ulrike Pospiech danke ich für korpuslinguistische bzw. schreibdidaktische Anreize zu Beginn meines Promotionsprozesses. Dank 
gilt Dr. Ulrike Pospiech des Weiteren dafür, einen Promotionsprozess neben meiner Vollzeittätigkeit in der Schreibdidaktik der Universität Duisburg-Essen und meinen familiären Aufgaben ermöglicht zu haben. Dr. Christiane Zehrer, Dr. Franziska Heidrich, Prof. Dr. Karolina Suchowolec und Mareike von der Stück M. A. danke ich für die konstruktive Kritik zu meiner Arbeit im Hildesheimer Doktoranden-Kolloquium wie auch den Essener Kommilitonen Dr. Jan Hendrik Boland und Dr. Marcus Wetzchewald. Für die kritische Durchsicht des Manuskripts danke ich Andrea Thomas B. A., Jessica Holste M. A. sowie den Mitarbeitenden des Verlags Frank \& Timme.

Herrn RA Christoph Schneider, Fachanwalt für Vergaberecht in der Koblenzer Kanzlei Webeler Rechtsanwälte, danke ich für den fachlichen Beistand bei juristischen Fragen zu Ausschreibungsunterlagen, -vorgängen und -voraussetzungen, die ich untersuchte. Dank gilt des Weiteren der Stadler Pankow GmbH, der Abellio Rail GmbH sowie dem Institut für Regional- und Fernverkehrsplanung (iRFP e. K.) dafür, Bildmaterial zur Verfügung gestellt zu haben. Dieses Material nutzte ich, um die Textexemplare, die dem Prüfungsausschuss vorlagen, in Bezug auf Corporate Design, Haltestellen bzw. Bahnstrecken zu anonymisierten. Ich danke darüber hinaus den Auftraggebern 1 und 2, den Fahrzeugherstellern 1 und 2 sowie dem bietenden Eisenbahnverkehrsunternehmen, die ich hier aus Gründen der Anonymität nicht namentlich nennen darf. Der Dank bezieht sich auf die tiefen Einblicke in die internen Arbeits-, insbesondere in die Kommunikationsprozesse.

Prof. Dr. Hartwig Kalverkämper danke ich für die kritische Durchsicht und bereitwillige Aufnahme meiner Arbeit in die Reihe „Forum für FachsprachenForschung“".

Ohne die Betreuung unseres Sohnes durch unsere Freunde, die Betreuerinnen der DuE Kids und der KiTa „Am Schniedtkamp“ in Essen-Katernberg wäre es nicht möglich gewesen, diese Arbeit fertigzustellen. Daher gilt ihnen allen ein besonderer Dank. Mein Sohn Matteo möge mir nachsehen, wenn ich nicht immer die Zeit für ihn aufbringen konnte, die ich gerne aufgebracht hätte. Meiner Frau Jessica und meinem Sohn gilt der größte Dank, weil sie mich auch auf den Durststrecken begleiteten und mir motivierend zur Seite standen - insbesondere meiner Frau und Arbeitskollegin als kritische Gesprächspartnerin. 


\section{Einleitung}

Viele Fachtextsorten, die in einer natur- oder ingenieurwissenschaftlichen Tradition stehen, nutzen nicht nur Schriftsprache, sondern auch Bilder, Diagramme, Tabellen etc. als Ausdrucksmittel. Diese Textsorten sind also multimodal gestaltet und können von den Experten ihres Faches nicht nur verstanden werden, sondern ermöglichen es auch, innerhalb des Fachs eindeutig, präzise und mit wenigen Zeichen - also effizient - zu kommunizieren. Fachkommunikative Effizienz kann dabei das Ergebnis von kommunikativen Optimierungsprozessen sein.

Fachkommunikationsoptimierung beschäftigt zudem große Teile der Fachkommunikationsforschung, die nicht nur Kommunikate wie Fachtexte, sondern auch deren Produktionsprozesse untersucht. In diesem Zusammenhang sieht die Fachkommunikationsforschung ein wichtiges Untersuchungsfeld in der Beschreibung von Text-Bild-Kombinationen (Schubert, 2009, S. 140). Für die Domäne der Technikkommunikation werden insbesondere Fachtexte als Kommunikate in Bezug auf ihr Layout und ihre Sprache-Bild-Relationen optimiert (HEIDRICH, 2016, S. $211 \mathrm{f}$.).

Inwieweit multimodale Ausdrucksmittel in Fachkommunikation noch effizient wirken, wenn sie gemeinsam mit Experten anderer Fächer in einem interfachlichen Verwendungskontext, also einer interfachlichen Domäne, genutzt werden, ist unklar und bildet in der Fachkommunikationsforschung einen Untersuchungsgegenstand. Das Ergebnis einer frühen Untersuchung von technischen Berichten, mit denen Betriebswirte, Ingenieure etc. eines Unternehmens eine staatliche Institution beraten, deutet bereits darauf hin, dass die Optimierung dieser multimodalen Texte von der Fächerkultur eines Kommunikanten bzw. von seiner Kompetenz abhängen kann, multimodale Mittel wie technische Zeichnungen oder Diagramme zu verstehen (PogneR, 1999, S. 165). So stellt sich für Kommunikanten die Frage, inwieweit ein multimodales Kommunikat solch einer interfachlichen Domäne für Experten aller beteiligten Fächer wie beispielsweise Juristen oder Betriebswirte nicht nur verständlich, sondern auch für die jeweilige Kommunikation optimiert ist. Möglicherweise ist dem Juristen die Bedeutung einer gestrichelten Linie in einer Zeichnung nicht geläufig, die besagt, welches 
Material an dieser Stelle der Zeichnung verbaut, also verwendet werden soll. Dem Techniker muss dagegen aber auch nicht klar sein, dass er sich mit einer gestrichelten Linie in einem Angebotstext verpflichtet, ein bestimmtes Material zu einem bestimmten Preis zu liefern. Dieses Beispiel veranschaulicht, inwiefern fachkommunikationswissenschaftliche Untersuchungen darauf abzielen können, kommunikative Optimierung in interfachlichen Domänen zu betrachten, die multimodale Mittel der verschiedenen beteiligten Fächer nutzen.

Mit Sprache-Bild-Relationen in Texten - ob als Teil von Fachkommunikationsoptimierung oder von Werbekommunikation - beschäftigen sich Modelle der Zeichentheorie, also der Semiotik. Dort werden Sprache-Bild-Relationen vor allem als Teil von Multimodalitätskonzepten behandelt. Insbesondere die Schule der systemisch funktionalen Semiotik widmet sich der sozialen Bedeutung und Funktion von Bildern bzw. von Sprache-Bild-Relationen (KRESS/VAN LEEUWEN, 22006; VAn Leeuwen, 2005a; Martin/Rose, 2008). Da fachliche Kommunikanten durch unterschiedliche Ausbildungen und Tätigkeitsbereiche mikrokulturell geprägt sind (HORN-HelF, 2010), hat die Verwendung von technischen Zeichnungen, Diagrammen und Schriftsprache in interfachlichen Domänen also in diesem Sinne eine soziale Dimension.

Im Anschluss an diese Schule der systemisch funktionalen Semiotik, aber auch im Anschluss an andere Ausgangspunkte entwickelten sich mit dem Fokus auf der Bedeutung und Funktion von Bildern in den Sprachwissenschaften, dem sogenannten pictorial turn, viele Konzepte, die nicht nur Sprache-Bild-Relationen behandeln. Teil der Theorien zu Sprache-Bild-Relationen ist auch deren Benennung: Dass hier oftmals noch kein Konsens gefunden wurde, zeigen die Diskussionen z. B. um die Bedeutung der Begriffe ,Modalität', ,Kodalität' und ,Medialität‘. Beispielsweise wird in einem Modell ,Kodalität‘ auf ein Zeichensystem bezogen, ,Modalität‘ dagegen auf eine Sinnesmodalität und ,Medialität auf ein technisches Medium (BALlSTAedt, 2016; LÜCKING/PfeIFFER, 2012, S. 595), sodass Bilder und Schriftsprache die Kodalität betreffen. In anderen Modellen hingegen werden die drei Begriffe als Synonyme behandelt (ADAMZIK, ${ }^{2} 2016$, S. 68).

Das Konzept von KLUG/STÖCKL (2015) differenziert Multimodalität im engeren und weiteren Sinne nach beteiligten Sinnesmodalitäten. Dabei bezeichnet, Multi- 
modalität im engeren Sinne` die Beteiligung mehrerer Sinnesmodalitäten wie Ton gegenüber Schrift und Bild, während ,Multimodalität im weiteren Sinne“ nur die Beteiligung einer Sinnesmodalität betrifft (ebd., S. 244). Sprache-Bild-Relationen werden demnach unter ,Multimodalität im weiteren Sinne' erfasst. Im Konzept von SchMitz (2016) stellt dagegen der Begriff ,Modus‘ im Sinne von Kommunikationsträger den Ausgangspunkt der Diskussion dar, der sich auf Gesprochenes, Geschriebenes, bewegte oder statische Bilder und Auditives wie Musik oder Geräusche bezieht (ebd., S. 331), von denen mindestens zwei in multimodalen Texten enthalten sind (ebd., S. 333). Auch in dieser Arbeit werden Multimodalität (JEWITT, ${ }^{2} 2014$ ) bzw. Sprache-Bild-Textsorten behandelt, sodass aus der Darstellung und Diskussion relevanter Konzepte eine Nominaldefinition für SpracheBild-Textsorten entwickelt werden kann.

Sowohl SchmiTz (ebd., S. 339) als auch STÖckL (2016, S. 25) betonen, dass sprachliche und bildliche Mittel eines Textes durch ihre Verwendung in der Domäne bzw. durch kontextuelle Faktoren geprägt werden. Diesen Zusammenhang des Kontextes mit sprachlich-bildlichen Darstellungsmitteln fokussieren besonders fachkommunikationswissenschaftliche Untersuchungen. Auch die bis hierhin aufgezeigten Konzepte fachkommunikativer Optimierung beziehen kontextuelle Faktoren von Domänen ein. Somit bilden Optimierungskonzepte für (inter-) fachliche Kommunikation einerseits und multimodale Textsorten andererseits die Grundlage für das zentrale Forschungsanliegen meiner Arbeit.

\subsection{Zentrale Forschungsfrage und deren Relevanz}

Diese Untersuchung geht der Frage nach, wie sich Interfachlichkeit auf die semiotische Effizienz von Sprache-Bild-Textsorten, insbesondere von Pflichtenheften, auswirkt. Diese Forschungsfrage wird in Kapitel 2.1.3, also im Anschluss an die Beschreibung des Modells kommunikativer Effizienz (s. Kapitel 2.1.1) und an die Kritik an diesem Modell (s. Kapitel 2.1.2), durch drei Thesen präzisiert.

Die Frage knüpft an das Desiderat zweier Forschungsrichtungen an: Bildlinguistische Untersuchungen (SCHMiTZ, 2011a, S. 40; 2016, S. 338 f.) fragen nach dem Zusammenhang, der zwischen der Gestaltung von Sprache-Bild-Texten und ihren Verwendungsdomänen in Form ihrer Sprechergruppen (u. a. fachliche Kommunikationsgemeinschaften) besteht. In der Fachkommunikationsfor- 
schung wird diese Frage in ähnlicher Form aufgeworfen (KALVERKÄMPER, 2016a, S. 289 f.; RoELCKE, 2012, S. 247). Textsortenkonzepte erfassen Verknüpfungen (ADAMZIK, ${ }^{2} 2016$, S. 111 f.) bzw. typische Verbindungen (BRINKER/CöLFEN/PAPPERT, ${ }^{9} 2018$, S. 139) von textuell-sprachlichen Ausdrucksmitteln und von situativ-funktionalen Aspekten, wie beispielsweise die Verwendung von Textsorten in einem Fach. Das aufgezeigte Desiderat bezieht sich nicht nur auf sprachliche, sondern auch auf die „Visualisierung möglicher Relationen“ (BAUER/ERNST, 2010, S. 33) zwischen Schrift- und Bildelementen eines Textes, sogenanntes Diagrammatisches (ebd., S. 32). ${ }^{1}$ Diese Relationen können die Positionierung von Schriftelementen in der Fläche, abstrakte, nicht sichtbare Beziehungen wie Begriffe betreffen und sind als Ergebnis soziokultureller Praktik zu verstehen (ebd., S. 33). Demnach sind diagrammatische Beziehungen strukturell, semantisch und pragmatisch geprägt. Multimodale Texte, die auf diesen drei Ebenen beschrieben werden, können als Diagramme verstanden werden. Sie können aber beispielsweise auch in Form einer technischen Zeichnung oder einer Tabelle Teil eines Textes sein. Im Anschluss daran möchte diese Arbeit den Zusammenhang beschreiben, der zwischen multimodalen Ausdrucksmitteln von Fachtextsorten und der Spezifik besteht, in der Kommunikanten unterschiedlicher Fächerkulturen diese Mittel verwenden.

Dabei werden Fachtextsorten üblicherweise in einer Domäne verwendet, in der Kommunikanten eines Fachs bzw. mehrerer Fächer interagieren. Z. B. wird in der Domäne behördlich-technischer Ausschreibungsprozesse vor allem die Fachtextsorte Pflichtenheft genutzt, deren Exemplare Juristen, Betriebswirte, Ingenieure und Betriebsplaner gemeinsam erstellen und überarbeiten. Das Pflichtenheft steht im Zentrum eines Textsortennetzes, das die Ausschreibungsprozesse anhand ihrer Kommunikationsprodukte erfasst.

Nicht nur die Kommunikationsprodukte, sondern auch die Kommunikationsprozesse in Form der gemeinsamen Überarbeitung von Exemplaren dieser Textsorten lassen sich mit linguistischen Mitteln beschreiben. Diese Beschreibung zielt darauf, den Kommunikanten der erforschten Domäne Hinweise für die Optimierung

Auch Relationen zwischen „schriftlichen und bildlichen Eigenschaften in der Schrift“ (BAUER/ERnST, 2010, S. 32) bezeichnet das Diagrammatische, stehen aber nicht im Fokus meiner Untersuchung. 
der Kommunikationsprozesse zu geben. Aus dem Diskurs fachkommunikativer Optimierung (s. Kapitel 2.1) eignet sich das Modell kommunikativer Effizienz (RoElCKe, 2002a), um die Überarbeitungsprozesse der Textsortenexemplare zu beschreiben und mögliche Optimierungshinweise zu geben. Denn dieses Modell berücksichtigt erstens eine Textebene und deren schriftsprachliche Ausdrucksmittel, zweitens den Zusammenhang zwischen diesen Ausdrucksmitteln als Grammatik und drittens die Fähigkeiten der Kommunikanten, diese Mittel zu verwenden.

Die oben formulierte Forschungsfrage stellt das Bemühen in den Vordergrund, mit dem Effizienz-Modell nicht nur schriftsprachliche Elemente, sondern auch Bilder zu erfassen, die bis dato vernachlässigt wurden. Dabei sollen - im Anschluss an die oben aufgeführten Desiderata - strukturelle und semantische Verflechtungen sowie das vorhersagbare Auftreten zwischen diesen multimodalen Ausdrucksmitteln und deren interfachlicher Verwendung bei einer Fachtextsorte aufgezeigt werden. Wie das Beispiel eines multimodalen technischen Berichts im interfachlichen Beratungskontext (PoGNER, 1999, S. 165) zeigt, interagieren Kommunikanten unterschiedlicher Fächer in dieser Domäne. Dabei steuern die Kommunikanten verschiedener Abteilungen innerhalb eines arbeitsteiligen kooperativen Schreibprozesses unterschiedliche thematische Elemente, aber auch unterschiedliche Zeichentypen zu diesem Bericht bei, beispielsweise Diagramme, Tabellen oder ausschließlich schriftsprachliche Elemente. Um dieses Beispiel wie auch die Texte meines Untersuchungskorpus erfassen zu können, ist es notwendig, das Modell kommunikativer Effizienz um die Kategorien Multimodalität und Text-Kontext-Verknüpfungen (also typische Verknüpfungen zwischen der Textgestaltung und dem situativen Kontext) zu erweitern. Die modifizierte Form des Modells bezeichne ich im Folgenden als Modell semiotischer Effizienz.

Antworten auf meine Forschungsfrage, wie sich Interfachlichkeit auf die semiotische Effizienz von Sprache-Bild-Textsorten auswirkt, sind für drei Zielgruppen relevant: Erstens wird der Diskurs der Fachkommunikationsforschung zu fachkommunikativer Optimierung weitergeführt. Zweitens schließt meine Untersuchung an den Diskurs der Angewandten Linguistik an, unbekannte Fachtextsorten zu beschreiben. Fokussiert werden dabei auch ihre Eigenschaften, Teil eines Textsortennetzes $\mathrm{zu}$ sein und Sprache-Bild-Beziehungen $\mathrm{zu}$ enthalten. Drittens 
versucht diese Arbeit, die praktischen Probleme der untersuchten Domäne zu beschreiben und den Praktikern auf dieser Grundlage Hinweise für Problemlösungen zu geben:

$\mathrm{Zu}$ 1. Ein Komplex von Forschungsaufgaben, der für die Erforschung von kommunikativer Optimierung aufgezeigt wird, betrifft den „Einsatz von Illustrationen und die Verknüpfung sprachlicher und nichtsprachlicher Mittel, insbesondere das Verhältnis zwischen Text und Bild sowie die Wahl zwischen beiden" (SCHUBERT, 2009, S. 140). D. h., Multimodalität von Kommunikaten, konkret von Texten, zu erforschen knüpft an den Diskurs zu kommunikativer Optimierung an.

$\mathrm{Zu}$ 2. Auch die Positionen der Technikkommunikationsforschung, die textlinguistisch orientiert sind, formulieren das Desiderat, weitgehend unbekannte technische Textsorten zu erforschen (HoRN-Helf, 2010, S. 571). An dieses Desiderat schließt vor allem die Analyse von Pflichtenheften an. Aber auch sogenannte Optimierungsvorschläge, Lastenhefte und Fahrplanvarianten werden im Folgenden untersucht. Bei der Erforschung von Textsorten spielen Formen des Textsortenwandels eine Rolle (HAUSER/KLEINBERGer/Roth, 2014, S. 10). Als Ergebnis dieses Wandels werden unter anderem die Multimodalität von Textsorten (ebd., 2014, S. 10) und die funktionale sowie thematische Vernetzung von Textsorten (FIX, 2014, S. 21 ff.) genannt. Diese beiden Formen des Wandels erscheinen für Pflichtenhefte besonders relevant, da Letztere Element eines funktionalen Textsortennetzes und multimodal gestaltet sind.

$\mathrm{Zu}$ 3. Die Relevanz der Fragestellung für die erforschte Domäne wird im Folgenden als praktisches Problem geschildert.

\subsection{Praktisches Problem der erforschten Domäne und dessen Relevanz}

Pflichtenhefte werden in der Domäne von Ausschreibungsverfahren erforscht (LuTZ, 2015, S. 343). Für den Schienenpersonennahverkehr (SPNV) existieren Ausschreibungsverfahren, in denen Schienenfahrzeuge und Dienstleistungen angeboten werden. Für diese Verfahren beauftragen die einzelnen Bundesländer sogenannte Auftraggeber - auch Aufgabenträger genannt - damit, im Rahmen der Vergabeverfahren Strecken, Dienstleistungen und Fahrzeuge für den SPNV 
auszuschreiben. Eisenbahnverkehrsunternehmen wie Abellio, die DB Regio AG, die Arriva Danmark A./S., die Keolis GmbH \& Co.KG usw. treten als Bieter auf, die ihre Angebote zu diesen Ausschreibungen abgeben. Meist finanzieren sich diese Unternehmen des Nahverkehrs - für den Fernverkehr gelten andere Gesetze - überwiegend oder sogar ausschließlich über Einnahmen, die aus diesen Verfahren resultieren.

Der SPNV, der Teil des öffentlichen Personennahverkehrs (ÖPNV) ist, trägt dazu bei, den PKW-Verkehr zu reduzieren und somit die Umwelt zu schützen, konkret die Luftverschmutzung zu reduzieren und für bessere Luftqualität zu sorgen. Da die Letztere in Deutschland kaum die Richtwerte der EU erfüllt, schlug die Bundesregierung der EU-Kommission im Jahr 2018 vor, die Luftqualität in Deutschland zu verbessern, indem sie unter anderem kostenlosen ÖPNV einführe (ZEIT ONLINE, 2018, o. S.). Da sich durch kostenlosen ÖPNV der Bedarf erhöht, sei es aber notwendig, Fahrzeuge zu beschaffen und Personal für den Betrieb, die Planung etc. einzustellen (ebd., o. S.), die Auftraggeber durch Vergabeverfahren beschaffen müssten, die über die bereits geplanten Verfahren hinausgehen.

Denn neben der aktuellen Problematik, zusätzliche Vergabeverfahren zur Verbesserung der Luftqualität zu veranstalten, müssen auch bestehende Strecken neu ausgeschrieben und vergeben werden, da die bestehenden Verträge zwischen Auftraggebern und Eisenbahnverkehrsunternehmen zeitlich befristet sind, d. h. regelmäßig auslaufen (BAG SPNV, 2018, o. S.). Für den bestehenden Bedarf und auch für den angestrebten Bedarf an ÖPNV, speziell an SPNV, ist es sowohl aufseiten der Auftraggeber als auch aufseiten der Eisenbahnverkehrsunternehmen notwendig, Schienenfahrzeugtechniker, Betriebswirte/Controller, Marketing-Fachkräfte, Betriebsplaner, technische Redakteure und Juristen zu beschäftigen, die in interfachlicher Projektarbeit als Autoren des Auftraggebers Lastenhefte und als Autoren der Eisenbahnverkehrsunternehmen Pflichtenhefte erstellen. Denn Lastenbzw. Pflichtenhefte stellen die wesentliche Vertragsgrundlage innerhalb der Ausschreibungsverfahren dar (LUTZ, 2015, S. 343). Auf dieser Grundlage ist geregelt, wie der Bieter, der eine Ausschreibung gewonnen hat, zukünftig die Dienstleistung zu erbringen hat, welche Vertragsstrafen drohen, wenn dieses Eisenbahnverkehrsunternehmen die Leistungen nicht wie vereinbart erfüllt, und wie es für diese Leistungen entlohnt wird. 
Mit einer Kollegin leitete ich die technische Redaktion eines dieser Bieter bei einem Ausschreibungsverfahren. Die Redaktion dieses Bieters erhält Teiltexte von Autoren, die zur einen Hälfte in verschiedenen Unternehmensabteilungen beschäftigt, zur anderen Hälfte zeitlich befristet im Ausschreibungsverfahren als Projektmitarbeitende beteiligt sind. Der Abteilungsleiter, der in diesem Unternehmen für Ausschreibungen zuständig ist, trat an die Universität Duisburg-Essen mit der Bitte heran, das Unternehmen bei der Textüberarbeitung zu unterstützen. Er erhoffte sich von meiner Unterstützung, „dass die unterschiedlichen Schreibstile und -farben harmonisiert werden“ (ABTEILUNGSLEITER DES BIETERS, 2011). Denn die Autoren der beteiligten Abteilungen schrieben sehr unterschiedlich, wodurch eine neutrale und unternehmensexterne Instanz gefragt sei, die die von unterschiedlichen Abteilungen gemeinsam erstellten Texte vereinheitliche. Als Maßstab für diese Vereinheitlichung nimmt der Leiter die Lesenden des Auftraggebers an (ebd., S. 638). D. h., seine Bezeichnung der Stilharmonisierung zielt auf eine abteilungsübergreifende Konventionalität der zu erstellenden Texte für die Rezipienten. Aufgabe der technischen Redaktion war und ist es somit, die Konventionalität der Texte zu beurteilen und die Texte der Fachautoren entsprechend umzugestalten.

Konventionalität bezeichnet in dieser Arbeit eine Textsortenkonvention bzw. Konventionalität als Eigenschaft von Textsorten. Letztere bezeichnen bekannte und gültige Muster, in denen funktional-pragmatische, strukturelle und semantische Eigenschaften von sprachlichen Handlungen (BRINKER/CÖLFEN/PAPPERT, ${ }^{9} 2018$, S. 139) bzw. funktional-pragmatische und visuelle sowie grammatische Eigenschaften semiotisch-komplexer Handlungen (SchMITZ, 2011a, S. 37) typisch verbunden sind. Da sich im Anschluss an die Aufhebung der Dichotomie von Fach- und Allgemeinsprache (KALVERKÄMPER, 1989) auch Fachtextsorten definitorisch nicht von Textsorten unterscheiden lassen, sondern lediglich der Fachsprachlichkeitsgrad innerhalb einer Textsorte bestimmt werden kann (GöPFERICH, 1995, S. 58), ist diese Definition von Textsorten(-konvention) auch für Fachtextsorten(-konventionen) gültig.

Inwieweit diesem Harmonisierungswunsch Rechnung getragen werden kann, greift meine Arbeit dadurch auf, dass sie Textsortenkonventionen in interfachlichen Kontexten, speziell das Zusammenwirken von Kontext und multimodalen 
Ausdrucksmitteln, untersucht. Im Zentrum des Interesses aller Autoren und des Abteilungsteilers stand die Frage, inwieweit ein Lesender die Teiltexte aller Abteilungen nachvollziehen könne und die Texte entsprechend gestaltet sein müssen (ABTEILUNGSLEITER DES BIETERs, 2011).

Des Weiteren dienten die Texte eines Unternehmens im Ausschreibungsverfahren als „Visitenkarte des Unternehmens, die wir beim Kunden abgeben“ (ebd.). Der Text soll dem Auftraggeber also ein positives Image vom Unternehmen und seinen Leistungen vermitteln. D. h., der Text hat auch die Funktion, den Auftraggeber von diesem Image bzw. dieser Leistungsfähigkeit zu überzeugen. Es wird zu zeigen sein, dass Textsortenfunktionen ${ }^{2}$ genutzt werden, um entsprechende kommunikative Ziele zu erreichen, wie beispielsweise dem Rezipienten nachvollziehbar Informationen zu übermitteln (Informieren) und ihn von einem Image des Unternehmens zu überzeugen (Anweisen bzw. Überzeugen).

Um die zu erstellenden Texte nachvollziehbar zu gestalten, trafen die Fachautoren Annahmen über die Textkompetenz der Rezipienten. Sowohl die Textkompetenz als auch die Erwartungen an diese erfasst RoELCKEs Effizienz-Modell als Teil der Kapazität von Kommunikanten, speziell der Kommunikationsfähigkeit von Kommunikanten. Inwieweit sich diese Annahmen der Textproduzenten mit Gegebenheiten ${ }^{3}$ bei den Rezipienten decken, versuchte ich durch Interviews mit zwei der lesenden Auftraggeber zu deren Rezeptionsprozess herauszufinden: Bei beiden Auftraggebern liest eine bzw. lesen zwei Personen alle Texte, die zum Angebot gehören. So antwortet Auftraggeber 2 auf die Frage, wie Optimierungsvorschläge als eine weitere Textsorte neben Pflichtenheften innerhalb der Organisation rezipiert werden, wie folgt:

„Die Texte liest der jeweilige Projektleiter - das Wettbewerbsteam des [Auftraggebers 2] besteht aus 4 Mitarbeitern. Dieser Leiter kann bei Bedarf Rücksprache mit einzelnen Abteilungsleitern oder anderen Mitarbeitern vom [Auftraggeber 2] halten.“(AuftragGeBer 2, 2010a, S. 1)

2 Deren Beschreibung lehnt sich in dieser Arbeit an die Sprechakttheorie an.

3 Einzuschränken ist dabei, dass die Aussagen der Auftraggeber, die über bestehende Strukturen und Abläufe hinausgehen, hier also Aussagen zu eigenen Einschätzungen zur Textgestaltung, sehr subjektiv und daher nur bedingt verallgemeinerbar sind. 
Auch Auftraggeber 1 bestätigt dieses Vorgehen (Auftraggeber 1, 2013, S. 9). Anzumerken ist an dieser Stelle, dass die befragten Projektleitenden durch ein Studium fachlich im Sinne des Fächerkanons der Universitäten geprägt sind und damit fachliche Kompetenzen in einem Studiengang erlangt haben, die sich sowohl auf das Wissen im Fach als auch auf dessen Darstellung durch verschiedene Zeichensysteme wie Zahlen, Bilder, Zeichnungen, Diagramme etc. beziehen. So schildert Auftraggeber 2 den fachlichen Hintergrund des Teams, das die Ausschreibungsunterlagen erstellt, wie folgt: „[W]ir sind von Hause aus Ingenieure und Geografen“ (AufTRAGGeBer 2, 2010b, S. 2). ${ }^{4}$ Die Ausschreibenden von Auftraggeber 1 sind dagegen fachlich durch ein anderes Studienfach geprägt: „MitarbeiterIn 1 ist als Diplom-Betriebswirt ausgebildet und betreut seit 5 Jahren das Ausschreibungswesen, MitarbeiterIn 2 ist als Diplom-Geograf ausgebildet und seit 2008 im Ausschreibungswesen tätig." (AUfTRAGGEBER 1, 2013, S. 2). Kompetenzen, die durch andere Studiengänge vermittelt werden, aber für Ausschreibungsverfahren relevant sind, haben sie bedingt erworben, indem sie bisherige Ausschreibungsverfahren durchgeführt haben (ebd., S. 5 f.). Die fachlich-universitäre Ausbildung der Rezipienten ist demnach unterschiedlich. Die Ausschreibenden haben aber die Möglichkeit, auf die Kenntnisse eines interfachlichen Teams zurückzugreifen.

Dass Projektleitende Rücksprache aber erst bei Bedarf suchen, kann dazu führen, dass scheinbar verständliche Passagen nicht korrekt erfasst oder daraus resultierende Probleme von den Projektleitenden nicht erkannt werden, da diesen das fachliche Wissen dazu fehlt.

Diese Annahme stützt die Selbsteinschätzung eines Projektleiters bei Auftraggeber 2, der die Unterlagen nur noch auf ihre Schlüssigkeit prüfe (AUFTRAGGEBER 2, 2010b, S. 1). Aus dieser Interviewantwort ergibt sich folgender Dialog:

„[AH] Das bedeutet, es gibt bei Ihnen keinen Ingenieur, der schaut, ob der technische Teil eines Angebots fachlich richtig ist?

Wichtig ist für meine Untersuchung, ob ein Angebotstext/Optimierungsvorschlag beim Aufgabenträger von einer Person oder von mehreren Fachautoren gelesen wird.

$4 \quad$ Verkehrsplanung und das für diesen Themenbereich relevante Ausschreibungswesen wird an einigen Universitäten als Teilgebiet des Fachs Geografie bzw. als Inhalt des GeografieStudiums angeboten. 
[AT] Natürlich, wenn das Fahrzeug nur 10 Meter lang ist, aber über 100 Sitze als Kapazität angegeben sind, werden wir auch stutzig. Es prüft aber kein Ingenieur mehr speziell, ob der Technikteil im Detail stimmt. Dazu ziehen wir auch die Testate der Fahrzeughersteller heran." (ebd.; S. 1 f.; Kursive im Original)

Sogenannte Testate, bei denen der staatliche Infrastrukturbetreiber bzw. der sogenannte Netzbetreiber prüft, inwieweit das angebotene Fahrzeug einen geplanten Fahrplan fahren kann und für die Strecken geeignet ist, beziehen auch Tabellen, Zeichnungen und Diagramme ein, die Teil der Pflichtenhefte, der Optimierungsvorschläge bzw. Fahrpläne sind. Während sich meine Frage an Auftraggeber $1 \mathrm{zu}$ Verständnisfragen auf die Fachterminologie bezieht, ist es auch möglich, dass die Projektleitenden der Auftraggeber zu anderen Fachtextsorten wie Bildfahrplänen oder zu Zeichensystemen, die die Textsorte Pflichtenheft umfasst (z. B. zu technischen Zeichnungen ${ }^{5}$ ), grundlegende Fragen haben. So kann sich ein Techniker des Bieters ,nicht vorstellen, dass der AT [Auftraggeber, AH] alle Daten aus dem Diagramm lesen und bewerten kann“(FAHRZEUGTECHNIKER DES BIETERS, E-Mail vom 9.4.2014). Er könne aber andere Stellen damit beauftragen.

Die Komplexität des Kommunikats Text - um es in der Terminologie des Effizienz-Modells zu erfassen - ist somit nicht nur durch sprachliche Mittel, sondern auch durch weitere, vor allem bildliche Darstellungsmittel geprägt. Aus der Annahme dieses Technikers und den zitierten Interviewaussagen von Auftraggeber 1 und Auftraggeber 2 resultiert für die technische Redaktion eines Bieters die Aufgabe, die Textsortenkonventionalität und -funktionalität eines Pflichtenheftexemplars dahingehend zu prüfen, dass die Rezipienten diese mit möglichst geringem Aufwand und den gegebenen sprachlichen und bildlichen Darstellungsmitteln präzise und eindeutig nachvollziehen können. D. h., dass der Bieter das jeweilige Pflichtenheft möglichst effizient gestaltet.

Nicht nur der Techniker des Bieters setzt die genutzten sprachlich-bildlichen Mittel des Pflichtenhefts in Bezug zu den Kompetenzen der Rezipienten, sondern auch diese Arbeit geht dieser Frage nach. Denn auch an vielen weiteren Stellen

$5 \quad$ Kapitel 5 zeigt, dass es sich bei technischen Zeichnungen um ein eigenes Zeichensystem handelt, weil die Bedeutung von Linienbreiten, -abschlüssen, -unterbrechungen, -anordnungen, Schraffuren von Flächen etc. in der Kommunikationsgemeinschaft der Ingenieure durch DIN-, EN- und/oder ISO-Normen unabhängig von einer Textsorte oder der Verwendungssituation festgelegt ist. 
stellt die Erwartung der Textüberarbeitenden an die Kenntnisse der Rezipienten zu Zeicheninventaren und Terminologie und die daraus resultierende Gestaltung der Pflichtenhefte eine grundlegende Frage dar.

Das Verhältnis zwischen der interfachlich-multimodalen Komplexität der Pflichtenhefte und den Erwartungen an die Kapazität der Rezipienten ergibt sich für die Textüberarbeitenden im Forschungsfeld als Problem. Dieses fließt in meine zentrale Forschungsfrage ein, nämlich wie sich Interfachlichkeit auf die semiotische Effizienz von Sprache-Bild-Textsorten auswirkt. Auf diese Frage versucht das Modell semiotischer Effizienz Antworten zu finden. Den Weg, auf dem diese Antworten gefunden werden sollen, behandelt der folgende Abschnitt.

\subsection{Aufbau der Arbeit}

Im Zentrum meiner Konzeption steht das Modell semiotischer Effizienz, das in Kapitel 2 entwickelt wird. Es wird aus dem Modell kommunikativer Effizienz (RoelcKe, 2002a) abgeleitet, das Kapitel 2.1.1 kurz darstellt. RoelCKes Modell fokussiert das Verhältnis zwischen der Komplexität eines Kommunikats, also der vorhandenen Zeichen und deren Relationen in einem Text oder Ähnlichem, und der Kapazität von Kommunikanten, also der Kommunikationsfähigkeit und -bereitschaft von Textproduzenten und Rezipienten dieses Textes. Mehrere Aspekte dieses Modells werden im Forschungsdiskurs kritisiert. Diese Kritik wird in Kapitel 2.1.2 wiedergegeben. Auf der Grundlage des Modells, der Kritik daran und der dargestellten Desiderata präzisiert Kapitel 2.1.3 die Forschungsfrage meiner Arbeit durch drei Thesen. Die Modellkategorien ,Kapazität der Kommunikanten“ und ,Komplexität des Kommunikats‘ werden in den Kapiteln 2.2 und 2.3 entsprechend diesen drei Thesen ausformuliert, sodass Kapitel 2.4 das Zusammenspiel der beiden erweiterten Kategorien behandeln kann.

RoElCKes Konzeption der Kapazität der Kommunikanten wird dadurch modifiziert, dass Kapitel 2.2.1 Textsortenkompetenzen von Kommunikanten in das Effizienz-Modell aufnimmt. Somit erfasst kommunikative Effizienz, inwieweit Kommunikanten über Textkompetenzen in dem Sinne verfügen, dass ihnen fachliche Textsortenkonventionen bekannt sind, die sie bei der Textproduktion und -überarbeitung berücksichtigen oder von denen sie abweichen können. So können Mitarbeitende in Ausschreibungsverfahren bereits zahlreiche Exemplare von 
Pflichtenheften rezipiert, verfasst und überarbeitet haben, um auf der Grundlage dieser Rezeptionserfahrungen Textsortenkompetenzen zu entwickeln. Fachliche Textsortennormen (RoELCKE, 2014; ${ }^{3} 2010$ ) werden in Kapitel 2.2.2 als Spezialfall fachlicher Textsortenkonventionen behandelt, bei dem eine konkrete Instanz sanktioniert, wenn Kommunikanten von einer fachlichen Textsortennorm abweichen.

Die Modellkategorie ,Kapazität der Kommunikanten“ erweitert Kapitel 2.2.2, indem es die Kommunikationsbereitschaft als Teil der Kapazität der Kommunikanten nicht als Intentionen und Interessen, sondern als Konventionen erfasst, die aus reziproken Erwartenserwartungen (GLOY, 2012) entstehen. Letztere bezeichnen das Phänomen, dass ein Kommunikant die Erwartungen seines kommunikativen Alter Egos zu antizipieren versucht, also Erwartungen an dessen Erwartungen hat. Daher wird dieses Erwartensverhältnis als reziprok bezeichnet. Textsortenkonventionen können sich domänenspezifisch aus diesen reziproken Erwartenserwartungen entwickeln. Präzisiert wird die Kategorie ,Kapazität der Kommunikanten“ für die fachliche Kommunikation, indem geeignete modellierte Kompetenzen von Fachkommunikanten aus dem Modell fachlicher Sprachkultiviertheit (ENGBERG/JANICH, 2007) entlehnt werden, die sich auf die individuelle Kommunikationsebene beziehen. Der Vorteil, diese Ebene zu fokussieren, besteht darin, das Modell semiotischer Effizienz in der exemplarischen Textanalyse einsetzen zu können. Denn Letztere betrachtet die individuelle Textebene.

Die Modellkategorie ,Komplexität des Kommunikats' differenziert Kapitel 2.3. Es bezieht sich dabei nicht auf die situativ-funktionalen, sondern auf die textinternen Eigenschaften von Textsorten. So beschreibt Kapitel 2.3.1 Zeichentypen (PEIRCE, 1998), die in Textsortenexemplaren verwendet werden können. Beispielsweise werden neben Schrift deren Typographie (SPITZMÜLLER, 2013), Bilder in Form von Fotografien und das Zusammenspiel aus Bild und Schrift als sogenannte rekonfigurierende Diagramme (BAUER/ERNST, 2010) beschrieben. Zu Letzteren gehören in Ausschreibungsverfahren vor allem technische Zeichnungen, daneben auch Bildfahrpläne usw., die entweder Teil von Pflichtenheften sind oder - im Fall der Bildfahrpläne - eine eigene Textsorte innerhalb des Textsortennetzes zu Ausschreibungsverfahren darstellen. Kapitel 2.3.2 differenziert Zeichentypen, die in multimodalen Texten enthalten sein können. Dazu werden 
BATEMANs (2008) semiotische Ressourcen von multimodalen Textsorten durch PEIRCEs (1998) Zeichenkonzept weiter aufgeschlüsselt. Kapitel 2.3.3 beschreibt die Verknüpfungen dieser Zeichentypen innerhalb einer Textsorte, indem es neben Grammatik (Text-)Design (SCHMITZ, 2011b; EHRENHEIM, 2011) behandelt. Dies gilt sowohl für das Zusammenspiel von ausschließlich bildlichen Elementen wie Farbe und Form als auch für das Zusammenspiel von bildlichen und typographischen Elementen.

Kapitel 2.4 konzipiert das Zusammenspiel von textexternen und -internen Eigenschaften, also das Zusammenwirken von Handlungskontexten mit Sprache-BildElementen und deren Grammatik bzw. Design. Das vorhersagbare Auftreten einerseits von bestimmten sozialen und funktionalen Merkmalen und andererseits von Realisierungsformen eines Sprachsystems wird als Kookkurrenz bezeichnet (Berruto, ${ }^{2} 2004$, S. 189). Den Schritt vom Sprachsystem zum Text vollzieht COSERIU ( ${ }^{4} 2007 \mathrm{a}$, S. 49 ff.). Textsortenkonzepte modifizieren dieses vorhersagbare gemeinsame Auftreten zu typischen Verbindungen bzw. Verknüpfungen der Textgestaltung und des situativen Kontextes. Für multimodale Fachtextsorten können dementsprechend die Verknüpfungen zwischen Sprache-Bild-Elementen und deren Gestaltung durch Grammatik sowie Design (Textinterna) mithilfe situativ-kontextueller Determinanten und Textfunktionen (Textexterna) beschrieben werden. Mit Blick auf das zu analysierende Korpus und das fokussierte Textsortennetz präzisiert Kapitel 2.4.1 die situativ-funktionalen Elemente bzw. die kontextuelle Einbettung durch Konzepte der Projekt-, Organisationen- und Domänenkommunikation. Kommunikanten unterschiedlicher Fächerkulturen interagieren innerhalb dieser drei Kommunikationsbereiche. Sie interagieren demnach interfachlich. So lassen sich Pflichtenhefte und Ausschreibungsverfahren mit zunehmendem Abstraktionsgrad als Projektkommunikation innerhalb einer Organisation und innerhalb der Domäne der SPNV-Ausschreibungsverfahren zuordnen. Kapitel 2.4.2 arbeitet heraus, wie die Skalen interfachlicher Kommunikation diese Interfachlichkeit erfassen können. So wird der Abstraktionsgrad einer Textsorte auf einer vertikalen Achse und die mehrfache Fächerverortung auf einer horizontalen Achse (GÖPFERICH, 1995; OSTAPENKO, 2009) abgetragen. Inwieweit Wissens- und Institutionenasymmetrien auf die Kommunikation Einfluss nehmen, diskutiert Kapitel 2.3.3. Relevant wird dies vor allem für die zu untersuchende Interaktion zwischen Bietern als Unternehmen und Auftraggebern als 
Behörden (sogenannte Business-to-Government-/B2G-Kommunikation). Diese Asymmetrien manifestieren sich in der für Behörden typischen Kommunikationsform Formular. Diese behandelt Kapitel 2.3.3, weil die zu untersuchenden Lastenhefte als Formularvordrucke und Pflichtenhefte als ausgefüllte Formulare gestaltet sind. Entsprechend ADAMZIKs (22016, S. 141) Spezifikation von Formularkommunikanten als Prozipienten werden die Auftraggeber als Produzenten der Vordrucke und gleichzeitig Rezipienten der ausgefüllten Pflichtenhefte beschrieben - Bieter werden als Rezipienten der Vordrucke und als Produzenten der Pflichtenhefte erfasst. Die Konzeption von situativem Kontext aus Kapitel 2.4 fasst das Kontextmodell zu B2G-Kommunikation (s. Abbildung 2-12) zusammen.

Kapitel 2.5 fasst die Ergebnisse der Argumentation zu der Frage zusammen, warum die drei Thesen (Kapitel 2.1.3) wahr sein können. Sie ergeben das Modell semiotischer Effizienz (s. Tabelle 2-2) und das Kontextmodell. Den Zusammenhang der Modellelemente erläutert in diesem Zwischenfazit die Definition des Begriffs ,semiotische Effizienz'. Die Anmoderation dieser Definition verdeutlicht die Vorteile des Modells semiotischer Effizienz gegenüber dem Modell kommunikativer Effizienz. Sie bestehen insbesondere darin, dass Multimodalität, Interfachlichkeit, Textsortenkonventionen und die Verquickung dieser Aspekte erfasst werden können. Dieses Zwischenfazit schließt mit einem tabellarischen Überblick, der bereits die Elemente enthält, die in der Analyse der Textsortenexemplare und Analyse der Beobachtungsprotokolle zu den Überarbeitungsprozessen in Kapitel 6 genutzt werden.

Da insbesondere die Analysekategorien für die Textsortenanalyse innerhalb des Modells semiotischer Effizienz noch zu abstrakt für eine Analyse von Textsortenexemplaren sind, spezifiziert Kapitel 3 diese Kategorien durch das integrierte Analyseraster interfachlicher Sprache-Bild-Textsorten. Bisherige Modelle, die als Standard für Textanalysen gelten können (BRINKER/CöLFEN/PAPPERT, ${ }^{9} 2018$; ADAMZIK, ${ }^{2} 2016$; HAUSENDORF/KeSSELHEIM, 2008), sind weitgehend monomodal angelegt, da sie beinahe ausschließlich schriftsprachliche Zeichen als Beschreibungsmittel berücksichtigen. Dementsprechend stellen diese Konzeptionen kaum strukturell-syntaktische Beschreibungsmittel für Bilder oder Textdesign zur Verfügung und erfassen kaum Funktionen von Bildern oder Sprache-Bild- 
Relationen. Des Weiteren implizieren diese Analyseraster eine Chronologie der Themenstruktur, die bildliche und diagrammatische Strukturen nicht berücksichtigt, sondern schriftsprachliche Zeile für schriftsprachliche Zeile von links oben nach rechts unten verläuft.

Daher knüpfe ich an den Forschungsdiskurs an dieser Stelle an, indem ich auf ein multimodal angelegtes Analyseraster zurückgreife: STÖCKL (2016) stellt ein Raster zur Verfügung, das auf dem monomodal ausgerichteten Raster in KESSELHEIM (2011) bzw. HAUSENDORF/KESSELHEIM (2008) basiert und das er um multimodale Elemente erweitert. STÖCKL (2016) eignet sich für die Textsortenanalyse in meinem Korpus besonders, da es nicht mehr von der textimmanenten Von-linksoben-nach-rechts-unten-Chronologie lateinischer Schriftsysteme (NöTH, ${ }^{2} 2000$, S. 358) ausgeht, sondern Textexemplare vielmehr in Handlungsabschnitte (stages) einteilt. Diese Abschnitte werden entsprechend der Salienz der einzelnen Schrift-Bild-Elemente, durch die ein Abschnitt repräsentiert wird, in unterschiedlichen Reihenfolgen, also Rezeptionspfaden, rezipiert. D. h., aufgrund von Farben, Formen, Größe, Positionierung eines Elements auf dem Blatt etc. lässt sich vermuten, ob es vor anderen Elementen rezipiert wird. So werden auch Bilder und diagrammatische Elemente Teil der Handlungs- oder Themenstruktur. Die so beschriebene Salienz der Handlungsabschnitte, der semantische Gehalt der schriftsprachlichen Elemente und Kontextuelles bilden demnach die Handlungs- und Themenstruktur eines Textes. Bei allen Vorteilen, die dieses an massenmedialen Textexemplaren veranschaulichte Analyseraster bietet, ist es für technische Textsortenexemplare nur bedingt geeignet. Beispielsweise sind fachspezifische Zeichensysteme wie die Konventionalisierung von technischen Zeichnungen oder abbildenden Diagrammen durch dieses Raster noch nicht analysierbar. ${ }^{6}$ Daher beschreiben Kapitel 3.1 bis einschließlich Kapitel 3.7, wie die folgenden Kategorien von STÖCKLs Konzeption für interfachlich-technische Textsortenexemplare wie Pflichtenhefte angepasst werden: 1. Gliederung, 2. Handlungsstruktur, 3. Themenstruktur, 4. multimodale Verknüpfung und 5. Intertextualität (ebd., S. 23 ff.). Diese Kategorien gliedern die Teilkapitel von Kapitel 3 weitgehend und werden wie folgt präzisiert oder auch modifiziert: 
STÖCKLs Kategorie ,Gliederung' modifiziert Kapitel 3.1 zur Kategorie Textdesign, die vor allem die oben beschriebenen Salienzaspekte Farbe, Form, kulturelle Bedeutung etc. als Zusammenspiel in Textsortenexemplaren berücksichtigt. Die Modellkategorie ,Handlungsstruktur' spezifiziert Kapitel 3.2 erstens durch eine Berücksichtigung von Funktionen nicht nur für schriftsprachliche Elemente, sondern auch für Bilder (SchMiTz, 2007) bzw. für Sprache-Bild-Kombinationen (VAN LEEUwEN, 2005a). Zweitens wird die Kategorie ,Handlungsstruktur ' präzisiert, indem die fünf auf SEARLEs Sprechakttheorie basierenden Grundfunktionen Informations-, Appell-, Obligations-, Kontakt- und Deklarationsfunktion (BRINKER/CÖLFEN/PAPPERT, ${ }^{9} 2018$, S.105 ff.) durch ein ebenfalls auf SEARLE (1982a) basierendes Textfunktionsmodell jeweils durch Unterkategorien, wie beispielsweise bilateral festgelegte Kommissiva mit Bezug auf ein Tauschobjekt, differenziert werden (RoLF, 1993). Diese Unterkategorien ermöglichen es, die Funktionen von Schrift-, Bild- sowie Schrift-Bild-Elementen in Textsortenexemplaren, aber auch die Grundfunktion eines Sprache-Bild-Textes präziser zu bestimmen.

Die STÖCKLsche Unterkategorie, Themenstruktur' präzisiert Kapitel 3.3 dadurch, dass es erstens raumdeiktische Mittel einbezieht, die für Technikkommunikation und die Relationen zwischen Sprache und Bild besonders relevant sind. Zweitens wird das in STÖCKL (2016) angelegte Konzept ausgeführt, die Themenstruktur von Textsortenexemplaren nach Themenabschnitte zu gliedern, aus denen sich mögliche Rezeptionspfade dieser Abschnitte ergeben. BRINKER/CöLFEN/PAPPERTs ( ${ }^{9} 2018$ ) Darstellung von Themenentfaltungsmustern impliziert, dass diese einer Von-links-oben-rechts-unten-Chronologie folgen, was Kapitel 3.3 kurz darstellt. Inwieweit diese Muster aber trotz der Durchbrechung dieser Chronologie für das Textanalyseraster relevant bleiben, begründet Kapitel 3.3.

Kapitel 3.4 differenziert STÖCKLs (2016) Kategorie ,logisch-semantische Sprache-Bild-Relationen', indem es das gleichnamige Konzept erläutert (VAN LEEUWEN, 2005a; UNSWORTH, 2007). Die Verknüpfungsart beleuchtet semantische Beziehungen zwischen schriftsprachlichen und bildlichen Elementen und basiert u. a. auf VAN LEEUWEN (2005a). Diese Relationen betreffen die Ebene textueller Kohärenz. Auch wenn sich das Konzept der Schwundgrammatik (SCHMITZ, 2017, S. 12 ff.) nicht auf logisch-semantische Sprache-Bild-Relationen bezieht, wird es in diesem Teilkapitel behandelt, weil es sowohl die Kohäsions- als auch die 
Kohärenzebene erfasst. Schwundgrammatik bezeichnet, dass ,gestaltete Beziehungen zwischen Wortlaut und visueller Erscheinung semiotische Ordnung schaffen, um Verständnis zu sichern“ (ebd., S. 14). Als Ausdruck kommunikativer Effizienz nehmen schriftsprachlich-grammatische Formen zugunsten von visuell-designbasierten ab (ebd.). Die Analysekategorie multimodaler Verknüpfungen erfasst also auch, dass schriftsprachliche Elemente durch bildliche Elemente ersetzt werden. Die Systematik dieser Sprache-Bild-Verknüpfungen ergänzt das Konzept des Textdesigns aus Kapitel 3.1, das Salienz, also einer relativen Auffälligkeit visueller Elemente eines Textes gegenüber anderen Elementen desselbigen, erfasst. D. h., Textdesign bezieht sich gegenüber logisch-semantischen Verknüpfungen überwiegend auf strukturell-syntaktische Relationen.

Kapitel 3.5 präzisiert die Analysekategorie ,Intertextualität', indem es auf das Konzept der Textsortenvernetzung zurückgreift. Die Analysekategorien der sogenannten funktionalen Text-Text-Relationen (KLEIN, ${ }^{2} 2014 \mathrm{a}$ ) beziehen sich auf festgeschriebene Verfahrensabläufe, also darauf, in welcher Reihenfolge Exemplare welcher Textsorten in einem institutionellen Verfahren vorkommen müssen oder können und welche funktionalen Relationen zwischen diesen Textsortenexemplaren innerhalb des Verfahrens bestehen. Diese verfahrensbedingten TextText-Relationen werden in Kapitel 3.5 herangezogen, da sie sich besonders eignen, um Pflichtenhefte als Teil des Textsortennetzes Ausschreibungsverfahren zu kategorisieren.

Somit gliedern die fünf Kategorien aus STÖCKL (2016) das integrierte Analyseraster für interfachliche Sprache-Bild-Textsorten. Die Teilkapitel passen diese Kategorien an, um fachliche Textsortenexemplare, insbesondere Pflichtenhefte und weitere Textsorten des Textsortennetzes Ausschreibungsverfahren, beschreiben und analysieren zu können.

Lediglich Kapitel 3.6 geht über die fünf Kategorien STÖCKLs hinaus, indem es den Zusammenhang zwischen STÖCKLs (2016) Handlungskontexten und Textmerkmalen als Verknüpfungen zwischen situativem Kontext und den fünf genannten Textebenen erfasst. Die Notwendigkeit, dieses Zusammenspiel zwischen Textebenen und situativem Kontext zu untersuchen, um fachlichen Forschungsgegenständen gerecht zu werden, betont die Fachkommunikationsforschung bereits früh (HOFFMANN, 1988, S. 125 f.). Ein Analyseraster interfachlicher 
Sprache-Bild-Textsorten, das diesen Zusammenhang ins Zentrum rückt, ermöglicht es demnach, fachliche Untersuchungsgegenstände zu untersuchen. Die Bedeutung, die der Zusammenhang zwischen kontextuellen und textuellen Kriterien für die Textanalyse hat, betonen neben HofFMANN (1988) für die Fachkommunikationsforschung auch BRINKER/CÖLFEN/PAPPERT ( ${ }^{9} 2018$, S. 140 ff.) für die Textlinguistik und STÖCKL (2016, S. 23) für eine multimodale Textlinguistik.

Kapitel 4 stellt das Forschungsfeld, den Zugang dazu sowie die Forschungsmethodik, das Korpus und die weitere Materialsammlung dar. Dementsprechend beschreibt Kapitel 4.1 die Methoden der teilnehmenden Beobachtung sowie qualitativer Interviews und die sogenannte methodische Triangulation als das Zusammenwirken unterschiedlicher Methoden (FLICK, ${ }^{8} 2017$, S. 519 f.), die aus der qualitativen Sozialforschung adaptiert wurde. Methodische Triangulation ermöglicht es, die Schwächen einer Methode durch die Stärken einer anderen Methode auszugleichen, sodass die Methoden einander ergänzen (ebd.). Beispielsweise macht die Dokumentation von Textänderungen nicht deutlich, warum eine Textstelle gelöscht, erweitert, ersetzt, verschoben etc. wurde. Wird beobachtet, wie Überarbeitende die Textüberarbeitungen aushandeln, beispielsweise welche Gründe sie für eine Textänderung anführen, können diese Aussagen als Anhaltspunkte für eine Interpretation der Gründe dienen. Zudem können Interviews mit den betreffenden Überarbeitenden, aber auch mit den Rezipienten diese Interpretationen untermauern oder widerlegen.

Kapitel 4.2 beschreibt das Textkorpus. Diese Beschreibung zielt darauf, das gesamte Textsortennetz des untersuchten Ausschreibungsverfahrens nachvollziehen zu können. Die Beschreibung des Korpus dient zugleich als Grundlage, um die Zusammensetzung des Textkorpus nachvollziehbar zu machen. Alle erhobenen und im Textkorpus enthaltenen Textsortenexemplare waren bisherigen Forschungsprojekten nicht zugänglich.

Kapitel 4.3 beschreibt die Materialsammlung, die den Anhang vervollständigt. Zu dieser Sammlung gehören Beobachtungsprotokolle, Interviews, E-Mails etc. Diese Materialsammlung soll einerseits die Analyse und Interpretation der Textbeispiele in Kapitel 5 unterstützen. Insbesondere bei der Interpretation der Textfunktionen verschiedener Textelemente werden Ausschnitte aus den Protokollen und Interviews herangezogen. Andererseits dient diese Materialsammlung 
in Kapitel 6 dazu, die protokollierten Überarbeitungsprozesse zu beschreiben und unter Aspekten der semiotischen Effizienz zu analysieren und zu interpretieren. Der Beschreibung der weiteren Materialsammlung in Kapitel 4.3 geht ein Überblick über die interfachlichen Projektstrukturen voraus, um Folgendes nachvollziehbar zu machen: a) die Analyse der Protokolle und Interviews; b) die der Textsortenexemplare; c) die Auswahl der Interviewpartner; d) der beobachteten Überarbeitungen. Damit bestimmt dieses Teilkapitel wesentlich das Element ,Interfachlichkeit' als Teil der Forschungsfrage, wie sich Interfachlichkeit auf die semiotische Effizienz von Sprache-Bild-Textsorten auswirkt. Ebenso werden Domäne sowie Auftraggeber- oder Bieter-Organisation beschrieben, weil sie die Projektstruktur bestimmen. Kapitel 4.4 begründet die Auswahl der Textsortenexemplare aus dem Textkorpus, die in Kapitel 5 analysiert werden, und listet diese Auswahl auf.

Kapitel 5 wendet das integrierte Analyseraster für interfachliche Sprache-BildTextsorten aus Kapitel 3 auf ausgewählte Exemplare des Korpus an. Kapitel 5.1 beschreibt und analysiert Exemplare der Textsorte Optimierungsvorschlag, die überwiegend schriftsprachlich geprägt sind. Exemplare dieser Textsorte verfassen Mitglieder aller Abteilungen innerhalb der Organisation.

Kapitel 5.2 beschreibt und analysiert Exemplare der Textsorten Lastenheft und Pflichtenheft. Die Hinführung zu den einzelnen Analysekategorien ab Kapitel 5.1.1 führt in Lasten- und Pflichtenhefte entsprechend Normen (vor allem VDI 2519-1: 2001) und wissenschaftlicher Literatur (LUTZ, 2015; KÖSLER, 2009 u. a.) ein. Diese kurze Einführung ist notwendig, weil Inhalte und Bezeichnungen der beiden Textsortenvarianten oft widersprüchlich verwendet werden. Lastenhefte haben die Auftraggeber als Tabellen gestaltet, die alle Bieter im Verfahren ausfüllen müssen. So soll gewährleistet werden, dass die Angebote der Bieter vergleichbar sind und das Verfahren infolgedessen diskriminierungsfrei abläuft. Diese Lastenhefte haben durch die Tabellenform, in der die Bieter auf offene oder geschlossene Fragen antworten müssen, den Charakter eines Formularvordrucks. Durch das Ausfüllen dieser Lastenheftvordrucke erstellt jeder Bieter innerhalb des Ausschreibungsprozesses ein individuelles Pflichtenheftexemplar. Diese Pflichtenheftexemplare greifen bei geschlossenen Fragen die vorgegebenen Kategorien der Lastenhefte auf bzw. führen die vorgegebenen Kategorien bei 
offenen Fragen thematisch aus. Da sich die Pflichtenhefte aus den Lastenheftvordrucken ergeben, erscheinen Lastenheftvordrucke und Pflichtenhefte als Textsorten-varianten. Während Lastenhefte überwiegend schriftsprachlich geprägt sind, nutzen Pflichtenhefte viele diagrammatische, also multimodale Sprache-Bild-Elemente. Diese Textsortenvarianten werden vor allem von Mitarbeitenden der Abteilung Schienenfahrzeugtechnik, also Ingenieuren, und der Abteilung Betriebsplanung produziert.

Kapitel 5.3 analysiert Varianten der Textsorte Fahrplan. So wird der geplante Betriebsablauf für die angebotenen Schienenfahrzeuge erstens als tabellarischer Fahrplan dargestellt, der Abfahrtzeiten und angefahrene Haltestellen in schriftsprachlicher Form zusammenbringt. Zweitens stellen sogenannte Bildfahrpläne diesen örtlich-zeitlichen Zusammenhang als abbildendes Diagramm mit einer Zeit- und einer Ortsachse dar, indem Linien zwischen diesen Achsen positioniert werden. Drittens stellen sogenannte Fahrzeugumlaufpläne in Tabellen dar, mit wie vielen Waggons ein Zug eine Strecke fährt und wann er wo gewartet wird. Während der Tabellenfahrplan überwiegend schriftsprachliche Elemente nutzt lediglich deren Verortung in einer Tabelle wirkt diagrammatisch -, nutzen Bildund Fahrzeugumlaufplan bildliche Elemente und diagrammatische Symbole. Diese Textsortenvarianten werden beinahe ausschließlich von der Abteilung Betriebsplanung produziert.

Kapitel 5.1, 5.2 und 5.3 beschreiben daher Stellen aus den ausgewählten Textsortenexemplaren, analysieren diese Exemplare vor dem Hintergrund des Analyserasters interfachlicher Sprache-Bild-Textsorten und interpretieren sie, indem Aussagen der Überarbeitenden aus den Beobachtungsprotokollen oder dort dokumentierte Rahmenaspekte zum Ablauf der Überarbeitung herangezogen oder durch eigene Argumentationen gestützt werden. Kapitel 5.4 fasst die Ergebnisse der Textanalysen zusammen und vergleicht die Analyseergebnisse zu den verschiedenen Textsorten - teilweise leisten dies bereits die Teilkapitel 5.1 bis Teilkapitel 5.3 .

Der Zusammenhang zwischen Kapitel 5 und Kapitel 6 ergibt sich aus dem Zusammenhang, der zwischen dem Modell semiotischer Effizienz (Kapitel 2.5) und dem integrierten Analyseraster interfachlicher Sprache-Bild-Textsorten (Kapitel 3) besteht. Das heißt, Kapitel 6 zieht die detaillierte Analyse von Textsorten- 
exemplaren aus Kapitel 5 heran, um die semiotische Effizienz sowohl der Exemplare als auch der beobachteten Überarbeitungsprozesse zu erfassen. Unterkategorien zur ,Komplexität des Kommunikats', also dem Ergebnis gegenüber dem Aufwand des Kommunikats, werden weitgehend durch die Analyseergebnisse in Kapitel 5 erfasst. Die ,Kapazität der Kommunikanten ' geht dagegen nicht aus den Ergebnissen in Kapitel 5 hervor. Diese Kapazität kann zwar nicht durch Beobachtungen oder Interviews empirisch erfasst werden. Aber die Aussagen der Überarbeitenden über Erwartungen an die Rezipienten und über den Rezeptionsprozess sowie die Aussagen der Rezipienten geben Hinweise auf die ,Kapazität der Kommunikanten'. Die Anwendung des integrierten Analyserasters für interfachliche Sprache-Bild-Textsorten (Kapitel 3) auf Exemplare der drei Textsorten führt dazu, die ,Komplexität des Kommunikats‘ in Kapitel 5.4 bestimmen zu können. Daher ist es nur noch notwendig, dass Kapitel 6.1 beobachtete Aussagen zu den Überarbeitungen und Interviewaussagen als ,Kapazität der Kommunikanten“ interpretiert, damit Kapitel 6.2 die Ergebnisse aus Kapitel 5.4 (also zur ,Komplexität des Kommunikats‘) und aus Kapitel 6.1 (zur ,Kapazität der Kommunikanten`) ins Verhältnis zueinander setzen kann. Dabei zielt das Modell semiotischer Effizienz nicht darauf ab, diese Relation zu quantifizieren, sondern vor dem Hintergrund ihrer Textsortenkonventionen und -funktionen zu interpretieren. Denn eine Quantifizierung dieser Relation ist nicht möglich. Die Einschätzung, inwieweit die untersuchten Textsortenexemplare konventionell und funktional sind, handeln die Fachautoren intersubjektiv in den beobachteten kooperativen Überarbeitungen aus. Meine Analyse der Textsortenexemplare, die Fachautoren produzierten, geht insofern über subjektive Maßstäbe hinaus, als sie sich an domänenspezifischen Texten wie DIN-Normen, Leitfäden, Interviewaussagen etc. orientiert.

Kapitel 7 fasst die wichtigsten Antworten auf die Fragestellung unter Berücksichtigung der drei Thesen in Kapitel 7.1 als Fazit zusammen. Die Übertragbarkeit der Ergebnisse und weiterführende Fragen diskutiert der Ausblick in Kapitel 7.2. Mit diesen beiden Unterkapiteln endet der deskriptive Teil meiner Untersuchung und leitet aus diesem in Kapitel 7.3 Orientierungspunkte für die Praxis ab. Damit wird die Untersuchung dem Anspruch gerecht, in dem Maße anwendungsorientiert zu sein, dass sie nach Lösungen für praktische Probleme des erforschten Feldes (s. Kapitel 1.2) sucht. 
Aufbauend auf meinen Analyseergebnissen schlägt Kapitel 7.3.1 vor, an welchen Stellen die Empfehlungen der Bundesarbeitsgemeinschaft für Schienenpersonennahverkehr (BAG SPNV) für Schienenfahrzeuge optimiert werden könnten. Bei der BAG SPNV handelt es sich um den Bundesverband der Auftraggeber, die Ausschreibungen für die einzelnen Bundesländer durchführen. Die BAG-SPNVEmpfehlungen nutzen Auftraggeber verschiedener Bundesländer, um ihre Lastenhefte zu erstellen. Wenn die BAG SPNV meine Vorschläge diskutiert und - ggf. in aufbereiteter Form - berücksichtigt, könnten die Vorschläge zu optimierten Lastenheften bei Ausschreibungsverfahren verschiedener Bundesländer führen.

Während dieser Vorschlag auf ein Kommunikat bzw. auf Gestaltungsmöglichkeiten der Auftraggeber zielt, skizziert Kapitel 7.3.2 eine Möglichkeit, die Textproduktionsprozesse aufseiten der Bieter zu verbessern. Hier sollen Textelemente, also sowohl schriftsprachliche als auch bildliche sowie schriftsprachlich-bildliche Elemente bisheriger Ausschreibungen modularisiert werden. Die aus diesen Textexemplaren entstehenden Textmodule könnten in eine Datenbank eingepflegt werden, die Fachautoren eines Bieters bei der Textproduktion und -überarbeitung unterstützen soll. Dazu müssen die extrahierten Textmodule erstens von der jeweiligen Ausschreibung, aus der der Ausgangstext stammt, abstrahiert werden. Beispielsweise müssten Ortsnamen, Uhrzeiten, Linienbezeichnungen, aber auch Spezifika getilgt werden, die daraus resultieren, dass eine Linie in zwei Nationalstaaten betrieben wird, also zwei Gesetzesgrundlagen, Nationalsprachen etc. berücksichtigt. Nach der Abstraktion innerhalb der Textmodule müssten diese Module nach einem einheitlichen Schema-z. B. nach thematischen und funktionalen Aspekten - annotiert werden. Denn diese Annotation kann den Autoren helfen, bei zukünftigen Textproduktionsprozessen geeignete Textmodule aufzufinden. Kapitel 7.3.2 deutet eine entsprechende Extraktion von Modulen aus den bestehenden Ausgangstexten, deren Abstraktion von der jeweiligen Ausschreibung und Annotation durch mögliche Kategorien an.

Vorerst präzisiert Kapitel 2.1 aber meine Forschungsfrage durch drei Thesen, die aus der Diskussion von RoELCKEs Modell zur kommunikativen Effizienz und den in Kapitel 1.1 aufgezeigten Desiderata resultieren. 



\section{Konzeption des Modells semiotischer Effizienz}

Kommunikative Effizienz wird als eine Form der sprachlichen Ökonomie definiert (Roelcke, 2002a, S. 43) und stellt eine Form von Kommunikationsoptimierung dar, weshalb SCHUBERTs (2007) Konzeption von Kommunikationsoptimierung dem Modell kommunikativer Effizienz gegenübergestellt werden kann (SCHUBERT/HEIDRICH, 2014, S. 88 f.):

Während Kommunikationsoptimierung „,bewusstes Eingreifen in das kommunikative Handeln“ (SCHUBERT, 2009, S. 110) zur Verbesserung bestimmter Merkmale von Kommunikationsmitteln oder kommunikativem Handeln (ebd.) beschreibt, erfasst kommunikative Effizienz Verhältnisse zwischen Elementen von Kommunikaten (also auch Texten) und Kommunikanten, beispielsweise Textproduzenten und -rezipienten (RoelcKe, 2002a, S. 54). Beide Modelle unterteilen Kommunikationsebenen, die es ermöglichen, unterschiedliche Kommunikationskontexte darzustellen: SCHUBERT (2007) bezieht Kommunikationsoptimierung auf drei Stufen, die nach zunehmendem kommunikativen Abstraktionsbzw. Nachhaltigkeitsgrad angeordnet sind (ebd., S. 334 f.): die des Werkstücks als Text, die des Arbeitsprozesses in Form von normierenden Leitfäden und Ähnlichem und die des Sprachsystems (SCHUBERT, 2007, S. 334 f.), beispielsweise in Form von Plansprachen (SCHUBERT, 2011). Das Modell kommunikativer Effizienz differenziert ähnlich diesen drei Stufen und in Anlehnung an SAUSSURE in die Sprachsystemebene (langue) und in die Performanz-Ebene (parole), wobei letztere innerhalb des Effizienz-Modells als Textebene konzipiert ist (ROELCKE, 2002a, S. 70).

Dass die parole-Ebene als Textebene betrachtet werden kann, mag auf den ersten Blick als konzeptionelle Verwechslung von Sprachkompetenz und Textkompetenz wirken. Denn die parole-Ebene wie auch die langue-Ebene betreffen in der SAUSSUREschen Konzeption die Sprachkompetenz (COSERIU, ${ }^{2} 2007 \mathrm{~b}$, S. 60), während eine Textsorten-Ebene die Textkompetenz von Kommunikanten betrifft. So spricht die Autonomie von Texten dagegen, „den Text einfach als eine Erscheinung der Einzelsprache anzusehen und somit keine Unterscheidung zwischen der Ebene der Einzelsprache und derjenigen des Textes zu treffen“ 
(COSERIU, ${ }^{4} 2007 \mathrm{a}$, S. 54). Als Gründe für die berechtigte Unterscheidung zwischen Text- und Sprachkompetenz wird aufgeführt, dass ein Textexemplar Realisate verschiedener Einzelsprachen - also beispielsweise des Italienischen und Englischen - enthalten kann, dass es von den Regeln einer Einzelsprache abweichen kann, dass es situativ bedingt ist, übereinzelsprachlichen Mustern wie Gattungen folgt (ebd., S. 50 ff.) und verschiedene Textfunktionen erfüllt (ebd., S. 60 f.). Diesen Gründen für eine Unterscheidung von Text- und Sprachkompetenz stellt COSERIU allerdings eine Unterteilung von drei Stufen sprachlichen Wissens gegenüber: textbezogenes Wissen (expressives Wissen), einzelsprachliches Wissen (idiomatisches Wissen) und allgemeines Sprachwissen (elokutives Wissen), d. h. von einer Einzelsprache unabhängiges Wissen (ebd., S. 55 ff.). Dies zeigt, dass in Coserius Modell die Stufe des Textwissens bzw. die Textebene zwar nicht an eine Einzelsprache gebunden ist. Das Stufenmodell ist aber derart angelegt, dass Textwissen nicht unabhängig von allgemeinem Sprachwissen ist, also von Wissen, das die Ebene des Sprachsystems betrifft. Dies erklärt, warum das Effizienz-Modell die parole-Ebene als Textebene gegenüber der langue-Ebene ausformuliert.

Dass Texte übereinzelsprachlichen Mustern folgen (ebd., S. 54), zeugt von ihrer Konventionalität im Sinne einer Textsortenkonvention. Auch bei Richtlinien und Leitfäden für die Textgestaltung handelt es sich um eine schriftlich fixierte Form ${ }^{7}$ der Textsortenkonvention. SchuberTs (2007) Konzept der Kommunikationsoptimierung berücksichtigt auf der mittleren Stufe der Arbeitsprozesse diese Gestaltungsrichtlinien, Redaktionsleitfäden etc. (ebd., S. 335). Textsortenkonventionen $\mathrm{zu}$ erfassen, ermöglicht es einem Kommunikationsmodell nicht nur, eine Ebene von Einzelfällen beschreiben zu können, sondern Konventionen zu berücksichtigen, die auch in anderen Situationen innerhalb dieser Domäne Gültigkeit haben. Im Anschluss daran kann ein Modell, das Textsortenkonventionen berücksichtigt, Hinweise auf bzw. Hinweise für zukünftige Schreibprozesse geben. Damit ein Effizienz-Modell, das auf RoELCKEs Modell aufbaut, dies auch leisten kann, ist eine Erweiterung des dichotomen Systems von Sprachsystem

7 Die schriftliche Fixierung wird bei Normen als Statuiertheit bezeichnet (GLOY, ${ }^{2} 2004$, S. 394). 
(langue) und Text/Performanz (parole) notwendig. Denn weder die Ebene des Sprachsystems noch die der konkreten (schriftsprachlich-bildlichen) Äußerung erfassen eine Musterhaftigkeit im Sinne einer Konvention. Innerhalb des Effizienz-Modells kann aber eine Ebene der Textmuster bzw. Textsorten ${ }^{8}$ zwischen die Text- und Systemebene gefügt werden. In diesem Sinne berücksichtigt die Fachsprachenforschung bereits früh eine Ebene fachlicher Textsorten (BAUMANN/KALVERKÄMPER, 1996), die nach wie vor Eingang in aktuelle Modelle der Fachkommunikationsforschung findet, beispielsweise in das ROELCKEs (2014).

Muster bzw. Sorten von Texten sind durch verschiedene Formen des Textsortenwandels (HAUSER/KLEINBERgER/Roth, 2014) multimodal geprägt. Die linguistische Forschung widmet sich dieser Texteigenschaft immer stärker, ${ }^{9}$ sodass für ein textsortenorientiertes Effizienz-Modell die Herausforderung besteht, (Fach-)Textsorten als multimodale Kommunikate zu erfassen. Einen entsprechenden Anknüpfungspunkt bietet die Konzeption semiotischer Ökonomie, die als maximale kommunikative Effizienz (maximal communicative efficiency) spezifiziert wird (SchMITZ, 2014, S. 279). Dabei wird das Konzept aus der Beschäftigung mit Medienkommunikation wie E-Mails, Webseiten und SocialMedia-Beiträgen abgeleitet, deren Gestaltung wie folgt zusammengefasst wird: „Verbal elements become parts of multimodal messages. They are mainly

8 Die grundlegende Idee, die langue-parole-Dichotomie durch eine Ebene individuell-sozialer Normen zu erweitern, die zwischen dem Sprachsystem einer Einzelsprache (langue) und konkreten sprachlichen Realisierungen (parole) steht, basiert auf COSERIU ( ${ }^{3} 1979$ ). So grenzt er die Norm-Ebene (norma) vom Sprachsystem wie folgt ab: „Was hingegen dem Individuum auferlegt wird, seine Ausdrucksfreiheit einschränkt und die vom System gebotenen Möglichkeiten innerhalb seiner fixierten Grenzen der traditionellen Realisierungen begrenzt, ist die Norm: die Norm kann in der Tat als System der obligatorischen Realisierungen der sozialen und kulturellen ,Auflagen“ angesehen werden; sie hängt von der Ausdehnung und der Natur der jeweiligen Gemeinschaft ab.“ (ebd., S. 57; Kursive im Original) Vor dem Hintergrund der Form von Fachkommunikation, die meine Arbeit untersucht, lege ich in dieser Arbeit einen anderen Norm-Begriff als den genannten aus COSERIU $\left({ }^{3} 1979\right)$ zugrunde. Der in dieser Arbeit verwendete Norm-Begriff ist als Spezialfall von Textsortenkonventionen zu verstehen (s. Kapitel 2.2.1).

9 Textsortenexemplare waren bereits vor dem pictorial turn in der Linguistik multimodal gestaltet, wie einige Untersuchungen zu Sprache-Bild-Texten belegen (u. a. SCHRÖDER, 1993; KALVERKÄMPER, 1993; SPILLNER, 1982). Linguistische Untersuchungen blendeten Bilder aber weitgehend aus (SCHMITZ, 2007). 
organized by visual design in order to be perceived as efficiently as possible." (ebd., S. 301) Ausgehend von dieser Beschreibung der Kommunikate zeichne sich semiotische Ökonomie durch die Anforderungen an die untersuchten Kommunikate aus, Informationen fehlerfrei (unerring), schnell (fast) und leicht erfassbar (easy to grasp) zu präsentieren (ebd., S. 295).

In dieser Konzeption der Ökonomie multimodaler Kommunikate werden noch keine sozio-funktionalen Aspekte berücksichtigt, die für die Fachkommunikationsforschung besonders relevant sind. So resümieren HEINE/SCHUBERT (2013) beispielsweise, dass ein sozio-kognitives Paradigma bzw. die sogenannte situierte Kognition die Fachkommunikationsforschung präge (ebd., S. 112). In der hier untersuchten interfachlichen Kommunikation stellt sich die Situierung in Form der jeweiligen fachlichen Prägung der Textsortenexemplare bzw. der beteiligten Kommunikanten dar.

\subsection{Kommunikative Effizienz}

Auf die folgende Beschreibung des Modells kommunikativer Effizienz (s. Kapitel 2.1.1) baut die Darstellung der Kritik auf, die andere Quellen an diesem Modell üben (s. Kapitel 2.1.2). Sowohl die Beschreibung von RoELCKEs Modell als auch die Kritik an diesem stellen die Grundlage für meine Thesenbildung dar (s. Kapitel 2.1.3), die darauf abzielt, das Modell kommunikativer Effizienz zum Modell semiotischer Effizienz zu erweitern (s. Kapitel 2.5).

\subsubsection{Das Modell kommunikativer Effizienz}

Das Modell kommunikativer Effizienz (RoELCKE, 2002a) wird in aktuellen linguistischen Arbeiten diskutiert, adaptiert und modifiziert, beispielsweise in Heidrich (2016), Schubert/Heidrich (2014, S. 88 f.) oder Pelikan (2015, S. 203 f.). Es wird auch in den Wirtschaftswissenschaften adaptiert, um ökonomische Implikationen von Sprachgemeinschaften zu erforschen (KoLBE, 2010, S. $40 \mathrm{ff}$.). RoElCKe (2002a) entlehnt wiederum die Effizienz-Kategorien aus den Wirtschaftswissenschaften, wie die Beispielobjekte Fertigungskosten, -stückzahl etc. (ebd., S. 23) veranschaulichen. In anderen grundlegenden Arbeiten zur Kommunikationsoptimierung (SCHUBERT, 2009) oder zu Verständlichkeitskonzepten (LuTZ, 2015, S. 139 ff. u. a.) wird das Modell dagegen nicht berücksichtigt. 
Effizienz wird im Modell kommunikativer Effizienz entweder als Aufwand- oder als Ergebniseffizienz beschrieben (RoELCKE, 2002a, S. 34). Denn ein maximales Ergebnis bei gleichzeitig minimalem Aufwand (Mini-Max-Prinzip) zu beschreiben (ebd.), hätte den Nachteil, dass nicht mehr messbar bzw. nachvollziehbar ist, ob die Veränderung der Variable ,Aufwand“ oder der Variable ,Ergebnis' einen Effekt erzielt. Deswegen wird eine der beiden Variablen ,Aufwand“ und ,Ergebnis' ceteris paribus - also konstant - gehalten: Aufwandeffizienz beschreibt ein „Minimum des Aufwands bei einem bestimmten Ergebnis“( (ebd., S. 34), während Ergebniseffizienz ein „Maximum des Ergebnisses bei einem bestimmten Aufwand“ (ebd.) beschreibt. Effizienz wird insoweit von Effektivität abgegrenzt, als Letztere lediglich eine Ergebniserwartung ausdrückt und den faktischen Zusammenhang mit dem Aufwand (Handlungen und Vorgänge) außer Acht lässt, der notwendig ist, um diese Erwartung zu erfüllen (ebd., S. 20).

RoelcKe (2002a) stellt der Entwicklung des Effizienz-Modells folgende sechs Forderungen voran, die es zu erfüllen habe (ebd., S. 34 f.): 1. nicht Sprache, sondern Sprachhandlungen und deren Bedingungen zu fokussieren; ${ }^{10} 2$. Bezug auf sämtliche Sprachebenen wie Wortschatz, Syntax, Text und Varietäten zu nehmen; 3. das Verhältnis zwischen Aufwand- und Ergebniseffizienz zu konzipieren; 4. sowohl systematische als auch pragmatische Aspekte einzubeziehen; ${ }^{11}$ 5. synchrone und diachrone Aspekte zu erfassen; 6. bestehende Modelle zu Sprachökonomie zu berücksichtigen. In Bezug auf meine Untersuchung erscheint es notwendig, zum einen die zweite Forderung um Ebenen des Layouts und Designs von Sprache-Bild-Textsorten zu erweitern und zum anderen Aufwand-ErgebnisEffizienz zu fokussieren. Dabei sollen die Kategorien nicht in ein quantitatives, sondern in ein qualitatives Verhältnis zueinander gesetzt werden, das sich an den Kriterien Konventionalität und Funktionalität ausrichtet.

10 Bei der Untersuchung von kommunikativer Effizienz grundsätzlich Sprachhandlungen und -kontext zu fokussieren, entspricht dem pragmalinguistischen Kontextmodell (ROELCKE, ${ }^{3} 2010$, S. 18 ff.).

11 Das Modell wird entsprechend der zweiten und vierten Forderung in die Ebene des Sprachsystems (RoElcKe, 2002a, S. 56 ff.) und die des sprachlichen Textes unterteilt (ebd., S. $63 \mathrm{ff}$.). 
Diese sechs Forderungen bilden die Grundlage für das Modell kommunikativer Effizienz, das sich aus drei Ebenen - gemeint sind hier Modellebenen und nicht die Sprachsystem-, Konventionen- oder Textebene - mit jeweils zwei Unterelementen zusammensetzt (S. Tabelle 2-1): Die oberste Ebene stellt die Grundeinheiten ,Komplexität des Kommunikats‘ und ,Kapazität der Kommunikanten' einander gegenüber. ,Komplexität' ergibt sich als Eigenschaft des Kommunikats aus der ,Intension“ (Ergebnis) und ,Extension“ (Aufwand), die Elemente der mittleren Modellebene bilden. Auf der untersten Modellebene setzt sich das ,Ergebnis des Kommunikats' wiederum aus den beiden Elementen ,Information“ und ,Instruktion` zusammen. Den ,Aufwand des Kommunikats' bedingen ,Textelemente' und deren ,Relationen'. ,Kapazität' wird als Eigenschaft der Kommunikanten aus den Elementen ,Kompetenz' und ,Konzentration' zusammengesetzt. Diese Kapazität der Kommunikanten entsteht auf der untersten Ebene aus den beiden Elementen ,Kompetenz ${ }^{6}$ - gemeint ist eine Kommunikationsfähigkeit - und ,Konzentration`, die eine Kommunikationsbereitschaft bezeichnet.

Diese Beschreibung bezieht sich auf eine generelle Ebene der kommunikativen Effizienz (ebd.) und wird für Elemente der Textebene wie auch der Sprachsystemebene ausformuliert. Für meine weitere Arbeit ist ausschließlich die Textebene relevant (s. Tabelle 2-1), da die Elemente, die diese konstituieren, auch genutzt werden, um die Ebene der Textsortenkonventionen zu konzipieren. Die Textebene des Modells kommunikativer Effizienz präzisiert RoELCKE (2002a) wie folgt:

Auf der obersten Modellebene entsteht die ,textuelle Komplexität des Kommunikats' aus verschiedenen Graden der ,textuellen Intension“ und der ,textuellen Extension', während sich die ,textuelle Kapazität der Kommunikanten' aus unterschiedlichen Graden ,textueller Kompetenz' und ,textueller Konzentration“ ergibt (s. Tabelle 2-1). ${ }^{12}$

12 Die Gliederung der folgenden Unterkapitel dieses zweiten Kapitels orientiert sich an den Kategorien des RoELCKEschen Effizienz-Modells. 


\begin{tabular}{|l|l|l|l|l|}
\hline $\begin{array}{l}\text { Grad } \\
\text { der }\end{array}$ & $\begin{array}{l}\text { Komplexität } \\
\text { (von einem) }\end{array}$ & $\begin{array}{l}\text { Kapazität } \\
\text { (von) }\end{array}$ \\
\hline & $\begin{array}{l}\text { Kommunikat } \\
\text { Intension } \\
\text { (Ergebnis) }\end{array}$ & $\begin{array}{l}\text { Extension } \\
\text { (Aufwand) }\end{array}$ & $\begin{array}{l}\text { Kommunikant } \\
\text { (Fähigkeit) }\end{array}$ & $\begin{array}{l}\text { Konzentration } \\
\text { (Bereitschaft) }\end{array}$ \\
\hline $\begin{array}{l}\text { gene- } \\
\text { rell }\end{array}$ & $\begin{array}{l}\text { Information } \\
\text { und Instruk- } \\
\text { tion }\end{array}$ & $\begin{array}{l}\text { Elemente } \\
\text { und deren } \\
\text { Relationen }\end{array}$ & $\begin{array}{l}\text { Intelligenz und } \\
\text { Instrument }\end{array}$ & $\begin{array}{l}\text { Intention und In- } \\
\text { teresse }\end{array}$ \\
\hline textuell & $\begin{array}{l}\text { Proposition } \\
\text { und Illoku- } \\
\text { tion }\end{array}$ & $\begin{array}{l}\text { Wörter, } \\
\text { Sätze und } \\
\text { Teiltexte }\end{array}$ & $\begin{array}{l}\text { Produktions- und } \\
\text { Rezeptionsver- } \\
\text { mögen }\end{array}$ & $\begin{array}{l}\text { Produktions- } \\
\text { und Rezeptions- } \\
\text { bereitschaft }\end{array}$ \\
\hline
\end{tabular}

Tabelle 2-1: Elemente effizienter Kommunikation im Überblick (in Anlehnung an ROELCKE, 2002a, S. 70).

Auf der mittleren Modellebene resultiert die ,textuelle Kompetenz einer Einzelperson' in Abhängigkeit von der ihr zugehörigen (fachlichen) Kommunikationsgemeinschaft graduell aus ihrem physischen und kognitiven ,Rezeptions- und Produktionsvermögen“; entsprechend konstituieren die ,Konzentrations- und Kommunikationsbereitschaft" im Sinne von ,Interesse“ und ,Intention“ einer Einzelperson die ,textuelle Konzentration“ (RoElCKe, 2002a, S. 64).

Die ,textuelle Kompetenz' wird als Teil der mittleren Modellebene durch das ,Produktions- und Rezeptionsvermögen' differenziert, die Teil der untersten Ebene sind. So hängt die textuelle Kompetenz - und dies ist für die Untersuchung interfachlicher Kommunikation von besonderer Bedeutung - „einer einzelnen Person mit deren Kenntnis einzelner Fachsprachen bzw. deren fachlichem Vermögen als sachlicher und sprachlicher Experte" (ebd.) zusammen. Auf der untersten Ebene ist bei der ,textuellen Konzentration“ „,von der wechselnden Bereitschaft einzelner Personen zu fachlicher Differenzierung auszugehen" (ebd., S. 65). Während die Ausdifferenzierung von textueller Kompetenz und Konzentration Teil der Kapazität eines Kommunikanten ist, werden die ,textuelle Intension" (textuelles Ergebnis) und die ,textuelle Extension“ (textueller Aufwand) als Teil der Komplexität des Kommunikats auf der untersten Modellebene wie folgt ausformuliert: Die beiden Elemente ,Proposition“ und ,Illokution' bestimmen das ,textuelle Ergebnis', die auf der mittleren Ebene gemeinsam mit dem 
,textuellen Aufwand' das textuelle Kommunikat bilden. So führen qualitative und quantitative Unterschiede - beispielsweise als Referenz von Lexik auf eine außeroder objektsprachliche Wirklichkeit - zu unterschiedlichen Graden des textuellen Ergebnisses (ebd., S. 63 f.).

Die Bezeichnungen ,Proposition“ für den Aussagegehalt von Textelementen und ,Illokution' für die Funktion eines Textteils deuten darauf hin, dass das EffizienzModell auf die Sprechakttheorie referiert, beispielsweise auf SEARLEs ( $\left.{ }^{12} 2013\right)$ Proposition und Illokution sind darin unter anderem Teil eines Sprechakts. Des Weiteren ergibt sich auf der untersten Modellebene die ,textuelle Extension' aus den beiden Elementen ,Wörter' bzw. ,Sätze‘. Dieser Aufwand resultiert erstens aus der Fachlexik eines Textes, die durch die syntaktischen, semantischen und pragmatischen Regeln der Systemebene bestimmt wird; zweitens resultiert er aus Sätzen und drittens aus ,Teiltexten', deren Art und Umfang zu unterschiedlichen Extensionsgraden zwischen einzelnen Texten führen können (RoELCKE, 2002a, S. 64).

Aus den Verhältnissen zwischen diesen Elementen der drei Modellebenen ergibt sich die kommunikative Effizienz, die den Kern des Effizienz-Modells darstellt:

„Kommunikative Effizienz liegt dann vor, wenn Textintension mit Proposition und Illokution als Kommunikationsergebnis und Textextension mit Wörtern und Sätzen als Kommunikationsaufwand einerseits und Textkompetenz mit Produktions- und Rezeptionsvermögen als Kommunikationsfähigkeit und Textkonzentration mit Produktions- und Rezeptionsbereitschaft als Kommunikationsbereitschaft andererseits in einem ausgewogenen Verhältnis zueinander stehen." (ebd., S. 67; Kursive im Original)

D. h., als textuell effizient gilt Kommunikation, wenn sich die Grade des Kommunikats und des Kommunikanten (s. Tabelle 2-1) entsprechen (ebd., S. 67 f.); dagegen gilt als textineffizient, wenn sich Kommunikationsaufwand und -ergebnis unterbieten oder der Grad des Kommunikats unter dem Grad des Kommunikanten liegt (ebd., S. 68). ${ }^{13}$ Effizienz von Kommunikation durch dieses Verhältnis

13 Kommunikative Effizienz wird nicht nur dadurch definiert, dass sie Effizienz aus dem Verhältnis ihrer Elemente bestimmt, sondern auch dadurch, dass kommunikative Effizienz von kommunikativer (In-)Effektivität abgegrenzt wird. Als textineffektiv gilt es, wenn das Kommunikationsergebnis unter dem Kommunikationsaufwand oder der Grad des Kommunikationsergebnisses unter dem Grad des Aufwands liegt (ebd.). Für die weitere 
von Graden der Kommunikanten und des Kommunikats zu konzipieren, führt dazu, dass Effizienz scheinbar quantitativ gemessen werden kann. Diese Form der Quantifizierung bildet den Ausgangspunkt für wesentliche Kritik am und Erweiterungen des Effizienz-Modells.

\subsubsection{Erweiterungsmöglichkeiten für das Modell kommunikativer Effizienz}

HEIDRICH (2016), die qualitative Faktoren wie Erwartungen für die Beschreibung bzw. die Beurteilung von Kommunikation ins Zentrum eines Konzepts zur Kommunikationsoptimierung rückt, kritisiert die quantitativ-formalisierte Ausrichtung von RoELCKEs Modell:

„Roelcke fordert eine mathematische Formalisierung des von ihm erstellten Konzepts. Mir stellt sich die Frage, wie beispielsweise der Faktor ,Kommunikationsbereitschaft" beziehungsweise ,Konzentration', beschrieben als Intention und Interesse, quantitativ erfasst werden soll. Meines Erachtens ist es schwierig, diesen Faktor überhaupt zu erfassen. Eventuell wäre es sinnvoller, diesen Faktor als Konstante zu betrachten, da ja Intention und Interesse für eine effektive Kommunikationshandlung vorausgesetzt werden sollten." (HEIDRICH, 2013, S. 255)

Aber nicht nur die formalisierende Quantifizierung an sich, sondern auch die daraus resultierenden Verhältnisse des Modells seien fragwürdig. So hinterfragt HEIDRICH (2016), „ob denn tatsächlich ein hoher Grad an Konzentration [...] einen geringen Grad an Kompetenz [...] ausgleichen kann“ (ebd., S. 255).

Das Problem, dass das Effizienz-Modell im Zentrum auf ein quantitatives Verhältnis abzielt, kritisiert auch DANNERER (2008). Sie begründet ihre Kritik mit einem Rückgriff auf Diskussionen zu Effizienz, die wesentlich früher in den Wirtschaftswissenschaften geführt wurden. Damit knüpft DANNERER (2008) an die Grundidee des Effizienz-Modells an, Modelle und Beispiele aus den Wirtschaftswissenschaften zu entlehnen, allen voran die Vermeidung des Mini-Max-Prinzips und Beispiele wie Fertigungs- und Stückzahlen etc. (s. Kapitel 2.1.1). So kritisiert DANNERER (2008) das Paradigma des homo oeconomicus, dem zufolge „ein Individuum seine Handlungsmöglichkeiten durch ein Kosten-Nutzen-Kalkül bewertet und sich dann rational handelnd nach dem Prinzip der Nutzenmaximie-

Untersuchung ist lediglich kommunikative Effizienz relevant, die sich aus dem Verhältnis ihrer Elemente ergibt. 
rung entscheidet" (ebd., S. 49). In den Wirtschaftswissenschaften lösten andere Paradigmen dieses Paradigma bereits ab. Auch die Voraussetzung des EffizienzModells, dass Entscheider über vollständige Informationen verfügen, wurde in den Wirtschaftswissenschaften am Modell des homo oeconomicus kritisiert. Im Anschluss daran stelle das Satisfication-Modell eine Alternative zum Paradigma des homo oeconomicus dar. Da ein Entscheider „,nicht alle denkbaren Alternativen wahrnehmen und abschätzen bzw. bewerten kann" (ebd.), orientiert er sich an bekannten Routinen, um ein Anspruchsniveau unterhalb des Entscheidungsoptimums realisieren zu können (ebd.). Übertragen auf Kommunikation drücke sich dies dadurch aus, dass Interaktanten kommunikative Effizienz realisierten, indem sie sich ,im Rückgriff auf Handlungsmuster und Textsorten auf bewährte Routinen [verlassen]“ (ebd., S. 50). MushCHININA (2017, S. 183 ff.) plädiert ebenfalls dafür, die Adaption von RoELCKEs (2002a) Modell auf Konventionen auszurichten. Denn „[a]us den wiederholten Fällen der erfolgreichen, effizienten Kommunikation kristallisieren sich Konventionen auf allen sprachlichen und kommunikativen Ebenen heraus“ (MushCHININA 2017, S. 172). Infolgedessen modelliert sie (ebd., S. 185) sprachzentriert die (In-)Akzeptanz von fachkommunikativen Konventionen.

DANNERER (2008), die sich der Organisationen- und Unternehmenskommunikation widmet, schlägt vor, Effizienz ,zu beziehen auf Teilziele von bestimmten Gruppen eines Unternehmens“ (ebd., S. 54). Aber auch diese Form der Effizienz bleibt schwer messbar (ebd.). DANNERER leitet aus ihrer Adressatenspezifik für das Effizienz-Modell ab, dass Kommunikationsbeiträge ,,angemessen sein [müssen] im Hinblick auf die Kapazität eines Adressaten“ (ebd.). Sie kritisiert aber, dass das Effizienz-Modell Kommunikationsbedingungen auf Verständlichkeit und Explizitheit reduziere, was weitere wichtige Faktoren nicht berücksichtigt (ebd., S. 54 f.). Ich greife die Argumentation auf, die quantitativ-formalisierende Betrachtung von menschlichem Verhalten als Teil des homo-oeconomicus-Paradigmas zugunsten einer Verhaltensbetrachtung durch Handlungsmuster und Textsorten aufzugeben, um den sozialen Kontext, beispielsweise in Form von Organisationenzielen, zu berücksichtigen. Im Anschluss an diese Neuausrichtung können zwar die grundlegenden Elemente des Effizienz-Modells beibehalten werden. Das Verhältnis zwischen diesen Elementen wird aber nicht mehr 
formalisierend-quantifizierend erfasst. Vielmehr könnte sich eine Textanalyse an der domänenspezifischen Textsortenkonventionalität und -funktionalität orientieren.

Denn Textsorten und deren Angemessenheit werden letztlich dadurch beschrieben, dass sie eine kommunikative Funktion erfüllen (COSERIU, ${ }^{4} 2007$ a, S. 60 f.). Die Erfüllung einer kommunikativen bzw. textuellen Funktion wird auch als adäquate Kommunikation bezeichnet, die wiederum das Ziel von Optimierung ist (Zehrer, 2014, S. 338 f.). Sie hängt dabei von Adressaten und Produzenten eines Textes ab (GÖPFERICH, 2002, S. 156 f.), was das Effizienz-Modell durch die Elemente ,Kompetenz der Kommunikanten“ und ,Konzentration der Kommunikanten` erfasst. Während der Adäquatheitsbegriff von Texten dem sogenannten Karlsruher Verständlichkeitsmodell (ebd.) zugrunde liegt, zielen die Konventionalität und Funktionalität von Textsorten in interfachlicher Kommunikation nicht auf Verständlichkeit im Sinne dieses oder anderer Modelle ${ }^{14}$.

Grund dafür ist, dass Verständlichkeitsmodelle sich in der vorhandenen Form nicht eignen, um kommunikative Effizienz in Kommunikationssituationen zu beschreiben, in denen Kommunikanten Vagheit intendieren. Beispielsweise zielt die Gestaltung von Patenten darauf ab, durch Vagheit von Begriffen den Anspruchs/Schutzumfang möglichst weit auszudehnen, den ein Patent hat (NICKL, 2006, S. 48; SCHAMLU, 1985, S. 123). In Rechtstexten wie Verordnungen und Gesetzen des Bereichs Technik werden abstrakte Begriffe genutzt, die weitgehend vage sind. Denn eine ständig stattfindende technische Innovation würde es erforderlich machen, präzisere Begriffe eines Rechtstextes regelmäßig zu aktualisieren. Daher verwenden Rechtstexte des Bereichs Technik vage, abstrakte Begriffe wie

Das Karlsruher Modell bezieht sich auf das Hamburger Modell nach LANGER/SCHULZ VON Thun/TAusch ( ${ }^{9} 2011$ ). Das Kremser Verständlichkeitsmodell baut als das aktuellste Modell sowohl auf dem Karlsruher als auch dem Hamburger Verständlichkeitsmodell auf. Um für das Konzept von Verständlichkeit eine kurze Orientierung zu geben, werden im Folgenden die Dimensionen des Kremser Modells dargestellt: Kompliziertheit, Komplexität, Gliederung, Usability, Korrektheit, Motivation, Kürze und Deutlichkeit (LuTZ, 2015, S. 243 ff.). Diese Dimensionen von Verständlichkeit werden durch folgende Randbedingungen determiniert: kommunikative Ziele, Situation, Modus und Medium, Textsorte, Fachsprache und Terminologie, Sprachkompetenz, Vorwissen und Kognition (ebd., S. 238 ff.). 
beispielsweise Stand der Technik. ${ }^{15}$ Wie die Beispiele von Begriffen in Rechtsverordnungen und Patentschriften zeigen, können Textoptimierungsmodelle Prozesse wie die Verwendung von vagen Begriffen behandeln, die Verständlichkeitskonzepte nicht zu erfassen vermögen.

Denn sowohl die Textproduktion als auch die Textrezeption basieren nicht auf einer kontextunabhängigen Verständlichkeit, sondern richten sich an Textsortenkonventionen, ggf. sogar -normen aus, die durch den kommunikativen Kontext bedingt sind:

„Auch das, was Leser im Hinblick auf Verständlichkeit in bestimmten Kommunikationsarenen und Textsorten erwarten (dürfen), wird durch kulturelle, funktionale und pragmatische Rahmenbedingungen präjudiziert oder sogar normativ vorgegeben (z. B. Schreiben von Bewerbungsunterlagen nach Vorgaben der deutschen DIN Norm [sic] 2008).“ (ANTOS/HASLER/PERRIN, 2011, S. 641; Fettdruck AH)

Diese Konventionen (zum Teil auch Normen), Erwartungen und die Adäquatheit von Kommunikationsoptimierung berücksichtigt das Modell des fachübersetzerischen Prozesses mit Fokus auf prozessoptimierende Einflussfaktoren und kommunikative Effizienz (HeIDRICH, 2016). ${ }^{16}$ In diesem Modell hängen Textsorten vor allem von den Erwartungen der Textrezipienten ab, die ein wesenliches Element für die Erweiterung des RoELCKEschen Effizienz-Modells darstellen:

„Über die [...] Teilkompetenzen hinaus definiert sich jeder der Akteure auch durch seine Einstellungen und Neigungen sowie seine Erwartungen (E). Diese Erwartungen basieren zu einem großen Teil auf kulturell unterschiedlichen Konventionen, u. a. auch Textsortenkonvention." (HEIDRICH, 2016, S. 226)

15 Die Vor- und Nachteile der begrifflichen Abstraktion werden häufig am Begriff Stand der Technik diskutiert (RoßNAGEL, 2001, S. 195 f.; LuKES, 1981, S. 186; SOFFritTI, 2002, S. 60).

Das Modell gliedert sich in die Akteurs- , Prozess- und Textebene, deren Interdependenzen als , lenkende Einflüsse' erfasst werden (HEIDRICH, 2016, S. 222 ff.). Auf der Akteursebene bilden ,Wissensdimensionen' und ,Erwartungen' zentrale Kategorien, während die Textebene durch die Kategorien ,Zweck', ,Qualität', ,sprachlicher Ausdruck' und ,fachlicher Inhalt' bestimmt ist. Die Prozessebene wird als Übersetzungs- und Schreibprozessebene konzipiert, die die Kategorie ,Effizienz' umfasst, welche wiederum auf das Kommunikationsprodukt Text Einfluss nimmt. Die Prozessebene geht aufgrund eines Übersetzungsprozesses zwischen Einzelsprachen von Ausgangs- und Zielkulturen aus. Als effizient gilt in diesem Modell die Rezeption eines Zieltextes dann, ,wenn die Verständlichkeit des Zieltextes und das Wissen des Zieltexte-Rezipienten einander entsprechen“" (ebd., S. 234). 
Heidrichs Übersetzungsmodell verknüpft hier Erwartungen und Textsortenkonventionen mit Ausgangs- und Zielkulturen verschiedener Einzelsprachen, die für ausschließlich in der Amtssprache Deutsch stattfindende Ausschreibungsprozesse nicht relevant sind. Der fachliche Hintergrund von Rezipienten kann in diesem Kontext als mikrokultureller Hintergrund gelten, der Einfluss auf die Erwartungen und letztlich auf die Textsortenkonventionen hat. Denn Fächer bzw. ihre Sprachgemeinschaft gelten als Mikrokulturen (HORN-HeLF, 2010), die innerhalb einer Einzelsprache einen Technolekt (ENGBERG, 1997) bzw. eine in einer Einzelsprache ausgeprägte Fachsprache, also eine Fachvarietät, verwenden. In interfachlicher Kommunikation spielen demnach mikrokulturelle Erwartungen sowohl der Textrezipienten als auch der -produzenten eine Rolle.

Da also die „Erwartungen des Zieltext-Rezipienten bzw. dessen Zielkultur [...] direkt Einfluss auf den Zweck und die Eigenschaften des Zieltextes“ (HEIDRICH, 2016, S. 228) nehmen, kann in interfachlicher Kommunikation die mikrokulturelle Erwartung eines Zieltext-Rezipienten Einfluss auf den Zweck eines Zieltextes haben. Nicht nur Textsortenkonventionen, sondern insbesondere mikrokulturelle Erwartungen erscheinen somit als Erweiterungsmöglichkeit von RoELCKEs Effizienz-Modell.

Neben Textsortenkonventionen und mikrokulturell geprägten Erwartungen behandelt der Diskurs um Modelle der Kommunikationsoptimierung Sprache-BildRelationen und Multimodalität und bietet damit einen Ansatzpunkt, das EffizienzModell zu erweitern, um an den aktuellen Forschungsdiskurs anzuknüpfen. So werden Kommunikationsoptimierungen auch durch Informationsstrukturierung und den Ansatz des sogenannten Funktionsdesigns (SCHÄFLEIN-ARMBRUSTER, ${ }^{2} 2014$ ) als multimodale Forschungsansätze erfassbar (HEIDRICH, 2016, S. 235). In diesen Ansätzen nehmen die Gestaltung von Sprache-Bild-Relationen, Bild-Sequenzierungen und Bildfunktionen im Text etc. (ebd., S. 211 f.) Einfluss auf die Effizienz des Übersetzungsprozesses bzw. eines Zieltextes. Wie bereits meine Einleitung darstellt, wird ein Komplex von Forschungsaufgaben für die Erforschung von kommunikativer Optimierung darin gesehen, den „Einsatz von Illustrationen und die Verknüpfung sprachlicher und nichtsprachlicher Mittel, insbesondere das Verhältnis zwischen Text und Bild sowie die Wahl zwischen beiden“ (SCHUBERT, 2009, S. 140) zu behandeln. SCHUBERT/HeIDrich (2014) 
schlagen für die Optimierung von Textsortenexemplaren vor, ,die verständnisund verwendungsgünstigste Gestaltung von Druckerzeugnissen in Typografie und Layout" (ebd., S. 88) zu berücksichtigen. Dieser Vorschlag resultiert aus dem Versuch, RoELCKEs Effizienz-Modell mit den vier Dimensionen des integrativen Modells der Fachkommunikation (SCHUBERT, 2007) zu verquicken, sodass ,also neben dem Arbeitsprozess der fachliche Inhalt, der sprachliche Ausdruck und das technische Medium“ (SCHUBERT/HeIDrICH, 2014, S. 88) Wege zur Kommunikationsoptimierung eröffnen.

Der Forschungsdiskurs verweist bei der Diskussion von RoELCKEs EffizienzModell auf diverse Aspekte. Dargestellt haben die vorangegangenen Ausführungen im Wesentlichen drei Aspekte, um die das Effizienz-Modell erweitert werden soll: Textsortenkonventionen, mikrokulturelle Erwartungen sowie Multimodalität in Form von Sprache-Bild-Relationen und Typographie.

\subsubsection{Drei Modifikationsthesen zum Modell kommunikativer Effizienz}

Wie die Einleitung ankündigt (s. Kapitel 1.1), präzisieren drei Thesen die zentrale Forschungsfrage, wie sich Interfachlichkeit auf die semiotische Effizienz von Sprache-Bild-Textsorten, insbesondere von Pflichtenheften, auswirkt. Grundlage für diese Präzisierung bildet das Effizienz-Modell von RoELCKE und dessen Adaption durch die Erweiterungen um Textsortenkonventionen, mikrokulturelle Erwartungen und Multimodalität von Fachtextsorten. Damit ergeben sich folgende drei Thesen:

\begin{tabular}{|l|l|}
\hline These 1 & $\begin{array}{l}\text { Das Verhältnis zwischen der Kapazität der Kommunikanten und } \\
\text { der Komplexität des Kommunikats, das kommunikative Effizienz } \\
\text { bestimmt, kann als Textsortenkonventionalität und -funktionalität } \\
\text { erfasst werden. }\end{array}$ \\
\hline
\end{tabular}

These 1 ist insofern überprüfbar, als die Kompetenz und Konzentration bzw. die Kapazität der Kommunikanten interpretiert werden können, da von der Performanz solchermaßen bedingt auf die Kompetenz eines Kommunikanten geschlossen werden kann (NeUBeRT, 2007, S. 124). Die Interpretationen zu den Kategorien ,Kompetenz' und ,Kapazität' werden im empirischen Teil meiner Arbeit anhand von protokollierten Aussagen der Textproduzenten über die Kapazität 
der Textrezipienten gestützt. These 1 bildet die Voraussetzung für These 2 und These 3 .

\begin{tabular}{|l|l|}
\hline These 2 & $\begin{array}{l}\text { Diese Textsortenkonventionen sind domänenspezifisch und mik- } \\
\text { rokulturell geprägt. In interfachlicher Kommunikation muss } \\
\text { ausgehandelt werden, welche Textgestaltung als konventionell } \\
\text { und funktional gilt, weil sich die Erwartungen der Kommunikan- } \\
\text { ten vor dem Hintergrund ihrer verschiedenen mikrokulturellen } \\
\text { Prägungen unterscheiden. }\end{array}$ \\
\hline
\end{tabular}

Während auch These 2 bzw. die Kapazität der Kommunikanten nur interpretierbar ist, kann sie aber in Bezug auf Aufwand und Ergebnis eines Kommunikats (also eines Textsortenexemplars) empirisch belegt oder widerlegt werden. Die Prüfung von These 2 soll dabei berücksichtigen, ob die Exemplare der unterschiedlichen Textsorten in geringem oder hohem Maße konventionalisiert werden.

Auch die Prüfung von These 3 soll berücksichtigen, ob die Exemplare der drei Textsorten, die der empirische Teil dieser Arbeit untersucht, in unterschiedlichem Maße semiotisch komplex, also in unterschiedlichem Maße monomodal oder multimodal, gestaltet sind. These 3 kommt die höchste Relevanz für meine Untersuchung zu, weil sie These 1 und These 2 zusammenfasst und sich unmittelbar auf die Forschungsfrage bezieht.

\begin{tabular}{|l|l|}
\hline These 3 & $\begin{array}{l}\text { Kommunikate sind in naturwissenschaftlich-technischen Kom- } \\
\text { munikationsbereichen multimodal gestaltet, nutzen also auf der } \\
\text { textuellen Aufwandsseite bildliche, schriftsprachliche und dia- } \\
\text { grammatische Elemente, die durch Grammatik und Textdesign } \\
\text { angeordnet bzw. gestaltet sind. Auf der textuellen Ergebnisseite } \\
\text { können alle Elemente Textfunktionen und -semantik repräsentie- } \\
\text { ren. Die Fähigkeit, wie diese Elemente rezipiert werden, wird } \\
\text { durch die mikrokulturelle Textkompetenz der einzelnen Kommu- } \\
\text { nikanten bestimmt. }\end{array}$ \\
\hline
\end{tabular}

Die folgenden Teilkapitel und Kapitel arbeiten aus dem Forschungsdiskurs Teile der Konzepte heraus, die relevant sind, um diese drei Thesen empirisch überprüfen zu können und konzeptionell zu stützen. 


\subsection{Kapazität der Fachkommunikanten als Textsortenkonventionen und Erwartungen}

These 1, die sich auf Textsortenkonventionen und -funktionen bezieht, wird im Folgenden dadurch gestützt, dass die ,Kommunikationsfähigkeit von Fachkommunikanten' durch Textsortenkonzepte und ihre Konventionalität ausgestaltet wird (s. Kapitel 2.2.1). Textsortennormen stellen dabei einen Sonderfall von Textsortenkonventionen dar, wie im Folgenden zu zeigen ist (s. Kapitel 2.2.2). Des Weiteren diskutiert Kapitel 2.2.2 These 1 dadurch, dass die ,Kommunikationsbereitschaft von Fachkommunikanten" in Form von Erwartenskonzepten der Textrezipienten oder Textproduzenten behandelt wird. Diese Konzepte umfassen dabei auch, dass (Textsorten-)Konventionen auf Sanktionen und Benefizierung von Texthandlungen basieren. Da Textsortenkonventionen und die Erwartungen an diese an ihren Verwendungskontext, also auch an eine fachliche Prägung bzw. mehrere fachliche Prägungen einer Verwendungsdomäne gebunden sind, setzen sich diese beiden Unterkapitel auch mit These 2 auseinander, die eine mikrokulturelle Prägung dieser Textsortenkonventionen unterstellt.

Entsprechend dem Modell kommunikativer Effizienz wurden bisher Kommunikanten und ihre Kapazität in allgemeiner Form thematisiert. Da ich im Folgenden Fachkommunikation behandle, fokussiere ich die Kapazität von Fachkommunikanten. Auch wenn nach wie vor die Begriffe Fach und Fachlichkeit nicht ,näher betrachtet, geschweige problematisiert, begrifflich geklärt [...] oder sogar definiert" (KALVERKÄMPER, 1998a, S. 1) werden, hilft die folgende Definition, den Begriff ,Fachkommunikation ${ }^{117}$ zu präzisieren:

„Die Fachkommunikation umfasst zielgerichtete, informative, mit optimierten Kommunikationsmitteln ausgeführte einsprachige und mehrsprachige mündliche und schriftliche Kommunikationshandlungen fachlichen Inhalts, die von Menschen in Ausübung ihrer beruflichen Aufgaben ausgeführt werden." (SCHUBERT, 2007, S. 210) ${ }^{18}$

17 Der cognitive turn der Fachsprachen- zur Fachkommunikationsforschung (vor allem HoffmanN, 1993, S. 614; aber auch Schubert, 2007, S. 158 f. und RoElcke, ${ }^{3} 2010$, S. 29 f.) wird erst an der Kategorie ,Kapazität‘ des Effizienz-Modells (s. Kapitel 2.2.1) unmittelbar deutlich.

18 Dies schließt auch Kommunikationshandlungen mit sich selbst (secum ipso) ein, z. B. beim „Niederschreiben eigener Gedanken“ (DICK 2019, S. 15) in Form von Recherchenotizen. 
Im beruflichen Kontext lassen sich Fachkommunikanten demnach dadurch bestimmen, dass sie an eine Einzelsprache gebundene Kommunikationshandlungen in ihrem Beruf ausführen, indem sie optimierte Kommunikationsmittel, also optimierte Fachkommunikate, nutzen. Dabei sind diese Kommunikationshandlungen an einen fachlichen Inhalt geknüpft, sodass Fachkommunikate wie Fachtextsorten daran ausgerichtet werden, auf welchen fachlichen Inhalt sie sich beziehen und wie sie in den kommunikativen Kontext eingebunden werden. Inhalt und Verwendung der Kommunikate sind dabei an ihre Textsortenkonventionen gekoppelt.

\subsubsection{Der Einfluss gültiger Textsortenkonventionen auf die Kommunikationsfähigkeit der Kommunikanten}

Konzepte von Textsorten, die sich an die Sprechakttheorie anlehnen, betonen neben der Intentionalität von sprachlichen Handlungen deren Konventionalität ${ }^{19}$ (BRINKER/CÖLFEN/PAPPERT, ${ }^{9} 2018$, S. 89). Übertragen auf Texte drückt sich diese Konventionalität in textuellen Mustern aus (HAUSENDORF/KeSSELHEIM, 2008, S. 163 f.), die Kommunikanten in gesellschaftlichen Funktionsbereichen anwenden (ebd., S. 166 f.) und in der Lektüresozialisation erlernt haben (ebd., S. 22). Konventionalität drückt sich dementsprechend in Regeln aus, denen Kommunikanten in spezifischen Verwendungssituationen folgen und die sie ,jeweils in ihrem Sozialisationsprozess mehr oder weniger vollkommen erlernt haben“" (BRINKER/CÖLFEN/PAPPERT, ${ }^{9} 2018$, S. 89). Die hervorgehobene Lektüresozialisation betont, dass Kommunikanten konventionelles Textwissen aufbauen. ${ }^{20}$ Während BRINKER/CÖLFEN/PAPPERT ( ${ }^{9} 2018$ ) diese konventionellen Muster von Texten als Textsorten erfassen (ebd., S. 139), betonen HeINEMANN/HEINEMANN (2002) die kognitive Seite dieser Muster und Textrezeptions- und Textproduktionsprozesse, indem sie Textsorten von Textmustern unterscheiden: Im Anschluss

19 Arbeiten zu Fachtextsorten (GÖPFERICH, 1995) und situierter Fachkommunikation (ZEHRER, 2014, S. 121) beziehen sich auf ein Konventionen-Konzept von LEWIS (1993, S. 199 ff.), das als eines von mehreren Grundmodellen der Linguistik angesehen wird (ROLF, 2008, S. 155 ff.).

20 Auf textbezogenes Wissen (expressives Wissen), das von allgemeinem Sprachwissen (elokutives Wissen) und einzelsprachlichem Wissen (idiomatisches Wissen) abgegrenzt wird (COSERIU, ${ }^{4} 2007 \mathrm{a}, \mathrm{S} .55$ f.), ist in der Hinführung zu Kapitel 2.2.1 bereits verwiesen worden. 
an das Wahrnehmen und Bewerten von Situation und Kommunikationspartner (ebd., S. 125) werden Textmuster aktiviert (ebd., S. 130), aus denen das „Verstehen/Verarbeiten konkreter Textexemplare“ (ebd., S. 140) als kognitive Prozesse und Textsorten als „Ergebnis kognitiver Operationen“ (ebd., S. 140) hervorgehen können. So sind Textmuster definiert als

„Rahmenmodelle [...] für den Ablauf spezifischer Kommunikationsereignisse, die den Handelnden ein schnelles verbales Agieren und Re-agieren in bestimmten wiederkehrenden Situationen erlauben, indem sie dieselbe [sic] Rahmen durch partiell wiederum ,vorgefertigte“ Äußerungseinheiten und -strukturen ,auffüllen“"“ (ebd., S. 130).

Das sogenannte Auffüllen der Äußerungseinheiten findet textuell statt, d. h., es ist als Schritt eines geistigen Erkenntnisprozesses Teil des Zeichens bzw. des Textes. In Abgrenzung von Textmustern definieren Heinemann/Heinemann (2002) Textsorten dadurch, dass ,konkrete Textexemplare [...] bestimmte Merkmale aufweisen, die es rechtfertigen, sie aus praktischen Gründen zu einer Klasse von Texten, vorläufig ,Textsorten“ genannt, zusammenzufassen“(ebd., S. 140).

Durch die Abstraktion von Textexemplaren lassen sich Textsorte und Textmuster nicht als Entsprechung zur langue und parole auffassen, weil Textsorten von konkreten Äußerungssituationen abstrahieren und Textmuster wiederum an konkrete Äußerungssituationen gebunden sind. Für diese Textmuster ist das Textualitätskriterium ,Kohärenz' relevant - je nach Definition (s. unten). Es bezeichnet in Anlehnung an BEAUgrande/Dresslers (1981) Modell ,den konzeptionellen Zusammenhang des Textes, d.h. die zugrundeliegende Konstellation von Begriffen und Relationen“ (BRINKER/CÖLFEN/PAPPERT, ${ }^{9} 2018$, S. 18), und wird in der weiteren Rezeption ,als eine Art ,regulative Idee“ beim Umgang mit Texten“ (ADAMZIK, ${ }^{2} 2016$, S. 112) konzipiert. WeTZCHEWALDs (2012) Definition von Kohärenz schlägt die Brücke zwischen HeInEMAnN/HeInEMANNs (2002) Definition von Textsorte und der von Textmuster dadurch, dass es die „Leistung des Rezipienten ist, die Kohärenz aktiv herzustellen“ (Wetzchewald, 2012, S. 110). Kohärenz ist in dieser Definition nicht nur eine Eigenschaft des Textes, sondern „beide Aspekte - sowohl die Beschaffenheit des Textes als auch die Rezeption durch den Leser - [sind] gemeinsam kohärenzstiftend“ (ebd.).

Diese Sichtweise auf Kohärenz unterstützen - unter der Annahme, dass ein Text als ein Zeichen angesehen werden kann - Zusammenhänge in PEIRCEs und 
MORRIS’ Zeichenmodellen: Bei einem Zeichen spielen Zeichenträger (Representamen), das Bezeichnete (Object) und die Erkenntnis des menschlichen Geistes (Interpretant) zusammen (PEIRCE, 1998, S. 272 f.): „A Sign is a Representamen of which some Interpretant is a cognition of a mind.“21 (ebd., S. 291; Kursive im Original) MORRIS' Zeichenmodell übernimmt PEIRCEs Konzeption weitgehend (NöTH, ${ }^{2} 2000$, S. 89) und erweitert es um den Interpreten, der den Interpretanten nicht wie bei PEIRCE als Erkenntnis des menschlichen Geistes, sondern als mittelbares Notiznehmen ausführe (MORRIS, ${ }^{2} 1988$, S. 93). Der Interpret ist damit in der Regel ein Rezipient. Semiose bezeichnet bei MORRIS ( $\left.{ }^{2} 1988\right)$,jede Situation, in der etwas durch die Vermittlung eines Dritten von etwas, das nicht unmittelbar kausal wirksam ist, Notiz nimmt“ (ebd., S. 92). ${ }^{22}$ Sowohl den Interpretanten als auch das Repräsentamen als textkonstituierend anzusehen, drückt folgende Feststellung ADAMZIKs insoweit aus, als Wissen in Anlehnung an MORRIS äquivalent zum Interpretanten behandelt wird: ${ }^{23}$

„Erst wenn man etwas wahrgenommen hat, kann man ihm aufgrund diverser Wis-
sensbestände irgendeinen Sinn zuschreiben; die beiden fundamentalen Quellen,
Wahrnehmung und Wissen, müssen also grundsätzlich gleichermassen herangezo-
gen werden. Dies eben entspricht dem sog. Prozess der Semiose; [...].“ (ADAMZIK,
${ }^{2} 2016$, S. 104; Fettdruck im Original)

Die Fokussierung von Textsorten unter anderem durch Wissensbestände spricht dafür, dass Textsortenexemplare bzw. deren Analyse Hinweise auf die Kapazität von Kommunikanten geben. Entsprechend WetzchewALDs Definition von Textkohärenz, PEIRCEs und MORRIS' Zeichenauffassung und ADAMZIKs Übertragung dieser Auffassung auf Texte verzichte ich auf die Differenzierung von Textsorte

21 Die Termini geistige Erkenntnis und menschlicher Geist entnehme ich folgender Übersetzung von PEIRCE durch PAPE: „Ein Zeichen ist ein Repräsentamen, dessen Interpretant eine Erkenntnis des menschlichen Geistes ist." (PEIRCE, 1982, S. 123; Kursive im Original)

22 MORRIS $^{2}\left({ }^{2} 1988\right.$, S. 93) Definition unterscheidet sich durch folgende drei Punkte von PEIRCEs Definition: 1. Die geistige Tätigkeit aus PEIRCEs Konzept wird durch einen Prozess des Interpreten variiert bzw. spezifiziert, bei dem der Interpret in einer unmittelbaren (Kommunikations-)Situation von etwas Notiz nimmt. 2. Ein unmittelbar kausaler Zusammenhang zwischen Denotat (bei PEIRCE Objekt) und Interpretant bzw. Interpret wird ausgeschlossen. 3. Der Prozess der unendlichen Semiose aus PEIRCEs Konzept wird in MORRIS‘ Definition nicht einbezogen. Für diese Arbeit ist lediglich das Textverständnis als Repräsentamen und gleichzeitig als Interpretant - wie oben gezeigt - grundlegend.

23 AdAMZIK (2016) setzt sich an dieser Stelle mit dem Textmodell von HausENDORF/KeSSELHEIM (2008) auseinander. 
und -muster, wie sie HeInEMANN/Heinemann (2002) vornehmen. Stattdessen beziehe ich mich auf einen Textsortenbegriff, der in Anlehnung an die Sprechakttheorie durch Konventionalität und Intentionalität geprägt ist (BRINKER/CÖLFEN/PAPPERT, ${ }^{9} 2018$, S. 89).

Textsortenkonzepte, die im Sinne des pragmalinguistischen Paradigmas sprechakttheoriebasiert sind, sind mit dem Ansatz der Fachtextsortenforschung kompatibel, Textsorten auf der Grundlage der Sprechakttheorie als Textschemata, also als Operationspläne, aufzufassen (RoELCKE, ${ }^{3} 2010$, S. 42). Zugleich stützt die bisherige Auseinandersetzung mit Bezugsebenen von (Fach-)Textsorten, speziell von Kohärenz, den Kern meiner These 1, dass das Verhältnis zwischen der Kapazität der Kommunikanten und der Komplexität des Kommunikats neben einer Textebene auch eine Ebene der Textsortenkonventionen betrifft.

These 1 spezifiziert Textsortenkonventionen durch ihre Eigenschaft, konventionell und funktional zu sein. Dieser Teil von These 1 bildet den Ausgangspunkt für die folgende Auseinandersetzung mit Textsortenkonzepten. Das sprechaktbasierte Textkonzept in BRINKER/CöLfEN/PAPPERT ( $\left.{ }^{9} 2018\right)$ leitet den Textfunktionsbegriff aus der Intentionalität ab, die Kommunikanten aus der Nutzung von sprachlichen Mitteln in einer konkreten Situation aufgrund der Konventionalität dieser Nutzung ableiten (ebd., S. 89 f.). Dabei gibt die Musterhaftigkeit eines Textes Auskunft darüber, inwieweit er eine Textfunktion mithilfe von spezifischen sprachlichen Mitteln oder auch ohne spezifische Mittel vorhersagbar ausdrückt: „Der Terminus ,Textfunktion“ bezeichnet die im Text mit bestimmten, konventionell geltenden, d. h. in der Kommunikationsgemeinschaft verbindlich festgelegten Mitteln ausgedrückte Kommunikationsabsicht des Emittenten.“ (ebd., S. 97; Fettdruck im Original) Die sprachlichen Indikatoren für Textfunktionen nach BRINKER/CÖLFEN/PAPPERT ( ${ }^{9} 2018$ ) bezeichnet KESSELHEIM (2011) als Hinweise, die ein zu analysierender Text aufweist und die „den Schluss von diesen Hinweisen auf die Textsortenzugehörigkeit eines Textexemplars“ (ebd., S. 357) zulassen. Zwar verwiesen sprachliche Indikatoren eines Textes auf eine Textfunktion (BRINKER/CÖLFEN/PAPPERT, ${ }^{9} 2018$, S. 97). ,[D]ass die Ermittlung der Textfunktion nicht allein aufgrund sprachlicher Kriterien [...] erfolgen kann, sondern dass die kontextuelle Analyse prinzipiell den Ausschlag gibt“ (ebd., S. 100; Fettdruck im Original), belege aber der Verweis von sprachlichen 
Indikatoren auf mehrere Textfunktionen. ${ }^{24}$ Textsortenfunktionen als die ,in einer historisch gewachsenen Diskurstradition stehenden Phänomene" (FANDRYCH/ THURMAIR, 2011, S. 20) werden auch in einem weiteren Textsortenkonzept definiert, das die Musterhaftigkeit der Textsortenfunktion betont. FANDRYCH/THURMAIR fordern von der Analyse dieser Funktionen, dass sie überindividuelle Handlungsabsichten eines Autors berücksichtigt:

„Vielmehr muss herausgearbeitet werden, welche typischen Zwecke mit bestimmten Textsorten immer wiederkehrend verbunden werden, mit welchen Absichten daher Autoren und Autorinnen im Regelfall solche Textsorten produzieren und mit welchen Zwecken und mit welcher Handlungsabsicht sie im Regelfall von Lesern rezipiert werden. [...] Einzelne Texte müssen so - um ihre Funktion bzw. Funktionen zu rekonstruieren - auf der Folie der in einer Sprachgemeinschaft üblichen Textsortenkonventionen und ihren Zwecken interpretiert werden." (ebd.)

Der Zweck eines Textes bzw. einer Textsorte wird auch als Zweck-Mittel-Relation ermittelt, die einzelne sprachliche Ausdrucksmittel eingehen können. So weisen sie erstens auf eine potenzielle Funktion eines Textes und als Bündel von Merkmalen zweitens auf den Kontext hin (ADAMzIK, ${ }^{2} 2016$, S. 174). Eine Gesamttextfunktion und die Zweck-Mittel-Relationen einzelner Ausdrucksmittel ergeben eine Textfunktion (ebd.). Inwieweit der Gebrauch bestimmter

24 Auch die Angemessenheit eines Textes wird daran bemessen, inwieweit ein Text eine Textfunktion wie Befehl, Lüge oder Ironie in einer bestimmten Sprechsituation erfüllt (COSERIU, ${ }^{4} 2007 \mathrm{a}, 60 \mathrm{f}$.) und entweder durch spezifische einzelsprachliche Mittel bzw. Verfahren gestaltet - wie die Textfunktion Befehl durch eine Imperativform - oder eine Textfunktion auch ohne entsprechende einzelsprachliche Verfahren ausdrückt - wie eine Anspielung, Feststellung oder Erwiderung (ebd., S. 62 f.). Denn Sprecher können auch einen Befehl aufgrund der Situation und Personenkonstellation ohne Imperativform als Befehl erkennen.

Wie die Beispiele Ironie und Lüge zeigen, basiert das Konzept der Textfunktionen bei COSERIU ( $\left.{ }^{4} 2007 \mathrm{a}\right)$ nicht auf der Sprechakttheorie (ebd., S. 61), sondern bezieht das dreigliedrige Varietätenmodell COSERIUs ( $\left.{ }^{2} 2007 b\right)$ von Allgemeiner Sprache - Einzelsprache und konkreter Äußerung auf eine Textebene. Und im Gegensatz zu Textkonventionalität und -funktionalität rückt COSERIUs $\left({ }^{4} 2007\right.$ a) Textkonzept Angemessenheit in den Mittelpunkt: „Eine Äußerung ist korrekt, wenn sie den Regeln einer bestimmten Sprache entspricht [...]. Auf der Ebene des Textes, der das expressive Wissen entspricht, spreche ich von ,Angemessenheit'; etwas kann angemessen oder auch unangemessen sein, ganz unabhängig davon, ob es korrekt oder inkorrekt ist. [...] Angemessenheit kann die Korrektheit aufheben, das sprachlich Nicht-Korrekte kann für gewisse Texte gerade das Angemessene sein." (ebd., S. 57; Kursive im Original) Angemessenheit lege ich meinem Effizienz-Konzept nicht zugrunde, da das Angemessenheitskonzept in der empirischen Analyse schwer zu operationalisieren ist bzw. für eine wissenschaftlich-beschreibende Analyse kaum Instanzen herangezogen werden können, die Angemessenheit beurteilen. 
Ausdrucksmittel also unmittelbar auf eine mögliche Funktion verweist, hängt davon ab, „wie konventionalisiert oder auch normiert der Gebrauch bestimmter Ausdrucksmittel bzw. wie gross die Wahlfreiheit des Produzenten ist" (ADAMZIK, 2016, S. 174). Die textuellen Gestaltungsmittel stehen also auch durch ihre Konventionalität in einer Zweck-Mittel-Relation (ebd.).

Im Zentrum der bisher beschriebenen Begriffe von Textfunktion steht neben dem Kontext ein Zweckbegriff: So werden Texte entsprechend ihren Zwecken interpretiert, um ihre Funktion zu rekonstruieren (FANDRYCH/THURMAIR, 2011, S. 20). Zur Begründung textueller Grundfunktionen dient in Anlehnung an die Sprechakttheorie „der illokutionäre Zweck (,illocutionary point')“ (BRINKER/CöLFEN/PAPPERT, ${ }^{9} 2018$, S. 103; Fettdruck im Original). Hinweise auf die Textfunktion gibt daher ,[a]lles, was dazu beiträgt, den Text als einen in spezielle Zwecksetzungen eingebetteten Zusammenhang von Sprachhandlungen erkennbar zu machen“ (HAuSENDORF/KeSSELHEIM, 2008, S. 139). Neben einer (mathematischen) Zuordnungsvorschrift verschiedener Elemente besteht eine Funktion im funktionalistischen Sinne ,in der Zweckdienlichkeit, die dem Funktionsträger hinsichtlich einer bestimmten, komplexen Bezugsgröße zukommt" (RoElCKE, 1994, S. 17). Diese Zweckdienlichkeit wird nicht nur für einen allgemeinen Funktionenbegriff, sondern auch für Texte bzw. als Kriterium ihrer Analyse herangezogen (ebd., S. 24 f.). Für sein Konzept einer funktionalen Pragmatik hält EHLICH ( $\left.{ }^{3} 2010\right)$ ebenso fest, dass „Zwecke der Handelnden die zentrale Kategorie bilden“ (ebd., S. 216). Dabei ist die „Interpretation des Zweckes als einer gesellschaftlichen Größe" (ebd.) sinnvoll, um die Kategorie der individuellen Ziele von überindividuellen Zwecken zu differenzieren. Diese Zwecke sind Teil von Handlungsmustern, Diskurs- und Textarten (ebd.). Auch FANDRYCH/THURMAIR (2011) fordern, Textsortenfunktionen unter Einbeziehung ,des institutionellen Rahmens“ (ebd., S. 20) überindividuell zu analysieren (ebd.), um Zwecke einer Textsorte herauszuarbeiten. ${ }^{25}$

25 Auch die Diskussion der Textualitätskriterien ,Intentionalität‘ und ,Akzeptabilität‘ (BEAUGRANDE/DRESSLER, 1981, S. 118 ff.) schließt an die der überindividuellen Ziele der Produzenten an. 
Eine Möglichkeit, Zwecke überindividuell zu analysieren, besteht demnach darin, den Handlungskontext von Textsorten, speziell gesellschaftliche bzw. institutionelle Handlungsbereiche, in die Analyse einzubeziehen. Denn die Analyse dieser Handlungskontexte stellt einen Bezugspunkt in der Analyse dar, der für alle handelnden Individuen innerhalb dieses Bereiches identisch und damit überindividuell ist. Beispielsweise sind in Ausschreibungsverfahren die Handlungsrollen der Kommunikanten durch gesetzliche Regelungen und technische Normen klar umrissen.

Gesellschaftliche Handlungsbereiche stellen als kontextueller Indikator neben der kommunikativen Intention des Produzenten und der Einstellung zum Textthema einen Indikator-Grundtypen dar, der unmittelbar an die Bestimmung von Textfunktionen durch ihren gesellschaftlichen Zweck anschließt (BRINKER/CöLFEN/PAPPERT, ${ }^{9} 2018$, S. 100 f.). So kann einerseits in private und öffentliche Handlungsbereiche nach Verbindlichkeitsgrad der Kommunikation differenziert werden (ebd., S. 100), andererseits in offizielle Bereiche (wie einem Amt oder Ähnlichem als institutionelle Rolle) gegenüber Massenkommunikation durch Zeitungen, Fernsehen etc. als Teil von öffentlichen Bereichen (ebd., S. 143). Vergleichbar mit gesellschaftlichen Handlungsbereichen sind gesellschaftliche Funktionsbereiche (HAUSENDORF/KeSSELHEIM, 2008, S. 166), die sich in Systemund Institutionenhinweise untergliedern. So können Texte Systemhinweise enthalten, die auf Funktionsbereiche der Gesellschaft wie Wirtschafts-, Wissenschafts- oder Rechtskommunikation, aber auch auf Intimkommunikation oder massenmediale Kommunikation verweisen (HAUSENDORF/KesSELHEIM, 2008, S. 167 f.). Diese Hinweise drücken sich dadurch aus, ,dass im Text Begriffe für Funktionssysteme aufgegriffen werden, um die Nützlichkeit der vollzogenen Texthandlungen in einen größeren Kontext zu stellen“ (ebd., S. 167) bzw. dadurch, dass in einen Text die charakteristische Semantik eines Funktionssystems eingebunden wird - beispielsweise die Orientierung der Rechtswissenschaft am Begriff Recht, der Wissenschaft an Wahrheit oder der Religion an Glauben (ebd., S. 168).

Textsortenexemplare können Institutionenhinweise enthalten, die auf institutionelle Bereiche hinweisen und dabei BRINKER/CöLFEN/PAPPERTs Grundtypen privater, öffentlicher und offizieller Handlungsbereiche ähneln: Ämter oder 
Ähnliches weisen als Funktionsrollen auf organisations- und institutionsspezifische Funktionen ${ }^{26}$ hin bzw. handelt es sich bei Institutionenbezeichnungen wie Universität oder das Firmenlogo der Deutschen Bahn, bei Amtsbezeichnungen wie Rektor oder Briefköpfen und -umschlägen um institutionelle Hinweise eines Textes (ebd., S. 168). Der Produzent spricht ,in einer bestimmten funktionsbereichsspezifischen Rolle“ (ebd.) den Rezipienten ,in einer komplementären Rolle“ (ebd.) an.

Letzteres Beispiel könnte den Fehlschluss nahelegen, dass eine Textfunktion die Wirkung eines Textes bezeichnete. Beispielsweise könnten Studierende, die vom Rektor dazu aufgefordert werden, ihren Studiengang zu Stichtag X zu beenden, ihr Studium bis zu diesem abschließen. Die Studierenden könnten aber auch beim AStA Unterstützung suchen, der mit dem Rektorat einen späteren Zeitpunkt für das Auslaufen des Studiengangs aushandelt. Das Schreiben des Rektors hätte damit keine Wirkung in dem Sinne, dass die Studierenden die vom Rektor intendierte Handlung ausführen. Nichtsdestotrotz hätten die Studierenden aber die im Rektoratsschreiben enthaltene Aussage verstanden, was eine vom Rektor intendierte Textfunktion sein könnte. Dieses Beispiel eignet sich, um die Differenzierung von Textfunktion und Textwirkung in der Textsortentheorie zu unterscheiden, die sich an die Differenzierung von Illokution und Perlokution in der Sprechakttheorie anlehnt:

„Wie der perlokutionäre Akt bei einfachen sprachlichen Handlungen, so ist auch die Textwirkung im Unterschied zur Textfunktion nicht konventionalisiert, sei sie nun beabsichtigt oder nicht beabsichtigt.“ (BRINKER/CÖLFEN/PAPPERT, ${ }^{9} 2018$, S. 98)

Demnach konstituiert nicht die Absicht eines individuellen Textproduzenten, sondern die Konventionalität die Textfunktion, während beabsichtigte und unbeabsichtigte Folgen als Textwirkung gelten. Entsprechend dieser Unterscheidung wird in anderen Textkonzepten anstelle einer Textwirkung und einer Textfunktion zwischen Perlokution und sozialer Wirkung differenziert:

HAUSENDORF/KESSELHEIM (2008) differenzieren zwar begrifflich in ,Institution“ und ,Organisation', nutzen die beiden Termini Institution und Organisation in den Ausführungen zu Beispielen aber anscheinend synonym (ebd., S. 166 ff.). 


\begin{abstract}
„Das Wissen über Folgen, die durch Vollzug einer illokutiven Handlung eintreten, ist durch die Kategorie kons repräsentiert. Unter kons werden dabei jene sozialen Konsequenzen verstanden, die sich in konventioneller Weise aus dem Vollzug einer illokutiven Handlung ergeben, nicht die Vielzahl möglicher Effekte, die ebenfalls durch illokutive Handlungen eintreten können. So kann z. B. ein Adressat eine illokutive Handlung als Beleidigung, Vorwurf $u$. a. verstehen, ohne daß dies vom Produzenten intendiert war. Diese Wirkungen sind in der Literatur unter dem Begriff der Perlokution zusammengefaßt worden." (HEINEMANN/VIEHWEGER, 1991, S. 102; Fettdruck im Original; Unterstreichung AH)
\end{abstract}

In anderen Textsortenkonzepten lässt sich die „Bewirkfunktion (Kommunikationseffekt oder Perlokution) von der Textfunktion abgrenzen" (GANSEL, 2011, S. 70). Die Bewirkfunktion wird ausschließlich rezipientenorientiert konzipiert und kann wie auch die Textfunktion konventionalisiert sein, was Intentionen und Wirkungen in eine enge Beziehung zueinander setze (GANSEL, 2011, S. 70 f.). Da ,Perlokution` als Synonym zu ,kommunikativer Effekt' aufgeführt wird, bedeutet ersterer Begriff in GANSEL (2011) anscheinend ,perlokutionärer Effekt". Dass dieser Effekt auch konventionalisiert sein könne, erscheint weniger differenziert als HEINEMANN/VIEHWEGERs (1991) Unterscheidung von erstens in konventioneller Weise resultierenden Konsequenzen (kons) und zweitens einer Vielzahl möglicher Effekte als Perlokution. Die Bewirkfunktion als kommunikativer Effekt stellt das Pendant zu BRINKER/CÖlfEN/PAPPERTs Kategorie ,Textwirkung' dar. Infolgedessen widerspricht GANSELS (2011) Auffassung von einem durchaus konventionalisierten perlokutionären Effekt der Konzeption von BRINKER/CÖLFEN/ PAPPERTs ,Textwirkung': Perlokutionäre Effekte zeichne Letzteren zufolge gerade aus, nicht konventionalisiert zu sein.

Grundsätzlich besteht eine Nähe zwischen der sozialen Wirkung als konventionalisierte Wirkung (HeinemanN/Viehweger, 1991, S. 102) und der textuellen Grundfunktion der Steuerungshinweise. ${ }^{27}$ Für Steuerungshinweise wird der Anspruch erhoben, Erfolg(-losigkeit) in Bezug auf das Bewirkpotenzial der textuellen Grundfunktion Steuerungshinweise zu messen (HAUSENDORF/KESSELHEIM, 2008, S. 148):28

27 Sie entsprechen der Klasse direktiver Illokutionen (SEARLE, 1982a, S. 41).

28 Dies wird grundsätzlich auch für illokutionäre Akte angenommen (AUSTIN, 2007, S. 133). 
„Bei der Steuerungsfunktion steht also das Bewirkungspotential des Textes ganz im Vordergrund, und ganz zugeschnitten auf diese Funktionalität zeigen sich die textuellen Erscheinungsformen. [...] Der Text, so die Suggestion und die auch in diesem Fall paradoxe Prätention, soll nicht gelesen, sondern sofort im Sinne einer Handlungsanweisung oder Einstellungsbeeinflussung umgesetzt werden.“ (HAUSENDORF/KesSELHEIM, 2008, S. 148)

D. h., dem Handeln geht ein Verstehen voran, das seinerseits nur dadurch beeinflusst werden kann, ob das Texthandeln von Kommunikanten den Textsortenkonventionen folgt. Grundsätzlich wird am Kriterium der Konventionalität kritisiert, dass nicht nur die Perlokution, sondern auch ,das illokutionäre Analogon zum perlokutionären Effekt, das Verstehen, [...] nicht durch Konvention garantiert werden kann“ (ROLF, 1993, S. 78; Kursive im Original).

Somit ergibt sich aus der Konventionalität der Regeln, die in bestimmten Verwendungssituationen gelten, dass Textrezipienten verstehen können, ob ein Produzent eine Aussage als Frage oder Befehl intendiert hat (BRINKER/CöLFEN/PAPPERT, ${ }^{9} 2018$, S. 89). Auf Texte übertragen ist konventionell festgelegt, durch welche Ausdrucksmittel ein Textproduzent eine Intention bzw. Kommunikationsabsicht ausdrückt (ebd., S. 97). Bestimmte Textfunktionen sind also an konkrete Textsorten gebunden, die diese Funktion durch die Verwendung bestimmter Ausdrucksmittel in den jeweiligen Kommunikationssituationen signalisieren. Gleichzeitig ermöglicht es die konventionelle Verwendung von Ausdrucksmitteln, dass Textproduzenten eine andere als die konventionell geltende Textfunktion verfolgen können, die mit der Verwendung bestimmter Ausdrucksmittel in einer Kommunikationssituation verknüpft ist. Also können Textproduzenten ihr Gegenüber durch diese Einbindung der Ausdrucksmittel täuschen oder manipulieren; ${ }^{29}$ beispielsweise das $J a$-Wort in der Situation einer

29 Möglicherweise intendiert auch der Rektor - um das Beispiel des Rektoratsschreibens zum Auslaufen eines Studiengangs erneut aufzugreifen - mit seinem Schreiben an die betroffenen Studierenden nicht, dass diese das Studium unmittelbar beenden, sondern dass diese sich mit der Bitte um politische, ggf. juristische Aushandlung mit dem Rektorat an den AStA wenden. Diese intendierte Anschlusshandlung könnte der Intention des Rektors folgen, den gesamten politischen Prozess innerhalb der Institution Universität einzuleiten, den Studiengang auslaufen zu lassen. Denn dem Rektor bzw. dem über Rektoratsamtsperioden hinaus agierenden Stab des Rektorats ist dieses Prozedere sicherlich aus vorherigen Verfahren bekannt. 
Trauung, um an das Geld eines Ehepartners zu gelangen (BRINKER/CÖLFEN/PAPPERT, ${ }^{9} 2018$, S. 90). ${ }^{30}$

Die Funktionalität einer Textsorte innerhalb eines Systems, einer Institution bzw. eines Funktions- oder Tätigkeitsbereichs ist obiger Diskussion zufolge durch die in einer Situation konventionelle Verwendung von Ausdrucksmitteln geprägt. Die Konventionalität einer Textsorte steht demnach im Zentrum des Konzepts und ist im Folgenden zu definieren. Diese Definition präzisiert insbesondere These 1 meiner Arbeit, semiotische Effizienz als Textsortenfunktionalität und -konventionalität zu erfassen. Auch in diesem zentralen Punkt lehnen sich Textsortenkonzepte an SEARLEs ( $\left.{ }^{12} 2013\right)$ Sprechakttheorie an: Konstitutive Regeln geben die ,konventionell geltende kommunikative Bedeutung einer sprachlichen Handlung“ (BRINKER/CÖLFEN/PAPPERT, ${ }^{9} 2018$, S. 90) an und erzeugen neue Formen des Verhaltens. Diese konstitutiven Regeln haben - übertragen auf Texte - folgende Form: „Die Äußerung bzw. der Text X gilt in einem bestimmten Situationsbzw. Handlungszusammenhang $\mathrm{C}$ als der Versuch des Sprechers/Schreibers, die (sprachliche) Handlung Y gegenüber dem Hörer/Leser zu vollziehen.“(ebd.)

Innerhalb von SEARLEs Konzept werden diese konstitutiven Regeln von regulativen Regeln abgegrenzt, die bereits existierendes und regelunabhängiges Verhalten bezeichnen (ebd.). Im Gegensatz dazu formuliert LEWIS (1993) ein Konventionenkonzept, das diese beiden Formen von Regeln nicht differenziert, aber ebenfalls auf der Bedeutung von Regeln für eine Sprechergemeinschaft basiert. LEWIS' Konventionenkonzept wird herangezogen, um das Konzept von Fachtextsortenkonventionen grundzulegen, wonach Konventionen ,nicht von einer höheren Instanz festgelegt werden, sondern sich unter gleichgestellten Partnern herausbilden“ (GöPFERICH, 1995, S. 159) und als stillschweigende, ungeschriebene Regel angesehen werden (ebd.). Das Konventionen-Konzept von LEWIS (1993) wird im Folgenden behandelt, um einen für (Fach-)Textsorten geltenden Konventionenbegriff näher zu differenzieren, dessen Bestimmung entsprechend These 1 für das Konzept semiotischer Effizienz zentral ist. LEWIS

30 Textfunktionen werden in BRINKER/CÖLFEN/PAPPERT ( ${ }^{9} 2018$, S. 140) aus Illokutionen der Sprechakttheorie abgeleitet. In der Sprechakttheorie können Kommunikanten primäre und sekundäre Illokutionen realisieren, also direkte und indirekte Sprechakte, was auch auf Textfunktionen übertragbar ist (s. Kapitel 3.2). 
(1993, S. 199 ff.) ${ }^{31}$ geht ebenfalls von Regeln als Grundlage für Konventionen kommunikativer Handlungen aus. Demnach bedingen Regeln eine Konvention innerhalb einer Sprechergemeinschaft bzw. einer sogenannten Population $p$ dadurch, dass a) sich jeder an diese Regeln hält, b) jeder davon ausgeht, dass sich alle anderen an diese halten. Dies begründe im Umkehrschluss wiederum, dass sich c) jeder selbst an diese Regeln hält. Des Weiteren begründe die Präferenz jedes Sprechers die Gültigkeit der Regel dadurch, dass sich d) jeder bzw. fast jeder innerhalb der Sprechergemeinschaft an diese Regel hält, obwohl es e) auch mindestens eine alternative Regel R' gebe, deren Einhaltung für die Sprechergemeinschaft plausibel (praktisch und epistemisch) wäre. Gleichzeitig seien diese Bedingungen der Individuen innerhalb der Gemeinschaft insoweit reziprok, als jeder wisse, dass alle anderen von diesen Bedingungen wissen - die ersten fünf Bedingungen von Konventionen sind „Gegenstand gemeinsamen (oder wechselseitigen) Wissens" (LEwIS, 1993, S. 200). Entsprechend diesen sechs Bedingungen werde die bewährte Praxis mit regulierender Funktion für zukünftiges kommunikatives Handeln präzisiert.

Diese sechs Bedingungen für Regeln, die für Fachtextsortenkonventionen herangezogen werden, sind mit den Konventionen für Textsorten in BRINKER/CöLFEN/PAPPERT ( ${ }^{9} 2018$ ) kompatibel, weil für die Untersuchung von bestehenden Textsortenkonventionen keine Differenzierung in bestehende und entstehende Konventionen vonnöten ist, aber in beiden Begriffen die Gültigkeit von Regeln in einer Kommunikationsgemeinschaft herangezogen werden. Ich folge in dieser Untersuchung der Bestimmung von Textsortenkonventionen durch GÖPFERICH $(1995)^{32}$ und durch BRINKER/CÖLFEN/PAPPERT ( $\left.{ }^{9} 2018\right)$, weil beide Begriffe durch den Bezug auf die Sprechergemeinschaft und die Gültigkeit von Regeln geeignet sind, zu untersuchen, welche kommunikativen Regeln in einer Domäne gültig sind. Diese Regeln diskutieren Fachkommunikanten in der gemeinsamen Überarbeitung von Textsortenexemplaren (s. Kapitel 6.1).

31 Eine kritische Darstellung zu LEWIS‘ Konventionen-Sprachtheorie findet sich in ROLF (2008, S. 155 ff.).

32 Wie oben aufgeführt ist, lehnt sie sich im Wesentlichen an LEWIS (1993) an. 
Im Anschluss an obige Diskussion von Textsortenkonventionen und -funktionen schließe ich mich vorläufig folgender sprechakt-/konventionenbasierter Textsortendefinition an:

„Textsorten sind konventionell geltende Muster für komplexe sprachliche Hand-
lungen und lassen sich als jeweils typische Verbindungen von kontextuellen
(situativen), kommunikativ-funktionalen und strukturellen (grammatischen und
thematischen) Merkmalen beschreiben. Sie haben sich in der Sprachgemeinschaft
historisch entwickelt und gehören zum Alltagswissen der Sprachteilhaber; sie be-
sitzen zwar eine normierende Wirkung, erleichtern aber zugleich den
kommunikativen Umgang, indem sie den Kommunizierenden mehr oder weniger
feste Orientierungen für die Produktion und Rezeption von Texten geben.“
(BRINKER/CÖLFEN/PAPPERT, ${ }^{9} 2018$, S. 139)

In Kapitel 2.3 setze ich mich mit der Abwandlung dieser Definition in ScHMITZ (2011a) auseinander, dessen Definition darauf abzielt, Text-Bild-Sorten zu erfassen.

Weil die Konventionen und im Zusammenhang damit die konventionalisierten Funktionen einer Textsorte ein gemeinsames, wechselseitiges Wissen der Kommunikanten darstellen, bildet dies sich in der Kapazität von Kommunikanten ab. Somit kann ein Teil der Kommunikantenkapazität durch Textsortenkonventionen und -funktionen erfasst werden. D. h., Kommunikantenkapazität als erstes der beiden Elemente, die sich bei semiotischer Effizienz entsprechen, kann durch Textsortenkonventionen und -funktionen bestimmt werden. Einzuschränken ist dabei, dass die Kapazität der Kommunikanten auf texueller Ebene nicht nur deren Produktions- und Rezeptionsvermögen, sondern auch deren Kommunikationsbereitschaft umfasst (s. Tabelle 2-1). Die obige Ausführung zu Konventionen und Funktionen von Textsorten bereitet somit den folgenden Schritt vor, These 1 konzeptionell zu untermauern: Das zweite Element des Entsprechungsverhältnisses semiotischer Effizienz, die Komplexität des Kommunikats, wird in Kapitel 2.3 konzeptionell ausgearbeitet. Kapitel 2.2.2 konzipiert dagegen die Kommunikationsbereitschaft der Kommunikanten, die mit deren Kompetenzen im Modell semiotischer Effizienz als Kommunikantenkapazität zusammengefasst wird. Dort findet auch die konzeptionelle Auseinandersetzung mit These 2 statt, dass diese Textsortenkonventionen mikrokulturell geprägt sind. 


\subsubsection{Auflösung der Modellkategorie ,Kommunikationsbereitschaft ${ }^{6}$ zugunsten von Textsortenkonventionen und fachkommunikativen Teilkompetenzen}

Das Modell kommunikativer Effizienz definiert Kommunikationsbereitschaft als Zusammenwirken von Intention und dem Interesse der Kommunikanten (s. Tabelle 2-1). Diese beiden Kategorien erzeugen die ,textuelle Konzentration“, bei der „,von der wechselnden Bereitschaft einzelner Personen zu fachlicher Differenzierung auszugehen" (RoELCKE, 2002a, S. 65) sei. Kommunikanten können ihre Kommunikationshandlung also mit wenigen Ausnahmen an Intentionen ausrichten. So setzt beispielsweise SEARLE $\left({ }^{12} 2013\right)$ voraus, dass Kommunikanten Sprachhandlungen an ihren Intentionen ausrichten: „Illokutionäre und propositionale Akte sind [...] dadurch charakterisiert, daß Wörter im Satzzusammenhang in bestimmten Kontexten, unter bestimmten Bedingungen und mit bestimmten Intentionen geäußert werden.“ (ebd., S. 41 f.) Wie das Beispiel des Heiratsschwindlers zeigt (Kapitel 2.2.1), sind Textsortenfunktion und Intention des Textproduzenten aber nicht miteinander gleichzusetzen. Denn eine Textsortenfunktion ist insoweit anhand von Ausdrucksmitteln identifizierbar, als deren Gebrauch in einer bestimmten Situation konventionalisiert ist. Dass das nicht ernst gemeinte JaWort eines Hochstaplers bei einer Trauung einer anderen Intention folgt als der, Treue zu schwören, kann weder der Ehepartner noch der Linguist erkennen. Ebenso wenig wie die Intentionen eines Textproduzenten kann das Interesse eines Kommunikanten empirisch untersucht werden. Beispielsweise könnte ein Angestellter durch Blickrichtung, Mimik und Gestik den Anschein erzeugen, an Aussagen seines Vorgesetzten besonders interessiert zu sein, obwohl er dessen Ausführungen nicht folgt.

Daher erscheinen mir weder die ROELCKEsche Modellunterkategorie ,Interesse“ noch die Kategorie ,Intentionen', die ihre Oberkategorie ,Kommunikationsbereitschaft" bestimmen (s. Tabelle 2-1), für eine empirische Analyse geeignet. Infolgedessen gebe ich die Kategorie ,Kommunikationsbereitschaft' auf, um zu prüfen, ob sie durch andere Unterkategorien determiniert werden kann. Diese neuen Unterkategorien müssten empirisch untersuchbar sein, damit sie für das Modell semiotischer Effizienz geeignet sind. Die in Kapitel 2.2.1 thematisierte Konventionalität und Funktionalität von Textsorten bilden den Ausgangspunkt, um mögliche Unterkategorien zu besprechen. Die neue Bestimmung der 
Kategorie ,Kommunikationsbereitschaft' gründet sich auf die zweite Hälfte der Textsortendefinition in BRINKER/CÖLFEN/PAPPERT ( $\left.{ }^{9} 2018\right)$, die an die oben diskutierte erste Hälfte anschließt:

„[S]ie [Textsorten, AH] besitzen zwar eine normierende Wirkung, erleichtern aber zugleich den kommunikativen Umgang, indem sie den Kommunizierenden mehr oder weniger feste Orientierungen für die Produktion und Rezeption von Texten geben.“(ebd., S. 139; Fettdruck AH)

Aus diesem zweiten Teil der Textsorten-Definition lässt sich ableiten, dass Textsortennormen mit Textsortenkonventionen einhergehen, weil Konventionalität und Funktionalität Textsorten begründen. Aber sowohl das genaue Verhältnis zwischen Norm und Konvention als auch der Norm-Begriff bleiben in der weiteren Darstellung in BRINKER/CÖLFEN/PAPPERT $\left({ }^{9} 2018\right)$ unklar: Weder wird der Begriff ,Norm‘ definiert noch weiter ausgeführt oder explizit anhand von Beispielen behandelt. Dies gilt auch für FANDRYCH/ThURMAIRs (2011) Darstellung der in einem Kommunikationsbereich „geltenden Handlungsnormen“ (ebd., S. 17), die die ,jeweils verwendeten Textsorten mit konstituieren“ (ebd.). ADAMZIK (2016) bestimmt Textsorten, die als zentral gesetzte Kategorie gelten, lediglich mit dem Verweis auf BRINKERs Einleitung des Handbuchs für Text- und Gesprächslinguistik, der sich auf Kommunikationsbereiche bezieht, „für die jeweils spezifische Handlungs- und Bewertungs-normen konstitutiv sind“ (BRINKER ET AL., 2000, S. XIX f. nach AdAMZIK, ${ }^{2} 2016$, S. 128). Dagegen vermeiden HAUSENDORF/KeSSELHEIM (2008) bei der Beschreibung von Textsorten und deren Einbindung in Kommunikationsbereiche einen Normbegriff (S. $171 \mathrm{ff}$.) und stellen ausschließlich die Musterhaftigkeit von Hinweisen in den Vordergrund (ebd.), die Textelemente auf ihre Einbindung in Kontext bzw. Situation geben.

Im Folgenden setze ich mich mit Norm-Begriffen und deren Verhältnis zu Konventionen mit dem Ziel auseinander, die Kategorie ,Kommunikationsbereitschaft' für das Modell semiotischer Effizienz genauer zu bestimmen: Unter die „sozialen Normen fallen als Teilmenge die Sprachnormen“ (GLOY, 2004, S. 394; Kursive im Original). In Analogie zur Diskussion um Textsorten und Sprachvarietäten ist auch an dieser Stelle zu bemerken, dass Sprachnormen bzw. fachsprachliche Normen nicht ohne Weiteres mit Textnormen gleichzusetzen sind. Den Brückenschlag zwischen Sprachnorm und Norm einer Fachtextsorte 
vollzieht in diesem Zusammenhang HorN-HeLf (2010, S. 95), indem sie sich auf die oben dargestellte Verknüpfung COSERIUs ( $\left.{ }^{4} 2007 \mathrm{a}\right)$ bezieht, dass Sprachwissen auch das Textwissen umfasse, die Tradition eines Textes bzw. einer Textsorte zu kennen.

HorN-Helf (2010, S. 94) untersucht in Anlehnung an obige Bestimmung von Textsortennormen nach BRINKER/CÖLFEN/PAPPERT ( ${ }^{9} 2018$ ) Konventionen der Sprachverwendung, also ,solche, die den Bezug zwischen sprachlichen Zeichen und ihrer Bedeutung regeln, und die sog. Textsortenkonventionen, die den Zweck haben, die Textproduktion für wiederkehrende Kommunikationssituationen zu standardisieren“ (ebd., S. 94). Einen Spezialfall von Normen bildeten Konventionen insoweit, als sie „eine kollektive Bewertung von Verhalten (im Sinne von was sein sollte oder nicht sein sollte), aber keine Sanktionierung nicht-konformen Verhaltens beinhalten“ (HoRn-Helf, 2010, S. 94; Kursive im Original). Sanktionierung stellt in anderen Konzepten das Differenzierungskriterium dar, um Normen von Konvention abzugrenzen: Eine Norm unterscheidet sich von einer Konvention dadurch, dass Sanktionen für ihre Nichtbeachtung „,in der Regel schriftlich fixiert und genau definierte Institutionen für die Verhängung zuständig sind“" (GöPFERICH, 1995, S. 159 f.). Dabei geht nach GloY (2012, S. 29) der Ansatz, „eine Norm als Kopplung einer Verhaltensregularität mit einer Sanktionspraxis [zu] bestimmen“ (ebd., S. 29; Kursive im Original), auf POPITZ (1980) zurück. Gegenüber der Bestimmung von Normen ausschließlich durch Sanktionierung diskutieren DuCHÉNE/HELLER (2012, S. 332) das Spannungsfeld zwischen normkonformem und nicht normkonformem Verhalten anhand einer Sanktionierungs- und Benefizierungspraxis. ${ }^{33}$

33 Sogenanntes Sprachmanagement in Unternehmen, speziell bei Callcenter-Anrufen mithilfe eines Gesprächsleitfadens, finde nicht nur in Form von normkonformen, sondern auch durch (sprach-)normabweichendes Verhalten (non-standard behaviour) statt (DUCHÉNE/HELLER, 2012, S. 332) und werde - je nach Einzelfall - benefiziert oder sanktioniert. An diese Einbindung von Benefizierung knüpft das Konzept des Normbenefiziars (GLOY, 1975, S. 35) an. Ihn charakterisieren Handlungen, die den dargestellten positiven Bewertungen von abweichendem Verhalten in DUCHÉNE/HELLER (2012) ähneln, falls die Kommunikation erfolgreich ist: „When communication is successful, the ability to adapt the specific communicative context is regarded as an asset. Not following scripts and rules in these instances is proof of creativity and initiative." (ebd., S. 332) 
Sowohl der Ansatz, Normen durch Sanktionierung und Benefizierung zu bestimmen, als auch der Ansatz, Konventionen als eine bestimmte Art von Norm aufzufassen, geht mit der Bestimmung von Textsorten in BRINKER/CÖLFEN/PAPPERT ( $\left.{ }^{9} 2018\right)$ konform, wonach die durch Konventionalität und Funktionalität determinierten Textsorten eine normierende Wirkung haben. Neben dem Konzept der Sanktionierung kann für die Erläuterung, wie sich Normen konstituieren, auch der Benefizierungsansatz herangezogen werden. Demzufolge können Rezipienten die Texthandlung eines Textproduzenten benefizieren, was in Ausschreibungsverfahren aber kaum empirisch untersucht werden kann. ${ }^{34}$

Empirisch untersucht werden kann dagegen die Konventionalität von Textsorten und deren normierende Wirkung, um die RoELCKEsche Modellkategorie „Kommunikationsbereitschaft" (s. Tabelle 2-1) für das Modell semiotischer Effizienz zu modifizieren: Unter der Voraussetzung, dass sich Textwissen als Teil von Sprachwissen auffassen lässt ${ }^{35}$ und demzufolge von Sprachwissen auf Textwissen geschlossen werden kann, behandle ich im Folgenden GLOYs Modell reziproker Erwartenserwartungen. Dadurch soll die Konstitution von Konventionen und damit von Textsortenkonventionen erklären werden.

Die Beschreibung von Sprachnormen als Regulation des Umgangs mit sprachlichen Einheiten rückt Erwartungen ins Zentrum einer Sprachnorm-Konzeption, da diese den Beginn einer Norm bilden:

34 So finden Sanktionierung und Benefizierung meist statt, bevor Kommunikationsprozesse zu beobachten sind, die sich bereits an Textsortenmustern orientieren und in Organisationen stattfinden. Konkret ist bei dem zu untersuchenden Textkorpus und den Beobachtungen der Textüberarbeitungen festzustellen, dass es keine Sanktionierung bzw. Benefizierung durch den im Ausschreibungsverfahren vorgesehenen Rezipienten, den Auftraggeber, gibt. Dies gilt unter der Voraussetzung, dass der Rezipient sanktioniert, indem er eine kommunikative Handlung des Textproduzenten korrigiert. Beispielsweise modelliert die Sprachmanagementtheorie (SPOLSKY, 2009; JERNUDD/NEKVAPIL, 2012; DovaliL, 2013, S. 68; NeKVAPIL, 2006, S. 311) auf der Mikroebene (micro dimension) entsprechende Korrekturen. Bezogen auf Ausschreibungsverfahren können Auftraggeber mit den Bietern nur schriftlich im Rahmen des Verfahrens kommunizieren, wobei keine Korrekturen von Angeboten vorgesehen sind. Die Bieter als Rezipienten der Verdingungsunterlagen können zwar durch Optimierungsvorschläge und Rügen Korrekturen in den Verdingungsunterlagen vorschlagen. Diese muss der Auftraggeber aber nicht umsetzen, zudem beziehen sich die Vorschläge und Rügen kaum auf die sprachlich-semiotische Gestaltung der Verdingungsunterlagen.

S. oben: Horn-Helf (2010, S. 94 f.) und CoSERIU ( ${ }^{4} 2007 \mathrm{a}$, S. 46 ff.). 
„Das normative Erwarten, das Handelnde wechselseitig aneinander richten, führt zu Strukturen reziproker Erwartenserwartungen normativer Art. Sie bilden, der Definition Luhmanns (1972: 65) zufolge, den Beginn einer Norm." (GLOY, 2012, S. 31 f.; Kursive im Original)

Konkret beziehen sich reziproke Erwartenserwartungen auf die Erwartung von Kommunikant 1, dass Kommunikant 2 eine bestimmte Erwartung an sein kommunikatives Handeln habe. Das inverse Verhältnis der Erwartungen von Kommunikant 2 an die Erwartung von Kommunikant 1 konstituiert das reziproke Verhältnis der Erwartungen bzw. der Erwartenserwartungen. Für die Institutionalisierung reziproker Erwartenserwartungen formuliert GLOY (2012) folgende Bedingung:

„Letztere ist institutionalisiert, wenn sich eigenes Erwarten (darüber, was ich zu tun habe) auf die Ansichten anderer Personen darüber, was ich zu tun habe, ferner auf meine Annahme über diese fremden Ansichten sowie auf die Annahme stützt, dass all dieses vice versa auch für die Anderen gilt.“ (ebd., S. 31 f.; Kursive im Original)

Demnach formuliert LEWIS' (1993) oben dargestelltes Konventionenmodell mit seinen sechs Bedingungen aus der Perspektive individueller Aktanten institutionalisierte reziproke Erwartenserwartungen. Normen gelten demnach ,als eine durch Erfahrung bewährte Praxis, der [...] eine regulierende Funktion für die Zukunft zugesprochen wird (Lewis 1975)“ (GLOY, 2004, S. 393). ${ }^{36}$ Weil ich in der exemplarischen Analyse die individuelle Ebene betrachte und LEWIS' (1993) Konventionen-Konzept die Modellierung von Textsortenkonventionen untermauert, ziehe ich in Betracht, die Modellkategorie ,Kommunikationsbereitschaft durch (reziproke Erwarten-)Erwartungen auszugestalten. Dem widerspricht aber, dass Konventionen im Modell semiotischer Effizienz bereits genutzt werden, um die Kategorie ,Kompetenz der Kommunikanten` zu beschreiben. Die Zuordnung von Erwartungen zu einer Modellkategorie ist weiter unten zu klären.

LEWIS (1993) konzipiert Konventionen, während GLOY (2004, S. 394) Voraussetzungen für Sprachnormen benennt. Dies verwundert insoweit nicht, als bereits HoRN-HELFs (2010) Sichtweise auf Konventionen als eine Unterkategorie von Normen beschrieben wurde. $\mathrm{Zu}$ beachten gilt aber, dass GLOY (2004) Normen und Konventionen sehr wohl unterscheidet, als es ,handlungstheoretisch fraglich [bleibt], ob die Konvention selber schon ein hinreichend normatives Motiv für die Auffassung, ihr auch folgen zu sollen, liefert" (ebd., S. 392). 
Weil Normungsprozessen in der Fachkommunikation unterstellt wird, in besonderer Art und Weise abzulaufen, ${ }^{37}$ wird die folgende Beschäftigung mit Fachsprachennormen herangezogen, um die normierende Wirkung von Textsorten bzw. Fachtextsorten entlang der gleitenden Skala der Fachsprachlichkeit (s. Kapitel 2.4.2) zu erläutern. Textwissen, wie es oben bereits in Anlehnung an COSERIU ( $\left.{ }^{4} 2007 \mathrm{a}\right)$ aufgeführt wird, begründet Textsorten wie auch Fachtextsorten:

„In der muttersprachlichen Fachkommunikation stützt sich der Fachmann potenziell sowohl auf sein Wissen um fachliche Sprachhandlungsschemata und kommunikative Normen als auch auf alltägliche Kommunikationserfahrungen, die ihm als Basis für sein spezialisiertes fachsprachliches Wissen und die fachkommunikative Kompetenz gedient haben und weiterhin dienen (und die umgekehrt durch die Herausforderungen und Erfahrungen in der Fachkommunikation erweitert bzw. modifiziert werden können)““. (ENGBERG/JANICH, 2007, S. 223 f.; Kursive im Original)

Diese Zusammenfassung stellt den Zusammenhang zwischen den vier zentralen Bereichen des Modells fachlicher Sprachkultiviertheit dar, die Abbildung 2-1 systematisiert: Alltagserfahrungen und Erfahrungen im Fach stehen sich gegenüber und ergänzen sich gleichzeitig, um fachkommunikative Ereignisse mithilfe von zentralen Teilkompetenzen zu lösen. Dabei zielt dieses Modell darauf ab, die

37 Normungsprozesse von Fachsprachen laufen nach AMMON ( ${ }^{5} 2016$, S. 470 f.) methodisch und institutionell anders ab als für Gemeinsprache. Als eine nicht spezifisch fachsprachenorientierte Institution dient beispielsweise das INSTITUT FÜR DEUTSCHE SPRACHE (IDS) der „Erforschung und Dokumentation der deutschen Sprache in ihrem gegenwärtigen Gebrauch und in ihrer neueren Geschichte" (ebd., 2018, o. S.) und lehnt es ab, den Sprachgebrauch zu normieren. Auch wenn eine Dichotomie von Fach- und Gemeinsprache zugunsten der gleitenden Skala der Fachsprachlichkeit aufgelöst wird (s. Kapitel 2.4.2), legt die Reihe DIN 820 des Deutschen InStituts FÜR NoRMUNG (DIN) explizit Normungs-, also auch Sprachnormungsprozesse fest. Z. B. thematisiert DIN 2342 (2011) Terminologie; Begriffe und Benennungen werden durch DIN 2330 (2011) geregelt, deren methodische Mängel und Bedeutung RoElCKE (2002b) diskutiert. Die Verbindlichkeit der in einem geregelten Prozess erstellten und in der fachlichen Öffentlichkeit diskutierten Normvorschläge (DIN 820-1: 2013, S. 6 f.) wird wie folgt vom DIN eingeschätzt: „Die Normen des Deutschen Normenwerkes stehen jedem zur Anwendung frei. Sie sollen sich als ,anerkannte Regeln der Technik' etablieren. [...] Eine Anwendungspflicht kann sich aufgrund von Rechts- oder Verwaltungsvorschriften sowie aufgrund von Verträgen oder sonstigen Rechtsgründen ergeben.“ (DIN 820-1: 2013, S. 8) Demnach sind DIN-Normen mit ihrer Verabschiedung nicht zwingend bindend oder verbindlich, sondern erlangen diesen Status erst durch die entsprechende Entscheidung durch die Legislative oder Exekutive eines Staates (u. a. OSTAPENKO, 2009). Damit ist eine DIN-Norm nicht nur an eine Einzelsprache, sondern auch an einen Nationalstaat und dessen Rechtsgebiet gebunden. 
,individualisierbare (allgemeinsprachliche und fachsprachliche) Kompetenz stärker in die Modellierung der Fachkommunikation einzubeziehen“" (ENGBERG/JANICH, 2007, S. 211). ${ }^{38}$ Dieser Ansatz ermöglicht es, individuelle Textüberarbeitungsprozesse von Fachkommunikanten zu beschreiben, um auf dieser Grundlage Teilkompetenzen zu interpretieren. Letztere dienen dazu, mit Textsortenkonventionen und -funktionen in der interfachlichen Kommunikation der zu untersuchenden Ausschreibungsprozesse umzugehen. Daher werden im Folgenden die Teilkompetenzen des Modells fachlicher Sprachkultiviertheit behandelt, um die Oberkategorie ,Kapazität der Kommunikanten“ im Modell semiotischer Effizienz auszugestalten.

Da der in diesem Modell verwendete Kompetenzbegriff ebenso unbestimmt bleibt wie der Sprachkompetenz-Begriff im integrativen Modell der Fachkommunikation (SCHUBERT, 2007, S. $260 \mathrm{f}$ ), fasse ich die Teilkompetenzen für die Textsortenebene des Modells semiotischer Effizienz als CoseriUs $\left({ }^{4} 2007 \mathrm{a}\right)$ expressives (textbezogenes) Wissen auf. Von den vier Teilkompetenzen (s. Abbildung 2-1) sind für das Modell semiotischer Effizienz und die Analyse des Textkorpus vor allem die kreative Kompetenz, die transsubjektive Kompetenz und metakommunikative Kompetenz (ebd., S. 219 ff.) relevant.

Denn die metakommunikative Kompetenz umfasst unter anderem Textsortenwissen (ebd., S. 222), die kreative Kompetenz rückt nonkonformes Sprachhandeln in den Fokus, „um konkrete Probleme zu lösen oder um bestimmte Zwecke zu erreichen“ (ebd., S. 220). Relevant ist diese Kompetenz für mein Modell und die Textanalyse, weil ich in der kommunikativen Praxis der Textüberarbeitungen entsprechende Probleme beobachten sowie protokollieren konnte und diese Fälle analysieren werde. Die transsubjektive Kompetenz ist relevant, weil sie das Handeln im interfachlichen Kontext thematisiert (ebd., S. 221). Im Folgenden werden diese drei Kompetenzen diskutiert.

38 Am Beispiel eines angenommenen Gerichtsurteils in Reimform wird veranschaulicht, dass „die Analyse von Norm- und Konventionalisierungsbefolgung nicht als Beschreibungsansatz ausreicht, um Effizienz und Effektivität fachlicher Kommunikation zu erklären“ (ENGBERG/JANICH, 2007, S. 229 f.). 


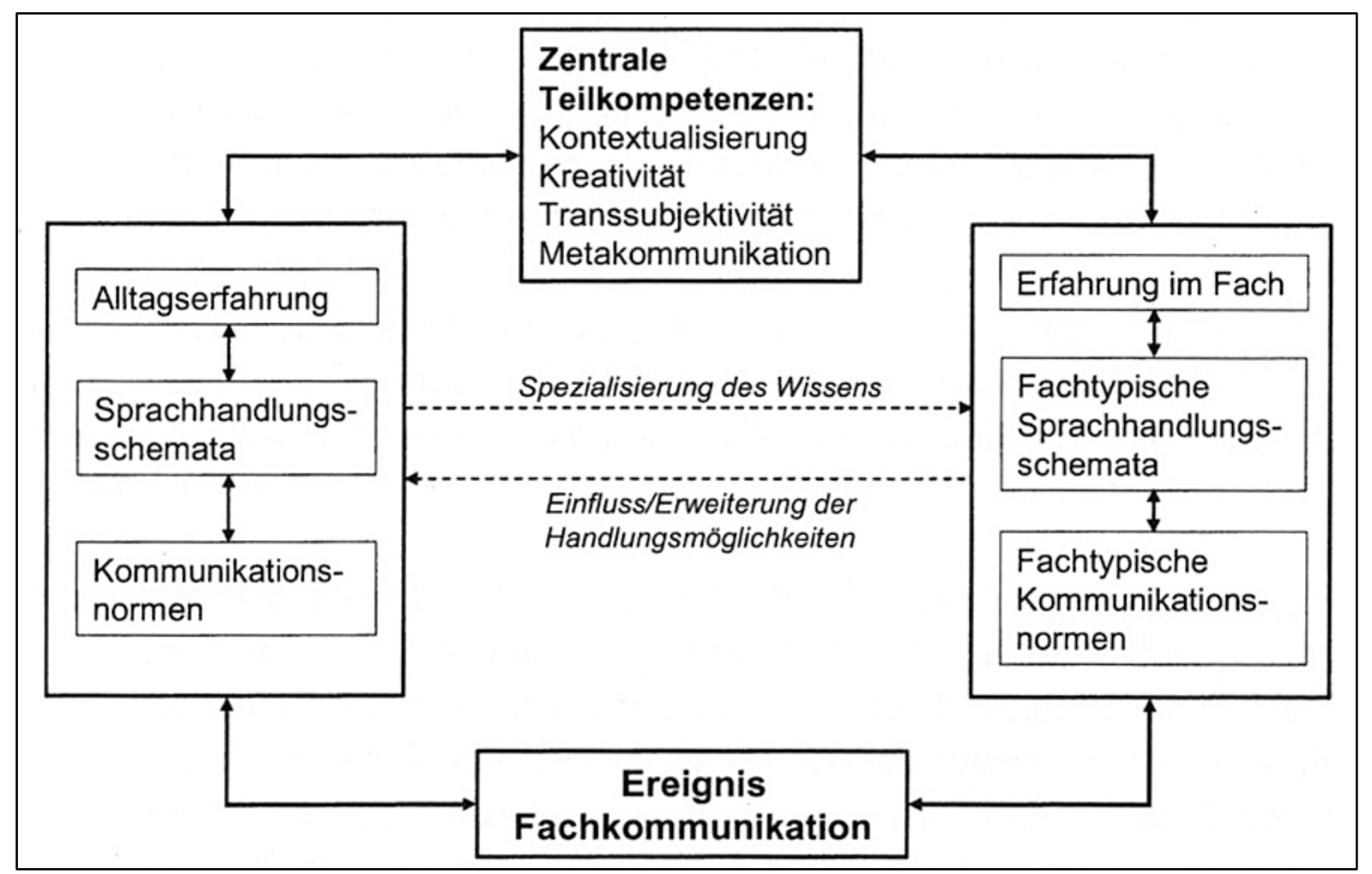

Abbildung 2-1: Elemente fachlicher Sprachkultiviertheit (ENGBERG/JANICH, 2007, S. 223).

Kreative Kompetenz wird als „Fähigkeit zur Übertragung von Bekanntem auf neue Situationen“ (ENGBERG/JANICH, 2007, S. 220) beschrieben. Darüber hinaus befähigt die Teilkompetenz

,jedoch auch zur absichtsvollen Abweichung von Konvention und zum nonkonformen Sprachhandeln, entweder um konkrete Probleme zu lösen oder um bestimmte Zwecke zu erreichen (z. B. um die Effizienz von Fachkommunikation über die fachkommunikativ geltenden Konventionen hinaus zu steigern und damit evtl. neue Normen zu prägen)“" (ebd.).

So erscheinen Normkonformität und Abweichung als Spannungsfeld, in welchem sich Fachkommunikanten bewegen können. Dieses Spannungsverhältnis erläutern DUCHÉNE/HELLER (2012) am Beispiel, wie Mitarbeitende in Call-Centern mit Gesprächsleitfäden umgehen: „Scripts tell the worker to behave following a format, yet employees must also prove their ability to manage unpredictable situations.“ (ebd., S. 332) Auch RothKegel (2008, S. 76 f.) modelliert implizit dieses Spannungsverhältnis, indem sie der Normierung (standardization) von kommunikativen Aufgaben Flexibilität, Variabilität (variability) und Kreativität gegenüberstellt. 
Als Normen lassen sich neben Gesprächsleitfäden (ebd., S. 330) auch Styleguides (FREI, 2008) oder Datenbanken auffassen, die in beruflicher Kommunikation einen Pol des beschriebenen Spannungsverhältnisses bilden. Kreativität als gegenüberliegender Pol dieses Verhältnisses ist beispielsweise im Umgang mit Problemen gefragt, die weak words ${ }^{39}$ (KRISCH/HOUdEK, 2015) bei datenbankbasierter Kontrollierter Sprache (LEHRNDORFFER/REUTHER, 2008) verursachen. Kreativität ist im technischen Schreiben grundsätzlich gefragt, sobald sich standardisierte Lösungen nicht eignen, um auf eine kommunikative Aufgabe zu reagieren:

„Erwünscht sind Problemlösungsstrategien, die auf der Basis von Analogie oder spielerischer Erfindung zu einem akzeptablen Ergebnis führen. Dabei geht es darum, entsprechende Räume für den kreativen Umgang mit Text offen zu halten (narrative Passagen, nicht-technische Visualisierungen, interessante Nutzungsszenarios, Serien und Comics, [sic] etc.).“ (ROTHKEGEL, 2008, S. 76)

Neben der Kreativkompetenz eignet sich für die Modellierung der Kommunikantenkapazität die transsubjektive Teilkompetenz, weil es durch sie möglich wird, den Umgang von Fachkommunikanten mit interfachlichen Kontexten wie Domänen-, Organisationen- oder Projektkommunikation (s. Kapitel 2.4.3) zu interpretieren. So umfasst diese Teilkompetenz den Umgang mit „Kommunikationsprobleme[n] zum Beispiel zwischen Fachmann und Laie oder zwischen Vertretern unterschiedlicher Fächer“ (ENGBERG/JANICH, 2007, S. 221). Für das Modell semiotischer Effizienz ist entsprechend nicht der horizontale Wissenstransfer bzw. die sogenannte Transgression, also die Kommunikation zwischen Experten und Laien, sondern die Kommunikation von Experten unterschiedlicher Fächer relevant. Probleme, die in diesen Kommunikationssituationen entstehen, sind nicht nur auf die unterschiedlichen Fachsprachenkompetenzen, sondern auch unterschiedliche Werteorientierungen und Perspektiven des jeweiligen Faches

KRISCH/HOUDEK (2015) untersuchen Textproduktionsprozesse der Technischen Dokumentation bei Daimler Benz, die datenbankgestützt sind. Sie definieren weak words wie folgt: „Weak words appear under several names; for example they are also called vague words or vague terms. In this contribution we call them weak words. Typical examples are 'long' and 'easily'. Looking at the requirement 'If the button is pressed for a long time ...', one could get the impression that 'long' is always harmful to the quality of a requirement. But contemplating the requirement 'The vector must be 24 bits long' one can see that the use of the word 'long' does not always lead to an imprecise requirement. Only certain readings and contexts do that." (ebd., S. 3) 
zurückzuführen (ebd.). Diesen Zusammenhang führen detailliert und am Beispiel JANICH/ZAKHAROVA (2014, S. 23) bei der Untersuchung von interdisziplinärer Projektkommunikation aus, wie die Beschreibung der Kontextkategorie ,Projektkommunikation' zeigen wird (s. Abbildung 2-10). Transsubjektive Kompetenz äußere sich bei Kommunikanten vor allem dadurch, dass sie bereit seien, ,absichtsvoll die Perspektive des Anderen einzunehmen, und zwar indem die eigene Perspektive als eine solche erkannt und reflektiert wird“" (ENGBERG/JANICH, 2007, S. 21 f.). Der Andere als fachliches Gegenüber in konkreten Fachkommunikationssituationen gibt demnach die Gelegenheit, das eigene kommunikative Handeln in Bezug auf seine fachliche Prägung zu kontrastieren und infolgedessen zu reflektieren.

Während die transsubjektive und kreative Kompetenz für das Modell semiotischer Effizienz besonders relevant sind, ermöglicht die Modellkategorie ,metakommunikative Kompetenz' lediglich, Wissen zu Textsorten neben dem zu Fachwortschatz und Grammatik (ebd., S. 222) zu modellieren. Diese Eigenschaft der metakommunikativen Kompetenz wird bereits präzise durch die Kompetenz beschrieben, Textsortenkonventionen zu beherrschen und ihnen entsprechend oder von ihnen abweichend Textexemplare zu gestalten (s. Kapitel 2.2.1). Die metakommunikative Kompetenz drücke sich des Weiteren aus als „Distanzierungsfähigkeit von der unmittelbaren Interaktion und Fähigkeit zur Reflexion grammatisch-semantischer und pragmatischer Normen“ (ebd.). Dadurch seien Kommunikanten befähigt, kommunikative Probleme wie methodisch-inhaltliche Konflikte zwischen verschiedenen, gültigen Normen zu lösen - beispielsweise verursachen unterschiedliche Terminologie und Begriffssysteme derartige Konflikte. Letztlich ist diese Form der metakommunikativen Kompetenz Voraussetzung für die kreative und die transsubjektive Kompetenz, weil die Modellierung beider Kompetenzen eine Distanzierungs-, Reflexionsfähigkeit und den Willen zur Konfliktlösung impliziert. Deswegen berücksichtige ich für das Modell semiotischer Effizienz und die Analyse des Textkorpus ausschließlich die kreative und die transsubjektive Kompetenz.

Die RoELCKEschen Modellunterkategorien ,Interesse“ und ,Intentionen', die die Oberkategorie ,Kommunikationsbereitschaft‘ bilden, sind für das Modell semiotischer Effizienz und damit für die empirische Analyse des Textkorpus 
ungeeignet. Als alternative Unterkategorien behandelt meine Arbeit die Kompetenz von Kommunikanten, mit Textsortenkonventionen transsubjektiv und kreativ umzugehen. Weil diese alternativen Unterkategorien der Kategorie ,Kommunikationskompetenz' und nicht der gegenüberstehenden ,Kommunikationsbereitschaft` zuzuschreiben sind (s. Tabelle 2-1), gebe ich die Kategorie ,Kommunikationsbereitschaft' auf. Anstelle eines Verhältnisses zwischen diesen beiden Kategorien determiniert im Modell semiotischer Effizienz die Kategorie ,Kapazität der Kommunikanten“ ausschließlich deren Kompetenz, also die Modellkategorie ,Kompetenz der Kommunikanten‘. These 1, auf die die oben beschriebene Konventionalität und Funktionalität von Textsorten das KapazitätKomplexität-Verhältnis Bezug nimmt, wird durch das in Kapitel 2.2.1 vorgestellte Textsortenkonzept gestützt. GLOYs Konzept der reziproken Erwartenserwartungen und die Konzeption von kreativer und transsubjektiver Kommunikationskompetenz untermauern These 2, die unterschiedliche kommunikative Erwartungen der Kommunikanten auf ihre verschiedenen mikrokulturellen Prägungen zurückführt. Im Folgenden wird These 3, der zufolge alle Textelemente Textillokutionen und -propositionen repräsentieren, diskutiert.

\subsection{Komplexität des Kommunikats als multimodale Textsorten}

These 3 schreibt Schriftsprache und Bildern zu, Textfunktionen und semantischen Gehalt von Texten zu repräsentieren, und geht damit von einem multimodalen Textsorten-begriff aus. Um diesen näher zu bestimmen, wird in Kapitel 2.3.1 BRINKERs oben dargestellte Definition (monomodaler) Textsorten mit der Definition multimodaler Textsorten von SCHMITZ (2011a) kontrastiert. Letzteres Konzept eignet sich für eine Kontrastierung, weil es Bezug auf BRINKERs Definition nimmt. Ausführlich wird bei dieser Kontrastierung das Kohärenzverständnis behandelt. Im Anschluss wird die Definition SCHMITZ' (2011a) von BATEMANs (2014) Definition multimodaler Textsorten abgegrenzt, um die Spezifika eines multimodalen Textsortenkonzepts zu schärfen und zu einer Nominaldefinition von Sprache-Bild-Textsorten zu gelangen.

BATEMANs Konzept bietet sich wiederum an, weil es den Ausgangspunkt für Kapitel 2.3.2 bildet, um Zeichentypen zu differenzieren, die in multimodalen Texten vorhanden sind. Seine textbezogene Zeichensystematik wird durch PEIRCEs 
Konzept von Zeichentypen präzisiert und an Beispielen veranschaulicht. PEIRCES Konzept ist wiederum der Anknüpfungspunkt für 1. die Diskussion eines Ähnlichkeitsbegriffs, der dem Konzept materieller Bilder zugrunde liegt; 2. das Konzept rekonfigurierender Diagramme (BAUER/ERnST, 2010);0 3. die Diskussion, ob Metaphern unter einen Bildbegriff - bzw. unter welchen - zu fassen sind. Auch wenn die Symbolizität von fachlicher Schriftsprache, ${ }^{41}$ insbesondere der Eisenbahnfachsprache, ${ }^{42}$ Anlass für weitere Ausführungen bietet, setzt sich meine Arbeit mit dieser Konzeption nicht weiter auseinander. Denn der Fokus meiner Arbeit liegt darauf, inwieweit die Textgestaltung bei gemeinsamen Überarbeitungen vom fachlichen Hintergrund der Überarbeitenden abhängt. Abschließend greift Kapitel 2.3.3 den Zusammenhang zwischen den von Kapitel 2.3.2 vorgestellten multimodalen Textelementen auf, indem es die Bedeutung von Salienz für Textelemente darstellt. Dabei diskutiert Kapitel 2.3.3, inwieweit von der Salienz der Textelemente auf Rezeptionspfade innerhalb eines Texts geschlossen werden kann und inwieweit die Methode Eye-Tracking diese Interpretation empirisch stützen kann.

40 Dieses Diagrammkonzept ist zwar in der Gliederung meiner Arbeit als Textelement eingeordnet, könnte aber als eine Alternative zu den Textkonzepten in Kapitel 2.3.1 fungieren, weil multimodale Texte - wie einzelne Bilder oder Schriftsprache - ebenso eine Form von rekonfigurierenden Diagrammen sein können (ebd., S. 44 ff.).

41 Zu fachlicher Terminologisierung s. z. B. ARnTz/Picht/SchMitz ( $\left.{ }^{7} 2014\right)$. Zum Konzept des Fachtextwortschatzes, demzufolge Terminologie von der Entität Text determiniert wird, s. ROELCKE ( ${ }^{3} 2010$, S. 56 ff.). RoElCKE (vgl. 2012, S. 233) bietet zu ARNTZ/PICHT/SCHMITZ ( $\left.{ }^{7} 2014\right)$ und vielen anderen ein alternatives Verständnis von Terminologisierung als Einführung und Aufbau von Terminologie in einen/-m Text.

42 Eine Systematik von Schienenfahrzeugen entwirft DIN 25003: 2001. Für die Praxis versucht WIEDEMANN ( $\left.{ }^{3} 2006\right)$, eine Terminologie für Ausschreibungsverfahren im Schienenpersonennahverkehr zu erstellen. Inwieweit diese in der Praxis verwendet wird, erforscht Kapitel 5. GERSTENKORN (2006) vergleicht die Terminologisierung der Eisenbahnfachsprache für den Terminus Zug diachron anhand einer Fahrdienstvorschrift aus den Jahren 1900, 1984 und 2003. Er fasst zusammen, dass der Begriff ,Zug' in den Fahrdienstvorschriften einheitlich definiert wird, indem „Fahrten, also Handlungen bzw. Vorgänge, mit Zügen gleich[ge]setzt [werden]“ (ebd., S. 262), also mit zielgerichteten Vorgängen (ebd.). Demnach bezeichnet der Begriff ,Zug' innerhalb der Fachsprache der Betriebsplanung eine geplante Fahrt eines Fahrzeugs innerhalb eines bestimmten Zeitraums. Im Gegensatz dazu bezeichnet der Terminus Fahrzeug in der Fachsprache den materiellen Gegenstand. 


\subsubsection{Sprache-Bild-Textsorten und Textdesign}

An den oben beschriebenen Diskurs um Textsortenkonventionen schließt die folgende Definition von Sprache-Bild-Textsorten ${ }^{43}$ an, indem sie BRINKERs Textkonzept modifiziert:

„Text-Bild-Sorten sind konventionell geltende Muster für komplexe semiotische Handlungen und lassen sich als jeweils typische Verbindungen von kontextuellen, kommunikativ-funktionalen und strukturellen (grammatischen und visuellen) Merkmalen beschreiben." (SCHMITZ, 2011a, S. 37)

Diese Definition weicht von der in Kapitel 2.2 diskutierten Textsortendefinition BRINKERs in zwei Punkten ab: Erstens sind kontextuelle Merkmale nicht als situative Merkmale konkretisiert und zweitens werden strukturelle Merkmale von Sprache-Bild-Textsorten nicht als grammatische und thematische, sondern als grammatische und visuelle Merkmale spezifiziert.

Die erste Abweichung legt entweder einen Ausschluss situativer Merkmale oder ein Kontext-Verständnis nahe, das situative Merkmale umfasst. Situative Merkmale bestimmt SCHMITZ (2016) als ,lebensweltliche Umgebung, in deren Rahmen der jeweilige Text eine Rolle spielt“ (ebd., S. 332), gegenüber kontextuellen Merkmalen, die sich als „semiotische Umgebung des Textes“ (ebd.) auffassen lassen. Semiotische Umgebung veranschaulicht SCHMITZ (2016) durch das Beispiel des Handbuches, das selbigen Artikel SchMitZ' (2016) umgibt. Die lebensweltliche Umgebung wird dagegen durch eine Diskussion des Artikels in einer Seminarsitzung veranschaulicht (ebd.). Das Begriffspaar ,Kontext ${ }^{6}-$,Situation` erscheint durch die Beispiele als Entsprechung zu PETÖFIs (1983, S. 293 f.) Begriffspaar ,Kotext ${ }^{\star}-$,Kontext ${ }^{\star}$ : ,Kotext ${ }^{\star}$ als Umgebung sprachlicher Äußerungen und ,Kontext ${ }^{\star}$ als außersprachliche Gegebenheiten. Ähnlich den in Kapitel 3.2 vorgestellten Texthinweisen von HAUSENDORF/KESSELHEIM (2008) konzipiert НАß (2018, S. 40) Kontexthinweise, die in Texten enthalten sind. НАß (2018) unterscheidet explizite und implizite Hinweise anhand des Kriteriums, ob Rezipienten den jeweiligen Kontext nur durch Schlussverfahren verstehen können: Bei impliziten Kontexthinweisen wie Assoziationen, Kategorisierungen oder

43 Anstelle des Terminus Sprache-Bild-Texte verwendet Schmitz (2011a) den Terminus Text-Bild-Sorte, dem ein Sehflächen-Begriff zugrunde liegt. In Sehfläche spielen „Schrift und Bild durch ein beide Seiten verbindendes Design formal und inhaltlich untrennbar ineinander" (ebd., S. 26). 
Merkmalszuschreibungen sind sprachreflektierte oder unreflektierte Schlussverfahren der Rezipienten notwendig; bei expliziten Kontexthinweisen als vollständig ausgedrückten Propositionen wie $d$. $h$., also etc., attributiven Relativsätzen usw. ist nur grammatisches Regelwissen notwendig (ebd., S. 40 f.). Auf fachliche Handlungen und fachliches Wissen wie semiotisches Fachwissen verweisen in Fachtexten meist keine vollständig ausgedrückten Propositionen Dieses Wissen ist beispielsweise notwendig, um die Bedeutung technischer Zeichnungen oder die juristische Verbindlichkeit von Bildern in einem Pflichtenheft zu erfassen. Vielmehr geben die Textsorte und der kommunikative Rahmen des Ausschreibungs-verfahrens, also der fachkommunikative Rahmen, diesen Hinweis. Der Fachrezipient kann demnach die Bedeutung solcher Zeichnungen und von Sätzen als Generalklauseln nur durch Schlussverfahren verstehen, indem er von impliziten Kontexthinweisen auf das fachliche Wissen der Kommunikanten im jeweiligen Text schließt. Daher lehnt sich meine Konzeption von SpracheBild-Textsorten an den Begriff impliziter Kontexthinweise in HАß (2018) an, sodass der Begriff ,Situation“ in meiner Konzeption der Beschreibung der konkreten Überarbeitungshandlungen der Kommunikanten vorbehalten bleiben kann, die ich beobachtete (s. Kapitel 4.1).

SCHMITZ' zweite Abweichung von BRINKERs Definition, strukturelle Merkmale von Sprache-Bild-Textsorten nicht als grammatisch-thematische Merkmale, sondern als grammatisch-visuelle Merkmale zu spezifizieren, lenkt das Augenmerk von Untersuchungen auf das Visuelle wie die Salienz von Sprache-Bild-Textsortenexemplaren. Die Diskussion, inwieweit Visuelles Thematisches beinhaltet, führt zur Bestimmung des Verhältnisses zwischen Kohärenz und Kohäsion in Sprache-Bild-Textsorten. Zu berücksichtigen ist, dass multimodale Textsorten auch logisch-semantische Relationen beinhalten (s. Kapitel 3.4) und Salienzkonzepte auch kulturelle Konventionen einbeziehen (s. Kapitel 3.1).

Das Kohärenz-Kohäsions-Verhältnis ist im Forschungsdiskurs zu (monomodalen) Textsortenkonzepten durch zwei gegensätzliche Standpunkte bestimmt: Um nicht als Nicht-Text bzw. als nicht kommunikativ zu gelten, müssen bei einem Text ,alle sieben Kriterien der TEXTUALITÄT erfüllt“ (BEAUGRANDE/DrEsSLER, 1981, S. 3; Versalien im Original) sein, zu denen als die ersten beiden Kriterien ,Kohäsion` und ,Kohärenz‘ gehören. Bei ,Kohäsion` als Phänomen des 
Oberflächentextes hängen die ,grammatischen Formen und Konventionen von einander $a b$, so daß Kohäsion auf GRAMMATISCHEN ABHÄNGIGKEITEN beruht“" (ebd., S. 4; Hervorhebungen im Original). Dagegen betrifft Kohärenz „die Komponenten der TEXTWELT, d.h. die Konstellationen von KONZEPTEN (Begriffen) und RELATIONEN (Beziehungen), welche dem Oberflächentext zugrundeliegen" (ebd., S. 5; Versalien im Original). Dieser Position BEAUgrande/Dresslers stellen BrinKer/CÖlFEN/PAPPERT $\left({ }^{9} 2018\right)$ folgendes Konzept gegenüber:

„In einigen textlinguistischen Arbeiten wird zwischen Kohäsion und Kohärenz unterschieden (etwa von Beaugrande/Dressler 1981, S. 3 ff.). ,Kohäsion“ meint dann die Verknüpfung der Oberflächenelemente des Textes durch bestimmte grammatische Mittel (auch Halliday/Hasan 1976), während ,Kohärenz' den konzeptionellen Zusammenhang des Textes, d.h. die zugrundeliegende Konstellation von Begriffen und Relationen, bezeichnet. Diese Unterscheidung ist unnötig; [...]. Wir gehen im Folgenden von einem umfassenden Kohärenzkonzept aus, das nach verschiedenen Aspekten (grammatisch, thematisch, pragmatisch, kognitiv; explizit, implizit usw.) differenziert wird.“ (ebd., S. 18)

Letzterem Standpunkt schließt sich ADAMZIK (2016) an und versteht „Kohärenz als eine Art ,regulative Idee ' beim Umgang mit Texten“ (ebd., S. 112), bei der als Frage an den Text folgende Dimensionen zusammenspielen: als Textexterna der situative Kontext, das Thema und die Funktion und als Textinterna die sprachliche Gestaltung sowie die Bestandteile des Zeichenkomplexes (ebd., S. 111 f.).

Wetzchewald betont bei der Behandlung von Beaugrande/Dresslers Textualitätskriterien, dass es die „Leistung des Rezipienten ist, die Kohärenz aktiv herzustellen“(WETZCHEWALD, 2012, S. 110). Er geht davon aus,

„dass beide Aspekte - sowohl die Beschaffenheit des Textes als auch die Rezeption durch den Leser - gemeinsam kohärenzstiftend sind. [...] Darüber hinaus ist mein Kohärenzbegriff auch in dem Sinne weit, dass ich darunter nicht nur den Sinnzusammenhang als semantische Eigenschaft des Textes, sondern explizit auch strukturelle Eigenschaften des Textes wie die bewusste Platzierung von Sätzen bzw. einen stringenten Aufbau, inhaltliche Aspekte wie die Vorstrukturierung des Themas sowie formale Charakteristika wie beispielsweise ein übersichtliches Layout und pragmatische Charakteristika fasse. Zu unterscheiden ist dennoch zwischen der Kohärenz und der Kohäsion, worunter grammatische Verknüpfungselemente wie Pro-Formen etc. gefasst werden. ${ }^{“ 44}$ (ebd.) 
Diese Definition von Kohärenz durch Kohäsion entspricht der Beschreibung, dass „[f]ormale Verknüpfungsmittel (Kohäsion) [...] den semantisch-kognitiven Sinnzusammenhang (Kohärenz) [unterstützen]" (SchMITZ, 2011a, S. 35 f.; Kursive im Original). Layout, Design und intermodale Wiederaufnahme seien Kohäsionsmittel, von denen Layout die Platzierung von Text und Bild in der Fläche umfasse und Design die ,zielgerichtete Gestaltung von Farbe und Form“ (ebd., S. 36). Die intermodale Wiederaufnahme bezeichne die Organisation von Darstellungen eines außersprachlichen Gegenstandes auf einer Sehfläche einerseits durch eine Nominalgruppe, andererseits durch ein Bild, wie am Beispiel einer Nutella-Verpackung veranschaulicht wird (ebd.). Das Verhältnis zwischen diesen kohäsiven Mitteln der Kohärenz des Zeichengebildes stellt SCHMITZ (2011a) durch Textelemente dar, die durch intermodale Wiederaufnahme auf der Bedeutungsebene ,zur kohärenten Sinnbildung beitragen“ (ebd., S. 35 f.). Auch das Konzept des logischen Textdesigns spezifiziert das Verhältnis zwischen Kohärenz und Kohäsion als Korrespondenz. Es besteht eine „systematische Korrespondenz der Signifikation auf typographischer Ebene mit der Signifikation auf thematischer Ebene“" (HAGEMANN, 2007, S. 77). EHRENHEIM (2011) überträgt HAGEMANNs Ansatz, der ausschließlich Typographie fokussiert, allgemein auf das Textlayout, indem sie diese Korrespondenz als ein „Sichtbarmachen der inhaltlichen Struktur des Textes“ (ebd., S. 169) durch Schrift und Bilder bezeichnet.

Im Folgenden schließe ich mich für Sprache-Bild-Textsorten der Definition von Kohäsion und Kohärenz in SCHMITZ (2011a) an, die das Zusammenspiel der Ebenen entsprechend der aufgeführten Modellierung in BRINKER/CÖLFEN/PAPPERT ( ${ }^{9} 2018$ ) anlegt. Der Vorteil dieser Modellierung liegt darin, in der empirischen Analyse nicht um eine strenge Abgrenzung der Kategorien bemüht sein zu müssen und vielmehr deren Interdependenzen untersuchen zu können. Im Anschluss an diese Definition greife ich die erweiterte Konzeption von Kohärenz in WeTZCHEWALD (2012) auf, sowohl durch das (sichtbare) Textsortenexemplar als auch durch die Leserrezeption bestimmt zu sein. Im Anschluss daran umfasst

kohäsionslose oder -arme, aber gleichzeitig kohärente Texte beschreibt. Diese können „durchaus ihren kommunikativen Zweck erfüllen“(ebd., S. 48). 
das von mir aufgegriffene Kohärenz-Konzept auch logisch-semantische SpracheBild-Relationen (s. Kapitel 3.4), die der Rezipient realisiert.

Im Folgenden wird die Definition von Sprache-Bild-Textsorten aus ScHMITZ (2011a) mit der Definition eines multimodalen Genre-Konzepts in BATEMAN (2014) kontrastiert, weil die Kontrastierung von zwei multimodalen Textkonzepten verspricht, Ergebnisse zu liefern, die über die Kontrastierung mit dem monomodalen Konzept in BRINKER hinausgehen. BATEMAN (2014) definiert multimodale Textsorten wie folgt:

„[A] brief overview of many approaches to genre can be found in Bateman (2008).

In Short: A genre in a linguistic sense is a socially recognized class of texts (either spoken or written) that is used for a specific social purpose and which has a regularly occurring structural organisation recognisable by virtue of distinctive patterns of linguistic phenomena.“ (ebd., S. 69)

Das Definitionselement ,konventionell geltendes Muster ${ }^{6}$ in SCHMITZ (2011a) entspricht BATEMANs sozial wahrnehmbaren Textklassen. Dabei verleiht die konventionelle Gültigkeit dem Textsortenbegriff eine höhere kommunikative Verbindlichkeit, als dies durch die soziale Wahrnehmbarkeit möglich wird. Schmitz (2011a) stellt die Gültigkeit der Muster in den Vordergrund, was auch die Beschreibung der „normierende[n] Wirkung“ (BRINKER/CöL-FEN/PAPPERT, ${ }^{9} 2018$, S. 139) von Textsorten im Folgesatz der Definition nahelegt. Diesen zweiten Teil der Textsortendefinition BRINKERs, der von der modalen Beschaffenheit unabhängig ist, führt SCHMITZ (2011a) nicht aus. BATEMAN (2014) betont dagegen die Wahrnehmbarkeit insbesondere von linguistischen Gestaltungsmitteln (recognisable by linguistic phenomena) in Texten und rückt somit den Rezeptionsprozess in den Vordergrund.

SchMitZ' (2011a, S. 37) Element ,komplexe semiotische Handlungen“ steht BATEMANs Klassen gesprochener oder geschriebener Texte und deren Gebrauch für spezifische soziale Anlässe gegenüber. Während beide Definitionen den Handlungscharakter von Textsorten betonen, grenzt BATEMANs Orientierung an Gesprochenem (spoken) und Geschriebenem (written) das Semiotische derart ein, dass zwar noch die typographische Gestaltung von Schriftsprache visuell wahrnehmbar ist, Bilder aber streng genommen nicht mehr eingeschlossen sind, da sie nichts Geschriebenes sind. 
BATEMAN (2014) nimmt an, dass die strukturelle Organisation ausschließlich durch spezifische Muster linguistischer Gestaltungsmittel wahrnehmbar ist. SchMitz (2011a, S. 37) bezieht die Eigenschaft von Textsorten, musterhaft zu sein, hingegen auf kontextuelle, kommunikativ-funktionale und strukturell-visuelle Merkmale. Er stellt somit textinterne Merkmale neben textexterne Merkmale als Teil von Textsorten. Diesen Schritt, spezifische Muster linguistischer Gestaltungsmittel mit sozialen Praktiken (social practice) zu verquicken, vollzieht BATEMAN (2008) im Genre- und Multimodalitäts-Modell (GeMmodel). In diesem wirken sich die konventionalisierten Gebrauchsweisen der Artefakte (established uses of the artefacts) auf die multimodalen Textproduktionsbedingungen und Textrezeptionsbedingungen (production and consumption constraints) im Genre aus (ebd., S. 16).

In einer ersten Annäherung fasse ich Sprache-Bild-Textsorten als kommunikative Muster auf, die sich aus der Konventionalisierung semiotisch komplexer Handlungen als prototypisches Bündel von kontextuellen, kommunikativ-funktionalen, strukturell-thematischen und -visuellen Merkmalen ergeben.

\subsubsection{Eigenschaften von Sprache-Bild-Texten: Ähnlichkeit materieller (fachlicher) Bilder, Diagrammatik rekonfigurierender Dia- gramme und Bildlichkeit von Metaphern}

BAtEMANs (2008) GeM-Modell (s. Abbildung 2-2) bezieht das Zusammenspiel von Zeichentypen (semiotic resources) auf die jeweiligen Seiten eines Textsortenexemplars. ${ }^{45}$ Im Modell bestimmt die räumliche Anordnung von semiotischen Ressourcen das Konzept von Layout (BATEMAn, 2008, z. B. S. 133).

Die semiotischen Ressourcen, die Abbildung 2-2 darstellt, bilden die,GeM base . Mit dieser spielt im GeM-Modell die ,layout base‘ zusammen, die sich auf räumliche Repräsentationen (area model) bezieht. Beide Ebenen (bases) verquickt das GeM-Modell mit der semantisch-strukturellen Ebene bzw. der multimodalen Makrostruktur (multimodal rhetorical structure), die durch die Layoutstruktur abgebildet wird (ebd., S. 142). Somit modelliert auch BATEMAN (2008) den

45 Dieses Modell konzipiert den Untersuchungsgegenstand Text entsprechend der Seitenmetapher als Seite (page), die als statisches Artefakt durch das Layout von sprachlichen, graphischen und bildlichen Informationen gestaltet ist (ebd., S. 9). 
Zusammenhang von Kohäsion (GeM base und layout base) und Kohärenz (multimodal rhetorical structure) im Text.

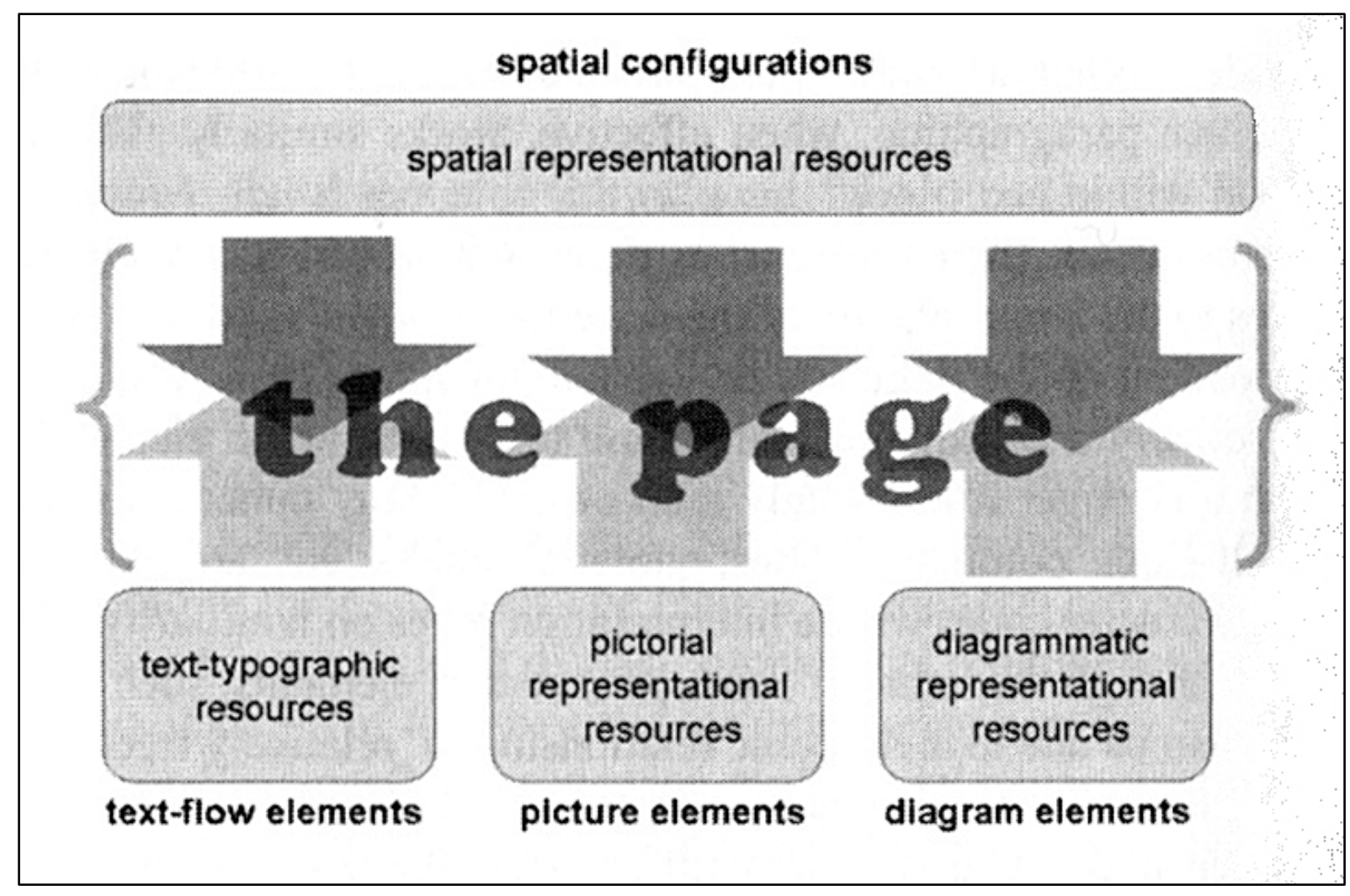

Abbildung 2-2: The page as a site of cooperation and integration of distinct semiotic modes (BATEMAN, 2008, S. 106).

Im GeM-Modell erzeugt das Zusammenspiel von Schriftelementen (text-typographic resources) den ,text-flow' und das Zusammenspiel von bildlichen Elementen (pictorial representational resources) den ,image-flow'. Beide Formen des flows werden zum ,page-flow' (the page) kombiniert (ebd.). Zwar wird für Diagramme (diagrammatic representational resources), die Abbildung 2-2 neben Schrift und Bild stellt, kein ,diagrammatic flow ${ }^{6}$ konzipiert. Diagramme wirken mit den flows der übrigen semiotischen Ressourcen aber im page-flow zusammen:

„Page-flow can combine elements of any of the semiotic modes appearing on a page, including text-flows, diagrams, graphs and so on. It adds to the individual contributions of these elements the possibility of the rhetorical unity supporting the communicative intentions of a document." (ebd., S. 176; Fettdruck AH)

In diesem Zusammenhang unterstütze der page-flow die kommunikative Funktion (communicative intentions) eines Textsortenexemplars. Konkret führt BATEMANs (2008) kommunikativ-funktionales Textkonzept die Anordnung und Verwendung 
von Textelementen (the way, semiotic resources are distributed and mobilised) auf die Textsorte (type of document/genre) zurück (ebd.).

Texttypographische, bildliche und diagrammatische Ressourcen der GeM base lassen sich als Zeichentypen in PEIRCE (1998) und den daran anschließenden Diskurs als Grundlage für ein multimodales Textsortenkonzept begründen. So setzt BATEMAN (2008) voraus, dass die Ressourcen nicht nur wahrnehmbar sind. Seine Systematisierung semiotischer Elemente einer multimodalen Textsorte geht von der Wahrnehmbarkeit ihrer Elemente aus, wie obige Auseinandersetzung mit BATEMANs Textsorten-Definition zeigt. Weil er die Zeichensys-tematik aus empirischen Analysen ableitet, schlussfolgert BATEMAN (2008), dass die Wahrnehmung der Ressourcen diese bereits reflektiert bzw. durch eine Interpretation geistig umschafft, weil der Rezipient diese Wahrnehmung bereits interpretiert.

Ich schließe mich BATEMANs Dreiteilung von semiotischen Ressourcen (s. Abbildung 2-2) an, die in Sprache-Bild-Textsorten zusammenwirken. BATEMANs (2008) Modell von ,Schriftsprache“ - ,Bild“ - ,Diagramm‘ lässt sich durch PeIRCEs (1998) Trichonomie des Ikons in folgende drei Hypoikons (hypoicons) ausdifferenzieren. Im Konzept der PEIRCEschen Zeichentrichotomie ,Ikon` - ,Index $^{6}$ - ,Symbol‘ lässt sich das Ikon differenzieren in ,Bild‘ (images) bzw. ,materielles Bild‘ (material image), ,Diagramm‘ (diagram) und ,Metapher' (metaphor), wobei die letzteren drei ,Hypoikons‘ (hypoicons) seien:

„Those [hypoicons; AH] which partake the simple qualities, or First Firstnesses, are images; those which represent the relations, mainly dyadic, or so regarded, of parts of one thing by analogous relations in their own parts, are diagrams; those which represent the representative character of a representamen by representing a parallelism in something else, are metaphors. “46 (PEIRCE, 1998, S. 274)

Als Beispiele sind für Bilder Pantomime, für ein Diagramm eine Straßenkarte und für eine Metapher eine „Biene als Zeichen für Fleiß“ (Schmitz, 2016, S. 344)

46 Dem Herausgeber und Übersetzer der deutschen Version des PEIRCE-Textes, Helmut Pape, lag möglicherweise eine andere Version des englischen Originals vor. Er übersetzt diese Stelle wie folgt: „Ikons lassen sich, wenn auch nur grob, unterteilen in jene, die Ikons aufgrund einer Empfindungsqualität, also Bilder sind, in jene, die Ikons in Bezug auf die dyadischen Relationen ihrer Teile zueinander, also Diagramme oder dyadische Analogien sind, und in jene, die Ikons in Bezug auf ihre intellektuellen Eigenschaften, also Beispiele, sind.“ (PEIRCE, 1982, S. 64 f.; Kursive im Original; Fettdruck AH) 
geeignet. Erstheit sei dabei das, „was so ist, wie es eindeutig und ohne Beziehung auf irgend etwas anderes ist" (PEIRCE, 1982, S. 55). Diese drei Zeichentypen werden im Anschluss unter folgenden Aspekten behandelt: 1. Ähnlichkeit und Konventionalität materieller Bilder und indexikalischer Fotos; 2. Diagrammatik rekonfigurierender Diagramme; 3. Bildlichkeit von Metaphern.

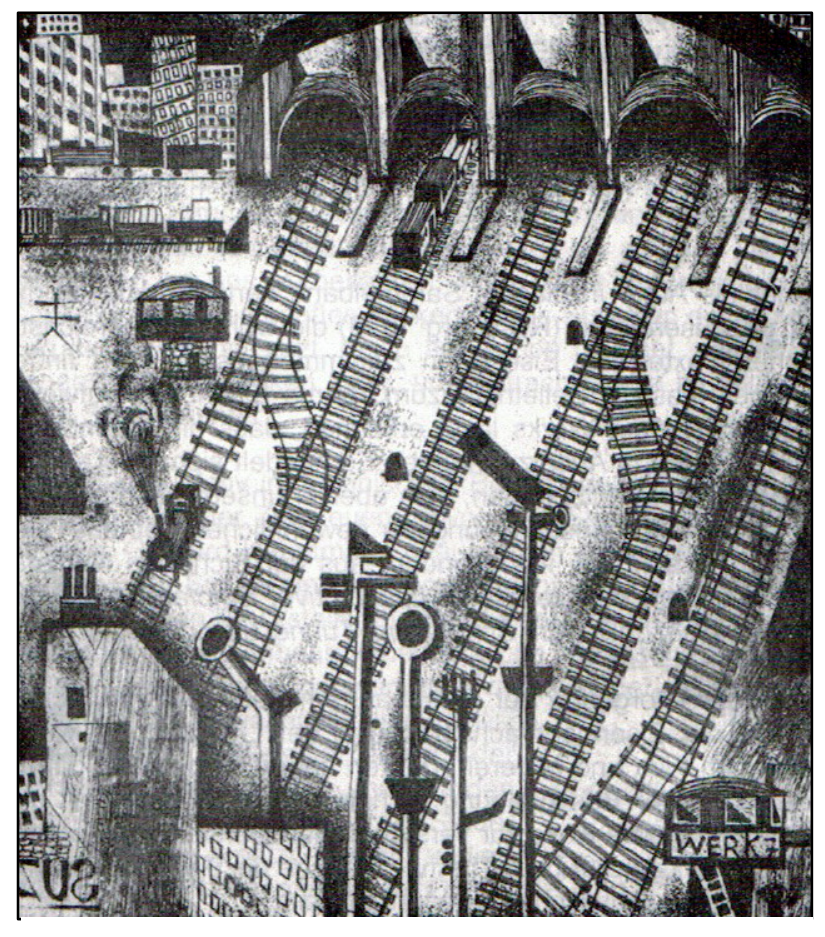

Abbildung 2-3: Gleisvorfeld, Christof Meckel (1910 in SCHMIDT, 2006, S. 277).

Das Konzept der Ähnlichkeit materieller Bilder geht von ihrer Konventionalität aus:

„Any material image, as a painting, is largely conventional in its mode of representation“ (PEIRCE, 1998, S. 273 f.). Konventionalität beziehe sich zum einen auf den kulturellen Kontext und zum anderen auf den mikrokulturellen Kontext. Den Grund dafür soll das folgende Beispiel veranschaulichen: Dass Christof Meckels Gleisvorfeld (s. Abbildung 2-3) ,der Stilrichtung eines fantastischen Surrealismus zuzuordnen [ist]“ (SCHMIDT, 2006, S. 276), lässt sich beispielsweise durch die Auflösung einer einheitlichen Perspektive nachvollziehen. Dieses Darstellungsmittel als kulturelle Konvention einer Epoche findet sich für die Mikrokultur des Technikwesens beispielsweise in der Konventionalisierung von Perspektivität für CAD-Darstellungen. So regelt DIN EN ISO 5456-4 (2002, S. 9), dass die Darstellung eines Gegenstands von dessen räumlicher Anordnung zu einem möglichen Rezipienten abhängt.

Während PEIRCE (1998, S. 273) Gemälde (paintings) als Beispiel für materielle Bilder als Unterklasse des Ikons aufführt, sind Indices ein „individual Second“ (ebd.). Den Charakter einer Zweitheit zeichnet aus, dass ,eine zweite Entität so ist, wie sie ist, ohne Beziehung auf etwas Drittes“ (PEIRCE, 1982, S. 55). Zu dieser zählen vor allem außersprachliche Erfahrungen, beispielsweise mit physikalischen Gegenständen (ebd.). Genuine Indices werden wie folgt beschrieben: 
„A genuine Index and its Object must be existing individuals (whether things or facts), and its immediate Interpretant must be of the same character" (PEIRCE, 1998, S. 274). Ein Beispiel ist der Zeiger einer Uhr (ebd.): So verstehe ich den Zeiger als Index und die abstrakte Größe Zeit als dessen Objekt. Demzufolge ist auch ein abbildendes Diagramm ein Index, das die Messung einer Geschwindigkeit, einer Zugkraft und eines Reibungs- und Luftwiderstandes abbildet beispielsweise das Zugkraft-Widerstandskraft-Geschwindigkeitsdiagramm (s. Abbildung 2-7). Darin stellen die Linien des Diagramms den Index dar, der aus der gemessenen Kraft bzw. dem gemessenen Widerstand resultiert und die Kraft bzw. den Widerstand als Objekt des Index'.

Ein genuiner Index kann sich aber auch auf eine Erstheit (Firstness) beziehen: „[A] genuine Index may contain a Firstness, and so an Icon, as a constituent part of it“. (ebd.) Letztere Bestimmung bezieht der Übersetzer Helmut Pape in seiner Übersetzung des obigen Zitats aus PEIRCE (1998, S. 274) auf Fotos, die gleichzeitig materielle Bilder und Indices sind,

„weil sie die physikalische Wirkung des Lichts beim Belichten eine existentielle eins-zu-eins-Korrespondenz [sic] zwischen Teilen des Fotos und den Teilen des Objekts herstell[en], und genau dies ist es, was an Fotografien oft am meisten geschätzt wird. Doch darüber hinaus liefert ein Foto ein Ikon des Objekts, indem genau die Relation der Teile es zu einem Bild des Objekts macht“ (PEIRCE, 1982, S. 65 ; Kursive im Original). ${ }^{47}$

Im Anschluss an diese Übersetzung behandele ich Fotos, die im Untersuchungskorpus vorkommen, als Ikone, speziell als materielle Bilder. Ich fasse die Konventionalität von materiellen Bildern neben der epochal-kulturellen und mikrokulturellen Konventionalität auch als funktionale Textsortenkonvention auf, da Bilder auch durch die Einbindung in die Textsorte konventionalisiert werden: Neben der möglichen Position in der textuellen Struktur der Themenentfaltung ist auch eine entsprechende Position in der Funktionsstruktur einer Textsorte denkbar (s. Kapitel 3.2).

47 Diese Übersetzung nutzt einen großen Interpretationsspielraum, der bei Übersetzungen notwendig sein kann. Diese Lesart findet sich in PEIRCE (1998, S. 274) nicht. 
So bildet beispielsweise das Foto (s. Abbildung 2-4) einen technischen Gegenstand in seiner Verwendung im Alltag ab. Es ist im Lehrbuch „Schienenfahrzeugtechnik“ (JANICKI/REINHARD, 2013) in eine Reihe von Fotos eingebettet, die verschiedene Arten von Fahrzeugeinstiegen veranschaulichen. Das Foto stellt aus einer Seitenansicht links zum dargestellten Objekt eine uniformierte Frau dar, die diesen Gegenstand bedient. Systematisierungen, Schematisierungen etc., wie es die beschrifteten Bilder und schematischen Zeichnungen von Türen in den vorherigen Teilkapiteln leisten, enthält dieses Foto nicht.

Für die Bildsorte ,fachliches Bild“ (STÖCKL,

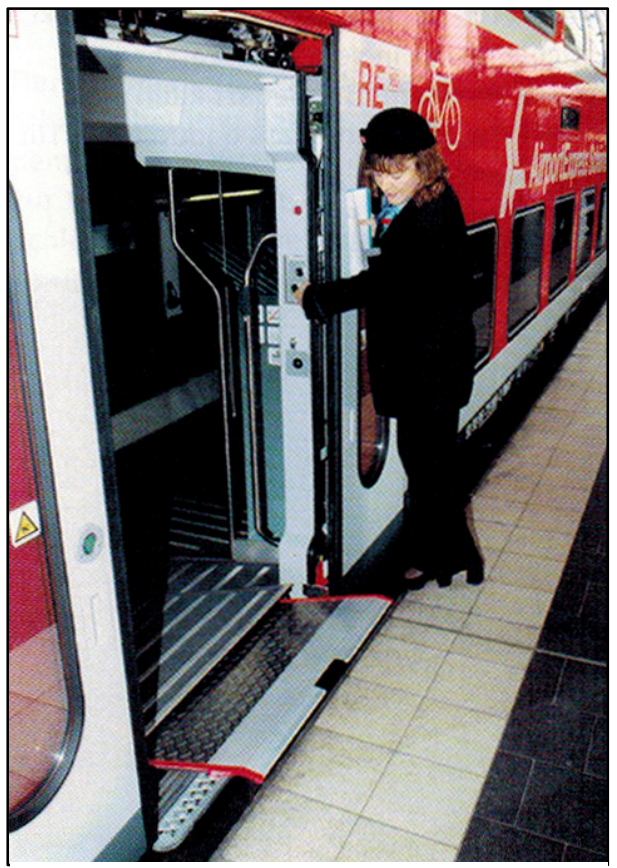

Abbildung 2-4: Überfahrrampe für Rollstühle bei einem Doppelstockwagen JANICKI/REINHARD, 2013, S. 482).

2004, S. 138 ff.) erscheint die technische Zeichnung (s. Abbildung 2-6) ${ }^{48}$ prototypisch.

Denn sie schematisiert, abstrahiert in der Abbildungspraktik und ist im Blick auf Perspektive, Schraffur, Linierung etc. durch DIN-Normen konventionalisiert, also symbolisch. Zudem werden technische Zeichnungen in der Experte-Experte-Situation zielgerichtet eingesetzt. Denn sie stellen Funktionsweisen und räumliche Anordnungen von Maschinenteilen durch deren Querschnitt, also durch nicht unmittelbar Sichtbares, dar. Dementsprechend zielen technische Zeichnungen darauf, Funktion und Struktur von Objekten und Prozessen darzustellen. Das Foto

48 Während den drei Abbildungen unterschiedliche Funktionen zugewiesen werden können, lassen sie sich in der psychologisch basierten Bildtypologie in BALLSTAEDT (2003, S. 12 ff.) alle dem Typen ,Abbild“ zuordnen, der „Wissen über visuelle Merkmale (Form, Farbe, Textur) und räumliche Anordnungen“" (ebd., S. 13) vermittelt. Abbildung 2-4 und Abbildung 2-5 lassen sich der Abbild-Unterkategorie ,Realbild“ zuordnen, ,die einen Realitätsausschnitt von einem festen Standpunkt und aus einer Perspektive abbilden“ (ebd., S. 14) - Abbildung 2-3 gehört der Unterkategorie ,Gemälde‘ an. Im Gegensatz zu Realbildern lässt sich Abbildung 2-6 der Abbild-Unterkategorie ,Schemabild“ zuordnen, die „typische visuelle und räumliche Merkmale repräsentiert, die bis zur Karikatur überzeichnet sein können“ (ebd., S. 14) und die „dem Experten eine schnelle Orientierung [ermöglichen]“"(ebd.). 
(s. Abbildung 2-4) lässt sich dagegen eher der Bildsorte ,Illustriertenbild“ (STÖCKL, 2004, S. 138 ff.) zuordnen, da es unter anderem die Abbildungspraktik ,detailgetreu-ikonisch' nutzt, als Bildinhalt den Fokus auf Personen und deren Lebenswelt legt und Kohäsivität durch Farbe, Form, Kontrast und Helligkeit herstellt. Ausschlaggebendes Kriterium für die Fachlichkeit eines Bildes sind seine Funktion innerhalb eines Fachtexts (KALVERKÄMPER, 1998c, S. 74) und die Einbindung des Bildes in den fachlichen Kontext:

„Fachlichkeit ist keine natürliche, gleichsam ,angeborene“ Eigenschaft, vielmehr wird sie verliehen: Und so bedürfen Bilder, um fachlich zu wirken oder zu sein, entsprechende sprachliche und fachliche handelnde Kontexte, sei es [...] den des phonetischen Lehrbuchs, sei es den der Anatomie-Vorlesung." (KALVERKÄMPER, 1993, S. 220; Fettdruck AH)

Die Fachlichkeit eines Bildes primär auf fachliche Handlungskontexte zurückzuführen, unterstützt die Tatsache, dass auch Fachsprache ihre Fachlichkeit durch die kontextuelle Einbindung erhält. KLAMMER (2017) definiert das fachliche Bild auf der Grundlage dieser Feststellung KALVERKÄMPERs (1993) und basierend auf SACHS-HOMBACHs Konzept von Bildern als Zeichen mit einer syntaktischen, einer semantischen und einer pragmatischen Seite als

„ein mehr oder weniger komplexes, visuelles, überwiegend nicht-sprachliche Zeichen, das gegenständliche und/oder nicht-gegenständliche fachbezogene Sachverhalte darstellt, in einem fachlichen Kontext steht und i. d. R. in einen Fachtext eingebettet ist bzw. von diesem begleitet wird" (ebd., S. 320).

Weil das fachliche Bild vom Fachtext begleitet oder in diesen eingebettet ist, kann es als Teil des fachlichen Sprache-Bild-Textes konzipiert werden (s. Kapitel 2.3.1).

Als weiteres Darstellungsmittel nutzt das Foto die Begrenzung auf einen gewählten außerbildlichen Realitätsausschnitt. Diesen begrenzten Ausschnitt, den das Foto abbildet, muss der Fotobetrachter einem entsprechenden Element des Fahrzeugs zuweisen. Letztere Feststellung korrespondiert mit STÖCKLs (2016) Feststellung, dass Sprache strukturell-syntaktisch stärker konventionalisiert und weniger motiviert ist, als Bilder es sind:

„Sind die Form-Inhalts-Zuordnungen der Zeichen willkürlich (arbiträr) und erklärt sich die Funktionsweise des Kodes nicht aus Umwelterfahrung oder Analogien, so ist die jeweilige Zeichenmodalität stark konventionell und nicht motiviert.“ (ebd., S. 12) 
Die Relation zwischen Repräsentamen und Interpretanten sei durch Vorwissen und Seherfahrungen als Teil des Verstehensprozesses geprägt, der in der PEIRCEschen Terminologie der Semiose einer geistigen Leistung entspricht:
„Zwei syntaktische Prinzipien im Bild sind die meronymische, d. h. auf Teil-Gan- zes-Bezügen beruhende Ordnung von Einzelzeichen [sic] und die Konvertierung flächiger Zeichen-Arrangements in räumliche Vorstellungen. In Anbetracht dieser syntaktischen ,Schwächen' des Bildkodes spielen Vorwissen, Kontext, Seherfah- rungen und inferierende Prozesse beim Bildverstehen eine vergleichsweise große Rolle.“"(STÖCKL, 2016, S. 11)

Mit der Rezeption eines Fotos kann der Rezipient für sich möglicherweise neues Wissen erzeugen, was auch als Inferenz bezeichnet wird. So lässt sich beispielsweise auch das Foto des behindertengerechten $\mathrm{WC}^{49}$ einerseits durch Vorwissen über die räumliche Zuordnung des WC-Raums im Schienenfahrzeug (s. Abbildung 2-5) erschließen. D. h., auch die Anordnung der nicht abgebildeten Gegenstände wie dem Eingang zum WC-Raum als Betrachterstandpunkt nimmt als Form von Vorwissen

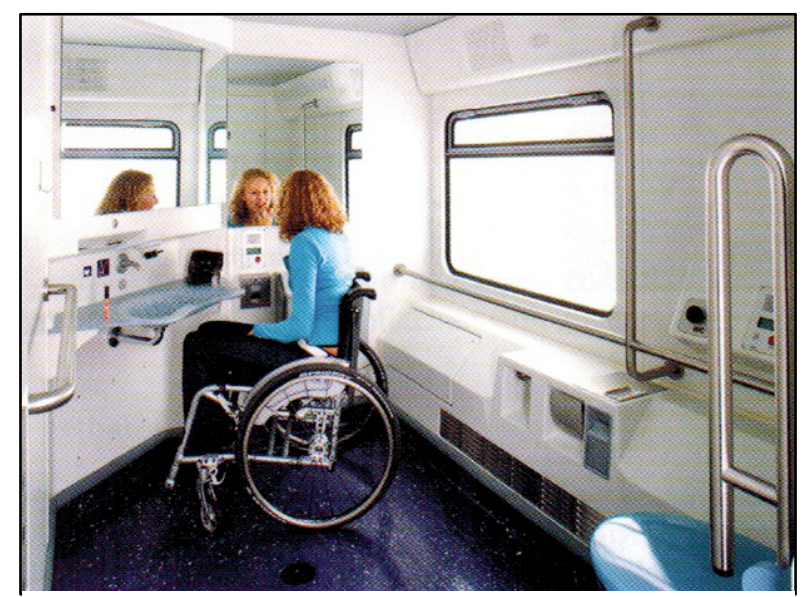

Abbildung 2-5: Behindertengerechtes WC im Doppelstock-Steuerwagen (JANICKI/REINHARD, 2013, S. 456). Einfluss auf die Rezeption. Andererseits bestimmt die kontextuelle Einbettung des Fotos in ein Textsortenexemplar bzw. in schriftsprachlichen Text Einfluss auf die Bedeutungs- und Funktionskonstitution.

Individuelle Seherfahrungen lassen sich zwar nicht unmittelbar als Teil einer Konvention darstellen, können durch Wahrnehmungsmodelle aber auf Konventionen basieren (ECO, ${ }^{2} 1991$, S. 271). So kann Vorwissen Voraussetzung und Ergebnis von individuellen Seherfahrungen sein und im Sinne von Voraussetzung als kulturell erlernt gelten. 
Neben Konventionalität erscheint Ähnlichkeit als zweite Eigenschaft von Ikonen, speziell von Bildern. So relativiert PEIRCE an späterer Stelle - in der „Nomenklatur und Unterteilung der Triadischen Relationen“ (ebd., 1982, S. 121 ff.) - bei der Besprechung des Ikons allgemein die Differenzierung von reinem Ikon und materiellem Bild. Ein Zeichen sei durch folgende Eigenschaft ikonisch: „But a sign may be iconic, that is, may represent its object mainly by its similarity, no matter what its mode of being." (PEIRCE, 1998, S. 273; Kursive im Original) In PeIrCEs (1998) Abschnitt „Nomenclature and Divisions of Triadic Relations, as Far as They Are Determined“ (ebd., S. 289 ff.) wird das Ikon weniger spezifisch definiert: „Anything, whatever, be it a quality, existent individual, or a law, is an icon of anything, in so far as it is like that thing und used as a sign of it." (ebd., S. 291) Während in der zweiten Beschreibung nicht unmittelbar von Similarität geschrieben wird, führt erstere Beschreibung diese explizit auf.

Similarität, die größtenteils mit dem Begriff, Ähnlichkeit' gleichgesetzt wird, ist das zentrale Charakteristikum von ikonisch-materiellen Bildern. Diese Art von Bildern seien als der ,(prototypische) Normalfall“ (WETZCHEWALD, 2012, S. 51) anzunehmen, auch wenn „Bilder [existieren], die nicht ikonischer Natur sind, wie dies bei abstrakter Kunst oder einigen symbolischen Bildern der Fall ist" (ebd.):

„In Anlehnung an REHKÄMPERS Theorie der Ähnlichkeit und an die Ähnlichkeitsauffassung der anthropologischen Bildtheorie nach JONAS werde ich in dieser Arbeit ebenfalls davon ausgehen, dass Bilder oder Teile von Bildern in einem gewissen Maße den Dingen, auf die sie verweisen, ähnlich sein können.“ (WETZCHEWALD, 2012, S. 51)

JONAS (2001) nimmt an, dass ein Bild ,eine erkennbare Ähnlichkeit mit einem anderen Ding zeigt“ (ebd., S. 107). Er schließt aber eine „,beidseitige, symmetrische Ähnlichkeit von Bild und Gegenstand aus“ (WetzchewALD, 2012, S. 51). ${ }^{50}$ Als zweite von WETZCHEWALD einbezogene Position zur Bestimmung von Bildern hinsichtlich ihrer Ähnlichkeit mit einem Objekt nimmt REHKÄMPER (2002) eine Ähnlichkeit zwischen einem Bild und einer P-Gestalt an, die ,[d]as

50 Letzteres ergibt sich aus Goodmans (1997, S. 15 f.) Kritik an der Reflexivität eines Ähnlichkeitsverhältnisses bzw. symmetrischer Ähnlichkeit: Nicht nur das Bild repräsentiert den dargestellten Gegenstand, sondern auch der dargestellte Gegenstand das Bild. Dies widerlege das Beispiel, dass der Herzog von Wellington nicht das ihn darstellende Gemälde repräsentiere. 
zweidimensionale, zentralperspektivische Abbild eines dreidimensionalen Gegenstands relativ zu seinem Augenpunkt und einem Sehkegel auf einer lotrechten Projektionsfläche ist" (REHKÄMPER, 2002, S. 115). ${ }^{51}$

WeTZCHEWALD (2012, S. 50) kritisiert an REHKÄMPERs Ausführung einerseits die Erweiterung der Definition um nichtperspektivische Darstellungen, andererseits die Annahme, dass die P-Gestalt repräsentationsunabhängig sei. Letztere Kritik begründet Wetzchewald (ebd.) damit, dass die P-Gestalt Teil der Repräsentation ist. Da Gestaltungsmittel konventionalisiert sind, ist im Anschluss an diese Kritik von WeTZCHEWALD auch die Repräsentation der P-Gestalt konventionalisiert. Für diese Position spricht beispielsweise, dass DIN-Normen in der Technikkommunikation Linien, aber auch perspektivische Darstellungen für technische Zeichnungen und CAD-Darstellungen konventionalisieren.

ECO konzipiert Ähnlichkeit dagegen als Verhältnis zwischen kulturalisiertem Inhalt und Bild bzw. Repräsentamen:

„Es wird in diesen Paragraphen deutlich werden, daß die Aussage, ein bestimmtes Bild sei etwas anderem ähnlich, nichts daran ändert, daß Ähnlichkeit auch von kultureller Konvention abhängt; im folgenden Paragraphen werde ich zu zeigen versuchen, daß der Begriff der Ähnlichkeit sich hier nicht auf das Verhältnis zwischen dem Bild und seinem Gegenstand bezieht, sondern auf das zwischen dem Bild und einem vorher kulturalisierten Inhalt.“ (ECO, ${ }^{2} 1991$, S. 271 f.)

Kulturalisierter Inhalt ließe sich im Zeichenmodell von PEIRCE als konventionalisierter Interpretant konzipieren, der wiederum die Wahrnehmung weiterer Objekte beeinflussen kann. Dafür spricht folgendes Argument: „Erkennungscodes (wie alle anderen Codes), angenommen sie existieren, sehen relevante Merkmale des Inhalts vor. Die Erkennbarkeit des ikonischen Zeichens hängt von der Selektion dieser Merkmale ab.“ (ECO, ${ }^{2}$ 1991, S. 274; Kursive im Original) Dies veranschaulicht ECO an der Erkennbarkeit eines Zebras durch seine auffälligen Streifen in Abgrenzung von einem streifenlosen Elefanten.

Dass der Inhalt einer Darstellung kulturalisiert bzw. kulturell konventionalisiert ist, führt ECO darauf zurück, dass Rezipienten eine unmittelbare Seherfahrung wie beispielsweise eine Sonnenwahrnehmung durch eine anschließende Seherfahrung

51 Eine vergleichbare Darstellung findet sich in DIN EN ISO 5456-4: 2002 (s. Abbildung 3-5). 
einer „,ikonographischen Konvention (die die ursprüngliche Erfahrung codifiziert)“ (ebd., S. 276) ergänzen. Beispielsweise wird die Sonne in Kinderzeichnungen in flächiger Darstellung als Kreis mit darum angeordneten Linien dargestellt. Es lassen sich nicht nur kindliche Darstellungen, sondern auch kunstgeschichtliche heranziehen, um ikonographische Kulturkonventionen zu beschreiben. ${ }^{52}$ Eine Seherfahrung ohne folgende Seherfahrung einer ikonographisch-konventionalisierten Darstellung ist demnach keine kulturalisierte Konvention (ebd., S. 274). D. h., die Sonne wahrzunehmen, ohne anschließend die übliche Darstellung der Sonne als Bild eines Kreises mit Linien zu sehen, erzeugt beim Betrachter keine kulturalisierte Konvention.

Ähnlichkeit und Konventionalität nehme ich entsprechend WETZCHEWALDs Kritik und ECOs Konzept in das Bild-Konzept auf, das meiner Untersuchung zugrunde liegt. Denn die Konventionalisierung von (fachlichen) Bildern sehe ich des Weiteren in ihrer Textsortenzuge-hörigkeit und deren Konventionalität begründet: Letztere sind (mikro-)kulturell konventionalisiert (s. Kapitel 2.2). Dafür spricht, dass Textproduzenten sich auf die Rezeptionserfahrung diverser Textsortenexemplare stützen, die zu einem prototypischen Textmuster abstrahiert werden können, oder - insbesondere in beruflichen Schreibkontexten - zu einer Vorlage, die als prototypisch für eine Textsorte angenommen wird.

Neben Peirces (1998) Ikonen kann auch dessen Diagramm-Konzept durch den Entwurf rekonfigurierender und abbildender Diagramme für Sprache-BildTextsorten präzisiert werden. Nicht nur technische Zeichnungen bzw. Grundrisse werden als Diagramme bezeichnet, sondern auch CAD-Darstellungen und Straßenkarten (BAUER/ERnST, 2010, S. 18), die für die Analyse meines Korpus besonders relevant sind. Konzeptuell charakterisiert die Weiterentwicklung der PEIRCEschen Zeichenunterklasse ,Diagramm' Folgendes:

„Die Eigenart von Diagrammen schließt die Möglichkeit zur praktischen Rekonfiguration der im Diagramm erstellten Relationen ein. Diagramme lassen sich abwandeln, um weitere Schlussfolgerungen anzustoßen. [...] Wichtig wird es aber

52 Als Beispiel führt ECO DÜRERs Darstellung eines Nilpferds durch dachziegelförmige Platten als kulturelle Vorstellung von Nilpferden an. Diese Darstellung hat in der Weise Imitationen in nachfolgenden naturwissenschaftlichen Darstellungen erzeugt, dass „Dürer und seine Nachahmer auf diese Weise gewisse Wahrnehmungsbedingungen wiederzugeben versuchten“" (ECO, ${ }^{2} 1991$ S. 273). 
[im Gegensatz zu einem Kuchendiagramm; AH] bei einem Grundriss, der die Aufteilung von Wänden, Türen, Fenstern und Zimmern in einem Gebäude zu erkennen gibt. Ein solcher Grundriss erlaubt es, Baumaßnahmen am Grundriss zu planen. Die Planungen werden schnell zu Skizzen und führen über die Skizzen zu einem neuen Grundriss. Das Diagramm wird zum Medium eines sowohl anschaulichen als auch schlussfolgernden Denkens, das sich in der gedanklichen Variation vollzieht. Das Denken interagiert im Diagramm mit einem Medium, das nicht nur betrachtet, sondern handgreiflich manipuliert und geprüft werden kann.“" (BAUER/ERNST, 2010, S. 46; Kursive im Original)

Zentral ist demnach, dass diagrammatische Darstellungen keine abbildende, sondern eine entwerfende Ähnlichkeit haben (BAUER/ERnst, 2010, S. 44). Ich schließe mich BAUER/ ERNSTs Definition von ,Diagrammatik' an:

„Die Diagrammatik ist eine kulturell in verschiedenen Existenzweisen manifestierte Form der Wechselwirkung zwischen der Wahrnehmung einer Zeichenkonfiguration, dem Denken in einer Zeichenkonfiguration und dem Handeln mit einer Zeichenkonfiguration. Als kulturelle Praxis ist die Diagrammatik eine Form des anschaulichen Denkens mit Zeichenkonfigurationen." (BAUER/ERNST, 2010, S. 49; Kursive im Original)

Auch Schriftsprache ist durch ihre typographische Gestaltung, also durch ihre Schriftbildlichkeit, diagrammatisch. ${ }^{53}$ Sie wird in der empirischen Untersuchung

53 KRÄMER ( ${ }^{2} 2009$, S. 162) unterscheidet ähnlich den drei Zeichenkorrelaten von MORRIS den Struktur-, Referenz- und Performanz-Aspekt von Schrift. D. h., Schrift wird als Medium, als Symbolsystem und als Kulturtechnik weiter ausdifferenziert. Als Medium ist Schrift wie folgt gekennzeichnet: „Die ,notationale Ikonizität‘ der Schrift mit ihren Merkmalen, disjunkt und differenziert zu sein, ist also ein Medium, welches das Prinzip der Differenzialität verkörpert und anschaulich zur Geltung bringt.“ (ebd., S. 163) D. h., Schrift arbeitet mit Lücken und Leerstellen, um mit ihrer Zwischenräumlichkeit eine Syntax-Visualität zu erzeugen (ebd.). Als Symbolsystem bzw. unter dem Referenzaspekt zeichnet Sprache Folgendes aus: „Einerseits tilgt die phonetische Schrift die mimetische, gestische, tonale Spur des menschlichen Körpers im Sprachgebrauch; andererseits verleiht sie der Sprache eine rein diskursive Materialität und Körperlichkeit.“ (ebd., S. 166) Daraus ergeben sich ihre skriptuale Existenz und ihr Status als Ding bzw. als Objekt (ebd.). Die Darstellung von Beispielen aus dem Umgang mit Schrift in Form von Ziffern und Buchstaben in der Mathematik und Logik führt KRÄMER ( $\left.{ }^{2} 2009\right)$ zu diesem Schluss: „Die operative Schrift ist nicht nur ein Beschreibungsmittel, sondern zugleich ein Werkzeug des Geistes, eine Denktechnik und ein Intelligenzverstärker.“ (ebd., S. 171) Schriftbildlichkeit systematisiert sie dementsprechend als visuelle Struktur, die als Teil von Simulationsbildern auf Computern mit Ziffern und Bildern vorkommt und ,zugleich dreierlei Funktionen ermöglicht: Arbeit, Gedächtnis und Präsentation“ (ebd., S. 174). Schrift operiert, speichert und stellt demzufolge dar (ebd.). Als ,Schriftbildlichkeit‘ bezeichnet ScHMITZ (2006b, S. 100) das Konzept ,tertiärer Schriftlichkeit‘. Es werden dabei primäre Schriftlichkeit, sekundäre Schriftlichkeit und tertiäre Schriftlichkeit unterschieden. Primäre Schriftlichkeit wird zwar nicht definiert. Tertiäre Schriftlichkeit bezeichnet die schriftsprachlichen Erscheinungen, „die Schrift als nicht autonomes Element in multimodalen Kontexten, vor allem in Text-BildGefügen erscheinen lässt"“ (ebd., S. 90). 
aber kaum einbezogen, weil für die zu untersuchenden Texte entsprechend These 3 vielmehr das Zusammenspiel von materiellen Bildern und technischen Zeichnungen mit Schriftsprache von Bedeutung ist. Zudem ist die Untersuchung der kulturellen Bedeutung von Typographie in anderen Untersuchungsfeldern fruchtbarer. ${ }^{54}$

Entsprechend der Unterscheidung von Gemälden bzw. ästhetisch darstellenden Zeichnungen gegenüber technischen Zeichnungen und CAD-Bildern lassen sich Diagramme von materiellen Bildern und reinen Ikonen als Strukturbilder unterscheiden: „Vorwiegend bild-ikonische Zeichen werden manchmal ,darstellende Bilder' genannt, Diagramme auch ,Strukturbilder'; z. B. Sachs-Hombach/Schirra 2011, 98.“ (SCHMITZ, 2016, S. 344; Kursive im Original) Diese Systematik findet sich explizit in PEIRCE (1998, S. 277) und wird auch von BAUER/ERnst (2010, S. 43 f.) aufgegriffen.

Auch technische Zeichnungen können als kulturelle Praktiken gelten (ein Beispiel für eine technische Zeichnung gibt Abbildung 2-6):

Es handelt sich bei technischen Zeichnungen insoweit um kulturelle Praktiken, als sie durch DIN-Normen, also durch statuierte Normen, konventionalisiert werden. Wird eine Zeichnung nicht entsprechend der Norm gestaltet, könnte deren Einbindung in einen fachlichen Handlungskontext wie in einen SPNV-Ausschreibungsprozess beanstandet, d. h. sanktioniert werden.

Konventionalisiert sind als Darstellungsmittel unter anderem: 1. die Punkt-StrichLinie in Schwarz mit einem festgelegten Linienbreitenverhältnis zwischen den Linien, um andere Linien zu kreuzen (DIN EN ISO 128-20: 2002, S. 6 ff.); 2. Lage und Art der Bezugslinie (DIN ISO 128-22: 1999, S. 5 f.) zur Beschriftung

54 So beschreibt das Konzept graphischer Variation (SPITZMÜLLER, 2013) die soziologisch gruppenspezifische Bedeutung der Verwendung (typo-)graphischer Ausdrucksmittel. Die Relevanz kommunikativen Wissens und dessen stratifizierende Funktion leitet SPITZMÜLLER (2013, S. 199) aus dem Beispiel ab, dass ein Typographie-Experte der schriftsprachlichen Aufforderung des Typographie-Ausschusses von einem Design-Verband nicht nachkommt. Grund dafür ist die typographische Gestaltung des Aufforderungsschreibens, die situativ-sozial nicht angemessen sei und infolgedessen das Expertentum des Ausschusses als Produzenten des Schreibens infrage stelle (ebd., S. 199 ff.). Die Kompetenz, Typographie situativ-sozial angemessen einzusetzen, und deren Knüpfung an die Zugehörigkeit zu einer sozialen Gruppe stellen zwei Kriterien dar, auf denen das Konzept graphischer Variation basiert. 
mit der Phrase $W C$; 3. ihre Perspektivität als orthogonale Projektionsmethode (DIN ISO 5456-2: 1998, S. 3 ff.) in Schnittansicht (DIN ISO 128-40: 2001, S. 6 ff.).

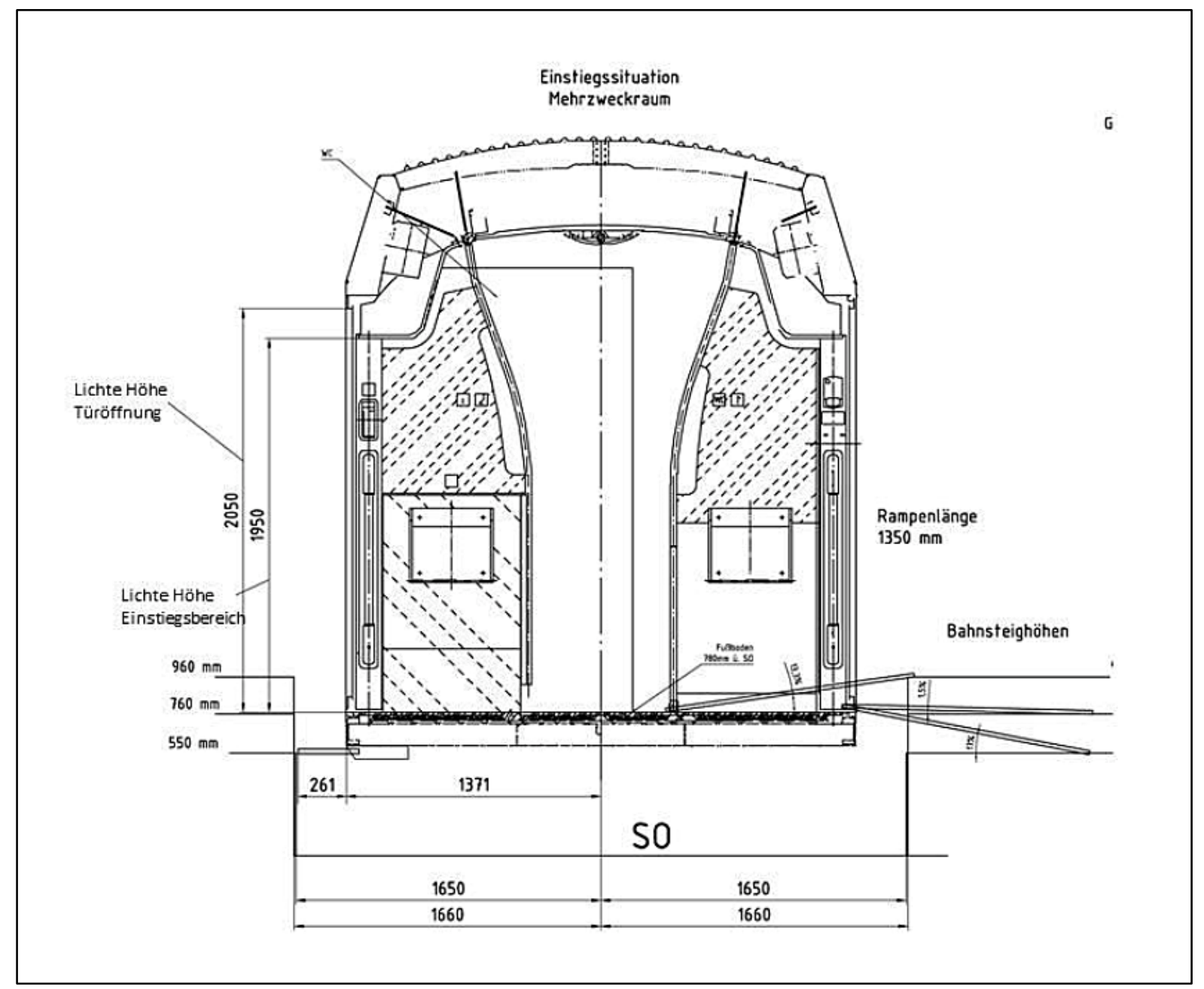

Abbildung 2-6: Einstiegssituation Mehrzweckraum (BAG SPNV, ${ }^{32016}$, S. 52).

Konventionalisiert ist aber auch die Bedeutung von Linien. So symbolisiert die Schraffur der Schnittflächen - insbesondere die Art der Linie und deren Anordnung bzw. Gruppierung als drei parallel angeordnete Strichlinien - Leichtmetalle als Unterkategorie der Metalle und festen Stoffe (DIN ISO 128-50: 2002, S. 4).

Diagramme sind für mein multimodales Textkonzept von besonderer Bedeutung, da technische Zeichnungen vielfach im Analysekorpus vorkommen. Auch Kuchendiagramme (zur Darstellung eines Wahlergebnisses etc.) werden als Objekte der Diagrammatik bezeichnet (BAUER/ERnst, 2010, S. 46), die zum Teil in meinem Analysekorpus vorkommen, erlauben aber keine entwerfende, sondern eine abbildende Ähnlichkeit (ebd., S. 44). Dementsprechend können sogenannte 
abbildende Diagramme einen Messvorgang von physikalisch auftretenden Kräften wie die Zugkraft einer Maschine darstellen. Ein Zugkraft-WiderstandskraftGeschwindigkeitsdiagramm (s. Abbildung 2-7) lässt sich beispielweise als Index beschreiben, das auf die gemessenen Objekte, Widerstandskraft‘ und ,Geschwindigkeit' verweist.

Um mithilfe der Zeichentypologie PeIRCEs (1998) die multimodalen Elemente in Sprache-Bild-Textsorten und deren Zusammenspiel als page flow zu bestimmen, bleibt näher zu beleuchten, inwieweit Metaphern in das Sprache-Bild-Textsortenkonzept einfließen können bzw. sollen.

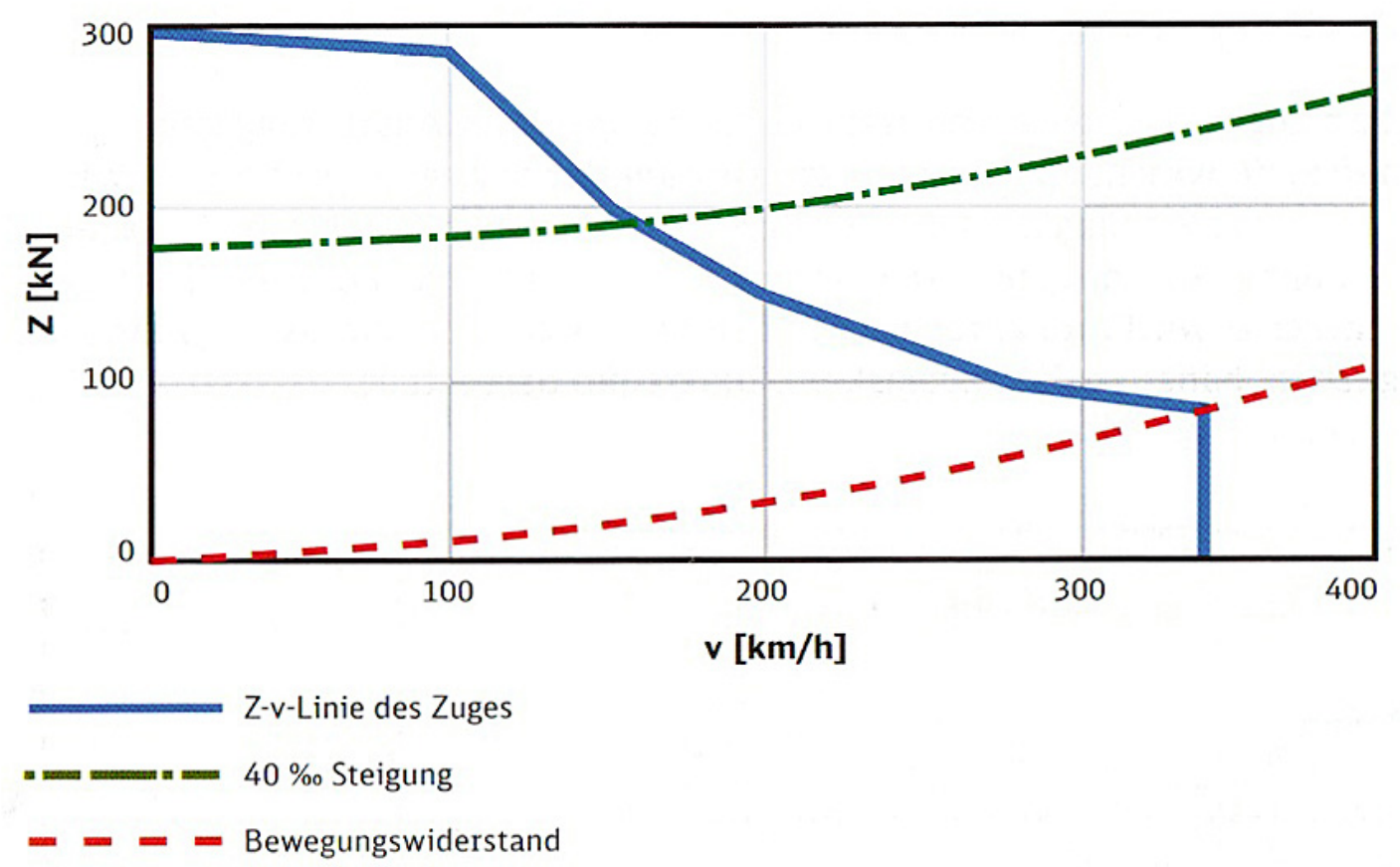

\section{Abbildung 2-7: Zugkraft-Widerstandskraft-Geschwindigkeitsdiagramm} (JANICKI/REINHARD, 2013, S. 57).

Metaphern $^{55}$ werden von Bild-Ikonen abgegrenzt und von PEIRCE (1998) wie folgt definiert: ,[T] hose [icons; $\mathrm{AH}]$ which represent the representative character

55 Von Metaphern werden metaphor related words ( $m r w$ ) unterschieden, zu denen Präpositionen, Pronomen etc. gehören. Dies zeigt folgendes Beispiel: „The essays in $</ \mathrm{mrw}>$ this $</$ mrw $>$ book do not amount $</$ mrw $>$ to $</$ mrw $>$ a programme: [...]. “ (STEEN ET AL., 2010, S. 777; Kursive im Original) Ich setze mich im Folgenden ausschließlich mit Metaphern auseinander, die durch Nomen und Verben realisiert werden. Die Abgrenzung von Metaphern zu Metonymien - wie beispielsweise die ersetzende Verwendung des Nomens Dach 
of a representamen by representing a parallelism in something else, are metaphors.“ (ebd., S. 274) Ausgehend von dieser Definition werden Metaphern unter dem Aspekt mentaler Modelle, insbesondere in der Techniksprache (JAKOB, 1991), behandelt.

Das Charakteristikum der Parallelität, das in PeIRCEs Gliederung eine Form der Ähnlichkeit darstellt, findet sich in LAKOFF/JOHNSON ( $\left.{ }^{6} 2008\right)$ in Form von drei Annahmen der Abgrenzung vom Vergleich: So sind Metaphern erstens „Sache des Denkens und Handelns und erst sekundär eine sprachliche Angelegenheit“ (ebd., S. 177). Im Gegensatz zum PEIRCEschen Zeichenkonzept fokussieren LAKOFf/Johnson ( $\left.{ }^{6} 2008\right)$ daher primär mentale Prozesse. Neben dieser ersten Annahme stellen LAKOFF/JOHNSON ( ${ }^{6} 2008$ ) die zweite Annahme auf, Ähnlichkeiten von Metaphern als kulturell konventionalisiert anzusehen, da sie ,in unserer Kultur real“ (ebd., S. 177) sind. Diese Annahme ist insoweit selbstverständlich, als die Versprachlichung einer Metapher als begriffliche Einheit aus Ausdruck und festgelegter Bedeutung bereits eine Form der Konventionalisierung darstellt und auch bildliche Ikonizität kulturell konventionalisiert sein kann (s. oben). Drittens prägt nach LAKOFF/JOHNSON ( ${ }^{6} 2008$ ) ein Begriff von (kulturellkonventionalisierter) Erfahrung die funktionale Perspektive auf Metaphern:

„Die primäre Funktion der Metapher ist die, uns zu ermöglichen, daß wir eine Art der Erfahrung von einer anderen Art der Erfahrung her partiell verstehen können. Dabei können präexistierende isolierte Ähnlichkeiten eine Rolle spielen, neue Ähnlichkeiten hergestellt werden und so weiter.“ (ebd., S. 177)

Zur Veranschaulichung eignet sich ein Beispiel, das PEIRCE (1998, S. 275) zur Erläuterung von Symbolizität gibt. In diesem Beispiel vermittelt ein Mann einem Kind die Bedeutung des Ausdrucks ,Ballon“ (balloon) durch sein Merkmal, rund zu sein. Dies geschehe in der geschilderten Beispielsituation nicht explizit, sondern durch die Parallelität zwischen dem gezeigten Objekt in der Luft und dem zunächst sprachlichen Ausdruck Seifenblase (like a great soap bubble). Diese Parallelität sei durch die Vergleichspartikel wie (like) explizit als Vergleich angelegt. In der Analyse des Beispiels wird die Seifenblase dabei als Bild bzw.

anstelle von Haus als Wörter desselben Begriffsfeldes (DÄSCHLER, ${ }^{5} 2016$, S. 430) - behandele ich nicht weiter, weil sie nicht zur Beantwortung meiner Forschungsfrage beitragen. 
wird ein Bild als Teil des Symbols bezeichnet (makes the image part of the sym$b o l)$, das an der Begriffsvermittlung beteiligt ist.

Ähnlich der Diskussion um die Bildlichkeit von Vergleichen beschäftigt sich der Forschungsdiskurs mit der Frage, inwieweit eine Metapher ein Bild sein kann bzw. welcher Bildbegriff dem zugrunde liegt. Entgegengesetzte Positionen zum Verhältnis von Metaphern und Bildlichkeit vertreten SCHMITZ (2007) und STÖCKL (2004):

„Im Ergebnis der Erörterung und Kommentierung einzelner Theorien des Bildes steht die Erkenntnis, dass materielle (oder visuelle) Bilder zwangsläufig mentale (oder innere) Bilder und auch sprachliche Bilder nach sich ziehen bzw. voraussetzen. Die Abhängigkeit dieser drei Bildmodalitäten ist grundlegend für jegliches Verstehen des Phänomens Bildlichkeit.“ (STÖCKL, 2004, S. 45)

Die Dreiteilung des Bildkonzeptes (s. oben) erscheint analog zur Differenzierung: 1. des Ikons als reinem Ikon, das weniger psychologisch angelegt als vielmehr eine Entsprechung zum mentalen Bild ist; 2. zum materiellen Bild und 3. zu einer Metapher als sprachlichem Bild. Diagramme bleiben in SCHMITZ (2005; 2006a; 2006b; 2007) noch außen vor, werden aber insbesondere im Rahmen der SpracheBild-Textsorte Infographik (STÖCKL, 2012; LIEBIG, 1999) oder bei Sehflächen der Werbekommunikation (ScHMITz, 2011b, S. 102 f.) ausführlich diskutiert. Als Beschreibung von Ikonizität erscheint mir STÖcKLs (2004) Berücksichtigung von Metaphern plausibel, da sie Parallelität kennzeichnet.

Beschränkt auf bild-ikonische Zeichenhaftigkeit wirkt die Berücksichtigung von Metaphern hingegen nicht plausibel, weil das Repräsentamen die Metapher schriftsprachlich repräsentiert, also symbolisch angelegt ist und insofern einem Interpretanten arbiträr zugeordnet wird (s. oben). Erst dieser Interpretant kann ein mentales Bild darstellen, das Qualitäten und Parallelen zu einem anderen Interpretanten oder Objekt aufweist. Während das mentale Bild als Qualizeichen eingeordnet werden kann und das materielle Bild dem Sinzeichen entspricht, betont die Metapher den Aspekt des Legizeichens, einen Begriff gesetzmäßig zuzuordnen. ${ }^{56}$

56 Im Rahmen der weiteren PEIRCEschen Trichotomie in ,Quali-“, ,Sin- “ und ,Legizeichen“ (PEIRCE, 1998, S. 291 f.) erscheint das Qualizeichen, „[that] is a quality which is a sign“ (ebd., S. 291), als reines Ikon. Als ,actual existing thing or event“ (ebd.) wird es zum Sinzeichen, ,that [...] involves a qualisign [...]. But these qualisigns are of a peculiar kind 
Dagegen erscheint die in STÖCKL (2004) angelegte Bedingtheit des materiellen Bildes durch ein reines Ikon bzw. mentales Bild durch den PEIRCEschen Semioseprozess wie auch durch den Prozess der Ecoschen kulturellen Konventionalisierung nachvollziehbar. Entsprechend PEIRCEs Systematik lassen sich Metaphern unter Ikone, aber nicht unter Bild-Ikone im Sinne von mentalen oder materiellen Bildern subsumieren ${ }^{57}$ Gleichzeitig lassen sich Metaphern entsprechend ihrer kulturellen Konventionalisierung (s. oben) aber auch unter Symbole subsumieren.

Entsprechend meiner obigen Zuordnung von Metaphern primär als Legizeichen ordne ich Metaphern der Schriftsprache zu und werde diese am Rande der Sprache-Bild-Textsortenanalyse berücksichtigen. So lassen sich Metaphern neben Schriftbildlichkeit, materiellen Bildern und Sprache-Bild-Verknüpfungen im Text untersuchen, wie dies STÖCKL (2011, S. 46 ff.) konzipiert. Ähnlich verfahren Ansätze der multimodalen Metaphern-Analyse (KLUG/STÖCKL, 2015, S. 256 f.). Für die Zuordnung zu Schriftsprache spricht, dass die Phoneme, die eine Bedeutung durch einen Ausdruck versprachlichen, keine unmittelbare Ähnlichkeit oder kulturell entwickelte Konventionalität der Darstellung (s. oben) beinhalten. Erst nach der Zuordnung eines Ausdrucks zu einer Bedeutung lässt sich ein Interpretant als gedankliches Bild (image) vorstellen. Im Gegensatz zu STÖCKL (2016, S. 28 ff.) behandele ich Metaphern nicht als eigene Modalität wie die als

and only form a sign through being actually embodied“ (ebd.). Dagegen bezeichnet ein Legizeichen ein von Menschen aufgestelltes Gesetz (vgl. ebd.), meist ein Symbol. Aufgrund „konventioneller Regeln der Bedeutungszuweisung [...] können aber auch indexikalische und symbolische Momente beteiligt sein" (SCHMITZ, 2016, S. 343 f.; Kursive im Original), um Bilder zu konstituieren. Diese gelten prototypisch als ikonische Zeichen (ebd., S. 343).

57 Schmitz (2005, S. 206 f.) kritisiert an STÖcKLs (2004) Konzeption das Verhältnis zwischen Metapher, Phraseologismus und materiellem Bild, was ihn zu folgendem Schluss führt: „Ich jedenfalls plädiere dafür, genau herauszuarbeiten, was materielle Bilder und geschriebene Sprache gemeinsam haben und was sie grundsätzlich unterscheidet." (SchmiTZ, 2005, S. 207) Wie Drewer (2003, S. 178 ff.) am Beispiel des Phraseologismus bzw. der Metapher schwarze Löcher veranschaulicht, werden Theoriemodelle in didaktisierenden und popularisierenden Textsorten der Experte-Laien-Kommunikation wie Schulbüchern und populärwissenschaftlichen Artikeln durch Metaphern veranschaulicht, aber auch in hochschuldidaktischen Lehrwerken. Es lassen sich auch Beispiele für die Verwendung von Metaphern in Experte-Experte-Kommunikation finden. 
Kategorien erfassten Modalitäten ,materielle Bilder und ,Schriftsprache', sondern als Teil von Schriftsprache.

In der Diskussion um Ikonizität als Teil von Sprache-Bild-Texten werden Metaphern im Rahmen der semantischen Analyse auf der Ebene der Wörter und Phraseologismen behandelt. In Bezug auf Multimodalität beschränkt sich die Analyse aber entsprechend BATEMAN (2008) auf bild-ikonische Zeichen im Sinne materieller Bilder aufgrund ihrer Konventionalität und Ähnlichkeit, auf Diagramme und auf Schriftsprache - nur zum Teil auf ihre Schriftbildlichkeit - und vor allem auf deren Zusammenspiel im Text durch Grammatik und Layout. Dieses Zusammenspiel fokussiert nicht nur die syntaktische Ebene, sondern bezieht auch die semantische und funktionale Ebene in die Analyse ein.

Materielle bzw. ikonische Bilder, abbildende und rekonfigurierende Diagramme sowie schriftsprachliche Elemente, zu denen ich auch Metaphern zähle, spielen als semiotische Ressourcen in Sprache-Bild-Textsorten kommunikativ-funktional zusammen, wie BATEMANs (2008) oben dargestellter page flow modelliert. Diese Systematisierung von Zeichentypen und deren Zusammenspiel bilden die Grundlage, um sich in der empirischen Analyse den Thesen 2 und 3 zu nähern. Im Folgenden wird anhand der Positionen von Schema- und Salienztheorie diskutiert, wie die Rezeption eines solchen Textes interpretiert werden kann und wie sich ein Sprache-Bild-Textsortenexemplar analysieren lässt.

\subsubsection{Salienztheorie und Annahmen zu Top-down-Rezeptionsprozessen}

Die Rezeption und Analyse von Diagrammen, Bildern und Schriftsprache als funktionale Einheiten von Sprache-Bild-Textsortenexemplaren modellieren die Schema- und die Salienz-Theorie: Der salienzbasierte Ansatz geht davon aus, dass „die Selektion vom Angebot selbst gesteuert wird“ (BUCHER, 2011, S. 142), wobei ,[i]m Falle der Angebotssteuerung [...] von einem Bottom-up-Prozess gesprochen wird, in dem das Angebot selbst die Relevanz der entsprechenden Elemente signalisiert" (ebd.; Kursive im Original). Dagegen wird in der SchemaTheorie „die Selektion entweder als intentionale Handlung des Rezipienten oder als Resultat seiner kognitiven Schemata“ (ebd., S. 135) vorausgesetzt, die „von einem Top-down-Prozess [ausgeht], bei dem der Rezipient darüber entscheidet, was für ihn relevant ist" (ebd.; Kursive im Original). 
Entsprechend lässt sich KRESS/VAN LEEUWENs (2006) Ansatz als salienzbasiert und VAn LeEuwens (2005b) Ansatz, der die Grundlage für STÖCKLs (2016, S. 22) Handlungsstrukturen bildet, als schemabasiert einordnen: Grammatisch-schriftsprachliche Linearität wird in KRESS/VAN LEEUWEN ( ${ }^{2} 2006$, S. 204 ff.) zugunsten der Salienz von multimodalen Texten aufgelöst, die die Rezeption steuere. Von diesem Ansatz grenzt VAN LEEUWEN (2005b, S. 81 f.) seinen Ansatz ab, da er die Analyse von der Textstruktur hin zu einem Rezeptionsweg (reading path) verlagert. ${ }^{58}$ Denn die vergleichbare Salienz von Textelementen (more or less equal in salience) ermöglicht mehrere Rezeptionspfade, wie VAN LEEUWEN (2005b, S. 82 ff.) an einem Beispiel demonstriert. Auf dieser Grundlage kommt er zu folgendem Schluss:

58 Dagegen wird mithilfe der Methode des Eye-Trackings versucht, den Rezeptionsprozess empirisch zu untersuchen (BUCHER, 2011; BUCHER, 2007; BUCHER/SCHUMACHER, 2006). Diese Untersuchungen kommen zu folgendem Ergebnis: „Blickaufzeichnungsdaten belegen empirisch, dass zur Erklärung der Aufmerksamkeitsverteilung und damit des multimodalen Verstehens Top-down- und Bottom-up-Prozesse, Angebots- und Nutzersteuerung, Intentionalität und Reaktivität gleichermaßen herangezogen werden müssen.“ (BUCHER, 2011, S. 145; Kursive im Original) Für diese Aussage ist einzuschränken, „dass Blickaufzeichnungen zwar darüber Aufschluss geben, was die Probanden anschauen, nicht aber darüber, was sie sehen“ (ebd., S. 152). Diese Einschränkung expliziert eine andere Publikation zu dieser Untersuchung von BUCHER: ,Attention as well as selection processes are not directly open to observation and are therefore constructions of the observer." (BUCHER/SCHUMACHER, 2006, S. 351) Für die technische Umsetzung lässt sich die Feststellung folgendermaßen begründen: ,[A]n eye tracker can track overt movements of the eyes; it cannot track covert movement of visual attention which happens without moving the eyes." (ebd., S. 354 f.) Die Schlussfolgerung, dass in der Überprüfung von Analysen KRESS/VAN LEEUWENs (2006) durch HolsANOVA/ HOLMQVIST/RAHM (2006) „prognostizierte Lesepfade [...] empirisch kaum bestätigt werden können“ (EHRENHEIM, 2011, S. 166), ist vor dem Hintergrund der oben dargestellten Grenzen von Eye-Tracking nicht zulässig. Ebenso wenig zulässig ist auch folgende Einschätzung zur Validität der Leser-Text-Interaktion, die durch trianguliertes Eye-Tracking, Interviews und Beobachtungen untersucht wird: „We can then investigate reader behaviour, the rationality behind that behaviour, as well as reader expectations and attitudes." (HoLsANOVA/HolmQVIST/ RAHM, 2006, S. 89) Denn die Notwendigkeit, „[d]iese interpretatorische Lücke [...] auszufüllen“" (BUCHER, 2011, S. 152), die dieser aufgezeigte Mangel des EyeTracking-Verfahrens hinterlässt, macht es notwendig, die kulturspezifische Bedeutungen einzubeziehen, als die Präsentationsformen ,im sozialen Kontext ihrer Verwendung verstanden werden“ (BUCHER, 2007, S. 52). Zu diesen gehört auch das Musterwissen zu einer Textsorte, über das Rezipienten als Kommunikanten verfügen. Dieses Wissen kann durch Eye-Tracking nicht untersucht, sondern nur interpretiert werden. 
„In other words, the text becomes an environment facilitating a number of staged, goal-oriented reading processes. It is an environment for such processes, and must be analysed as a kind of map, a spatial structure designed to facilitate a range of specific activities.“ (ebd., S. 85)

Vorstellbar ist auch eine Rezeption, die nicht ausschließlich einer Chronologie, also nicht ausschließlich einem Rezeptionspfad folgt, sondern eine Rezeption, bei der ,einem ersten Gesamteindruck vergleichsweise schnell (top down) kleinere Teileindrücke ein[gefügt] oder zu[gefügt]“ (SchMITZ, 2006a, S. 188) werden. D. h., ,[t]ypischerweise erfasst man mit einem Blick zunächst einen optischen Eindruck des Ganzen als Gestalt" (ScHMITZ, 2011a, S. 31), an den sich ein Rezeptionspfad anschließt. Dieser erste Eindruck steuert „die folgende Reihenfolge und Deutung der Teile, deren Wahrnehmung das Ganze teilweise aber auch modifizieren kann" (ebd.). Aus ihrer ebenfalls salienzbasierten Untersuchung von Stellenanzeigen leitet EHRENHEIM (2011) ab, dass die Textsortenexemplare ,als ein Gesamttext wahrgenommen [werden], bevor sich der Rezipient detaillierten Bestandteilen wie Bildern oder typographischen Elementen zuwendet" (ebd., S. 330). Die Analysekategorie ,Textstruktur' wird dabei auf der zweithöchsten Abstraktionsebene zwischen den Polen ,Linearität' und ,Modalität' angelegt, weil Anzeigen einerseits „mit linear fortlaufenden Schrifttexten ausgestaltet sind“ (ebd., S. 177). Andererseits sind Absätze visuell strukturierend bzw. sind „manche Anzeigen nicht nur inhaltlich, sondern auch visuell modulartig aufgebaut" (ebd., S. 178).

Gegen eine strikte Trennung von salienz- und schemabasiertem Ansatz spricht bei der Analyse von Sprache-Bild-Textsorten, dass Letztere sowohl als Textsortenmuster konzipiert werden können, die Teil des Wissens der Kommunikanten sind, als auch als Zeichenrepräsentation, deren Salienz beschrieben werden kann. Weil nicht das Wissen der Kommunikanten, sondern ausschließlich die Textsortenexemplare als Ausdrucksmittel der Kommunikanten untersucht werden können, fokussiert meine empirische Analyse die Salienz der Textsortenexemplare. Während Kapitel 2.3 die Multimodalität von Textsorten präzisiert, um These 3 empirisch zu prüfen, bleibt der zweite Teil zum Zusammenhang zwischen multimodalen Ausdrucksmitteln und deren kontextueller Einbettung offen. Letzterem widmet sich Kapitel 2.4. 


\subsection{Kontext}

These 2 zufolge sind Textsortenkonventionen domänenspezifisch und mikrokulturell geprägt. Entsprechend These 3 bestimmt die mikrokulturelle Textkompetenz der einzelnen Kommunikanten, wie sie bildliche, schriftsprachliche und diagrammatische Elemente in naturwissenschaftlich-technischen Textsorten rezipieren.

Ergebnisse der drei folgenden empirischen Untersuchungen interfachlicher Kommunikation legen des Weiteren nahe, dass die Funktionen von Sprache-BildTextsorten in interfachlichen bzw. interdisziplinären Kontexten mikrokulturell determiniert sind. Die Ergebnisse stützen demnach These 3:

1. Bei der Textproduktion von Patentschriften arbeiten Ingenieure und Juristen Hand in Hand, wie die Textprodukte belegen: Die technischen Zeichnungen (inklusive schriftsprachlicher Elemente der Technik) fungieren ausschließlich für Ingenieure als Anleitung für einen Nachbau des Produkts (BRAMBILlA, 2013, S. 156; LIU, 1992). Die schriftsprachlichen Kapitel mit Beschreibungen des Objekts, die auch Techniksprache umfassen, des Umfangs und des Kontextes eines Patents sind für Juristen relevant (BRAMBILlA, 2013; GÖPFERICH, ${ }^{2} 2006$; SCHEEL, 1997, S. 153; SCHAMLU, 1985, S. 123 f.). Dementsprechend sind Patentschriften zweifach fachsprachlich (GÖPFERICH, 1995, S. 126; OSTAPENKO, 2009, S. 237) bzw. doppelt fachsprachlich (SOFFRITTI, 2002, S. 60) geprägt (s. Kapitel 2.4.2).

2. Ingenieure und Wirtschaftswissenschaftler kommunizieren in interfachlichen Projekten mithilfe einer Plansprache, die auch nichtsprachliche Symbole umfasst und durch ein interdisziplinäres Forschungsprojekt untersucht wird (JAKOBS, 2011a; JAKOBS, 2011b). JAKOBS (2011a) kritisiert auf der Metaebene des kooperativen Forschungsprojekts aus Psychologie, Linguistik, Ingenieur- und Wirtschaftswissenschaften, dass Forschungspartner der Ingenieurwissenschaften Visualisierungen ,als weitgehend ,sprachfrei“ und daher als fehlerarm“ (ebd., S. 118) einschätzen. Diese Einschätzung legt nahe, dass Visualisierungen der Schriftsprache in den Ingenieurwissenschaften vorgezogen werden.

3. Ingenieure, Juristen und Betriebswirte eines interfachlichen Projekts in einem Planungsbüro beraten eine Stadtverwaltung zu ihrem Energiekonzept. Wesentliches Kommunikationsmittel zwischen Planungsbüro und Stadt bildet ein Bericht, 
der neben schriftsprachlichen Elementen viele Diagramme, Zeichnungen und Tabellen enthält (Pogner, 2012, S. 94 f.; Pogner, 2003; Pogner, 1999). Den Zusammenhang zwischen modaler Selektion während des Rezeptionsprozesses und dem mikrokulturellen bzw. fachlichen Hintergrund der Rezipienten stellt PogNer (1999) als ein Ergebnis seiner Interviews mit den beteiligten Textproduzenten bzw. den Projektmitarbeitern heraus:

„Nach Ansicht der Projektmitarbeiter haben Tabellen auch die kurze und präzise
Wiedergabe von Sachverhalten mit anderen als rein sprachlichen Mitteln zum Ziel
bzw. die zusammenfassende Darstellung von manchmal unterschiedlichen Ergeb-
nissen verschiedener Vorgängerberichte. Sie erleichtern den Lesern außerdem das
schnelle Finden von Daten, wenn sie in einem Bericht etwas nachschlagen wollen.
Schaltbilder und Zeichnungen können - jedenfalls von Experten - unabhängig vom
laufenden Text gelesen werden und sollen der Forderung nach technischer Präzi-
sion entgegenkommen.“ (POGNER, 1999, S. 165; Fettdruck AH)

POGNER belegt dieses Ergebnis mit der Interviewaussage desselben Inhalts, die von einem Maschineningenieur stammt. Dieser Umstand und das Zielen auf technische Präzision grenzen Expertentum als technische Expertise ein. Demnach sind Teile des Berichts modal-exklusiv für Experten einer Mikrokultur zugänglich. Eine Asymmetrie modalen Wissens gegenüber Experten anderer beteiligter Mikrokulturen ist anzunehmen. Augenfällig ist an dieser Rezeptionsbeschreibung des Weiteren, dass Texte modalspezifisch selektiert werden.

ADAMZIKs ( $\left.{ }^{2} 2016\right)$ Textsortenkonzept modelliert, wie Kontext und Texfunktion (Textexterna) mit der Textgestaltung (Textinternum) ,miteinander verknüpft sein können“ (ebd., S. 112). Auch BATEMAN (2008, S. 176) schreibt dem page flow als Resultat der Textgestaltung zu, die textuelle Funktion zu unterstützen. Brinker/CÖlfen/PAPPERTs ('2018, S. 139) und SChMitZ' (2011a, S. 37) Textsortendefinition gehen von typischen Verbindungen dieser Ebenen aus. Meine zentrale Fragestellung zielt auf diese typischen Verknüpfungen. Während das integrierte Modell der Sprache-Bild-Textsorten die Textinterna präzisiert, werden im Folgenden die Textexterna in Form des Kontextes beschrieben, um die Thesen 2 und 3 empirisch untersuchen zu können. Ich lehne mich in meiner Konzeption von Sprache-Bild-Textsorten an den Kontext-Begriff in НАß (2018) an (Kapitel 2.3.1), demzufolge der Rezipient von impliziten Kontexthinweisen auf Entitäten, die außerhalb des zu rezipierenden bzw. analysierenden Textsorten- 
exemplars liegen, mithilfe von Assoziationen etc. durch sprachreflektierte oder unreflektierte Verfahren schließt.

Kapitel 2.4.1 konzipiert die Entität ,Kontext ${ }^{`}$ als interfachlichen Kontext, indem es die Begriffe ,Domäne', ,Organisation“ und ,Projektkommunikation“ bespricht - ähnlich einer systemtheoretischen Gliederung von Kommunikationsgemeinschaften als Makro-, Meso- und Mikroebene (RopoHL, 2012). Diese Konzepte sollen dabei helfen, die Thesen 2 und 3 empirisch untersuchen zu können. Zweifache Fachsprachlichkeit, also die Gestaltung einer Textsorte durch kommunikative Mittel zweier Fächer, und eine entsprechende Skala der doppelten Fachsprachlichkeit beziehen diese kontextuellen Faktoren auf die Ausdrucksmittel. Die Wissens- und Institutionen-Asymmetrien, die in Formularkommunikation zwischen den eingebundenen Kommunikaten bestehen, stellt Kapitel 2.4.3 vor, weil die zu untersuchenden Lasten- und Pflichtenhefte durch diese Kommunikationsform gestaltet werden. Die Ergebnisse aus der Diskussion dieser Kontextaspekte fasst das Kontextmodell zu Business-to-Government-/B2G-Kommunikation (s. Abbildung 2-12) zusammen.

\subsubsection{Interfachlichkeit in Domänen-, Organisationen- und Projektkommunikation}

Folgende Beschreibung eignet sich, um das Phänomen der interfachlichen Kommunikation zu erfassen, weil der Fachkommunikator bzw. -kommunikant als Mittler seines Fachs auftritt:

„Fachkommunikatoren kommunizieren jedoch nicht beim Handeln im Fach, zumindest handeln sie nicht in demselben Fach, das Inhalt ihrer Kommunikation ist. Das Fach, in dem ein Fachkommunikator handelt, ist die Fachkommunikation. Der fachliche Inhalt der Mitteilungen ist jedoch die Straßenverkehrsordnung, der Betrieb einer Kunststoffbecherdruckmaschine oder die Kontraindikation von Medikamenten. Fachkommunikatoren sind nicht nur Sprachmittler, sondern zugleich Fachmittler.“ (SCHUBERT, 2007, S. 214)

So kann ein Fachkommunikant als Experte eines Faches als Mittler gegenüber Experten eines anderen Faches auftreten. Diese Konstellation wird auch als Interfachlichkeit definiert: 
,(3) der Fachmann eines Faches spricht mit dem Fachmann eines anderen Faches über Inhalte seines bzw. dessen Faches: $\quad$ Exp F1 - F1 - Exp F2

Exp F1 - F2 - Exp F2

(4) der Fachmann eines Faches spricht mit dem Fachmann eines anderen Faches über Inhalte eines gänzlich anderen Faches: Exp F1 - Fx - Exp F2““ (KALVERKÄMPER, 1998b, S. 35).

Voraussetzung für diese Definition ist die Systematisierung von Fächern nach horizontaler Gliederung und vertikaler Schichtung: Die horizontale Gliederung zwischen Fächern stellt diese nebeneinander; die vertikale Schichtung nach ihrer Spezialisierung (ENGBERG, 2011, S. 192) bzw. der Abstraktionsstufe des fachlichen Inhalts (ebd.; ähnlich in KALVERKÄMPER, 1998b, S. 34 f.) hierarchisiert die Fächer auf einer vertikalen Skala. ${ }^{59}$ Entlang dieser vertikalen Skala kann zwischen Experten am oberen Ende und Laien am unteren Ende der Skala Vermittlungskommunikation stattfinden - sogenannte Transgression (KALVERKÄMPER, 1998b, S. 37) bzw. vertikaler Wissenstransfer ${ }^{60}$ (ANTOS, 2001, S. 20).

Kommunikationskonstellationen, die sich daraus ergeben, veranschaulicht Abbildung 2-8.

Abhängig vom Gegenstand der Kommunikation kann in der interfachlichen Kommunikation zwischen zwei Experten ,einer der beiden Experten oder ggf. [können] beide Experten als Laien angesichts des anderen Faches auftreten“" (ROELCKE, 2014, S. 165). Diese Konstellation symbolisiert die Ziffer 4 in Abbildung 2-8. In Abhängigkeit vom Kommunikationsgegenstand kann die interfachliche

Im Gegensatz dazu wird Interdisziplinarität als Kommunikationssituation ausschließlich zwischen wissenschaftlichen Experten zu einem lebensweltlichen, wissenschaftlich reflektierten Problem definiert, deren komplementär gefundene Lösung möglichst außerhalb der Wissenschaft Anwendung finden möge (JANICH/ZAKHAROVA, 2014, S. 6). Transdisziplinarität bezieht sich auf die Kommunikationskonstellation zwischen Wissenschaftlern und Praxisvertretern, die ein lebensweltliches Problem zu lösen versuchen (JANICH/ZAKHAROVA, 2011, S. 191). Unklar bleibt, was als lebensweltlich gelten kann. Wissenschaftliche Experten und Experten der Praxis unterscheide ich im Anschluss hieran in Bezug auf ihr Interesse an einem Erkenntnisgewinn gegenüber dem Interesse an der Lösung eines konkreten, lebensweltlichen Problems. Im Bereich der zum Teil extrem anwendungsorientierten Gebiete wie der Betriebswirtschaftslehre oder den Ingenieurwissenschaften, die intensiv mit Unternehmen kooperieren, lassen sich diese Bereiche nicht zwingend trennen.

60 Dieser umfasst beispielsweise sprachlich-konzeptionelle Übernahmen aus der Wissenschaft in den Alltag, Popularisierung und Didaktisierung (ANTOS, 2001, S. 20). 
Kommunikation zwischen Experten unterschiedlicher Fächer auch auf horizontaler Ebene als ,horizontale (zwischen Fächern) [...] Transferorientierung“ (BusCH, 2001, S. 87) bzw. horizontale Transferkommunikation stattfinden. Diese Konstellation repräsentiert Ziffer 2 (s. Abbildung 2-8).

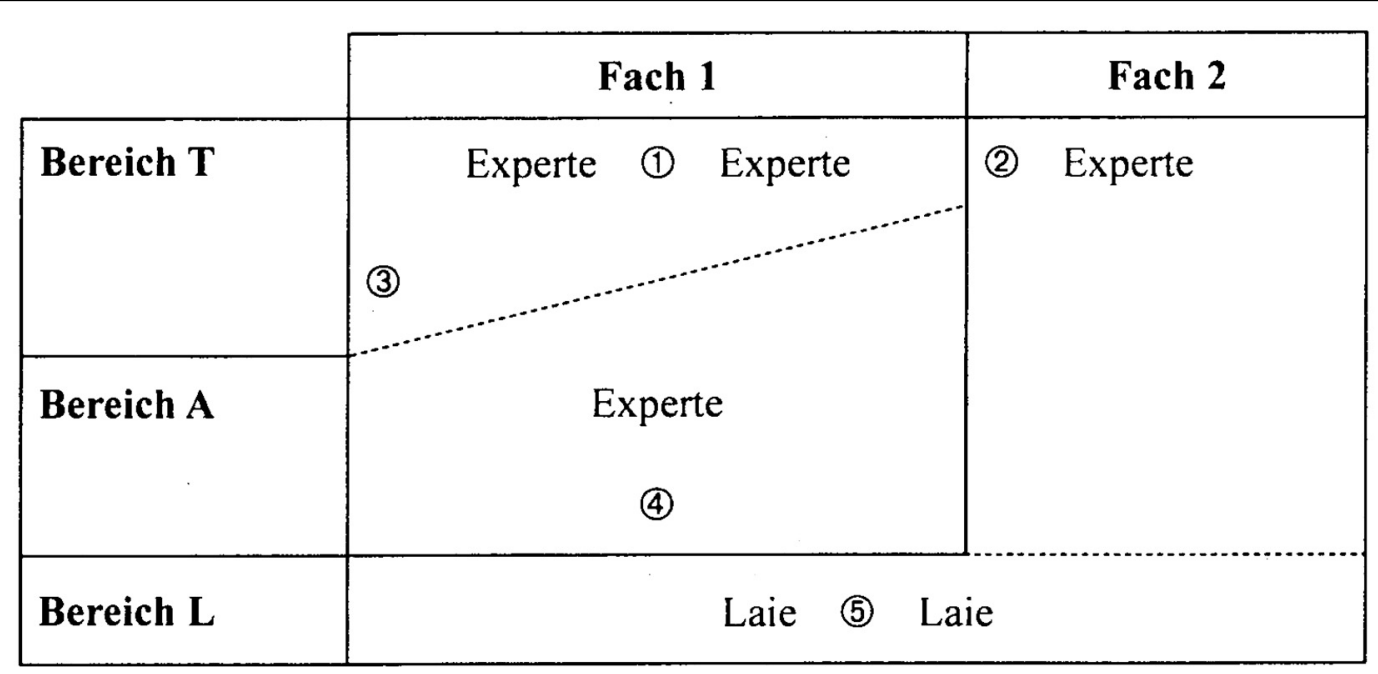

Abbildung 2-8: Typen der Kommunikation zwischen Experten und Laien (RoELCKE, 2014, S. 164).

Interfachlichkeit definiere ich für meine Untersuchung als Kommunikation ausschließlich zwischen Experten einer lebensweltlichen Praxis (horizontale Transferkommunikation) mit dem Interesse an der Lösung eines lebensweltlichen Problems in Abgrenzung vom Interesse an wissenschaftlicher Erkenntnis. Abhängig von den Teilgegenständen der interfachlichen Kommunikation können Experten eines Faches gegenüber Experten anderer Fächer als Laien erscheinen.

Experten handeln im Beruf häufig als Schreibende. Dieses interfachliche Expertenverhältnis besteht vor allen in Domänen, die das Kontextmodell für berufliche Schreibprozesse als eine von mehreren Ebenen (s. Abbildung 2-9) erfasst.

Für meine Analyse, die berufliche Schreibprozesse fokussiert, werden die relevanten Ebenen ,Domäne“ und ,Organisation“ behandelt. Des Weiteren werden Konzepte zu Projektkommunikation diskutiert, die das Kontextmodell nicht erfasst, die für meine exemplarische Analyse aber relevant sind, weil die beobachteten Textüberarbeitungen in der Projektkommunikation stattfanden (s. Kapitel 4.3.1). 


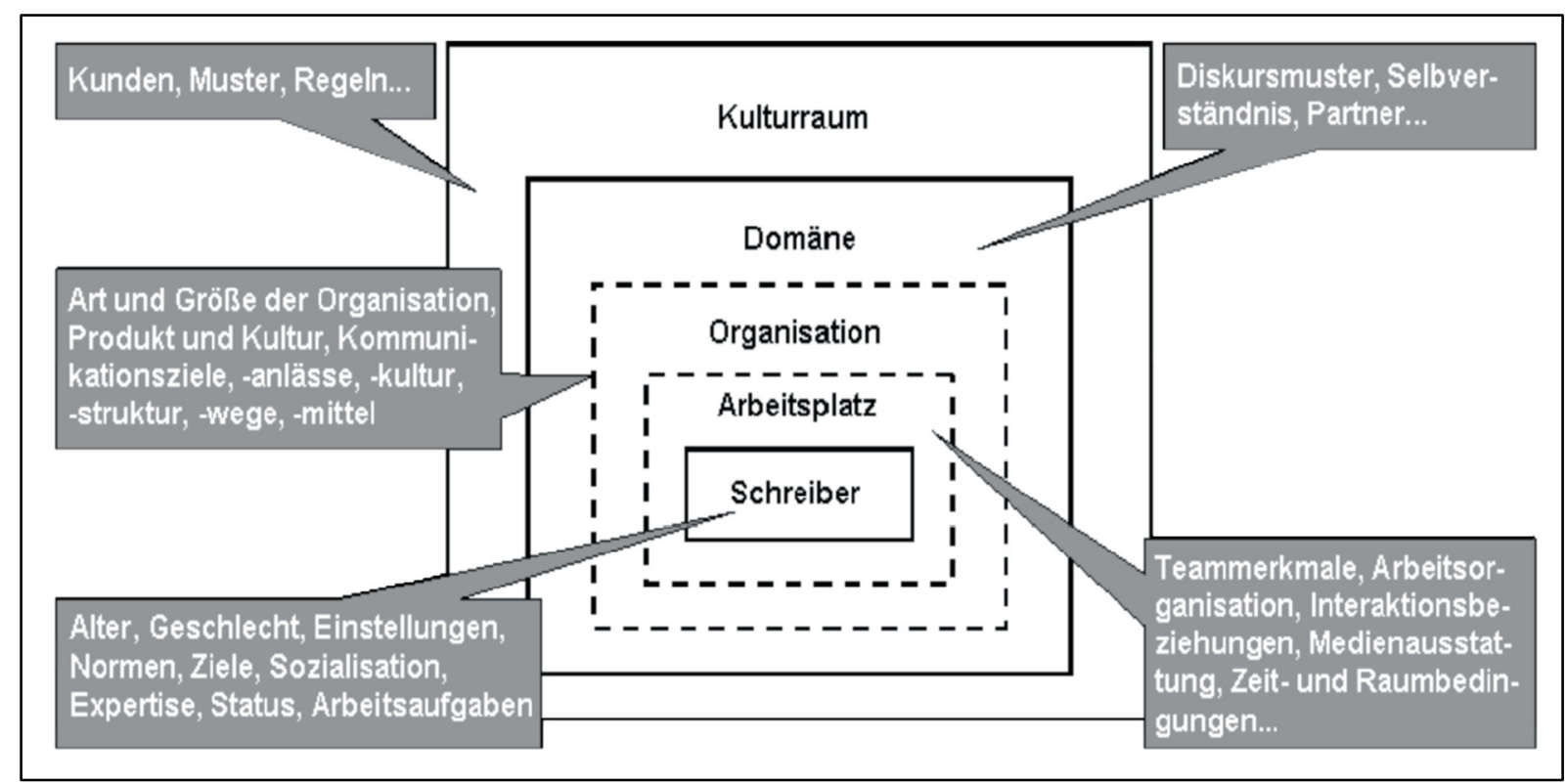

Abbildung 2-9: Kontextmodell des Aachener Forschungsansatzes (JAKOBS, 2011b, S. 82).

Die drei Konzepte zu Domänen in Abgrenzung zum Fach in JAKOBS/SPINUZZI (2014), JANICH (2009) und POGNER (2012) beziehen sich auf die Entitäten ,Diskurs', ,Text' bzw. ,Schreibprozess'. JAKOBS/SPINUZZI (2014) modellieren Domäne als Kontextualisierung von kommunikativen Prozessen in Form von Textproduktionsmustern und weiteren kommunikativen Konventionen etc.:

„Here, domains are socially established contexts with domain-specific topics, discourse communities, communication, and interaction tasks and genres. Domainspecific discourse communities have their own explicit and tacit rules, norms, conventions, and patterns of text production.“ (JAKOBS/SPINUZZI, 2014, S. 325; Kursive im Original)

Deutlich wird die Eignung dieser Definition für meine Untersuchung durch den Bezug auf Textsorten (genres) und Schreibprozessmuster (patterns of the text production) im Rahmen „beruflich konstituierter Diskursgemeinschaften“ (JAKOBS, 2011b, S. 83). Mit Letzteren rücken nicht die kommunikative Handlung, sondern die gesellschaftliche Situierung bzw. Kontextualisierung und soziologische anstelle sprachlicher Faktoren bzw. kommunikativer Mittel in den Vordergrund. Entsprechend der Bedeutung von Normen etc. nehmen auch Erwartungen Raum im Konzept von beruflichen Domänen ein (ebd.). ,Domäne‘ und ,Diskursgemeinschaft' bedingen sich im Kontextmodell beruflichen Schreibens (s. Abbildung 2-9) als Einheiten. 
JANICH (2009) nimmt Bezug auf ein interaktions- und wissenstheoretisches Diskurskonzept (WARnKe/SPITZMÜLLER, 2011, S. 65 ff.). JANICHs (2009) Modell von Textsorten-in-Vernetzung impliziert ein rahmendes bzw. hierarchisches Verhältnis zwischen Diskurs und Domäne: Diskurse rahmen Domänen, wobei Domänen als Handlungsfelder (GIRNTH, 1996) bzw. als Interaktionsrahmen (KLEIN, ${ }^{2} 2014 \mathrm{a}$ ) verstanden werden. Diese konzeptionellen Bezugnahmen spiegeln sich auch in den Interaktionsrollen der Kommunikanten wider (JANICH, 2009, S. 5), die ein Akteur in der Kommunikation einnehmen kann (ebd., S. 5 f.): Funktionsträger, Diskursakteur, Beteiligungsrolle und Mitglied einer Sprachgemeinschaft.

PoGNER (2012) kontrastiert für berufliches Schreiben die Entitäten ,Diskursgemeinschaft ${ }^{\star}$ gegenüber ,Prozessgemeinschaft‘. Auch dieses Konzept von Diskursgemeinschaften bezieht sich auf ein wissenstheoretisches Diskurskonzept - allerdings ohne weitere Bestimmung. Obigen drei Domänen-Konzeptionen als Diskurs, Diskursgemeinschaft und sozialer Kontext ist gemeinsam, dass sie Konventionen fokussieren: ob in Form von ,interaction layers ' bzw. ,rules, norms, conventions and patterns ${ }^{6}$ (JAKOBS/SPINUZZI, 2014, S. 325) oder als Sprachkonventionen in Form von „funktional orientierte[n], fachsprachenübergreifende[n] Sprachvarietäten“" (ADAMZIK/ANTOS/JAKOBS, 1997, S. 2). Dieser Aspekt der drei diskutierten Begriffe von ,Domäne' schließt an das Sprache-Bild-TextsortenKonzept an, weil auch Letzteres primär durch Konventionen und Funktionen bestimmt ist (s. Kapitel 2.1.1). Folgende Domänen-Definition impliziert diese Konventionen- und Funktionsorientierung und bezieht auch den Begriff ,Fachsprache' ein:

„In den Wissenschaften, in der Wirtschaft, den Massenmedien, in der Technik und im Verkehrswesen entstehen und expandieren funktional orientierte, fachsprachenübergreifende Sprachvarietäten. Diese ergänzen, vermehren und bereichern gesellschaftliche Diskurse, die - spezifiziert nach bestimmten Funktionen - hier als Domänen zusammen gefaßt werden soll [sic]. Neben traditionellen Domänen ( $\mathrm{Fa}-$ milie, Arbeit, Religion, kulturelles Leben/Literatur etc.) sind dies auch Domänen, die verwandte Fachsprachen bündeln.“ (ADAMZIK/ANTOS/JAKOBS, 1997, S. 2)

Das Konzept von Fachsprachen dient also als Grundlage für die Entwicklung des Konzepts von Domänen bzw. von domänenspezifischen Sprachvarietäten. Unscharf bleibt bei dieser Definition von ,Domäne“ der Begriff ,Fach“, der 
grundsätzlich als unbestimmt gilt. ${ }^{61}$ Ich schließe mich dieser Definition von Domäne an, weil sie es ermöglicht, die interfachlichen Konstellationen in meiner empirischen Analyse zu erfassen.

Als zweite Ebene des Kontextmodells (s. Abbildung 2-9) wird die Entität ,Organisation' bzw. ,Organisationenkommunikation‘ behandelt, die im Modell Teil von Domänen ist. Das Verhältnis zwischen Organisation und Organisationenkommunikation lässt sich aus linguistischer Perspektive kaum trennen:

\begin{abstract}
„Organisationen sind einerseits ein kommunikativer Prozess. Sie sind andererseits ein kommunikatives Produkt. [...] Zur Organisationenkommunikation zählen alle zeichenhaften (verbalen, visuellen usw.) Vorgänge in einem Interaktionskontinuum (einer Produzenten-Rezipienten-Kette), die auf den Prinzipien arbeitsteiligen, ineinander greifenden Handelns beruhen und außerdem eine normative Komponente haben (Weick 1995).“ (MÜLLER, 2008, S. 22)
\end{abstract}

Diese semiotisch komplexe Bestimmung von Organisationenkommunikation und letztlich von Organisation als kommunikativem Vollzugs- und Konstitutionsprozess ist auch in HABSCHEIDs (2003) Organisationenbegriff angelegt. Dieser Begriff wird im Folgenden näher behandelt, um die Relevanz von Organisationen auf die zu analysierenden Texte und protokollierten Gespräche erfassbar zu machen - die Kommunikanten gehören zu Auftraggebern und Bietern, die Organisationen sind. HABSCHEID (2003) zielt auf eine linguistische Analyse eines organisationalen Handlungsfeldes durch ein Organisationskonzept, aus dem für den Fachkommunikanten-Begriff die Merkmale a) ,Diskursivität' (ebd., S. 86 ff.), b) ,Mehrdimensionalität‘ (ebd., S. 124), c) ,Vollzugswirklichkeit“ (ebd., S. 123) für die Diskussion institutioneller (A-)Symmetrie und d) das ,Spannungsfeld‘ von Formalisierung und Intersubjektivität (ebd., S. 70 ff.) relevant

61 Während die Begriffe ,Fach` und ,Fachlichkeit‘ nicht „näher betrachtet, geschweige denn problematisiert, begrifflich geklärt werden oder sogar definiert sind“" (KALVERKÄMPER, 1998a, S. 1), resümiert RoELCKE ( ${ }^{3} 2010$, S. 15) in seiner Diskussion von Fachkommunikationsbegriffen, dass Letzterer ,eine handlungsbezogene Bestimmung“ (ebd., S. 15) von ,Fach“ zugrunde liegt. So wird auch KALVERKÄMPERs Begriff von Fach ,in seiner Plakativität"“ (BAUMANN, 2012, S. 43) durch drei Aspekte charakterisiert: durch den fachlichen Gegenstand, durch die Kommunikation-im-Fach sowie durch ,die Interaktion zwischen Fachleuten und zwischen Fachleuten (desselben oder affiner Fächer) wie auch zwischen Fachleuten und den mit ihnen zu tun habenden Nichtfachleuten" (ebd.; Kursive im Original). 
sind. ${ }^{62}$,Diskursivität ${ }^{6}$ determiniert Organisationen, weil sie auf ,,alltäglichen sozialen Praktiken der symbolischen Interaktion/Kommunikation“ (ebd., S. 123) basieren. ,Mehrdimensional' sind organisationale Interaktionen in Bezug auf „Gesprächsorganisation, Beziehungsgestaltung, Sachverhaltsdarstellung, Handlung usw.“ (ebd., S. 124), weil sie durch politische Strukturen und Handlungsziele normiert und geleitet werden. Die Kategorie, Vollzugswirklichkeit" bestimmt Organisationen dadurch, dass Letztere durch regelmäßigen Handlungsvollzug hervorgebracht und aufrechterhalten werden. Dies gilt vor allem, weil die in einer Organisation Handelnden eine organisationale Wirklichkeit herstellen und Situationen durch Erwartungen der Beteiligten determinieren (ebd., S. 123). Organisationale Handlungen lassen sich aus linguistischer Perspektive als semiotisch komplex bestimmen und konstituieren damit die Organisation. Auch DOMKE (2011) stellt die „Herstellung organisationaler Wirklichkeit durch den Vollzug von (sprachlichen) Handlungen“ (ebd., S. 207) in das Zentrum ihrer Argumentation. $^{63}$

62 Das verbleibende Kriterium der, Selbstreferentialität ' wirkt auf eine Organisation dadurch, dass ihre Mitglieder ihr Selbstbild verändern, das aus einer Wahrnehmung resultiert, die auf einem „die eigene Identität betreffenden Sinngebungsmuster“ (ebd., S. 124) basiert.

63 Dieser Organisationen-Begriff lässt sich vom Institutionen-Begriff in EHLICH/REHBEIN ( $\left.{ }^{2} 1980\right)$ durch die Direktionalität des Verhältnisses zwischen Sprache - und Bild - gegenüber der Institution (bzw. Organisation) abgrenzen: „Die Sprache in Institutionen ist weitgehend in repetitiven Abläufen organisiert, die durch die institutionsspezifischen Zwecke gesteuert werden. Das führt dazu, daß viele sprachliche Handlungen in relativ starren Formen verlaufen, bis hin zu festen Formeln, die in den einzelnen Abläufen ihren Stellenwert haben und sich dem Handelnden anbieten (Dittmann 1979).“ (EHLICH/REHBEIN, ${ }^{2} 1980$, S. 334) Sprachliche Formen werden demnach durch institutionelle Zwecke, d. h. durch Institutionen, konstituiert. So hat „das Gesundheitswesen besondere sprachliche Verfahren hervorgebracht“" (ebd., S. 340). Des Weiteren bildet ,gemeinschaftliche Arbeit, Ursprung des Bedürfnisses der Sprache“ (ebd., S. 339) die Entität ,Institutionen“. Sprache selbst als Institution zu definieren, lehnen EHLICH/REHBEIN $\left({ }^{2} 1980\right.$, S. 334) ab, auch wenn eine Differenzierung von Sprache und Institution nicht möglich sei. Inwieweit Institutionen durch Sprache konstituiert werden oder ein reziprok-konstituierendes Verhältnis wie bei obigen Organisationen-Begriffen besteht, lässt sich nur für die unterschiedlichen Institutionen feststellen, nicht aber für Institutionen allgemein. Die oben aufgeführten Begriffe von ,Organisation' können nicht vollständig unter den aufgeführten Institutionen-Begriff EHLICH/REHBEINs $\left({ }^{2} 1980\right)$ gefasst werden. Zwar ließen sich die Organisationen-Kriterien ,Diskursivität', ,Selbstreferentialität‘, ,Vollzugswirklichkeit‘, ,Spannungsverhältnis ' und ,Mehrdimensionalität‘ auch auf die Institution Familie anwenden; die Entität ,Familie“ wird aber nicht als Organisation aufgefasst. Vielmehr stellen die oben dargestellten Organisationenbegriffe auf Unternehmen ab. Beispielsweise spielen in der Erforschung von Organisationenkommunikation meist Optimierungsbestrebungen und kommunikative 
Für meine empirische Untersuchung folge ich dem Ansatz HABSCHEIDs (2003, S. 68 ff.), den Begriff ,Organisation' durch die Kriterien ,Diskursivität', ,Vollzugswirklichkeit‘ und ,Mehrdimensionalität‘ zu spezifizieren. Des Weiteren beziehe ich HABSCHEIDs Bedingungen ein, dass für Organisationen-Mitglieder bei der Kommunikation ein Spannungsverhältnis zwischen Formalisierung und Intersubjektivität besteht. Ähnlich beschreibt dieses Verhältnis Kapitel 2.2.2 auf der Ebene der Kompetenzen von Kommunikanten als Spannungsverhältnis zwischen der Kenntnis und Befolgung von Konventionen und der Abweichung von diesen als kreative Kompetenz. Im Gegensatz zum Institutionen-Begriff beziehe ich den Organisationen-Begriff mit Blick auf meine empirische Analyse nicht nur auf Unternehmen (zu denen Bieter gehören), sondern auch auf Behörden (zu denen in SPNV-Ausschreibungen die Auftraggeber gehören). ${ }^{64}$

Die dritte für die empirische Untersuchung relevante Kontextebene - sie ist nicht im Kontextmodell beruflichen Schreibens aufgeführt - bildet das ,Projekt' bzw. die ,Projektkommunikation'. ,Projektkommunikation' definieren GRUCZA/ AlnAJJAR/GRUCZA (2014) wie folgt:

„Im Allgemeinen wird ein Projekt als zeitlich begrenztes Vorhaben, das unternommen wird, um ein einzigartiges Produkt, eine einzigartige Dienstleistung oder ein einzigartiges Erlebnis zu erstellen, definiert (s. PMBOK 2008: 5, G. Patzak/G. Rattay 2009).“(GruCZA/AlNAJJAR/ GrUCZA (2014, S. 161)

Das Kriterium der ,Einzigartigkeit ${ }^{65}$ der Dienstleistung ${ }^{6}$ bzw. des Produkts als Kriterium von Projektkommunikation bezeichnet RuSCH (2011, S. 54 f.) als ,Dedikation', nämlich als Widmung einer einzigen konkreten, soziotechnischen Aufgabe. Mit der Projekt-Definition in GrucZa/AlnAJJAR/GrucZA (2014,

Effizienz eine Rolle (DANNERER, 2008), während Letztere bei der Erforschung der Kommunikation in der Institution Familie (EHLICH/REHBEIN, ${ }^{2}$ 1980, S. 240) kaum eine Rolle spielen.

64 Auch Verwaltungssprache wird als Teil einer Organisationenkultur diskutiert (HEINRICH, 2014).

65 Insbesondere das Kriterium der (ausbleibenden) Wiederholung einer Aufgabe erscheint für SPNV-Ausschreibungsverfahren relevant. Zwar unterscheiden sich bei Ausschreibungen erstens die jeweils ausgeschriebene Strecke, zweitens der Umfang der Dienstleistung und drittens deren Art, sodass die Dienstleistung einzigartig bleibt. Aber Auftraggeber schreiben sehr ähnliche Dienstleistungen und Produkte aus und versuchen die Ausschreibungsprozesse dadurch zu optimieren, dass sie Ausschreibungsunterlagen vereinheitlichen (s. Kapitel 4.2). Daraus resultiert, dass die Textsortenexemplare verschiedener Ausschreibungen eines Auftraggebers weitgehend identisch sind (s. Kapitel 5). 
S. 160) stimmt RUSCH (2011, S. 50 f.) auch bezüglich des Kriteriums der zeitlich begrenzten Dauer (,Termination') überein. Dagegen behandelt nur RUSCH (2011, S. 54) die Begrenzung des Ressourceneinsatzes von Energie, Personal etc. als das Kriterium ,Limitierung'. Auch mit dem Kriterium ,Heterogenität', demzufolge Projekte ,personell und kulturell inhomogen zusammengesetzt“ (ebd., S. 50) sind, rückt nur RUSCH (2011) das Thema der Interfachlichkeit in den Fokus. Letzteres Kriterium ist besonders relevant für die empirische Untersuchung, weil es konzeptionell ermöglicht, die kommunikativen Kompetenzen der Projektmitglieder zu betrachten. Heterogenität beschreibt RUSCH (2011, S. 52) dadurch, dass die Fachkommunikanten den drei Organisationen ,Auftragnehmer', ,Auftraggeber und ,Dienstleister' und gleichzeitig verschiedenen Abteilungen innerhalb einer Organisation entstammen. Die daraus resultierende Doppelrolle eines jeden Kommunikanten erzeuge ein vermeintliches Konfliktfeld, weil die Interessen der Abteilungen und die des Projekts konfligieren können, das organisationsübergreifend angelegt ist.

Die Kriterien ,Dedikation“ und ,Heterogenität‘ spiegeln sich in der Neun-FelderMatrix (s. Abbildung 2-10) wider, die JANICH/ZAKHAROVA (2014) aus der empirischen Untersuchung von interdisziplinärer Kommunikation ableiten. ${ }^{66}$ Diese sollen im Folgenden kurz dargestellt werden, um die genannten Kriterien der Projektkommunikation zu diskutieren. Dabei fokussiere ich insbesondere das Kriterium ,Heterogenität‘, weil dies Aspekte der Interfachlichkeit beschreibt. ${ }^{67}$ Auch JANICH/ZAKHAROVAs (2014) Erkenntnisinteresse fokussiert Aspekte, die RUSCHs Kriterium ,Heterogenität‘ betreffen. Weil JANICH/ZAKHAROVA (2014) die Kategorie ,Formulierungsbarrieren“ (s. Abbildung 2-10) nicht explizit auf

JANICH/ZAKHAROVA (2014, S. 4) untersuchen als Begleitforschungsprojekt die Kommunikation im wissenschaftlichen Forschungsprojekt „Proliferationsresistente Gestaltung von Fusionsreaktoren. Beitrag zur Entwicklung einer effektiven und gerechten nuklearen Ordnung für das 21. Jahrhundert" unter Beteiligung von Physik und Politikwissenschaft. Das untersuchte Projekt ist ebenfalls zeitlich begrenzt und durch die Projektfinanzierung sind monetäre und personelle Mittel limitiert, sodass dieses Projekt RUSCHs Kriterien ,Termination' und ,Limitierung' erfüllt.

67 RUSCHS Kriterium ,Dedikation“ entspricht JANICH/ZAKHAROVAs (2014) Beschreibung zum Matrixfeld ,Inhaltsebene' - ,Problemdimension', in dem die soziotechnische Aufgabe vor allem durch die Zieldefinition festgelegt wird. Das Matrixfeld ,Inhaltsebene ${ }^{6}-$,Formulierungsbarrieren' problematisiert Aspekte, die aus der Einigung auf eine soziotechnische Aufgabe resultieren. 
weitere Modalitäten als Schriftsprache beziehen, kann deren Untersuchung aber nicht herangezogen werden, um These 3 zu stützen oder infrage zu stellen.

Vor allem das Feld ,Beziehungsebene - ,Problemdimensionen“ (s. Abbildung 2-10) thematisiert Ergebnisse zu Heterogenität innerhalb der erforschten interdisziplinären Kommunikation. Die Spalte ,Interaktionsrollen“ (ebd.) - die ähnlich den Akteursrollen im oben beschriebenen Domänenkonzept JANICHs (2009) angelegt sind - präzisiert, in welchen Rollen die Projektbeteiligten auftreten können. Dadurch entsteht eine Heterogenität, die sich nicht nur aus der Kommunikation von Kommunikanten unterschiedlicher wissenschaftlicher Disziplinen ergibt (sieh Matrixfeld ,Inhaltsebene' - ,Interaktionsrollen'), sondern auch durch die drei Rollen (s. Spalte ,Interaktionsrollen') in der Projektkommunikation.

\begin{tabular}{|c|c|c|c|}
\hline $\begin{array}{l}\text { Diskursive } \\
\text { Ebene }\end{array}$ & Problemdimensionen & Formulierungsbarrieren & Interaktionsrollen \\
\hline $\begin{array}{l}\text { Inhalts- } \\
\text { ebene }\end{array}$ & $\begin{array}{l}\text { - Semantik/Theoret. } \\
\text { Grundlage } \\
\text { - Methodik } \\
\text { - Zieldefinition } \\
\text { - Fachliche Autorität }\end{array}$ & $\begin{array}{l}\text { - Kriterien vs. Ziele (b) } \\
\text { - Unstrukturierte vs. struk- } \\
\text { turierte Ziele (c) } \\
\text { - Ziele und Formulierungs- } \\
\text { vorschläge vs. Normen/ } \\
\text { Standards (e) }\end{array}$ & $\begin{array}{l}\text { Mitglieder einer } \\
\text { disziplinären Kom- } \\
\text { munikations- } \\
\text { gemeinschaft }\end{array}$ \\
\hline $\begin{array}{l}\text { Verfahrens. } \\
\text { ebene }\end{array}$ & $\begin{array}{l}\text { - Schreibprozess } \\
\text { (Formulieren, Ändern, } \\
\text { Überschreiben, } \\
\text { Streichen) } \\
\text { - Zeitrahmen }\end{array}$ & $\begin{array}{l}\text { - Vage vs. klare Kriterien } \\
\text { (a) } \\
\text { - Ziele vs. Formulierungs. } \\
\text { vorschläge (d) } \\
\text { - Widersprüchlichkeiten (f) } \\
\text { - Prospektive Konstruktion } \\
\text { vs, retrospektive Prüfung } \\
\text { (g) }\end{array}$ & $\begin{array}{l}\text { Beteiligungsrollen } \\
\text { als Schreiber, Leser, } \\
\text { Korrektor ... }\end{array}$ \\
\hline $\begin{array}{l}\text { Beziehungs- } \\
\text { ebene }\end{array}$ & $\begin{array}{l}\text { - Fachliche Asymmetri- } \\
\text { en (unterschiedliche } \\
\text { Wissensbestände) } \\
\text { - Funktionale Hierarchi- } \\
\text { en (Projektleiter/Pro- } \\
\text { fessor vs. Mitarbeiter) }\end{array}$ & $\begin{array}{l}\text { Ergeben sich gleichzeitig } \\
\text { im Rahmen der Barrieren d } \\
\text { und } g\end{array}$ & $\begin{array}{l}\text { Funktionsträger im } \\
\text { Projekt }\end{array}$ \\
\hline
\end{tabular}

Abbildung 2-10: Dimensionen einer, gemeinsamen Sprache‘ (JANICH/ZAKHAROVA, 2014, S. 23). 
JANICH/ZAKHAROVA (2014, S. 21) beziehen die Diskursebene ,Formulierungsbarrieren' auf alle drei Interaktionsrollen. Diesen Bezug leiten JANICH/ZAKHAROVA als Forschungsergebnis aus der Interviewaussage eines beteiligten Politikwissenschaftlers ab.

Dieser gibt an, den Vertretern der Physik einen arbeitsteiligen Schreibprozess für den Projektantrag vorgeschlagen zu haben, um Einmischungen durch die jeweils andere Disziplin zu vermeiden,

„auf der Ebene des Schreibprozesses (Beteiligungsrollen: wer bestimmt, was im Antrag bleibt bzw. was umgeschrieben wird), auf der Ebene der inhaltlichen Einigung (Mitglied einer disziplinären Kommunikationsgemeinschaft: wer setzt welche Ziele durch und welche Begriffskonzepte bestimmen diese näher) sowie auf der Ebene der sozialen Hierarchie (Funktionsträger: wer hat welche Autorität bzw. argumentiert mit welcher Autorität)“ (ebd., S. 21).

Die in der interdisziplinären Wissenschaftskommunikation auftretenden Formulierungsbarrieren veranschaulichen die von RUSCH (2011) formulierten Interessenkonflikte, die das Kriterium Heterogenität mitbestimmen. Denn sowohl RUSCH als auch JANICH/ZAKHAROVA führen unterschiedliche institutionelle Rollen als Ursache auf: bei Ersterem als Aktant einer Unternehmensabteilung und gleichzeitig als Vertreter der Organisation Auftraggeber, Bieter oder Dienstleister innerhalb des Projektes; bei Letzteren als Fachvertreter und gleichzeitig in der Beteiligungsrolle als Schreibender, Korrektor etc. sowie als Funktionsträger.

JANICH/ZAKHAROVA (2014) halten fest, dass wesentliches Ergebnis des Begleitforschungsprojektes die Reflexion der kommunikativen Aufgaben war,

„nicht nur die fachspezifischen Perspektiven und die Terminologie des Kooperationspartners einigermaßen nachvollziehen zu können, sondern auch die jeweils anderen disziplinären Standards, kommunikativen Gepflogenheiten und Fachkulturen (hier auch verstanden als Muster sozialer Gefüge, als typischen Umgang mit Hierarchien, als Begutachtungspraxen usw.).“ (ebd., S. 23 f.)

Die Relevanz von Asymmetrie verdeutlichen Konflikte, die die Problemdimension als ,[f]achliche Asymmetrie (unterschiedliche Wissensbestände)“ (s. Abbildung 2-10) spezifizieren. Für die Konzeption meiner Untersuchung von Interfachlichkeit sind das Kriterium, Heterogenität" und der Konflikt relevant, der aus der Doppelanforderung an Kommunikanten als Projekt- und Organisationsmitglieder resultiert. 


\title{
2.4.2 Skalen interfachlicher Kommunikation
}

Ausgangspunkt für die Skala einer interfachlichen Fachsprachlichkeit bildet die Konzeption der zweifachen Fachsprachlichkeit in der Texttypologie der Naturwissenschaften und Technik (GÖPFERICH, 1995): Patentschriften werden darin als „als Texte mit ,zweifacher' Fachsprachlichkeit“ (ebd., S. 126) bezeichnet. Ähnlich dem Konzept zweifacher Fachsprachlichkeit wird die Terminologisierung chemischer Fachbegriffe durch juristische Texte bzw. im Kontext einzelner juristischer Texte als doppelte Fachsprachlichkeit ${ }^{68}$ konzipiert:

\begin{abstract}
„Im Rahmen meines Beitrags definiert sich [...] doppelte Fachsprachlichkeit als Eigenschaft, die anhand von juristischen Regulierungstätigkeiten in Lebensbereichen entsteht, in denen der Stand der Technik eine Fachkommunikation bereits erfordert und etabliert hat. Das bedeutet: Bereiche, in denen es schon Fachleute, Fachtexte und (mindestens) Ansätze einer Fachterminologie gibt, in die darüber hinaus auch der Gesetzgeber oder eine regulierende Behörde eingreift und dabei Texte produziert. Über eine schon vorliegende Fachsprachlichkeit legt sich also die Fachsprachlichkeit, die den Norm setzenden juristischen Text kennzeichnet und in einem gewissen Sinne erst legitimiert." (SOFFRITTI, 2002, S. 60; Fettdruck AH)
\end{abstract}

Sowohl die Beschreibung von bidirektionaler Sprachdiffusion als auch die von doppelter Fachsprachlichkeit beschreiben eine der beteiligten Fachsprachen als aktiv beeinflussende Fachsprache und die andere Fachsprache als beeinflusste Fachsprache. Anstelle dieses Verhältnisses zwischen zwei Fachsprachen, die in einer Fachtextsorte interagieren, konzipiert GÖPFERICH (1995) eine Typologie von Fachtextsorten, die entlang einer vertikalen Skala des Abstraktionsgrads und einer horizontalen Skala der Fächerbeteiligung angeordnet sind. Patentschriften weisen in dieser Typologie demnach ,sowohl einen naturwissenschaftlichtechnischen als auch einen juristischen Fach(sprach)lichkeits- und Abstraktionsgrad auf“ (ebd., S. 125 f.). Auf der vertikalen Skala sind diese ,an dem Typologieende mit dem höchsten Fach(sprach)lichkeits- und Abstraktionsgrad zu plazieren“ (ebd., S. 126). Entsprechend nimmt sowohl der Fachsprachlichkeits-

68 Zweifache Fachsprachlichkeit wird in der Beschreibung anderer interfachlicher Projektkommunikation zwischen Informatikern und Ingenieuren auch als asymmetrisch bewertet: Es bestehe eine bidirektionale Sprachdiffusion durch den ,Einfluss der Informatik und ihr sprachliches Vordringen in die Sprachwelt anderer Fachbereiche (hier des Ingenieurwesens) und die gegenseitige Veränderung der jeweiligen Fachsprache" (SATZGER/ASTAPENKO, 2006, S. 134). Diese Beschreibung stellt keine bidirektionale, sondern eine einseitige Beeinflussung durch die Fachsprache der Informatik dar. 
als auch der Abstraktionsgrad in der Typologie von Fachtexttypen in folgender Reihenfolge ab: von juristisch-normativen, über fortschrittsorientiert-aktualisierende, über didaktisch-instruktive hin zu wissenzusammen-stellenden Texten (ebd., S. 124 f.).

GöPfERichs (1995, S. 24 f.) Konzeption lehnt sich an die gleitende Skala der Fachsprachlichkeit (KALVERKÄMPER, 1989, S. 124 ff.) an, die die Dichotomie Fach- und Gemeinsprache auflöst und damit auf das Problem reagiert, beide Varietäten nicht voneinander abgrenzen zu können. Das Gleiten zwischen den Polen Gemein- und Fachsprachlichkeit wird wie folgt konzipiert:

„Es hängt an den Möglichkeiten und den Interessenlagen der Kommunikations-
partner in ihrer Situation, wo dieser Prozeß jeweils endet. Daraus läßt sich die
Einsicht ableiten, daß sich die referentielle Kommunikation zwischen
fachsprachlich (extrem) merkmalarm über fachsprachlich merkmalangereichert zu
fachsprachlich (extrem) merkmalreich verdichtet, und - in anderer Richtung - sie
sich auflockert. Ein skalares Gleiten ist somit die angemessene modellhafte
Vorstellung." (KALVERKÄMPER, 1989, S. 118)

Sämtliche Merkmale, die die Fachsprachen- bzw. Fachkommunikationsforschung in den vergangenen Jahrzehnten herausarbeitete (KALVERKÄMPER, 2016a), können demnach herangezogen werden, um Hinweise zu geben, ob ein Text als merkmalsarm, -angereichert oder -reich auf der gleitenden Skala verortet werden kann.

Im Gegensatz zu dieser Typologisierung des Fachsprachlichkeitsgrads in KALVERKÄMPER (1989) wird der Fachlichsprachlichkeitsgrad in der Untersuchung von OSTAPENKO (2009, S. 237) wie in GÖPFERICH (1995) zwischen zwei Fächern konzipiert (s. Abbildung 2-11).

Normen, die in der Typologie GöPFERICHs wie Patentschriften zu den juristischnormativen Fachtexttypen gehören, bewegen sich auf der Skala zwischen Rechtsund Bauwesen (s. Abbildung 2-11) aufgrund ihres Fachsprachlichkeitsgrades. „[S]owohl Funktion und Beziehungen der Texte zueinander als auch ihre stilistischen und lexikalischen Merkmale" (OSTAPENKO, 2009, S. 237) bestimmen dabei diesen Fachsprachlichkeitsgrad. Diese Systematik OstAPENKOs (2009) kann in meiner Untersuchung aufgrund der Einbindung mehrerer Abteilungen in die Projektkommunikation als Fachsprachlichkeitsgrad zwischen den Fachsprachen des Rechts, der Technik und der Wirtschaft übertragen werden. 
Bei der Übertragung sind drei Aspekte zu beachten:

1. Aufgrund mehrerer beteiligter Abteilungen bzw. Fächer in der zu untersuchenden Projektkommunikation ist auf der horizontalen Achse nicht von einer doppelten oder zweifachen Fachsprachlichkeit, sondern von einer mehrfachen Fachsprachlichkeit zu sprechen. Dass sich eine Fachsprache innerhalb eines Fachtextsortenexemplars interfachlicher Projektkommunikation über die übrigen im Text vorkommenden Fachsprachen legt, nehme ich in die Konzeption nicht auf, weil diese Feststellung bereits ein Analyseergebnis vorwegnimmt. Die Untersuchung dieses Zusammenhangs steht in meiner Untersuchung noch aus.

2. Die Gliederung von Textsorten nach ihrem Abstraktionsgrad auf einer vertikalen Achse entsprechend GÖPFERICH (1995) und OSTAPENKO (2009) behandele ich zusätzlich zu ihrer horizontalen Fächerverortung. Das Zusammenwirken der horizontalen und vertikalen Achse, wie es Abbildung 2-11 darstellt, ist strenggenommen als eine Art Koordinatensystem zu bezeichnen. Da diese Bezeichnung in der Fachkommunikationsforschung unüblich ist, es sich bei der horizontalen und der vertikalen Skala aber um unterschiedliche Skalen handelt, bezeichne ich diese im Folgenden mit dem Plural ,Skalen'.

3. GÖPFERICH (1995) betrachtet mit der Patentschrift wie auch OSTAPENKO (2009) mit DIN-Normen des Bauwesens eine Textsorte, die technische Zeichnungen und weitere multimodale Elemente wie Tabellen neben schriftsprachlichen Elementen beinhalten. Beide Autorinnen fokussieren in ihrer Systematik ausschließlich Schriftsprache bzw. Fachsprache. 


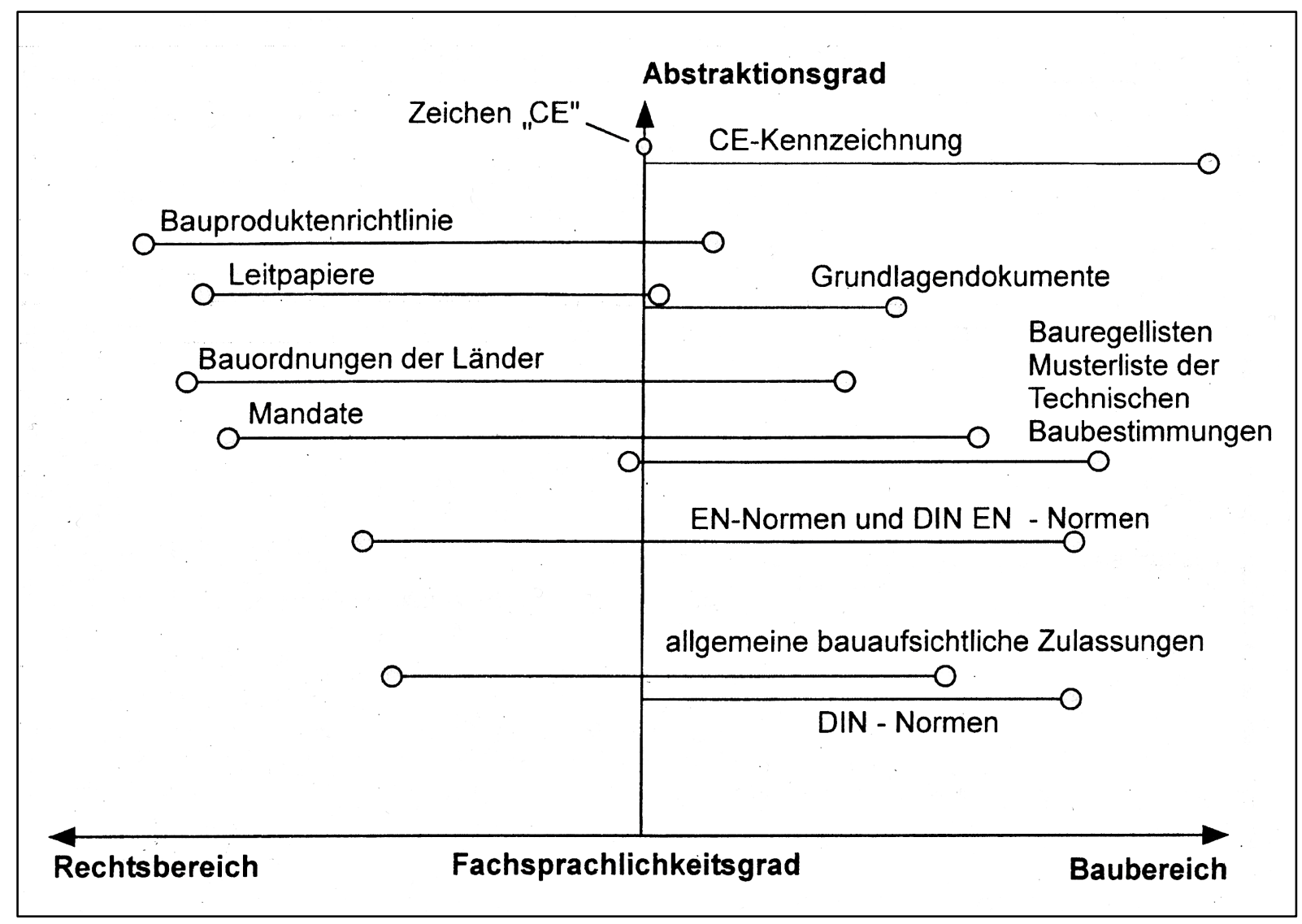

Abbildung 2-11: Fachsprachlichkeits- und Abstraktionsgrad aufgeführter Texte (OSTAPENKO, 2009, S. 237).

Entsprechend meinem Forschungsinteresse integriere ich auch bildliche und diagrammatische Elemente in die Untersuchung von Textsorten interfachlicher Projektkommunikation (s. Kapitel 2.3). Auch wenn Fachsprachlichkeit Ausgangspunkt der Betrachtung multimodaler Texte sein kann, erzeugt die Bezeichnung ,Fachsprachlichkeit` den Eindruck, dass ausschließlich sprachliche Elemente betrachtet werden. Meine Untersuchung bezieht die Skalen interfachlicher Projektkommunikation, zu denen auch bildliche und diagrammatische gehören, auf fachkommunikative Mittel. Daher ist die Bezeichnung, Skalen interfachlicher Kommunikation“ für meine Untersuchung geeigneter als ,Skala der Fachsprachlichkeit'. Projektkommunikation wird aber nicht nur durch die Kommunikationsmittel mehrerer Fächer, sondern auch durch Asymmetrien zwischen Kommunikanten bestimmt. 


\subsubsection{Asymmetrische Formularkommunikation zwischen Prozipienten}

Die Domänenspezifik von Textsortenkonventionen, auf die These 2 abstellt, wird durch institutionelle bzw. organisationale Asymmetrien bestimmt, wie auch JANICH/ZAHKAROVAs (2014) Rollen der Kommunikanten institutionell asymmetrisch sind (s. Abbildung 2-10). Die Kapazität der Kommunikanten, die These 1 behandelt, beeinflusst die Projektkommunikation als Wissensasymmetrie. Denn je nach Fächerzugehörigkeit verfügen Kommunikanten in interdisziplinären Projekten über Fachwissen, über das Projektmitglieder mit einem anderen Fachhintergrund nicht verfügen, wie JANICH/ZAHKAROVAs (2014) Untersuchung zeigt. Institutionen- und Wissensasymmetrien finden sich auch in interfachlicher Projektkommunikation wie in öffentlicher Ausschreibungskommunikation (public procurement; ${ }^{69}$ RODRÍGUEZ ET AL., 2013), die zwischen staatlichen Institutionen/Behörden und Unternehmen - ,Business-to-Government-Kommunikation“ $(\mathrm{B} 2 \mathrm{G})^{70}-$ stattfindet.

Institutionelle Asymmetrie charakterisiert, dass ,vielfach der Vertreter der Institution die Initiative [ergreift]“ (PIITUlainen/Reuter/TitTTUla, 2007, S. 13) oder innerhalb der Institution der „Ranghöhere“ (ebd.) die kommunikativen Abläufe bestimmt - beispielsweise der Projektleiter gegenüber einem Mitarbeiter (s. Abbildung 2-10). ${ }^{71}$ In B2G-Ausschreibungskommunikation entsteht die organisationale Asymmetrie vor allem dadurch, dass die beteiligte staatliche Organisation per Gesetz oder Verordnung mit einer Zwangsgewalt ausgestattet ist, über die das Unternehmen nicht verfügt und dem sich das Unternehmen durch das Agieren im Rechtsraum dieses Staates unterwerfen muss. In B2G-Kommunikation vertritt der Auftraggeber die staatliche Organisation, weil er letztlich Teil der Verwaltung ist:

69 PÜNDER/SCHELlenBerg (Hg., 2011, S. 97) bezeichnen diese Kommunikation als government procurement.

70 WANNENWETSCH (2005, S. 31) spricht von ,Business-to-Administration-Kommunikation“ (B2A).

71 Machtverhältnisse werden nicht weiter behandelt, da ,[p]räzise Gründe [für genau beschriebene Abläufe; $\mathrm{AH}$ ] allerdings [...] in diesem Zusammenhang nur hypothetisch formuliert werden [können] und eine erschöpfende Klärung der Sprechermotivation [...] prinzipiell nicht möglich“ (PETERS, 2008, S. 37) ist. 
„Freilich muß jede Verwaltung mit Zwangsgewalt ausgerüstet sein, sonst hätte sie keinen Sinn und keinen Effekt. Wird der Steuertermin nicht beachtet, so erhebt die Finanzverwaltung ein Säumnisgeld. Wird das Haltesignal, die rote Ampel, nicht beachtet, so fordert die Polizei eine Buße, und wenn sie das Versäumnis nachweist, kann sie die Buße erzwingen." (STERNBERGER, 1981, S. 16)

Im Rahmen des Gesellschaftsvertrags ist die Zwangsgewalt-Asymmetrie auf das Gewaltmonopol des Staates und auf dessen Verpflichtung gegenüber seinen Bürgern zurückzuführen, ihre Grundrechte zu sichern. So kommt der Staat mit Dienstleistungen im ÖPNV seiner Daseinsvorsorgepflicht für seine Bürger nach (s. Kapitel 4.3.1).

Dass die Kommunikanten-Konstellation zwischen Experten unterschiedlicher Fächer auch als Experte-Laien-Situation diskutiert wird, zeigt Kapitel 2.4.1. Im Anschluss daran kann in Projektkommunikation zwischen Fachkommunikanten eine Wissensasymmetrie durch den fachlichen Gegenstand entstehen: ${ }^{72}$ Die beteiligten Kommunikanten thematisieren in ihrer Rolle als Mitglieder einer (Fach-) Sprachgemeinschaft einen interfachlichen Teilgegenstand des Gesamttextgegenstands. In Bezug auf einen oder mehrere der Teilgegenstände verfügen die jeweiligen beteiligten Kommunikanten verschiedener Fächer über Expertenwissen, während ihnen für das Verständnis der übrigen Teilgegenstände das notwenige Fachwissen in der Regel fehlt.

B2G-Ausschreibungskommunikation findet auch als Formularkommunikation statt, wie sich in meiner empirischen Untersuchung anhand von Lastenheftvordrucken und Pflichtenheften zeigt. In Formularkommunikation können sich sowohl institutionelle als auch wissensbezogene Asymmetrien ausdrücken. Formularkommunikation wird definiert als „Transformation von mündlicher und schriftlicher Kommunikation“" (BECKER-MrotZEK/EHLICH/FICKERMANN, 1992, S. 235; Kursive im Original). Aufbauend auf der Charakterisierung von

72 Wissensasymmetrien bzw. Wissensgefälle (SCHUBERT, 2013, S. 54) werden vielfach in Beispielen zu (Formular-)Verständlichkeit in Bürger-Behörde-Kommunikation (FISCH/ Marglies, Hg., 2014; Fluck/Blaha, Hg., 2010; RADTKe, Hg., 1981; Grosse/MentruP, Hg., 1980) aufgezeigt. Verständlichkeit wird in diesen Publikationen weitgehend mit Bürgernähe gleichgesetzt. SCHUBERT (2013) merkt dagegen an, dass Bürgernähe und Verständlichkeit keine gleichrangigen Ziele bei der Optimierung von Verwaltungskommunikation sind: „Das Verständlichmachen ist seinerseits eine Maßnahme, die dazu dient, Bürgernähe, Serviceorientierung usw. zu erreichen.“" (ebd., S. 53) Weiteres dazu auch in KLEIN (2014b). 
Formularen als „standardisierten schriftlichen Dialogen“ (GÜLICH, 1981, S. 341 f.) konzipieren BECKER-MrotZEK/SCHERNER (2000, S. 637) das Formular als Versuch, ,eine Äußerungssequenz (Sequenz - Sprecherwechsel) schriftlich zu realisieren“" (ebd.). Daraus leitet sich folgende Formularstruktur ab:

„Die erste Phase beginnt mit dem leeren Formular, der Produktion des Formulargebers. Es enthält die Fragen oder kurz: die Frageseite. Eine Frage kann man auch als Vorgabe einer Kategorie verstehen, zu der die jeweils spezifische Ausprägung erbeten wird." (WICHTER, 2011, S. 113)

Auf der Prozessebene ergibt sich daraus eine Modifikation des Kommunikanten ,Produzent' und ,Rezipient' hin zum sogenannten ,Prozipienten“, wie er im Zusammenhang mit Internetkommunikation bzw. Wikipedia-Artikeln beschrieben wird:

„Angesichts der immer stärker werdenden interaktiven und kollaborativen Elemente des Internets [...] wird dem Benutzer daher auch eine neue, und zwar gemischte Rolle des sog. Prosumenten zugesprochen. [...] Da es in der Sprachwissenschaft üblich ist, von Produzenten und Rezipienten zu sprechen, scheint mir Prozipient der geeignetere Ausdruck zu sein.“ (ADAMZIK, ${ }^{22016, ~ S . ~ 141) ~}$

Für die Kommunikation mit Formularen werden Prozipienten als prototypisch angenommen, sowohl in digitaler Umgebung als auch in Papierform (ebd., S. 149). Vorgegeben wird durch Formulare, ,was anzukreuzen oder auszufüllen ist und wie viel Platz dafür zur Verfügung steht“" (ebd.). Die Bezeichnung der Kommunikanten in Formularkommunikation als ,Prozipienten“ übernehme ich für Textsorten in B2G-Kommunikation, die als Formulare gestaltet sind (s. Abbildung 2-12).

Formulare sind grundsätzlich thematisch und funktional unbestimmt, also eine Kommunikationsform, ${ }^{73}$ und werden erst durch ihre thematisch-funktionale Bestimmtheit zu einer Textsorte - beispielsweise als Antragsformular. Ihre thematische Bestimmtheit resultiert aus dem jeweiligen Interesse von Behörden, mit

73 Aufgrund ihrer Polyfunktionalität werden Kommunikationsformen von Textsorten abgegrenzt (ZIEGLER, 2007, S. 26 f.; BRINKER/CÖLFEN/PAPPERT, ${ }^{9} 2018$, S. 142). Kommunikationsformen sind „kommunikative Konstellationen, die über ein Hilfsmittel erst möglich gemacht werden, aber auch solche, die ohne ein Hilfsmittel auskommen“ (DÜRSCHEID, 2005, S. 5). Sie ,setzen die größeren medialen und situativen Konfigurationen für die Produktion von multimodalen Textsorten" (STÖCKL, 2016, S. 9). Face-to-face-Kommunikation und E-Mails zählen beispielsweise zu Kommunikationsformen (ZIEGLER, 2007, S. 25). GÜLICH (1981, S. 328 f.) bezeichnet erst die thematisch bestimmte Form des Antragsformulars als Textsorte. Ähnlich in STICKEL (1981, S. 292 f.). 
Formularen Informationen $\mathrm{zu}$ erheben (BECKER-MROTZEK/SCHERNER, 2000, S. 636) und diese Erhebung streng zu formalisieren (GROSSE, 1981, S. 271). Grund dafür ist, dass keiner der Kommunikanten, der Informationen durch ein Formular an die Behörde gibt, gegenüber einem anderen Kommunikanten diskriminiert werden soll.

In Formularkommunikation kommt diese institutionelle Asymmetrie dadurch zum Ausdruck, dass ,sich die Klienten mittels Angaben/Ankreuzen (Helbig 1980) unter die an den Leerstellen fixierten Kategorien (Kodierungen) der Behörde subsumieren“ (REHBEIN, 1998, S. 665) müssen. In Ausschreibungsverfahren verfügt der staatliche Auftraggeber über eine entsprechende Zwangsgewalt, indem er Kriterien für die Zuschlagserteilung aufstellen, Bieter unter bestimmten Bedingungen aus dem Verfahren ausschließen oder aus definierten Gründen erst gar nicht zulassen kann (s. Kapitel 4.2).

Eine institutionelle Asymmetrie kann sich aber nicht nur auf Formularkategorien oder Positionierungen von Angaben, sondern auch auf die Konsequenzen von Änderungen am Formularvordruck beziehen. Dies beschreibt ein Ratgeber für öffentliche Ausschreibungsverfahren:

„Auch wenn der Bieter in einem LV [Leistungsverzeichnis/Leistungsbeschreibung, $\mathrm{AH}]$ einen Fehler entdeckt, darf er diesen nicht eigenmächtig korrigieren. Wird z. B. eine Teilleistung mit einer Einheit in Quadratmetern ausgeschrieben, richtig wäre jedoch die Einheit ,laufende Meter' gewesen, muss der Bieter seinen Preis auf Quadratmeter umrechnen oder den ÖAG um Aufklärung bitten.“ (BELKE, 2012, S. 80; Fettdruck im Original)

Dieser Ratgeber beschreibt die kommunikative Bedeutung einer Formularänderung mit Verweis auf die Rechtslage, die ein Urteil des BGH zum Handeln des öffentlichen Fachkommunikanten darstellt (BGH, Urteil vom 16.04.2002 - X ZR 67/00, IBR 2002, 374 nach BELKE, 2012, S. 80):

„Mit der Korrektur des offensichtlichen Fehlers ändert der Bieter die Angebotsunterlagen und muss ausgeschlossen werden. Mit dem dogmatischen Verbot von Änderungen der Vertragsunterlagen soll die Vergleichbarkeit der Angebote gewährleistet werden.“ (BELKE, 2012, S. 80; Fettdruck im Original)

Inwieweit in B2G-Kommunikation eine Wissensasymmetrie während des Erstellens oder Ausfüllens von Formularen besteht, ist zu untersuchen. In meiner Untersuchung bleibt zu klären, inwieweit Unternehmen interne oder externe Experten für behördliche und juristische Kommunikation als Unterstützung 
hinzuziehen. Die Ergebnisse zur Diskussion obiger Kontextaspekte fasst Abbildung 2-12 zusammen.

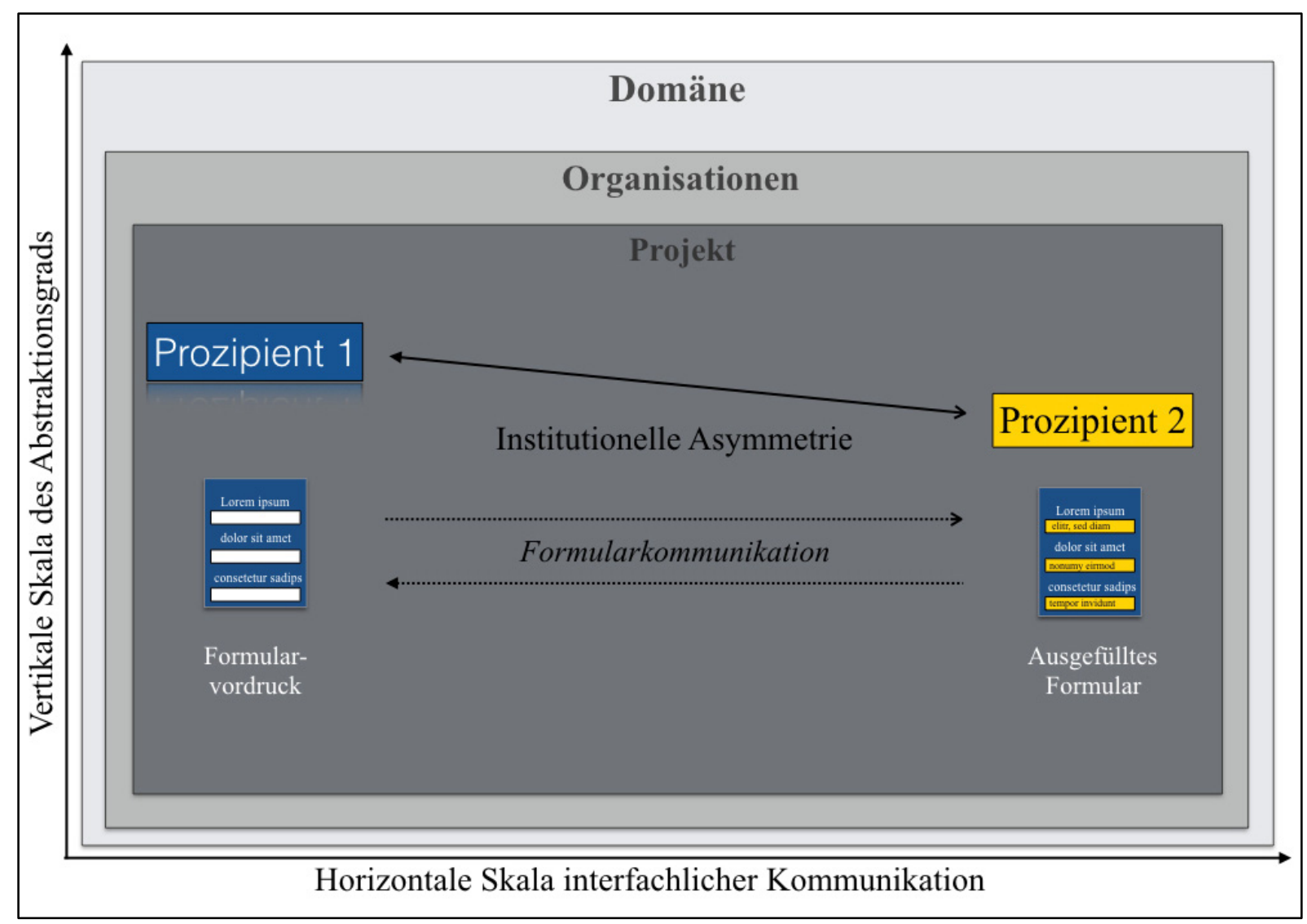

Abbildung 2-12: Kontextmodell zu B2G-Ausschreibungsverfahren (eigene Darstellung in Anlehnung an ADAMZIK, ${ }^{2016}$; KALVERKÄMPER, 1989; u.a.).

Das Kontextmodell zu B2G-Ausschreibungsverfahren stellt einen Teil des Modells semiotischer Effizienz dar: So wird die darin angegebene Ebene ,Kontext ${ }^{\star}$ durch das Kontextmodell ausdifferenziert. Sowohl die Übersicht zum Modell semiotischer Effizienz (s. Tabelle 2-2) als auch die Übersicht zum Kontextmodell (s. Abbildung 2-12) sollen als Orientierung bei der Analyse von Textsortenexemplaren und Beobachtungsprotokollen dienen. Diese Diskussion der Asymmetrien in Formularkommunikation, insbesondere für B2G-Kommunikation, ermöglicht es, die Thesen 1 und 2 empirisch zu prüfen. 


\subsection{Zwischenfazit: Modell semiotischer Effizienz}

Die Behandlung obiger Konzepte zielte darauf, These 1 bis These 3 zu untermauern und für die empirische Analyse überprüfbar zu machen. Entsprechend These 1 kann das Verhältnis zwischen der Kapazität der Kommunikanten und der Komplexität des Kommunikats, das kommunikative Effizienz bedingt, als Textsortenkonventionalität und -funktionalität bestimmt werden. Entsprechend These 2 sind diese Textsortenkonventionen domänenspezifisch und mikrokulturell geprägt und müssen von den Kommunikanten im interfachlichen Kontext ausgehandelt werden, weil ihre unterschiedliche mikrokulturelle Prägung unterschiedliche Erwartungen bei den Kommunikanten erzeugt. These 3 zufolge nutzen Textsorten naturwissenschaftlich-technischer Kontexte neben Schriftsprache ikonisch-materielle Bilder und Diagramme als Ausdrucksmittel. Die Fähigkeit, wie diese Mittel rezipiert werden können, bestimmt die mikrokulturelle Textkompetenz der einzelnen Kommunikanten.

Das Resultat obiger Diskussion geeigneter Konzepte fasst das Modell semiotischer Effizienz zusammen (s. Tabelle 2-2). Es modifiziert das Modell kommunikativer Effizienz (s. Tabelle 2-1) wie folgt: Die Dichotomie einer langueund einer parole-Ebene wird zugunsten einer Textsortenebene aufgegeben, während die generelle Ebene (Roelcke, 2002a, S. 70) erhalten bleibt. Diese Modifikation ergibt sich aus These 1, die als Ergebnis aus der Diskussion vor allem des Textsortenkonzepts von BRINKER/CÖLFEN/PAPPERT ( $\left.{ }^{9} 2018\right)$ hervorgeht.

Weil die Kategorie ,Kommunikationsbereitschaft' aufgegeben wurde (s. Kapitel 2.2.2), kann diese nicht mehr ins Verhältnis zur Kategorie ,Kommunikationsfähigkeit‘ gesetzt werden. Beide Unterkategorien bildeten in RoELCKE (2002a) die Oberkategorie ,Kapazität der Kommunikanten“ (s. Tabelle 2-1). Im Modell semiotischer Effizienz bestimmt ausschließlich die ,Kommunikationsfähigkeit‘ bzw. ,kommunikative Kompetenz' die Kapazität der Kommunikanten. Denn Intentionen und Interessen, die die Bereitschaft bestimmten, lassen sich nicht empirisch untersuchen. Auch dieses Diskussionsergebnis stieß die Diskussion von These 1 unter Bezug auf das BRINKERsche Textsortenkonzept am Beispiel des Heiratsschwindlers an. Dass auch die Kompetenz der Kommunikanten empirisch nicht unmittelbar untersucht werden kann, setze ich voraus. Die Kategorie ,Kompe- 
tenz' bleibt im Modell aber erhalten, weil meine protokollierten Beobachtungen von Textüberarbeitungen und Interviewaussagen der Kommunikanten Hinweise auf die Kompetenzen geben, denen sich die Analyse interpretativ nähert. Im Gegensatz zu Kompetenzen lassen sich aus Interviewaussagen und Beobachtungen kaum die Kommunikantenintentionen und -interessen interpretieren. Dementsprechend wird im Modell semiotischer Effizienz die Kategorie ,kommunikative Kompetenz' mit der ,Kommunikantenkapazität' gleichgesetzt.

Kommunikative Kompetenz wird durch drei Elemente bestimmt: 1. Kenntnisse der Textsortenkonventionen und -funktionen, die im Schreibprozess als reziproke Erwartenserwartungen der Textproduzenten in Bezug auf die vermuteten Erwartungen der Rezipienten auftreten; 2. das Spannungsverhältnis zwischen dem Erfüllen von Konventionen bzw. den angenommenen Erwartungen und das Abweichen von diesen Konventionen. Kommunikanten können in Schreibprozessen eine kreative Kompetenz nutzen, um dieses Abweichen zu gestalten; 3. die transsubjektive Kompetenz, durch die Kommunikanten in Projekt-, Organisationenbzw. Domänenkommunikation interfachlich handeln können. Dieses Diskussionsergebnis präzisiert These 1 dadurch, wie Kommunikanten mit Konventionen umgehen können, sodass sich auch das Abweichen von diesen auf das Verhältnis zwischen Kommunikantenkapazität und Kommunikatskomplexität auswirkt. Die Aufnahme der transsubjektiven Kompetenz von Kommunikanten (ENGBERG/ JANICH, 2007) resultiert aus These 2, die durch dieses Diskussionsergebnis konzeptionell gestützt wird: Die Fähigkeit der Kommunikanten, Textsortenkonventionen in interfachlicher Kommunikation auszuhandeln, wird durch die transsubjektive Kompetenz fassbar.

Die Aufwandsseite des Kommunikats (s. Tabelle 2-1) wird nicht mehr nur durch schriftsprachliche Elemente modelliert, sondern durch die folgenden SpracheBild-Textelemente: (schriftbildliche) Wörter, Sätze, Teiltexte, ikonisch-materielle Bilder sowie abbildende und rekonfigurierende Diagramme ${ }^{74}$. Das Textde-

74 Sprache-Bild-Texte sind letztlich rekonfigurierende Diagramme, werden hier aber als Teil von diesen Texten systematisiert. Dadurch wird es möglich, technische Zeichnungen, die vielfach Teil von Sprache-Bild-Textsorten der Technikkommunikation sind, zeichentheoretisch zu erfassen und gleichzeitig weitere Elemente wie Schriftsprache und materielle Bilder einer Textsorte als gleichwertige Elemente zu technischen Zeichnungen zu beschreiben. 
sign und die Grammatik einer Textsorte arrangieren diese Elemente. Die Konventionalität und Funktionalität von Textdesign und Grammatik einer Textsorte determinieren die Ergebnisseite des Kommunikats. Nach wie vor wird die Komplexität des Kommunikats durch das Zusammenspiel dieser Elemente von Aufwands- und Ergebnisseite festgelegt. Die Aufnahme unterschiedlicher Zeichentypen in das Sprache-Bild-Textsortenkonzept resultiert vor allem aus der Diskussion der Textkonzepte in Schmitz (2011a) und BATEMAN (2008). Das Diskussionsergebnis stützt These 3 konzeptionell - auch wenn nicht der Teilaspekt der These gestützt wird, dass es sich um eine Eigenschaft speziell von SpracheBild-Textsorten der Naturwissenschaften und Technik handelt. Die Diskussionsergebnisse schließen dies aber nicht aus. Vielmehr ergibt sich die Gültigkeit für Textsorten dieser Domäne daraus, dass allgemeinsprachliche Textsortenkonzepte auf fachsprachliche Textkonzepte übertragen werden können. Entsprechend resultiert These 3 aus der mikrokulturellen Prägung, ob Kommunikanten Zeichensysteme rezipieren können. Diesen Teil der These konnte die Diskussion der Konzepte $\mathrm{zu}$ Interfachlichkeit weder stützen noch widerlegen. Zumindest die aufgeführten Ergebnisse aus empirischen Untersuchungen, die Kapitel 2.4 zu Beginn dargestellt, stützen These 3 .

Das Modell semiotischer Effizienz konzipiert den Kontext als neue Ebene. Auf diesen gibt der Text implizite Hinweise, die der Rezipient nur durch Schlussverfahren verstehen kann. Diese Ebene wird neben die Kommunikantenkapazität und Kommunikatskomplexität gestellt, um zu explizieren, dass der Kontext die Konventionalität und Funktionalität der Textsorten wie auch die kommunikative Kompetenz der Kommunikanten determiniert. Die Kompetenz der Kommunikanten bezieht sich wiederum auf ihre Kenntnis der Textsortenkonventionalität und funktionalität. Die Kontextebene des Modells semiotischer Effizienz soll es ermöglichen, These 2 und These 3 empirisch zu überprüfen.

Das Verhältnis zwischen Kapazität, Komplexität und Kontext ist im Modell semiotischer Effizienz nicht wie im Modell kommunikativer Effizienz als quantitativ-graduelles angelegt. Vielmehr stellt das Modell semiotischer Effizienz die Relationierung dieser drei Ebenen in die Tradition von PEIRCEs und MORRIS' 
Zeichentheorie: ${ }^{75}$ Im Anschluss an ADAMZIKs (2016) Auseinandersetzung mit Hausendorf/Kesselheims (2008) Modell des Textwissens als Teil eines Semioseprozesses (s. Kapitel 2.2.1) fasse ich die zu untersuchenden Textsortenexemplare als PEIRCEsche Repräsentamen auf. Diese verweisen auf die beim Kommunikanten vorhandenen, individuellen Vorstellungen von Textsortenkonventionen und werden Teil seiner kommunikativen Kompetenz - Kompetenz selbst wird weder bei PEIRCE noch bei MORRIS thematisiert. Das Repräsentamen verweist im Modell semiotischer Effizienz also auf das Textwissen als Interpretanten und indirekt auf den Kommunikanten als MORRISschen Interpreten.

Aus den Diskussionsergebnissen zu den Thesen 1 bis 3 leite ich folgende Definition von semiotischer Effizienz ab:

Semiotische Effizienz liegt auf der Ebene von Textsorten vor, wenn Kommunikanten über die Kompetenz verfügen, die Konventionalität und Funktionalität von Textsortenexemplaren erstens zu erkennen und zu verstehen. Zweitens befähigt sie diese Kompetenz dazu, Textdesign, -grammatik, -semantik und -funktionen derart zu wählen, dass sie entsprechend ihrem kommunikativen Zweck in den situativen Kontext eingebunden sind. Dies schließt in Form einer kreativen Kompetenz auch Abweichungen von Konventionen ein, die gefragt sind, wenn Standardlösungen diesen Zweck nicht erfüllen. Textsortenkonventionen sind dabei an den fachlichen Hintergrund der Rezipienten gebunden; die Kommunikanten handeln diese Konventionen im interfachlichen Kontext mithilfe ihrer transsubjektiven Kompetenz aus. Um derart kommunikativ zu handeln, arrangieren die Kommunikanten folgende Ausdrucksmittel durch Textdesign und Grammatik: (schriftbildliche) Wörter, Sätze, Teiltexte, ikonisch-materielle Bilder und Diagramme.

Diese Definition erläutert den Zusammenhang zwischen den Elementen des Modells semiotischer Effizienz, die Tabelle 2-2 systematisiert.

Das Modell semiotischer Effizienz wird im Folgenden herangezogen, um die Kommunikation in Ausschreibungsverfahren zu untersuchen. Weil dieses Modell noch zu unspezifisch ist, um einzelne Textsortenexemplare $\mathrm{zu}$ analysieren und damit These 1 und 3 zu überprüfen, wird im Folgenden das integrative Analyseraster für interfachliche Sprache-Bild-Textsorten auf der Grundlage des Textanalyserasters multimodaler Textsorten (STÖCKL, 2016) entwickelt.

75 Die Elemente beider Theorien erläutern die Fußnoten 21 und 22 in kurzer Form. 

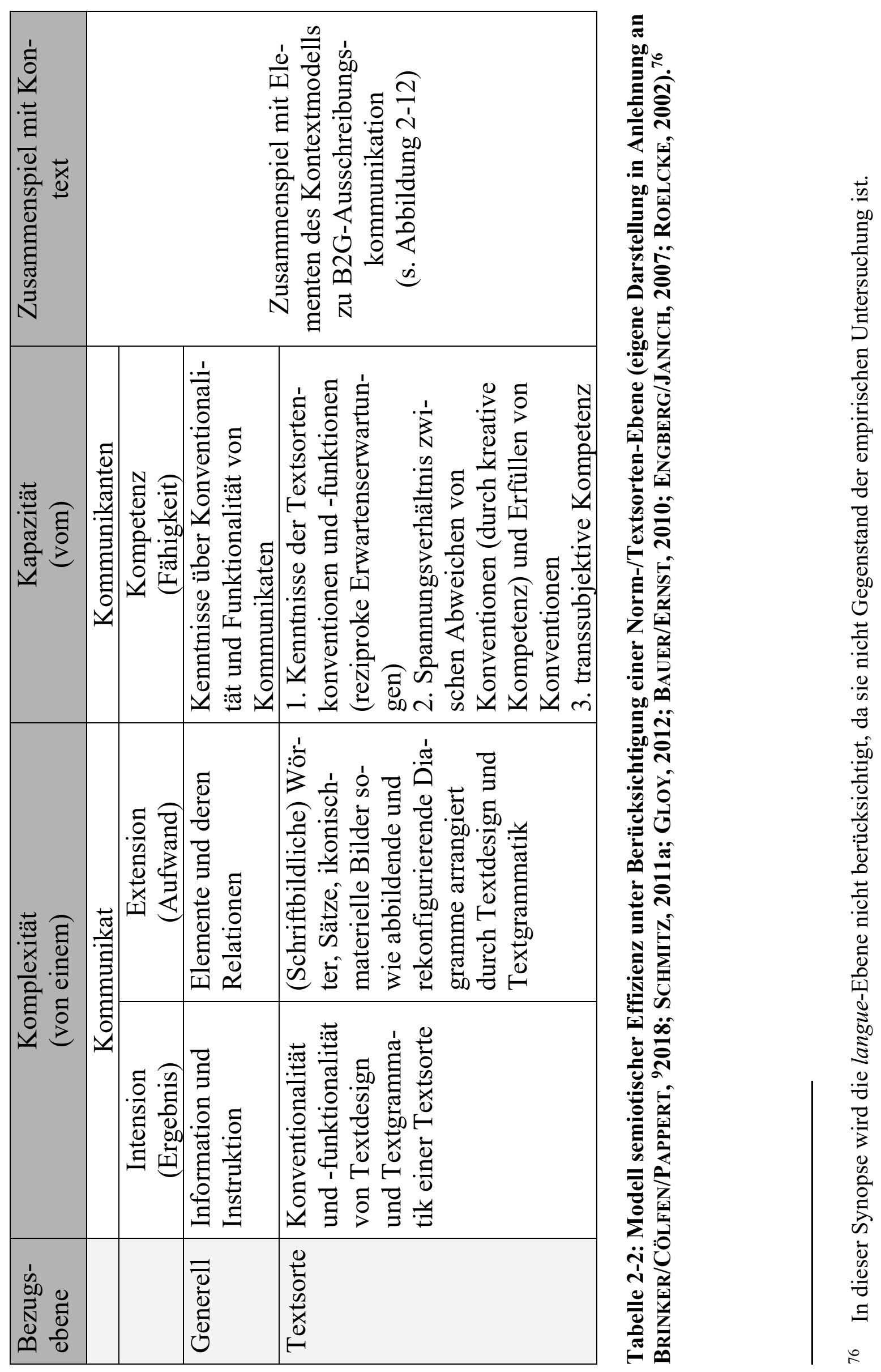


\section{Integriertes Analyseraster für interfachliche Sprache-Bild-Textsorten}

Die Monografie BRINKER (1985) kann für die deutsche Textlinguistik mehr oder weniger als Standard gelten: Nicht nur dessen Funktionstypologie ist ,[d]ie immer noch am weitesten verbreitete Unterscheidung" (FANDRYCH/THURMAIR, 2011, S. 19), sondern auch viele andere Elemente dieses Textkonzepts wie das Verhältnis mehrerer Funktionen eines Textes zueinander (RoLF, 2000) Textualität allgemein (ADAMZIK, ${ }^{2} 2016$, S. 101) oder Themenentfaltungsmuster bzw. Strukturhinweise (HAUSENDORF/KESSELHEIM, 2008, S. 91 ff.) werden in anderen Werken zur Textlinguistik herangezogen. In der aktuellen Ausgabe von BRINKER wird als neue Entwicklung aufgeführt, „dass der Anteil ausschließlich verbaler Texte zurückgeht“ (BRINKER/CÖLFEN/PAPPERT, ${ }^{9} 2018$, S. 21 f.) und diese ,zunehmend durch visuelle Elemente ergänzt, ja teilweise sogar verdrängt“ (ebd., S. 22) werden. Die Frage, „ob und wenn ja auf welche Weise die nichtsprachlichen Informationsträger unterschiedlicher Art (Fotos, Bilder, Piktogramme, Diagramme etc.) in den Textbegriff einfließen sollten“ (ebd.), fasse ich als Desiderat auf. Denn auch wenn in einer Beispielanalyse (ebd., S. 115 ff.) ein Sprache-Bild-Text auf seine Funktion hin untersucht wird, bleibt das eher monomodal ausgerichtete Analyseraster aus BRINKER (1985, S. 137) in BRINKER/CÖLFEN/PAPPERT ( ${ }^{9} 2018$, S. 155) unverändert. Es wird also nicht zu einem multimodalen Raster erweitert. Eine entsprechende Erweiterung nimmt GROßE (2011) vor. Sie beginnt mit einer Analyse des Kontextes als Textexterna, geht dann auf die vollständig isolierten textinternen bildlichen Elemente ein, analysiert im Anschluss weitgehend isoliert textinterne sprachliche Elemente eines Textsortenexemplars und nimmt erst zusammenfassend eine Synthese nicht nur der Textinterna und -externa als Konventionen und Textfunktionen, sondern auch eines (multimodalen) Gesamttextes vor (ebd., S. 250 ff.).

Ein integriertes Analyseraster für multimodale Texte legt dagegen STÖCKL (2016) vor, das sich wiederum an einer monomodalen Konzeption von KESSELHEIM (2011, o. S. nach STÖCKL, 2016, S. 24) orientiert. Weil die Dichotomie ,Fachsprache‘ und ,Allgemeinsprache‘ zugunsten einer Skala der Fachsprachlichkeit 
aufgelöst wurde (KALVERKÄMPER, 1989), eignet sich für die Analyse von Fachtextsortenexemplaren ein Analyseraster für Textsorten, das nicht fachsprachenspezifisch ist, sondern lediglich den Fachsprachlichkeitsgrad des jeweiligen Textsortenexemplars berücksichtigt (GÖPFERICH, 1995, S. 58). Dementsprechend dienen die folgenden Grunddimensionen einer multimodalen Textsortenanalyse von STÖCKL (2016, S. 23) dem integrierten Analyseraster meiner Untersuchung multimodaler Fachtextsorten als Grundlage: ,Gliederung/Abgrenzung', ,Handlungsstruktur', ,Themenstruktur', ,multimodale Verknüpfung ' und ,Intertextualität‘.

Die Grunddimensionen Handlungs- und Themenstruktur sowie Gliederung/Abgrenzung lassen sich den MoRrisschen Dimensionen Pragmatik, Semantik und Syntax zuordnen und finden sich in mehreren anderen textlinguistischen Konzepten wieder, die ebenfalls auf MORRIS` Zeichenmodell Bezug nehmen. Die Dimension ,Gliederung/Abgrenzung ' umfasst Textflächen, Bilder, Schriftzeilen und Logos, aber auch Linien, Rahmungen und akustische Signale, die textinterne Gliederungsmerkmale für die sortentypische Handlungs- und Themenstruktur bilden und auch den Text extern zu anderen Texten abgrenzen etc. (ebd.). Sogenannte Handlungsabschnitte (,stages ${ }^{\text {}}$ ) bilden in der Dimension ,Handlungsstruktur funktionale Einheiten einer Funktionsstruktur von einem Text, die durch verschiedene Modalitäten wie Schrift und Bild repräsentiert werden. Dass auch Bilder Funktionen im Sinne der Sprechakttheorie repräsentieren können, wird zwar als unbewiesen dargestellt, im Konzept aber letztlich vorausgesetzt (ebd.). Das Verhältnis zwischen verschiedenen Funktionen einer Textsorte, wie beispielsweise einer Grundfunktion und weiteren Textfunktionen (BRINKER/CÖLFEN/PAPPERT, ${ }^{9} 2018$, S. 101 ff.), wird nicht behandelt. Die Dimension ,Themenstruktur' bezeichnet eine Struktur des Textes, in der unterschiedliche Modalitäten Teilthemen als Themenmodule repräsentieren können; dabei wird die Frage aufgeworfen, ob auch mehrere Modalitäten ein Teilthema als Koreferenz bilden können (ebd.), also mehrere Elemente eines Textes wie ein Bild und ein Schriftelement dasselbe Teilthema repräsentieren. Unberührt bleibt die Frage, ob Themen- und Funktionsstruktur deckungsgleich sind bzw. ob die textuellen Repräsentanten eines Teilthemas und einer funktionalen Einheit deckungsgleich sind. Die Themen- und Funktionsstruktur geben nur eine bedingte Antwort auf die Frage, wie die Zeichen- 
modalitäten verknüpft sind, wobei diese Verknüpfungen als Dimension ,multimodale Verknüpfung' im Mittelpunkt einer multimodalen Textanalyse stehen (ebd.). Zu diesen Verknüpfungen gehören sowohl solche, die Kohärenz - also den semantisch-funktionalen Zusammenhang - stiften, als auch solche, die Kohäsion - also den Zusammenhang der Repräsentationsmittel - erzeugen (ebd.). Die Dimension ,Intertextualität' fasst sowohl explizite Bezüge auf andere Texte als auch implizite Bezüge in Form von gestalterischen Ähnlichkeiten zwischen Texten zusammen (ebd., S. 25).

Über diese Grunddimensionen hinaus werden Textexterna als Teil der Kommunikationsform betrachtet, die STÖCKL (2016) als Spezifikation von Zeichenmodalitäten konzipiert:

„Dieses mehrdimensionale Modell des Konzepts Zeichenmodalität unterscheidet Aspekte der sinnlichen Wahrnehmbarkeit von Zeichen (psychologisch), ihrer strukturierten Kodiertheit (semiotisch) und ihrer materiell-technischen Realisierung (medial).“ (ebd., S. 7)

Eine Berücksichtigung der Fächerkultur ermöglicht das Raster der Kommunikationsformen aber nicht. Dementsprechend wird das multimodale Textsortenanalyseraster von STÖCKL (2016) erweitert um die typischen Verknüpfungen zwischen der Textgestaltung und dem Kontext (s. Kapitel 2.4.2). STÖcKLs (2016) oben ausgeführte fünf Grunddimensionen von Sprache-Bild-Texten und die von mir eingeführte Dimension der Text-Kontext-Verknüpfung werden in den folgenden Teilkapiteln dieser Arbeit ausformuliert oder modifiziert.

\subsection{Textdesign}

STÖCKL (2016, S. 23) fasst Textflächen, Bilder, Schriftzeilen und Logos, aber auch Linien, Rahmungen unter die Grunddimension ,Gliederung/Abgrenzung', die textinterne sortentypische Funktions- und Themenstrukturen repräsentiert und den Text als geschlossene Einheit gegenüber anderen Texten abgrenzt. Diese visuell-bildlichen und -sprachlichen Mittel erscheinen als Ausdrucksmittel, um Kohäsion zu erzeugen, also einen Zusammenhang an der Textoberfläche. In mehreren anderen Konzepten (RoTH/SPITZMÜLLER, Hg., 2007; EHRENHEIM, 2011) werden diese Textelemente als Teil von Textdesign konzipiert. Dieser Bezeichnung schließe ich mich an und bezeichne diese Analysekategorie entsprechend als 
Textdesign. Gleichzeitig kann sich Kohärenz, also ein inhaltlich-funktionaler Zusammenhang, in diesen Formen der Kohäsion widerspiegeln.

STÖCKL (2016) erfasst den Kohärenz-Kohäsions-Zusammenhang durch die Repräsentation der Themen- und Funktionsstruktur mithilfe der Gliederungs- und Abgrenzungsmittel. Die Funktion dieser Mittel, den Text, der die Mittel enthält, von anderen Texten abzugrenzen, erweitert den Textbegriff. Denn ein wesentliches Merkmal von Texten ist es, dass sie als abgeschlossene Einheit von anderen Texten und Zeichengebilden abgrenzbar sind (Schmitz, 2016, S. 331). Verschiedene Positionen existieren zu der Frage, ob ein Text sowohl durch seine Ausdrucksmittel als auch in Bezug auf seinen Inhalt abgeschlossen - also kohäsiv und kohärent - sein muss, um als Text zu gelten. Die multimodale Textkonzeption in STÖCKL (2016), die Kohäsion und Kohärenz im Sinne der Funktions- und Themenstruktur umfasst, schließt als Kohäsionsmittel nicht nur sprachliche Ausdrucksmittel, sondern auch visuell-schriftsprachliche und weitere visuell-bildliche Mittel ein.

Elemente der Grunddimension ,Gliederung/Abgrenzung ' erfasst das oben dargestellte Konzept von Schmitz (2011a, S. 35 f.) als Layout bzw. als Design: Layout sei gekennzeichnet als die Positionierung von Elementen in der Fläche. ${ }^{130}$ Design beziehe sich dagegen auf Farb- und Formgestaltung. Eine bedingte Übereinstimmung mit der Design-Layout-Dichotomie findet sich im Kompositionskonzept Kress/van LeEuwens ( ${ }^{2} 2006$, S. 210), das die Auffälligkeit von Farben, Formen etc. als Salienz (salience) bezeichnet. Aber auch die Positionierung von Elementen in der Fläche (placement in the visual field) ermögliche es, Salienz zu erzeugen. Während diese Kategorie ,Salienz' Elemente zusammenfasst, die in den ScHMiTZschen Kategorien ,Design“ und ,Layout' unterschieden werden, gleichen die beiden weiteren Kategorien von KRESS/VAN LEEUwENs Kompositionskonzepts eher Schmitz' Kategorie Layout: KRESs/VAn LeEUwens ('2006, S. 210) ,Rahmung' (framing) bezeichnet die Platzierung und Markierung von Kommunikationselementen im Vordergrund oder Hintergrund, und die Kategorie ,Informationswert' (information value) enthält die Unterkategorie Anordnung von

130 Im Konzept des Textdesigns nach EhrenheIM (2011, S. 168 ff.) wird vor allem die Positionierung von Elementen in der Fläche für Strukturtypen einer Textsorte systematisiert. 
Elementen in ,zentraler Position“ - ,Randposition“ (center-margin), aber auch die Unterkategorie von ,Bekanntem`- ,Unbekanntem‘ (given - new), die eher die Kohärenzebene als die Kohäsionsebenen von Layout und Design betrifft. Die Positionierung in der Fläche und auch die Nutzung von Farben und Formen subsumiert Ehrenheim (2011, S. 17) unter den Begriff Textdesign. BATEMAN (2008, S. 106) fasst dagegen die räumliche Anordnung (spatial configurations) und Gestaltung von ikonisch-bildlichen, schriftsprachlich-typographischen, diagrammatischen und weiteren graphischen Elementen auf einer Text-Seite als deren Multimodalität (multimodal page) zusammen. Im Folgenden bezeichne ich auch die Flächenpositionierung und Farb-Form-Gestaltung als Textdesign, untergliedere die Analysekategorie Textdesign aber in die Unterkategorien Design (Kapitel 3.1.1) und Layout (Kapitel 3.1.2).

Design und Layout werden dabei als strukturell visuelle Merkmale von Text-BildSorten (Schmitz, 2011a, S. 37) bzw. von Sprache-Bild-Textsorten behandelt. Design und Layout (ebd., S. 35 f.) bzw. Textdesign (EhrEnHEIM, 2011, S. 168 ff.), die Gestaltungsprinzipien dieser Merkmale darstellen, beschreiben Kohäsion von Sprache-Bild-Texten und bilden das Pendant zu grammatisch-strukturellen Merkmalen in monomodalen Textkonzepten.

Als wesentliches Element von Textdesign, d. h. für die Präzisierung von Kohäsion, wird das Konzept von Salienz herangezogen. Wie dargestellt (s. Kapitel 2.3.3) ermöglicht es Salienz, in soziosemiotischer Konzeption ,,[to] create a hierarchy of importance among the elements, selecting some as more important, more worthy of attention than others“" (KRESS/VAN LEEUwEN, ${ }^{22} 2006$, S. 201). Dazu nutzt Salienz

„a complex trading-off relationship between a number of factors: size, sharpness of focus, tonal contrast [...], colour contrasts [...], placement in the visual field [...], perspective, and also quite specific cultural factors, such as the appearance of a human figure or a potent cultural symbol“" (ebd., S. 202).

Der Zusammenhang zwischen Salienz und Textdesign stellt für die von EHRENHEIM (2011) untersuchte Textsorte ,Stellenanzeige ' insoweit das wesentliche Element in der Konzeption dar, als ,die (positiv bewertete) Salienz einer Anzeige die Grundvoraussetzung für die Wahrnehmung und Beurteilung einer Anzeige durch den Rezipienten darstellt“ (ebd., S. 330). Einige der in KRESS/VAN LEEUWEN (2006) beschriebenen Elemente von Salienz finden sich im Text- 
design-Konzept von EHRENHEIM (2011, S. 17) als Ebenen wieder: 1. Multimodalität/multimodaler Text, 2. Struktur: Linearität gegenüber Modularisierung von Textelementen, 3. Bildeinsatz als Ausdruck entweder durch Bilder oder durch Sprache und als Sprache-Bild-Relationen, 4. Bedeutung und Wirkung von Farben und 5. Typographie. Die Elemente Schärfe, (Farb-)Kontrast, Platzierung und Perspektive aus obiger Salienz-Definition in KRESS/VAN LEEUWEN (2006, S. 202) können in EHRENHEIMs Konzept als Teil der Elemente Bild, Typographie und Sprache-Bild-Relationen erfasst werden.

Während sich insbesondere EHRENHEIMs Element ,Multimodalität‘ kaum von den übrigen Elementen des Textdesigns abgrenzen lässt, sondern diese vielmehr umfasst, berücksichtigt STÖCKLs (2016) Konzeption der Funktionsstruktur und der Themenstruktur bereits mögliche Modularisierungen und Delinearisierungen. Letztere fließen in meine Konzeption der entsprechenden Analysekategorien (s. Kapitel 3.2; Kapitel 3.3) ein. Das Element ,Typographie“ wird in meiner Arbeit als Teil von Design (s. Kapitel 3.1) behandelt. Sprache-Bild-Relationen werden zwar als Ergebnis der Themen- und der Funktionsstruktur beschrieben, sie werden aber in STÖCKLs (2016) Raster als eigene Textanalysekategorie unter Kohärenzaspekten diskutiert. Mein Analyseraster spezifiziert diese Relationen als logischsemantische Sprache-Bild-Relationen (s. Kapitel 3.4). Der Differenzierung, Sprache als Alternative zu Bild neben Sprache-Bild-Relationen zu stellen, folge ich nicht, da ich alle sprachlichen und ikonisch-bildlichen Elemente im Sprache-BildText als relational erfasse. Denn sie sind Teil eines kohärenten und kohäsiven Textsortenexemplars.

Den Zusammenhang zwischen diesen fünf Textteilbereichen erläutert EHRENHEIM (2011) anhand einer angenommenen Rezeptionschronologie:

„Textdesign wird verstanden als das gesamte visuelle Erscheinungsbild eines Textes und differenziert beschreibbar durch eine Aufteilung in fünf verschiedene Teilbereiche, wobei die Anordnung analog der Reihenfolge der Wahrnehmung bzw. der Wahrnehmungstiefe erfolgt: Zunächst - auf den ersten Blick bzw. mit dem ersten Blick - wird die Stellenanzeige als ein Gesamttext wahrgenommen, bevor sich der Rezipient detaillierteren Bestandteilen wie Bildern oder typographischen Elementen zuwendet.“ (ebd., S. 330)

Dass dieses Textdesign-Konzept als Teil von Kohäsion diskutiert wird, ist weniger auf die Annahmen zum Rezeptionsweg zurückzuführen, der den Zusammenhang zwischen den verschiedenen Modellebenen herleitet. Vielmehr wird diese 
Bezugnahme auf Kohäsion durch EHRENHEIMs Beschreibung der einzelnen Modellebenen erklärt, die sich unter Aspekten multimodaler Kohäsion erfassen lassen: Die Verknüpfung der Textdesign-Elemente und des außertextuellen Kontextes wird im Modell durch die Kontext-Ebene erfasst (s. Abbildung 2-12). Dadurch wird deutlich, dass die handlungstheoretische Begründung von Textdesign in EHRENHEIM (2011) auch durch den Ansatz multimodaler Semiotik möglich ist. Für die Darstellung von Kohäsion ist diese Verknüpfung insoweit von Bedeutung, als sie sich sowohl auf die Darstellungsmittel als auch auf die Bildung von Kohärenz bezieht. ${ }^{131}$

Folgende Elemente aus KRESS/VAN LEEUWENs (22006, S. 210) sogenanntem Kompositionskonzept, also systematische Zusammenhänge von Elementen innerhalb eines Bildes oder multimodalen Textes, fließen in die folgende Operationalisierung des Textdesign-Konzepts ein: Der Informationswert (information value) als Hierarchisierung von Ober-, Unter- und Nebenordnung von Kommunikationselementen; Salienz (salience) als visuelle und zugleich funktional-thematische (kulturelle) Auffälligkeit von Kommunikationselementen; Rahmung (framing) als Platzierung und Markierung von Kommunikationselementen im Vorder- oder Hintergrund. ${ }^{132}$ Alle drei Kompositionskategorien fließen in Kapitel 3.1 (Textdesign) ein.

Präzisere Operationalisierungsmöglichkeiten für Textdesign als KRESS/VAN LEEUWEN ( $\left.{ }^{2} 2006\right)$ bietet vor allem BERTIN (22010): Konkret kann das TextdesignKonzept meiner Arbeit entsprechend den Variablen des graphischen Bildes (BERTIN, ${ }^{2} 2010$, S. 96) konkretisiert werden, ${ }^{133}$ während KRESS/VAN LEEUWENs

131 Konzepte, die überwiegend semantische Entsprechungen zu diesen Strukturen und deren pragmatische Verwendung berücksichtigen (UNSWORTH, 2007, S. 1175; s. Kapitel 3.4), werden als Teil von Kohärenz behandelt.

132 Erweiterungen stellen in BUCHER (2007, S. 56 f.) dar: Die Lokalisierung der Kommunikationspartner beispielsweise durch ein Logo oder Typographie (Identifizierungs- und Lokalisierungsproblem), der Kommunikationsstand im Sinne einer Positionierung im Kommunikationsangebot z. B. durch ein Inhaltsverzeichnis oder Seitenzahlen (Orientierungsproblem) und die Verweisart von einem Kommunikationselement zum anderen, beispielsweise durch einen Link oder Seitenhinweise (Navigationsproblem).

133 LischeId (2012, S. 323 ff.) nutzt diese Systematik in BERTIN ( $\left.{ }^{2} 2010\right)$ als Grundlage für die Differenzierung von visuell-strukturellen Darstellungsmitteln und der Typologie von Struktur- und Prozessdiagrammen. Die Kommunikationsdesignansätze in ABDULLAH/ 
(2006) Kompositionskategorie ,Rahmung‘ durch das Konzept von Panels (MäLZER, 2015) und ,Positionierung ' durch Sehgesetze (METZGER, ${ }^{3} 1975$ ) und Formulargestaltung konkretisiert wird.

\subsubsection{Design: Visuelle Variablen von Sprache-Bild-Texten}

Die vier Prinzipien (s. Abbildung 3-1) der zwei Flächendimensionen (two planar dimensions) Assoziation (association) und Selektion (selection), Ordnung (order) und Quantität (quantity) (BERTIN, ${ }^{2} 2010$, S. 49) bzw. Proportionalität organisieren die sechs visuellen Variablen (ebd., S. 65 ff.). Die Prinzipien ,Assoziation“ und ,Selektion“ unterscheiden sich dadurch, dass zwei ähnliche Zeichen (similar marks) in unterschiedlicher Anordnung (differing in the position on the plane) einzeln (selective) oder als Gruppe (associative) wahrgenommen werden (ebd., S. 49).

SCHWESINGERs (2007) $)^{134}$ Definition von Formulargestaltung greift auf BERTINs Konzept zurück und beschreibt Design als Variation der graphischen Variablen, die „Zusammenhänge und Hierarchien zwischen den einzelnen Elemente [sic] darstellen sowie darin Bedeutungen und Eigenschaften codieren“ (SCHWESINGER, 2007, S. 125). Dementsprechend lassen sich aus linguistischer Sicht die visuellen Variablen als Phänomene der Kohäsionsebene und Ausdruck von Kohärenz erfassen. Die drei Prinzipien in BerTIN (22010, S. 49) sind an dieser Stelle von Bedeutung, da sie die Beschreibungen der sechs trennenden Variablen (retinal variables) gliedern nach Quantität, Ordnung und Dissoziation/Assoziation des Rezeptionsprozesses (perception). Die folgende Beschreibung orientiert sich an den

HENZE (2007) und SchweSINGER (2007) beziehen BERTINs (2010) Systematik auf den Objektbereich von Formularen.

134 Die Quelle SCHWESINGER (2007) lässt sich der Ratgeberliteratur zuordnen und für wissenschaftliche Zwecke kritisch hinterfragen. Denn die enthaltenen Empfehlungen beruhen auf impliziten Wertungen oder Maximen, deren Grundlagen kaum begründet oder durch Quellenbelege überprüfbar gemacht werden. Die enthaltene Biographie des Autors werde in Ratgeberliteratur häufig als Legitimationsmittel genutzt: „Die Angaben zu Profession, beruflichem Erfolg und akademischem Habitus lassen sich als Stützungen des Anspruchs verstehen, als normsetzende Instanz hinreichend legitimiert zu sein." (BREMERICH-VOS, 2009, S. 2321) Zu hinterfragen bleibt, inwieweit Wertungen und Normsetzungen von Forschenden als Teil wissenschaftlicher Literatur nicht ebenso durch die Biographie der Autoren gestützt werden. SCHWESINGER (2007) dient daher als Anreiz für die Operationalisierung multimodaler Kohäsion. 
trennenden Variablen (s. Abbildung 3-1), die sie mit den oben aufgeführten Salienz-Kriterien abgleicht, und erfasst diese als Mittel der Kohäsion.

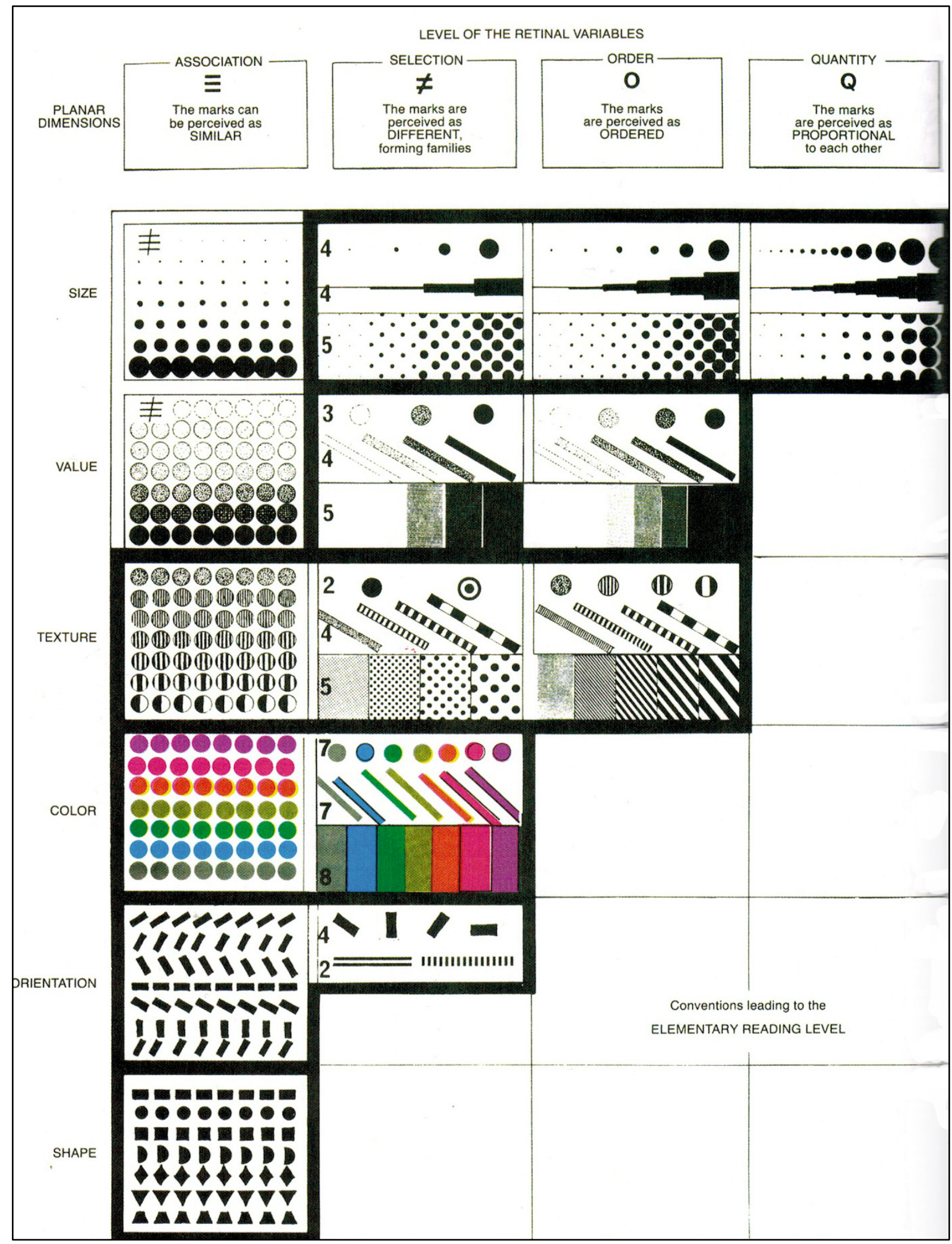

Abbildung 3-1: Level of the retinal variables (BERTIN, ${ }^{22010,}$ S. 96). 
Die Variable ,Größe' (size variation) erscheint im Salienz-Konzept von KRESS/ VAN LEEUWEN (2006, S. 202; s. Kapitel 3.2.5), das ich an dieser Stelle mit BERTINs graphischen Variablen zusammenführe, als Kategorie ,Größe' und damit als Element von Salienz. Die kartographischen Spezifikationen von ,Größe' in BERTINs (2010) Konzept beziehen sich auf Repräsentationen von Einwohnerzahlen etc. durch Punktgrößen (point representation), auf Dicke von Linien für Autobahnen etc. als Linienrepräsentation (line representation) und auf die Größe von Punkten oder Linien für Gegenden als Raumrepräsentation (area representation (ebd., S. 71). Diese spezifisch kartographische Konzeption lässt sich nicht unmittelbar auf sämtliche Sprache-Bild-Texte übertragen, da diese keine Landkarten sind bzw. nicht mit den Anliegen der Kartographie betrachtet werden.

Aber das proportionale Verhältnis von Linien, Punkten und Kombinationen aus beidem ist relevant für Sprache-Bild-Texte: Denn einerseits nutzt Typographie Schriftgrößen, um Überschriften von einem Fließtext abzugrenzen. So werden Fettdruck und die Positionierung in der Fläche für Schriftelemente genutzt. Andererseits lassen sich in technischen Zeichnungen die Größen einzelner Objekte aufgrund von Maßstabstreue relationieren. Dieses ikonisch-bildliche Darstellungsmittel wird in technischen Zeichnungen parallel zur Bemaßung durch Ziffern als symbolische Repräsentation der Größe bzw. der Relation genutzt.

Die Variable ,Helligkeit bzw. Kontrast“ (value variation) entspricht in obiger Salienz-Definition tonalem Schwarz-Weiß-Kontrast. Diese Variable bezeichnet den Zusammenhang zwischen einer jeweiligen Graustufe eines Schwarz-Weiß-Elements und dem Untergrund, der auf Papier gedruckt nicht zu $100 \%$ weiß, sondern ca. zu $90 \%$ weiß und $10 \%$ grau ist (BERTIN, ${ }^{22} 2010$, S. 73). D. h., eine Verknüpfung entsteht nicht zwischen Elementen auf dem Papier, sondern zwischen dem Untergrund und einem Element. Kontrast ist durch Grauabstufungen geordnet (ebd.). Als Beispiele werden Flächen abgebildet, die Grauabstufungen durch Punktierungen oder Schraffuren erzeugen (ebd., S. 75).

Für die Variable ,Textur' (texture variation) findet sich in obiger Salienz-Definition keine Entsprechung. Diese Variable wird durch die Anzahl und Anordnung von Punkten (number of marks) in einer bestimmten Fläche (given area with a regular pattern) bestimmt (ebd., S. 79). Die Variable ist für die Analysekategorie ,Design` als Teil von Textdesign aber relevant, weil beispielsweise unterschied- 
liche Schraffuren und Kontraste in technischen Zeichnungen entsprechend DIN ISO 128-50 (2002, S. 4 ff.) unterschiedliche Stoffe repräsentieren. Für technische Zeichnungen sind beide Variablen, Kontrast und Muster, relevant. Unterschiedliche Bedeutungen von Bewegungswiderstand (Reibung zwischen Schiene und Rädern) und Widerstand aufgrund einer Steigung können in technischen Zeichnungen des Weiteren nicht nur durch Farben, sondern auch durch unterschiedliche Liniensegmentierung ${ }^{135}$ (Punkte, Striche) der repräsentierenden Linien ausgedrückt werden. ${ }^{136}$ Liniensegmentierungen können neben Schraffuren also auch unter die visuelle Variable Muster gefasst werden.

Die Variable ,Farbvariation“ (colour variation) entspricht der Salienz-Kategorie Farbkontrast (colour contrast). Diese Variable kann als Farbunterschied zwischen gleichen Flächen identischen Kontrastes (uniform areas having the same value) wahrgenommen werden (BERTIN, ${ }^{2} 2010$, S. 85). Eine Farbvariation geht mit einer Kontrastvariation einher, indem ein reiner Farbton (pure tone, satured tone), der weder durch Weiß noch durch Schwarz verwaschen ist, in einem Spektrum durch Schwarz und Weiß variiert wird (ebd., S. 85 ff.). Die Kontrastrezeption dominiert dementsprechend die Farbrezeption (ebd.). Farben kann zudem ein Symbolwert (colour symbolism) zugeordnet werden. Beispielsweise wird im Kontext der Kartographie die Farbe Grün für Vegetation und Blau für Wasser genutzt (ebd., S. 90). Eine Relation zwischen dem strukturell-visuellen Merkmal Farbe und dessen Bedeutung im Sprache-Bild-Text besteht beispielsweise in Diagrammen wie dem Zugkraft-Geschwindigkeits-Diagramm, das mehrere gemessene physikalische Kräfte durch unterschiedliche Farben der Messlinien darstellt: Die Farbe Rot repräsentiert den Bewegungswiderstand, der durch Reibung zwischen Schiene und Rädern erzeugt wird, Blau repräsentiert das Verhältnis zwischen Zugkraft und Geschwindigkeit. Dabei kodiert die Legende die Farbsymbolik und kann nicht unabhängig von dieser für andere Diagramme als Konvention angenommen

135 Für technische Zeichnungen wird die Art der Segmentierung von Linien in Form von Linienarten (DIN EN ISO 128-20, 2002, S. 4) konventionalisiert. Dabei werden Linien als Darstellungsmittel, also auf der Ebene der Struktur, konventionalisiert. Schraffuren werden in DIN ISO 128-50 dagegen Bedeutungen zugeordnet wie ,Stein` oder ,Metall‘. D. h., diese Konventionalisierung betrifft die Semantik-Ebene.

136 Entsprechend DIN 128-24 (1999, S. 13) repräsentieren Liniensegmentierungen eine Endstellung beweglicher Teile. 
werden. In der Farbenlehre von ITTEN $\left({ }^{28} 2003\right.$, S. 45 ff.) sind des Weiteren Kaltwarm-Farbkontraste zu berücksichtigen, bei denen beispielsweise die Farbe Rot die Farbe Blau dominiert.

Die Variable ,Formvariation“ (shape variation) erfasst den Zusammenhang, der zwischen unterschiedlichen Elementen auf einer Textseite entsteht, indem sie gleichartig (similar) geformt sind (BERTIN, ${ }^{2} 2010$, S. 94 f.). Diese Form von Similarität behandelt auch das Gesetz der Gleichartigkeit als eines der Gestaltgesetze: „Gleichartiges strebt - auch über beträchtliche Zwischenräume hinweg [...] - zum Zusammenschluß.“ (MeTZGER, ${ }^{3} 1975$, S. 88) Gestaltgesetze werden dabei als psychologische Gesetze (ebd., S. 37) im Sinne einer Wahrnehmungslehre (ebd., S. 22 f.) behandelt. Inwieweit die Seherfahrung und daraus resultierende Muster sowie kulturelle Konventionalisierung (ECO, ${ }^{2} 1991$, S. 271 ff.) an der Konstitution dieser Gesetze beteiligt sind, wird aus deren Ableitung aus Einzelbeispielen nicht deutlich.

Formen finden aber kein Pendant im Salienz-Konzept von KRESS/VAN LEEUwEN (2006). Unter der Voraussetzung, dass Elemente von Layout in Textdesign einbezogen werden, erweitere ich Salienz im Rahmen dieser Operationalisierung um Formen. Gleichartigkeit (similarity) konstituiert Formen als assoziative Variable (BERTIN, ${ }^{2} 2010$, S. 95) im Sinne von bildlicher Ikonizität. Dabei bezieht sich Similarität einerseits auf das Verhältnis zwischen zwei Formen der Repräsentation als auch auf eine repräsentierende Form und Entitäten außerhalb der Repräsentation wie Personen, Tiere oder Objekte (persons, animals, objects) (ebd.): Letztere Relation wird als mimetisch (mimetic) bezeichnet, erstere sind dagegen geometrischer Natur (geometric) und entweder similar (similar) oder sehr ähnlich (highly familiar). Beispielsweise können unterschiedlich geformte Piktogramme von Rollstühlen nicht durch ihre Form, sondern aufgrund einer außertextuellen Vorstellung von einem Rollstuhl relationiert werden. Diese exakte Bemaßung eines Rollstuhls wird in der Norm TSI PRM (2008, S. 204) zwar schriftsprachlich festgelegt, nicht aber in der Darstellung seiner Form in Zeichnungen oder Piktogrammen konventionalisiert. Ein weiteres Beispiel, das die Konventionalisierung von Form betrifft, bezieht sich auf Schriftbildlichkeit: DIN 1421 (1983, S. 1) gibt vor, wie die Textstruktur durch Absätze und Abschnitte in Texten dargestellt werden soll. 
Die Variable ,Orientierung bzw. Richtung' (orientation variation) wird nach BERTIN (2010, S. 93) als Unterschied des Betrachter-Winkels bzw. der Betrachtungsperspektive auf ein Feld (difference in angle between fields) definiert, der durch mehrere nebeneinander angeordnete Zeichen erzeugt wird (created by several parallel signs). Diese Beschreibungen zu BERTINs sechs trennenden Variablen und ihre Ergänzungen bilden die Analyekategorie ,Design" als Unterkategorie des ,Textdesigns', zum dem auch die Unterkategorie ,Layout gehört, die im Folgenden dargestellt wird.

\subsubsection{Layout: Positionierung in der Fläche und Rahmung}

An die Behandlung der visuellen Variable Orientierung bzw. Perspektivität schließt das Salienzkriterium Positionierung in der Fläche (placement in the visual field) an. Da Bezugsgrößen für das Modell visueller Variablen vor allem Diagramme, ${ }^{137}$ d. h. Koordinatensysteme sind (ebd., S. 50 ff.), wird die Anordnung in der zweidimensionalen Fläche als Abtragen von Werten auf einer X- und einer Y-Achse modelliert. Die Operationalisierung von Komposition in Sprache-BildTexten erfordert darüber hinaus aber, die Positionierung in der zweidimensionalen Fläche unabhängig von einem Koordinatensystem zu konzipieren. Positionierung lässt sich im Kompositionskonzept (composition) nicht nur durch Salienz, sondern auch durch den Informationswert (information value) und die Rahmung (framing) bestimmen. Denn Rahmnung bezeichnet die Gruppierung von Elementen durch visuell-grammatische, aber auch semantische und pragmatische Mittel. Der Informationswert bestimmt die Positionierung in der Fläche durch die Dichotomie zentral - peripher. Rahmung lässt sich als Gruppierung von Elementen durch das aus der Comic-Analyse abgeleitete Konzept von Panel und Gutter operationalisieren: Panels, die als Rechtecke oder als andere geometrische Figuren Bild- sowie Schriftelemente rahmen und eine visuelle Einheit bilden, stellen die Grundlage für Gutter (Leerräume) dar. Dies wird dadurch möglich, dass der farblose Hintergrund zwischen zwei Panels ein Gutter erzeugt (MCCloud,1993, S. 67). Dementsprechend werden Gutter, aber auch Text-Bild-Abfolgen im Sinne von Panel-Abfolgen (MäLzer, 2015, S. 61) in Kapitel 4.4 .2 behandelt.

137 Auch die weiteren Darstellungsmittel Netze und Landkarten lassen sich zum Teil als zweidimensionale Koordinatensysteme auffassen. 
Positionierung lässt sich des Weiteren auch durch das Gesetz der Nähe als Gesetz der Bildung von Gruppen beschreiben, das mit dem Gesetz der Gleichartigkeit konkurriert (METZGER, ${ }^{3} 1975$, S. 88):

„Das Gesetz der Nähe bestimmt also nicht nur, was Figur wird (S. 38), sondern häufig auch, welche Figuren [...] sich zu Gruppen oder Haufen oder auch zu geordneten Verbänden zusammenschließen." (ebd., S. 83; Kursive im Original)

Das Zusammenspiel dieser visuellen Variablen kann ikonisch-bildliche, schriftsprachlich-typographische, diagrammatische und weitere graphische Elemente gestalten. Dieses Zusammenwirken bestimmen die genannten Prinzipien der Flächendimensionen, die eine Art visuelle Grammatik bilden. Visuelle Variablen können im Anschluss daran „Zusammenhänge und Hierarchien zwischen den einzelnen Elementen darstellen sowie darin Bedeutungen und Eigenschaften codieren" (SCHWESINGER, 2007, S. 125). D. h., die Bedeutung von bestimmten Zusammenhängen bzw. Variationskonstellationen wird konventionalisiert. Die folgende Synopse (s. Abbildung 3-2) fasst die Analysekategorie, Textdesign“ mit den Unterkategorien ,Design' und ,Layout‘ zusammen.

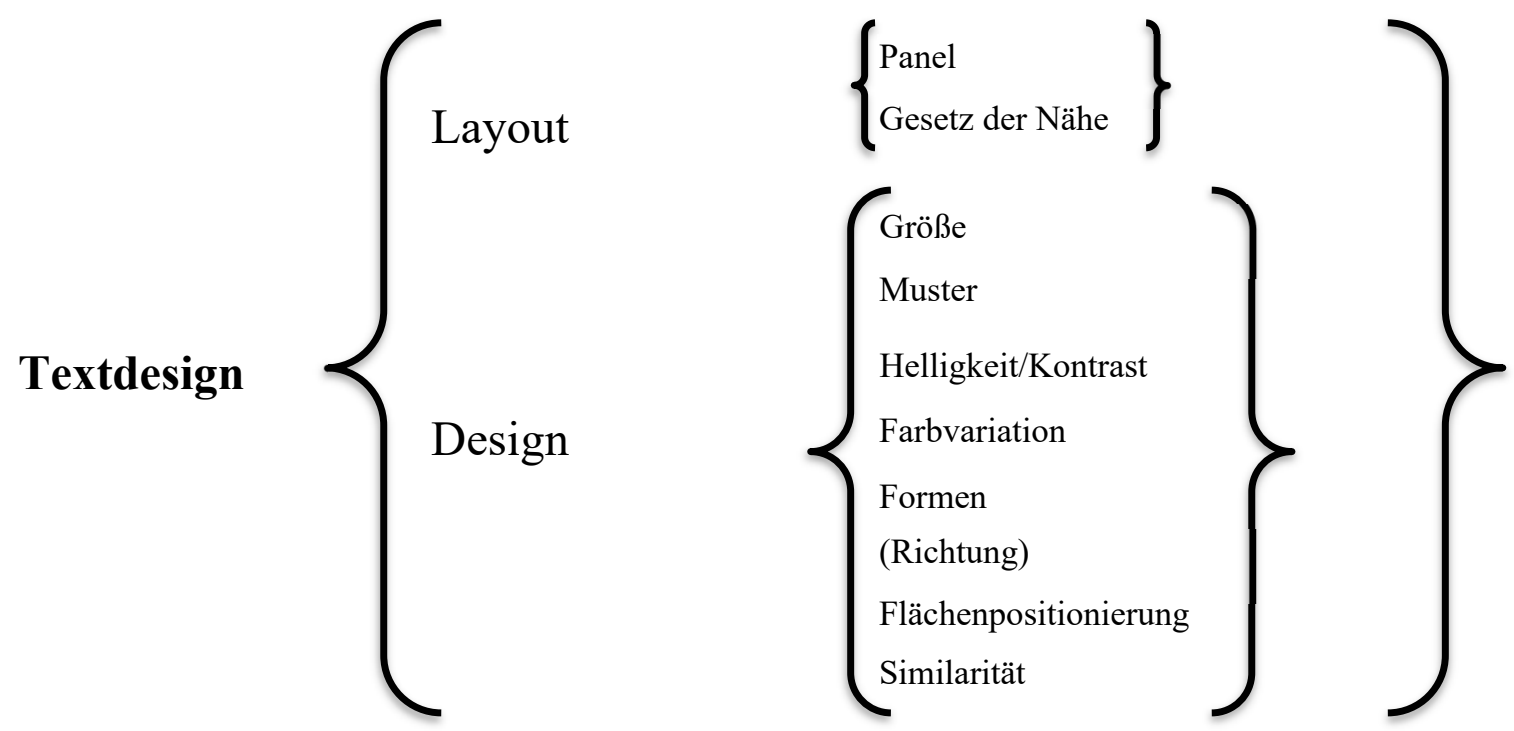

Abbildung 3-2: Zusammenfassung zur Analysekategorie ,Textdesign' (eigene Darstellung in Anlehnung an KRESS/VAn LEEUWEN, 2006; BerTin, 2010; u. a).

Bezogen auf Sprache-Bild-Texte repräsentieren multimodale Struktureinheiten eines Sprache-Bild-Textes thematisch-funktionale Einheiten. Diese Konventionalisierung spiegelt das Verhältnis von Kohäsion als visuelle Grammatik und Kohärenz als semantische und pragmatische Ebene einer Sprache-Bild-Textsorte wider. Eine textsortenspezifische Anordnung von Themenabschnitten in der Fläche, 
aber auch die übrigen visuellen Variablen einer textsortenspezifische Themenund Funktionsstruktur bilden den Übergang von multimodaler Kohäsion zu multimodaler Kohärenz. Dementsprechend berücksichtigt die folgende Beschreibung des Analysekriteriums Funktionsstruktur nicht nur schriftsprachliche, sondern auch bildliche und weitere diagrammatische Elemente.

\subsection{Funktionsstruktur}

Textsorten lassen sich durch die Musterhaftigkeit ihrer Funktionsweise in Form von Texthandlungen erfassen: „Erkennt man die Texthandlung, kann man von ihr auf die vorliegende Textsorte schließen und umgekehrt.“"(KESSELHEIM, 2011, S. 357) Die textuelle Einbettung in Funktionsbereiche der Gesellschaft gibt den entscheidenden Hinweis auf die Grundfunktion einer Textsorte, da diese Einbettung die Textsortenfunktionen bestimmt (ebd., S. 358). Bei diesen Grundfunktionen besteht in JAKOBSON (2007, S. 163 ff.) eine Nähe zu Sprachfunktionen, auf die sich auch die Konzeption von Funktionen in KESSELHEIM (2011) gründet. Darin wird JAKOBSON (2007, S. 163 ff.) als Erweiterung der Sprachfunktionen des Organon-Modells (BÜHLER, ${ }^{3}$ 1999) behandelt, die VAN LEEUWEN (2005a, S. 78) von den Metafunktionen in Halliday/Hasan ( $\left.{ }^{2} 1989\right)$ und Kress/Van LeEUweN (2006) absetzt (s. Kapitel 3). ${ }^{138}$

Weil diese Analysekategorie als ,textuelle Grundfunktion“ (BRINKER/CÖLFEN/PAPPERT, ${ }^{9} 2018$, S. 101 ff.), ,Hinweise auf Textfunktionen“ (HAUSENDORF/KeSSElHEIM, 2008, S. 139 ff.) bzw. ,Textfunktion“ (FANDRYCH/Thurmair, 2011, S. 27 ff.; ADAMZIK, ${ }^{22} 2016$, S. 173 ff.) bezeichnet wird, erscheint mir die Bezeichnung als ,Funktion“ für diese Analysekategorie gebräuchlicher als ,Handlung(-sstruktur)'. STÖCKLs (2016) und auch VAN LEEUWENs (2005a, S. 78) multimodale Ansätze gehen davon aus, dass Funktionselemente nicht zwingend linear - im Sinne einer Von-links-oben-nach-rechts-unten-Chronologie - rezipiert werden. So kann die Salienz verschiedener Funktionselemente ihre Struktur in einem Textsortenexemplar modularisieren. Weil nicht nur eine Matrix multimodaler Module (STÖCKL, 2016, S. 23), sondern auch eine Struktur von Funktionsele-

138 Die Metafunktionen in HALLIDAY/HASAN ( $\left.{ }^{2} 1989\right)$ sind grundsätzlich nicht mit denen in JAKOBSON (2007) vergleichbar (VAN LEEUWEN, 2005a, S. 78). 
menten nicht besagter Links-rechts-Chronologie folgen muss, bezeichne ich diese Analysekategorie als ,Funktionsstruktur'.

BRINKER/CÖLFEN/PAPPERT ( ${ }^{9} 2018$, S. 105 f.) vollziehen den Schritt, das Konzept von Sprachfunktionen bzw. Illokutionen als Teil von Sprechakten auf Textsortenfunktionen zu übertragen. Neben diesen Textsortenfunktionen wird in Kapitel 3.2.2 das weitere Konzept von Funktionen der Gebrauchstextsorten (RoLF, 1993, S. 65 ff.) dargestellt, das sich ebenfalls auf die sprechakttheoretische Illokutionen-Taxonomie (SEARLE, 1982a; Austin, 2007, S. 116 f.) bezieht. ${ }^{139}$

Der „ungeklärte[n] Frage, ob alle Zeichenmodalitäten überhaupt kommunikative Handlungen im Sinne von Sprechakten ausführen können“(STÖCKL, 2016, S. 23), nähert sich Kapitel 3.2.1 an, indem es Konzepte zu Bildakten bzw. Bildfunktionen (SchmitZ, 2007, S. 423 ff.; VAN LeEUWen, 2005a, S. 122; KJøRUP, 1978, S. 60 ff.) diskutiert.

\subsubsection{Bildakte einer multimodalen Funktionsstruktur}

Theorien zu Bildakten beziehen sich auf unterschiedliche Ausgangspunkte in der Sprachtheorie: Sprechakte (speech acts) in HALLIDAY (1985, S. 68 nach VAN LEEUWEN 2005a, S. 118) bilden nicht nur für das Konzept in KRESS/VAN LEEUWEN (2006), sondern auch für Bildakte (image acts) in VAN LEEUWEN (2005a, S. 120 f.) den Ausgangspunkt. Letztere Konzeption von Bildakten bedient sich vor allem Ausgestaltungen der dichotomen Kategorien ,offer ${ }^{6}$ - ,demand (ebd.) von HALLIDAYs ideatischer Metafunktion, geht aber ebenso wie weitere Bildfunktionskonzepte ${ }^{140}$ mit den Textfunktionen des Analyserasters in BRIN-

139 Das sprechakttheoretische Verhältnis zwischen Illokution und Perlokution behandelt bereits Kapitel 2.2.

140 Bildfunktionen behandeln u. a. KJøRUP (1978) und DOELKER (1997). KJøRUP (1978, S. 60) stützt sich wie auch SCHMiTz (2007, S. 426 ff.) auf SEARLEs Sprechakttheorie und greift propositional acts und illocutionary acts auf (KJØRUP, 1978, S. 61 ff.), systematisiert diese aber nicht entsprechend den Klassen in SEARLE (1982a). SCHMITZ (2007, S. 426) spricht sich gegen dessen Bezeichnung pictorial speech acts aus. DOELKER (1997) unterscheidet folgende Funktionen: ,registrativ' (Spurbilder: Bild nicht als Ereignis, sondern als Spur eines Ereignisses), ,mimetisch`(Abbilder: visuelles Repräsentieren von Realem), ,simulativ ${ }^{6}$ (Surrogatbilder: hyperrealisierende Bilder von Essen als Werbung, Skulpturen für Macht etc.), ,explikativ‘ (Schaubilder: Verwendung der bisherigen Funktion zum Zeigen im Sinne visueller Kodierung), ,diegetisch` (Phantasiebilder: ungewisser Wirklichkeitsbezug durch dargestellte Bildinhalte), ,appellativ‘ (Pushbilder: entsprechend BüHLER), 
KER/CÖlfen/PAPPERT ( ${ }^{9} 2018$ ) konform. Dieses Textfunktionskonzept nutze ich an den Stellen, an denen das Analyseraster in STÖCKL (2016, S. 21) Textfunktionen nicht ausdifferenziert. BRINKER/CÖLFEN/PAPPERT ( ${ }^{9} 2018$ ) beziehen sich auf die SEARLEsche Sprechakttheorie mit den fünf Sprechaktklassen (s. Kapitel 3.2.2), auf die sich auch das Konzept der Bildfunktionen bzw. der illokutionären Bildakte in SCHMITZ (2007) bezieht. Aufgrund dieses gemeinsamen konzeptionellen Ausgangspunkts lege ich dem Analyseraster multimodaler Textsorten in STÖCKL (2016) das Konzept der Bildakte in SCHMITZ (2007) zugrunde.

Die Konzeption von Bildakten fokussiert die Übertragbarkeit illokutionärer Akte auf visuelle Kommunikation (ScHMITZ, 2007, S. 423), die er an Plakatwerbung exemplifiziert. Bildakte werden dabei als Teil einer zerdehnten Kommunikationssituation konzipiert (EHLICH, 1984, S. 18 nach SCHMITZ, 2007, S. 423). Zur Übertragbarkeit von Illokutionen der SEARLEschen Sprechakttheorie auf Bilder werden nicht nur die fünf Sprechaktklassen am Beispiel (SCHMITZ, 2007, S. 424), sondern auch die drei grundsätzlichen Fragen (ebd., S. 427) diskutiert, 1. ob sich ein illokutionärer Akt aus einem oder mehreren Bildern zusammensetzt, 2. ob ein Bild mehrere illokutionäre Akte ausübt und 3. ob indirekte Bildakte existieren. SCHMITz (2007) diskutiert diese Fragen bzw. die Behandlung von Bildern als illokutionäre Akte bzw. als Bildakte am Beispiel eines Einzelfalls von Plakatwerbung, die in vielen deutschen Städten innerhalb eines bestimmten Zeitraums aufgestellt war.

Die Übertragung dieser Fragen einerseits vom Bildakt auf das Konzept multimodale Textsorten, andererseits vom Untersuchungsobjekt Plakat auf Pflichtenheft etc. als multimodale Textsortenexemplare erfordert es, diese drei Fragen SCHMITZ' umzuformulieren. Denn diese Textsorte ist im Gegensatz zu Plakatwerbung erstens in Experte-Experte-Kommunikation eingebunden, zweitens auf

,dekorativ' (Zierbilder: Nutzung schmückender Elemente und Verzierungen), ,phatisch“ (Füllbilder: Kennzeichnung des Kanals), ,ontisch (Clipbilder: Bild als Kunst, Zwecklosigkeit entsprechend poetischer Funktion), ,energetisch“ (Wirkbilder: Ergänzung des Appells mit ständiger Wirkung auf Rezipienten). Die Bildfunktionen in DOELKER (1997) sind dagegen nicht sprechakttheoretisch ausgerichtet. Weiteres in WETZCHEWALD (2012, S. 85 ff.). Da der Fokus in dieser Arbeit auf einer sprechakttheoretischen Konzeption von Sprache-Bild-Textsortenfunktionen liegt, wird die Klassifikation nicht weiter einbezogen. 
mehreren Seiten in anderer Art und Weise multimodal gestaltet ist und der Chronologie der Seitennummerierung folgt:

(1a) Setzt sich ein illokutionärer Akt aus mehreren Bildern, aus Schriftsprache und Bildern oder nur aus einem schriftsprachlichen oder einem bildlichen Element eines multimodalen Gebrauchstextes zusammen? Daran schließt folgende Frage zur Hierarchisierung von Funktionen an: ${ }^{141}$

(1b) Dominiert eine Textfunktion (Brinker/CöLfEn/PAPPERT, ${ }^{9} 2018$, S. 123) bzw. der Hinweis auf eine Texthandlung (HAusENDORF/KesselHeim, 2008, S. 161 f.) die illokutionären Akte aller bildlichen und schriftsprachlichen Elemente eines Textsortenexemplars?

(2) Übt ein bildliches oder schriftsprachliches Element eines multimodalen Gebrauchstextsortenexemplars einen oder mehrere illokutionäre Akte aus?

(3) Realisieren bildliche oder schriftsprachliche Elemente eines multimodalen Textsortenexemplars Typen von indirekten illokutionären Akten?

An alle drei Fragen, insbesondere an Frage 1b, Frage 2 und bedingt auch Frage 1a, schließt die Behandlung der textuellen Illokutionsstruktur an.

Frage $1 \mathrm{~b}$ ist durch die Nummerierung insoweit Frage 1a und nicht Frage 2 zugeordnet, als die Übertragung von Illokutionen bzw. Sprechakten auf Texte und Textsorten meist davon ausgeht, dass sich ein Text aus mehreren Illokutionen zusammensetzt, anstatt die Entität ,Sprechakt ${ }^{\star}$ mit der Entität ,Text ${ }^{`}$ gleichzusetzen. Frage 1b nimmt im Verhältnis zur Auseinandersetzung mit den übrigen Fragen viel Platz ein, weil sie die Konzeption einer Funktionsstruktur ins Zentrum rückt. Frage 2 und Frage 3 sind nur scheinbar deckungsgleich: Übt ein Bild einen direkten und einen indirekten Bildakt aus, könnte es derart aufgefasst werden, dass das Bild zwei, also mehrere, Bildakte ausübt. Ich verstehe die Gliederung der obigen Fragen aus SchMiTz (2007) aber so, dass sich Frage 2 und Frage 3 ausschließen, sich Frage 2 also auf die Ausübung nur von direkten Sprechakten bezieht. Ansonsten wären Frage 2 und Frage 3 teilweise redundant. Die folgenden Ausfüh-

141 Da der Zusammenhang zwischen perlokutionärem Akt und perlokutionärem Effekt ebenso wenig eindeutig bestimmbar ist wie jener zwischen Textfunktion und Textwirkung (s. Kapitel 2.2), behandele ich die Perlokution für multimodale Texte ebenso wenig, wie dies für Bilder in SCHMITZ (2007) geschieht. 
rungen gliedern sich entsprechend diesen drei bzw. vier Fragen, wobei diese Fragen nicht erschöpfend geklärt werden können, sondern vielmehr das Analyseraster STÖCKLs (2016) operationalisieren:

Die Beschäftigung mit Frage 1a geht vom Konzept der Diagrammatik in BAUER/ERNST (2010) aus, das sich auf Kombinationen von ikonischen Bildern, Symbolen wie sprachlichen Zeichen und Typographie (s. Kapitel 2.3) bezieht. Weil schriftsprachliche Elemente in Sprache-Bild-Texten durch die sie repräsentierenden Buchstaben und deren Schriftbildlichkeit wie der Anordnung und Typographie bereits diagrammatisch sind, werden illokutionäre Akte bereits durch diagrammatische Mittel ausgedrückt. Dass darüber hinaus auch ikonische Bilder und Sprache-Bild-Kombinationen illokutionäre Akte darstellen, halte ich für wahrscheinlich, kann es vorerst aber nicht belegen. ${ }^{142}$ Deswegen soll sich die Analyse der Sprache-Bild-Textexemplare Frage 1a annähern. Auch Frage 2 zur Ausübung mehrerer Illokutionen durch ein bildliches oder schriftliches Element kann an dieser Stelle nicht geklärt werden, sondern die empirische Analyse soll sich Frage 2 nähern.

Von der numerischen Chronologie weicht die folgende dieses Teilkapitels ab, weil Frage 2 und Frage 3 - wie oben aufgezeigt - verwandte, wenn auch unterschiedliche Teilthemen betreffen. Die Beschäftigung mit Frage $1 \mathrm{~b}$ würde zu viel Raum einnehmen, um diese thematische Verwandtschaft nachvollziehen zu können und schließt daher an die Auseinandersetzung mit Frage 3 an. Frage 3 nach dem Vollzug indirekter illokutionärer (Bild-)Akte, die ich als Teil des BildaktKonzepts (SchMiTz, 2007) auf multimodale Textsorten übertrage, erfordert es, den Vollzug von Typen illokutionärer Akte bzw. von Textfunktions- und Textsortenklassen in indirekte und direkte Sprechakte zu differenzieren. Die grundlegende Konzeption in SEARLE (1982b) legt einen Sprechakt dementsprechend multifunktional an, was für die anschließende Diskussion zur (Multi-)Funktionalität

142 In EHRENHEIMs Textdesign-Konzept, das auf der empirischen Analyse von Stellenanzeigen basiert, bewegen sich zwar Exemplare dieser Textsorte als Rezeptionsangebot zwischen Linearität und Modularität (ebd., S. 177 f.), behandeln dabei aber nicht explizit die Funktionsstruktur. 
einer Textsorte relevant ist. So veranschaulicht SEARLE (1982b) am Beispiel einer Frage, dass diese auch als Bitte aufgefasst werden bzw. intendiert sein kann:

„In Fällen wie diesem kann ein Satz, dessen Indikator der illokutionären Rolle auf einen bestimmten Typ von illokutionärem Akt hinweist, geäußert werden, um $z u$ sätzlich einen illokutionären Akt eines anderen Typs zu vollziehen." (ebd., S. 51; Kursive im Original)

Ein Sprecher vollzieht einen primären illokutionären Akt, indem er einen sekundären illokutionären Akt vollzieht, wobei der „sekundäre Akt wörtlich ist“ (ebd. S. 54), während ,[d]er primäre illokutionäre Akt [...] es nicht [ist]“ (ebd.). So könne beispielsweise ein Sprecher auf den Vorschlag eines anderen Sprechers, ins Kino zu gehen, antworten, dass er für eine Prüfung lernen müsse. Diese Antwort beinhaltet zum einen eine Feststellung (sekundäre Illokution), zum anderen kann die Feststellung als Ablehnung (primäre Illokution) verstanden werden bzw. gemeint sein, da Hintergrundwissen zur zeitlichen Umsetzbarkeit vorhanden, das Konversationsprinzip eines relevanten Gesprächs erfüllt und nur die Antwortmöglichkeiten Zustimmung, Ablehnung, Gegenvorschlag oder Diskussion möglich sind (ebd., S. 55 f.). Wenn dieser sprachzentrierte Ansatz auf Bildakte übertragbar ist, wäre es somit möglich, dass ein Bild innerhalb einer Sprache-BildTextsorte beispielsweise einen Assertiv als direkte/-n Bildakt/Textfunktion und gleichzeitig einen Direktiv als indirekte/-n Bildakt/Textfunktion ausübt oder umgekehrt. ${ }^{143}$ Wie zu Frage 1a und Frage 2 wird diese Auseinandersetzung mit Frage 3 nicht endgültig klären, ob Bilder in Sprache-Bild-Textsorten gleichzeitig direkte und indirekte Textfunktionen realisieren, sondern überlässt der empirischen Analyse in Kapitel eine Annäherung an die Antwort auf Frage 3.

Frage $1 \mathrm{~b}$ nach dem Verhältnis von Textfunktionen ${ }^{144}$ innerhalb einer SpracheBild-Textsorte berührt ROELCKEs ( $\left.{ }^{3} 2010\right)$ Konzeptionalisierung semiotisch komplexer Texte in einer Hierarchie von Funktionen: Er spricht textkonstitutiven Zeichnungen und Diagrammen zu, einen ,funktionalen Beitrag zu der kommunikativen Gesamtfunktion eines Textes [zu leisten]“ (ebd., S. 99). Da diese nonverbalen Elemente aber lediglich „den linearen Informationsfluss des sprachlichen

143 Insbesondere Direktive (ebd., S. 56 ff.), aber auch Kommissive (ebd., S. 76 ff.) werden für meine Untersuchung indirekter Textsortenfunktionen relevant (s. Kapitel 5.4.3).

144 Für eine detaillierte Darstellung des Textfunktionsdiskurses monomodaler Konzepte s. ROLF (2000). 
Textes“ (ebd.) verdeutlichen und ergänzen, bezieht dieses Konzept nicht-sprachliche Zeichen nicht explizit als gleichwertige Elemente der Funktionsstruktur ein. An diesen Ausführungen wird bereits deutlich, dass die Hierarchisierung von Textfunktionen in einer Funktionsstruktur der jeweiligen Textsorte relevant wird.

In diesem Zusammenhang ist nicht nur die Frage nach der Repräsentation eines illokutionären Aktes durch ein oder mehrere multimodale Textelemente (Frage 1a), sondern auch die Frage nach der Repräsentation einer oder mehrerer Funktionen durch ein Textexemplar (Frage 1b) relevant. Auch wenn BRINKER/CöLFEN/PAPPERT ( ${ }^{9} 2018$, S. 98 f.) von einer Grundfunktion einer Textsorte, also von einer dominierenden Funktion, ausgehen, nimmt dieses Konzept an, dass eine Textsorte auch weitere Zusatzfunktionen realisieren kann (ebd., S. 101; S. 123). Die Zusatzfunktionen leiten sich aus der Grundfunktion einer Textsorte oder dem sozialen Kontext $\mathrm{ab}$, in den die Textsorte funktional eingebunden ist. Auch ADAmzIK (2016, S. 179) konzipiert die Klassifikation und Anordnung von Textsortenfunktionen als sogenannte subsidiäre Illokutionen ${ }^{145}$, also Textfunktionen, im Verhältnis zum Hauptanliegen eines Textes. Konkret nimmt sie für die Textproduktion an, dass obligatorische Basisfunktionen und fakultative Zusatzfunktionen in einem chronologischen Ablauf ausgewählt werden und in einem Inklusionsverhältnis ${ }^{146}$ zueinander stehen (ebd., S. 204 ff.). Auch Roelcke ( ${ }^{3} 2010$, S. 93) konzipiert auf der Grundlage einer Gesamttextfunktion das Verhältnis zwischen Mikrostrukturen auf der Satz- und Absatzebene zur Makrostruktur eines Fachtextes als hierarchisches Verhältnis, in dem „Teiltextfunktionen wiederum in ihrer Gesamtheit die Erfüllung der übergeordneten Textfunktion leisten“ (ebd.). Dagegen gehen FANDRYCH/ThURMAIR (2011, S. 19 f.) auf der Grundlage ihrer empirisch-induktiven Untersuchungen grundsätzlich von einer Polyfunktionalität von Textsorten aus und legen nahe, dass die Annahme einer Monofunktionalität einer Textsorte Kennzeichen deduktiver Ansätze sei. Auch die differenzierte Funktionentypologie in RoLF (1993), die Kapitel 3.2.2 aufgreift, weil es die

145 Während BRINKER/CÖLFEN/PAPPERT ( ${ }^{9} 2018$, S. 98 f.), HAUSENDORFF/KESSELHEIM (2008) u. a. die Übertragung von Funktionen als Teil der SEARLEschen Sprechakte auf Texte als ,Textfunktionen' bezeichnen, behalten einige Konzepte wie RoLF (1993), ADAMzIK (2016) u. a. die Bezeichnung, Illokution“ bei der Übertragung auf Texte bei, wenn sie das hierarchische Verhältnis von Textfunktionen bzw. Illokutionen eines Textes behandeln.

Weiteres in HEINEMANN/VIEHWEGER (1991, S. 150). 
exemplarische Textanalyse präzisiert, geht von einer kennzeichnenden Textsortenfunktion aus, nach der die Textsorten kategorisiert werden. Um dieses Konzept in das Analyseraster aufnehmen zu können, schließe ich mich der oben dargestellten Position BRINKERs von einer textuellen Grundfunktion mit Zusatzfunktionen an. Dies bildet zwar keine Antwort auf Frage 1b, positioniert meine Untersuchung aber innerhalb des Forschungsdiskurses.

Das hierarchische Verhältnis zwischen Grund- und Zusatzfunktionen kann in eine Funktionsstruktur übertragen werden, wie bereits obige Darstellung des Verhältnisses von Funktionen der Mikro- und Makrostruktur bzw. der Teiltextfunktionen und Gesamttextfunktion in RoELCKe ( $\left.{ }^{3} 2010\right)$ zeigt. HAUSENDORF/KeSSELHEIM (2008, S. 165 f.) erweitern dabei eine ausschließlich vertikal ausgerichtete Funktionsstruktur aus Haupt- und Unterhandlungen durch Nebenhandlungen, die in einem horizontalen Verhältnis zueinander stehen. Auf Nebenhandlungen weise auf schriftsprachlicher Ebene beispielsweise die Konjunktion wobei hin, auf Unterhandlung die Konjunktion indem.

Auf Sprache-Bild-Textsorten werden diese linearen Konzepte durch die Zusammenführung der beiden konzeptionellen Erweiterungen übertragbar, in der Textstruktur einen selektiven Rezeptionsprozess in einer sowohl vertikalen als auch horizontalen Funktionsstruktur anzunehmen, also aufgrund der Salienz von Textelementen nicht mehr einer Von-links-oben-nach-rechts-unten-Chronologie zu folgen. Diesen Ansatz untermauert die (monomodale) Konzeption von untergeordneten, stützenden Illokutionen zu übergeordneten, gestützten Illokutionen einer Illokutionshierarchie in LEY (2006, S. 109 f.). In den Beispielanalysen werden diese Illokutionen jeweils einem Satz zugeordnet (ebd.), wobei diese Illokutionshierarchie nicht zwingend der Linearität des Textes folgt (ebd.). ${ }^{147}$ Aufgrund

147 Ähnlich, aber nicht unmittelbar an die SEARLEsche Funktionentypologie anschließend, konstruieren in

RothKEgELs (2005, S. 99) Konzeption text actions - beispielsweise BESCHREIBEN (DESCRIBING) oder MODIFIZIEREN (MODIFYING) - ein Textmuster (construct some text patterns). Diese Liste von text actions ermöglicht es, Textsortenexemplare in Analysen auf der Ebene der Textsorte (text types) in Form ihrer Textfunktion (on the level of text illocutions) zu erfassen: ,Text illocution provides a proper means for the patterning of text types.“ (ebd.) Aus dem hierarchischen Verhältnis zwischen einzelnen Sprachhandlungen und einer dominierenden Sprachhandlung bzw. einer dominierenden Illokution ergibt sich 
des multimodalen Ansatzes von Sprache-Bild-Textsorten, der neben die monomodale Konzeption einer rein schriftsprachlichen Von-links-oben-nach-rechtsunten-Chronologie eine modularisierte Textstruktur stellt (s. Kapitel 2.3), folge ich dem Konzept einer Funktionsstruktur aus Grundfunktion und Zusatzfunktionen, wobei mehrere Zusatzfunktionen als Nebenfunktionen existieren, sodass eine sowohl horizontale als auch vertikale Funktionsstruktur entsteht. Im SpracheBild-Textsorten-Ansatz wird diese sowohl durch bildliche als auch durch schriftsprachliche Elemente und diagrammatische Elemente repräsentiert.

Einen Sonderfall stellen multimodale Funktionsstrukturen von Formulartexten dar, die für die Beschreibung von als Formular gestalteten Lasten- und Pflichtenheften relevant sind. Grundsätzlich scheinen eine selektive Rezeption sowie Haupt-, Neben- und Unterhandlungen von Formularen möglich: So könnten saliente graphische Elemente wie Antwortfelder, Linien etc. ebenso den Rezeptionsprozess steuern, wie Textsortenkonventionen einer Formulartextsorte den Rezeptionsprozess steuern. Beispielsweise könnten Rezipienten beim Ausfüllen eines Wohngeldantrags erwarten, dass ein Feld die beantragte Summe und das Einkommen abfragt. Eine Besonderheit stellt die Konstellation von zwei Prozipienten dar, die das Textsortenexemplar sowohl produzieren als auch rezipieren (s. Abbildung 2-12): Der Rezeptionsprozess kann aber dann nicht als selektiv angenommen werden, wenn der Ausfüllende zum Ausfüllen aller Felder verpflichtet wird und den Formulartext entsprechend linear rezipieren und durch ergänzend-ausfüllenden Vollzug produzieren muss. Diese Verpflichtung könnte aus der Konstellation der Prozipienten resultieren (s. Kapitel 4.1.2). Fachtextbaupläne von Formulartexten ermöglichen es, innerhalb der Illokutionsstruktur auf ,ausdrückliche Hinweise zu der betreffenden Teiltextfunktion“ (ROELCKE, ${ }^{32} 2010$, S. 94) zu verzichten, insbesondere durch Wörter, Zahlen oder Sätze bzw. Textpassagen (ebd.). Damit tragen Formulartexte als Fachtexte dem fachsprachlichen Prinzip der Ausdrucksökonomie Rechnung, die textkondensierend wirke.

Nicht nur das Verhältnis von Grundfunktion und Zusatzfunktionen - ob als Formulartext oder als Textsorte einer anderen Kommunikationsform -, sondern auch

die chronologische Abfolge der Teilhandlung in einem komplexen Handlungsmuster wie INFORMIEREN oder RAT-GEBEN (ebd., S. 94 ff.). 
das Verhältnis von Textsorten beschäftigt den Forschungsdiskurs. Beispielsweise wird dies bei der Typologisierung von Textsorten nach Funktionen, der Zusammenfassung von Textsorten zu Klassen und Typen oder der Relationierung von Sub- und Großtextsorten thematisiert. ${ }^{148}$ Verbindungen zwischen Textsorten im Textsortennetz zu SPNV-Ausschreibungsverfahren (s. Tabelle 4-3) werden auf der Grundlage des Modells zu Text-Text-Relationen (s. Kapitel 3.5) erfasst. Die folgenden Darstellung von Funktionstypologien dient dazu, die Funktionsmodule und die Funktionsstruktur beschreibbar zu machen.

\subsubsection{Textfunktionen-Typologie}

Weil das Analyseraster in STÖCKL (2016, S. 23) keine Funktionentypologie für multimodale Texte bereitstellt - nur in den Beispielanalysen werden einige Funktionen genannt, die aber nicht der SEARLEschen Typologie zugehören -, ergänze ich mein Analyseraster für die exemplarische Analyse der Sprache-Bild-Textsortenexemplare durch die Typologie von fünf Textfunktionen in BRINKER/CöLFEN/PAPPERT ( ${ }^{9} 2018$, S. 105 ff.). Diese Typologie lehnt sich an die entsprechende Taxonomie illokutionärer Akte in SEARLE (1982b, S. 31) an, die hier ausgeführt werden, weil sich das ausdifferenzierte, unten aufgenommene Textfunktionskonzept in ROLF (1993) ebenfalls auf SEARLE (1982b) bezieht:

148 Die Gliederung von Textsorten nach deren Funktionen mündet in der „Zusammenfassung verschiedener Textsorten zu größeren Klassen“ (ROLF, 1993, S. 65) - beispielsweise als Zeitung. Auch Heinemann/Heinemann (2002, S.143) ordnen Textsortenvarianten (Reisewetterbericht) einer Textsorte (z. B. Wetterbericht) zu, die wiederum einer Textsortenklasse (z. B. Zeitungstexte) untergeordnet ist. Textsortenklassen werden auf der abstraktesten Modell-Stufe zu Text-Typen (z. B. informierende Texte) zusammengefasst. FANDRYCH/THURMAIR (2011, S. 26) setzen Großtextsorten und ihre zugehörigen Teiltexte (Kondolenzbuch - zugehörige einzelne Einträge) bzw. Subtexte (Reiseführer - zugehöriger Audioguide) funktional ins Verhältnis: „Wir sprechen von Teiltexten, wenn die hierarchisch kleineren Einheiten funktional gleich sind und von Subtexten, wenn die Textfunktionen variieren.“ (ebd.) Die Funktion der Subtexte wird durch die „Gesamt-Textfunktion der Großtextsorte bestimmt" (ebd.). Aber eine lineare Abfolge von Subtexten und Subtextfunktion innerhalb der sogenannten Textarchitektur einer Großtextsorte wird durch die Möglichkeit eingeschränkt, das Großtextsortenexemplar selektiv zu rezipieren: So können Großtexte auch auf selektive Rezeption angelegt sein (ebd., S. 27) und ihre Funktionsstruktur entsprechend als nichtlinear angenommen werden. 
- $\quad$ Assertive legen den Sprecher darin fest, dass die Proposition wahr ist.

- $\quad$ Direktive bezeichnen Versuche des Sprechers, ,den Hörer dazu zu bekommen, daß er etwas tut" (ebd., S. 32).

- $\quad$ Kommissive legen den Sprecher auf ein bestimmtes Verhalten fest, wobei „das [...] nicht unbedingt [heißt], daß dann auch ein Versuch vorliegt, ihn dazu zu bekommen, daß er es tut" (ebd., S. 33).

- $\quad$ Expressive bringen entsprechend der Aufrichtigkeitsbedingung den „psychischen Zustand zum Ausdruck“ (ebd., S. 34).

- Deklarative vollziehen sich dadurch erfolgreich, dass „eines ihrer Elemente eine Korrespondenz von propositionalem Gehalt und Realität zustande bringt“ (ebd., S. 36): „Vollziehe ich erfolgreich die Handlung, dich zum Vorsitzenden zu ernennen, dann bist du Vorsitzender.“(ebd.)

Aus diesen fünf Illokutionen leiten BRINKER/CöLFEN/PAPPERT ( ${ }^{9} 2018$, S. 105 f.) die Funktionen Information, Appell, Obligation, Kontakt und Deklaration an, nach denen auch die Textsortenklassen Textsorten systematisieren. So existieren Informations-, Appell-, Obligations-, Kontakt- und Deklarationstexte (ebd., S. 140). Dass Elemente einer Sprachtheorie wie Funktionen aufgrund der Autonomie von Texten nicht ohne Weiteres auf Texte übertragen werden können, diskutiert - wie oben dargestellt - bereits Coseriu ( ${ }^{4} 2007$ a, S. 49 f.). Diese Übertragung der Funktionentypologie SEARLEs diskutieren BRINKER/CÖLFEN/PAPPert $\left({ }^{9} 2018\right.$, S. 97 f.) und machen den Bezug auf Texte durch eine Benennung der Textfunktionsklassen deutlich, die von SEARLEs Bezeichnung der Illokutionen abweicht. BRINKERs Typologie der Textfunktionen leistet die Übertragung der Sprechaktklassen ,,im Hinblick auf die Gebrauchstextsorten im Prinzip durchaus richtig“" (RoLF, 1993, S. 67) und ,ist in der Textlinguistik wohl immer noch die am weitesten verbreitete“ (ADAMZIK, ${ }^{2} 2016$, S. 176). ${ }^{149}$

Im Gegensatz zu BRINKERs Typologie behält ROLF (1993) die Benennungen von Illokutionen SEARLEs auch in seinem Konzept der Textfunktionen für Gebrauchstextsorten bei. Ich folge dieser Benennung, weil sie eher mit dem behandelten Bildkonzept in SCHMITZ (2007) und der Ausdifferenzierung der einzelnen 
Funktionen nach RoLF (1993) kompatibel ist. ${ }^{150}$ RoLFs Ausdifferenzierung der Textsortenfunktionen halte ich für besonders geeignet, weil sie es ermöglicht, die Exemplare des Textkorpus präziser zu beschreiben, als BRINKERs Raster dies vermag. Im Anschluss an die Darstellung dieser Typologie wird neben den fünf Textfunktionen eine sechste Textfunktion, die ästhetische Funktion, diskutiert, die aus JAKOBSONs Theorie der Sprachfunktionen entlehnt ist und in den Textfunktionsmodellen von HAUSENDORF/KESSELHEIM (2008) und ROELCKE (1994), aber auch in ADAMZIKs (2016) Ertragsmodell ${ }^{151}$ übernommen wird.

Daher folge ich der Bezeichnung der Textsortenfunktionen in RolF (1993, S. 79 f.), der „Searles Bezeichnungen für die Illokutionsklassen (assertiv, direktiv, kommissiv, expressiv, deklarativ) [übernimmt]“ (BRINKER/CÖLFEN/PAPPERT, ${ }^{9} 2018$, S. 105), ,um die enge Verwandtschaft zu der Sprechakttypenklassifikation Searles [...] begrifflich herauszustellen“ (RoLF, 1993, S. 79). Die Typologie der fünf Textsortenklassen entsprechend den fünf Funktionen differenziert RoLF (1993, S. 170 f.) in drei Ebenen aus, die er aus den drei Erfolgsbedingungsarten in SeArle/VAnDERVEKen (1985, S. 12 ff.) ableitet: die oberste Ebene des Handlungszwecks bzw. Handlungsziels (illocutionary point) wie ,Assertive“ oder ,Deklarative"; die mittlere Ebene der Zielerreichungsweise bzw. der Durchsetzungsmodus (mode of achievement) wie die Kategorien ,darstellend“ oder ,bindend“; die unterste Ebene mit weiteren Differenzierungen der Zielerreichungsweise als vorliegende Bedingungen (preparatory point) wie die Unterkategorien ,emittie-

150 Wie oben gezeigt gelten auch allgemeine Textanalyseraster für Fachtextsorten als brauchbar und differenzieren lediglich den Grad der Fachlichkeit.

151 Das Modell unterscheidet angestrebte und nicht-angestrebte Erträge und differenziert Erstere entsprechend SEARLE (1982b) in nichtdeklarierte/implizite und deklarierte/mit konventionellen Mitteln ausgedrückte. Das Modell umfasst die folgenden neun Ertragsdimensionen (ADAMZIK, ${ }^{2} 2016$, S. 195): ,intellektuell/kognitiv', ,handlungsorientierend', ,emotional-psychisch', ,sozial', ,formbezogen', ,metasprachlich/meta-kommunikativ', ,unterhaltend', , praktisch ${ }^{‘}$ und , geistig-moralisch ${ }^{`}$. Kritisiert wird vor allem die ,Operationalisierung, d.h. Messbarmachung der jeweiligen Erträge“" (BRINKER/CöLFEN/PAPPERT, ${ }^{9} 2018$, S. 125; Fettdruck im Original), insbesondere wenn diese nicht mit konventionellen Mitteln ausgedrückt werden und daher Erträge entsprechend den Rezipienten individuell unterschiedlich ausfallen können (ebd.). Das Ertragsmodell konzipiert Textfunktionen als interpretatorische Leistung der Rezipienten, das kaum alle Funktionsklassen gleichzeitig realisiere (ADAMZIK, ${ }^{2} 2016$, S. 196). Der Rezipient ,wählt das aus der eigenen Perspektive jeweils Relevante“ (ebd.) aus, wobei das Relevante sich bei erneuter Rezeption verschieben könne. 
rend' oder ,judizierend'. Beispielhaft ist dies für die Klasse der Textsorten dargestellt, die RoLF (1993) der Textfunktion ,Kommissiv‘ zuordnet (s. Abbildung 3-3).

Wie bereits Kapitel 3.2.1 ausführt, zielt meine Präzisierung der Textfunktion für dieses Analyseraster nicht auf eine weitere Hierarchisierung von Textsortenvarianten, -klassen, -typen etc., sondern darauf ab, ein möglichst präzises Beschreibungswerkzeug für die Funktionsstruktur in einem Textsortenexemplar und ggf. für die funktionalen Relationen zwischen Sorten innerhalb eines Textsortennetzes zu bilden.

Eine erste Analyse des Textkorpus legt es nahe, dass folgende Aspekte aus ROLFs (1993) Konzept für die Textsortenexemplare, insbesondere für die zentrale Textsorte Pflichtenheft, relevant sind. Die Relevanz dieser Aspekte berücksichtigt die detaillierte, exemplarische Analyse in Kapitel 5:

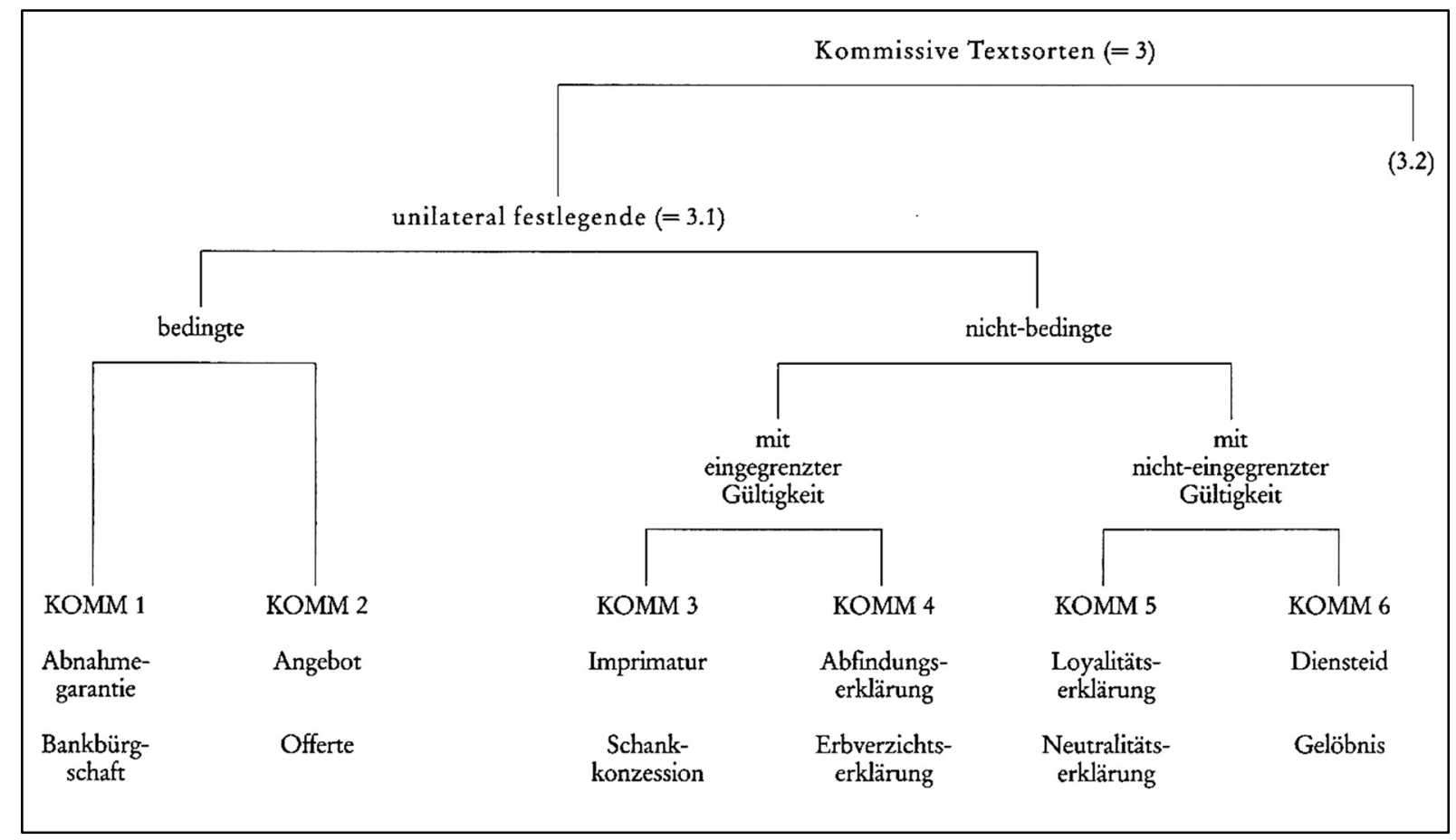

Abbildung 3-3: Kommissive Textsorten (RoLf, 1993, S. 275).

1. Es erscheint naheliegend, dass der Textsortengruppe KOMM 2 (s. Abbildung 3-3) - also bedingt (vorliegende Bedingung) unilateral festgelegtes (Zielerreichungsebene) Kommissiv (Handlungsziel) - Pflichtenhefte zuzuordnen sind. Diese Textsortengruppe beschreibt RoLF (1993) wie folgt: 
„Die festlegende, verpflichtende Qualität der Angebote und Offerten entfaltet sich ebenfalls erst dann, wenn eine bestimmte Bedingung erfüllt ist. Diese Bedingung besteht in der Annahme, im Akzeptieren des Angebots bzw. der Offerte. Wird ein Angebot angenommen, ist ihr Emittent darauf festgelegt, sich seinem Angebot gemäß zu verhalten. Er kann in der Regel nicht mehr dahinter zurückgehen." (ebd., S. 265; Kursive im Original)

Plausibel erscheint eine Zuordnung, da sich der Bieter mit der Angebotsabgabe verpflichtet, eine festgelegte Dienstleistung und festgelegte Waren (die Züge) zu einem festgelegten Preis für einen festgelegten Dienstleistungszeitraum anzubieten (Weiteres s. Kapitel 5).

2. Des Weiteren legt die erste Sichtung der Pflichtenheftexemplare des Korpus nahe, dass diese alternativ der Textsortengruppe KOMM 14 - bilateral festgelegtes (Zielerreichungsebene) Kommissiv (Handlungsziel) bei Bezugnahme auf Tauschaktionen (vorliegende Bedingung) - zuzuordnen sind. Diese Gruppe charakterisiert die Bedingung, „daß es Tauschaktionen, waren-, miet- bzw. pachtobjektbezogene Transaktionen, sind, auf die bei Realisierungen entsprechender Textsorten Bezug genommen wird“ (ebd., S. 274). Zwar handelt es sich bei Pflichtenheften nicht um Verträge. Im Textsortennetz der Ausschreibungsverfahren (s. Kapitel 4.2.2) verleiht der sogenannte Verkehrsvertrag den Pflichtenheften aber diese kommissive Funktion, weil die Pflichtenhefte bei erfolgreicher Teilnahme am Wettbewerbsverfahren Teil des Verkehrsvertrags werden. Daraus lässt sich die Frage abstrahieren, inwieweit Textsortenexemplare innerhalb eines Textsortennetzes Funktionen durch Exemplare anderer Textsorten des Textsortennetzes erhalten. Dies ist in der Analyse (s. Kapitel 6.2) am Beispiel des Lastenheftes und Verkehrsvertrages genauer zu untersuchen.

3. Auch die Beschreibung der Textsorte ,Stellenausschreibungen und -gesuche‘, die als Beispieltextsorten für die Textsortenklasse DIR 13 - also für nicht-bindendes (Zielerreichungsebene) Direktiv (Handlungsziel) mit beiderseitigem Interesse (vorliegende Bedingung) (RoLF, 1993, S. 250) - aufgeführt wird, deutet darauf hin, dass diese Klasse für die Textsorte Pflichtenheft relevant ist. Exemplare dieser Textsortenklasse werben ebenso indirekt für den Textproduzenten, der gleichzeitig Gegenstand des Textes ist, wie Werbeanzeigen, die dieser Klasse zugehören. Werbende Textfunktionen werden vor allem für die Textsorte 
Werbeanzeigen ${ }^{152}$ beschrieben. Diese charakterisiere, dass sie indirekt aufforderten, da eine direkte Aufforderung ,der Werbeintention hinderlich sein [könnte]“ (BRINKER/CÖLFEN/PAPPERT, ${ }^{9} 2018$, S. 113).

Auf der Ebene der Zielerreichungsmodalität gelten grundsätzlich solche Textsortenillokutionen als bindend, ,die von ihren jeweiligen Adressaten ausgeführt oder unterlassen werden müssen" (RoLF, 1993, S. 224; Kursive im Original). Dementsprechend lassen sich Stellenausschreibungen und -gesuche daraufhin prüfen, ob sie indirekte nicht-bindende Direktive vollziehen. Denn Bewerber sind nicht an die Aufforderung des Ausschreibenden gebunden, sich zu bewerben. Gebunden sind sie bei einer Bewerbung aber an ihre Anforderungen. Ein Angebot kann wiederum indirekt werben, ohne den (Stellen-)Ausschreibenden daran zu binden, den Bewerber in die engere Auswahl zu nehmen. So erscheinen mir auch Streckenausschreibungen und Angebotstexte bei einer indirekt direktiven Illokution nicht bindend. Indirekte Aufforderungshandlungen wie solche in Werbeanzeigen $^{153}$ (BRINKER/CöLFEN/PAPPERT, ${ }^{9} 2018$, S. 113), die als Teil von ExperteLaien-Kommunikation oder Laie-Laien-Kommunikation erscheinen, sind in Pflichtenheften nicht möglich. Da aber auch „Werbung, im Fach', die Werbung von Fachleuten für Fachleute desselben Faches“ (KALVERKÄMPER, 2004, S. 140 f.), möglich ist, erscheint es denkbar, dass Angebote nicht-bindende direktive Illokutionen mit beiderseitigem Interesse sind: So können Fachinformationen in Fachmann-Fachmann-Kommunikation (arte) Teil von Werbetexten (seducción) sein (ebd., S. 141) und durch Lexik, Visualisierungen, Text-Bild-Relationen, Textstrategien und kulturspezifische Präsentationsweisen werben (ebd., S. 145). Dies legt nahe, dass auch Pflichtenhefte eine werbende Funktion realisieren und der oben genannten direktiven Textsortenklasse zugehören, die direktive Funktion aber als indirekte Textfunktion neben dem Kommissiv oder einer anderen Grundfunktion realisieren.

152 BRINKER/CÖLFEN/PAPPERT $\left({ }^{8} 2014\right.$, S. 113) ordnen Werbeanzeigen den Textsorten mit Appellfunktion $\mathrm{zu}$.

153 Indirekte Aufforderungshandlungen von Werbeanzeigen beschreiben BRINKER/CÖLFEN/ PAPPERT $\left({ }^{9} 2018\right.$, S. 113) unter anderem durch Einstellungsbekundungen in Form von IchAussagen eines Agens mit Vorbildfunktion. Diese indirekten Formen der Aufforderungsrealisierung sind in Pflichtenheften nicht möglich, weil in diesen kein Agens mit Vorbildfunktion unmittelbar erkennbar wird (s. Kapitel 5). 
Diese drei Aspekte berühren die Fragen 2 und 3, die Kapitel 3.2.1 aus ScHMITZ (2007) auf multimodale Textsorten überträgt: Kann ein Textelement mehrere Illokutionen vollziehen? Kann ein Textelement neben sekundären Illokutionen indirekte primäre Illokutionen vollziehen? Diese drei Aspekte sollen die exemplarische Textsortenanalyse dabei unterstützen, die Funktionsstruktur genauer zu beschreiben.

Des Weiteren dient auch die folgende Beschäftigung mit der textlinguistischen Adaption der poetischen Sprachfunktion (JAKOBSON, 2007) dazu, die Beschreibungsinstrumente zu präzisieren. Funktionshinweise in HAUSENDORF/KeSSELHEIM (2008, S. 143 ff.) erweitern die Fünf-Klassen-Typologie aus SEARLE bzw. BRINKER und ROLF (1993) um den Unterhaltungshinweis als eine weitere Grundfunktion, indem sie „den Reflex der Jakobson'schen Sprachfunktionen erkennen (Jakobson 1972)“(KesselHeIM, 2011, S. 357) lassen, die sie mit der Sprechakttheorie harmonisieren (ADAMZIK, ${ }^{2} 2016$, S. 176). Die poetische Sprachfunktion charakterisiert der „selbstreflexive Bezug des Texts zu seiner Form (,Unterhaltung')“ (KesselHeIM, 2011, S. 357) bzw. „,[d]ie Einstellung auf die Botschaft als solche, die auf die Botschaft um ihrer selbst willen zentriert ist" (JAKOBSON, 2007, S. 168; Kursive im Original). Die poetische Grundfunktion übernimmt auch ADAMZIK (2016, S. 194 f.) ,[a]ngesichts der immer grösseren Bedeutung der (meist zusätzlichen) Unterhaltungsfunktion“ (ebd., S. 194) als ,formbezogene Ertragsdimension“ in ihr Ertragsmodell (ebd., S. 195). An die Aufnahme der poetischen Funktion in das Analyseraster schließt die Frage an, inwieweit Unterhaltung für fachliche Kommunikation relevant ist. Diese Frage verweist wiederum auf KALVERKÄMPERs (2004) oben dargestellte Ausführung zur Werbung in Expertenkommunikation.

Auf den ersten Blick wirkt es irritierend, die Unterhaltungsfunktion in mein Analyseraster als sechste Textfunktion aufnehmen zu wollen, um Fachtextsortenexemplare zu beschreiben. Denn Fachkommunikation dient der Ausübung beruflicher Aufgaben (SCHUBERT, 2007, S. 210), konkret zeichnen sich Fachtexte „neben lexikalischen und grammatischen Merkmalen [...] durch genuin textuelle Besonderheiten aus, welche die Fachkommunikation unterstützen (sollen) und deren Grad an Fachlichkeit bestimmen“ (RoELCKE, ${ }^{3} 2010$, S. 111). Die Nützlichkeit eines Unterhaltungshinweises besteht dagegen, „so die paradoxe Suggestion, in 
seiner vermeintlichen Nutzlosigkeit, in einer Autonomie der von allen externen Zwecken befreiten Wahrnehmung der Form des Textes um seiner selbst willen“" (Hausendorf/Kesselheim, 2008, S. 158). Für einen Fachtext eine poetische Funktion bzw. einen Unterhaltungshinweis als mögliche Analyseklasse anzunehmen, stellt aber nur scheinbar einen Widerspruch dar. Wenn Unterhaltung als Teil von fachlicher Kommunikation, auch technisch-juristischer Kommunikation, aufgefasst wird, ist diese Unterhaltungsfunktion auch relevant, um technischjuritische Fachtextsortenexemplare wie Pflichtenhefte zu beschreiben. Auf die Relevanz der Unterhaltungsfunktion für Fachkommunikation deutet bereits das dargestellte Konzept von KALVERKÄMPER (2004) hin. Diese Argumentation stützt auch der folgende Gedanke: Die „Ästhetizität eines Kunstwerkes in dessen Autoreflexivität für den Rezipienten [zu] interpretier[en]“" (RoELCKE, 1994, S. 33), ermöglicht es wiederum - unter der Annahme, dass ein Fachtext als Kunstwerk betrachtet wird -, den Bezug zum Rezipienten herzustellen. So könnte ein fachlicher Textproduzent mit einer poetischen Funktion intendieren, den Rezipienten durch die Ästhetizität seines Fachtextes von der eigenen Leistungsfähigkeit zu überzeugen, also gleichzeitig eine indirekte direktive Illokution zu vollziehen. Die Übertragung der Ästhetizität des Kunstwerks Fachtext auf die Leistungsfähigkeit des Textproduzenten in den beworbenen Angebotsbereichen leistet z. B. auch ein Stellenausschreiber bei der Sichtung von Bewerbungsschreiben (s. Kapitel 4.2). Dass die Ästhetizität eines Fachtextes das Ergebnis davon ist, seine Ausdrucksmittel derart zu gestalten, dass er die Unterhaltungsfunktion repräsentiert, unterstreicht auf eine neue Weise die Bedeutung des Textdesigns von fachlichen Sprache-Bild-Texten.

Die Analysekategorie ,Funktionsstruktur' berücksichtigt entsprechend dem bisher Dargestellten folgende Kategorien (s. Tabelle 3-1): 


\begin{tabular}{|l|l|}
\hline \multicolumn{2}{|l|}{ Zusammenfassung: Funktionsstruktur } \\
\hline $\begin{array}{l}\text { Sprech-, Bildakte und mul- } \\
\text { timodale Akte in Textsor- } \\
\text { ten }\end{array}$ & $\begin{array}{l}\text { Lokution, Proposition, Illokution und perlokutio- } \\
\text { näres Ziel, perlokutionärer Effekt (Textwirkung) }\end{array}$ \\
\hline Textfunktionen & $\begin{array}{l}\text { Assertive, Direktive, Kommissive, Expressive, } \\
\text { Deklarative, ggf. poetische Funktion }\end{array}$ \\
\hline Illokutionsarten & $\begin{array}{l}\text { Direkte und indirekte Textfunktionen einer Text- } \\
\text { sorte/eines Funktionsmoduls }\end{array}$ \\
\hline Textfunktionsebenen & $\begin{array}{l}\text { 1. Handlungszweck/-ziel (illocutionary point): } \\
\text { assertiv, deklarativ etc. } \\
\text { 2. Zielerreichungsweise bzw. Durchsetzungsmo- } \\
\text { dus (mode of achievement); darstellend oder bin- } \\
\text { dend } \\
\text { 3. Differenzierung von 2. durch vorliegende Be- } \\
\text { dingungen (preparatory point): emittierend, ju- } \\
\text { dizierend etc. }\end{array}$ \\
\hline Funktionsstruktur & $\begin{array}{l}\text { Funktionselemente, die Grund-, Unter- und Ne- } \\
\text { benfunktionen repräsentieren }\end{array}$ \\
\hline Modularisierung & Funktionselemente und deren Salienz \\
\hline Hinweise für die Analyse & $\begin{array}{l}\text { 1. Realisation von Direktiven und Kommissiven } \\
\text { in der Fachmann-Fachmann-Kommunikation } \\
\text { (arte) als Werbetextelemente (seducción) in } \\
\text { Pflichtenheften } \\
\text { 2. Kein Eins-zu-eins-Verhältnis zwischen The- } \\
\text { men- und Handlungsstruktur }\end{array}$ \\
\hline
\end{tabular}

Tabelle 3-1: Zusammenfassung zur Analysekategorie ,Funktionsstruktur' (eigene Darstellung).

\subsection{Themenstruktur}

Wie die Hinführung erläutert, bezeichnet STÖCKLs (2016) Dimension ,Themenstruktur', dass unterschiedliche Modalitäten Teilthemen repräsentieren können, die zur Themenstruktur eines Textes gehören. Dabei wird die Frage aufgeworfen, ob auch mehrere Modalitäten ein Teilthema als Ko-Referenz bilden können (ebd., S. 23), also mehrere Elemente eines Textes wie ein Bild und ein Schriftelement dasselbe Teilthema repräsentieren. Im Verhältnis zur Funktionsstruktur stellt sich 
die Frage, inwieweit diese beiden Strukturen deckungsgleich sind. Für Gebrauchstexte nimmt RoLF (2000, S. 424) grundsätzlich an, dass kein Eins-zu-einsVerhältnis zwischen Satz und Illokution besteht. Dieses Annahme teilen auch BRINKER/CÖLFEN/PAPPERT ( ${ }^{9} 2018$ ) und legen ihrem Textkonzept zugrunde, dass „die Textstruktur primär als thematische Struktur vor dem Hintergrund bestimmter Grundformen der Themenentfaltung" (ebd., S. 96 f.) zu beschreiben ist. Auch nach Heinemann/Heine-MAnN (2002, S. 147) lässt sich die Textstrukturierung von Thematizität und Strukturiertheit herleiten. Für die Analyse der Textsortenexemplare folge ich dieser Annahme eines fehlenden Deckungsverhältnisses zwischen Themen- und Funktionsstruktur, leite daraus den Anspruch ab, beide Strukturen gleichwertig zu analysieren.

Semantische Verknüpfungen (logical relations) zwischen Sprache und Bild (Martin/Rose, 2008, S. 177 ff.; VAn LeEuwen, 2005a, S. 220 ff. u. a.) erzeugen nach STÖCKL (2016, S. 23) sowohl die Funktions- als auch die Themenstruktur neben Verknüpfungen, die unabhängig von diesen Strukturen realisiert werden. Meine exemplarische Analyse beider Strukturen eines Sprache-Bild-Textsortenexemplars zielt dementsprechend darauf ab, diese Relationen zu beschreiben.

Da auch die Themenstruktur in STÖCKL (2016) nicht systematisch dargestellt wird, beziehe ich mich grundsätzlich auf BRINKER/CÖLFEN/PAPPERT ( $\left.{ }^{9} 2018\right)$ und weiche davon lediglich durch die Beschreibung der Modularisierung der Mikround Makrostruktur nach HAUSENDORF/KeSSELHEIM (2008) ab. Weil die zu analysierenden Pflichtenhefte auch zur Technikkomunikation gehören, in der Raumdeixis eine besondere Stellung einnimmt (RothKEGEL, 2010, S. 33 ff.), sind die Ausführungen zu Raumdeixis in Kapitel 3.1.1 relevant. ${ }^{154}$ Die Gliederung der weiteren Teilkapitel orientiert sich an der Erweiterung des thematischen Analyserasters um bildliche Mittel der Textmikrostrukur (Kapitel 3.3.2) und der Modularisierung der Themenentfaltungsmuster (Kapitel 3.3.3). Dabei bezieht sich die Mikrostruktur auf Zusammenhänge ,zwischen einzelnen Sätzen oder Bildeinheiten einerseits (Textmikrostruktur)“ (RoELCKE, ${ }^{3} 2010$, S. 93), zu denen Anaphorika und Kataphorika, Pronomen, Rekurrenz und Ellipsen gehören (ebd.,

154 Weder BRINKER/CÖLFEN/PAPPERT ( $\left.{ }^{9} 2018\right)$ noch STÖCKL (2016) systematisieren in ihrem Raster Raumdeixis. 
S. 115 ff.; ähnlich in Hausendorf/Kesselheim, 2008, S. 103 ff.). Die Makrostruktur beschreibt „Einheiten, die aus jeweils mehreren Sätzen oder Bildsequenzen bestehen“ (ROELCKE, ${ }^{3} 2010$, S. 93), insbesondere Themenentfaltungsmuster, die als globale Vertextungsstrategie eine vertikale Verknüpfung dar[stellen] (der Faden)“(HAusendorf/KesselHeim, 2008, S. 90). Die Mikrostruktur verkette dagegen horizontal (ebd.).

\subsubsection{Raumdeiktische Mittel zur Spezifikation von Technikkommunikation}

„[D]ass Raumstrukturen bereits in der Semantik des Wortschatzes verankert sind“ (RothKEGEL, 2010, S. 33), gelte insbesondere für technische Kommunikation. D. h., Raumdeixis ist ein wesentlicher Aspekt der Themenstruktur eines interfachlichen Sprache-Bild-Textes der Technik und anderer Fächer. Bei der Darstellung von Raumstrukturen „kommt es darauf an, dass die Teilgegenstände geortet und identifiziert werden und dass die räumliche Struktur vorstellbar gemacht wird“ (ebd., S. 34).

In Patentschriften, also in interfachlichen Sprache-Bild-Textsorten der Technik und des Rechts, werden Raumstrukturen multimodal repräsentiert, indem verschiedene Formen der Deixis eingesetzt werden:

„Die Raumdeixis, die in den Ausführungsbeispielen gut zu erfassen ist, gliedert sich in Positionsdeixis und Dimensionsdeixis. Die Positionsdeixis vollzieht sich durch Positionsnummern. Ihre Funktion ist das Verweisen vom Text auf die Zeichnungen. Durch sie wird die Korrespondenz zwischen Text und Bild hergestellt. Es ist ein Transkodieren des sukzessiven Textes in die Simultaneität der Zeichnungen." (Liv, 1992, S. 166; Fettdruck im Original)

Dimensionsdeixis wird anhand von Adverben (vorn, oben/unten, links/rechts etc.) in Bezug auf eine Projektionsansicht wie eine Frontansicht als funktionale Darstellung besprochen, die aus ihrer Einsatzweise resultiert (LIU, 1992, S. 166). Dagegen bleiben ikonisch-bildliche Darstellungen von technischen Zeichnungen unbehandelt. Dimensionsdeixis als Raumdeixis lässt sich in primäre, sekundäre und kardinale Deixis differenzieren (DÜRR/SCHLO-BINSKI, ${ }^{3} 2006$, S. 187 ff.): Primäre Deixis beschreibt von der BÜHLERschen Origo von „Hier, Jetzt und Ego des Sprechers“ (ebd., S. 188) ausgehend das ,relevante Wahrnehmungs- und Handlungsfeld des Sprechers“ (ebd., S. 189) als Gesprächskontext, beispielsweise für die Verwendung der Opposition der Adverbien hier und dort. Sekundäre Deixis setzt 
primäre Deixis voraus, geht aber von einem dreidimensionalen Raum aus (ebd., S. 190).

Sekundäre Deixis gliedert sich zum einen in die deiktische Perspektive, bei der der Sprecher „Origo eines dreidimensionalen Koordinatensystems mit Spiegelachsen für oben-unten [sic] in der Vertikalen und vorn-hinten [sic] sowie linksrechts [sic] in der Horizontalen“ (ebd., S. 190) wird (s. Abbildung 3-4).
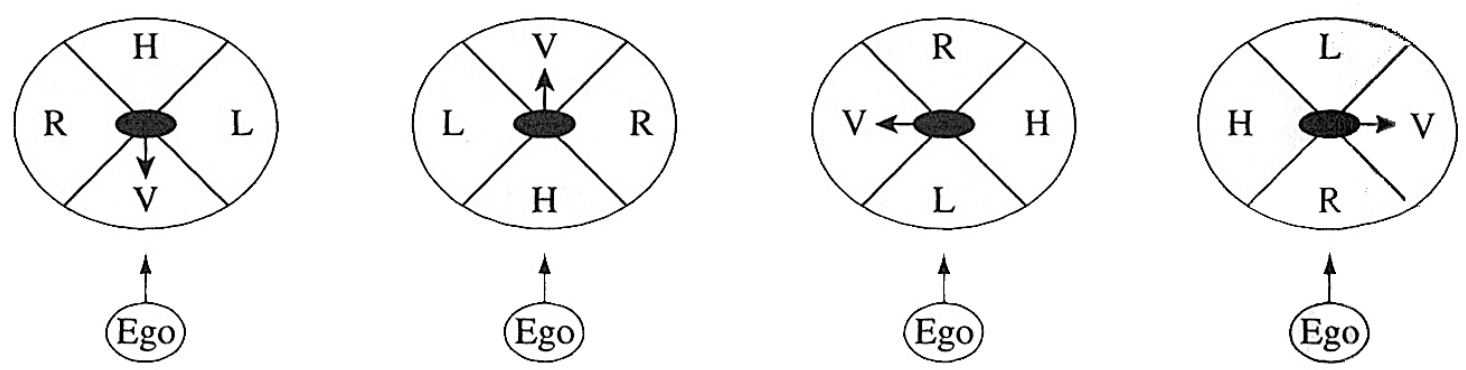

Intrinsische Verortung eines Objektes
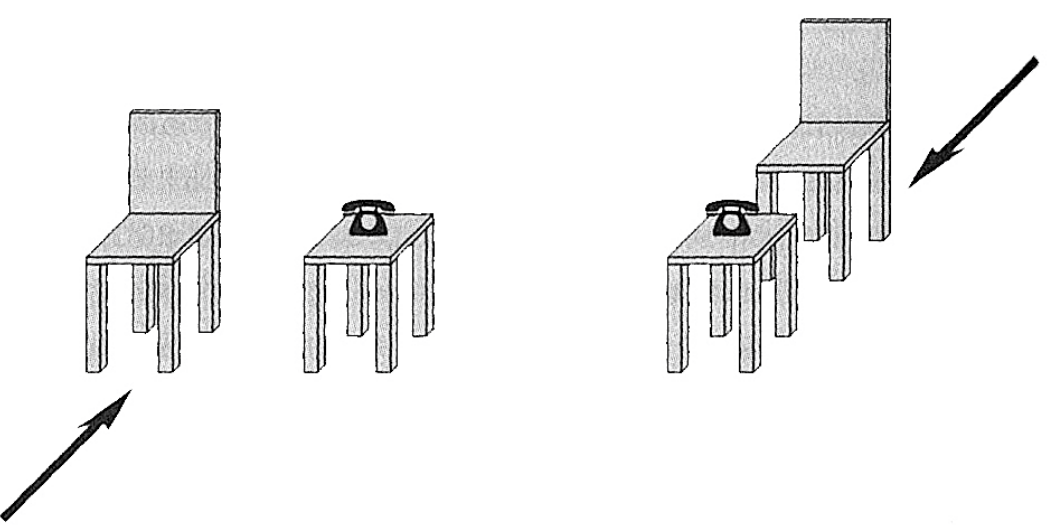

Intrinsisch:

links des Stuhles

vor dem Stuhl

Deiktisch: rechts des Stuhles

Abbildung 3-4: Deiktische und intrinsische Perspektive (DüRR/SCHLOBINSKI, ${ }^{32006,}$ S. 192).

Zum anderen unterscheidet sekundäre Deixis die intrinsische Perspektive (ebd., S. 191), die vom Objekt ausgehend die räumliche Relation zwischen diesem Gegenstand und einem zweiten beschreibt (s. Abbildung 3-4). Primäre und sekundäre Deixis werden auch als origobezogene Referenzsysteme bezeichnet. Letztere Deixis wird nach einem deiktischen und einem intrinsischen Referenzrahmen differenziert (GuTERMAnN, 1996, S. 30). Die beiden Perspektiven sekundärer Deixis können konfligieren und zu Missverständnissen führen, wenn nicht deutlich ist, 
von welchem räumlichen Bezugspunkt aus die räumliche Bestimmung ausgeht (DÜRR/SCHLOBINSKI, ${ }^{3} 2006$, S. 191).

Als dritte Art von Deixis stellt die kardinale Deixis oder geozentrische Deixis die Position von Körpern im Raum auf der Grundlage eines absoluten Koordinaten-

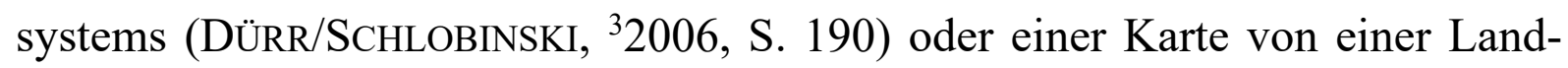
schaft dar (ebd., S. 193). „Längen- und Breitengrade oder Planquadrateinteilungen“ (GUTERMANN, 1996, S. 30) fungieren als absolutes Referenzsysteme, indem sie eine Landkarte zu einem Koordinatensystem machen. Auch Benennungen von Teilen eines Raumes können als Teil dieses Referenzsystems verstanden werden, weil bei der Definition eines absoluten Referenzsystems „Teilen des entsprechenden Raums ,Namen“ gegeben werden“ (ebd.). Dies wird vor dem Hintergrund eines (mikro-)kulturell entwickelten Schemas möglich. Denn vergleichbar mit der kulturell determinierten Vorstellung von Bildern wird die Konstitution von Raum beschrieben:

„Zur Entwicklung einer abstrakten Raumvorstellung tragen die kulturell entwickelten und vermittelten Systeme und Instrumente der Raumorientierung bei, wie z.B. Karten, Meßinstrumente für Himmelsrichtungen und Entfernungen etc. Das jeweilige Sprachsystem expliziert durch die raumbezüglichen sprachlichen Ausdrücke die in Objektschemata und Relationskonzepten enthaltene räumliche Information und hebt sie somit in den Status eigentlichen räumlichen Wissens.“ (GUTERMANN, 1996, S. 28 f.; Fettdruck im Original) ${ }^{155}$

Im Anschluss an die Konzeption, bei der Rezeption von Textsortenexemplaren in die Konstitution des Textes vorhandenes Fachwissen des Fachrezipienten einzubinden (s. Kapitel 2.2), kann das Raumkonzept eines Fachrezipienten im Rezeptionsprozess als Teil des interfachlichen Sprache-Bild-Textsortenexemplars interpretiert, wenn auch nicht unmittelbar untersucht werden. So verweisen in der Patent-Beschreibung (s. Beispielsatz 3-1) folgende Termini auf Raumkonzepte:

155 Grundsätzlich lässt sich annehmen, dass Raumkonstitution nicht von einer aktuellen Rezeption, sondern von einer grundlegenden Raumerfahrung des Rezipienten bzw. einem entsprechend konstituierten imaginären Raum abhängig ist, ,allerdings ist bei deren Verwendung [perzeptueller Faktoren; $\mathrm{AH}$ ] die jeweilige Referenzwahl deutlich durch perzeptuelle Faktoren beeinflußt“" (FrIEDERICI, 1989, S. 33). 
Wagen eines Schienenfahrzeugs (19) des Typs, der einen Boden (4) umfasst, der mindestens eine bewegliche Plattform (22) und eine Standard-Plattform (16) umfasst, [...]

\section{Beispielsatz 3-1}

Der Terminus Boden kann als Verweis auf eine Position innerhalb eines mikrokulturellen Schemas bzw. Konzeptes von einem Schienenfahrzeug interpretiert werden.

$\mathrm{Zu}$ prüfen ist im Folgenden, ob sich die Konzepte sprachlicher Raumdeixis auf die vorhandenen Konzepte der Deixis für Bilder, insbesondere für technische

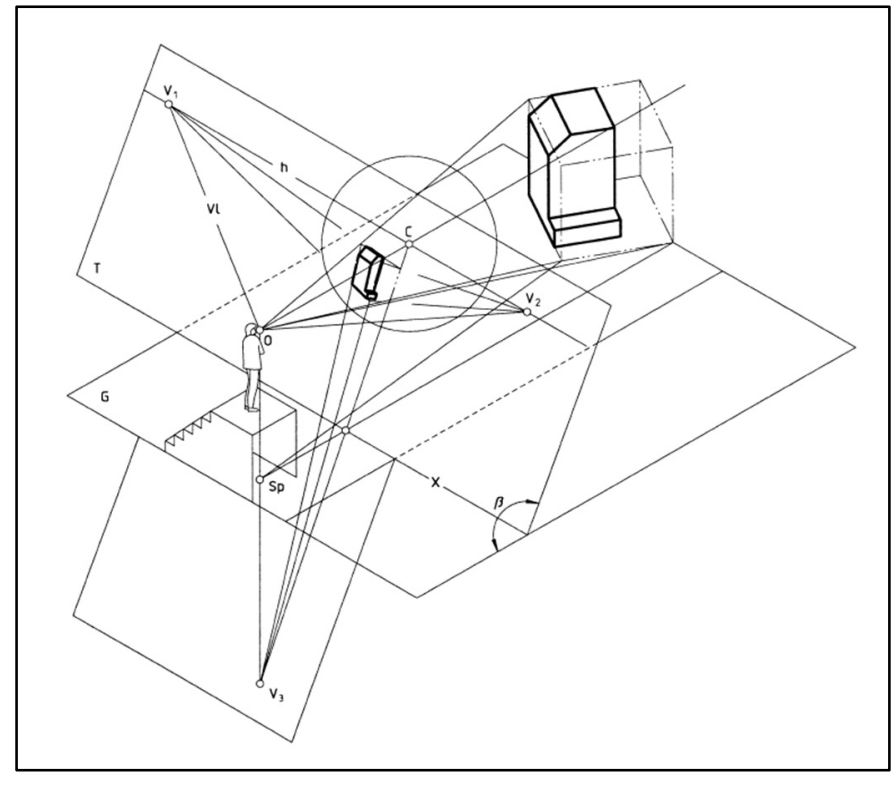

Abbildung 3-5: Projektionsmodell mit schräger Projektionsebene und einem Gegenstand in beliebiger Lage zur Projektionsebene $\left(\beta>90^{\circ}\right)($ DIN EN ISO 5456-4, 2002, S. 9).
Zeichnungen übertragen oder ob sie sich modifizieren lassen. Bei einer orthogonal zweidimensionalen Projektionsmethode, also wenn es sich um zweidimensionale Parallelität zwischen dem dargestellten Gegenstand und der Projektionsebene (s. Abbildung 3-5) handelt, ist die bildliche Darstellung vergleichbar mit der sekundären Deixis deiktischer Perspektive, da das Objekt von einem externen Betrachterstandpunkt , $\mathrm{o}^{6}$ dargestellt wird (s. Abbildung 3-5).

Technische Zeichnungen erscheinen aber auch mit kardinaler Deixis von sprachlichen Darstellungen vergleichbar. Denn sie stellen Objekte nicht nur relativ bemaßt dar, ${ }^{156}$ sondern auch absolut durch die Eintragung von Maßlängen einzelner Objekte (Einzelbemaßung) und Koordinatenbemaßung als „Bezugsbemaßung in einem Koordinatensystem

156 So werden beispielsweise die Relationen zwischen Elementen (Bezugsbemaßung), Mittellinien zur Darstellung der geometrischen Mitte, Symmetrielinien etc. genutzt (DIN 40610, 1992, S. 2 f.). 
(kartesisch oder polar)“(DIN 406-10, 1992, S. 3). Dabei handelt es sich bei dieser Interpretation um eine monomodal-bildliche Konzeption. Ergänzt durch die genannte Bezifferung zur indirekten Benennung von Bestandteilen durch schriftsprachliche Termini lässt sich die monomodal-bildliche Konzeption zu einer multimodalen erweitern.

Grundlegende Bezugspunkte von Raumdeixis stellen Objekt, Sprecher oder absolutes Koordinatensystem als Bezugspunkt (einerseits sekundäre Deixis aus deiktischer oder intrinsischer Perspektive, andererseits kardinale Deixis) sowie die vertikale und horizontale Achse aus oben - unten, rechts - links und vorne hinten (DÜRR/SCHLOBINSKI, ${ }^{3} 2006$, S. 193) dar. Diese sind - wie das Beispiel der Patentschrift gezeigt hat - für die Untersuchung von Raumdeixis in Pflichtenheften relevant. In einem erweiterten Modell (GuTERMANN, 1996, S. 31 ff.) lässt sich die sprachliche Konstitution von Raumdeixis durch die Relationen zwischen Objekten, Teilobjekten, Objektachsen, Raumachsen, Richtungsvektoren, Gegenstand, Vorgang und Eigenschaften darstellen: Objekte lassen sich dabei als physikalische Objekte (z. B. Kassette), Gegenstände dagegen als Textgegenstand (z. B. Verschiebung), Vorgänge als Prozesse (z. B. Darstellung) interpretieren, während Raum- und Objektachsen Hilfslinien darin ähneln, um die Lage von Objekten zu beschreiben. Richtungsvektoren ähneln Hilfslinien darin, um Vorgänge darzustellen.

Für die sprachliche Beschreibung von Bewegungen im Raum werden daher die Dimensionen Ziel, Raum und Durchquerung genutzt (DÜRR/SCHLOBINSKI, ${ }^{3} 2006$, S. 194). Aber auch technische Zeichnungen können Bewegungen darstellen, indem sie zwei Zustände eines beweglichen Teils darstellen: So wird durch „StrichZweipunktlinie (langer Strich), schmal“ (DIN 128-24, 1999, S. 13) die „Endstellung beweglicher Teile“ (ebd.) dargestellt bzw. „dürfen Alternativen und Extremlagen beweglicher Teile gezeigt werden“ (DIN 128-34, 2002, S. 15). Beispielsweise werden die End- und Zwischenposition der Überfahrbrücke durch eine Strich-Zweipunktlinie dargestellt (s. Abbildung 2-6). Dementsprechend werden in einer Zeichnung Zustände zu zwei Zeitpunkten dargestellt, da der Gegenstand nicht gleichzeitig beide Stellungen einnehmen kann. D. h., Zeitdeixis spielt sowohl für bildliche als auch für sprachliche Darstellungen von Bewegungen im Raum eine Rolle. 
Um die Dynamik bzw. Bewegungen von Objekten zu beschreiben, eignet sich Zeitdeixis. Zeitdeixis kann dabei als Metapher von Raumdeixis beschrieben werden, wie aus den Beispielen von Zuständen eines Unternehmens - Gipfel für gute Zeit und Talfahrt für schlechte Zeit - abgeleitet wird (DÜRR/SCHLOBINSKI, ${ }^{3} 2006$, S. 195). ${ }^{157}$

Im Anschluss daran ließe sich die Bewegung, die durch die Präposition an aus dem Teilsatz um die Höhe der Plattform an die Höhe des Bahnsteigs anzupassen realisiert wird, als Metapher verstehen. Auch in ikonisch-bildlichen Darstellungen können Punkte in der zweidimensionalen Fläche der Raumdeixis als Metapher für zeitdeiktische Verortungen interpretiert werden. So kann der Punkt in der Fläche eines Diagramms als Metapher für Zeit oder einen bestimmten Zustand eines Objektes in einem physikalischen Prozess wie Krafteinwirkung o. Ä. verstanden werden, beispielsweise als Punkt im Zugkraft-Geschwindigkeits-Diagramm (s. Abbildung 2-7). Räumliche Anordnung konstituiert wie weitere Ausdrucksmittel die horizontale Themenstruktur eines Textes.

\subsubsection{Multimodale Mittel horizontaler Themenstruktur}

$\mathrm{Zu}$ den Mitteln der horizontalen Themenstruktur zählen die semantisch- bzw. lexikalisch-thematischen Aspekte implizite Wiederaufnahme, Rekurrenz, Ko-Referenz, partielle Synonymie, Substitution, räumliche Anordnung etc. Die bereits behandelte räumliche Anordnung lässt sich sowohl zur horizontalen als auch zur vertikalen Themenstruktur zählen.

Als sprachliche Mittel entwickeln

„die einfache und die transformierende Wiederholung, der (anaphorische und kataphorische) Gebrauch von Pro-Formen, die Paraphrasierung, die Verwendung von (partiellen) Synonymen, [sic] sowie der Gebrauch von sprachlichen Einheiten, die in einer paradigmatischen Bedeutungsrelation stehen, [...] (RoELCKE, ${ }^{3} 2010$, S. 105$)^{158}$

157 Grundsätzlich lassen sich zeitdeiktische Ausdrücke wie bestimmte Präpositionen in Abhängigkeit als Metapher von Raum auffassen.

$158 \mathrm{Zu}$ Hinweisen der Themenentwicklung werden des Weiteren paradigmatische Bedeutungsrelationen bzw. lexikalische Hinweise, Metaphorik, Metonymie und Homonymie gezählt (ROELCKE, ${ }^{3} 2010$, S. 120 ff.). 
die mikrostrukturelle Themenstruktur, die zum Teil mit der horizontalen Themenstruktur vergleichbar ist. Durch Rekurrenz als „Wiederholung bedeutungsgleicher [...] sprachlicher Einheiten“ (ebd.) werden im Fachtext Rekurrenz- und Isotopieketten gebildet. Dabei ist die einfache Wiederholung des Terminus Linguistik (ebd.) vergleichbar mit der einfachen Wiederholung des Terminus Schienenfahrzeug als Genitiv-Attribut der Nominalphrasen Wagen eines Schienenfahrzeugs, Tür des Schienenfahrzeugs, Wagen des Schienenfahrzeugs. Einfache Wiederholung als „Wiederholung gleicher Wortformen oder -gruppen“ (HAUSENDORF/ KesselHeIM, 2008, S. 119) wird auch als Rekurrenz bezeichnet (ebd.). Mit der Nominalphrase Wissenschaft von der Sprache als transformierender Wiederholung des Nomens Sprachwissenschaft (ebd., S. 106) ist die Transformation des Nomens Schienenfahrzeug durch die Nominalphrase Fahrzeug auf Schienen vergleichbar. ${ }^{159}$

In multimodaler Perspektive stellt sich die Frage, ob sich Rekurrenz auch auf einen Terminus eines Textes und ein Bild dieses Textes bezieht, die beide auf denselben Gegenstand referieren. Beispielsweise können sowohl der Terminus Schienenfahrzeug als auch die Zeichnung eines Schienenfahrzeugs in Seitenansicht auf denselben außertextuellen Gegenstand verweisen. Möglicherweise besteht aufgrund der Unterschiede in den Teilbedeutungen zwischen Terminus und Bild aber auch nur eine partielle Synonymie. Die Analyse der Textsortenexemplare (Kapitel 5) untersucht auf entsprechende Fälle.

Bei impliziter Wiederaufnahme existiert keine Referenzidentität zwischen Bezugsausdrücken und den Referenzträgern, wobei zwischen Letzteren Bedeutungsbeziehungen bestehen wie z. B. Teil-Ganzes-Relationen (BRINKER/CöLFEN/PAPPERT, ${ }^{9} 2018$, S. 36). Diese Bedeutungsbeziehungen lassen sich als semantische Kontiguitätsverhältnisse differenzieren in ontologische, d. h. einem Naturgesetz entsprechend wie zwischen Blitz - Donner, logisch-begriffliche wie zwischen Frage - Antwort, Problem - Lösung etc. und kulturelle wie zwischen Straßen-

159 Für den Bereich Schienenfahrzeugtechnik wirkt eine entsprechende Transformation von Termini grundsätzlich unüblich, da sie nicht mit dem fachsprachlichen Postulat der Exaktheit (BAUMANN, 1998a) bzw. dem fachsprachlichen Anspruch auf Exaktheit und (Ein-)Eindeutigkeit (RoElcke, ${ }^{3} 2010$, S. 68 ff.) vereinbar sind, auch wenn Synonymie in einigen Fachterminologien der Technik nachweisbar ist (ebd., S. 71). 
bahn-Schaffner, Stadt-Bahnhof. (ebd. S. 37 f.). Diese Beziehungen sollen auch für bildliche bzw. diagrammatische Elemente in der exemplarischen Analyse geprüft werden.

Isotopie, die „sich aus der Wiederkehr semantischer Merkmale in einem Text“ (ebd., S. 130) ergibt, kann grundsätzlich mit diesen Kontiguitätsverhältnissen verglichen werden. In Form der Isotopiekette erscheint dieser Zugang als Teil einer horizontalen Themenstruktur, auch wenn Isotopie ebenso zur Bildung der vertikalen Themenstruktur beiträgt. Bei Isotopie wird „eine semantische Beziehung zwischen unterschiedlichen Referenzausdrücken in einem Text durch die Wiederkehr eines semantischen Merkmals signalisiert" (HAUSENDORF/ KeSSELHEIM, 2008, S. 131). Beispielsweise bilden die Termini Toilettenraum, Rollstuhl und Toilettensitz in Abbildung 3-6 eine Isotopiekette zur Eigenschaft eines Schienenfahrzeugs, für Rollstuhlfahrer geeignet zu sein (Konformität mit der Norm TSI PRM, 2008).

Bezogen auf technische Zeichnungen lassen sich ebenfalls Isotopieketten ableiten. Beispielsweise bildet Abbildung 3-6 die Isotopiekette, ein rollstuhlgerechtes Schienenfahrzeug darzustellen bzw. zu normen.

Die Größe des Toilettenraums ist so zu wählen, dass ein Rollstuhl gemäß Anhang M in eine Position neben dem Toilettensitz bewegt werden kann (siehe Abbildung 8a).

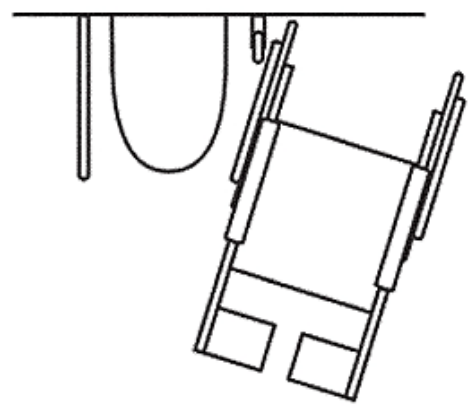

Seitlicher Zugang

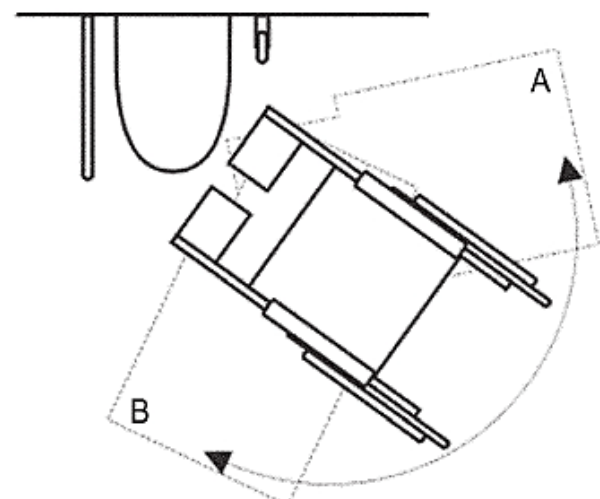

Diagonaler Zugang

ABBILDUNG $8 a$

Abbildung 3-6: Toilettenzugänge für Rollstühle (TSI PRM, 2008, S. 119). 
So stellt Abbildung 3-6 die Eigenschaft eines rollstuhlgerechten Schienenfahrzeugs dar, eine Toilette ohne fremde Hilfe benutzen zu können, weil dazu die Maße eines Rollstuhls und der entsprechende Rangierraum berücksichtigt werden - in den beiden Abbildungen, die in der Norm TSI PRM (2008, S. 119) auf Abbildung 3-6 folgen, wird eine ausklappbare Haltevorrichtung für die selbstständige Benutzung der Toilette dargestellt (ebd., S. 119 f.).

$\mathrm{Zu}$ berücksichtigen ist bei diesem Beispiel der Isotopiekette ,rollstuhlgerechtes Schienenfahrzeug' aber, dass sich die Analyse aufgrund der vielen Teilthemen, die sich zwischen diesen Abbildungen befinden (Abbildung 3-37 befindet sich auf Seite 57, Abbildung 3-6 dagegen auf Seite 119), auf der Makroebene bewegt. Darüber hinaus wirft der Satz, der über der technischen Zeichnung in Abbildung 3-6 positioniert ist, die Frage auf, ob die technischen Zeichnungen in SpracheBild-Textsortenexemplaren Isotopieketten unabhängig von Schriftsprache bilden können.

Kataphorische Hinweise wie Titel und Überschriften, Fragen, das Horizontpronomen es etc. bezeichnen den Verweis sprachlicher Elemente auf weitere Elemente desselben Textes, die in der linearen Textchronologie noch folgen (HAUSENDORF/KESSELHEIM, 2008 S. 114). Anaphorische Hinweise verweisen auf sprachliche Elemente, die in der Textchronologie bereits realisiert wurden (ebd.), beispielsweise die Nominalphrase der Wagen des Schienenfahrzeugs am Ende des Satzes der Beschreibung (s. Beispielsatz 3-1), die durch den bestimmten Artikel der auf den in der Textchronologie bereits behandelten Wagen verweist. Bezogen auf Sprache-Bild-Textsortenexemplare, in denen schriftsprachliche und ikonischbildliche Elemente durch Ziffern relationiert werden, können Ziffern am Anfang eines Textes als kataphorische Verweise aufgefasst werden, wenn diese im Text aufgegriffen werden, beispielsweise das Nomen Rollstuhl im anmoderierenden Satz zur Rollstuhlpositionierung auf die ikonische Darstellung des Rollstuhls (s. Abbildung 3-6). Voraussetzung für die Anwendung des Konzepts von Anaphorika und Kataphorika ist allerdings die Annahme, dass sprachliche, bildliche und diagrammatische Elemente in Sprache-Bild-Texten in der Von-links-obennach-rechts-unten-Chronologie rezipiert werden, also in Abbildung 3-6 zunächst der anmoderierende Satz und erst dann das ikonische Bild des Rollstuhls. Diese 
Annahme steht der Perspektive entgegen, dass die Salienz der Textelemente die Chronologie durchbricht.

Als weiteres sprachliches Mittel des anaphorischen Verweisens werden Proformen, insbesondere Pronomen wie das Personalpronomen er und das Possessivpronomen seinen systematisiert, die innerhalb eines Textes auf ein bereits eingeführtes Nomen verweisen (HAusendorf/Kesselheim, 2008, S. 117 ff.). Pronomen können in literarischen Texten bereits am Textanfang genutzt werden, um „eine Art willkürlichen Einblick in eine schon andauernde Textwelt" (ebd., S. 119) zu geben. So wie sich das Verhältnis zwischen schriftsprachlichen und ikonisch-bildlichen Elementen eines Sprache-Bild-Textsortenexemplars als Rekurrenz oder Synonymie beschreiben lässt, stellt sich die Frage, ob beide Elemente jeweils als Proform des anderen Elements interpretiert werden können. Entsprechende Verknüpfungen behandelt aber ausführlicher Kapitel 3.4.

Die Behandlung von Isotopie hat bereits gezeigt, dass die Relationen von sprachlichen und bildlichen Elementen eines Sprache-Bild-Textes nicht trennscharf auf der Ebene der horizontalen Themenstruktur eines Textes verortet werden können, sondern möglicherweise auch auf dessen Makroebene der Themenentfaltung. Dies gilt zum Teil auch für implizite Wiederaufnahmestrukturen.

\subsubsection{Multimodale Mittel vertikal-modularisierter Themenstruktur}

STÖCKL (2016, S. 26 f.) zieht in der exemplarischen Analyse eines Sprache-BildTextsortenexemplars ein argumentatives Themenentfaltungsmuster heran, systematisiert aber weder dieses noch andere Themenentfaltungsmuster, um sie in der Analyse anderer Beispiele verwenden zu können. Verbreitet ist auch für diese Analysekategorie die Systematik in BRINKER/CöLFEN/PAPPERT ( $\left.{ }^{9} 2018\right)$, die ich für mein Analyseraster übernehme.

Sie unterscheiden vier Grundformen der thematischen Entfaltung (ebd., S. 60 ff.): deskriptive, narrative, explikative und argumentative Themenentfaltung. Ähnlich übernehmen HAUSENDORF/KESSELHEIM (2008) diese Themenentfaltungsformen als Struktur- bzw. Verknüpfungshinweise, die die „Charakteristik des Weltbezugs [...] in die Nähe der Themahinweise [bringt], die signalisieren, auf welche Aspekte von Welt der Text Bezug nimmt“" (ebd., S. 91). Lediglich die explikative Themenentfaltung bezeichnen HAUSENDORF/KESSELHEIM (2008), die von BRIN- 
KERs Benennung abweichen, als explanativer Hinweis. HAUSENDORF/KESSELHEIM (2008) beschreiben diese Strukturhinweise als

„- narrative Hinweise auf die Erzählbarkeit vergangener Ereignisse,

- argumentative Hinweise auf die Begründbarkeit von Handlungen,

- deskriptive Hinweise auf die Wahrnehmbarkeit von Objekten im Raum,

- explanative Hinweise auf die Erklärbarkeit von Sachverhalten“"

(ebd.;Kursive im Original).

Die erste Analyse von Pflichtenheftexemplaren, Optimierungsvorschlägen und anderen interfachlichen Textsortenexemplaren des Korpus legen nahe, dass deskriptive und argumentative Hinweise bzw. deskriptive und argumentative Themenentfaltungsformen für die Untersuchung relevant sind. ${ }^{160}$

Bei der Anwendung dieser Konzepte von Themenentfaltungsmustern ist des Weiteren zu berücksichtigen, dass Textsortenexemplare durchaus mehreren Mustern folgen können, weil beispielsweise Teilthemen einem anderen Muster folgen als die gesamte Themenstruktur. Diese Schlussfolgerung ziehen HAUSENDORF/KesSELHEIM (2008, S. 95) aus der Analyse einzelner Elemente eines Zeitungsartikels. Und auch BRINKER/CöLFEN/PAPPERT ( ${ }^{9} 2018$, S. 64) gehen davon aus, dass Teiltexte anderen Themenentfaltungsformen folgen können als das Textganze, beispielsweise in Form der deskriptiven Themenentfaltung als Ausgangspunkt einer Argumentation, also einer argumentativen Themenentfaltung (ebd., S. 64).

Die argumentative Themenentfaltung (s. Abbildung 3-7) entwickelt eine Themenstruktur nach BRINKER/CÖLFEN/PAPPERT ( ${ }^{9} 2018$, S. 73 ff.) aus folgenden Elementen:

Für narrative Hinweise bzw. die narrative Themenentfaltung ist die Abfolge von Situierung (in der Textchronologie zuerst durch das Element Weg zur Hütte), Repräsentation(-sphasen) (dann durch das Textelement Sturz des Erzählers) und Resümee (abschließend durch das Textelement Blindheit und sehend werden) als Teil von Alltagserzählungen zu einem Ereignis charakteristisch (BRINKER/CÖLFEN/PAPPERT, ${ }^{9} 2018$, S. 65 ff.). Explikative Themenentfaltungen folgen vor allem für wissenschaftliche Erklärungen dem Hempel-Oppenheim-Schema (H-O-Schema) aus zu erklärendem Sachverhalt etc. (,Explanandum') und erklärenden anderen Sachverhalten (,Explanans'), das sich wiederum aus Randbedingungen und Gesetzmäßigkeiten zusammensetzt (ebd., S. 69 ff.). Sowohl BRINKER/CöLFEN/PAPPERT ( ${ }^{9} 2018$, S. 69 f.) als auch HAUSENDORF/KeSSELheim (2008, S. 100 f.) ziehen konzeptionell wie auch exemplarisch Naturgesetze als Explanans heran. Dass narrative Themenentfaltungsmuster in fachlichen Sprache-Bild-Textsorten der juristisch-technischen Kommunikation wie in Patentschriften nicht vorkommen, stützt diese Annahme des Weiteren. Zu klären ist dies aber letztlich in der detaillierten exemplarischen Analyse. 


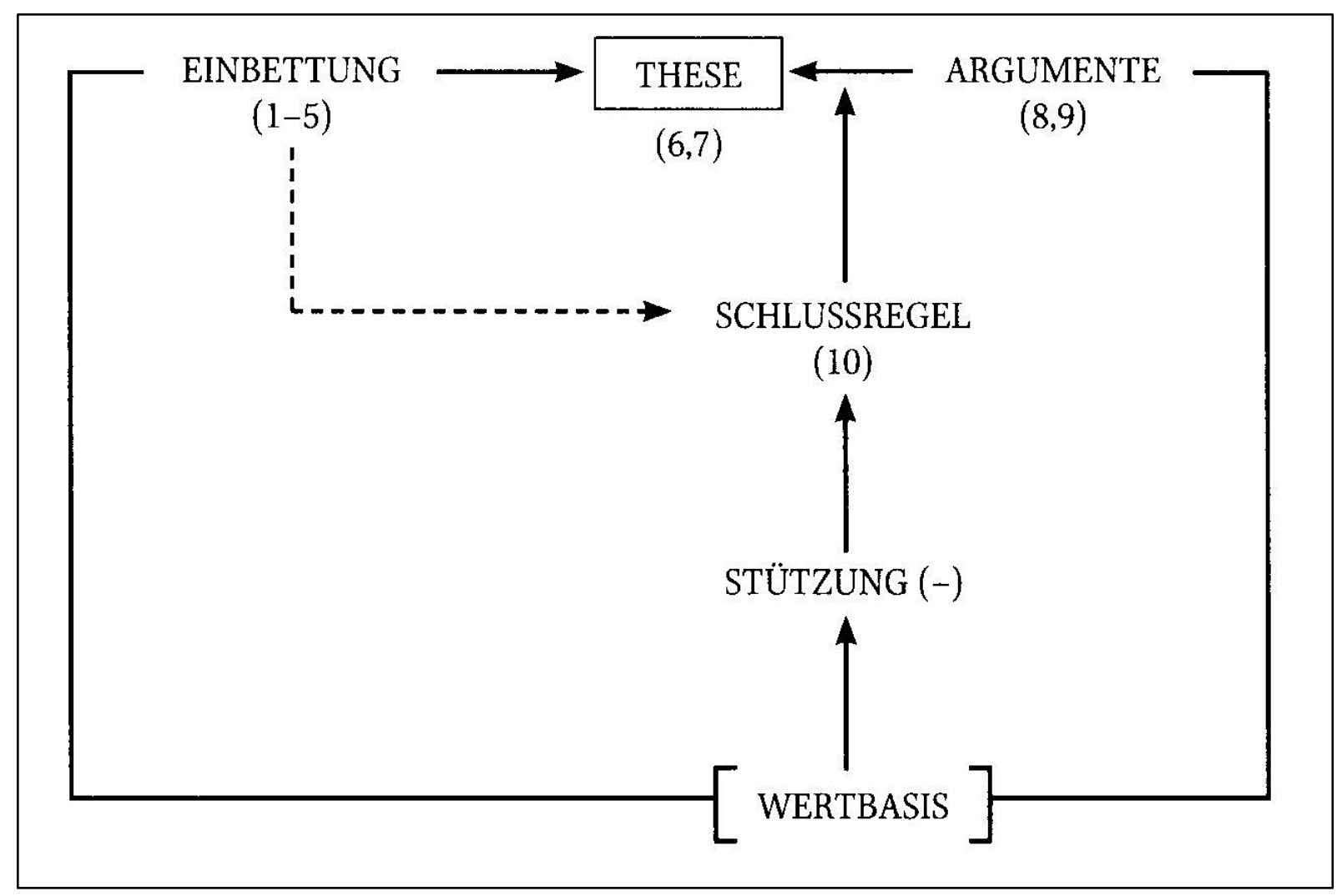

Abbildung 3-7: Schematische Darstellung der Struktur argumentativer Themenentfaltung (BRINKer/Cölfen/ PAPPERT, ${ }^{9}$ 2018, S. 79).

,These' (Hans ist deutscher Staatsbürger) - ,Argument" (Hans wurde in D. geboren) - ,Schlussregel' (Wenn man in D. geboren ist, wird man i. d. R. deutscher Staatsbürger) - ,Stützung' (aufgrund folgender Gesetze). Einerseits werden These und Argument situativ eingebettet und alle Elemente der argumentativen Themenentfaltung durch eine, Wertbasis‘ grundgelegt. Diese Basis wird von Produzenten und Rezipienten gemeinsam „konsensuell präsupponiert“ (ebd., S. 79). Andererseits wird der Geltungsgrad einer These als ,Modaloperator' (Dt. Staatsbürger wird man vermutlich) und die Gültigkeitseinschränkung der Schlussregel als ,Ausnahmebedingungen“ (z. B. beide Elternteile waren Ausländer) einbezogen.

Dieses Themenentfaltungsmuster konzipieren HAUSENDORF/KeSSELHEIM (2008, S. 94 ff.) als argumentative Strukturhinweise: Äußerungen bzw. Aussagen antworten auf eine strittige Frage und stellen dabei eine selektive Entscheidung aus mehreren möglichen Antworten (eine Behauptung) dar, die eine Begründung erfordern. Letztere fußen auf Kontextwissen und verlangen eine allgemeine, meist 
alltagslogische Schlussregel, weniger eine Gesetzmäßigkeit wie ein Naturgesetz. Die Schlussregel kennzeichnen verschiedene Hinweise. ${ }^{161}$

Die deskriptive Themenentfaltung gliedert sich nach Gegenstand bzw. Thema eines Textes nach einmaligem Vorgang, regelhaft dargestelltem Vorgang und Lebewesen oder (physikalischem) Gegenstand (BRINKER/CöLFEN/PAPPERT, ${ }^{9} 2018$, S. 60 ff.): „Die Themenentfaltung vollzieht sich nach der Teil-Ganzes- oder Enthaltenseins-Relation“ (ebd., S. 63), beschreibt die wesentlichen Merkmale des Gegenstandes oder Lebewesens und macht dabei quantitative Angaben, möglicherweise zur Raumanordnung und zum Verwendungszweck. ${ }^{162}$ Dies ist für Pflichtenhefte, die sich nach dem physikalischen Gegenstand Schienenfahrzeug gliedern, von besonderem Interesse.

Ähnlich thematisieren deskriptive Strukturhinweise Weltausschnitte in Form von Gegenständen, Personen, aber auch Bildern etc. ,im Hinblick auf Materialität (Beschaffenheit und Bestandteile, Gestalt, Form und Farbe) und Räumlichkeit“" (HAUSENDORF/KeSSELHEIM, 2008, S. 98), wodurch Dinge benannt, im Raum verortet oder ihnen Eigenschaften zugeschrieben werden. Verschiedene Formen der Raumdeixis (links, auf der Unterseite) sind demnach als deskriptive Strukturhinweise aufzufassen (ebd., S. 99). In Bezug auf die Linearität dieser Textbeschreibungen wird eine Übereinstimmung mit dem beschriebenen Objekt angenommen: „Die Abfolge und Hierarchie der Textteile folgt der Hierarchie der Objektteile.“ (ebd., S. 98) ${ }^{163}$ Konkurrieren kann diese Gliederung aber durch die Einbindung der Beschreibung in ihren funktionalen Zusammenhang, beispielsweise mit der

161 Zu diesen gehören (ebd., S. 96 f.): (1) kausale Relationen (weil, daher, ...), (2) wenn-dannRelationen, (3) Adjektive bzw. Adverbien, die Allgemeingültigkeit verleihen (alle, immer, ...), (4) Partnerorientierung durch Appelle, (5) Nomen, Adjektive, Verben etc., die Strittigkeit oder Argumentation anzeigen wie Vorurteil, fragwürdig, bezweifeln, rechtfertigen, (6) Gültigkeit einschränkende Operatoren (wahrscheinlich), (7) Relevanz in Form einer allgemeinen Regel, die einem System angehört (Rechtsstaat, Religion, ...).

Neben prototypisch informierenden Texten wie Nachrichten kann die deskriptive Themenentfaltung auch Teil von appellativen Texten sein (ebd., S. 64), bei denen sich Vorgänge mit einem bestimmten Ereignisablauf wiederholen (ebd., S. 61).

$163 \mathrm{Zu}$ den deskriptiven Strukturhinweisen gehören nach HAUSENDORF/KESSELHEIM (2008, S. 99 f.) Konkreta, Verben der Wahrnehmung (sehen) oder von Vorgängen/Zuständen (aussehen, klingen), z. B. Status- und Qualitätsprädikate (befindet sich), Wahrnehmungsurteile (so etwas wie ein), Lokaladverbien (oben), Attribute als Ausdruck von Merkmalen und Eigenschaften und (verdeckt) performative Hinweise (Beschreibung). 
Perspektivierung durch eine Person, wie einen Anwender. So werden in einer Anleitung die Handlungsschritte aus der Perspektive eines bestimmten Beobachters konzipiert (ebd.): „[D]as Prinzip einer imaginären Wanderung (man kommt von der Küche in einen geräumigen Salon) oder das Prinzip der Augenreise (links sieht man)“ (ebd., S. 99; Kursive im Original) sind charakteristisch für die suggerierte Perspektivübernahme durch den Text. Daher ist die Textstruktur als Themenentfaltungsmuster an diese Perspektive gebunden und legt einen spezifischen Fokus auf die Struktur des physikalischen Objekts.

Werden diese Themenentfaltungsmuster auf modularisierte Sprache-Bild-Textsorten übertragen, wie dies bereits Kapitel 3.2.2 für die Funktionsstruktur diskutiert, ist anzunehmen, dass diese Übertragung beim deskriptiven Themenentfaltungsmuster eher als bei argumentativen Themenentfaltungsmustern möglich ist. Denn letzteres Entfaltungsmuster ist als lineares Schema angelegt, sodass dessen Konstitution auf die Abfolge seiner Elemente angewiesen ist. Im Gegensatz dazu ist ein Teilthema der deskriptiven Themenentfaltung nicht zwingend auf eine vorausgegangene Beschreibung eines anderen Teilthemas angewiesen. So kann die Beschreibung des physikalischen Gegenstands Schienenfahrzeug aus der funktionalen Perspektive eines Nutzers mit dem Einstiegsbereich beginnen und in der Beschreibung der Toilettenbereiche oder der Sitze weitergeführt werden (s. Kapitel 5.2.3). Auch ein selektiver Rezeptionsprozess durch Experten (Textüberarbeitende des Bieters/Auftraggeber als Rezipienten) ist möglich.

STÖCKL (2016, S. 26 f.) orientiert sich bei der Interpretation einer argumentativen Themenstruktur für Exemplare der Textsorte Werbeanzeige zwar nicht an den oben aufgeführten Teilthemen der argumentativen Themenentfaltung nach BRINKER/CÖLFEN/PAPPERT ( ${ }^{9} 2018$ ), stellt aber den Zusammenhang und die Salienz von Elementen in den Vordergrund, die Teilthemen repräsentieren. Meine exemplarische Analyse der Textsortenexemplare fokussiert dementsprechend auch primär die Salienz von deren Textelementen. Die bisher beschriebene Konzeption zu Themenstrukturen fasst Tabelle 3-2 zusammen: 


\begin{tabular}{|c|c|}
\hline Isan & hemenstruktur \\
\hline $\begin{array}{l}\text { Multimodale Mit- } \\
\text { tel der Raumdeixis }\end{array}$ & $\begin{array}{l}\text { (a) deiktische sekundäre Perspektive, intrinsische se- } \\
\text { kundäre Perspektive und kardinale Deixis }\end{array}$ \\
\hline & $\begin{array}{l}\text { (b) Zeitdeixis neben Lexik durch Doppelrealisation } \\
\text { zweier Zustände in technischen Zeichnungen }\end{array}$ \\
\hline & $\begin{array}{l}\text { (c) sprachlich-bildliche Relationierungen von Objekten, } \\
\text { Teilobjekten, Objektachsen, Raumachsen, Richtungs- } \\
\text { vektoren, Gegenstand, Vorgang und Eigenschaften } \\
\text { (auch für Raumbewegung) }\end{array}$ \\
\hline & $\begin{array}{l}\text { (d) technische Zeichnungen aufgrund der Einbettung in } \\
\text { das Koordinatenraster kardinal-deiktisch; Normdarstel- } \\
\text { lungen gleichzeitig intrinsische oder deiktische Per- } \\
\text { spektive auf Gegenstand }\end{array}$ \\
\hline & $\begin{array}{l}\text { (e) Realisation durch Sprache, ikonisch-materielle Bil- } \\
\text { der, technische Zeichnungen und Ziffern }\end{array}$ \\
\hline $\begin{array}{l}\text { Mittel horizontaler } \\
\text { Themenstruktur }\end{array}$ & $\begin{array}{l}\text { Realisation von (a) und (b) durch Bild und Sprache } \\
\text { oder: }\end{array}$ \\
\hline & $\begin{array}{l}\text { (a) Semantisch-strukturell: Rekurrenz, Ko-Referenz, } \\
\text { partielle Synonymie, Mittel der Raumdeixis; ontologi- } \\
\text { sche/logisch-begriffliche/kulturelle implizite Wieder- } \\
\text { aufnahme; Isotopie }\end{array}$ \\
\hline & $\begin{array}{l}\text { (b) Grammatisch-strukturell: anaphorische Verweise, } \\
\text { kataphorische Verweise, pronominale Hinweise/Profor- } \\
\text { men, Enumeration }\end{array}$ \\
\hline & $\begin{array}{l}\text { (c) Satzwertige Ellipsen als Phänomen der Schwund- } \\
\text { grammatik }{ }^{164} \text { : Genitivattribute, Präpositionalgruppen, } \\
\text { attributive und prädikative Adjektivverwendung, Nomi- } \\
\text { nalisierungen etc. }\end{array}$ \\
\hline $\begin{array}{l}\text { Mittel vertikal-mo- } \\
\text { dularisierter The- } \\
\text { menmatrix }\end{array}$ & $\begin{array}{l}\text { Funktionale Perspektive auf Text(-sub-)themen: Konsti- } \\
\text { tution durch (nicht-physikalische) Objekte/Gegen- } \\
\text { stände: (a) statisch (Zustände, Gegenstände, Personen), } \\
\text { (b) dynamisch (Vorgänge) }\end{array}$ \\
\hline
\end{tabular}

164 Diese betrifft Sprache-Bild-Relationen, die die Kohärenz- und die Kohäsionsebene betreffen (s. Kapitel 3.4). Aufgrund der Darstellung sind sie unter der Wortebene der Themenstruktur zusammengefasst. 


\begin{tabular}{|l|l|}
\hline $\begin{array}{l}\text { Modularisierte } \\
\text { Themenentfaltung }\end{array}$ & $\begin{array}{l}\text { (a) argumentativ: für Strittiges (b) deskriptiv: für Ge- } \\
\text { genstand, Objekt (c) explikativ: Erklärbarkeit (d) narra- } \\
\text { tiv: Erzählbarkeit }\end{array}$ \\
\hline $\begin{array}{l}\text { Hinweise für die } \\
\text { Analyse }\end{array}$ & $\begin{array}{l}\text { Argumentative und deskriptive Themenentfaltung im } \\
\text { Korpus }\end{array}$ \\
\hline
\end{tabular}

Tabelle 3-2: Zusammenfassung zur Analysekategorie ,Themenstruktur' (eigene Darstellung).

\subsection{Logisch-semantische Sprache-Bild-Relationen}

Im Zentrum von STÖCKLs (2016) multimodalem Textanalyseraster stehen Relationen zwischen den Zeichenmodalitäten, die der Text enthält, und den Funktionen, die durch sie realisiert werden:

„Im Kern einer multimodalen Textsortenanalyse muss die Frage stehen, wie die beteiligten Zeichenmodalitäten verknüpft sind. Darauf geben Themen- und Handlungsstruktur nur zum Teil eine Antwort. Der genaue Blick auf die Bezüge zwischen den Modalitäten erhellt, welche Elemente sich in welcher Weise kohäsiv oder kohärent zueinander verhalten und welche pragmatischen oder rhetorischen Funktionen die Modalitäten in wechselseitiger Bezogenheit füreinander übernehmen." (STÖCKL, 2016, S. 23; Fettdruck AH)

Kohärenz bzw. Kohäsion wird demnach durch die Themen- und Funktionsstruktur, aber auch durch die Bezüge zwischen den Modalitäten erzeugt. ${ }^{165}$ Im Rahmen dieses Analyserasters werden Textdesign (Kapitel 3.1) als überwiegend ${ }^{166}$ Kohäsionsmittel, dagegen logisch-semantisch Sprache-Bild-Relationen als Teil von Kohärenzmittel behandelt. STÖCKL (2016) stellt auch für diese Analysekategorie keine Systematik an Unterkategorien zur Verfügung, sodass diese hier entwickelt wird. In der folgenden Hinführung werden weitere Konzepte angerissen, die die Kohärenz-Ebene betreffen, bevor der Kern dieser Analysekategorie, die logischsemantischen Sprache-Bild-Relationen, differenziert wird.

Das Konzept der Gutter bzw. Panels (s. Kapitel 3.1.2) lässt sich ebenfalls als Mittel der Kohärenz heranziehen, insbesondere für die Beschreibung von SpracheBild-Relationen in Formularen. Es eignet sich, um Bilder und Tabellen in

Kohärenz und Kohäsion von Sprache-Bild-Textsorten behandelt ausführlich Kapitel 2.3.

Salienz als zentrales Kriterium von Textdesign beziehen KRESS/VAN LEEUWEN (2006) auch auf kulturelle Aspekte (s. Kapitel 3.1), die sich auf kohäsive Ausdrucksmittel beziehen, aber mit Kohärenz einhergehen. 
Pflichtenheften zu erfassen, die durch Linien und Leerräume von anderen Bildern und Tabellen bzw. dem weißen Hintergrund abgegrenzt werden und meist eine Sinneinheit bilden. Semantisch werden Panels als Einheiten des Zeichensystems Comic behandelt, die Bild und Text denselben Raum zuweisen (MÄLzER, 2015, S. 50) und deren Verknüpfung durch Rezipienten als kohärenzstiftend aufgefasst werden. ${ }^{167}$ Die Verknüpfung zwischen Panels lässt sich aber auch durch logischsemantische Sprache-Bild-Relationen nach VAN LEEUWEN (2005a) und dessen Variationen beschreiben.

Als Teil dieser Relationen wird auch die Konkurrenz von Sprache und Bild erfasst (Unsworth, 2007, S. 1177 f.). Auch wenn das Konzept der Schwundgrammatik (SCHMITZ, 2017) nicht als logisch-semantisches Konkurrenz-Verhältnis zwischen Sprache und Bild verstanden wird, streift es diesen Themenbereich, sodass es an dieser Stelle kurz ausgeführt wird. Denn es ist für die Beschreibung von Pflichtenheften relevant, wie die erste Analyse gezeigt hat. Das Konzept der Schwundgrammatik fußt auf FrIES' (1987) Konzept der Randgrammatik und bezieht dieses auf multimodale Texte. Exemplarische Analysen von Sprache-Bild-Texten zeigen, dass die ,hochgradige Bindung an bestimmte Situations- und Text-Spezifika (außerhalb der visuellen Kontexte blieben sämtliche Texte in beiden Beispielen sinnlos oder unverständlich)“ (SCHMITZ, 2017, S. 12) für die sprachlichen Elemente der Sprache-Bild-Texte besteht. Grundsätzlich stellt er Folgendes fest: „Je mehr die visuellen Gestaltungsmittel semiotische Ordnung schaffen, desto weniger bleibt für die herkömmlichen Textordnungsmittel zu tun, insbesondere für Grammatik." (SCHMITZ, 2017, S. 13) Diese Feststellung macht es notwendig, für Sprache-Bild-Texte Konzepte zu visueller Kommunikation und Randgrammatik zu verquicken. Im Anschluss daran entwickelt SCHMITZ (2017) das Konzept der

167 In Anlehnung an die ,linguistischen Kategorien Syntax, Deixis und Semantik“ (MÄLzER, 2015, S. 56 ff.) entstehen eine räumlich-syntaktische, eine deiktische und eine logisch-semantische Ebene.

Panelsequenzen können als Bild-Text-Beziehungen in Form der folgenden Gutter-Relationen (MCCLOUD, 1993, S. 74) systematisiert werden, die für Pflichtenhefte relevant sind: Handlung zu Handlung (Action-to-Action), Gegenstand zu Gegenstand (Subject-to-Subject), Themenaspekt zu Themenaspekt (Aspect-to-Aspect) und unlogische Folge (Non-Sequitur). Die weiteren Relationen ,Moment-to-Moment ${ }^{\star}$ und ,Scene-to-Scene' sind als Teile narrativer Themenentfaltungsmuster für Pflichtenhefte kaum relevant (s. Kapitel 3.3.3). 
Schwundgrammatik. Dieses zeichnet aus, dass ,gestaltete Beziehungen zwischen Wortlaut und visueller Erscheinung semiotische Ordnung schaffen, um Verständnis zu sichern“ (ebd., S. 14). Als Ausdruck kommunikativer Effizienz nehmen schriftsprachlich-grammatische Formen zugunsten von visuell-designbasierten ab (ebd.). Für Pflichtenhefte wird dies bei elliptischen Konstruktionen von sprachlichen Elementen relevant, deren Bedeutung als Frage oder Antwort sich erst durch deren Positionierung in Formularfeldern ergibt (s. Kapitel 5.2.1).

Im Gegensatz zum Konzept der Schwundgrammatik zielen Konzepte zu logischsemantischen Sprache-Bild-Relationen auf eine Systematisierung dieser Verknüpfungen zwischen den Modalitäten, die im Folgenden diskutiert werden, um mein Analyseraster zu entwickeln. Dabei werden die Systematiken logisch-semantischer Sprache-Bild-Relationen (image-word relations) in UNSWORTH (2007), Martin/Rose (2008), Martinec/SAlway (2005) und VAN LEEUWEN (2005a) gegenübergestellt.

Am Beispiel der Textseite zum Mulgabusch-Hinterland (mulga plains) demonstrieren MARTIN/RosE (2008) die vier logisch-semantischen Sprache-Bild-Bezüge ,Elaboration“ (elaboration) durch Veranschaulichung oder Kommentierung, ,Erweiterung' (extension) um Ausnahmen oder Alternativen, ,Verbesserung' (enhancing) um Zeit, Ort, Grund oder Bedingung und ,Projektion“ (projection) als Lokution oder Vorstellung. Diese vier Kategorien eignen sich bereits für eine Analyse, werden aber differenzierter in UNSWORTH (2007, S. 1175) behandelt (s. Abbildung 3-8). 


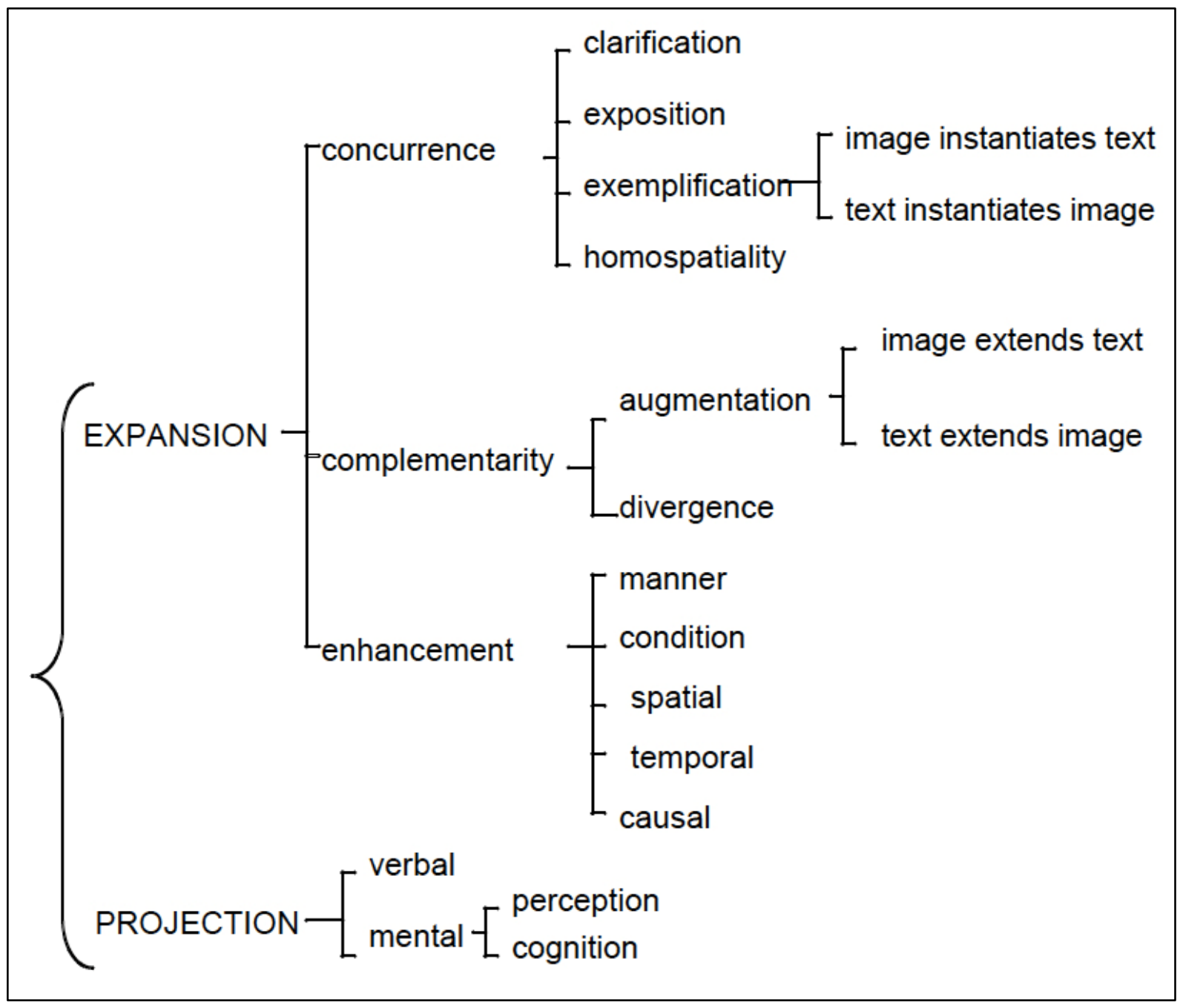

Abbildung 3-8: Towards a framework of image-language relations in the construction of ideational meaning (UNSWORTH, 2007, S. 1175).

Für die übergeordnete Ebene in UNSWORTH (2007) sind aus VAN LEEUWEN (2005a, S. 230; s. Abbildung 3-9) nicht nur die Kategorien ,Erweiterung'(extension) und ,Elaboration“ (elaboration) als gleichgeordnete Oberkategorie relevant, die auch MARTIN/Rose (2008, S. 34; S. 178 f.) verwenden. Die beiden Kategorien ,Verbesserung' (enhancing) und ,Projektion“ (projection) aus UnsworTh (2007; s. Abbildung 3-9) ergänzen unter anderem die Systematik in VAN LEEUWEN (2005a).

Für den Vergleich mit UNSWORTH (2007) sind vor allem die Relationen-Kategorien der mittleren Ebene in VAN LEEUWEN (2005a, S. 230; s. Abbildung 3-9) relevant: ,Komplement' (complement), ,Kontrast' (contrast) und ,Similarität' (similarity). In UNSWORTH (2007) vereint die Kategorie ,Konkurrenz' (concurrence) VAN LEEUWENs Kategorien ,Kontrast“ und ,Similarität‘ : „Concurrence referred to 
ideational equivalence between image and text." (UnSwORTH, 2007, S. 1175) Die Kategorie ,Komplementarität" (complementarity) aus UNSWORTH (2007) erscheint mit der gleichnamigen Kategorie in VAN LEEUWEN (2005a, S. 230) vergleichbar.

\begin{tabular}{|l|l|l|}
\hline Image-text relations & $\begin{array}{l}\text { The image makes the text more specific (illustration) } \\
\text { The text makes the image more specific (anchorage) } \\
\text { The text paraphrases the image (or vice versa) }\end{array}$ \\
\hline Extension & Specification & Similarity \\
& Contrast & The content of the text is similar to that of the image \\
Complement & $\begin{array}{l}\text { The content of the text contrasts with that of the image } \\
\text { that of the text, and vice versa ('relay') }\end{array}$ \\
\hline
\end{tabular}

Abbildung 3-9: Overview of visual-verbal linking (VAN LEEUWEN, 2005a, S. 230).

Im Folgenden werden Unterkategorien der vier Systematiken aus UNSWORTH (2007), Martin/Rose (2008), Martinec/SALWAy (2005) und VAN LEeUwen (2005a) diskutiert, die sich auf der obersten Konzeptebene nach den Kategorien ,Konkurrenz', ,Erweiterung', ,Komplementarität‘, ,Verbesserung' und ,Elaboration' gliedern.

\subsubsection{Konkurrenz (concurrence)}

Die Konkurrenz-Unterkategorie ,Exposition“ verwendet UNSwORTH (2007, S. 1177) in Anlehnung an Martinec/Salway (2005, S. 362) als Sprache-BildRelation, die zwischen Bildern und ihren Betitelungen (caption) besteht. D. h., diese Kategorie bezieht sich auf ein strukturelles und nicht auf ein logisch-semantisches Merkmal von Sprache-Bild-Relationen. Die Unterkategorie ,räumliche Koinzidenz' wird als Zusammenspiel unterschiedlicher Zeichenmodalitäten in einer räumlichen Position (two different semiotic modes cooccur in one spatially bonded homogenous entity) dargestellt. Somit handelt es sich bei ,Exposition“ und ,räumliche Koinzidenz' um formal-strukturelle, nicht um semantische Merkmale. Diese sind in meinem Analyseraster dem Textdesign zuzuordnen und als logischsemantische Relationen ungeeignet. 
Die Konkurrenz-Unterkategorie ,Verdeutlichung' (clarification) wird nur sehr kurz als präzisierende Erklärung (be precise since image explains text) eines schriftsprachlichen Textes durch ein Bild paraphrasiert (UNSWORTH, 2007, S. 1175) bzw. durch ein Beispiel mit derselben Paraphrasierung veranschaulicht (ebd., S. 1177). Nicht nachvollziehbar ist erstens, warum ,Verdeutlichung' nicht unter die Kategorie ,Komplementarität', sondern unter die Kategorie ,Konkurrenz' geordnet ist: So kann die Erklärung eines Bildes durch Text auch als ,Augmentation“ verstanden werden. Zweitens lässt sich das Beispiel auch als ,Augmentation" analysieren, da die Nominalphrase ,aus einer PET-Flasche konstruierte Fliegenfalle" (fly traps constructed by old PET drink containers; ebd., S. 1177) durch ein Bild lediglich präzisiert wird, aber auch ohne das Bild nachvollziehbar ist. Demnach kann die Unterkategorie ,Verdeutlichung' UnSWORTHs (2007) Komplementaritäts-Unterkategorie ,Augmentation` ersetzen.

\subsubsection{Erweiterung (extension)}

Die Konkurrenz-Unterkategorie ,Veranschaulichung' (exemplification) subsumiert auf der untersten Konzeptebene ,Präzisierung ( dern durch Sprache als auch von Sprache durch Bilder. Gegenüber der Systematik in VAN LEEUWEN (2005a), die überwiegend von Sprache bzw. (schriftsprachlichem) Text ausgeht, ist die Systematik in UNSWORTH (2007) damit weniger logozentrisch. Die Kategorie ,Exemplifikation“ wird aus MARTINEC/SALWAY (2005, o. S. nach UNSWORTH, 2007, S. 1181) ohne weitere Beschreibungen entlehnt. ,Veranschaulichung' (exemplification) ist insoweit mit der getilgten Oberkategorie ,Elaboration“ (elaboration) aus VAN LEEUWEN (2005a) vergleichbar, als diese ,Veranschaulichung' und ,Kommentierung' umfasst. UnSwORTHs (2007) Konkurrenz-Unterkategorie, Veranschaulichung' (exemplification) durch VAN LEEUWENs (2005a) Oberkategorie ,Elaboration“ (elaboration) zu ersetzen, vereinfacht daher mein Analyseraster. Denn die Veranschaulichung von Inhalten schriftsprachlicher Elemente durch ikonisch-materielle Bilder oder umgekehrt kann als Similaritäts- oder Konkurrenzverhältnis charakterisiert werden (s. Abbildung 3-10). 


\subsubsection{Komplementarität (complement)}

Des Weiteren subsumiert UnSWORTH (2007, S. 1176) unter ,Komplementarität‘ als Unterkategorien ,Augmentation“ (augmentation) und ,Divergenz' (divergence). Dabei beschreibt ,Augmentation‘ (ebd., S. 1185) die konsistente Ergänzung von Bedeutungen, die Elemente einer Zeichenmodalität repräsentieren, durch Bedeutungen, die Elemente einer anderen Modalität realisieren (mode provides meanings additional to and consistent with those provided in the other mode). ,Divergenz' bezeichnet dagegen die ,Variation“ (variance) eines Bildinhalts durch versprachlichten Inhalt bzw. analog ,as 'parallel combinations' where 'words and pictures seem to follow very different courses - without intersecting' (McCloud, 1994:154)“" (UNSWORTH, 2007, S. 1190). ,Augmentation“ wird durch zwei Unterkategorien ausdifferenziert, die zum einen die Perspektive der Schriftsprache und zum anderen die Perspektive Bildmodalität berücksichtigen (s. Abbildung 3-8). Sämtliche Analysekategorien logisch-semantischer Sprache-Bild-Relationen können aus der Perspektive eines Bild- und auch der eines Schriftelement beschrieben werden. Daher werden diese Unterkategorien zu ,Augmentation“ nicht in das Analyseraster aufgenommen (s. Abbildung 3-10).

\subsubsection{Verbesserung (enhancement)}

Besonders elaboriert und relevant für die Analyse ist die Kategorie ,Verbesserung' (enhancement), weil sie es ermöglicht, auf die Hilfsfragen von Sachtexten wie Nachrichtentexten ${ }^{168} \mathrm{zu}$ antworten, zu denen die Texte des Korpus gehören: Aus Martinec/Salway (2005, S. 353 ff.) übernimmt Unsworth (2007, S. 1194 ff.) die Unterkategorien ,Zeit' (time), ,Raum‘ (place) und ,Grund“ (cause), die auch MARTin/Rose (2008, S. 34) ausdifferenzieren. Lediglich die Unterkategorie ,Grund' findet sich in modifizierter Form als , Grund oder Bedingung' (cause or condition) in MARTin/Rose (2008, S. 34). UnSworth (2007, S. 1194) führt dagegen ,Bedingung' (condition) als separate Unterkategorie neben ,Grund' (cause) auf, die MARTINEC/SALWAY (2005, S. 353) als ,Grund/Intention‘ (reason/purpose) bezeichnen. UNSWORTH (2007, S. 1175) ergänzt die

168 Diese Fragen lauten: Wann? (Zeit), Wo? (Ort), Warum? (Grund), Wie? (Art und Weise) und Wodurch bedingt? (Bedingung). 
Systematik aus Martinec/Salway (2005, S. 353 ff.) des Weiteren um die Unterkategorie ,Art und Weise' (manner/means) (s. Abbildung 3-8).

MARTINEC/SALWAY (2005) veranschaulichen drei Unterkategorien der, Verbesserung' (enhancement) am multimodalen Beispiel einer Flughafenzeichnung, unter der die schriftsprachlich repräsentierte Aussage zur Ankunft einer Passagierin angeordnet ist. Daraus leiten MARTINEC/SALWAY (2005) ab, dass durch die Unterkategorie ,verbesserte Ortsangabe“ (enhancement of place) ein Bild den ideationalen Gehalt (ideational content) der Ortsangabe von schriftsprachlichen Elementen präzisiert (ebd., S. 353). Dies kann analog auch Schriftsprache für ein Bild leisten. Die Zeitangabe als Teil der schriftsprachlichen Repräsentation situiert den Inhalt des Bilds zeitlich, was als Beispiel für die Unterkategorie, verbesserte Zeitangabe' (enhancement of time) dient (ebd.). An einem zweiten Beispiel wird die Unterkategorie, verbesserte Angabe des Grundes' (enhancement of reason/purpose) veranschaulicht (ebd., S. 354): Eine Zeichnung repräsentiert Leichensäcke in einer Halle. Die darunter angeordneten schriftsprachlichen Elemente repräsentieren den ideatischen Gehalt, dass ein Feuer durch einen Kurzschluss entstanden sei. Somit wird bei der Kategorie, verbesserte Angabe des Grundes' der Inhalt des Bildes als Folge des ideatischen Gehalts der schriftsprachlichen Repräsentation konzipiert.

Die Unterkategorie Bedingung (condition) exemplifiziert UNSWORTH (2007) durch das Beispiel eines schriftsprachlichen Textes, der Bewegung gegenüber Unbewegtheit in Bezug auf die Wahrnehmung von Farben und Formen thematisiert. Dies stellt die Bedingung dar. Dagegen gibt das ikonisch-materielle Bild mithilfe des visuellen Mittels der Unschärfe die Bewegung eines Kinderkarussells wieder. Dies stellt die Auswirkung dar (ebd., S. 1195). Die Unterkategorie Art und Weise (manner/means) wird am Beispiel eines populärwissenschaftlichen Zeitschriftenartikels veranschaulicht, in dem die schriftsprachliche Beschreibung einer Methode zur DNA-Modifikation durch eine Schemazeichnung präzisiert wird (ebd., S. 1195 f.).

Ich greife die Relationen-Kategorien, verbesserte Angabe von Zeit, Ort bzw. Grund' entsprechend MartineC/SALWAy (2005) und Martin/Rose (2008) ebenso auf wie die Differenzierung zwischen den Unterkategorien ,Grund' und ,Bedingung' sowie die Unterkategorie ,Art und Weise' entsprechend UNSWORTH 
(2007). Denn dadurch lassen sich die logisch-semantischen Sprache-Bild-Relationen der Unterkategorie ,Verbesserung' als Antworten auf die Fragen Wann? (Zeit), Wo? (Ort), Warum? (Grund), Wie? (Art und Weise) und Wodurch bedingt? (Bedingung) differenzieren (s. Abbildung 3-10).

\subsubsection{Elaboration (elaboration)}

Auf der zweiten Ebene zur Oberkategorie ,Expansion“ (expansion) wird - wie die erste empirische Analyse zeigte - die Unterkategorie Elaboration (VAN LEEUWEN, 2005a) relevant. In der Diskussion von UnsworThs (2007) Kategorie ,Konkurrenz' tilgte ich deren Unterkategorie ,Exemplifikation` zugunsten von VAN LEEUWENs (2005a) Kategorie ,Elaboration‘. Zu dieser zählen die Unterkategorien ,Exemplifikation“ (exemplification), ,Veranschaulichung' durch ein Bild (illustration) oder durch den schriftsprachlichen Text (anchorage). In keiner der vier Systematiken, die sich teilweise auf HALLIDAY (2004, S. 220) beziehen, findet sich dessen Unterkategorie ,Kommentierung (commenting). In der empirischen Analyse werde ich entsprechend der Modifikation der Systematik aus UNSWORTH (2007) die Unterkategorie ,Exemplifikation“ aufgreifen und als weitere Unterkategorie ,Kommentierung' prüfen (s. Abbildung 3-10):

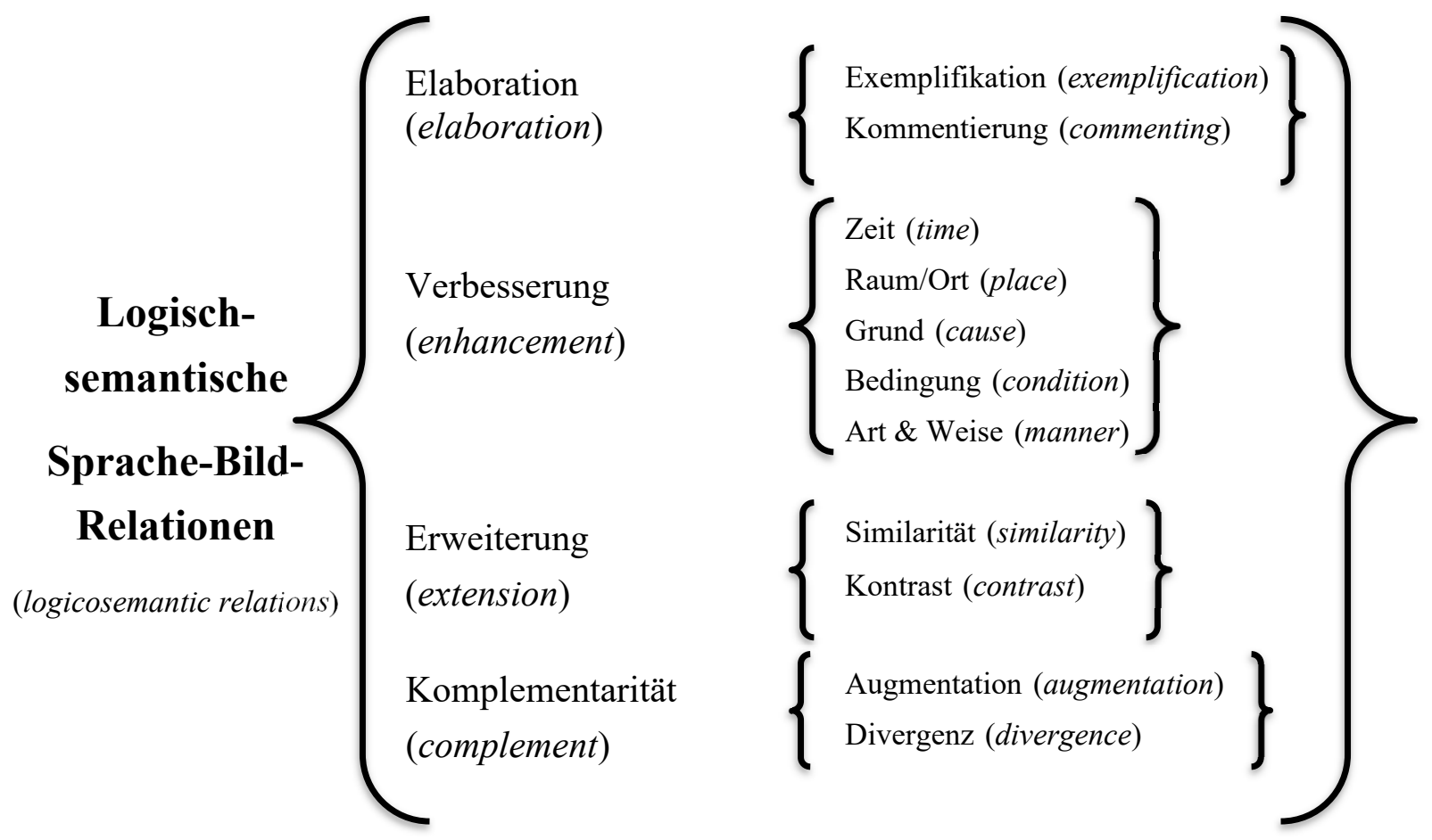

Abbildung 3-10: Zusammenfassung zur Analysekategorie ,Logisch-semantische Sprache-Bild-Relationen' 


\subsection{Intertextualität: Verfahrensbedingte Textsortennetze}

StÖcKL (2016, S. 25) fasst in der Dimension ,Intertextualität‘ explizite Bezüge auf andere Texte und implizite Bezüge durch gestalterische Ähnlichkeiten zwischen Texten zusammen. Die zu untersuchende Ausschreibungskommunikation ist in ihrem Ablauf und der Wahl der Textsorten durch Verordnungen streng festgelegt. Das Modell funktionaler Text-Text-Relationen entwickelt KLEIN (2014a) für die Beschreibung von verfahrensbedingten, statischen Verfahren, sodass es im Folgenden herangezogen werden kann, um Intertextualität in Ausschreibungsverfahren darzustellen. KLEIN (2014a) beschreibt den Interaktionsrahmen Gesetzgebung als verfahrensgeregelte Abfolge von Handlungen bzw. als verfahrensbestimmte Text-Text-Relationen, d.h. als Abfolge von Textexemplaren unterschiedlicher Textsorten, die aus den verfahrensbedingten Handlungen resultieren. Dieses Modell wird als Alternative zu Fachtextsortentypologien konzipiert, denen folgende Nachteile angelastet werden:

„Dabei können die Ergebnisse [zu Fachtextklassifikationen und Texttypologien; AH] bisher aufgrund der Mehrdimensionalität von Texten, d. h. aufgrund der Überschneidungen von Textformen und Textfunktionen ebensowenig eindeutige Abgrenzungskriterien und Zuordnungsmöglichkeiten für das konkrete Textexemplar anbieten wie die altbekannten Modelle zur Sprachtypologie, wie z. B. die mehrstufige, pragmatische Texttypologie von Gläser (1993) zeigt.“ (FLUCK, 1996, S. 250; Kursive im Original)

Dieses Problem versucht das Modell der Text-Text-Relationen (KLEIN, ${ }^{2} 2014 \mathrm{a}$ ) zu lösen, indem es ,funktionale intertextuelle Zusammenhänge vor und unabhängig von wissenschaftlicher Analyse“ (KLEIN, ${ }^{2} 2014 a$ a, S. 339) zu beschreiben versucht, also den wissenschaftlichen Fokus der Aggregation zu Typologien verwirft. Folgende Argumente werden für den Ansatz aufgeführt, Textentitäten als Textsortennetze zu erforschen:

„Welchen Nutzen hat nun diese Betrachtung von Textsortennetzen? Zunächst ist natürlich an einen theoretischen Wert zu denken, insofern man Konsens darüber erzielen kann, dass solche Beziehungen zwischen Textsorten zu einer angemessenen Sicht auf das Universum der Texte verhelfen und dabei insbesondere Beteiligtenperspektive und dem Textsortenwissen besser gerecht werden, als taxonomische Ansätze das leisten können.“ (ADAMZIK, 2011, S. 380)

Ausschreibungsverfahren als Textsortennetz zu erfassen, hat somit den Vorteil, das Textwissen als Teil der Kapazität von Kommunikanten (s. Kapitel 2.2) zu erfassen. Insbesondere der Berücksichtigung der Beteiligtenperspektive wird meine 
Arbeit durch die teilnehmenden Beobachtungen von Textüberarbeitungen durch die Experten des Bieters und durch Interviews mit ihnen sowie den Auftraggebern gerecht. Auch JANICH (2009), die in ihr Modell der Textvernetzung ebenfalls KLEIN (2014a) einbezieht, fordert „die möglichst empirisch gestützte, stärkere Einbeziehung der Kommunikanten [...] zum untersuchten Textsorten-Netz (z.B. durch Befragung und/oder teilnehmende Beobachtung)“ (ebd., S. 24).

OSTAPENKO (2009) adaptiert KLEINs ( $\left.{ }^{2} 2014\right)$ Vernetzungskonzept und modelliert dabei die zweifache Fachsprachlichkeit (s. Kapitel 2) der Domänen des Rechts und der Technik (OstapenKo, 2009, S. 236 f.). Im Folgenden werden die für meine Untersuchung relevanten Analysekategorien KLEINs ( $\left.{ }^{2} 2014 \mathrm{a}\right)$ und OsTAPENKOs (2009) dargestellt. ${ }^{169}$

\subsubsection{Text-Text-Relationen in Gesetzgebungsverfahren vs. Wissens- bearbeitung in verwaltungsinstitutionsspezifischen Verfahren}

KLEIN ('2014a, S. 341) hebt hervor, dass ein Gesetzestext während des Verfahrens nicht vollendet ist, sondern sich in Überarbeitung befindet. Auf diesen Gesetzestext beziehen sich alle Verfahrenshandlungen, die ,überwiegend selbst Textcharakter“ (ebd.) haben oder in Texten resultieren. Zum einen beschreibt er „TextText-Relationen zum Gesetzestext g“ (ebd.), zum anderen Relationen zwischen Texten und Verfahrensschritten (ebd.).

Die dazugehörige Tabelle „Texte, Textsorten, Relationen und Textkomplexe im Gesetzgebungsverfahren“ (ebd., S. 343 ff.) zeigt die Relationen zwischen dem jeweiligen Textexemplar und dem vom Verfahren angestrebten Gesetzestext $(t, g)$, die OSTAPENKO (2009) und meine Arbeit (Tabelle 4-3) aufgreifen: konstituierend (KNST), Stellung nehmend (STN), über das Gesetz informierend (INF), Informationen erfragend (FRA), Geltung verleihend (GELT), referierend (REF). Davon getrennt sind die Relationen zwischen dem jeweiligen Textexemplar und Verfahrensschritten $(t, v)$ erfasst: über das Verfahren informierend (INF), das Verfahren prozedierend (PROZ), regelnd (REG), durch strategische Überlegungen

169 Die Adaption von KLEIN ( $\left.{ }^{2} 2014 a\right)$ in DiATLOVA (2003) ist auf Unternehmenskommunikation als Wirtschaftskommunikation ausgerichtet, aber nur bedingt für die Beschreibung von Ausschreibungskommunikation geeignet. 
kommentierend (STR). Das jeweilige Exemplar steht mindestens in einer der angegebenen Relationen zum Gesetzestext oder zum Verfahren.

Drei Aspekte ergeben sich aus der Beschäftigung mit dem Text-Text-RelationenModell, die auch für meine Untersuchung relevant sind: erstens das Verhältnis zwischen Textexemplar und Textsorte, zweitens die Art der Relation zwischen den Textsorten und drittens die Relationen zwischen Texten und dem Verfahren.

Das Verhältnis zwischen Textexemplar und der Textsorte, zu der das Exemplar gehört, thematisiert KLEIN (2014a) nicht, unterscheidet diese aber in der Systematik. KLEIN (2007, S. 34) unterscheidet in der Wiedergabe seines Modells zum Gesetzgebungsverfahren aus KLEIN ( $\left.{ }^{2} 2014 a\right)$ explizit die Ebene der Textexemplare als Intertextualität (Text-Text-Relationen) von der Ebene der Textsorten als Textsorten-Intertextualität. Er differenziert diese beiden Bezugsebenen im Modell aber nicht weiter. KLEIN spricht sich dafür aus, neben Forschungsansätzen, die Zusammenhänge zwischen Textsorten vergleichend oder subsumierend „in der wissenschaftlichen Analyse [zu] konstituieren“(22014a, S. 339), „funktionale Zusammenhänge vor und unabhängig von wissenschaftlicher Analyse“ (ebd.) zu betrachten, beispielsweise den Zusammenhang zwischen Gesetzentwurf und Ausschussbericht. Wesentlich für die Untersuchung dieser Textsortenverknüpfung KLEIN beschreibt diese am Beispiel von politischen Textsorten - ist die Berücksichtigung des sie einbettenden Interaktionsrahmens, der ,nicht identisch mit formalen Institutionsgrenzen“ (ebd., S. 340) ist, sondern „vielmehr gesetzt [wird] durch die politischen Hauptfunktionen, wie sie in der Verfassung skizziert und in der Verfassungswirklichkeit ausgeformt sind“ (ebd.). Bei der Übertragung dieses Konzepts zur Textsortenverknüpfung auf andere Bereiche besteht die Aufgabe, eine Entsprechung der dort geltenden Hauptfunktion zu finden.

Der Interaktionsrahmen ist durch das Verfahren geprägt, das die innere Struktur darstellt (KLEIN, 1991, S. 251) ${ }^{170}$ und durch ,[d]ie Anzahl möglicher Handlungen und deren Abfolge [...] durch Rechtsvorschriften geregelt“ (ebd.) ist. Das Verfahren zielt auf eine Gesetzesverabschiedung, daher ist KLEINs Konzeption zum

170 Lediglich diese Textstellen der ersten Auflage, KLEIN (1991), wurden aus der zweiten Auflage, KLEIN ( $\left.{ }^{2} 2014 a\right)$, gekürzt. Daher ziehe ich hier KLEIN (1991) heran. 
einen auf die Relationen von Textsorten zur Bezugstextsorte Gesetz bzw. zum entsprechenden in Transformation befindlichen Bezugs-text-Exemplar angelegt. Zum anderen fokussiert das Konzept Texte, die auf das Verfahren oder dessen Schritte Bezug nehmen (ebd., S. 252).

Hier schränkt KLEINs Konzeption die Übertragbarkeit des Modells auf Verfahren ein, die auf die Modifikation oder auf die Erstellung der Endversion eines Textexemplars abzielen bzw. eine Textsorte als Bezugspunkt aller Relationen annehmen. Einerseits impliziert KLEINs Definition von Verfahren als Abfolge der Textsorte eine syntagmatische Relation, die zwischen den Textsorten exklusive der Bezugstextsorte Gesetz besteht. Durch den Bezug aller weiteren Textsorten auf die Bezugstextsorte konzipiert KLEIN ( $\left.{ }^{2} 2014 a\right)$ die Relationen aller Textsorten des Verfahrens aber nicht als ausschließlich syntagmatische Relation, sondern als Nebeneinander von Textsortensyntagma und Textsortennetz, bei dem die Bezugstextsorte jede weitere Textsorte des Verfahrens relationiert.

Den Objektbereich von Verfahrensabläufen in öffentlicher Verwaltung systematisieren BECKER-MROTZEK/SCHERNER (2000) ebenfalls unter Berücksichtigung der ,Zweckbestimmtheit von Verwaltung, d. h. der funktionalen Einbettung in Institutionen“ (ebd., S. 634). Ausgangspunkt ihrer Verfahrenssystematik bildet die Annahme, dass für „Bearbeitungsschritte der Wissensbearbeitung je eigene Textsorten bereitstehen und dass sich die Teilzwecke in den Textstrukturen sowie den verwendeten sprachlichen Mitteln niederschlagen“ (ebd.). ${ }^{171}$ Diese Systematik betrachtet eher prototypische Textsorten der Bürger-Behörde-Kommunikation, aber keine Übergangstypen wie Patente oder Pflichtenhefte, auch wenn der Prozesscharakter wie in KLEIN ( ${ }^{2} 2014$ a) berücksichtigt ist. ${ }^{172}$

171 Sie nehmen vier Textsorten in folgender Verfahrensanordnung an (ebd., S. 631): 1. Texte mit regulierender Funktion, die den Handlungs- und Wissensrahmen vorgeben wie Verordnungen und Gesetze; 2. Texte mit wissenserhebender bzw. -vermittelnder Funktion zwischen Behörde und Klienten wie Anträge; 3. Texte mit wissensbearbeitender Funktion als verwaltungsinterne Kommunikation wie Verwaltungsakte und 4. Texte mit handlungsschließender Funktion wie Bescheide oder Erlaubnisse.

172 BusSE (2000) erstellt eine detaillierte Textsortentypologie zu Textsorten des Rechts und der Justiz. 


\subsubsection{Fachtextsortennetze in technisch-juristischen Harmonisierungsprozessen}

Nicht nur für den Bereich des Rechtswesens und der Behörden lässt sich die Relevanz von Textvernetzung und Verfahrensgebundenheit nachweisen, sondern auch im Bereich von technischen Ausschreibungen, bei denen der technische Anteil zumindest in der Untersuchungskonzeption überwiegt, lässt sich der Vernetzungsaspekt nachweisen. So hält POGNER (1999) zur ausschreibungsbedingten Projektarbeit, an der Techniker beteiligt sind, fest, dass Schreiben am Arbeitsplatz „ein Teil von umfassenden Kommunikationsketten oder -netzen“ (POGNER, 1999, S. 270) ist, die „durch mündliche und/oder schriftliche Kommunikation/Interaktion aus[gelöst]“ (ebd.) wird.

Nicht nur JANICH (2009) sieht in der Beschreibung von Textsortennetzen die Grundlage für Kommunikationsoptimierung für die Arbeit der Kommunikanten im Untersuchungsfeld, sondern auch OSTAPENKO (2009) ${ }^{173}$ gesteht dieser Beschreibung das Potential zu, ein unmittelbar einsetzbares Instrument für die Textarbeit der Kommunikanten im Feld zu sein:

„Anhand der Ermittlung des relationalen Status einer Textsorte im Netz können
wesentliche Auskünfte über die Funktion des Textes, seine fach(sprach)liche Spe-
zifik, die kulturelle Einbettung u.a. gewonnen werden. Diese Erkenntnisse können
ausschlaggebend bei der Produktion bzw. Rezeption von Texten sein. Somit gehört
das Wissen um das Textsortennetz einschließlich des Wissens um den Kommuni-
kationsrahmen, in dem das Textsortennetz situiert ist, zur notwendigen Kompeten-
zen [sic] bei der Auffassung und Herstellung von Texten. Diese Kompetenzen kön-
nen z.B. dazu dienen, Konflikte in den Kommunikationsabläufen zu vermeiden, sie
können darüber hinaus bei der Texterstellung oder Übersetzung vorteilhaft sein.“
(OSTAPENKO, 2009, S. 238)

OSTAPENKO systematisiert die Regelung der Harmonisierung im Bauwesen (s. Abbildung 3-11). Diese Systematik ist nach Zuständigkeiten der EU und des Bundes für Gesetzgebung unterteilt (2007, S. 40). Dabei differenziert sie den Kommunikationsrahmen in die folgenden drei Interaktionsfelder (OSTAPENKO, 2009, S. 233):

173 Der Artikel OstaPenKo (2009) fasst die Monographie OsTAPENKO (2007) pointiert zusammen und entwickelt diese zum Teil weiter. Auf die Monographie greife ich im Folgenden nur zurück, falls diese relevante Aspekte darstellt, die im kürzeren Artikel nicht enthalten sind. 
- Regelung der Handhabbarkeit von Bauprodukten (v1)

- Regelung der Brauchbarkeit von Bauprodukten (v2)

- Regelung der Verwendbarkeit von Bauprodukten (v3)

In Anschluss an eine Übersicht der funktionalen Relationen zwischen Textsorten sowie Textsorten und Verfahren im Bereich Harmonisierung des Bauwesens stellt OSTAPENKO (2007) in Bezug auf Relationen zwischen Interaktionsrahmen (s. o.: v1, v2, v3) fest:

\begin{abstract}
„Anzumerken ist, dass Relationen sowohl im Rahmen eines durch das jeweilige Verfahren determinierten Interaktionsfeldes (z.B. die Erstellung von Grundlagendokumenten wie in der Richtlinie gefordert (v1)) als auch zwischen den Interaktionsfeldern (z.B. die Erstellung von DIN EN-Normen wie durch EN-Normen bedingt (v1, v2)) möglich sind.“(ebd., S. 50)
\end{abstract}

Auf eine weitere Ausdifferenzierung dieser Relationen verzichtet OSTAPENKO (2009) ebenso wie KLEIN (2014a). Als funktionale Vernetzungsarten stellt OstAPENKo (2009, S. 233) als funktionale Relationen heraus, 1) jene zwischen Textsorten und 2) jene, ,die die Einbettung des Textes in das Verfahren kennzeichnen" (ebd.; Kursive im Original). Als referentielle Relationen beschreibt sie solche zwischen Textsorten (ebd.). Die Relationen gehen aus den „funktionalen Text-Text-Relationen und verfahrensbedingten Relationen hervor und lassen sich direkt im Text nachweisen“" (ebd., S. 234).

Die funktionalen Relationen zwischen Textsorten, die OSTAPENKO (2009, S. 233 f.) beschreibt, lassen sich von den Relationen KLEINs ( ${ }^{2} 2014 \mathrm{a}$ ) abgrenzen. Diese Kategorien der Textrelationen (s. Abbildung 3-11) fließen detailliert in die Beschreibung des Textsortennetzes in SPNV-Ausschreibungsverfahren ein (s. Tabelle 4-3). Daher werden OstAPENKOs Text-Text-Relationen im Folgenden ausführlich dargestellt:

- $\operatorname{Erst}(\mathrm{g}, \mathrm{t})$ : Gesetzestext fordert die Erstellung von Text $\mathrm{t}$ (Erweiterung zu KLEINs Schema)

- Gelt $\left(\mathrm{t}_{\mathrm{a}}, \mathrm{t}_{\mathrm{b}}\right)$ : Text $\mathrm{t}_{\mathrm{b}}$ verleiht $\mathrm{t}_{\mathrm{a}}$ Geltung (identisch mit KLEIN, $\left.{ }^{2} 2014 \mathrm{a}\right)$

- Präz (t, g): Text t präzisiert das in Gesetzestext g beschriebene Verfahren als Auslegung (KLEINs Kategorie ,Stellungnahme/STN` bezieht dagegen explizit Pro-/Kontra-Argumente ein) 
- Spe (t, g): Text t spezifiziert bestimmte Punkte in Gesetzestext $\mathrm{g}$ als detaillierte Bedeutungsbestimmung (KLEINs Kategorie ,Erfragen/FRAG` impliziert dagegen, dass eine Bedeutung nur bei Bedarf von entsprechend berechtigten Dialogpartnern durch Nachfragen bestimmt wird)

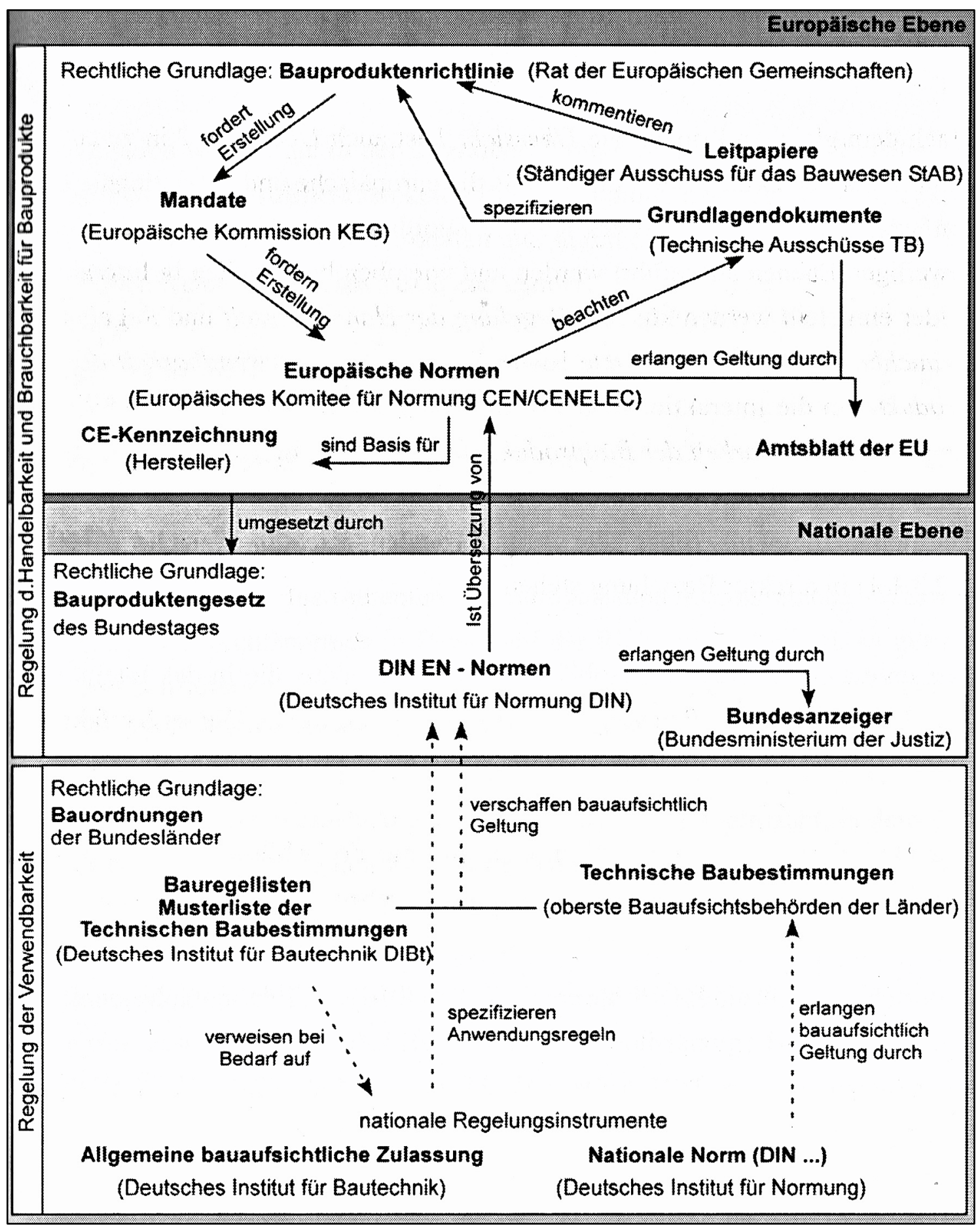

Abbildung 3-11: Textsortennetz im Kommunikationsrahmen ,Harmonisierung im Bereich des Bauwesens' (OSTAPENKO, 2009, S. 235). 
- Ums $\left(\mathrm{t}_{\mathrm{a}}, \mathrm{t}_{\mathrm{b}}\right)$ : Text $\mathrm{t}_{\mathrm{b}}$ ist die nationale Umsetzung von Text $\mathrm{t}_{\mathrm{a}}$ (Erweiterung zu KLEINs Schema, der nur nationales Recht berücksichtigt)

- Kennz $(\mathrm{t}, \mathrm{g})$ : Text $\mathrm{t}$ kennzeichnet, dass für Produkt X Gesetz $\mathrm{g}$ angewendet wird (Erweiterung zu KLEINs Schema, der keine Produkte einbezieht)

- $\operatorname{Erw}\left(\mathrm{t}_{\mathrm{a}}, \mathrm{t}_{\mathrm{b}}\right)$ : Text $\mathrm{t}_{\mathrm{a}}$ erweitert Text $\mathrm{t}_{\mathrm{b}}$, der im Verfahren als nicht ausreichend erscheint (vergleichbar mit KLEINs Kategorie ,Konstituent/KNST‘)

OSTAPENKO (2009, S. 234) $)^{174}$ unterscheidet folgende funktionale Relationen, die kennzeichnen, wie ein Text in das jeweilige Verfahren eingebunden ist:

- $\operatorname{Reg}(\mathrm{g}, \mathrm{v})$ : Ein (Gesetzes-)Text regelt und beschreibt das Verfahren (v)

- $\operatorname{Proz}(\mathrm{t}, \mathrm{v})$ : Ein Text leitet ein im Gesetzestext beschriebenes Verfahren ein bzw. dient dazu, es zu prozedieren

Referentielle Funktionen, die auf formaler Ebene erfassen, ob eine Textstelle explizit, implizit, vollständig oder teilweise auf ein anderes Textsortenexemplar verweist (ebd.), stelle ich nicht dar, weil meine Untersuchung die funktionalen Relationen zwischen den Textsortenexemplaren fokussiert.

Die beiden Modellierungen von KLEIN (2014a) zu Gesetzgebungsverfahren und von OSTAPENKO (2009) zu technisch-juristischen Harmonisierungsprozessen veranschaulichen die Systematik der funktionalen Relationierung von Texten durch ein Verfahren. Da diese Verfahren in juristisch-behördlichen Domänen durch Verordnungen und Gesetze, in technischen Bereichen durch Verfahrensnormen und in unternehmerischen Domänen durch Leitlinien bzw. Leitfäden als Verfahren auf einer Ebene der Performanz konventionalisiert bzw. normiert sind, werden diese beiden Modelle herangezogen (s. Kapitel 4.2.2).

Die bisher diskutierten Aspekte fasst im Folgenden Tabelle 3-3 zusammen:

174 Auch hier bezieht sie sich auf KLEIN (1991), der für Gesetzgebungsverfahen darüber hinaus Inf $(\mathrm{t}, \mathrm{v})$ als Informieren über ein Gesetz und $\operatorname{Str}(\mathrm{t}, \mathrm{v})$ als Einbezug strategischer Überlegungen aufführt (ebd., S. 252). 


\begin{tabular}{|c|c|}
\hline \multicolumn{2}{|c|}{ Zusammenfassung: Verfahrensbedingte Textsortenvernetzung } \\
\hline Text-Text-Relationen & $\begin{array}{l}\text { (a) Erst }(\mathrm{g}, \mathrm{t}) \text { : Gesetzestext fordert die Erstellung } \\
\text { von Text } \mathrm{t} \\
\text { (b) Gelt }\left(\mathrm{t}_{\mathrm{a}}, \mathrm{t}_{\mathrm{b}}\right) \text { : Text } \mathrm{t}_{\mathrm{b}} \text { verleiht Text } \mathrm{t}_{\mathrm{a}} \text { Geltung } \\
\text { (c) Präz }(\mathrm{t}, \mathrm{g}) \text { : Text } \mathrm{t} \text { präzisiert das in Gesetzestext } \mathrm{g} \\
\text { beschriebene Verfahren als Auslegung } \\
\text { (d) Spe }(\mathrm{t}, \mathrm{g}) \text { : Text } \mathrm{t} \text { spezifiziert bestimmte Punkte } \\
\text { in Gesetzestext } \mathrm{g} \text { als detaillierte Bedeutungsbestim- } \\
\text { mung } \\
\text { (e) } \operatorname{Ums}\left(\mathrm{t}_{\mathrm{a}}, \mathrm{t}_{\mathrm{b}}\right) \text { : Text } \mathrm{t}_{\mathrm{b}} \text { als nationale Umsetzung von } \\
\text { Text } \mathrm{t}_{\mathrm{a}} \\
\text { (f) } \operatorname{Kennz}(\mathrm{t}, \mathrm{g}) \text { : Text } \mathrm{t} \text { kennzeichnet, dass für Pro- } \\
\text { dukt X Gesetz } \mathrm{g} \text { angewandt wird } \\
\text { (g) Erw }\left(\mathrm{t}_{\mathrm{a}}, \mathrm{t}_{\mathrm{b}}\right) \text { : Text } \mathrm{t}_{\mathrm{a}} \text { erweitert Text } \mathrm{t}_{\mathrm{b}} \text {, der im Ver- } \\
\text { fahren als nicht ausreichend erscheint }\end{array}$ \\
\hline $\begin{array}{l}\text { Text-Verfahren-Relati- } \\
\text { onen }\end{array}$ & $\begin{array}{l}\text { (a) Reg (g, v): Ein (Gesetzes-)Text regelt und be- } \\
\text { schreibt das Verfahren v } \\
\text { (b) Proz }(\mathrm{t}, \mathrm{v}) \text { : Ein Text leitet ein im (Gesetzes- } \\
\text { )Text beschriebenes Verfahren v ein/dient dazu, es } \\
\text { zu prozedieren }\end{array}$ \\
\hline $\begin{array}{l}\text { Referentiell-formale } \\
\text { Relationen }\end{array}$ & $\begin{array}{l}\text { (a) implizite Definitionsübernahmen } \\
\text { (b) Verweis auf andere Gesamttexte (Nennung im } \\
\text { Text) } \\
\text { (c) Verweis auf andere Texte im Ganzen (mittels } \\
\text { Zeichen) }\end{array}$ \\
\hline
\end{tabular}

Tabelle 3-3: Zusammenfassung zur Analysekategorie ,Verfahrensbedingte Textvernetzung' (eigene Darstellung).

Die bisher dargestellten Kategorien des Textanalyserasters beziehen sich auf weitgehend auf Textinterna, deren Zusammenspiel mit Textexterna das folgende Teilkapitel beleuchtet. 


\subsection{Verknüpfungen zwischen Textgestaltung und Kontext}

Über die Gliederung meines Analyserasters nach den fünf Kategorien in STÖCKL (2016) geht dieses Teilkapitel zu typischen Verknüpfungen von Textgestaltung und Kontext hinaus. Die zugrundeliegende Konzeption dieser Verknüpfungen stellt bereits Kapitel 2.4 dar, das den Zusammenhang zwischen Handlungskontexten und Textmerkmalen als Verknüpfung zwischen Kontext und den fünf Textebenen (Textdesign, Funktions- und Themenstruktur, logisch-semantische Sprache-Bild-Relationen und funktionale Text-Text-Relationen) erfasst. Die Notwendigkeit, dieses Zusammenspiel zwischen Textebenen und Kontext zu untersuchen, um fachlichen Forschungsgegenständen gerecht zu werden, betont die Fachkommunikationsforschung bereits früh (HofFMANN, 1988, S. 125 f.). Ein Analyseraster interfachlicher Sprache-Bild-Textsorten, das diesen Zusammenhang ins Zentrum rückt, ermöglicht es demnach, fachliche Untersuchungsgegenstände zu untersuchen. Die Bedeutung, die der Zusammenhang zwischen kontextuellen und textuellen Kriterien für die Textanalyse hat, betonen HOFFMANN (1988) für die Fachkommunikationsforschung, BRINKER/CÖLFEN/PAPPERT ( ${ }^{9} 2018$, S. 140 ff.) für die Textlinguistik und STÖCKL (2016, S. 25) für eine multimodale Textlinguistik:

„In jedem Falle muss es darauf ankommen, das Zusammenspiel aller beteiligten Zeichenmodalitäten in der Struktur und Gestaltung des multimodalen Texts als Funktion von typischen Kontext- und Situationsfaktoren beschreiben und so zur Charakterisierung einer spezifischen multimodalen Textsorte gelangen zu können.“ (STÖCKL, 2016, S. 23)

Diese Vorgabe für das eigene Modell von STÖCKL (2016) verstehe ich als Entsprechung auf textueller Ebene zu den oben dargestellten Desiderata (s. Kapitel 3) von RoElCKe (2013) und SchMitz (2011a) aus einem soziosemiotischen Interesse heraus, die fachliche Spezifik semiotisch komplexer Kommunikate zu untersuchen.

Kapitel 3.1 bis Kapitel 3.5 stellen die Textinterna dar, Kapitel 2.5 die Textexterna wie Domäne, Organisation und Projekt. Folgende Übersicht fasst zusammen, zwischen welchen Textinterna und Textexterna ein Zusammenhang in der exemplarischen Analyse untersucht werden soll (Tabelle 3-4): 


\begin{tabular}{|c|c|}
\hline \multicolumn{2}{|c|}{$\begin{array}{l}\text { Zusammenfassung: } \\
\text { Typische Verknüpfungen von Textgestaltung und Kontext }\end{array}$} \\
\hline $\begin{array}{l}\text { Themenstruk- } \\
\text { tur }\end{array}$ & $\begin{array}{l}\text { (a) Verknüpfung gebündelter Fächer, Normen, Akteurs- } \\
\text { handlungen etc. einer Domäne mit dynamischem oder sta- } \\
\text { tischem Gegenstand/Objekt einer Textsorte } \\
\text { (b) Bestimmung der Textsortenkonventionen, insbeson- } \\
\text { dere des Textgegenstands und Themenentfaltungsmusters } \\
\text { durch Diskursgemeinschaft und vice versa } \\
\text { (c) Asymmetrie fachlichen Wissens zwischen Experten } \\
\text { entsprechend einem Teilgegenstand in Projekten oder } \\
\text { zwischen Organisationsvertretern und Externen } \\
\text { (d) Verknüpfung der soziotechnischen Aufgabe (Dedika- } \\
\text { tion) mit dem Textgegenstand } \\
\text { (e) Bestimmung der Position einer Textsorte im Textsor- } \\
\text { tennetz aufgrund des Textsortenthemas und vice versa }\end{array}$ \\
\hline $\begin{array}{l}\text { Funktions- } \\
\text { struktur }\end{array}$ & $\begin{array}{l}\text { (a) Domäne bestimmt die Illokutionsebenen } \\
\text { (d) Verknüpfung von Heterogenität der Projektmitglieder } \\
\text { entsprechend Projekt-, Abteilungs- oder Organisationsmit- } \\
\text { gliedschaft mit einer intendierten Textwirkung (beispiels- } \\
\text { weise Verwendung von Wörtern und Zeichnungen mit } \\
\text { großem Bedeutungsumfang zur Ausdehnung des Gel- } \\
\text { tungsumfangs eines Patents) } \\
\text { (e) Bestimmung der Position einer Textsorte im Textsor- } \\
\text { tennetz aufgrund der Textsortenfunktion und vice versa }\end{array}$ \\
\hline $\begin{array}{l}\text { Textdesign } \\
\text { und logisch- } \\
\text { semantische } \\
\text { Sprache-Bild- } \\
\text { Relationen }\end{array}$ & $\begin{array}{l}\text { (a) Asymmetrie in Bezug auf Wissen über verwendete } \\
\text { Zeichenmodalitäten je nach Fächerbeteiligung } \\
\text { (b) Repräsentation institutioneller Asymmetrie durch } \\
\text { Frage-Antwort-Positionierung (Textdesign) in der Kom- } \\
\text { munikationsform Formular }\end{array}$ \\
\hline
\end{tabular}

Tabelle 3-4: Zusammenfassung der Analysekategorie, Verknüpfung von Textinterna und Textexterna' (eigene Darstellung). 


\section{Datenerhebung, Korpus und Beschreibung des Forschungsfeldes}

Ausgangspunkt für meine Untersuchung bildet meine sechsmonatige Tätigkeit als Redakteur bei einem Eisenbahnverkehrsunternehmen (EVU) für Ausschreibungsverfahren im Schienenpersonennahverkehr (SPNV). Das EVU, das im Verfahren als Bieter auftritt, organisiert die Verfahrensteilnahme unternehmensintern als Projekt, an dem Mitarbeitende aus den Unternehmensbereichen Recht, Betriebsplanung, Schienenfahrzeugtechnik, Controlling und Marketing beteiligt sind. Die Aufgabe besteht darin, im Rahmen des Ausschreibungsverfahrens zuerst Texte getrennt nach Unternehmensbereichen zu verfassen und diese im Anschluss als interdisziplinäres Team zu überarbeiten. Adressaten der Texte sind die Auftraggeber der Ausschreibungen, die sogenannten Aufgabenträger.

Während der Tätigkeit hat sich mein Eindruck verstärkt, dass diese Fachkommunikation entgegen den Forderungen der Fachkommunikationsforschung weder exakt noch verständlich, präzise oder eineindeutig ist. Daraus ist die Vermutung entstanden, dass nur Fachrezipienten Texte nachvollziehen können, die durch Mitarbeiter unterschiedlicher Unternehmensbereiche mit unterschiedlicher fachlicher Ausbildung gemeinsam überarbeitet werden. Diese Fachrezipienten müssten über das Fachwissen aller beteiligten Bereiche verfügen. D. h., dass die Rezipienten sowohl über Wissen zur Gültigkeit juristischer Formulierungen als auch über die Kompetenz verfügen müssen, Berechnungen zu Motorleistungen nachvollziehen sowie technische Zeichnungen und Betriebsfahrpläne lesen zu können. Aus dieser Vermutung lässt sich folgendes Problem ableiten: Ein Projekt unter Beteiligung von Mitarbeitern unterschiedlicher Abteilungen läuft Gefahr, dass die Adressaten der Texte, die im Projekt gemeinsam produziert werden sollen, diese Texte nicht nachvollziehen können, da die Adressaten nicht über das Fach- und Code-Wissen aller beteiligten Bereiche verfügen.

Wie die Einleitung darstellt (s. Kapitel 1.1 und 1.2), leitete ich aus diesem Problem aus linguistischer Perspektive die Forschungsfrage ab, wie sich Interfachlichkeit auf die semiotische Effizienz von Sprache-Bild-Textsorten, insbesondere von Pflichtenheften, auswirkt. Bei der Auswahl der Konzepte, aber auch der Elemente 
aus diesen Konzepten spielten praktische Erfahrung und die Ergebnisse aus einer ersten Analyse des Materials eine wesentliche Rolle. Im Anschluss daran führte ich auf der Basis der Kenntnisse über geeignete Methoden Beobachtungen und Interviews durch. Des Weiteren erhob, selektierte und verarbeitete ich weiteres empirisches Material, vor allem Textsortenexemplare. Dieses gesamte Material soll in Kapitel 5 und 6 analysiert werden, um die Forschungsfrage zu beantworten und deren Ausformulierung durch die drei Thesen (s. Kapitel 2.1.3) zu prüfen. ${ }^{122}$ Als Antwort auf die Frage könnte aus der folgenden empirischen Analyse im Fazit (s. Kapitel 7.2) auf konzeptioneller Ebene hervorgehen, dass das Modell semiotischer Effizienz (s. Kapitel 2.5) bestätigt oder modifiziert wird. Die Empfehlungen (s. Kapitel 7.3), die sich aus der Analyse ableiten, könnten dazu dienen, die Auftraggeber und Bieter dabei zu unterstützen, das oben aufgezeigte Problem zu lösen, das sich im Forschungsfeld stellt. Zu diesen Empfehlungen gehören die Konzeption einer Datenbank und Überarbeitungsvorschläge für die Empfehlungen der BAG SPNV, dem Verband der Auftraggeber.

Die folgende empirisch-qualitative Analyse hat eine explorative Funktion und erhebt keinen Anspruch auf Repräsentativität, weil das erhobene Material in Umfang und Zusammensetzung nicht repräsentativ sein kann. Es wird aber jeweils die Anzahl der Exemplare einer Textsorte angegeben, die das Korpus erhält, um deutlich zu machen, ob ein oder mehrere Textsortennetze bzw. Ausschreibungsverfahren untersucht wurden. Der Vergleich ermöglicht es eher, übertragbare Ergebnisse in den Analysen zu erzielen. In den folgenden Teilkapiteln wird dementsprechend für die Teilkorpora ${ }^{123}$ bestimmt, inwieweit diese Analysen zulassen, deren Ergebnisse verallgemeinerbar und auf andere Exemplare der Textsorte oder auch auf andere Domänen übertragbar sind.

Diese Arbeit gliedert das empirische Material einerseits in ein Textkorpus (Kapitel 4.2), andererseits in weiteres empirisches Material (Kapitel 4.3), weil es sich um zwei verschiedene Datentypen handelt. Diese werden zunächst getrennt

122 Zum Vorgehen in Forschungsprojekten in der Angewandten Linguistik beispielsweise GÖPFERICH (2014, S. 151 f.).

123 Diese setzen sich aus Textsortenexemplaren zu Verdingungsunterlagen wie die Bewerbungsbedingungen, Leistungsbeschreibung oder der Verkehrsvertrag, zu Pflichtenheften und Fahrplänen etc. zusammen. 
behandelt: Das Textkorpus dient der Textanalyse (Kapitel 5) als Grundlage, während die durchgeführten Interviews und Beobachtungen der weiteren Materialsammlung dazu genutzt werden, die Überarbeitungsprozesse zu analysieren (Kapitel 6).

Die Zusammensetzung des Textkorpus wird durch das verfahrensbedingte Textsortennetz (KLEIN, ${ }^{2} 2014 \mathrm{a}$ ) bestimmt, das sich aus dem Ausschreibungsverfahren ergibt. Diese beschriebene Konzeption von Textsortennetzen (s. Kapitel 3.5) eignet sich für die Analyse der vorliegenden Textsortenexemplare, weil KLEINs Konzept rechtlich bindende Verfahrensphasen in Form von Textsortenexemplaren abbildet, die in der zugehörigen Phase produziert bzw. rezipiert werden. Für die Zusammenstellung des Korpus bedeutet dies, dass das Verfahren das Textsortennetz und damit das Korpus determiniert. Damit das Ausschreibungsverfahren nachvollzogen werden kann, enthält das Korpus mehr Material als die Textsortenexemplare, die exemplarisch in Kapitel 5 analysiert werden. Denn die Analyse aller Exemplare würde ein ineffizientes Aufwand-Nutzen-Verhältnis erzeugen. Die Analyse aller Textsortenexemplare auf ein einziges Textkriterium hin würde nicht obiger Forschungsfrage entsprechen. Daher richtet sich die exemplarische Analyse einzelner Textsortenexemplare auf die wenigen Textsorten des Textsortennetzes, die im Zentrum des Verfahrens stehen. Da sich Funktionen von Textsorten der exemplarischen Analyse aber aus dem Textsortennetz bzw. indirekt aus anderen Textsorten des Netzes ergeben, wird das Verfahren anhand von Exemplaren aller Textsorten des Netzes dargestellt.

Die Auswahl der jeweiligen Exemplare aus dem Korpus wird detailliert in Kapitel 4.4 begründet, die auch eine Auflistung der analysierten Exemplare enthält. ${ }^{124}$

\subsection{Feldzugang und Erhebungsmethodik}

Ausschreibungsverfahren im Schienenpersonennahverkehr sind für Verfahrensexterne grundsätzlich nicht offen zugänglich. Lediglich Ausschreibungsbekanntmachungen sind über die digitale Plattform Tenders EleCtronic DaILY (2018; URL) für jedermann einsehbar. ${ }^{125}$ Die Ergebnisse aller bundesweiten Ausschrei-

124 Kapitel 4.4 führt diese Exemplare auf.

125 s. Tabelle 4-3. 
bungen eines Kalenderjahres macht die BAG SPNV öffentlich zugänglich. Des Weiteren erläutern Auftraggeber in ihren Internetauftritten grundsätzlich, wie und welche Vergabeverfahren ablaufen. Die eigentlichen Bewerbungs- und Vergabeprozesse verlaufen aber unter Ausschluss der Öffentlichkeit.

Das bietende Eisenbahnverkehrsunternehmen (EVU) bzw. der Bieter sprach im Jahr 2009 die Schreibwerkstatt an, für die ich zu diesem Zeitpunkt als wissenschaftliche Hilfskraft tätig war. Der Kontakt zu dieser Einrichtung war durch den Hinweis einer ehemaligen Redaktionsmitarbeiterin entstanden, die als Alumna der Universität Duisburg-Essen auf die Schreibwerkstatt verwiesen hatte. So erhielt ich die Möglichkeit zu einem Vorstellungsgespräch beim Bieter, infolgedessen ich im Rahmen von zwei Betriebspraktika ein Ausschreibungsverfahren als Teil der Redaktion begleitete und anschließend bei der Optimierung der Ausschreibungsteilnahmen mitwirkte. Vor meiner Tätigkeit musste ich eine Geheimhaltungserklärung unterzeichnen und erhielt die Genehmigung für eine erste Ausschreibung durch den Abteilungsleiter (2011) und eine Genehmigung für weitere Untersuchungen erst durch eine Vorstellung meines Forschungsinteresses beim Vorstand des Unternehmens. An den weiteren Ausschreibungsprozessen war ich als externer Berater beteiligt, um verdeckt-teilnehmend beobachten zu können, was aufgrund der Unabhängigkeit der Forschung unentgeltlich geschah.

Im Anschluss an die Beobachtungen führte ich Interviews mit Auftraggeber 1 und Auftraggeber 2 durch, die Ausschreibung 1 und 2 veranstalteten. Grundsätzlich agieren Auftraggeber als Prozipienten. Prozipienten sind in Formularkommunikation sowohl Produzenten eines Formularvordrucks als auch Lesende desselben ausgefüllten Formulars (ADAMZIK, ${ }^{2} 2016$, S. 141). Auftraggeber sind demnach in Ausschreibungsverfahren sowohl Lesende der Bieter-Texte als auch Produzenten der sogenannten Verdingungsunterlagen, die die Anforderungen an Leistungen und Fahrzeuge etc. beinhalten. Neben den Veröffentlichungsgenehmigungen für die Interviews von AufTRAGGeBER 1 (2013, S. 15) und AufTRAGGEBER 2 (2010a, S. 6; 2010b, S. 3) erhielt ich Genehmigungen für die Verwendung von Unterlagen des Bieters, bei dem ich die Textüberarbeitungsprozesse beobachtete, und für die Veröffentlichung von relevanten Stellen. Des Weiteren führte ich Interviews mit Fahrzeugherstellern, die den Bieter als Lieferanten bei der Angebotserstellung unterstützten. Auf die Verdingungsunterlagen nahmen Fahrzeughersteller indirekt 
Einfluss, weil die BAG SPNV mit den „Systemhäusern Alstom, Bombardier, Siemens und Stadler" (BAG SPNV, ${ }^{2} 2010$, S. 7), also den Fahrzeugherstellern, die Empfehlungen für Fahrzeuganforderungen vor der Veröffentlichung diskutierten.

Die Personen, die bei Fahrzeughersteller, Bieter und Auftraggeber meine Anfragen genehmigten, waren sogenannte Gatekeeper. Gatekeeper zeichnen sich dadurch aus, dass sie a) ,in der Lage [sind], dem Forscher Zugang zum Feld zu verschaffen“ (MAYER, 2012, S. 46) und b) „Eigeninteresse verfolgen können“ (ebd.). Die genehmigenden Mitarbeiter des Bieters verfolgten das Eigeninteresse, einen Lösungsvorschlag für oben dargestellte praktische Probleme des Forschungsfeldes zu erhalten. Einem möglichen verdeckten Interesse - beispielsweise dass Führungskräfte Informationen über die eigenen Mitarbeitenden gewinnen wollten - versuchte ich durch Anonymisierung der Personen und Verfahren entgegenzuwirken. Darüber hinaus könnte mein Forschungsvorhaben, bei dem ich auch mit den Auftraggebern Kontakt aufnahm, auch das weitere Ziel des Bieters verfolgen, beim Auftraggeber das Unternehmensimage zu verbessern: So könnte die Erforschung der Arbeitsprozesse beim Bieter als Qualitätsmerkmal erscheinen. Sowohl der Bieter als auch der Auftraggeber könnten des Weiteren das Interesse verfolgt haben, Einsicht in die Arbeitsabläufe, Team-Zusammensetzungen etc. beim Alter Ego der Ausschreibungskommunikation zu erhalten.

Die Auftraggeber sind ebenfalls Gatekeeper im Feld, weil sie die Interviewführung und -veröffentlichung wie auch den Zugang zu den Verdingungsunterlagen genehmigen oder untersagen können. Da den Auftraggebern bekannt war, dass eine Zusammenschau der Interviews und der Analyse von Verfahrensabläufen veröffentlicht wird, könnten sie das Interesse verfolgt haben, darzustellen, dass sie die vorgeschriebenen Vorgehensweisen und Ziele öffentlicher Ausschreibungen korrekt umsetzen: So haben sie per Verordnung die Transparenz der Verfahren und Diskriminierungsfreiheit von Bietern zu gewährleisten (s. Kapitel 4.3.1). Relevant ist für meine Annahme, dass ich alle Interviewpartner darüber informierte, meine Ergebnisse nach Veröffentlichung allen Bietern zugänglich zu machen. Konkrete Unterstützung bot ich keinem Interviewpartner an. Richtschnur für dieses Vorgehen war die Forschungsmaxime, dass Forschende ,problematische Ankündigungen oder gar Versprechungen“ (WOLFF, ${ }^{7} 2009$, S. 348) vermeiden sollten, während zu diskutieren ist, ob der Grund dafür in „der Trivialität 
dessen [liegt; AH], was der Forscher faktisch anzubieten hat". (ebd.) Inwieweit meine Analyseergebnisse für das Forschungsfeld trivial sind, haben die Teilnehmenden des Forschungsfeldes zu beurteilen.

Bei den Gatekeepern der Fahrzeughersteller erschien mir kein unmittelbares Eigeninteresse durch meinen Forschungsprozess ersichtlich. Dadurch erkläre ich mir auch, dass die Hürden für Interviews bei Letzteren im Vergleich zu Auftraggebern und Bietern am höchsten lagen. So sichert sich Fahrzeughersteller 2 durch eine händisch zu unterzeichnende Vertraulichkeitsvereinbarung gegen den Verrat von Unternehmensgeheimnissen ab. In dieser Erklärung ist eine hohe Summe als Schadensersatz für den Fall fixiert, dass ich diese Vereinbarung verletzte. Forderungen wie diese werden in der Literatur empirischer Forschungsmethodologie wie folgt reflektiert: Die Forderung nach einer entsprechenden Erklärung zielt in der Regel darauf, bei den „betroffenen Einrichtungen oder Gruppen“ (WoLFF, ${ }^{7} 2009$, S. 345) keinen Schaden zu verursachen. Auch wenn die Einweihung in ein internes Geheimnis Forschende grundsätzlich ,vor die Alternative von Verrat und Selbstzensur stell[en]“ (ebd.) könnte, sehe ich an dieser Stelle nicht die Gefahr einer Selbstzensur oder eines Verrats. Denn das Interview führt der Fahrzeughersteller in dem Wissen, dass es für eine Publikation vorgesehen ist. Zudem fordert redliche Forschung, von Interviewpartnern das Einverständnis für Publikationen einzuholen. Dementsprechend entscheidet ein Interviewpartner, hier Fahrzeughersteller 2, worüber er Auskunft geben kann bzw. darf. Die Analyseergebnisse der anonymisierten Daten (s. Kapitel 6) wiegen m. E. den Geheimhaltungsaufwand auf.

Folgende Übersicht fasst die Genehmigungen, Zeugnisse etc. zusammen, die den Zugang zum Forschungsfeld belegen (s. Tabelle 4-1): 


\begin{tabular}{|l|l|l|}
\hline Erteilt von & Genehmigung für & Datum/Jahr \\
\hline EVU/Bieter & $\begin{array}{l}\text { Zeugnisse über Tätigkeit in der Redaktion } \\
\text { und Unternehmensorganisation }\end{array}$ & $\begin{array}{l}08.06 .2009 ; \\
30.09 .2009\end{array}$ \\
\hline EVU/Bieter & $\begin{array}{l}\text { Beobachtung von Textüberarbeitungen in } \\
\text { Ausschreibungen durch Abteilungsleiter } \\
\text { und Vorstandsvorsitzenden }\end{array}$ & $\begin{array}{l}10.09 .2009 ; \\
01.02 .2010\end{array}$ \\
\hline Auftraggeber 2 & Interview & 22.09 .2010 \\
\hline Auftraggeber 2 & Interview & 27.09 .2010 \\
\hline Auftraggeber 1 & Interview & 06.02 .2014 \\
\hline Auftraggeber 1 & $\begin{array}{l}\text { Verdingungsunterlagen für Ausschrei- } \\
\text { bung 1 }\end{array}$ & 06.02 .2014 \\
\hline Auftraggeber 2 & Verdingungsunterlagen Ausschreibung 3 & 10.04 .2014 \\
\hline Auftraggeber 2 & Verdingungsunterlagen Ausschreibung 2 & 28.10 .2014 \\
\hline $\begin{array}{l}\text { Fahrzeugherstel- } \\
\text { ler 2 }\end{array}$ & Interview mit Fahrzeughersteller 2 & 18.07 .2014 \\
\hline $\begin{array}{l}\text { Fahrzeugherstel- } \\
\text { ler 1 }\end{array}$ & Interview mit Fahrzeughersteller 1 & 09.10 .2014 \\
\hline EVU/Bieter & $\begin{array}{l}\text { Freigabe von Textstellen aus Pflichten- } \\
\text { heften 1, 2 und 3 }\end{array}$ & 29.06 .2015 \\
\hline EVU/Bieter & Freigabe von Textstellen aus allen OV & 27.10 .2015 \\
\hline
\end{tabular}

Tabelle 4-1: Übersicht über Genehmigungen und weitere Dokumente des Feldzugangs.

Obige Beschreibung der Genehmigungen und Zeugnisse (s. Tabelle 4-1) lässt sich als folgende fünf Erhebungsphasen zusammenfassen, die sich teilweise überschneiden:

Phase 1: Tätigkeit im Feld als Praktikant im Jahr 2009.

Phase 2: Teilnehmende Beobachtung im Jahr $2010 \mathrm{zu}$ Textüberarbeitungen, Texterhebung sowie zwei qualitative Interviews mit Auftraggeber 2 in Ausschreibung 3. Des Weiteren im Bieterunternehmen: teilnehmende Beobachtung der Überarbeitungsprozesse von Ausschreibungstexten, Texterhebung zu den 
Ausschreibungen 5 und 6 sowie Gespräche mit Fachautoren, Projektleitern, externen Prüfern; des Weiteren ein qualitatives Interview mit dem Bereichsleiter Ausschreibungswesen im Bieterunternehmen.

Phase 3: Auf der Grundlage der Auswertung von Daten aus Phase 2 teilnehmende Beobachtung, Texterhebung und qualitatives Interview mit Auftraggeber 1 im Jahr 2013 entsprechend Phase 2; zusätzliche Erhebung der Verdingungsunterlagen zu Ausschreibung 1. Des Weiteren teilnehmende Beobachtung und Texterhebung zu den Ausschreibungen 3 und 4. Analyse der Texte und Dokumente.

Phase 4: Interviews mit den Fahrzeugherstellern im Jahr 2014 und mit weiteren Auftraggebern im Jahr 2015 auf der Grundlage der Analyseergebnisse zu den Textexemplaren und Interviews, die in Phase 3 durchgeführt bzw. erhoben wurden.

Phase 5: Genehmigungen zum Vorlegen von Dokumenten für das Prüfungsverfahren und für die Veröffentlichung in den Jahren 2010, 2013, 2014 und 2015 beim Bieterunternehmen und den Auftraggebern.

In diesen fünf Phasen spiegelt sich zum Teil die Beschreibung des ethnographischen Forschungsprozesses wider, wie ihn LÜDERS (72009, S. 386) aus einem Blickwinkel der qualitativen Sozialforschung beschreibt: a) die Phase der Problemdefinition, b) die Kontaktaufnahme, c) der Feldeinstieg, d) die Etablierung einer Feldrolle und ihre Aufrechterhaltung, e) das Erheben und Protokollieren von Daten, f) der Ausstieg aus dem Feld, g) die Auswertung, h) die theoretische Verarbeitung und schließlich i) die Veröffentlichung der Ergebnisse.

Im Gegensatz zum Ansatz in LÜDERS ( ${ }^{7} 2009$, S. 386) ist mein Forschungsinteresse aus der praktischen Tätigkeit entstanden und hat nicht vor dem Feldeinstieg bestanden. Die Etablierung der Feldrolle als Moderator des gemeinsamen Textüberarbeitungsprozesses - d. h. als Beteiligter bei der Optimierung des Ausschreibungsprozesses während der Praktika - hat meine verdeckte teilnehmende Beobachtung während der Textüberarbeitungsprozesse in Phase 1 und 2 begünstigt, da ich den Projektmitgliedern bei diesen Textüberarbeitungen bereits aus den vorherigen Ausschreibungsverfahren bekannt war und von ihnen vermutlich in der Rolle als externer Berater wahrgenommen wurde. 


\subsubsection{Teilnehmende Beobachtungen}

Aus formaler Sicht lassen sich die Beobachtungen in Phase 1 und 2 dieser Untersuchung entsprechend der Beobachtungsfaktoren in SCHAEDER (1998, S. 233) $)^{126}$ wie folgt spezifizieren: Meine Feldbeobachtung der Gruppe der Projektmitglieder während der Textüberarbeitung lässt sich als nicht standardisiert, nicht wiederholbar, umfassend, direkt, stationär, verdeckt, aktiv sowie teilnehmend klassifizieren, die Erhebungssituation als authentisch und natürlich.

Die Warnung vor einer Mystifizierung der Rolle des Forschenden (KLÄRNER, 2002, S. 6) berücksichtigte ich bei der Verarbeitung der Beobachtungsprotokolle. Nicht nur KLÄRNER (2002), sondern auch WOLFF (72009, S. 336) schätzt ein, dass beim Berichten über Feldforschung die Gefahr bestehe, die Beschreibung des Feldzugangs in besonderer Weise zu stilisieren. Zwar zielt WolfFs Kritik im Detail auf klassische ethnographische Erforschung indigener Kulturen. ${ }^{127}$ Er überträgt diese Problematik aber auch auf Organisationenforschung: Für Feldforschung in Organisationen steht der Forscher vor der Aufgabe, die Mitgliedschaftsrolle von der Grenzerhaltung als Forschender abzugrenzen (ebd., S. 340). Dementsprechend intensivierte ich einerseits die Mitgliedschaftsrolle, gab diese andererseits bei den Beobachtungen und insbesondere nach dem Verlassen des Feldes nach und nach auf: So konnte ich mit zunehmender Wahrnehmung der Aufgaben im Feld und mit zunehmender Anzahl der Beobachtungen Großteile der besprochenen Inhalte erarbeiten, sodass die Beobachtungsprotokolle im Jahr 2013 genauer wurden. Z. T. protokollierte ich im Jahr 2010 Aussagen, deren Sinn sich mir erst durch Nachfragen beim Redaktionsteam des Bieters im Jahr 2013 erschlossen. Bei den Beobachtungen im Jahr 2013 richtete ich zahlreiche und ausführliche Fragen an eine der Redakteurinnen, die inklusive der Antworten im angehängten Dokument als Kommentare sichtbar sind. Meine Abgrenzung vom erforschten Tätigkeitsfeld erfolgte beispielsweise durch die oben dokumentierte Reflexion der Gatekeeper-Rollen. Eine Distanzierung fiel mir durch die Tatsache leicht, dass ich mich weder von einem Bieterunternehmen noch von einem Auftraggeber für die Forschungstätigkeit bezahlen ließ, um mich finanziell nicht

\footnotetext{
126 Ähnlich in LÜDTKE (2004, S. 1033 f.).

127 WOLFF bezieht sich dabei insbesondere auf die Veröffentlichung des Forschungstagebuchs von MALINOWSKI (1967, o. S. nach WOLFF, ${ }^{7} 2009$, S. 337).
} 
abhängig zu machen. Ich nahm auch weder vom Auftraggeber noch vom Bieter ein Beschäftigungsangebot an.

\subsubsection{Qualitative Interviews}

Das Konzept qualitativer Interviews (HoPF, ${ }^{7} 2009$, S. 350 ff.), insbesondere problemzentrierter Interviews (WITZEL/REITER, 2012), bildeten die methodologische Grundlage für meine Interviews. Problemzentrierte Interviews zeichnet Folgendes aus:

„Das unvermeidbare, und damit offenzulegende Vorwissen dient in der Erhebungsphase als heuristisch-analytischer Rahmen für Frageideen im Dialog zwischen Interviewern und Befragten." (WITZEL, 2000, S. 2)

In meiner Untersuchung bzw. bei meinen Interviews dienten die Beobachtungen im Überarbeitungs- bzw. im Rezeptionsprozess, über den die Überarbeitenden an vielen Stellen spekulierten, als Anreiz für meinen Interviewleitfaden bzw. für die Gesprächsführung während der Interviews.

Da ich die Auftraggeber und Projektmitglieder des Bieters als Experten interviewte, berücksichtigte ich bei der Konzeption des Leitfadens und der Interviewdurchführung auch die Merkmale von Experteninterviews. Letztere zeichnet aus, dass Personen, die ,in der Funktion als Experte[n] für bestimmte Handlungsfelder“ (MAYER, 2012, S. 38) interviewt werden, als „Repräsentant einer Gruppe in die Untersuchung einbezogen" (ebd.) werden. D. h., diese Personen sind „FunktionsträgerInnen innerhalb eines organisatorischen oder institutionellen Kontextes“ (Meuser/NAGEL, 1991, S. 444), die vom Forschenden als „Repräsentanten einer Organisation oder Institution“ (ebd.) angesprochen werden. Gegenstände des Experteninterviews sind ,[d]ie damit verknüpften Zuständigkeiten, Aufgaben, Tätigkeiten und die aus diesen gewonnenen exklusiven Erfahrungen und Wissensbestände“"(ebd.). Experten sind demnach nicht zwingend sogenannte Professionelle, die über Sonderwissen verfügen, „das in Bildungsinstitutionen formalisiert vermittelt und zertifiziert wird“ (PFADENHAUER, ${ }^{2} 2005$, S. 123).

Auch Forschende qualifizieren sich als Interviewer, indem sie zum Quasi-Experten auf gleicher Augenhöhe werden (ebd., S. 127): Voraussetzung dafür ist, am praktischen Geschehen als Mitglied mitzuwirken und so eine existentielle Innensicht zu gewinnen (ebd.). Experteninterviews sind demnach auf vorab durchgeführte Beobachtungen im Feld angewiesen (ebd.). Für meine Untersuchung lässt 
sich festhalten, dass ich Experten durch die Aussagen der Projektmitglieder während der beobachteten Textüberarbeitungsprozesse und anhand ihrer Textprodukte in Form der analysierten Texte der gemeinsamen Überarbeitung identifizierte. Infolgedessen interviewte ich die für die jeweiligen Ausschreibungen zuständigen Mitarbeitenden der Auftraggeber und der Fahrzeughersteller sowie den Leiter des Ausschreibungswesens beim Bieter und einige Mitarbeitende der gemeinsamen Textüberarbeitung.

Bei der Konzeption des Leitfadens berücksichtigte ich, dass ein Leitfaden „,viele Spielräume in den Frageformulierungen, Nachfragestrategien und in der Abfolge der Fragen eröffnet" (Hopf, ${ }^{7} 2009$, S. 351). Eine Orientierung für die Leitfäden bot mir grundsätzlich das sogenannte SPSS-Prinzip. Dieses Akronym setzt sich aus folgenden Wörtern und damit auf methodologischer Ebene aus folgenden Ar-

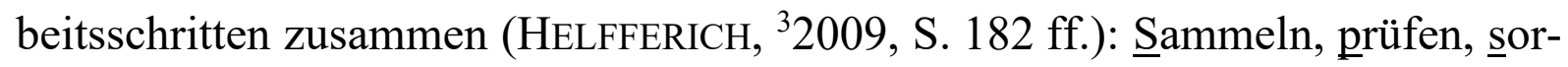
tieren und subsumieren. In diesem Konzept zielen die ersten beiden Arbeitsschritte auf die Aktivierung und Reflexion des Vorwissens der Forschenden: 1. Sammeln von Fragen als Brainstorming auf der Grundlage von Forschungsliteratur in Form einer Frageliste; 2. Prüfen der Liste auf Faktenfragen, auf ausschließlich geschlossene Antwortmöglichkeiten, auf Bestätigung des ForscherVorwissens und auf abstrakte Fragen, die die Forschungsfrage unmittelbar beantworten sollen. Alle entsprechenden Fragen seien zu tilgen, um die Umsetzung des Offenheitsprinzips zu gewährleisten; 3. Sortiert werden sollen die Fragen nach einer zeitlichen Abfolge oder nach Inhaltsaspekten; 4. Einzelfragen sollen zu Bündeln zusammengefasst werden.

Schritt 1 entsprach ich nur bedingt, weil ich Fragen zum Teil aus linguistischer Forschungsliteratur, zum Teil aus Fragen ableite, die sich aus den Beobachtungen ergeben. Alle weiteren Schritte berücksichtigte ich bei der Konzeption der Interview-Leitfäden. Diese Leitfäden nutzten die Interviewpartner zur Vorbereitung, auch weil sie mich um diesen Leitfaden gebeten hatten.

Auf Wunsch der Interviewpartner verzichtete ich auf ein Aufnahmegerät und fertigte eine Mitschrift an, die ich in eine Verschriftlichung des Interviews überführte. Die Interviewpartner lasen diese Verschriftlichung vor der Genehmigung gegen und äußerten zum Teil Änderungswünsche, die ich einarbeitete. So sind die Interviews nicht mit Transkriptionen vergleichbar und verfolgen auch keine 
gesprächsanalytischen Ziele wie die Analyse von Asymmetrie zwischen Gesprächspartnern anhand von turn taking etc. Wie sich bereits bei der Konzeption der Leitfäden für Experteninterviews zeigte, sind diese Formen des Interviews auf Beobachtungen angewiesen und werden mit diesen trianguliert. Triangulation wird in der qualitativen Sozialforschung wie folgt beschrieben.

\subsubsection{Triangulation der Beobachtungs-, Interviewauswertung sowie der Analyse von Sprache-Bild-Textsortenexemplaren}

Die Ergebnisse der Textanalyse mit den Ergebnissen der Beobachtungs- und Interviewanalysen zusammenzuführen, folgt dem Prinzip der Triangulation, deren Vorteile für den Forschungsprozess methodologisch reflektiert sind. Triangulation wird wie folgt definiert:

„In der Sozialforschung wird mit dem Begriff ,Triangulation“ die Betrachtung eines Forschungsgegenstandes von (mindestens) zwei Punkten aus bezeichnet." (FLICK, ${ }^{7} 2009$, S. 309) Im Rahmen von Gütekriterien qualitativer Forschung ${ }^{128}$ (STEINKE, ${ }^{72009)}$ erscheint diese Definition von Triangulation zunächst als Validierungsstrategie. Unter den verschiedenen Formen der Triangulation ${ }^{129}$ ist für meine Untersuchung insbesondere die methodologische von Interesse. Bei methodologischer Triangulation handelt es sich um ,einen komplexen Prozess des Gegeneinander-Ausspielens jeder Methode gegen die andere, um die Validität von Feldforschungen zu maximieren“ (DENZIN, ${ }^{2} 1978$, S. 304). An der Perspektive des methodischen Gegeneinanderausspielens wird grundsätzlich Folgendes kritisiert: „We should combine theories and methods carefully und purposefully with the intention of adding breadth or depth to our analysis, but not for the purpose of pursuing 'objective' truth." (FiElding/Fielding, 1986, S. 33) Auch wenn Breite und Tiefe in dieser Konzeption nicht weiter ausgeführt werden, erscheint an dieser Kritik folgende Schlussfolgerung wesentlich: „Theoretical triangulation does not necessarily reduce bias, nor does methodological triangulation

128 Die Gütekriterien quantitativer Forschung - Objektivität, Reliabilität und Validität - werden für qualitative Untersuchung zum Teil zugunsten anderer Kriterien aufgegeben (STEINKE, ${ }^{7}$ 2009).

129 Triangulationsformen lassen sich unterscheiden nach: Daten, Investigatoren (Interviewer/Beobachter), Theorien (verschiedenen Perspektiven und Hypothesen) Methoden (verschiedene Methoden kombiniert). 
necessarily increase validity.“(ebd.) Basierend auf dem Ansatz in DENZIN ( $\left.{ }^{2} 1978\right)$ und der resultierenden Kritik in FIELDING/FIELDING (1986) definiert FLICK (72009) den Begriff ,Triangulation' folgendermaßen:

„Triangulation wird inzwischen weniger als Strategie der Validierung in der qualitativen Forschung, sondern als Strategie, Erkenntnisse durch Gewinnung weiterer Erkenntnisse zu begründen und abzusichern, gesehen.“ (ebd., S. 311)

Diese Definition von Triangulation ergänzt die oben aufgeführte Bestimmung, einen Gegenstand von zwei (erhebungsmethodischen) Standpunkten zu betrachten. Im Anschluss daran verwende ich den Begriff Triangulation in dieser Arbeit als Betrachtung eines Forschungsgegenstandes auf der Grundlage von Material, das durch mindestens zwei unterschiedliche empirische Methoden entsteht, um Erkenntnisse durch weitere Erkenntnisse zu begründen. In diesem Sinne trianguliert diese Untersuchung einerseits Analyseergebnisse aus den Beobachtungen der gemeinsamen Textüberarbeitungen durch Ergebnisse aus den geführten Interviews mit Auftraggebern und Projektmitgliedern des Bieters, andererseits durch die Ergebnisse der Textanalyse. Die Interpretation der Textüberarbeitungsprozesse basiert wiederum auf den Textanalysen.

\subsection{Zusammensetzung und Umfang des Korpus}

Im Folgenden wird der Umfang des Textkorpus zusammenfassend und im Anschluss für die Textsorten differenziert beschrieben. Nach dem Überblick über das Gesamttextkorpus wird das Textsortennetz zum SPNV-Ausschreibungsverfahren dargestellt, um die Zusammensetzung des Korpus zu untermauern, die sich aus dem Ausschreibungsverfahren abbildenden Textsortennetz ergibt. Für die einzelnen Textsorten wird im Anschluss daran nicht nur der Umfang der jeweiligen Teilkorpora vorgestellt, die zu den einzelnen Textsorten des Textsortennetzes erstellt werden. Es wird für die einzelnen Teilkorpora auch jeweils diskutiert, inwieweit die Analyseergebnisse zu den Textsortenexemplare eines Teilkorpus verallgemeinert und auf andere Domänen oder Textsorten übertragen werden können.

\subsubsection{Umfang des Korpus}

Die Anzahl der Exemplare, die das Korpus pro Textsorte umfasst, gibt Tabelle 4-2 an. Auf eine Angabe von Types und Token sowie eine Relation zwischen 
beiden Größen verzichte ich bewusst, da die Textanalyse in Kapitel 5 nicht quantitativer, sondern ausschließlich qualitativer Natur ist.

\begin{tabular}{|l|c|c|}
\hline Textsorte & $\begin{array}{c}\text { Anzahl der } \\
\text { Exemplare }\end{array}$ & Summe der Seiten \\
\hline Optimierungsvorschläge & 23 & 33 \\
\hline Pflichtenhefte & 4 & 7 \\
\hline $\begin{array}{l}\text { Technische Zeichnungen (in ei- } \\
\text { nem zum Pflichtenheft separaten } \\
\text { Dokument) }\end{array}$ & 7 & 42 \\
\hline Lastenhefte & 6 & 346 \\
\hline $\begin{array}{l}\text { Weitere Verdingungsunterlagen } \\
\text { (Bewerbungsbedingungen, Leis- } \\
\text { tungsbeschreibung, Verkehrsver- } \\
\text { trag, ...) }\end{array}$ & 4 & 11 \\
\hline Fahrpläne & 3 & \\
\hline
\end{tabular}

Tabelle 4-2: Quantitative Angaben zum Gesamttextkorpus.

Wichtiger als die Anzahl der Exemplare ist für diese qualitative Untersuchung die Auswahl der Textsortenexemplare. Daher wird im Folgenden das verfahrensbedingte Textsortennetz vorgestellt, dessen Textsorten und funktionale Relationen (KLEIN, $\left.{ }^{2} 2014 \mathrm{a}\right)$ zwischen den Textsortenexemplaren die Zusammensetzung des Korpus bestimmen.

\subsubsection{Das Textsortennetz Ausschreibungsverfahren als Grundlage für die Zusammensetzung des Korpus}

Wie bereits oben beschrieben wird, bildet das Textsortennetz den Prozess des Ausschreibungsverfahrens als Kommunikationsprodukte zu den einzelnen Prozessschritten ab. Diese Konzeption von verfahrensbedingten Textsortennetzen beschreibt Kapitel 3.5 ausführlich, bei dem besonders die funktionalen Relationen zwischen den Textsorten relevant sind. Entsprechend diesem Konzept wird das Textsortennetz zu SPNV-Ausschreibungsverfahren dargestellt (s. Tabelle 4-3). 
Damit deutlich wird, welche Verfahrensschritte das Textsortennetz repräsentiert, zeigt die folgende Übersicht eine Variante, wie SPNV-Ausschreibungsverfahren ablaufen. Der Ausschnitt stammt aus den Bewerbungsbedingungen von Ausschreibung 1 und beschreibt nicht nur die Verfahrensschritte, sondern nennt zum größten Teil bereits die Textsorten des Netzes:

„11 Ablauf des Verhandlungsverfahrens

(1) Der Ablauf des Verhandlungsverfahrens gestaltet sich im Einzelnen wie folgt:

a. Verfahrensunterlagen

Die Verfahrensunterlagen können im Internet im geschützten Bereich unter der in Ziffer 8 Abs. 2 angegebenen Stelle eingesehen und heruntergeladen werden.

\section{b. Änderungsvorschläge}

Die Bieter haben im ersten Schritt die Möglichkeit, zu den Vergabeunterlagen Änderungsvorschläge schriftlich an die unter Ziffer 11 Abs. 3 genannte Stelle der Aufgabenträger zu richten. Die Änderungsvorschläge sind Grundlage für die dann folgenden Verhandlungsgespräche. Näheres zu den Änderungsvorschlägen regelt Abs. 2.

\section{c. Verhandlungsgespräche}

Auf Grundlage der schriftlich eingereichten Optimierungsvorschläge der Bieter werden die Aufgabenträger Verhandlungsgespräche mit den Bietern durchführen, bei denen die Bieter ihre Vorschläge erörtern können. Die Bieter werden rechtzeitig über den Termin informiert und von den Aufgabenträgern zu den Verhandlungsgesprächen schriftlich eingeladen.

\section{d. Aktualisierung der Verfahrensunterlagen}

Die Aufgabenträger behalten sich vor, die Anforderungen an die Angebote im Laufe des Verfahrens unter Beachtung aller vergaberechtlichen Vorgaben nach Abschluss der Verhandlungen näher zu präzisieren, zu konkretisieren, zu ergänzen und/oder in einzelnen Punkten aufzuheben.

e. Abgabe der endgültigen Angebote

Nach Abschluss der Verhandlungsgespräche werden den EVU auf den Ergebnissen der Verhandlungsgespräche basierend modifizierte Verfahrensunterlagen und Verträge zeitnah unter der in Ziffer 8 Abs. 2 angegeben Webseite zur Verfügung gestellt. Es liegt allein im Ermessen der Aufgabenträger, Änderungsvorschläge zu berücksichtigen oder auch nicht. Ein Anspruch der Bieter auf Umsetzung ihrer Optimierungen besteht nicht.

Auf Grundlage der den Bietern vorliegenden, modifizierten Vergabeunterlagen sind diese aufgefordert, jeweils ein verbindliches Angebot für die zu vergebende Leistung abzugeben. Mit Abgabe des verbindlichen Angebotes ist die 1. Verhandlungsrunde abgeschlossen.

Die Aufgabenträger beabsichtigen nach der 1. Verhandlungsphase den Zuschlag auf das insgesamt wirtschaftlichste der vorliegenden Angebote zu erteilen."

(BewerbungsBedingungen ${ }^{130}$; Ausschreibung 1, S. 11 f.; Fettdruck AH)

130 Wie beim Verweis auf Verordnungen etc. in Wissenschaftstexten wird im Folgenden bei Verdingungsunterlagen nicht der Urheber der betreffenden Quelle, sondern der Titel des Textes angegeben, weil es sich um einen Rechtstext handelt. Zitate aus Interviews etc. mit Auftraggebern, die auch Urheber der Verdingungsunterlagen sind, werden dagegen mit der Angabe des Urhebers belegt, weil Interviews keine Rechtstexte sind. 
Diese Beschreibung des Verfahrensablaufs in Ausschreibung 1 ermöglicht es, folgende Textsorten als Teil des Textsortennetzes zu systematisieren:

- Verdingungsunterlagen; auf diese nehmen Auftraggeber 1, AuftraggeBER 2 und der Abteilungsleiter des Bieters (2011) im Interview Bezug; ${ }^{131}$ in der obigen Beschreibung des Verfahrensablaufs (Ausschreibung 1) werden nicht alle Textsorten explizit aufgeführt, aus denen sich die Verdingungsunterlagen zusammensetzen. Als Textsorten gehören zu diesen die Bewerbungsbedingungen, die Leistungsbeschreibung, deren Anhänge wie die Mindestanforderungen an Fahrzeuge und das Lastenheft sowie der Verkehrsvertrag. Die Verdingungsunterlagen sollen entsprechend obiger Beschreibung im Verfahren in einer ersten und in einer modifizierten Form vorliegen. Die Modifikationen sind für die gesamten Verdingungsunterlagen in Ausschreibung 1 durch die WORD-Funktion „Änderungen nachverfolgen" kenntlich gemacht worden.

- Änderungs- bzw. Optimierungsvorschläge, ${ }^{132}$ die von den Bietern des Verfahrens einzureichen sind.

- Verhandlungsgespräche zwischen dem Auftraggeber und jeweils einem Bieter, die auf den Optimierungsvorschlägen aufbauen und innerhalb des Verfahrens als einzige Textsorte mediale Mündlichkeit zulassen, was sich aus dem Gebot für die Auftraggeber ergibt, das Verfahren für alle Beteiligten transparent zu gestalten. Diese Gespräche konnte ich nicht beobachten.

- Das Angebot des Bieters; auch hier nennt die obige Beschreibung des Verfahrens keine konkreten Textsorten, führt diese aber an späterer Stelle auf. So hat ein Bieter im Verfahren für ein vollständiges Angebot das Angebotsschreiben, Fahrpläne und deren Testate, Beschaffungszusagen der Fahrzeughersteller, den unterzeichneten Verkehrsvertrag, die Fahrzeugcheckliste bzw. das ausgefüllte Lastenheft, also das Pflichtenheft, etc. abzugeben (BewerbungsBedingungen; Ausschreibung 1, S. 22 f.).

131 Die zugehörige Verordnung, die Verdingungsordnung für Leistungen (VOL - Teil A), differenziert die sogenannten Vergabeunterlagen in die Aufforderung zur Angebotsabgabe und die Verdingungsunterlagen (ebd., § 9, Abs. 1).

132 Diese beiden Benennungen werden nicht nur in obiger Beschreibung des Verfahrensablaufs aus den Bewerbungsbedingungen, sondern auch während der Überarbeitungsprozesse synonym verwendet. 
- Den Zuschlag, den der Auftraggeber dem Bieter erteilt, der die Ausschreibung gewonnen hat.

Diese Beschreibung dieser Verfahrensvariante ist für den ausgeschriebenen Gegenstand der SPNV-Verkehrsleistungen insoweit auf andere Verfahren und Auftraggeber übertragbar, als sie der Verdingungsordnung für Leistungen folgt (BEWERBUngSBEDINGUngeN; Ausschreibung 1, S. 4). Gleichzeitig schränkt AuFTRAGGEBER 1, der Ausschreibung 1 veranstaltet, im Interview ein, dass AUFTRAGGEBER 2 ,in der Regel einen anderen Verfahrensablauf im Verhandlungsverfahren“ (AuftraGgeBer 1, 2013, S. 3) wählt, indem er die Bieter ein sogenanntes indikatives, also ein unverbindliches, Angebot vor der Abgabe der Optimierungsvorschläge einreichen lässt, das bei Auftraggeber 1 meist nicht gefordert wird. Dieses Verfahren bestätigt auch Auftraggeber 2 in Bezug auf Ausschreibung 2 aus dem Jahr 2010, wobei er das endgültige Angebot als verbindliches Angebot bezeichnet (AUFTRAGGEBER 2, 2010b, S. 1).

Vor dem Verfahren, Optimierungsvorschläge abzugeben, forderte Auftraggeber 2 in vergangenen Verfahren (aus dem Jahr 2009) von den Bietern ca. 60- bis 100seitige Angebotstexte und Anhänge wie das Lastenheftformular, die als Fließtext den größten Teil der Pflichtenhefte ausmachten. ${ }^{133}$ Als Grund für den Wechsel von Angebotstexten zu Optimierungsvorschlägen und Gesprächen gab Auftraggeber 2 an:

„Der Bietermarkt ist klein, wir möchten die Angebote so einfach wie möglich haben. So optimieren wir den Vorgang für die Bieter und für uns als Aufgabenträger. Denn lange Angebotstexte bergen die Gefahr in sich, dass man etwas übersieht, beispielsweise einen Teil der Mindestanforderungen.“ (AUfTRAGGEBER 2, 2010b, S. 2)

Der Wechsel von Angebotstexten zu Optimierungsvorschlägen (OV) und Anhängen macht deutlich, dass der Ablauf des Verfahrens variiert werden kann. So schränkt AUfTRAGGEBER 1 auch ein, dass sich ,[d]ie allgemeine Tendenz, OV zu verwenden, [...] wieder ändern“ (AUfTRAGGEBER 1, 2013, S. 4) kann:

133 Diese Angebotstexte überarbeitete ich während meiner Tätigkeit beim Bieter vor Beginn dieses Forschungsprojekts. 
„Die für das SPNV-Ausschreibungswesen relevante Verdingungsordnung für Leistungen - Teil A (VOL - A) lässt unter bestimmten Bedingungen verschiedene Verfahren zu. Standardverfahren ist das offene Verfahren, bei dem Rückfragen möglich sind, aber keine OV [Optimierungsvorschläge; $\mathrm{AH}$ ] gefordert oder Gespräche geführt werden. Dieses Verfahren haben wir früher verwendet. U. a. mit Implementierung [eines Modells; $\mathrm{AH}$ ] unserer Kollegen [von Auftraggeber 2; $\mathrm{AH}$ ] wurde als Verfahrensart das Verhandlungsverfahren gewählt, in dem es die Möglichkeit der Verhandlungsgespräche mit der vorherigen Abgabe von Optimierungsvorschlägen gibt.“ (ebd., S. 3)

Auch wenn die Verdingungsunterlagen und damit das Textsortennetz je nach Verfahren verschiedene Textsorten enthält bzw. nicht enthält - beispielsweise Bietergespräche und Optimierungsvorschläge -, sind die Unterlagen grundsätzlich vergleichbar. So sind insbesondere Lastenhefte und Pflichtenhefte, aber auch Fahrplanvarianten in allen untersuchten Ausschreibungen obligatorisch. Dies legt auch die Tatsache nahe, dass AUfTRAGGEBER 1 bei Ausschreibungsverfahren eng mit Auftraggeber 2 zusammenarbeitet. Die Zusammenarbeit wird notwendig, weil die geographischen Zuständigkeitsgebiete beider Auftraggeber aneinander grenzen und eine ausgeschriebene Strecke häufig beide Gebiete durchläuft. In dieser Zusammenarbeit strebt Auftraggeber 1 (2013, S. 4) eine Standardisierung der Verdingungsunterlagen an und auch AufTRAGGEBER 2 (2010b, S. 2) bestätigt, die Verdingungsunterlagen unabhängig vom jeweiligen Ausschreibungsverfahren zu standardisieren.

Demnach und aufgrund der Standardisierung dieser öffentlichen Ausschreibungsverfahren durch die Verdingungsordnung für Leistungen sind Erkenntnisse, die aus obiger Beschreibung des Verfahrensablaufs hervorgehen, wie auch das daraus resultierende Textsortennetz auch auf andere SPNV-Ausschreibungsverfahren der beiden Auftraggeber übertragbar. Wie die Analyse der Interviews mit weiteren Auftraggebern zeigt (s. Kapitel 4.2.3), sind die Erkenntnisse zum Teil auch auf Verfahren anderer Auftraggeber übertragbar.

Da das Ziel dieser Arbeit darin besteht, semiotische Effizienz im Ausschreibungsverfahren zu erforschen, bietet es sich an, das Untersuchungskorpus aus Textsortenexemplaren zusammenzustellen, die Teil des Textsortennetzes zu Ausschreibungsverfahren sind. Demnach setzt sich das Korpus zusammen aus Textsorten der Verdingungsunterlagen, aus Optimierungsvorschlägen, Pflichtenheften und Fahrplänen des beobachteten Bieters sowie Beobachtungen der gemeinsamen Textüberarbeitungen für die endgültige Abgabeversion. 
Die Synopse (s. Tabelle 4-3) zeigt, dass eine Vielzahl der Kategorien verfahrensbedingter funktionaler Relationen nach KLEIN (2014a) und OSTAPENKO (2009) Textsorten des Netzes öffentlicher Ausschreibungsverfahren zugeordnet werden können. Dies verdeutlicht die Relevanz dieser Textsortenkonzeption für die vorliegende Untersuchung. So finden sich im Textsortennetz zu Ausschreibungsverfahren folgende funktionale Relationen aus KLEIN (2014a) und OSTAPENKO (2009): funktionale Text-Text-Relationen, Text-Verfahrensrelationen, aber auch komplexe Relationen, in denen eine Textsorte des Textsortennetzes mit anderen verfahrensbedingten Textsortennetzen verknüpft ist. Die genannten Konzeptionen erfassen die funktionalen Relationen aus SPNV-Ausschreibungsverfahren aber nicht vollständig. 


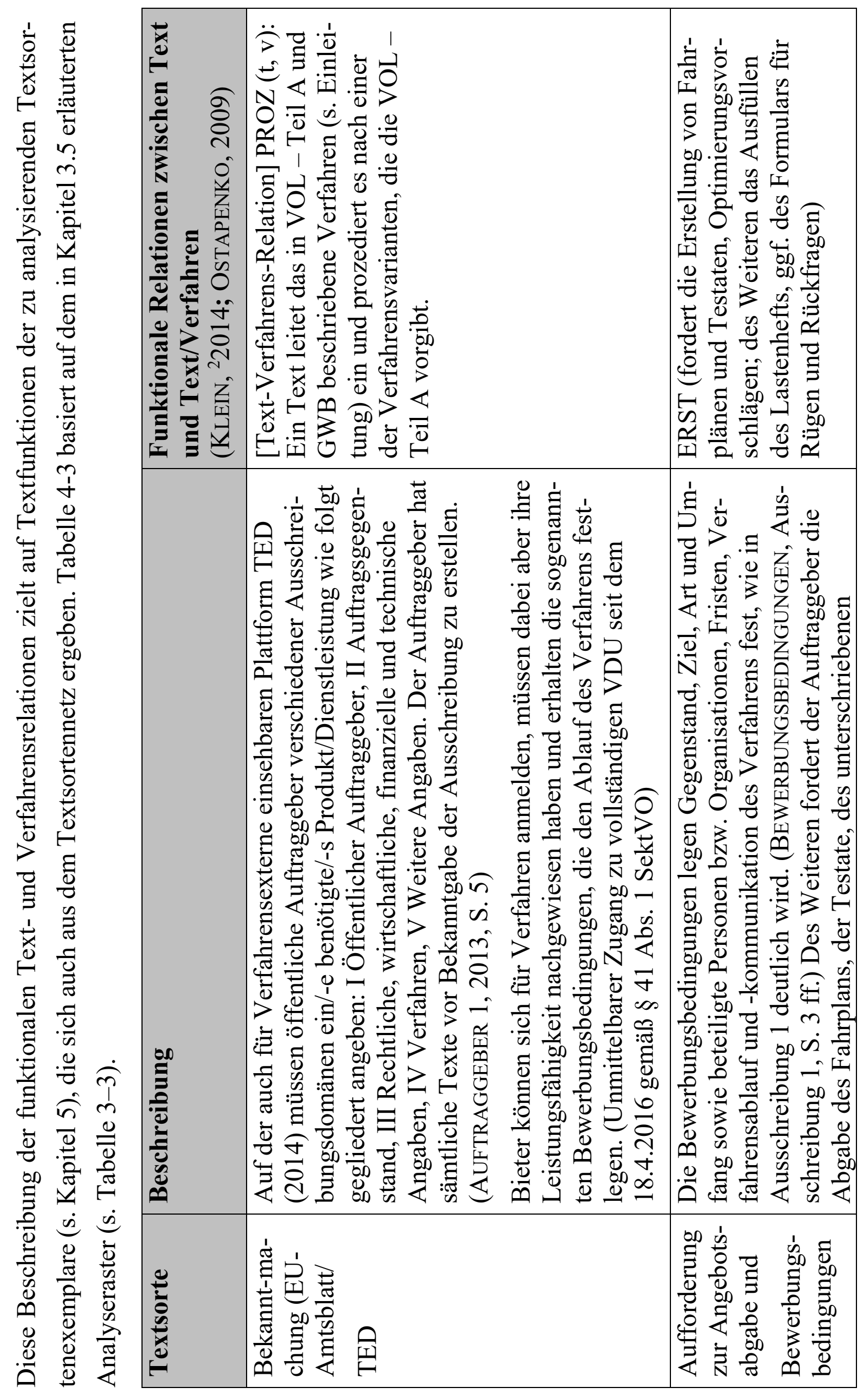




\begin{tabular}{|c|c|c|c|c|c|c|}
\hline 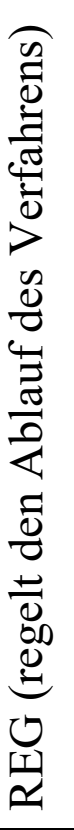 & 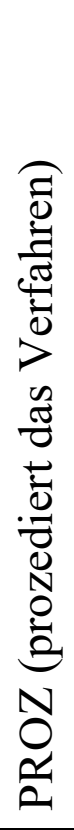 & 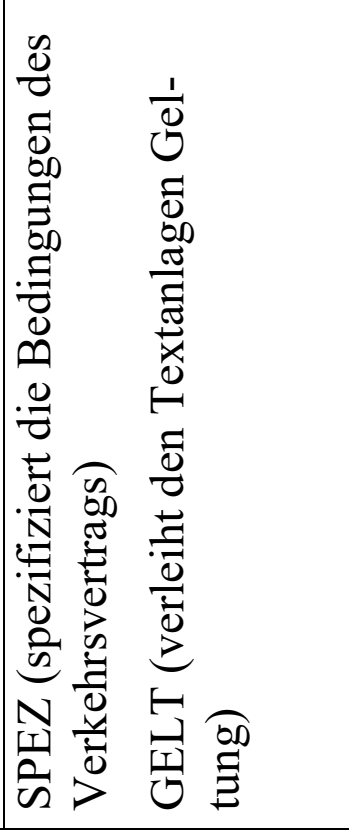 & & 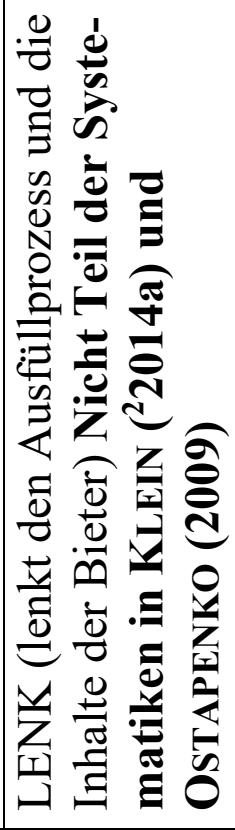 & 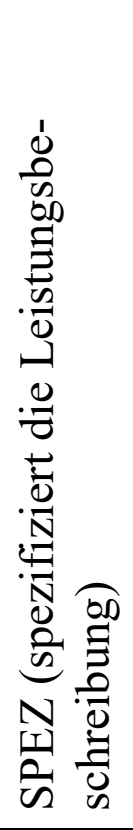 & 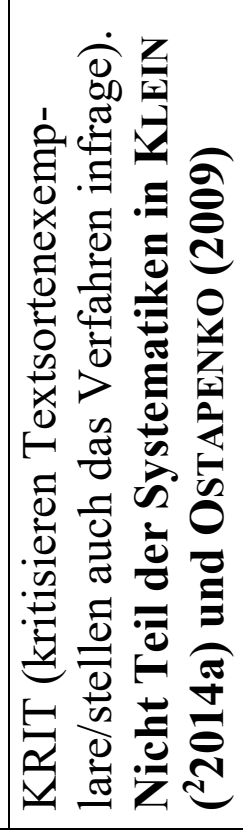 \\
\hline 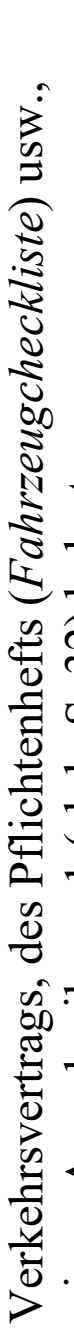 & 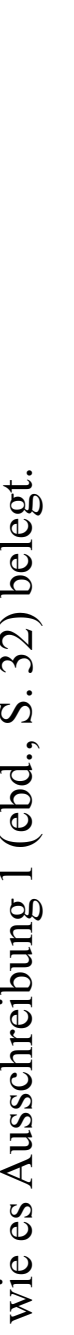 & 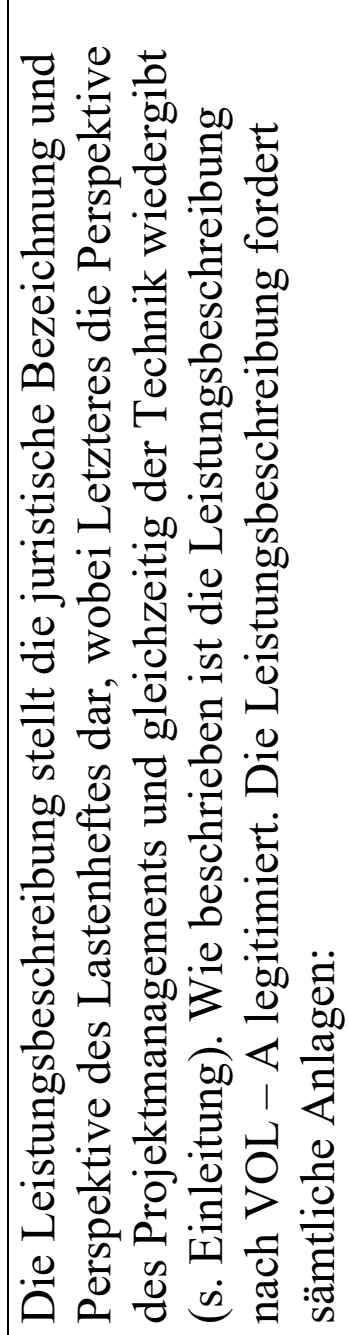 & 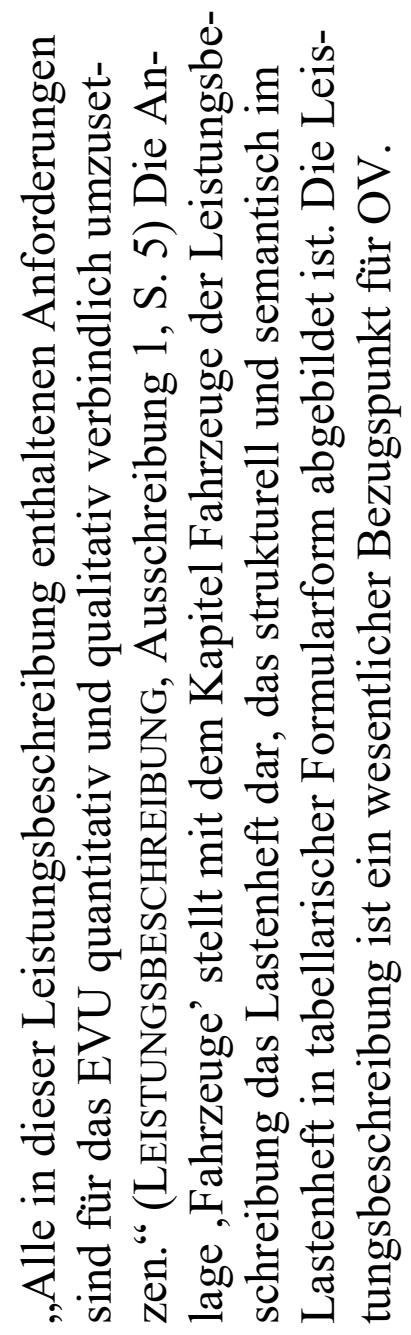 & 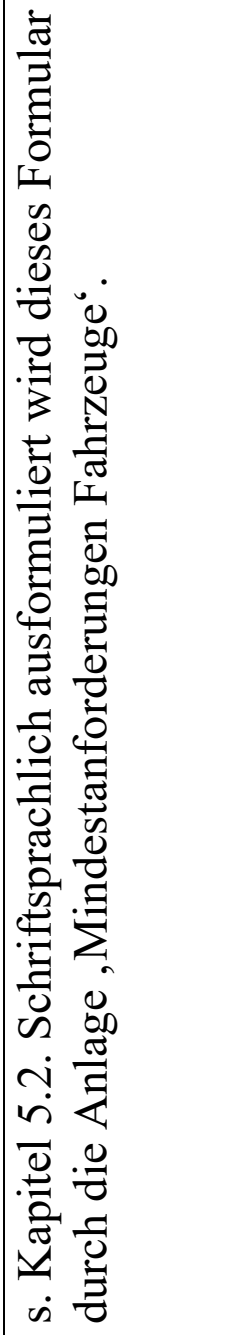 & & 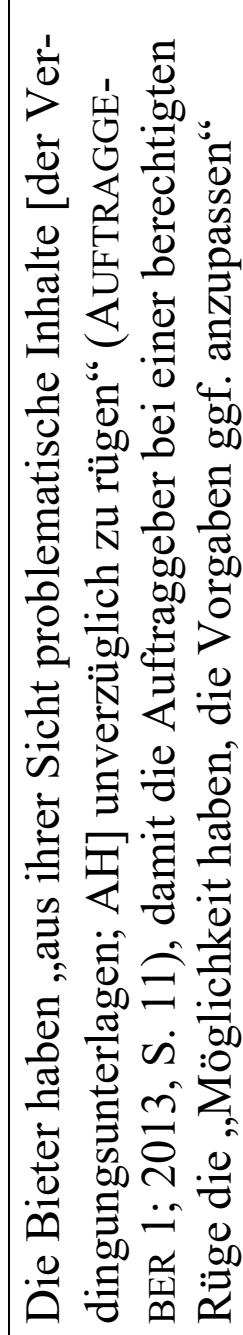 \\
\hline & & 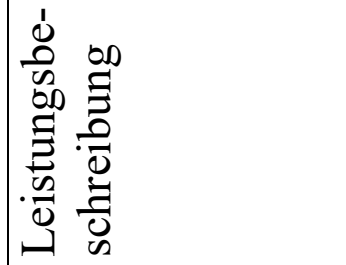 & & 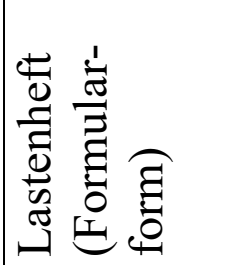 & & 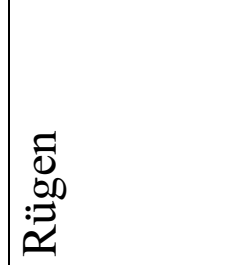 \\
\hline
\end{tabular}




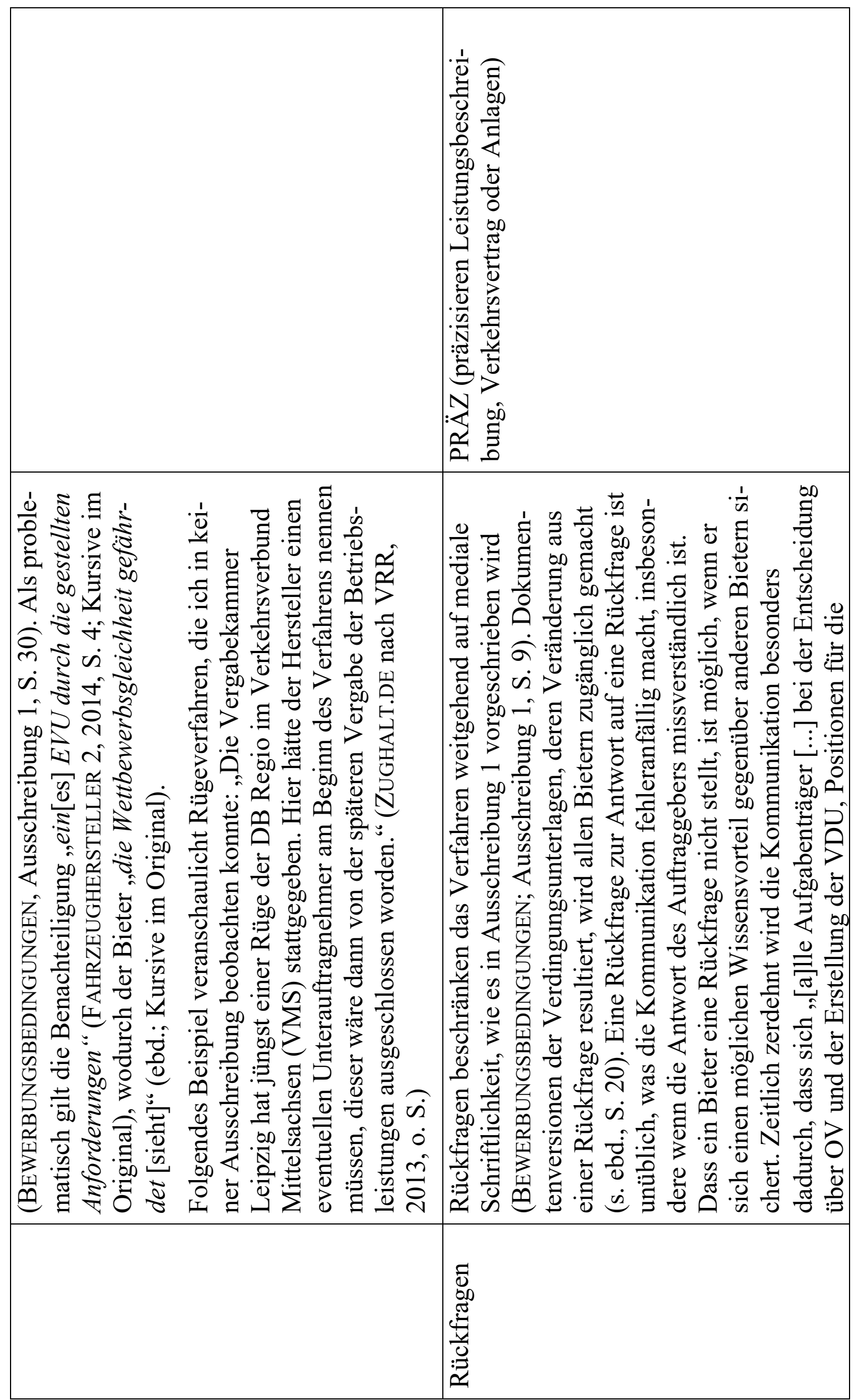




\begin{tabular}{|c|c|c|}
\hline & 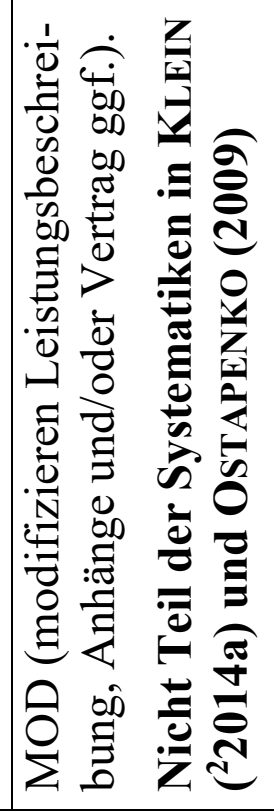 & 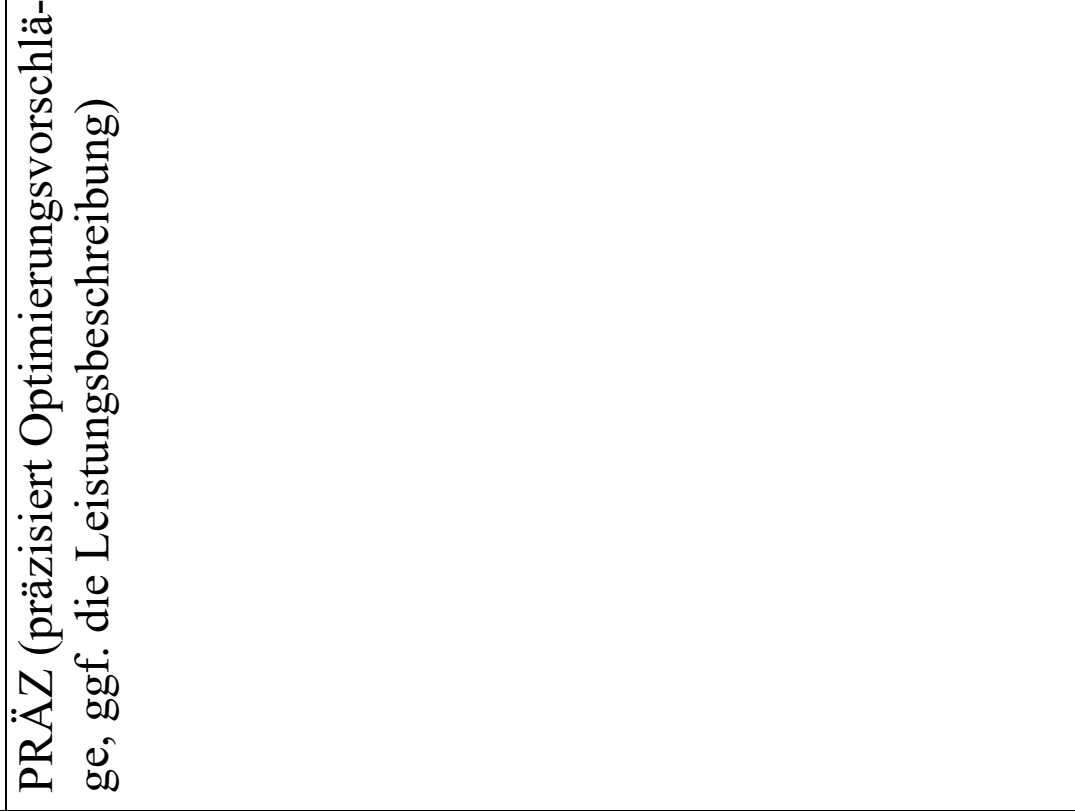 \\
\hline 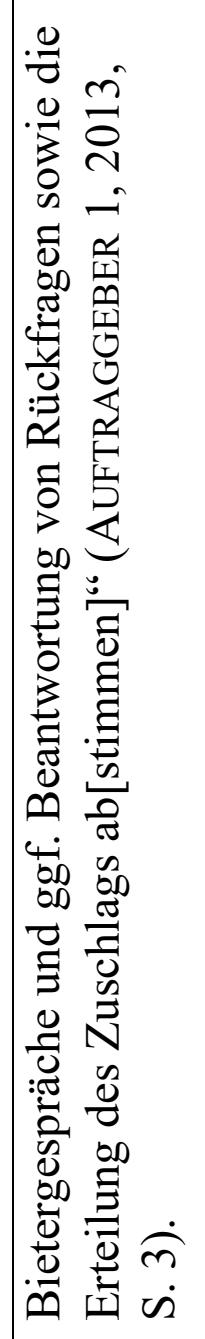 & 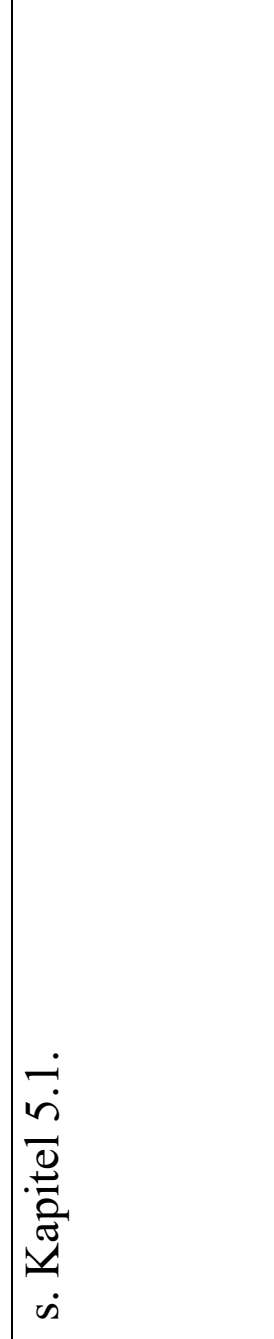 & 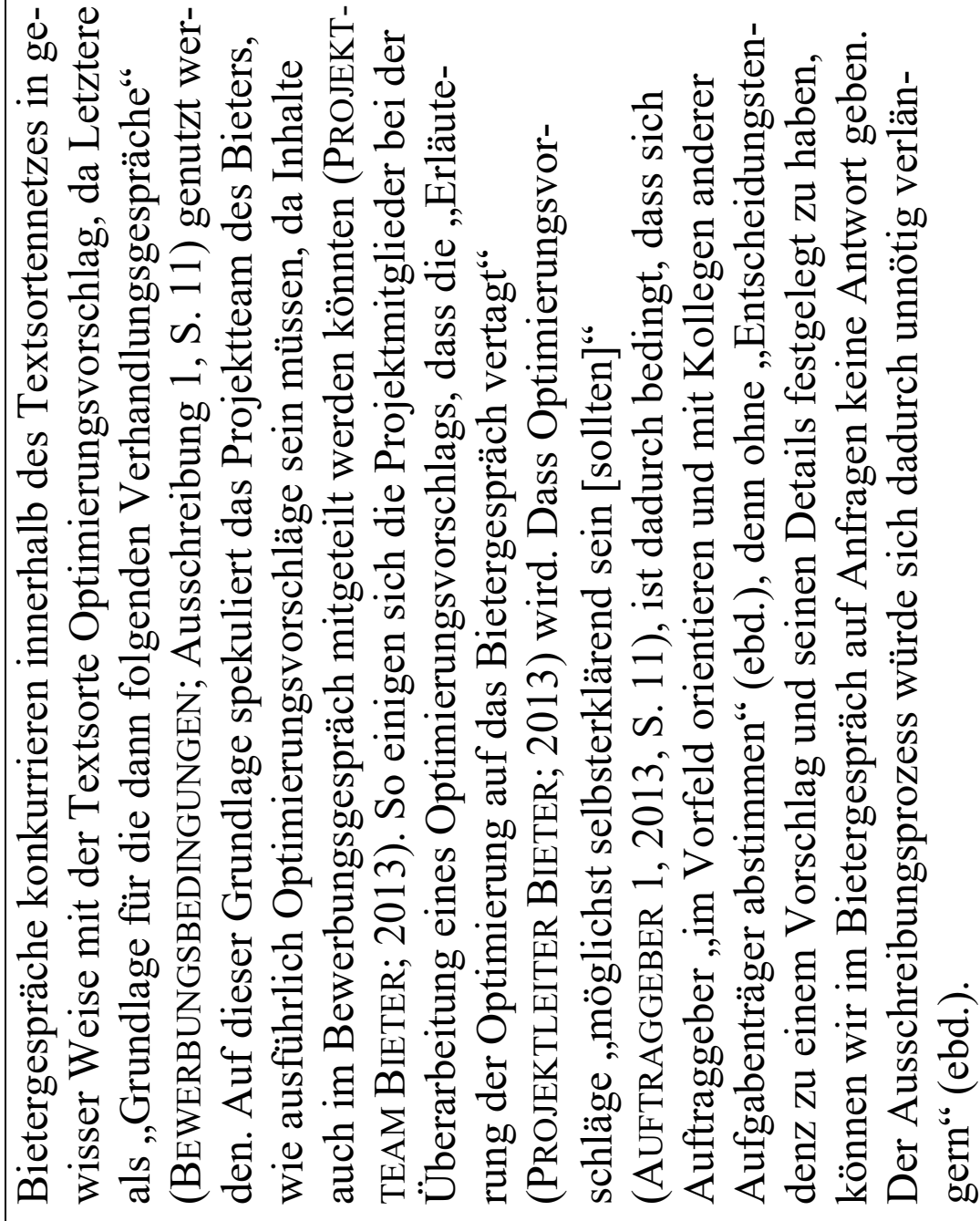 \\
\hline & 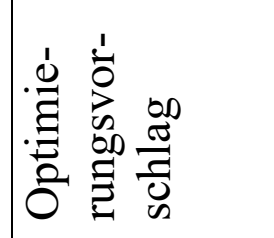 & 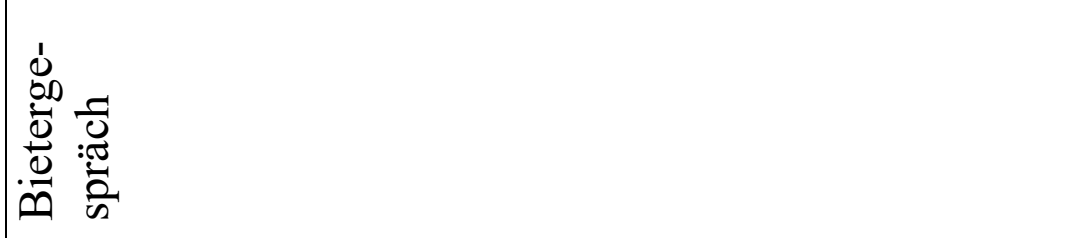 \\
\hline
\end{tabular}




\begin{tabular}{|c|c|c|c|}
\hline 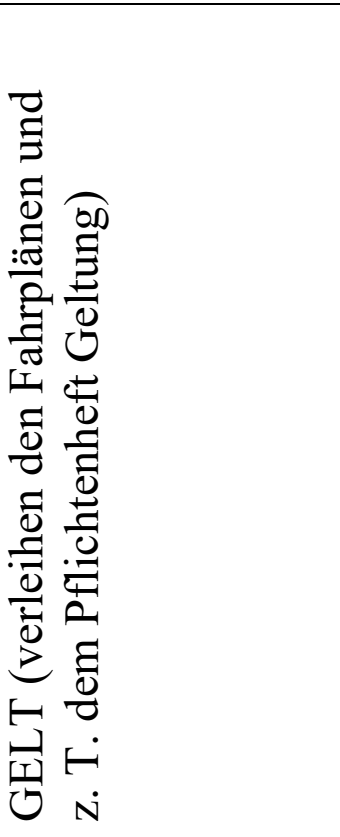 & 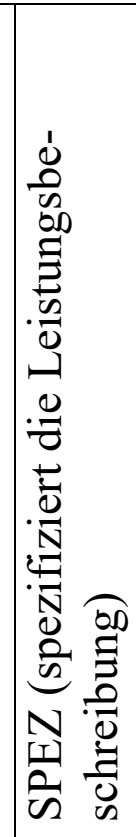 & 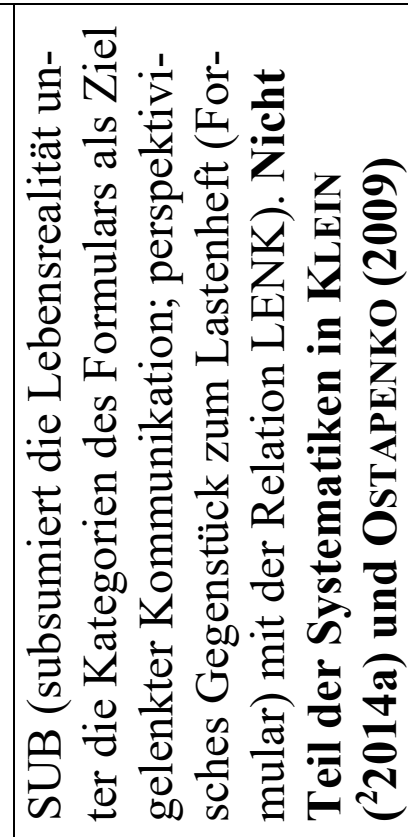 & 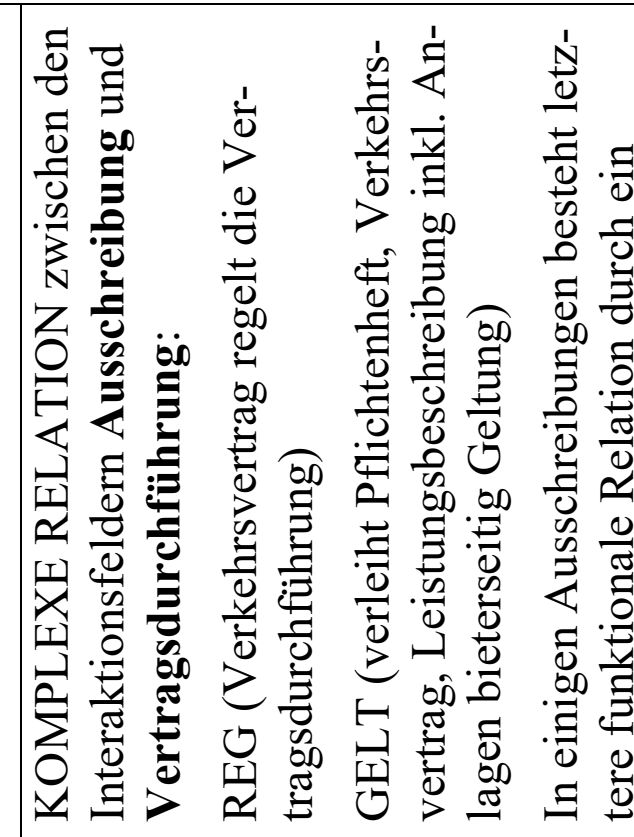 \\
\hline 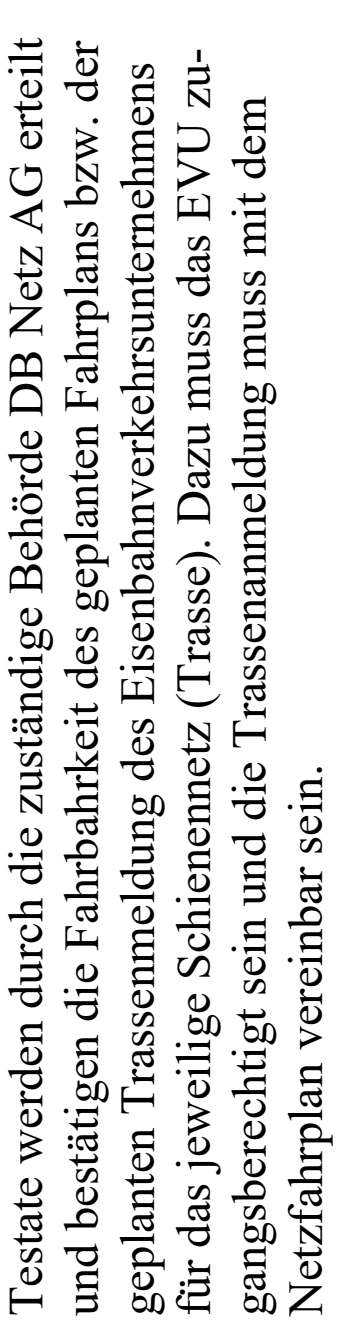 & & 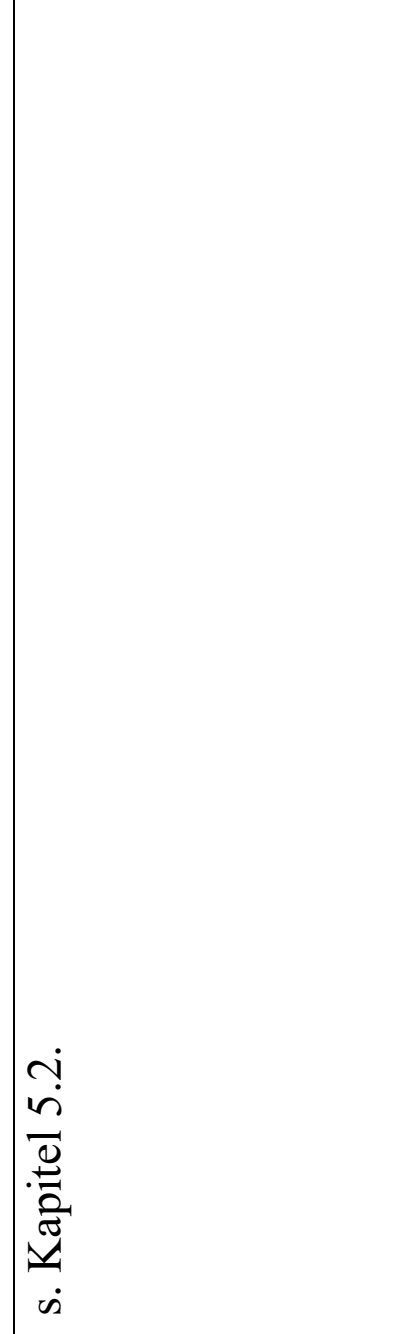 & 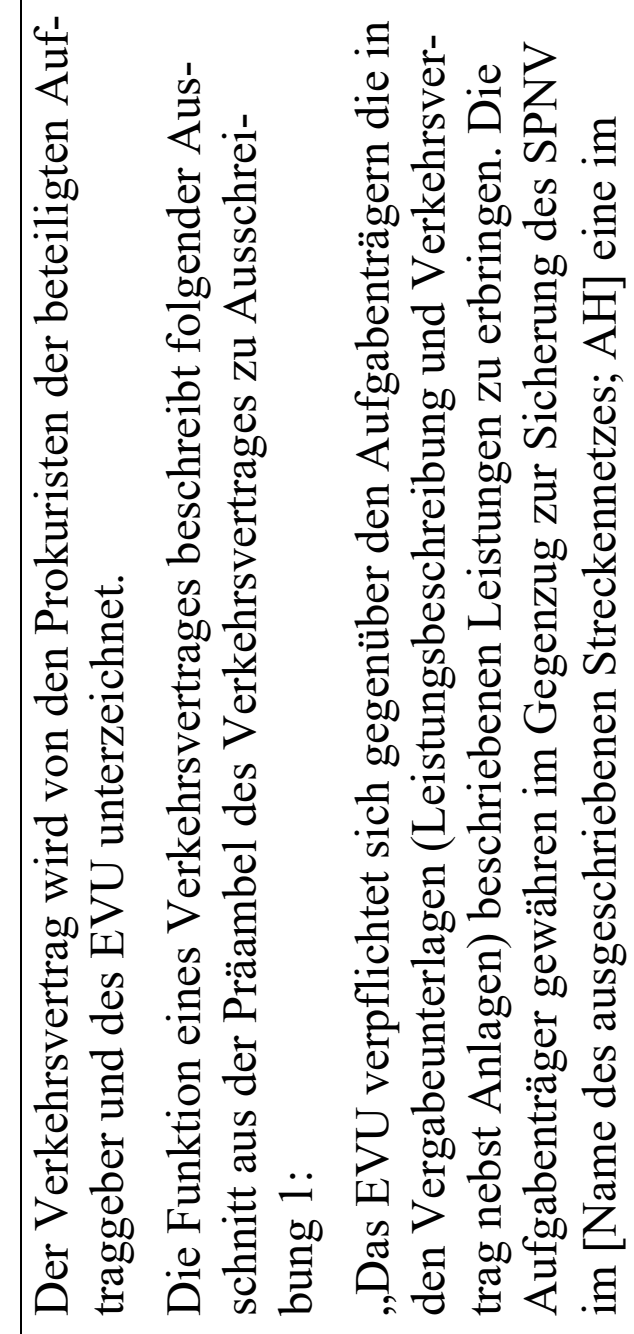 \\
\hline 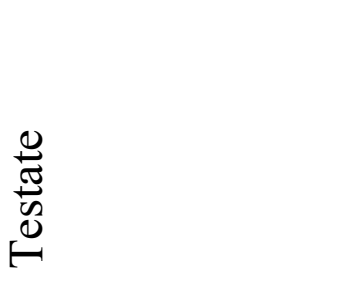 & 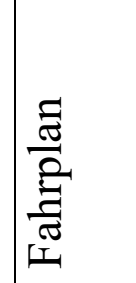 & 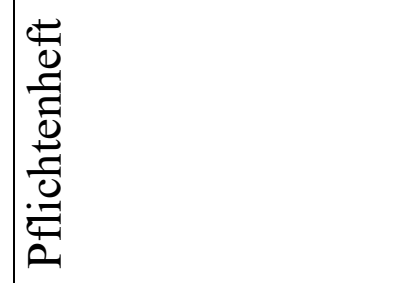 & 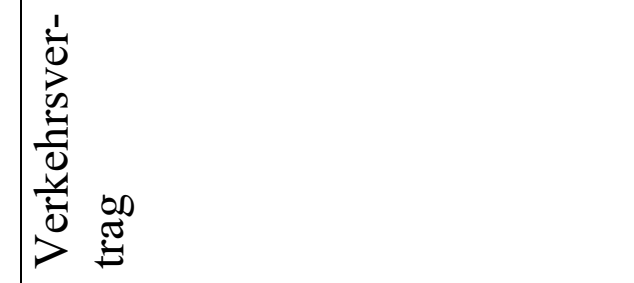 \\
\hline
\end{tabular}



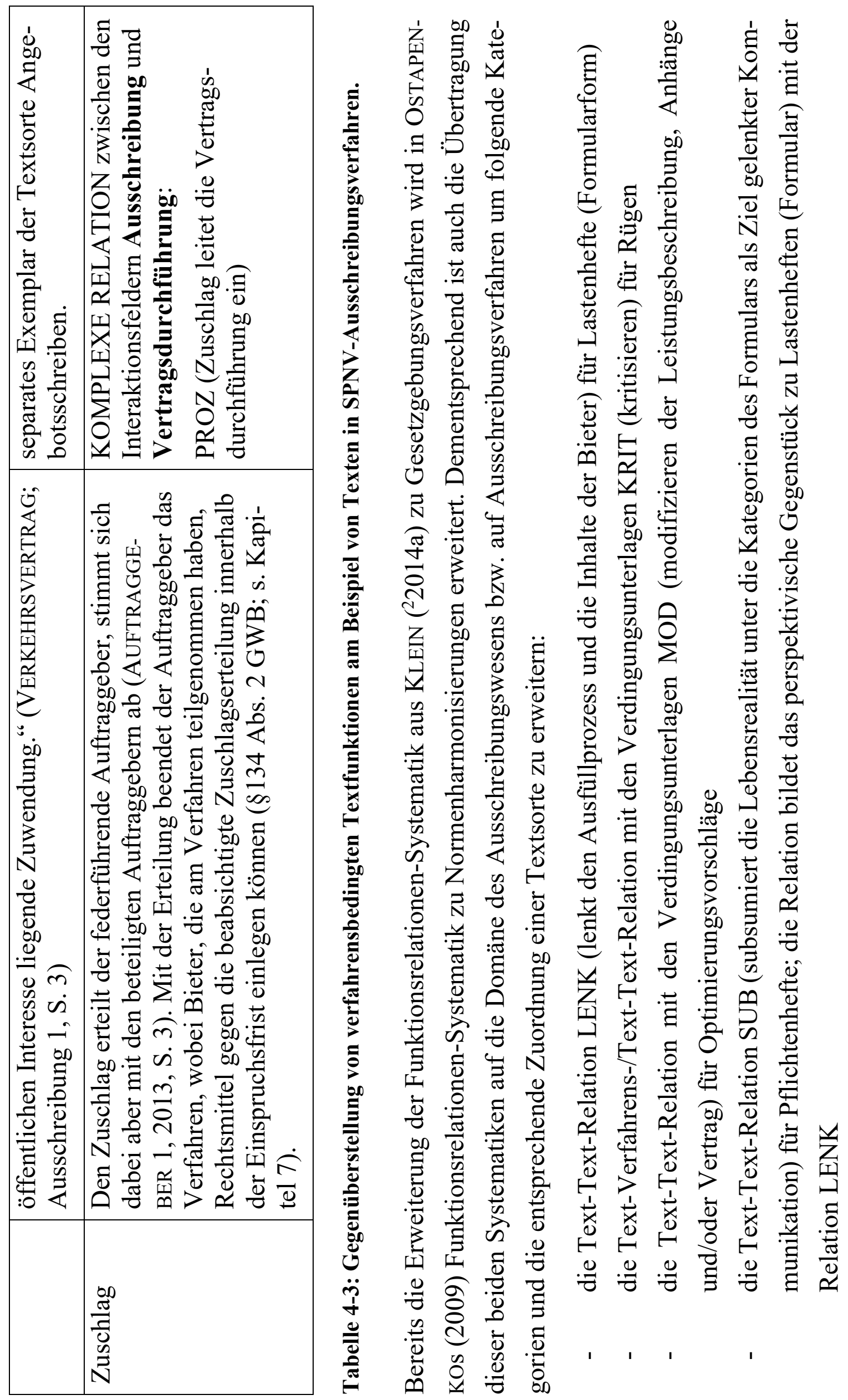
Im Zentrum der anschließenden Textanalyse stehen vor allem Relationen, die die Textsorten Lasten- und Pflichtenheft, aber auch Optimierungsvorschläge betreffen.

Neben der Funktionsrelationen-Systematik charakterisieren thematische Fixierung, enge Kooperation der Kommunikanten und weitgehend offiziell-dialogische Kommunikation das Textsortennetz: Die Textsorten des Textsortennetzes werden thematisch stark fixiert, indem jeder Textsorte ein Thema und eine Position im Textsortennetz zugewiesen werden. Beispielsweise thematisieren Lastenhefte Teilaspekte der Anforderungen an das Angebot zu Fahrzeugen und deren Betrieb, während Pflichtenhefte Teilaspekte der Verpflichtung des entsprechenden Angebots formulieren. Auch die Fahrplanvarianten sind thematisch durch Teilaspekte der Anforderungen in den Verdingungsunterlagen bestimmt bzw. ist das Textthema der Fahrplanvarianten durch die Bedeutung der Verdingungsunterlagen standardisiert. Lediglich die Optimierungsvorschläge sind in der Themenentwicklung insoweit frei, als sie ein beliebiges Teilthema der Verdingungsunterlagen oder ein aus diesen Unterlagen abgeleitetes Thema behandeln können.

Durch die Bewerbungssituation der Bieter ist davon auszugehen, dass diese eine intensive Kooperation anstreben. Der Grad der Kooperationsbereitschaft der Auftraggeber wird durch die Vorgabe bestimmt, Transparenz und Diskriminierungsfreiheit zu gewährleisten. D. h., die Kooperationsbereitschaft ist an der Stelle als intensiv anzunehmen, an der Kommunikation es den Auftraggebern ermöglicht, alle Bieter gleichberechtigt zu behandeln und dieses Handeln transparent zu machen. Die Kooperationsbereitschaft eines Bieters endet an der Stelle, an der ein Bieter diskriminiert oder das Verfahren intransparent wird. Ein hoher Grad an Öffentlichkeit ist durch die Regulierung des Verfahrens auf der Grundlage von Gesetzen und Verordnungen sowie der Möglichkeit gegeben, eine Vergabekammer oder ein Gericht bei Widersprüchen einzuschalten. Demnach besteht ein sehr hoher Grad an Öffentlichkeit.

Auch die zu gewährleistende Transparenz des Verfahrens erfordert einen hohen Grad an Öffentlichkeit innerhalb des Verfahrens - so werden beispielweise Änderungen der Vorgaben durch Rückfragen und Rügen anderer Bieter allen Bietern bekannt gegeben. Öffentlichkeit erscheint dementsprechend eher durch das Oppositionspaar offizielle und inoffizielle Kommunikation beschreibbar: Die 
Ausschreibungskommunikation ist in hohem Maße offiziell und darf aufgrund der Gebote von Transparenz und Diskriminierungsfreiheit nicht inoffiziell sein. Für die Kategorisierung entsprechend dem Paar ,offiziell ${ }^{\star}$ - , inoffiziell' spricht des Weiteren, dass die Geheimhaltungsklausel zum Verfahren ausschließt, dass Verfahrensexterne (Gerichte, externe Berater und Vergabekammer ausgenommen) an der Kommunikation als Produzent oder Rezipient teilnehmen können. Daher sind die Dokumente dieser Ausschreibungskommunikation für Untersuchungen äußerst schwierig zugänglich (s. Kapitel 4.1).

Die Kommunikation mittels Optimierungsvorschlägen und Fahrplanvarianten als Antwort der Bieter auf die Verdingungsunterlagen des Auftraggebers ist weitgehend dialogisch. Die Kommunikationsform Formular prägt die Textsorten(-varianten) Lasten- und Pflichtenheft, wie die Vorgabe aus den Bewerbungsbedingungen in Ausschreibung 1 verdeutlicht:

„Für das Angebot sind die von den Aufgabenträgern vorgegebenen Formblätter/Vordrucke (ggf. in Kopie) zu verwenden. Die Verwendung selbstgefertigter Fassungen ist unzulässig, sofern in den Vergabeunterlagen nichts anderes geregelt ist.“ (BEWERBUNGSBEDINGUNGEN; Ausschreibung 1, S. 16)

Diese Formalisierung dient einerseits dem Ziel von Formularkommunikation, Anträge von Klienten vergleichbar zu halten, andererseits dem Ziel der Auftraggeber, Qualität und Angemessenheit des Preises zu gewährleisten (s. Kapitel 4.3.1). D. h., in Ausschreibungskommunikation verfolgt die Wahl der Formularkommunikation einerseits das Ziel, die Angebote der Bieter vergleichbar zu halten und damit Transparenz und Diskriminierungsfreiheit zu gewährleisten. Andererseits wird durch die Lastenhefte als Vordrucke sichergestellt, dass die Fahrzeuge in künftigen Ausschreibungen eingesetzt werden können, weil die Vordrucke sich an den Empfehlungen für Fahrzeuge der BAG SPNV orientieren, die auf die Normierung der Vorgaben aller Auftraggeber im deutschen SPNV zielen.

Bei Lasten- und Pflichtenheft handelt es sich um einen medial und konzeptionell verschriftlichten Dialog, der in den Texten medial (KOCH/OESTERREICHER, 1985) bzw. der modal auch ikonisch-bildlich repräsentiert wird. Denn die verschriftlichten Sprecherspuren des zeitlich zerdehnten Dialogs zwischen Auftraggeber und Bieter werden durch Textdesign angeordnet (mediale Schriftlichkeit). Lastenheftvordrucke entstehen durch die Transformation von Gesetzen und Verordnungen, aber auch durch die Begrenzung der schriftsprachlichen und bildlichen Antwort- 
möglichkeiten für das Pflichtenheft. D. h., die Bieter müssen die Komplexität ihres Angebots unter die Kategorien der Auftraggeber subsumieren (s. Kapitel 4.3.1). Teil der konzeptionellen Verschriftlichung bzw. Verbildlichung ist auch die Vorgabe, Vordrucke des Auftraggebers nicht verändern zu dürfen. Denn diese Vorgabe dient dem Ziel der Diskriminierungsfreiheit bzw. der Vergleichbarkeit von Angeboten: „Änderungen an den Vergabeunterlagen sind unzulässig.“ (Bewerbungsbedingungen; Ausschreibung 1, S. 16)

Darüber hinaus sind Lasten- und Pflichtenheften als Formulare gestaltet, sodass die Kommunikanten als Prozipienten (s. Abbildung 2-12) spezifiziert werden können: Der Auftraggeber wird durch das Lastenheft zum Produzenten des Ausgangstextes, der die Antwortmöglichkeiten des Bieters begrenzt. ${ }^{133}$ Ein Prozipient ist der Auftraggeber insoweit, als er nicht nur Produzent des Lastenhefts, sondern gleichzeitig Rezipient des Pflichtenhefts der Bieter ist. Die Bieter sind ebenfalls Prozipienten, da sie Rezipienten der Lastenhefte und Verdingungsunterlagen, gleichzeitig aber auch Produzenten der Pflichtenhefte sind. Diese Beschreibung des Textsortennetzes und seiner Relationen dient dazu, die anschließende Beschreibung der Teilkorpora, deren Einteilung und Differenzierung nachvollziehen zu können.

\subsubsection{Verdingungsunterlagen der Auftraggeber}

Das Teilkorpus der Verdingungsunterlagen umfasst mehrere Textsorten, deren Exemplare das Teilkorpus wie folgt zusammensetzen (s. Tabelle 4-4):

\begin{tabular}{|l|c|c|}
\hline Textsorte & $\begin{array}{c}\text { Anzahl der } \\
\text { Exemplare }\end{array}$ & Summe der Seiten \\
\hline Bewerbungsbedingungen & 1 & 21 \\
\hline Leistungsbeschreibung & 3 & 199 \\
\hline Verkehrsvertrag & 1 & 26 \\
\hline
\end{tabular}

133 Damit handelt es sich beim Lastenheft als Kommunikationshandlung entsprechend dem integrativen Modell der Fachkommunikation (s. Kapitel 2.1.2) um eine Vorkommunikationshandlung des Auftraggebers, die die Kommunikationshandlung des Bieters lenkt. 


\begin{tabular}{|l|c|c|}
\hline $\begin{array}{l}\text { (Mindest-)Anforderungen Fahr- } \\
\text { zeug }\end{array}$ & 4 & 100 \\
\hline Lastenheftvordruck & 6 & 42 \\
\hline
\end{tabular}

Tabelle 4-4: Übersicht und quantitative Angaben zum Teilkorpus Verdingungsunterlagen (eigene Darstellung).

Zusätzlich zu diesem Überblick von Textsortenexemplaren, die ausschließlich nach Textsorten gegliedert sind, differenziert Tabelle 4-5 die Verdingungsunterlagen nach Textsorten und Ausschreibungsverfahren, um den Zusammenhang mit dem beschriebenen Erhebungsprozess herstellen zu können.

\begin{tabular}{|l|l|l|c|}
\hline $\begin{array}{l}\text { Ausschreibung } \\
\text { (anonym) }\end{array}$ & Auftraggeber & Art des Dokuments & $\begin{array}{c}\text { Summe } \\
\text { der Seiten }\end{array}$ \\
\hline $\begin{array}{l}\text { Ausschreibung 1 } \\
(2013)\end{array}$ & Auftraggeber 1 & Bewerbungsbedingungen & 31 \\
\hline & & $\begin{array}{l}\text { Leistungsbeschreibung } \\
\text { Anlage - Anforderungen } \\
\text { an die einzusetzenden } \\
\text { Fahrzeuge }\end{array}$ & 37 \\
\hline & & Lastenheftvordruck & 8 \\
\hline $\begin{array}{l}\text { Ausschreibung 2 } \\
(2013)\end{array}$ & Auftraggeber 2 & Lerkehrsvertrag & 26 \\
\hline & & $\begin{array}{l}\text { Anlage - Mindestanforde- } \\
\text { rungen Fahrzeuge }\end{array}$ & 15 \\
\hline $\begin{array}{l}\text { Ausschreibung 3 } \\
(2010)\end{array}$ & Auftraggeber 2 & Lastenheftvordruck & 13 \\
\hline & & $\begin{array}{l}\text { Anlage 2 Mindestanforde- } \\
\text { rungen Fahrzeuge }\end{array}$ & 21 \\
\hline $\begin{array}{l}\text { Ausschreibung 4 } \\
(2012)\end{array}$ & Auftraggeber 3 & Fahrzengeftreibung & 52 \\
\hline & & Lastenheftvordruck & 34 \\
\hline
\end{tabular}




\begin{tabular}{|l|l|l|c|}
\hline $\begin{array}{l}\text { Ausschreibung 5 } \\
(2011)\end{array}$ & Auftraggeber 3 & Lastenheftvordruck & 3 \\
\hline $\begin{array}{l}\text { Ausschreibung 5 } \\
(2011)\end{array}$ & Auftraggeber 3 & Lastenheftvordruck & 3 \\
\hline
\end{tabular}

Tabelle 4-5: Übersicht über das Teilkorpus Verdingungsunterlagen (eigene Darstellung).

Die vorliegenden Verdingungsunterlagen von Auftraggeber 1 und 2 eignen sich dazu, übertragbare Aussagen zu Texten dieses Auftraggebers zu treffen. Denn die Verdingungsunterlagen werden auf der Grundlage von Mustertexten bzw. Vorlagen erstellt. Dies belegt das Interview mit Auftraggeber 2:

„Wir haben 2009 Mustervergabeunterlagen entworfen, die mit einem Lückentext vergleichbar sind. Diese passen wir bei Verfahren nur noch den entsprechenden Zielwerten für eine auszuschreibende Linie an, beispielweise passen wir die Anforderungen an Kapazitäten an. Das dauert nur wenige Stunden, beispielweise konnte ich letzte Woche Verdingungsunterlagen für ein anstehendes Verfahren an einem Nachmittag anpassen.“ (AUfTRAGGEBER 2, 2010b, S. 2)

Der Vergleich der Verdingungsunterlagen von Auftraggeber 2 in Ausschreibung 3 (im Jahr 2010) und in Ausschreibung 2 (im Jahr 2013), insbesondere der Vergleich der Lastenhefte, belegt die Aussage von Auftraggeber 2.

Das Interview mit Auftraggeber 1 zeigt, dass Verdingungsunterlagen vergangener Ausschreibungen bei diesem Auftraggeber die Grundlage für Unterlagen anstehender Ausschreibungen sind. D. h., modifizierte Verdingungsunterlagen werden wiederverwendet:

„Wir arbeiten nach dem Baukastensystem: Die VDU der letzten Ausschreibungen dienen als Grundlage für die anstehende Ausschreibung. Dabei nutzen wir die letzte Version dieser VDU, d. h. eine Version, in die OV und Rückfragen der letzten Ausschreibung eingeflossen sind.

Des Weiteren beziehen wir in die Überarbeitung der alten VDU die Erfahrungen des Vertragscontrollings im Hause ein, das laufende Verkehrsverträge (also auch bereits vergebene Ausschreibungen) überwacht. Wenn es Probleme gab oder gibt, passen wir die VDU an der entsprechenden Stelle an, um diese Probleme bei der kommenden Ausschreibung auszuräumen.“(AUfTRAGGEBER 1, 2013, S. 5)

Nicht nur die Selbstaussagen zu Bestrebungen beider Auftraggeber machen deutlich, dass die Textsortenexemplare der Verdingungsunterlagen vereinheitlicht werden sollen, sondern auch die konkreten Aussagen zum Vorgehen bei der Textproduktion mithilfe von Mustervorlagen oder auf der Grundlage eines sogenannten Text-Baukastensystems machen dies deutlich. Auch die festgestellte Einheit- 
lichkeit der Verdingungsunterlagen zu Ausschreibung 2 und 3, die Auftraggeber 2 im Abstand von drei Jahren durchführte, untermauern diese Aussagen.

Der Grund für diese Vereinheitlichung der Texte liegt aber nicht nur in der Motivation begründet, den Aufwand bei der Textproduktion zu minimieren und textuelle Fehlerquellen durch Schreibprozesse auszuschließen. Letztlich ist die Vereinheitlichung der Verdingungsunterlagen beim selben Auftraggeber und auch zwischen verschiedenen Auftraggebern durch den ökonomischen Nutzen motiviert, die geforderten Fahrzeuge im Anschluss an die Vertragslaufzeit beim selben Auftraggeber oder bundesweit bei anderen Auftraggebern einsetzen zu können und so teure Neuanschaffungen zu vermeiden. Denn während die meisten Verkehrsverträge zu einer Ausschreibung 12 Jahre laufen, werden die Fahrzeuge ca. 30 Jahre genutzt. Dieser Motivationspunkt, die Verdingungsunterlagen verschiedener Auftraggeber zu vereinheitlichen, geht aus dem Interview mit Auftraggeber 1 hervor:

„Eine fehlende Standardisierung wäre ein Kostentreiber: Wenn die Anforderungen an die Fahrzeuge in den Ausschreibungen nicht standardisiert wären, bestünde eine [sic] hohes Restwertrisiko, ob Fahrzeuge in anderen zukünftigen Verfahren verwendet werden könnten." (AUFTRAGGEBER 1, 2013, S. 6 f.)

Auch die Empfehlungen für Fahrzeuge vom BAG SPNV verdeutlichen die Bemühungen um Vereinheitlichung der Verdingungsunterlagen für Ausschreibungsverfahren: Da „zu individuelle oder zu eng gefasste Vorgaben für Fahrzeuge und ihre Ausstattung die Fahrzeugindustrie zu teuren Anpassungen und Sonderentwicklungen nötigen“ (BAG SPNV, ${ }^{32} 2016$, S. 1), werden Vorgabeempfehlungen für Fahrzeuge durch die BAG SPNV notwendig (ebd., S. 1 f.). Somit standardisieren diese Empfehlungen nicht nur die Fahrzeuge als physikalische Objekte, sondern auch die Verdingungsunterlagen.

Wie bereits die Beschreibung des Textsortennetzes ankündigt, ist an dieser Stelle zu behandeln, inwieweit von den Ergebnissen aus Analysen zu Texten und Schreibprozessen bei Auftraggeber 1 und Auftraggeber 2 Rückschlüsse auf Texte und Schreibprozesse bei anderen Auftraggebern gezogen werden können, die nicht mit Auftraggeber 1 und 2 zusammenarbeiten. Einsicht in die Arbeit aller Auftraggeber hat die BAG SPNV. Meine mehrmalige schriftliche Anfrage zur Repräsentativität von Verdingungsunterlagen eines Auftraggebers blieb unbeantwortet. In einem Telefonat gab der Mitarbeiter der BAG SPNV an, dass 
ausschließlich die jeweiligen Auftraggeber Auskunft über die Ausschreibungsverfahren und Ausschreibungsunterlagen geben können.

Daher bat ich bei folgenden drei weiteren Auftraggebern aus verschiedenen Bundesländern um Verdingungsunterlagen. AufTRAGGeBER 5 gab Folgendes an: „Diese Art von Lastenheften werden seitens [Auftraggeber 5; AH] nicht eingesetzt.“ (E-Mail vom 29.12.2015) Denn AufTRAgGeBer 5 ,hat bisher keine Fahrzeuge beschafft und daher keine diesbezüglichen Lastenhefte erstellt" (ebd.).

Auftraggeber 4 führte aus:

„[B]ei der Vergabe von Leistungen im Schienenpersonennahverkehr (SPNV), welche wir im Auftrag [zweier Bundesländer; $\mathrm{AH}$ ] durchführen, formulieren wir unsere Anforderungen vor allem in Textform in einem fortlaufenden Textdokument mit Kapiteln und Absatznummerierungen. Diese Anforderungen stellen vor allem Mindestanforderungen dar, z.B. Mindestsitzplatzanzahl etc. Mit dem Angebot hat das EVU eine Reihe von Unterlagen einzureichen, z.B. Fahrzeugzeichnungen etc.“ (AUfTRAGGEBER 4; E-Mail vom 23.12.2015)

Allerdings weicht die Gestaltung der Lastenhefte von denen in Ausschreibung 1, 2 und $3 \mathrm{ab}$, während die Gestaltung der Pflichtenhefte offen ist (s. Kapitel 5.2.1). AufTRAGGEBER 3 teilte mit, dass die Gestaltung von Verdingungsunterlagen davon abhängt, ob Fahrzeuge durch das EVU gekauft werden oder Fahrzeuge aus einem eigenen Fahrzeugpool des Auftraggebers zu nutzen sind (E-Mail vom 23.12.2015). In ersterem Fall werden vergleichbare Lastenhefte erstellt (s. Kapitel 5.2). Die Mindestanforderungen inklusive Lastenhefte für Ausschreibung 4 und das Lastenheft zu Ausschreibung 5 wurden mir von AufTRAGgeBer 3 zur Verfügung gestellt (E-Mail vom 23.12.2015).

Über die Auftraggeber hinaus lässt sich die Verallgemeinerbarkeit von Ergebnissen aus den vorliegenden Verdingungsunterlagen für die weiteren beteiligten Akteure, also für Bieter, aber auch die neue Rolle von Fahrzeugherstellern als Bieter diskutieren: Inwieweit die Ergebnisse aus den Analysen von Texten der EVU übertragbar sind, ist nach Textsorten differenzierbar. Beispielsweise unterscheiden sich Exemplare der Textsorte Optimierungsvorschlag verschiedener Bieter stärker, als dies bei Pflichtenheften der Fall sein kann. Grund dafür sind die Vorgaben für Letztere, die aus der Formularkommunikation resultieren.

Ausschreibung 6 (E-Mail vom 17.6.2015) ist in zwei Teilausschreibungen - sogenannte Teillose - gegliedert: In Teillos 1 richtete sich das Fahrzeuglastenheft 
unmittelbar an die EVU als Bieter, falls sie über Gebrauchtfahrzeuge verfügten. Nur für den Fall, dass EVU Neufahrzeuge anboten, beauftragten diese einen Fahrzeughersteller damit, ein Fahrzeugangebot zu erstellen. Dieses Angebot reichten die EVU wiederum beim Auftraggeber ein; das Fahrzeuglastenheft richtete sich in diesem Fall also mittelbar an die Fahrzeughersteller. Möglich ist es aber auch, dass Auftraggeber ausschließlich Fahrzeuge ausschreiben und sich das zugehörige Fahrzeuglastenheft damit unmittelbar an Fahrzeughersteller richtet. Dies praktizierten Auftraggeber in wenigen Fällen. Würde diese Praxis zum Regelfall, hätte dies möglicherweise zur Folge, dass die Ausschreibungsunterlagen und das Textsortennetz modifiziert werden. Daher habe ich Auftraggeber 2 zur Verallgemeinerbarkeit der Analyseergebnisse zu Texten in Ausschreibung 1, 2 und 3 befragt. Er schätzt diese wie folgt ein:

„[Bei Ausschreibung 6; AH] haben wir gegenüber anderen Standard-Ausschreibungen eine völlig andere Ausschreibungsform (direkte Herstellerausschreibung + Verfügbarkeit (Wartung und Instandhaltung über den Lebenszyklus gewählt) [sic]. [...] Die Ausschreibungsunterlagen und auch das Fahrzeuglastenheft sind mit herkömmlichen Ausschreibungen nicht vergleichbar, da bei einer direkten Herstellerausschreibung viel mehr Anforderungen (nicht nur aus Fahrgastsicht) berücksichtigt werden müssen. Die gewählte Ausschreibungsform ist sicherlich nicht in jedem Teilnetz und bei jeder Ausschreibung anwendbar. Es setzt eine gewisse Flottengröße voraus, [...].“ (AufTRAGGEBBER 2; E-Mail vom 17.6.2015)

Somit bleiben die Analyseergebnisse auf Ausschreibungen bei den untersuchten Auftraggebern übertragbar. Fahrzeughersteller könnten in Zukunft aber als Bieter auftreten, falls die Ausschreibungen differenziert werden in Teilausschreibungen für Fahrzeuge und Wartung gegenüber Teilausschreibungen der Dienstleistung, diese Fahrzeuge zu betreiben, zu bewerben etc. Eine entsprechende Entwicklung wird in der auftraggebernahen Fachzeitschrift „Nahverkehrs-praxis“ diskutiert. Im Interview mit diesem Fachorgan argumentiert der Fahrzeughersteller-Mitarbeiter EMMELHEINZ für eine Bieterrolle von Fahrzeugherstellern in Deutschland. Grundlage bildet seine Erfahrung in Ausschreibungen anderer europäischer Länder (Komplettausschreibungen definiert er aus Sicht der Fahrzeughersteller):

„Komplettausschreibungen, das heißt Ausschreibungen, die die Lieferung von Fahrzeugen sowie deren Wartung umfassen, sind in Deutschland ein Novum. [...] Zunehmend verlagern Bahnbetreiber die Verantwortung für die Zustände der Bahnsysteme auf die Hersteller, zum Teil bis zum Ende des geplanten Lebenszyklus der Systeme.“ (EMMELHEINZ, 2013, S. 28) 
$\mathrm{Zu}$ berücksichtigen ist, dass der interviewte Mitarbeiter eines Fahrzeugherstellers möglicherweise das Interesse verfolgt, eine Entwicklung von Teilausschreibungen forcieren zu wollen. Fahrzeughersteller könnten zukünftig durchaus in der Kommunikantenrolle der Bieter auftreten.

Abschließend lässt sich die Verallgemeinerbarkeit und Übertragbarkeit der Analyseergebnisse zu den vorliegenden Texten für die Domäne des Schienenpersonennahverkehrs bzw. für andere Domänen diskutieren. Dies geschieht durch Kontrastierung mit der Domäne des Ausschreibungswesens für eGovernance: Den Geschäftsführer eines Softwareunternehmens befragte ich dazu, wie vergleichbar Ausschreibungsverfahren im eGovernance und SPNV sind. Letztere veranschaulichte ich durch die Nennung von grundsätzlichen SPNV-Verfahrensschritten (GESchäFTSFÜHRER SOFTWAREUnTERNEHMEN, E-Mail vom 16.4.2014). Dazu gab er an, dass folgende Schritte Teil von eGovernance-Ausschreibungen seien: Veröffentlichung der Verdingungsunterlagen inklusive Pflichtenheft, Rügen und Rückfragen zu Verdingungsunterlagen, Gespräche zwischen Bietern und dem Auftraggeber, Abgabe des ausgefüllten Lastenhefts und weiterer Dokumente wie Testate etc., Zuschlagserteilung, Vertragsabschluss nach Ende der Einspruchsfrist (s. ebd.). Auch wenn ich nur einen Kommunikanten der Domäne befragte, spricht für eine Übertragbarkeit der Ergebnisse auf andere Domänen, dass die Verdingungsordnung für Leistungen ( $\mathrm{VOL}-\mathrm{A}$ ) und das Gesetz gegen Wettbewerbsbeschränkungen (GWB) domänenübergreifend gültig sind und die Gestaltung von Verdingungsunterlagen grundlegen.

\subsubsection{Optimierungsvorschläge (OV) des Bieters}

Während die Verdingungsunterlagen ausschließlich von Aufraggebern verfasst werden, produzieren Bieter Optimierungsvorschläge auf der Grundlage der Anforderungen der Auftraggeber. Diese Vorschläge dienen dazu, die Verdingungsunterlagen derart zu modifizieren, dass Bieter dem jeweiligen Auftraggeber ein günstigeres Angebot machen können. Das Teilkorpus Optimierungsvorschläge setzt sich wie folgt aus Exemplaren des beobachteten Bieters zusammen (s. Tabelle 4-6): 


\begin{tabular}{|l|c|c|}
\hline Ausschreibung & Anzahl der Exemplare & Summe der Seiten \\
\hline Nr. 1 & 11 & 14 \\
\hline Nr. 2 & 7 & 14 \\
\hline Nr. 3 & 5 & 5 \\
\hline$\underline{\text { Summe }}$ & $\underline{23}$ & $\underline{33}$ \\
\hline
\end{tabular}

Tabelle 4-6: Übersicht und quantitative Angaben zum Teilkorpus Optimierungsvorschläge (eigene Darstellung)

Während der Überarbeitungsprozesse wurden von den Textproduzenten bzw. Textüberarbeitenden 3 Versionen von Optimierungsvorschlägen erstellt, die jeweils zu den Ausschreibungen 1 und 3 vorliegen:

Version 1 - Überarbeitung der Textversion eines Fachautoren durch die Redaktion vor der gemeinsamen Überarbeitung (Dokumentation der Überarbeitungsprozesse durch die WORD-Funktion „Änderungen nachverfolgen“).

Version 2 - Gemeinsame Überarbeitung im sogenannten Qualitätsportal, bei der die Redaktion, alle Fachautoren, die Projektleitung und am Verfahren bisher nicht beteiligte externe Prüfer (u. a. ein Jurist) anwesend sind. Die Dokumentation der Überarbeitung fand zusätzlich durch eine teilnehmende Beobachtung mithilfe von WORD statt. Während des Qualitätsportals wurde ich den Teilnehmenden in der Rolle eines Beraters für Fragen zur Orthografie als Teil des Feldes vorgestellt, beispielsweise zu Ausschreibung 3.

Version 3 - Erneute Überarbeitung der Textsortenexemplare durch die Redaktion und die Projektleitung. Diese Version 3 wird beim Auftraggeber eingereicht.

Die folgenden Exemplare lagen dem Prüfungsausschuss in der dritten Version vor, die entsprechend den Ausschreibungen sortiert waren (s. Tabelle 4-7):

\begin{tabular}{|l|l|l|}
\hline Ausschreibung & Auftraggeber & Optimierungsvorschlag (OV) \\
\hline Ausschreibung 1 & Auftraggeber 1 & OV 1 bis OV 11 \\
\hline Ausschreibung 2 & Auftraggeber 2 & OV 1 bis OV 7 \\
\hline Ausschreibung 3 & Auftraggeber 2 & OV 1 bis OV 5 \\
\hline
\end{tabular}

Tabelle 4-7: Übersicht über vorliegende Optimierungsvorschläge (eigene Darstellung). 
Die vorliegenden Exemplare dieser Textsorte können nicht in Bezug auf alle Textebenen als verallgemeinerbar und übertragbar gelten, weil ich nur einen Bieter untersuchen konnte. Zwar werden Optimierungsvorschläge lexikalisch durch den hohen Grad an Verbindlichkeit des Lastenheftes normiert (AUFTRAGGEBER 2, 2010a, S. 3). Optimierungsvorschläge (OV) anderer Bieter können aber auf anderen Textebenen von den vorliegenden Exemplaren abweichen, wie aus dem Interview mit AUfTRAGGEBER 1 hervorgeht: „Die OV der EVU unterscheiden sich in Umfang und Struktur, wobei sich daraus keine Wertung ergibt.“ (2013, S. 9) Wegen der normierten Lexik können von diesem Teilkorpus nur Analyseergebnisse zur lexikalischen Ebene auf Texte anderer Bieter und Ausschreibungen übertragen werden. Es werden aber alle weiteren Textebenen des Analyserasters (s. Kapitel 3) untersucht, um die Ergebnisse zu den verschiedenen untersuchten Textsorten kontrastieren zu können (s. Kapitel 5.4).

\subsubsection{Pflichtenhefte des Bieters}

Während Lastenhefte Teil der Verdingungsunterlagen sind, die als Formularvordrucke gelten können (s. Kapitel 4.3.1), füllen Bieter die Lastenhefte aus und erzeugen so die Pflichtenhefte. Weil die Bieter die Pflichtenhefte wesentlich prägen, werden die Exemplare als separates, bieterseitiges Teilkorpus aufgeführt. Das Teilkorpus Pflichtenhefte setzt sich wie folgt zusammen (s. Tabelle 4-8):

\begin{tabular}{|l|c|c|}
\hline Textsorte & $\begin{array}{c}\text { Anzahl der } \\
\text { Exemplare }\end{array}$ & $\begin{array}{c}\text { Summe } \\
\text { der Seiten }\end{array}$ \\
\hline Pflichtenhefte & 4 & 49 \\
\hline Technische Zeichnungen zu Pflichtenheften & 7 & 7 \\
\hline
\end{tabular}

Tabelle 4-8: Übersicht und quantitative Angaben zum Teilkorpus Pflichtenhefte (eigene Darstellung).

Die folgenden Exemplare lagen dem Prüfungsausschuss in der dritten Version vor, die nach Ausschreibungen sortiert waren (s. Tabelle 4-9). 


\begin{tabular}{|c|c|}
\hline Ausschreibung & Pflichtenheft \\
\hline Ausschreibung 1 & Pflichtenheft 1 \\
\hline Ausschreibung 2 & Pflichtenheft 2 \\
\hline Ausschreibung 3 & Pflichtenheft 3 \\
\hline
\end{tabular}

Tabelle 4-9: Übersicht über vorliegende Pflichtenhefte (eigene Darstellung).

Die Ergebnisse aus den Analysen von Teilen der Pflichtenhefte, die die Lastenheftvordrucke bilden, können auf Pflichtenhefte des Bieters zu anderen Ausschreibungen der AufTRAGGEBER 1 und 2 übertragen werden. Denn die Diskussion um die Übertragbarkeit und Verallgemeinerbarkeit der Verdingungsunterlagen gilt auch für die Lastenheftvordrucke 1, 2 und 3, die jeweils Teil der Verdingungsunterlagen sind.

Der vom Bieter ausgefüllte Teil ist in den Pflichtenheften zu den drei Ausschreibungen weitgehend deckungsgleich (s. Kapitel 5.2), und auch bei den Überarbeitungsprozessen greifen die Projektmitglieder auf Pflichtenheftexemplare zurückliegender Ausschreibungen zurück (Protokoll zu Ausschreibung 1, 2013). Dies legt nahe, dass die Ergebnisse, die aus der Analyse der vorliegenden Exemplare hervorgehen, auf andere Pflichtenhefte des Bieters übertragen werden können.

Für andere Auftraggeber als AUFTRAGGEBER 1 und 2 können die Analyseergebnisse zu den vorliegenden Lastenheftvordrucken nur sehr bedingt als verallgemeinerbar und übertragbar gelten. Dies legt zumindest die Aussage von FAHRZEUGHERSTELLER 2 nahe, dass diese Pflichtenhefte nur für Auftraggeber 1 und 2 typisch seien:

„Ist der Ausfüllprozess der Fahrzeugcheckliste (FCL) [zu Ausschreibung 2/Fahrzeug 1; AH] Ihrer Erfahrung nach repräsentativ für aktuelle Ausschreibungen, bei der Sie als potentieller Fahrzeugzulieferer für [den beobachteten Bieter; AH] auftreten? $[\mathrm{AH}]$

Für [das betreffende Bundesland; AH] ja. Zweckverbände aus anderen Bundesländern definieren ihre Fahrzeuganforderungen nicht über eine auszufüllende Checkliste, sondern über entsprechende Lastenhefte." (FAHRZEUGHERSTELLER 2, 2014, S. 1; Kursive im Original)

Demnach sind die vorliegenden Lastenheftvordrucke für Auftraggeber des entsprechenden Bundeslands verallgemeinerbar und übertragbar, aber nicht zwingend für Auftraggeber anderer Bundesländer, mit denen FAHRZEUGHERSTELLER 2 zusammenarbeitet. Die Gültigkeit dieser Aussage wird aber dadurch einge- 
schränkt, dass nicht alle Bieter mit FAHRZEUGHERSTELLER 2 zusammenarbeiten. Daher wurde es notwendig, andere Auftraggeber zur Formulargestaltung der eigenen Lastenhefte zu befragen.

Auftraggeber 4 belegt die Aussage von FAHRZeughersteller 2 durch die Aussage, dass er keine Lastenhefte fordert, weil er keine Fahrzeuge anschafft. So kommentiert AufTRAgGeBer 4 die Gestaltung der Verdingungsunterlagen folgendermaßen: „Die von Ihnen beschriebene Tabellenstruktur entspricht daher nicht unserer Unterlagenstruktur.“ (E-Mail vom 23.12.2015) Diese Antwort von AufTRAGGEBER 4 basiert auf meiner Beschreibung von Lastenheften durch folgende Eigenschaften: die Struktur der Verdingungsunterlagen, die Anlage zu Fahrzeuganforderungen und die zeichenmodale Gestaltung der Lastenheftvordrucke von AuftraggeBer 1 und 2 und der Pflichtenhefte des Bieters. Zu meiner Frage nach der zeichenmodalen Gestaltung der Fahrzeugbeschreibungen (E-Mail vom 29.12.2015) resümiert AUFTRAGGEBER 4 für seine Verdingungsunterlagen:

„Wir geben den Bietern vor, dass die Fahrzeugzeichnungen dem Fahrzeugkonzept als Anlage beizufügen sind. Die Bieter reichen dann die Zeichnungen und viele andere geforderte Dokumente als separate Anlagen zum Angebot ein. Dem Angebot liegen geforderte Konzepte bei, z.B. das Fahrzeugkonzept, die textlich den roten Faden mit Verweisen auf die Anlagen bilden." (AufTRAGGEBER 4; E-Mail vom 29.12.2015)

Da AuftraggeBer 5 keine Fahrzeuge beschafft und dementsprechend keine Lastenhefte einsetzt, finden sich im Interview (E-Mail vom 29.12.2015) keine Aussagen, die Rückschlüsse zur Aussage von FAHRZEUGHERSTELLER 2 zulassen.

Dagegen schränkt AufTRAGgeBER 3 die Gültigkeit der Aussage von FAHRZEUGHERSTELLER 2 ein. Denn AUfTRAGGEBER 3 gestaltet Lastenhefte in Formularform, bei denen der Ankauf von Neufahrzeugen durch das EVU Teil der Ausschreibung sein kann:

„[G]rundsätzlich kommen derartige Fahrzeuglastenhefte bei uns nur in den Ausschreibungen zum Einsatz, bei denen wir nicht selbst über unseren landeseigenen SPNV-Fahrzeugpool die zu nutzenden Fahrzeuge beistellen. [...] Auszufüllende Dokumente zu den angebotenen Fahrzeugeigenschaften gab es somit bei von uns federführend durchgeführten Ausschreibungsverfahren nur in den Ausschreibungen [5 und 4; AH].“ (AufTRAGGeBer 3; E-Mail vom 23.12.2015)

Auch Auftraggeber 4 schränkt die Aussage von FAHRZEUGHERSTELLER 2 insoweit ein, als Bieter in der Kommunikation mit Fahrzeugherstellern Lastenhefte als Formulare gestalten könnten: 
„Es ist durchaus möglich, dass ein Eisenbahnverkehrsunternehmen (EVU) aus unseren Anforderungen dann ein Lastenheft in der von Ihnen beschriebenen Struktur erarbeitet und an den Fahrzeughersteller übergibt - mit der Bitte, dies in ein Pflichtenheft umzuwandeln. In diesen Prozess haben wir als Vergabestelle jedoch keinen Einblick.“ (AufTRAGGEBER 4; E-Mail vom 23.12.2015)

Auf der Grundlage der Aussagen von Fahrzeughersteller 2, AuftraggeBER 1, 2, 3 sowie 4 und deren Interpretation lässt sich zusammenfassen, dass die Übertragbarkeit der Analyseergebnisse zu Pflichtenheftexemplaren lediglich für den Teil der Pflichtenhefte gültig ist, der aus den Lastenheftformularen stammt. Denn Letztere sind entsprechend standardisiert (s. Kapitel 4.2.4). Insbesondere bei Bildern und Text-Bild-Relationen, die ausschließlich in Pflichtenheften vorkommen, existieren kaum Gestaltungsvorgaben für die Bieter als Textproduzenten. D. h., der Grad der Standardisierung durch die Auftraggeber ist für diese Textelemente relativ gering. Sind Bilder in Pflichtenheften technische Zeichnungen, ist für diese aber ein hoher Grad an Standardisierung anzunehmen, weil sie „DIN-konform“ (BAG SPNV, ${ }^{3} 2016$, S. 80) sein sollen. Dementsprechend sind Analyseergebnisse zu technischen Zeichnungen in Pflichtenheften grundsätzlich verallgemeinerbar und übertragbar, soweit sie DIN-konform sind. Zu prüfen ist in den vorliegenden Pflichtenheftexemplaren aber, inwieweit deren technische Zeichnungen DIN-konform sind.

Der Frage, ob die Ergebnisse aus dem vorliegenden Teilkorpus auf Pflichtenhefte anderer Domänen übertragbar sind, nähert sich die Analyse des Interviews mit dem Geschäftsführer eines IT-Unternehmens aus der Domäne Ausschreibungswesen für eGovernance. Er gibt an, dass Lastenheftvordrucke auszufüllen sind, die sich in der Gestaltung in verschiedenen Verfahren ähneln (GESCHÄFTSFÜHRER SOFTWAREUNTERNEHMEN; E-Mail vom 16.4.2015). Technische Zeichnungen und die dazugehörigen DIN-Normen spielen aber keine Rolle (ebd.). Somit sind die Analyseergebnisse nicht auf Domänen übertragbar, die keine technischen physikalischen Gegenstände ausschreiben, die sich durch technische Zeichnungen darstellen lassen. Festzuhalten bleibt aber, dass der Zusammenhang zwischen Lastenheft und Pflichtenheft als Vordruck und ausgefüllter Vordruck als Teil von Formularkommunikation auch in anderen Domänen besteht. Diese Schlussfolgerung untermauert auch die Beschreibung von Lastenheftvordrucken als Teil von Ausschreibungsunterlagen in Lehrwerken, beispielsweise in TEICH/KOLBENSCHLAG/REINERS (2008, S. 123). 


\subsubsection{Fahrpläne des Bieters}

Auch die Fahrplanvarianten sind Textsortenexemplare, die Bieter in Ausschreibungsverfahren erstellen, weil Auftraggeber diese fordern, wie die Bewerbungsbedingungen zu Ausschreibung 1 bei der Beschreibung des Textsortennetzes veranschaulichen (s. Kapitel 4.2.2). Varianten der Textsorten Fahrplan stellen der Tabellenfahrplan, der Bildfahrplan und der Fahrzeugumlaufplan dar. Alle drei Varianten bilden den Fahrzeugbetrieb aus unterschiedlichen Perspektiven bzw. mit unterschiedlichen Zielen und entsprechend unterschiedlichen Gestaltungskonventionen ab. Das Teilkorpus Fahrpläne setzt sich wie folgt zusammen, die alle aus Ausschreibung 1 zu Fahrzeug 1 stammen (s. Tabelle 4-10):

\begin{tabular}{|l|c|c|}
\hline Textsortenvarianten & Anzahl der Exemplare & Summe der Seiten \\
\hline Tabellenfahrplan & 1 & 3 \\
\hline Bildfahrplan & 1 & 1 \\
\hline Fahrzeugumlaufplan & 1 & 7 \\
\hline$\underline{\text { Summe }}$ & $\underline{3}$ & $\underline{11}$ \\
\hline
\end{tabular}

Tabelle 4-10: Übersicht und quantitative Angaben zum Teilkorpus Fahrpläne (eigene Darstellung).

Bei diesem Teilkorpus handelt es sich um das kleinste Korpus innerhalb des Gesamtkorpus erhobener Texte. Es dient der Veranschaulichung der Textsorte, weil es in seiner multimodalen Gestaltung eine Sonderrolle einnimmt: So kommen einige der Varianten weitgehend ohne schriftsprachliche Elemente aus und folgen Gestaltungskonventionen, die einerseits durch die Software zur Erstellung vorgegeben, andererseits als Lehrbuchwissen vermittelt werden. Diese Textsorte steht nicht im Fokus der Betrachtung. Die Textsortenanalyse dient dazu, die Darstellung der ausgewählten Textüberarbeitungen (s. Kapitel 6.1) nachvollziehbar zu machen.

Für die Übertragbarkeit und Verallgemeinerbarkeit der Analyseergebnisse aus dem jeweiligen Exemplar zu einer Fahrplanvariante lässt sich Folgendes festhalten: Während Bildfahrpläne durch den integrativen Taktfahrplan in Bezug auf Inhalt und Darstellung normiert sind (die Exemplare müssen kompatibel sein) und die Tabellenfahrpläne durch den Auftraggeber vorgegeben werden, sind Umlauf- 
pläne ausdrucksseitig weniger stark konventionalisiert, da das technische Medium viele Darstellungsmöglichkeiten zur Verfügung stellt. Dies bestätigt auch der Experte Prof. Dr.-Ing. Jörn PACHL (Lehrstuhlinhaber TU Braunschweig):

\begin{abstract}
„Bei Umlaufplänen habe ich Zweifel, ob es da überhaupt noch eine über alle EVU einheitliche Symbolik gibt. Das Grundprinzip ist natürlich immer gleich. Die Balken werden mit der zugehörigen Leistung (z. B. Zugnummer) und der Anfangs- und Endzeit beschriftet. In den Lücken zwischen den Balken wird die Betriebsstelle angegeben. Eine Beschreibung findet sich vermutlich in den einschlägigen Berufsschullernbüchern für ,Eisenbahner im Betriebsdienst', wie z. B. ,Grundwissen Bahn` von Marks/Fährmann.

Hinsichtlich Farben, Schraffuren und sonstiger Symbole können die EVU aber individuelle Regeln nutzen. Es hängt teilweise auch von der verwendeten Software ab. Im Anhang habe ich als Beispiel mal einen Auszug aus einem Umlaufplan beigefügt, der mit der Software FBS erstellt wurde (Quelle: www.irfp.de). In dem gelb markierten Fenster sind die Daten des Zuges 13236 aufgeführt, so dass man diese mit der Darstellung im Umlaufplan vergleichen kann. Da FBS auch von [dem beobachteten Bieter; AH] benutzt wird, orientiert es sich sehr stark an den Anforderungen der Deutschen Bahn. [...] Andere Programme zur Umlaufplanung haben z. B. die Firmen IVU und Trapeze." (PACHL E-Mail vom 29.10.2014)
\end{abstract}

Im Anschluss an die Aussage von PACHL erkundigte ich mich nach der Software, die der beobachtete Bieter nutzte. Der FAHRZEUGTECHNIKER DES BIETERS (E-Mail vom 29.10.2014) nannte mir den Softwarehersteller und die Software, mit deren Hilfe er die Textsortenexemplare produzierte, die kooperativ überarbeitet wurden.

Diesen Hersteller bat ich um die Anleitung für die genannte Software, um Erkenntnisse zu erlangen, inwieweit die Software die multimodale Gestaltung der Textsortenexemplare begrenzt. Leider konnte ich die entsprechende Anleitung zu dieser Software aber nicht erhalten: „[N]ach Rückfrage mit dem Fachbereich teilen wir Ihnen mit, dass es sich hierbei um interne Unterlagen handelt, die wir leider nicht herausgeben können." (HERSTELlER VON UMLAUFPLANSOFTWARE; E-Mail vom 31.10.2014) $\mathrm{Zu}$ berücksichtigen bleibt auch, dass weitere Softwarehersteller existieren, auf deren Produkte andere Bieter zurückgreifen können. Die Symbolik für die Darstellung verschiedener Betriebsarten von Fahrzeugen beispielsweise eine Fahrt mit zwei Waggons, die sogenannte Doppeltraktion, oder eine Ruhezeit für einen Zug - kann bei Software von derjenigen abweichen, die der Bieter bei der beobachteten Überarbeitung nutzte.

Festzuhalten bleibt, dass die Analyseergebnisse zu den vorliegenden Exemplaren von Bild- und Tabellenfahrplänen dadurch verallgemeinerbar und übertragbar werden, dass diese Gestaltungskonventionen einen hohen Grad an Normierung 
aufweisen. Der Netzbetreiber prüft die Darstellung und kann Exemplare aufgrund ihrer Gestaltung für ein Testierungsverfahren zurückweisen. Die Gestaltungskonventionen von Umlaufplänen werden dagegen zwar als Lehrbuchwissen vermittelt, lassen aber viel Gestaltungsspielraum, beispielsweise nutzen sie keine einheitliche Symbolik für die Darstellung verschiedener Betriebsarten von Fahrzeugen. Darüber hinaus sind die Darstellungen für diese Fahrplanvarianten nicht vom Netzbetreiber mit Anträgen anderer EVU abzugleichen, sodass dieser die Umlaufpläne bei einem Testierungsverfahren nicht wegen mangelnder Vergleichbarkeit zurückweisen kann. Wie die obige Einführung in die Materialsammlung bereits aufzeigt, trennt sie das Textkorpus und die weitere Datensammlung. Denn das Textkorpus ist Grundlage für die Textanalyse entsprechend dem integrierten Textanalyseraster (s. Kapitel 3), während Interviews und Beobachtungsprotokolle die Grundlage für die Interpretation des Textproduktionsprozesses (s. Kapitel 6.1) liefern.

\subsection{Beschreibung weiteren Materials und des interfachlichen Kontextes}

Die weitere Datensammlung dient dem Zweck, den Kontext näher zu erläutern, in den die Textsortenexemplare des Textkorpus funktional-pragmatisch eingebettet werden. So geht dem eigentlichen Überblick über Interviews und Protokolle eine Beschreibung des Kontextes voraus. Insbesondere bei der Beschreibung der Projekte steht deren interfachliche Zusammensetzung im Fokus, sodass dieses Teilkapitel ein Grundelement der Forschungsfrage präzisiert, wie sich Interfachlichkeit auf die semiotische Effizienz von Sprache-Bild-Textsorten auswirkt. Die Projektkommunikation ist wiederum durch die Voraussetzungen der Domäne und die Vorgaben der beteiligten Auftraggeber- sowie Bieterorganisationen bestimmt. Daher werden die Domäne und diese Organisationen vorab beschrieben.

\subsubsection{Beschreibung der interfachlichen Projektstrukturen als Teil der erforschten Domäne und Organisationen}

Die Strukturen von Domäne, Organisation und Projekt sind eng verwoben, teilweise sind diese Kategorien nicht trennscharf, sodass sich Eigenschaften des Kontexts mehreren dieser gesellschaftlichen Strukturen zuweisen ließen. Die folgende Beschreibung ordnet Domäne, Organisation und Projekt entsprechend ihrem Grad 
der Abstraktion vom Allgemeinen zum Speziellen an. Interfachlichkeit als Teil der zentralen Forschungsfrage steht bei der Beschreibung aller drei Gesellschaftsstrukturen im Vordergrund.

Die Domäne Ausschreibungskommunikation im SPNV ist als interfachliche Diskursgemeinschaft geprägt. Deutlich wird dies in der dritten Ausgabe des

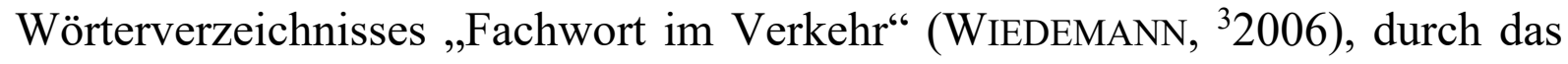
der Verband deutscher Verkehrsunternehmen (VDV) versucht, Terminologie von Ausschreibungskommunikation im öffentlichen Personennahverkehr (ÖPNV) zu konventionalisieren. Der Vorsitzende des VDV-Ausschusses Recht und Wirtschaft, Heinz RUNDE, beschreibt diese Interfachlichkeit in der Einleitung mit Bezug auf die Auflösung des Regionalverkehrsmonopols durch die Marktliberalisierung und Einführung der Ausschreibungspflicht im Jahr 1992:

\begin{abstract}
„Aber die Welt des Verkehrs hat sich in dieser Zeit [seit Erscheinen der ersten Ausgabe 1964; AH] extrem gewandelt, neben vielem anderen gibt es technische Neuerungen und eine Fülle neuer Rechtsgrundlagen und Rechtsprechung [...]. Es erscheint schon heute schwer vorstellbar, dass in der Ausgabe von 1992 zum Beispiel das inzwischen so wesentliche Vergaberecht als Stichwort nicht existiert.“ (RUNDE, 2006, S. 8)
\end{abstract}

Nicht nur an der VDV-Arbeit zum „Fachwort im Verkehr“ (WIEDEMANN, ${ }^{3} 2006$ ) sind Mitarbeitende des Bereichs Recht und Wirtschaft beteiligt, sondern auch die Domäne SPNV-Ausschreibungen bündelt die Fachsprachen von Ingenieuren, Juristen und Betriebswirten. Dabei beziehen sich die Kommunikanten des Handlungsfelds auf Textsortenkonventionen, die das Textsortennetz zu SPNV-Ausschreibungsverfahren (s. Kapitel 4.2) realisiert. Juristen und Betriebswirte können in dieser interfachlichen Kommunikation als Laien gegenüber Ingenieuren auftreten, wenn die gemeinsame Kommunikation Elemente eines außersprachlichen technischen Prozesses oder Ähnliches behandelt. Dies gilt vice versa für Kommunikation über juristische und betriebswirtschaftliche Prozesse. $\mathrm{Zu}$ prüfen ist, inwieweit Projektmitglieder interfachliches Wissen unabhängig von ihrem Ausbildungs- und Abteilungshintergrund durch langjährige, regelmäßige Tätigkeit in Projekten erwerben können. Beispielsweise könnten ein Ingenieur und ein Betriebswirt die Bedeutung einer juristischen Generalklausel für den gesamten Text nachvollziehen. Ein Jurist oder Betriebswirt könnte die Bedeutungen von Linienschraffuren in einer technischen Zeichnung, die Bedeutung der Nominalphrase (Anzahl Türen pro) Fahrzeugseite - d. h. pro Waggon oder pro Zug für die 
korrekte Angabe - oder der Abkürzung DMU (Diesel multiple unit/Dieseltriebwagenzug) kennen. Ein Ingenieur und Jurist könnten das Verfahren der Barwertmethode kennen und Erläuterungen des Betriebswirts zu einer entsprechenden Angabe in einem Pflichtenheft nachvollziehen.

Das praktische Problem im Forschungsfeld (s. Einleitung) stellt sich für den Auftraggeber anders dar als für die Bieter: Auftraggeber kommen den Anforderungen für Ausschreibungspflicht und Daseinsvorsorge nach, während Bieter versuchen, eine Ausschreibung zu gewinnen bzw. den Zuschlag für eine Ausschreibung zu erhalten oder die Zuschlagserteilung für einen Konkurrenten zu verhindern.

Auftraggeber vertreten den Staat und nehmen dementsprechend Teile seiner Aufgaben wahr, insbesondere die Aufgabe der Daseinsvorsorge. ${ }^{134}$ Aufgabe des Staates ist es, „die Bereitstellung einer ausreichenden Nahverkehrsversorgung zu angemessenen Preisen und angemessener Qualität" (LINKE, 2010, S. 32) sicherzustellen und damit aus Sicht der Daseinsvorsorge mangelnde Marktergebnisse zu kompensieren. ${ }^{135}$ Dabei hat Wettbewerb eine „Verbesserung des Verkehrsangebots in qualitativer und quantitativer Hinsicht" (ebd., S. 33) zum Ziel und vermeidet eine „Ausdünnung des Verkehrsangebots“ (ebd.) oder eine „,von Oligopolen

134 Daseinsvorsorge hat in der Vergangenheit „Veranstaltungen der öffentlichen Hand beschrieb[en], die sie zur Befriedigung seiner Bedürfnisse dem Einzelnen zur Verfügung stellt" (SCHNIEDERS, 2010, S. 35), vor allem Elektrizität, Gas, Wasser, Eisenbahnverkehr und der öffentliche Nahverkehr (ebd.). Die Begrenzung auf lebensnotwendige Leistungen ist aufgegeben worden und ,erstreckte den Daseinsvorsorgeauftrag auf alle nützlichen Leistungen, die der Allgemeinheit angeboten werden“" (LINKE, 2010, S. 20), wobei mit dessen Zuordnung zur Leistungsverwaltung der „Entzug von den Wettbewerbsregeln“ einhergehen sollte (ebd., S. 21). Der heutige Begriff von Daseinsvorsorge hat diesen ,postulierte[n] Ausschluss der Wettbewerbsregeln“ (ebd.) aufgegeben. SCHNIEDERS (2010, S. 36) schätzt ein, dass sich aus dem heutigen Begriff von Daseinsvorsorge keine rechtlichen Schlussfolgerungen ableiten lassen. Er wendet zugleich aber Folgendes ein: „Wenn man dem Begriff heute unter Geltung des Grundgesetzes überhaupt einen materiellen Gehalt geben kann, so den des Subsidiaritätsgedankens: Der Staat ist dort auf den Plan gerufen, wo die Gesellschaft ihre Bedürfnisse ohne staatliche Mitwirkung nicht zu erfüllen in der Lage ist." (ebd.)

135 Bock (2010, S. 265) stellt die Hypothese auf, dass in Deutschland SPNV-Vergabeverfahren nach dem Prinzip ,Mehr Schein als Sein' durchgeführt werden, da seit der Marktliberalisierung 1996 nur 31,7 \% der Betriebsleistungen ausgeschrieben wurden. Die relativ geringe Abnahme vom Marktanteil des ehemaligen Monopolisten Deutsche Bahn von $75 \%$ (2012) auf $69 \%$ (2016) (BAG SPNV, 2015, o. S.) untermauert die Hypothese, dass die Marktstruktur nicht polypolistisch, also nicht liberal geprägt ist. 
geprägte[ ] Marktstruktur“ (ebd.). Darüber hinaus haben Auftraggeber zwei weitere Restriktionen zu berücksichtigen:

„Die wettbewerbliche Vergabe dieser SPNV-Leistungen muss derzeit nach dem Gemeinschaftsrecht lediglich im Rahmen eines diskriminierungsfreien und transparenten Verfahrens erfolgen.“ (ВосK, 2010, S. 264)

Die Ziele der Qualitätssicherung zu einem angemessenen Preis, aber auch Sicherung von Transparenz und Diskriminierungsfreiheit unter den Bietern finden sich auch in der Antwort eines interviewten Auftraggebers zur Frage, ob und wie Optimierungsvorschläge in die Anforderungen aufgenommen werden: „Entscheidend ist die Überlegung, was den Preis senkt, die Qualität der zu erbringenden Leistung dabei nicht wesentlich mindert und vergaberechtlich zulässig ist.“ (Auftraggeber 1, 2013, S. 7 f.)

Bieter verfolgen dagegen das Ziel, einen Zuschlag zu erhalten, da sie sich überwiegend über Ausschreibungsaufträge finanzieren. Möglicherweise könnten sie auch das Ziel verfolgen, eine Zuschlagserteilung für einen Konkurrenten zu verhindern, beispielsweise durch Antrag auf Aufhebung eines Verfahrens. Letzteres berücksichtigen bereits die Bewerbungsbedingungen bei der Darstellung des Verfahrensablaufs (s. Kapitel 4.2.2). Sinnvoll würde für einen Bieter, der den $\mathrm{Zu}$ schlag im Verfahren nicht erhält, die Verfahrensaufhebung zu beantragen, damit er die eigene Marktposition innerhalb der Konkurrenzsituation nicht verschlechtert.

Neben dem Ziel, den Zuschlag zu erhalten, kann für einen Bieter bei Angeboten das weitere Ziel bestehen, das eigene Image aufzubauen oder zu verbessern. Dies belegt die Aussage des Bieters:

„Angebotstexte sind der überwiegende Bestandteil eines Angebots, das wir unserem Kunden, dem Aufgabenträger, bei einem Ausschreibungsverfahren machen. Der Angebotstext ist in einem Verfahren die Visitenkarte des Unternehmens, die wir beim Kunden abgeben. ${ }^{\text {"136 }}$ (BEREICHSLEITER DES BIETERS, 2011, S. 1)

Da sich andere Bieter ebenfalls in der vergleichbaren Konkurrenzsituation wie der interviewte Bieter befinden und wie dieser Bieter regelmäßig bei denselben

136 Zum Zeitpunkt des Interviews forderten die Auftraggeber noch Angebotstexte anstatt Optimierungsvorschläge, was Kapitel 4.2.2 bei der Darstellung des Entwicklungsprozesses von Ausschreibungsunterlagen behandelt. 
Auftraggebern an Ausschreibungen teilnehmen, ist davon auszugehen, dass auch andere Bieter dieses Ziel der Imagepflege bei Auftraggebern verfolgen.

Organisationen agieren in der Domäne des SPNV-Ausschreibungswesens und bestimmen zugleich die interfachliche Projektkommunikation durch ihre Regeln und Abläufe. $\mathrm{Zu}$ den allgemeinen Charakteristika einer Organisation (s. Kapitel 2.4) zählt das Spannungsverhältnis zwischen Formalisierung und Intersubjektivität, das während der gemeinsamen Textüberarbeitungsprozesse kaum zu beobachten ist. Dies führe ich darauf zurück, dass die Textüberarbeitungsprozesse dem stark-formalisierten Bereich der Organisationenkommunikation zuzuordnen sind: So wird die Anordnung der Verfahrensschritte durch den Auftraggeber vorgegeben, aber auch innerhalb der Organisation wird der Verfahrensablauf durch eine Leitlinie standardisiert. ${ }^{137}$

Die Organisationen werden im Folgenden über das Verhältnis charakterisiert, das zwischen ihnen während Ausschreibungsverfahren besteht. So wird das Verhältnis zwischen den Organisationen Bieter und Auftraggeber anhand der Kategorien ,institutionelle Asymmetrien“ und ,Wissensasymmetrie' beschrieben. An den Vorgaben der Auftraggeber wird deutlich, dass die Kommunikation zwischen Auftraggeber und Bietern durch eine institutionelle Asymmetrie (s. Kapitel 2.4) geprägt ist. Denn der Auftraggeber nutzt als Organisation die Möglichkeit, Kommunikation zu gestalten, Initiativen zu ergreifen und sich zurückzuhalten. Sanktionierungsmittel des Auftraggebers ist der Ausschluss von Bietern. Kriterien für den Ausschluss werden festgelegt durch die „Verdingungsordnung für Leistungen - Teil A“. Die institutionelle Asymmetrie wird dadurch deutlich, dass der Auftraggeber Kommunikationsprozess und -produkt normiert:

Den Kommunikationsprozess standardisieren die Auftraggeber zum einen dadurch, dass sie das Textsortennetz durch die Auswahl der Textsorten thematisch bestimmen. Dadurch wird die Qualität der Angebote sichergestellt: Beispielsweise werden Testate für Fahrzeuge und Fahrpläne von der zuständigen Behörde DB Netz AG gefordert, aber auch die schriftliche Versicherung über die

137 Das entsprechende Dokument, das diesen Prozess standardisiert, konnte ich der Prüfungskommission nicht zugänglich machen, hatte es aber als Moderator des Qualitätsportals zu einer Ausschreibung und als Mitglied des Unternehmensbereichs Vorstand im Jahr 2009 vorliegen. 
Einhaltung der Mindestanforderungen mit dem Angebotsschreiben. Dadurch, dass der Auftraggeber die Reihenfolge der Textsorten des Textsortennetzes festlegt (s. Kapitel 4.2.2), wird gewährleistet, dass das Verfahren innerhalb eines bestimmten Zeitraums abgeschlossen wird. Diesem Ziel dient auch die Festlegung von Fristen für die Einreichung von Textsortenexemplaren - hier von Rügen -, die unverzüglich mitzuteilen sind (BEWERBUngSBEDINGUNGEN, Ausschreibung 1, S. 10). Gleichzeitig verpflichtet sich der Auftraggeber, Rückfragen ,unverzüglich und höchstens bis 6 Tage vor Ablauf der Angebotsfrist“" (ebd.) zu beantworten.

Des Weiteren verpflichtet sich der Auftraggeber zu medialer Schriftlichkeit der Antworten: „Mündliche Auskünfte bzw. mündliche Antworten auf sachdienliche Rückfragen und/oder Rügen zu den Ausschreibungsunterlagen werden nicht erteilt.“ (ebd., S. 9) Damit wird gewährleistet, dass kein Bieter diskriminiert wird, weil er aus der Kommunikation ausgeschlossen wird, und dass der Auftraggeber keine geheimen Absprachen mit einem Bieter trifft. Letzteres dient dem Ziel der Transparenz, die auch dadurch gewährleistet wird, dass „Änderungen in den oder Erläuterungen zu den Vergabeunterlagen“ (ebd., S. 10) mitgeteilt werden, die sich aus Rückfragen und Rügen ergeben. Es besteht allerdings keine vollständige Transparenz, da den Bietern nicht alle Rückfragen und Rügen anderer Bieter mitgeteilt werden. Die Kommunikationsprodukte, d. h. die Kommunikate, standardisieren die Auftraggeber vor allem durch die Kommunikationsform Formular (s. Kapitel 2.4.3). Eine Änderung der Ausschreibungsunterlagen durch den Bieter, beispielsweise die Korrektur von Rechtschreibfehlern, kann durch einen Ausschluss aus dem Verfahren sanktioniert werden (ebd.).

Des Weiteren dürfen Bieter „Inhalte gegenüber verfahrensunbeteiligten Dritten nicht kommunizieren und/oder Unterlagen weitergeben" (BEwERBUNGSBEDINGUNGEN; Ausschreibung 1, S. 10). Somit wird zwar gewährleistet, das Verfahren innerhalb eines bestimmten Zeitraums abzuschließen. Gleichzeitig wird eine Transparenz des Verfahrens außerhalb der beiden Organisationen Bieter und Auftraggeber aber verhindert. Dies gilt beispielsweise für Bieter, die zu dem Verfahren nicht zugelassen worden sind. Transparenz besteht demnach nur innerhalb der Organisationen, die am Verfahren beteiligt sind, aber nicht für alle Organisationen, die Teil der Domäne sind. 
Der Auftraggeber nutzt die institutionelle Asymmetrie, um Themen des Textsortennetzes, die Reihenfolge und Zeitpunkte von Kommunikationsschritten, mediale Schriftlichkeit (die vorgesehenen Bietergespräche ausgenommen) und die Kommunikanten festzulegen. Dies dient dazu, die Ausschreibungsziele, Rechtssicherheit, Transparenz und eine zeitliche Überschaubarkeit im Verfahren, aber auch die Qualität der geforderten Dienstleistung zu gewährleisten. Gleichzeitig soll die Diskriminierung von Bietern verhindert werden.

Bei der Wahl des Bedeutungsumfangs von Wortgruppen innerhalb der Anforderungen an die Dienstleistung bewegt sich der Auftraggeber in dem Spannungsverhältnis, zu enge oder zu vage Vorgaben zu machen:

„Auf Tagungen [wie der Fachveranstaltung ,Wettbewerb im SPNV“ der BAG SPNV im Februar 2013 in Fulda; AH] und in Gesprächen werfen EVU uns manchmal vor, dass wir zu viel vorschrieben, zu streng definierten. Wenn wir darauf reagieren und Formulierungen bewusst offen lassen, haben wir die Erfahrung gemacht, dass zu eben diesen Formulierungen die Rückfrage kommt, was genau gemeint sei. Z. B. haben wir die Formulierung ,Personenbediente Verkaufsstelle in der Nähe zum Bahnhof' gewählt und Nähe nicht genauer definiert. Im Rahmen des Rückfrageverfahrens kam dann die Rückfrage, was mit Nähe gemeint sei, was wir infolgedessen definiert haben. Wir interpretieren den Wunsch nach Präzisierung so, dass EVU häufig die Sorge haben, aus dem Verfahren auszuscheiden, wenn ihre Ausgestaltung unserer Vorgaben - auch in den Optimierungsvorschlägen - nicht unseren Vorstellungen entsprechen [sic]; wenn wir beispielsweise unter Nähe eine geringere Entfernung vom Bahnhof verstehen als ein vom EVU benannter Ort. Die Hürden für einen Ausschluss von Bietern bei nicht konkret bestimmten Anforderungen sind allerdings sehr hoch.“ (AUFTRAGGEBER 1, 2013, S. 7; Kursive im Original)

Diese Möglichkeiten der Kommunikationsprozess- und Kommunikationsproduktgestaltung erhält der Auftraggeber als staatliche Organisation, der durch Verordnungen und Gesetze eine Zwangsgewalt zugeordnet wird. So kann der Auftraggeber Bieter aus dem Verfahren ausschließen, nicht zulassen und den Zuschlag erteilen, aber auch die Kriterien für die Erteilung des Zuschlags festlegen. Kommunikate werden demnach durch die Kommunikationsform Formular normiert, gleichzeitig wird die thematische Gestaltung durch Rückfragen und weitere Rückmeldungen zu den Verdingungsunterlagen ausgehandelt.

Aber auch die Bieter-Organisationen erhalten als Kommunikanten die Möglichkeit, Initiative zu ergreifen. Dies wird auch in den Bewerbungsbedingungen von Auftraggeber 1 im Kapitel „Kommunikation im Verfahren“ festgelegt: 
„Enthalten die Vergabeunterlagen nach Auffassung des Bieters Unklarheiten und/oder Rechtsverstöße, so haben die Bieter die Aufgabenträger unverzüglich, schriftlich und ausschließlich in deutscher Sprache darauf hinzuweisen." (BEWERBungsBedingungen, Ausschreibung 1, S. 9)

Ein Bieter hat die Möglichkeit, eine Rüge prüfen zu lassen: „Ist die Rüge begründet, so hilft ihr das Gericht ab, indem es das Verfahren fortführt, soweit dies aufgrund der Rüge geboten ist.“ (§ 71a Abs. 5 GWB)

Nicht nur die inhaltliche Gestaltung der Verdingungsunterlagen kann gerügt werden, sondern ein Bieter kann auch Einspruch gegen die Erteilung des Zuschlags einlegen. So kann die Vergabekammer in einem Nachprüfungsverfahren ( $\$ 107$ Abs. 1 GWB) die (Un-)Zulässigkeit des Antrags von einem Bieter prüfen ( $\$ 110$ Abs. 2 GWB). Größtmögliche Konsequenz wäre die Aufhebung des Verfahrens. Nach Zuschlagserteilung sind die möglichen Abfindungen aber nur gering, da nicht in Höhe der Vergabesumme kompensiert wird. ${ }^{138}$ Durch die Kodifizierung der Bieteransprüche innerhalb des Verfahrens wird die Dominanz der Auftraggeber als Teil der institutionellen Asymmetrie beschränkt.

Eine Wissensasymmetrie (s. Kapitel 2.4) besteht zwischen den Organisationen Bieter und Auftraggeber nicht, weil beide über entsprechende Abteilungen und Mitglieder verfügen. Diese Mitglieder besitzen diejenige Expertise, die für das Verständnis und die Gestaltung der Textsortenexemplare relevant ist. So verfügt sowohl der Auftraggeber 1 über Experten aus den Bereichen ,Fahrzeugtechnik', ,Betriebsplanung', ,Marketing' und ,Controlling'(Auftraggeber 1, 2013, S. 5) als auch der Bieter, wie die beobachtete Anwesenheit von Kommunikanten während der Qualitätsportale zeigt (HoLSTE $\left.{ }^{139} ; 2013,2010\right)$. Während der Bieter über juristische Experten verfügt, zieht AUFTRAGGEBER 1 externe Berater dafür hinzu:

„Eine externe juristische Fachkraft berät uns während der Erstellung der VDU und im weiteren Vergabeverfahren. Aus der externen Beratung vergangener Ausschreibungen nimmt man auch einiges für zukünftige Ausschreibungen mit, z. B. sind Konjunktivformulierungen in den VDU nicht angebracht, das Wort installiert drückt etwas anderes aus als ist zu installieren." (2013, S. 5; Kursive im Original)

Auch Auftraggeber 2 gibt an, organisationsextern juristische Experten herangezogen zu haben: „Diese Mustervergabeunterlagen haben wir zu viert erstellt -

138 s. Kapitel 7.3.1.

139 Auf Beobachtungsprotokolle wird mit dem Namen HoLsTE auf mich als Protokollanten verwiesen. Diese werden nicht im Literaturverzeichnis, sondern in Kapitel 4.5 aufgelistet. 
wir sind von Hause aus Ingenieure und Geografen, daher haben wir noch juristische Unterstützung hinzugezogen.“ (AUfTRAGGEBER 2; 2010b, S. 2)

Während zwischen den Organisationen Auftraggeber und Bieter eine Wissenssymmetrie besteht, macht die Aussage von AufTRAGGEBER 1 zu juristischer Beratung deutlich, dass zwischen den Mitarbeitenden eines interfachlichen Projektteams in einer Organisation Wissensasymmetrien bestehen. Dagegen besteht zwischen den Organisationen eine institutionelle Asymmetrie, weil der Auftraggeber teilnehmende Bieter bei Fehlern aus dem Verfahren ausschließen kann und durch die gesetzlichen Regelungen für staatliche Ausschreibungen das Recht erhält, den Verfahrensablauf und dessen Bedingungen (im Rahmen des gesetzlich Zulässigen) festzulegen.

Das interfachliche Projektteam bei den Organisationen Auftraggeber und Bieter kann in der Domäne zu SPNV-Ausschreibungsverfahren über die beiden Projektkriterien ,Dedikation“ und ,Heterogenität' (s. Kapitel 2.4) beschrieben werden. Das Kriterium ,Dedikation' beschreibt grundsätzlich die konkrete soziotechnische Aufgabe. In diesen Ausschreibungsverfahren hat der jeweilige Auftraggeber die Aufgabe, ein transparentes, diskriminierungsfreies Verfahren durchzuführen und einen angemessenen Preis bei angemessener Qualität zu sichern. Für die Bieter besteht die Aufgabe darin, den Zuschlag am Ende des Verfahrens zu erhalten oder möglicherweise zu verhindern, dass ein Konkurrent den Zuschlag erhält. Des Weiteren kann eine Aufgabe sein, gegenüber den Auftraggebern ein positives Image aufzubauen oder dieses zu pflegen, weil Letztere auch in zukünftigen Verfahren darüber entscheiden, wer den Zuschlag erhält.

Das Projektkriterium ,Heterogenität' beschreibt grundsätzlich die Zusammenarbeit zwischen den Organisationen Auftraggeber, Bieter und externer Dienstleister, die in einem Projekt zusammenarbeiten. In SPNV-Ausschreibungsverfahren bestimmt dies einerseits der Auftraggeber durch den Verfahrensablauf (s. Kapitel 4.2.2). Andererseits ist diese Heterogenität jeweils innerhalb der Organisation Bieter durch die beschriebenen Arbeitsbereiche ,Fahrzeugtechnik', ,Betriebsplanung', ,Recht', ,Marketing ' und ,Controlling' festgelegt, sodass innerhalb eines Projektteams die Wissensasymmetrie besteht, die bereits oben bei der Behandlung von Organisationen beschrieben wurde. 
Auch die Organisation ,Auftraggeber' arbeitet im interfachlichen Team an Pflichtenheften und an anderen Textsorten des Textsortennetzes. So führt AUfTRAGGEBER 4 als Antwort auf meine Frage nach der fachlichen Zusammensetzung des Ausschreibungsteams an:

„Die Abteilung ,Vergabe SPNV“ versteht sich als interfachliches Team - bestehend aus Ingenieuren und Betriebswirten, welches die Expertise der einzelnen Fachabteilungen der [Auftraggeber 4; AH] (z.B. Angebotsplanung, Fahrausweisvertrieb etc.), von Juristen und ggf. von externen Sachverständigen einbezieht.“ (E-Mail vom 29.12.2015)

Dass Auftraggeber 1 und AuftraggeBer 2 Ausschreibungsunterlagen in interfachlichen Teams erstellen, belegen deren Interviewaussagen (s. Kapitel 6.1). So läuft die Kommunikation sowohl aufseiten der Auftraggeber als auch der Bieter als interfachliche Projektkommunikation ab.

Nur sehr bedingt interfachlich scheint die Textproduktion innerhalb der Organisation Fahrzeughersteller abzulaufen, da das entsprechende Bearbeiten der Pflichtenhefte auch nicht im Projektteam durchgeführt wird. Diese Annahme belegt die Aussage von Fahrzeughersteller 2: „Das Ausfüllen obliegt dem Technical Bid Manager. Einzelne Passagen werden ggf. in Zusammenarbeit mit den Fachbereichen (Systemengineering) beantwortet.“ (FAHRZEUGHERSTELLER 2, 2014, S. 1) Darüber hinaus belegt diese Annahme die Beschreibung des organisationsinternen Textproduktionsprozesses durch FAHRZEUGHERSTELLER 1:

„Da wir uns ausschliesslich auf die fahrzeugrelevanten Anforderungen der FCL konzentrieren, sind bei uns ausschliesslich Fahrzeugtechniker aus der technischen Projektierung an der Beantwortung der einzelnen Fragen beteiligt. Diese werden anschliessend durch das Vertriebsteam geprüft und im Einklang mit den kundenspezifischen Anforderungen an das Angebot gebracht.“ (2014, S. 2)

Dementsprechend stehen sich in der Ausschreibungskommunikation innerhalb der jeweiligen Bieter- und Auftraggeberseite Projektteams gegenüber (s. Abbildung 4-1). Die Projektkommunikation ${ }^{140}$ innerhalb des gemeinsamen Textüberarbeitungsprozesses bewegt sich in der Schnittmenge der Teilbereiche

140 PeliKan (2019, S. 180 f.) ordnet Projektkommunikation keiner Fachsprache entsprechend den Gegenstandsbereichen (LSP on object level: Maschinenbau, neue Medien, ...) zu, die einem Wirtschaftssektor zugewiesen sind. Sie ordnet Projektkommunikation vielmehr einem Sektor zu, der von diesen Gegenstandsbereichen auf eine institutionelle Ebene des Projekts (LSP on project/meta level) abstrahiert. 
(s. Abbildung 4-1), wobei diejenigen, die am Textüberarbeitungsprozess beteiligt sind, Annahmen über den Rezeptionsprozess aufseiten der Auftraggeber treffen.

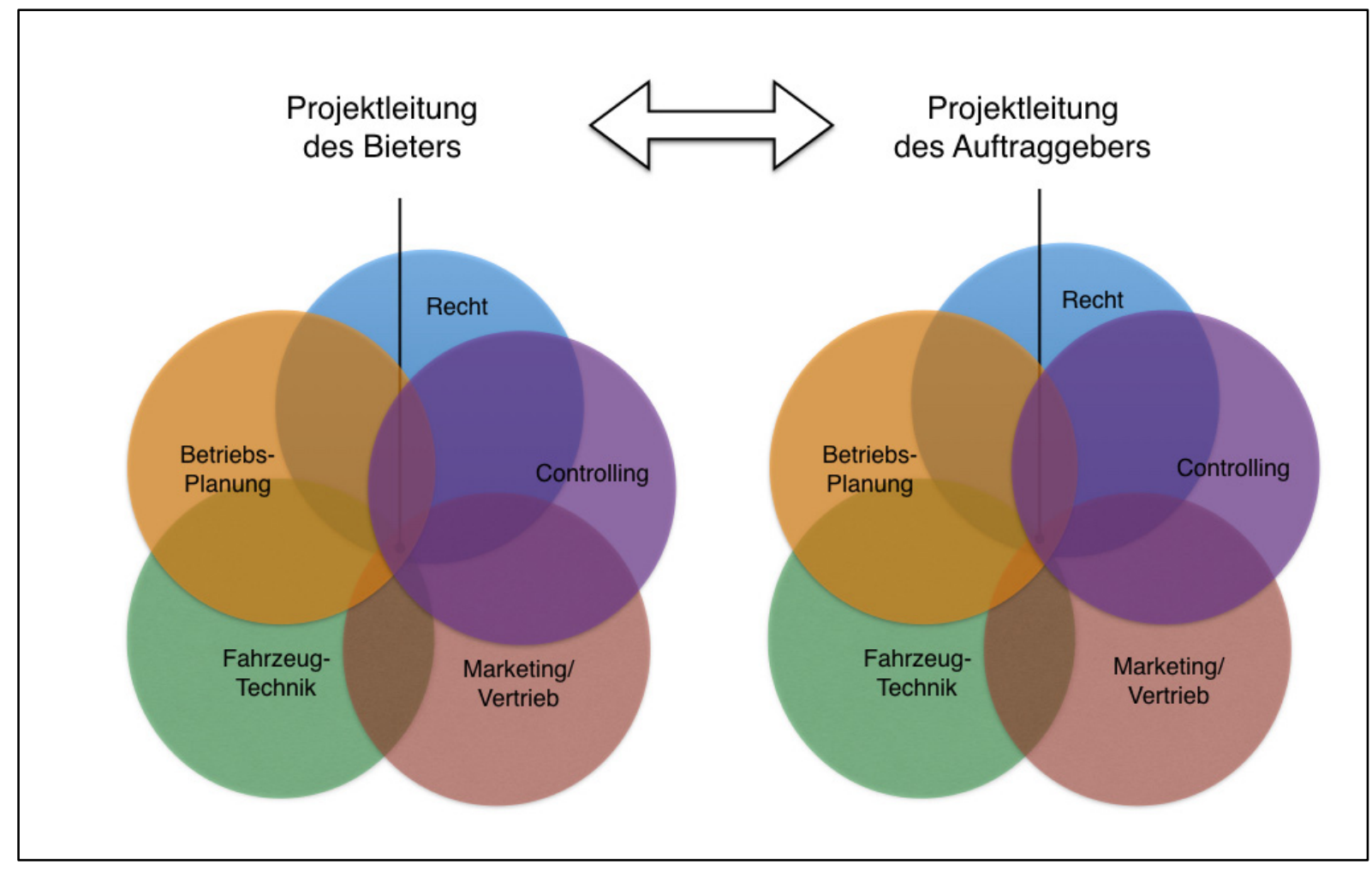

Abbildung 4-1:Interfachliche Projektzusammensetzung bei Organisationen in der Domäne zu SPNV-Ausschreibungsverfahren.

Während der gemeinsamen Textüberarbeitung stellen die Kommunikanten der einzelnen Organisationsbereiche Textsortenexemplare vor, die ihrem Teilbereich zuzuordnen sind. So sind folgende Projektrollen-Textsorten-Paare zuzuordnen: zu Fahrzeugtechnikern das Pflichtenheft, zu Betriebsplanern Fahrplanvarianten sowie die Testate über die sogenannte Fahrbarkeit eines Fahrplans und zu Controlling-Mitarbeitenden Kalkulationsschemata. Optimierungsvorschläge sind Mitarbeitenden aller Organisationsbereiche zuzuordnen. Dadurch können Letztere sowohl Veränderungen im Bereich Fahrzeugtechnik als auch in der Kalkulation etc. thematisieren. Juristen sind bei der gemeinsamen Textüberarbeitung aller Textsortenexemplare beteiligt.

Vergleichbar mit der Beschreibung zweifacher Fach(sprach)lichkeit (s. Kapitel 2.4.2) - der entsprechend sich die juristische Fachsprachlichkeit ,[ü]ber eine schon vorliegende Fachsprachlichkeit legt [...] und in einem gewissen Sinne erst legitimiert" (SOFFRITTI, 2002, S. 60) - wird die juristische Perspektive als weitere 
Ebene eines Textsortenexemplars jedes Organisationsbereichs geprüft. Die Projektleitung (s. Abbildung 4-1) muss entsprechend ihrer Aufgabe über Grundkenntnisse in allen Bereichen verfügen, um die Vorschläge der einzelnen Abteilungsmitglieder einschätzen und beurteilen zu können. Diese Grundkenntnisse erwerben Projektleitende meist durch Learning on the job, d. h., sie haben bereits an mehreren Ausschreibungsverfahren als Experten eines Organisationsbereichs teilgenommen. ${ }^{141}$

Vergleichbar mit der Struktur eines Projekts aufseiten der Bieter wird die Projektstruktur aufseiten der Auftraggeber beschrieben, was für die Einschätzung der Produktion der Verdingungsunterlagen (VDU; s. Kapitel 4.2.3) relevant ist:

„Die VDU werden von mehreren Autoren verfasst, die eine unterschiedliche (fachsprachliche) Ausbildung mitbringen [...] Die VDU werden durch mehrere Autoren im Hause und anschließend mit anderen am Verfahren beteiligten Aufgabenträgern abgestimmt [...].“ (AUfTRAGGEBER 1, 2013, S. 5 f.)

Die Projektleitung von AuftraggeBer 1 besteht aus Mitarbeitenden, die bereits über mehrjährige Erfahrung in Ausschreibungskommunikation bei Auftraggebern verfügen (ebd., S. 2). Im Bereich der Qualifikation durch die praktische Tätigkeit differenzieren sie für die Textproduktion auf die Frage, ob und wie ein Learning on the job stattfindet, wie folgt:

„,Learning on the job“ im engeren Sinne findet beispielsweise durch Hinweise des externen Juristen zu vergangenen und aktuellen Ausschreibungen statt [...]. ,Learning on the job" im weiteren Sinne findet dadurch statt, dass die Autoren Textbausteine aus VDU vergangener Ausschreibungen verwenden können, die entweder sie selbst oder Kollegen betreut haben [...].“142 (ebd., S. 8)

Die Heterogenität innerhalb der Projektteams lässt sich demnach sowohl aufseiten der Organisation Auftraggeber als auch der Organisation Bieter nach fachlicher Ausbildung, aber auch nach Funktionsrollen im Projekt differenzieren - z. B. als Experte eines Bereichs oder als Leitung. ${ }^{143}$

141 Meine entsprechende Erfahrung konnte ich aus Gründen des Datenschutzes nicht durch Interviews absichern.

142 Auftraggeber 2 (2010b, S. 2) beschreibt die Lernerfahrung aus der Kooperation mit externen Juristen ähnlich.

143 Unberücksichtigt bleibt dabei, dass Projektmitarbeitende als Mitarbeitende der Organisation zwei Funktionsrollen wahrnehmen: erstens als Mitglieder einer Abteilung der Organisation, zweitens als Projektmitglied der Organisation. Diese Doppelstruktur kann zu Konflikten im Projekt führen, wenn sich die Ziele eines Projekts und diejenigen der 
Interfachlichkeit macht sich demnach in Projektteams in Form von Wissensasymmetrien bemerkbar, die Projektbeteiligte durch längere Tätigkeit in Projekten reduzieren können. Deutlich wird auch, dass Projektkommunikation die Organisationen Bieter und Auftraggeber einschließt und die Konzepte Projekt und Organisation verknüpfen. Diese Beschreibung des Kontextes dient als Grundlage, um die Auswahl der Interviewpartner, die den folgenden Interviews zugrunde liegt, und der Beobachtungen nachvollziehbar zu machen.

\subsubsection{Durchgeführte Beobachtungen von gemeinsamen Textüberarbeitungen}

Nach meiner Tätigkeit beim Bieter beobachtete ich die Textüberarbeitungen zu den drei Ausschreibungsverfahren, zu denen im Textkorpus Textsortenexemplare vorliegen. Wie bereits beschrieben (s. Kapitel 4.1.1) waren diese Beobachtungen nicht standardisiert, nicht wiederholbar, umfassend, direkt, stationär, verdeckt, aktiv und teilnehmend. Folgende Beobachtungen von Textsortenexemplaren aus dem oben angegebenen Textkorpus wurden durchgeführt (s. Tabelle 4-11):

\begin{tabular}{|l|l|}
\hline Ausschreibung & Bezug auf folgende Textsortenexemplare \\
\hline Ausschreibung 1 & $\begin{array}{l}\text { Beobachtung der Überarbeitungen zu } \\
\text { Optimierungsvorschlägen aus Ausschreibung 1 }\end{array}$ \\
\hline Ausschreibung 1 & $\begin{array}{l}\text { Beobachtung der Überarbeitungen des Pflichtenhefts } \\
\text { und der Fahrplanvarianten aus Ausschreibung 1 }\end{array}$ \\
\hline Ausschreibung 2 & $\begin{array}{l}\text { Beobachtung der Überarbeitungen des Pflichtenhefts } \\
\text { aus Ausschreibung 2 }\end{array}$ \\
\hline Ausschreibung 3 & $\begin{array}{l}\text { Beobachtung der Überarbeitungen zu } \\
\text { Optimierungsvorschlägen aus Ausschreibung 1 }\end{array}$ \\
\hline Ausschreibung 3 & $\begin{array}{l}\text { Beobachtung der Überarbeitungen des Pflichtenhefts } \\
\text { und der Fahrplanvarianten aus Ausschreibung 3 }\end{array}$ \\
\hline
\end{tabular}

Tabelle 4-11: Übersicht Beobachtungsprotokolle (eigene Darstellung).

Es wurde nur ein Bieter beobachtet, weil mir dieser eine Genehmigung für die Beobachtungen nur unter der Voraussetzung erteilte, dass ich keine Beobachtungen bei Konkurrenz-unternehmen durchführte. Grund für dessen Forderung war

Abteilungen widersprechen. Dies kann z. B. bei der Aufteilung der Arbeitskraft von Mitarbeitenden der Fall sein. 
die Sorge, dass ich interne Informationen an die Konkurrenten - gewollt oder ungewollt - weitergeben könnte.

Sowohl aus den Beobachtungen als auch aus der ersten Analyse von Exemplaren aus obigem Textkorpus ergaben sich Fragen, denen ich in Interviews nachging.

\subsubsection{Durchgeführte Interviews und Befragungen}

Die Analyse von Exemplaren aus dem obigen Textkorpus und die Beobachtungen der Textüberarbeitungsprozesse gaben den Anstoß, Interviews mit den Auftraggebern der Ausschreibungen 1, 2 und 3 als Lesende der Textsortenexemplare zu führen. Um die Übertragbarkeit und Verallgemeinerbarkeit der Analyseergebnisse aus obigem Textkorpus zu prüfen (s. Kapitel 4.2.3), befragte ich andere Auftraggeber der Domäne SPNV-Ausschreibungsverfahren, den Bundesverband dieser Auftraggeber und einen Bieter aus einer anderen Domäne. Auch die Projektmitarbeitenden des Bieters, die an den Textüberarbeitungen beteiligt waren, interviewte ich, um Beobachtetes zu präzisieren und Interpretationen des Beobachteten zu überprüfen (s. Tabelle 4-12). ${ }^{144}$

\begin{tabular}{|l|l|}
\hline Ausschreibung & Interviewpartner/Organisation \\
\hline Ausschreibung 1 & Auftraggeber 1; beide Leiter für Ausschreibung 1 \\
\hline Ausschreibung 3 & $\begin{array}{l}\text { Auftraggeber 2; Leiter für Ausschreibung 3 (erstes Tele- } \\
\text { foninterview) }\end{array}$ \\
\hline Ausschreibung 3 & $\begin{array}{l}\text { Auftraggeber 2; zweites persönliches Interview in den } \\
\text { Geschäftsräumen; Leiter für Ausschreibung 3 }\end{array}$ \\
\hline $\begin{array}{l}\text { Ausschreibungen 6 } \\
\text { sowie 2 und 3 }\end{array}$ & $\begin{array}{l}\text { Auftraggeber 2; Nachfolger des Verantwortlichen für } \\
\text { Ausschreibungen }\end{array}$ \\
\hline Ausschreibung 4 & Auftraggeber 3; Verantwortlicher für Ausschreibung 4 \\
\hline$/$ & Auftraggeber 4; Ansprechpartner für Ausschreibungen \\
\hline$/$ & Auftraggeber 5; Ansprechpartner für Ausschreibungen \\
\hline$/$ & BAG SPNV \\
\hline Ausschreibung 2 & $\begin{array}{l}\text { Fahrzeughersteller 1; Verantwortlicher für Ausschrei- } \\
\text { bung 2 }\end{array}$ \\
\hline
\end{tabular}

144 Die Teildatensammlung führt Befragungen/Interviews unabhängig von der Kommunikationsform - E-Mail oder Protokoll zu Face-to-Face-Situation - auf. 


\begin{tabular}{|l|l|}
\hline $\begin{array}{l}\text { Ausschreibungen } \\
1 \text { und 3 }\end{array}$ & $\begin{array}{l}\text { Fahrzeughersteller 2; Verantwortlicher für Ausschrei- } \\
\text { bung 1 und 3 }\end{array}$ \\
\hline $\begin{array}{l}\text { Ausschreibungen } \\
1 \text { und 3 }\end{array}$ & $\begin{array}{l}\text { Fahrzeughersteller 2; Vertraulichkeitserklärung zu Befra- } \\
\text { gungen von Fahrzeughersteller 2 }\end{array}$ \\
\hline Ausschreibung 1 & $\begin{array}{l}\text { Fahrzeughersteller 3: Interview/Kontaktaufnahmever- } \\
\text { such }\end{array}$ \\
\hline $\begin{array}{l}\text { Ausschreibungen } \\
1,2 \text { und 3 }\end{array}$ & $\begin{array}{l}\text { Bieter/EVU; Bereichsleiter für die Abteilung Wettbe- } \\
\text { werb im Bieterunternehmen }\end{array}$ \\
\hline $\begin{array}{l}\text { Ausschreibungen } \\
1 \text { und 2 }\end{array}$ & Bieter/EVU; Fahrzeugtechniker \\
\hline $\begin{array}{l}\text { Ausschreibungen } \\
1,2 \text { und 3 }\end{array}$ & Bieter/EVU; Redakteurin 1 \\
\hline$/$ & $\begin{array}{l}\text { Geschäftsführer des Bieterunternehmens in der Domäne } \\
\text { behördlicher Ausschreibungen für Software }\end{array}$ \\
\hline
\end{tabular}

Tabelle 4-12: Übersicht über Interviews und Befragungen (eigene Darstellung).

Im Folgenden wird dargestellt und begründet, welche Exemplare des Textkorpus für die exemplarische Textanalyse herangezogen werden. Beinahe alle aufgeführten Beobachtungen und Interviews fließen in die Analyse zu semiotischer Effizienz (s. Kapitel 6) ein, die auf den Ergebnissen der Textanalyse aufbaut. Teilweise sind Interviewaussagen bereits oben verarbeitet worden, um die Übertragbarkeit und Verallgemeinerbarkeit der Textanalyseergebnisse einschätzen zu können beispielsweise Aussagen von Auftraggeber 3, Auftraggeber 4 und Auftraggeber 5 .

\subsection{Auswahl an Textsortenexemplaren für die Textanalyse}

Für die Analyse der Textsorten werden alle Exemplare herangezogen, die der Bieter erstellte, ${ }^{145}$ also

- alle Optimierungsvorschläge aller drei Ausschreibungsverfahren,

- $\quad$ alle drei Pflichtenhefte aller drei Ausschreibungsverfahren,

145 Ein tabellarischer Überblick über die verwendeten Dokumente findet sich in Kapitel 4.5. 
- alle drei Lastenheftvordrucke aller drei Ausschreibungsverfahren (LHV 1; LHV 2; LHV 3) und

- alle Fahrplanvarianten.

Dagegen geht die Analyse auf die Verdingungslagen in AusschreIBUng 1, also die Dokumente von AuftraggeBer 1 (mit Ausnahme des Lastenheftvordrucks) nur vereinzelt ein. Diese Unterlagen werden aufgeführt, um die Modellierung des Textsortennetzes zu SPNV-Ausschreibungsverfahren (s. Tabelle 4-3) überprüfbar zu machen. Durch die Verdingungsunterlagen der AufTRAGgeBer 3, 4 und 5 wird überprüfbar, inwieweit sich die analysierten Exemplare von AUFTRAGGEBER 1 und 2 von den Exemplaren der anderen Auftraggeber unterscheiden. Darüber hinaus ermöglichen diese Verdingungsunterlagen es, die Gestaltung mit den Empfehlungen der BAG SPNV $\left({ }^{2} 2010 ;{ }^{3} 2016\right)$ zur Gestaltung der Lastenhefte abzugleichen.

Die Analyse bezieht sich in der Regel auf die Verdingungsunterlagen von AusSCHREIBUNG 1, z. B. auf die Bewerbungsbedingungen und die Leistungsbeschreibung. Denn die Dokumente zu Ausschreibung 1 sind am vollständigsten und ermöglichen es am ehesten, Beobachtungen, Interviews und analysierte Textsortenexemplare aufeinander zu beziehen. Die Beobachtungsprotokolle zu den beiden Treffen, bei denen Textsortenexemplare vom interfachlichen Team in AusSCHREIBUNG 1 überarbeitet wurden, sind im Vergleich zu den übrigen Protokollen insoweit von höherer Qualität, als ein Redaktionsmitglied mein Protokoll zu der gemeinsamen Textüberarbeitung prüfte, an der sie ebenfalls teilnahm. Darüber hinaus beantwortete sie Fragen zu diesem Protokoll detailliert, indem sie die Antworten auf meine Fragen in das WORD-Dokument schrieb. Sie und weitere Projektmitglieder aus AUSSCHREIBUNGSVERFAHREN 1 beantworteten schriftliche Anfragen per E-Mail.

An AussCHREIBUNG 1 ist des Weiteren besonders, dass ich mit dem Auftraggeber des Verfahrens - AUfTRAGGEBER 1 (2013) - ein ausführliches Interview führte, das er detailliert überarbeitete, bevor er es für die Veröffentlichung freigab. Er machte mir auch sämtliche Verdingungsunterlagen zugänglich. Auch der FAHRZEUGHERSTELLER 2 (2014), dessen Fahrzeug bei der gemeinsamen Textüberarbeitung zu Ausschreibung 1 besprochen wurde, gab ein ausführliches Interview. 
So dienen die Textsortenexemplare zu Ausschreibung 1 meist als Muster in der Analyse, während die Exemplare der Ausschreibungsverfahren 2 und 3 herangezogen werden, um identische Merkmale oder von Dokumenten aus AUSSCHREIBUNG 1 abweichende Merkmale herauszustellen. Durch die Fokussierung einer Ausschreibung werden die Interviewaussagen vom Fahrzeughersteller, vom Auftraggeber, von Mitarbeitenden des Bieters, die Beobachtungsprotokolle der gemeinsamen Textüberarbeitungen und die Ergebnisse der Textanalyse trianguliert.

$\mathrm{Zu}$ den Textsortenexemplaren des Bieters ist anzumerken, dass es sich mit wenigen Ausnahmen um die Abgabeversion handelt. Grundsätzlich existieren drei Versionen, wobei in einigen Fällen nur die Abgabeversion verfügbar war. ${ }^{146}$ Dementsprechend werden die Textsortenexemplare aus Ausschreibung 1 fokussiert: Pflichtenheft 1, Lastenheftvordruck 1, der zugehörige Fahrzeugumlaufplan und Bildfahrplan, verschiedene Optimierungsvorschläge, von denen die für die Analyse wichtigsten in Tabelle 4-13 aufgeführt sind.

Darüber hinaus werden im Folgenden Textsortenexemplare der Ausschreibungen 2 und 3 benannt, die in der Textanalyse eine besondere Rolle spielen.

\begin{tabular}{|l|l|}
\hline Textsorte & Bezeichnung/Spezifikation des Dokuments \\
\hline PH & Pflichtenheft 3 zu Ausschreibung 3 (Auftraggeber 2; Fahrzeug 1) \\
\hline OV & Optimierungsvorschlag 1 in Ausschreibung 1 \\
\hline OV & Optimierungsvorschlag 2 in Ausschreibung 1 \\
\hline OV & Optimierungsvorschlag 7 in Ausschreibung 1 \\
\hline OV & Optimierungsvorschlag 10 in Ausschreibung 1 \\
\hline OV & Optimierungsvorschlag 1 in Ausschreibung 2 \\
\hline
\end{tabular}

Tabelle 4-13: Ausgewählte Textsortenexemplare für die Analyse (eigene Darstellung).

146 Von Optimierungsvorschlägen werden im beobachteten Unternehmen drei Versionen erstellt: das Exemplar 1. des Fachautors, 2. der gemeinsamen Überarbeitung, 2. der Abgabe nach abschließender Überarbeitung der Redaktion und des Teamleiters. Von Pflichtenheft 1 und 2 waren nur die Abgabeversion verfügbar. Von PH 3 sind dagegen die Vorversion und die Abgabeversion verfügbar. Während der gemeinsamen Textüberarbeitungen wurden Pflichtenhefte als PDF-Dateien bearbeitet, sodass die WORD-Funktion „Änderungen nachverfolgen“" nicht genutzt werden konnte. Auch Fahrpläne waren nur in der Endversion zugänglich. 
Die Auswahl dieser Exemplare begründet sich wie folgt: OV 1 und 2 aus AusSCHREIBUNG 1 werden herangezogen, weil sie reziprok aufeinander verweisen. OV 7 wird genutzt, weil er durch den Einsatz von Säulendiagrammen in seiner Zeichenkomplexität gegenüber den übrigen Vorschlägen auffällt. Zudem wurde er als einziger Vorschlag im Verfahren in die Verdingungsunterlagen aufgenommen. OV 10 aus AusschreiBung 1 ist aufgrund der enthaltenen Tabelle ebenso relevant wie OV 1 aus AusschreiBung 2, um den Einfluss des fachlichen Hintergrunds auf die Textgestaltung untersuchen zu können. Im Folgenden wird in Überblick über das Textkorpus und weitere Material gegeben, das in der Analyse herangezogen wird.

\section{5 Überblick über das Textkorpus und weitere Material für die Analyse}

Die folgende Tabellen stellt das Material dar, das in der Analyse der Texte (Kapitel 5) und der Überarbeitungsprozesse (Kapitel 6) herangezogen wird. Darin werden auch die Bezeichnungen für die Dokumente angegeben, die die Analysen verwenden. Der 889-seitige Anhang mit dem gesamten erhobenen Material lag dem Prüfungsausschuss im Rahmen meines Promotionsverfahrens wie auch allen Professoren/-innen der Fakultät für Geisteswissenschaften an der Universität Duisburg-Essen im Rahmen der Auslage von Dissertation und den Gutachten der Prüfenden vor, die die Prüfungsordnung vorschreibt. Aus Gründen der Geheimhaltung kann ich diesen Anhang an dieser Stelle nicht veröffentlichen, sondern zitiere die Auszüge in den Analysekapiteln - Kapitel 5 und Kapitel 6. Wie üblich (z. B. ZeHRER, 2014, S. 395 ff.), gebe ich im anschließenden Überblick auch die die Abkürzungen für die Dokumente an, die ich in der Analyse verwende. 


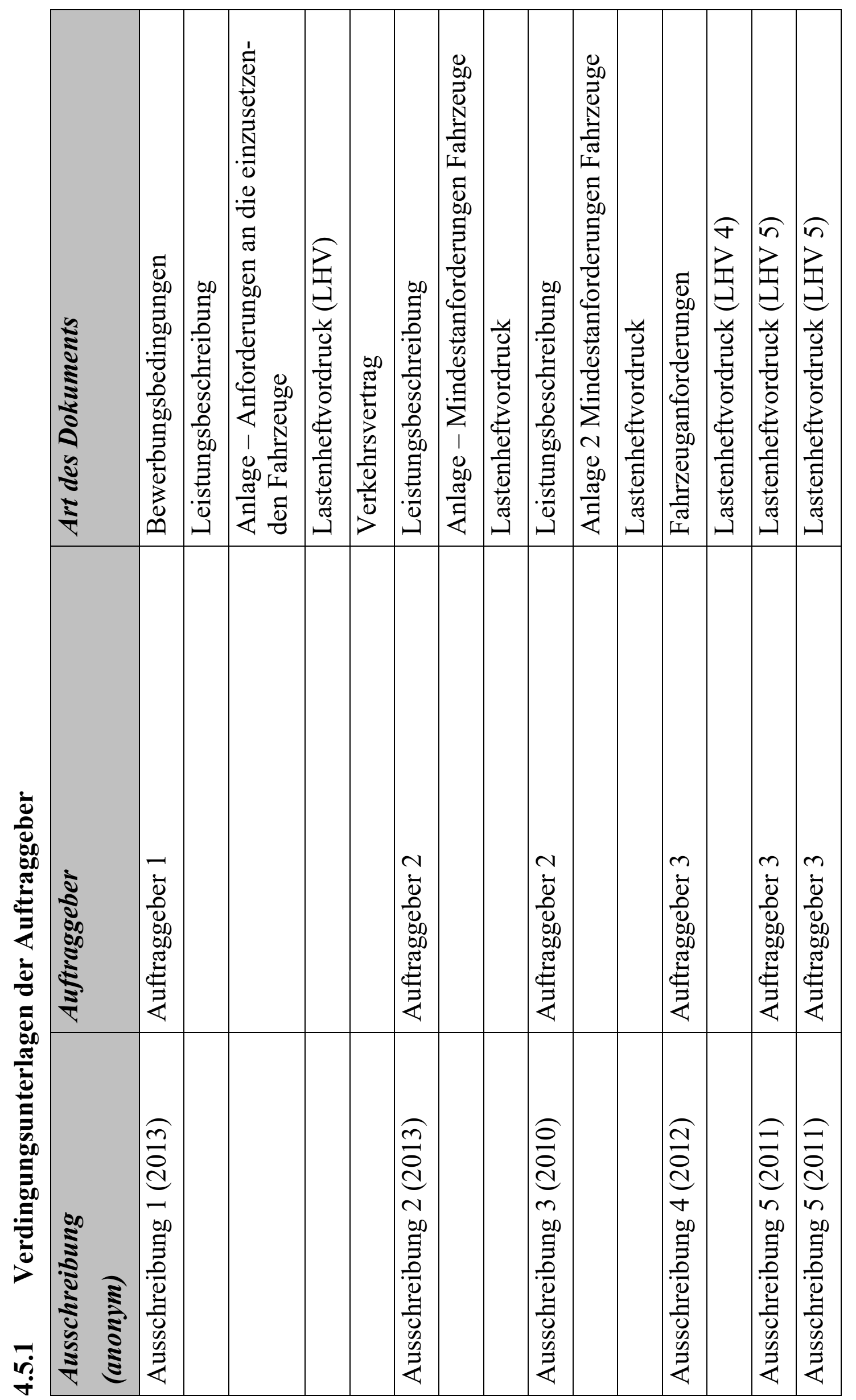




\subsubsection{Optimierungsvorschläge (OV) des Bieters}

\begin{tabular}{|l|l|l|}
\hline Ausschreibung & Auftraggeber & Optimierungsvorschlag (OV) \\
\hline Ausschreibung 1 & Auftraggeber 1 & OV 1-OV 11 \\
\hline Ausschreibung 2 & Auftraggeber 2 & OV 1-OV 7 \\
\hline Ausschreibung 3 & Auftraggeber 2 & OV 1-OV 5 \\
\hline
\end{tabular}

\subsubsection{Pflichtenhefte und Zeichnungen des Bieters}

\begin{tabular}{|l|l|l|}
\hline Ausschreibung & Hersteller & Fahrzeug \\
\hline Ausschreibung 1 & Hersteller 2 & Fahrzeug 1 \\
\hline Ausschreibung 2 & Hersteller 1 & Fahrzeug 2 \\
\hline Ausschreibung 3 & Hersteller 2 & Fahrzeug 1 \\
\hline
\end{tabular}

\subsubsection{Fahrpläne des Bieters}

\begin{tabular}{|l|l|l|}
\hline Ausschreibung & Fahrplanvariante & Weiteres \\
\hline Ausschreibung 1 & Tabellenfahrplan & Fahrzeug 1 \\
\hline & Bildfahrplan & Fahrzeug 1 \\
\hline & Fahrzeugumlaufplan & Fahrzeug 1 \\
\hline
\end{tabular}

\subsubsection{Durchgeführte Beobachtungen von gemeinsamen Textüberarbeitungen}

\begin{tabular}{|l|l|}
\hline Ausschreibung & Textsortenexemplare \\
\hline Ausschreibung 1 & $\begin{array}{l}\text { Beobachtung der Überarbeitungen zu den Optimierungs- } \\
\text { vorschlägen aus Ausschreibung 1 (Holste 2013a) }\end{array}$ \\
\hline Ausschreibung 1 & $\begin{array}{l}\text { Beobachtung der Überarbeitungen des Pflichtenhefts und } \\
\text { der Fahrplanvarianten aus Ausschreibung 1 (Holste } \\
\text { 2013b) }\end{array}$ \\
\hline Ausschreibung 2 & $\begin{array}{l}\text { Beobachtung der Überarbeitungen des Pflichtenhefts aus } \\
\text { Ausschreibung 2 (Holste 2013c) }\end{array}$ \\
\hline Ausschreibung 3 & $\begin{array}{l}\text { Beobachtung der Überarbeitungen der Optimierungsvor- } \\
\text { schläge aus Ausschreibung 3 (Holste 2010a) }\end{array}$ \\
\hline Ausschreibung 3 & $\begin{array}{l}\text { Beobachtung der Überarbeitungen des Pflichtenhefts und } \\
\text { der Fahrplanvarianten aus Ausschreibung 3 (Holste } \\
\text { 2010b) }\end{array}$ \\
\hline
\end{tabular}




\subsubsection{Durchgeführte Interviews und Befragungen}

\begin{tabular}{|c|c|}
\hline Ausschreibung & Interviewpartner/Organisation \\
\hline Ausschreibung 1 & Auftraggeber 1 (2013); beide Leiter für Ausschreibung 1 \\
\hline Ausschreibung 3 & $\begin{array}{l}\text { Auftraggeber } 2 \text { (2010a); Leiter für Ausschreibung } 3 \text { bei } \\
\text { (erstes Telefoninterview) }\end{array}$ \\
\hline Ausschreibung 3 & $\begin{array}{l}\text { Auftraggeber } 2 \text { (2010b); zweites persönliches Interview } \\
\text { in dessen Geschäftsräumen; Leiter für Ausschreibung } 3\end{array}$ \\
\hline $\begin{array}{l}\text { Ausschreibungen } \\
6 \text { sowie } 2 \text { und } 3\end{array}$ & $\begin{array}{l}\text { Auftraggeber 2; Nachfolger des Verantwortlichen für } \\
\text { Ausschreibungen (E-Mail vom 17.6.2015) }\end{array}$ \\
\hline Ausschreibung 4 & $\begin{array}{l}\text { Auftraggeber } 3 \text { (E-Mail vom 23.12.2015); Verantwortli- } \\
\text { cher für Ausschreibung } 4\end{array}$ \\
\hline $\begin{array}{l}\text { Ohne Ausschrei- } \\
\text { bung }\end{array}$ & $\begin{array}{l}\text { Auftraggeber } 4 \text { (E-Mails vom 23.12.2015 \& 29.12.2015); } \\
\text { Ansprechpartner für Ausschreibungen }\end{array}$ \\
\hline $\begin{array}{l}\text { Ohne Ausschrei- } \\
\text { bung }\end{array}$ & $\begin{array}{l}\text { Auftraggeber } 5 \text { (E-Mail vom 29.12.2015); Ansprechpart- } \\
\text { nerin für Ausschreibungen }\end{array}$ \\
\hline $\begin{array}{l}\text { Ohne Ausschrei- } \\
\text { bung }\end{array}$ & BAG SPNV (E-Mail vom 20.10.2015) \\
\hline Ausschreibung 2 & $\begin{array}{l}\text { Fahrzeughersteller 1 (2014); Verantwortlicher für Aus- } \\
\text { schreibung } 2\end{array}$ \\
\hline $\begin{array}{l}\text { Ausschreibungen } \\
1 \text { und } 3\end{array}$ & $\begin{array}{l}\text { Fahrzeughersteller } 2 \text { (2014); Verantwortlicher für Aus- } \\
\text { schreibung } 1 \text { und } 3\end{array}$ \\
\hline $\begin{array}{l}\text { Ausschreibungen } \\
1 \text { und } 3\end{array}$ & $\begin{array}{l}\text { Fahrzeughersteller } 2 \text { (2014); Vertraulichkeitserklärung zu } \\
\text { Befragungen von Fahrzeughersteller } 2\end{array}$ \\
\hline Ausschreibung 1 & $\begin{array}{l}\text { Fahrzeughersteller } 3 \text { (E-Mail vom 17.4.2014): Inter- } \\
\text { view/Kontaktaufnahmeversuch }\end{array}$ \\
\hline $\begin{array}{l}\text { Ausschreibungen } \\
1,2 \text { und } 3\end{array}$ & $\begin{array}{l}\text { Bieter/EVU; Bereichsleiter (2011) für die Abteilung } \\
\text { Wettbewerb im Bieterunternehmen }\end{array}$ \\
\hline $\begin{array}{l}\text { Ausschreibungen } \\
1 \text { und } 2\end{array}$ & $\begin{array}{l}\text { Bieter/EVU; Fahrzeugtechniker (E-Mails vom 9.4.2014 \& } \\
\text { 29.10.2014) }\end{array}$ \\
\hline $\begin{array}{l}\text { Ausschreibungen } \\
1,2 \text { und } 3\end{array}$ & Bieter/EVU; Redakteurin 1 (E-Mail vom 1.4.2014) \\
\hline l & $\begin{array}{l}\text { Geschäftsführer des Bieterunternehmens in der Domäne } \\
\text { behördlicher Ausschreibungen für Software (16.4.2014) }\end{array}$ \\
\hline
\end{tabular}




\subsubsection{Praktikumszeugnisse, Genehmigungen und Vertraulichkeitserklärung}

\begin{tabular}{|l|l|}
\hline Erteilt von & Dokument/Genehmigung für \\
\hline EVU/Bieter & Praktikumszeugnis - Redaktion \\
\hline EVU/Bieter & Praktikumszeugnis - Prozessoptimierung \\
\hline EVU/Bieter & $\begin{array}{l}\text { Genehmigung für Textüberarbeitungen und Dokumen- } \\
\text { tenverwendung }\end{array}$ \\
\hline Auftraggeber 2 & Genehmigung Interview \\
\hline Auftraggeber 2 & Genehmigung Interview \\
\hline Auftraggeber 1 & Genehmigung Interview \\
\hline Auftraggeber 1 & Genehmigung Verdingungsunterlagen Ausschreibung 1 \\
\hline Auftraggeber 2 & Genehmigung Verdingungsunterlagen Ausschreibung 3 \\
\hline Auftraggeber 2 & Genehmigung Verdingungsunterlagen Ausschreibung 2 \\
\hline Fahrzeughersteller 1 & $\begin{array}{l}\text { Genehmigung Interview mit } \\
\text { Fahrzeughersteller 1 }\end{array}$ \\
\hline EVU/Bieter & Genehmigung Fahrzeugcheckliste Fahrzeughersteller 1 \\
\hline Fahrzeughersteller 2 & $\begin{array}{l}\text { Genehmigung Interview mit } \\
\text { Fahrzeughersteller 2 }\end{array}$ \\
\hline EVU/Bieter & Freigabe von Textstellen aus allen OV \\
\hline EVU/Bieter & Freigabe von Textstellen aus Pflichtenheften 1, 2 und 3 \\
\hline
\end{tabular}

\subsubsection{Weiteres}

\begin{tabular}{|l|l|}
\hline Prof. Dr.-Ing. Jörn Pachl & E-Mail vom 29.10.2014 \\
\hline Anfrage an Hersteller von Umlaufplansoftware & E-Mail vom 31.10.2014 \\
\hline Fahrzeughersteller 2 & Datenblatt Fahrzeug 1 \\
\hline Fahrzeughersteller 1 & Referenzen Fahrzeug 2 \\
\hline
\end{tabular}





\section{Exemplarische Analyse ausgewählter Sprache-Bild-Textsorten}

Diese empirische Analyse dient dazu, semiotische Effizienz der SPNV-Ausschreibungskommunikation als Verhältnis der Kommunikate (s. Kapitel 2.5) zur Kapazität der Kommunikanten (ebd.) zu interpretieren. Dadurch sollen die drei Thesen (Kapitel 2.1.3) überprüft werden, die bereits die Konzeption des Modells semiotischer Effizienz leiten. Die Aufwands- und Ergebnisseite des Kommunikats - hier der Textsortenexemplare - als Kategorien des Modells semiotischer Effizienz (s. Tabelle 2-2) sind zu ungenau, um eine Analyse von Textsortenexemplaren durchzuführen. Daher wird im Folgenden das integrierte Analyseraster zu Sprache-Bild-Textsorten (s. Kapitel 3) herangezogen, um die ausgewählten Exemplare (s. Kapitel 4.4) der Textsorte Optimierungsvorschlag, der Textsortenvarianten Lasten- und Pflichtenheft sowie Fahrplanvarianten zu beschreiben, zu analysieren und zu interpretieren. Interpretiert werden dabei nicht mögliche Rezeptionspfade (s. Kapitel 2.3.3), über die nur spekuliert werden kann. Die Ergebnisse zu den Beschreibungen, Analysen und Interpretationen stellen bei der Bestimmung semiotischer Effizienz das Kommunikat dar. Diese Ergebnisse zieht Kapitel 6 heran, um das Kommunikat ins Verhältnis zur Kapazität der Kommunikanten zu setzen. Letzteres leistet die Beschreibung und Interpretation der protokollierten Überarbeitungen und Interviews.

Die Analyse gibt an wenigen Stellen Definitionen von Beschreibungskategorien aus wissenschaftlicher Literatur wieder, um die Textsortenexemplare anhand dieser Definitionen zu analysieren. Weil diese Definitionen (beispielsweise von Ellipsen oder Arten von Präpositionalgruppen) weder diskutiert werden noch derart abstrakt sind, dass sie in das Analyseraster (s. Kapitel 3) oder das Modell semiotischer Effizienz (s. Kapitel 2) einfließen, werden sie im Folgenden in Fußnoten wiedergegeben. Durch diese Positionierung soll die Trennung zwischen Diskussion von Theorie und Konzeption gegenüber der empirischen Analyse aufrechterhalten bleiben.

Die Analysekategorie ,Intertextualität', die Teil des integrierten Analyserasters ist, stellt bereits Kapitel 4.2.2 als funktionale Text-Text-Relationen in SPNV- 
Ausschreibungsverfahren (s. Tabelle 4-3) dar. Diese Beschreibung behandelt Intertextualität in Form funktionaler Relationen für die drei zu analysierenden Textsorten Optimierungsvorschlag, Lasten- und Pflichtenheft sowie Fahrplanvarianten. Daher wird Intertextualität nicht erneut für die einzelnen Textsorten, sondern lediglich im Zwischenfazit zur Textanalyse wiedergegeben.

\section{$5.1 \quad$ Textsorte Optimierungsvorschlag (OV)}

Die Textsorte Optimierungsvorschlag ist funktional und thematisch eng an die Textsorten Leistungsbeschreibung und deren Anhänge gebunden, deren erste Version diese Vorschläge modifizieren sollen (s. Kapitel 4.2.2; Tabelle 4-3). Strukturell sind Optimierungsvorschläge nicht durch die Leistungsbeschreibung festgelegt, aber in allen drei Ausschreibungen, in denen ich sie über drei Jahre erhob (s. Kapitel 4.1), relativ einheitlich gestaltet. Die einzelnen Textebenen sind dabei zu besprechen. Im Folgenden wird das integrierte Analyseraster zu SpracheBild-Textsorten auf die genannten Optimierungsvorschläge angewendet.

\subsubsection{Textdesign}

Die Analyse der Optimierungsvorschläge gliedert sich nicht entsprechend einem angenommenen Rezeptionspfad, der als Pfad von einem Überblick zu Details entsprechend ihrer Salienz bzw. als Top-down-Prozess beschrieben wird (s. Kapitel 3.1), sondern nach den Kriterien der Unterkategorie ,Textdesign“ (s. Abbildung 3-2). Das Beispiel in Abbildung 5-1 basiert auf der Gestaltung aller OV in Ausschreibung 1 und Ausschreibung 2, konkret auf OV 2 in Ausschreibung 1, und ist für diese prototypisch. Die folgenden Ausführungen beziehen sich auf dieses Beispiel und präzisieren Angaben mit Verweis auf einzelne Optimierungsvorschläge des Anhangs. Abweichungen von diesem Prototypen werden im Anschluss dargestellt. Die Analyse des Textdesigns kann sich beim Prototypen dieser Textsorte nur auf seine Schriftbildlichkeit beziehen, weil die erhobenen Textsortenexemplare nur in Ausnahmefällen abbildende Diagramme oder Tabellen, aber keine ikonisch-materiellen Bilder verwenden - nur Ausschreibung 2 nutzt Tabellen regelhaft für Anhänge.

Entsprechend finden sich zum Kriterium ,Panel` lediglich Kopf- und Fußzeilen, die einen Fließtext abgrenzen. Es finden sich aber keine weiteren durch Linien 
abgegrenzte Rechtecke etc. innerhalb dieses Fließtextes. D. h., es sind keine ,Panels' vorhanden, wie sie in Comics bzw. entsprechend der Comic-Theorie beschrieben werden (s. Kapitel 3.1). Erst die Beschreibung weiterer Texteigenschaften, die zur Unterkategorie ,Design“ gehören, ermöglicht es, das ,Gesetz der Nähe‘ als zweites Kriterium der Unterkategorie ,Layout' zu analysieren.

Sämtliche Optimierungsvorschläge nutzen Blocksatz, die Schriftart, -größe und -graustufe der Fließtexte (,Form‘, ,Größe', ,Kontrast') unter den Überschriften ist einheitlich gestaltet (,Similarität' als Teil von ,Design'). Diese Fließtextelemente sind in einem regelmäßigen Abstand zwischen der Kopf- und Fußzeile ,positioniert'. Durch den ,Graustufenkontrast ${ }^{`}$ zum Weiß des Hintergrunds heben sich diese Fließtextelemente, aber auch die Überschriften vom Hintergrund ab. Solche Mittel der Schriftbildlichkeit, die Fließtextelemente zu Textkörpern machen, bilden mehrzeilige Fließtextflächen. Jene Schriftflächen werden von den Überschriften abgehoben, indem nur die Überschriften in die ,Form' des Fettdrucks gesetzt werden. Neben den Überschriften werden in der untersten Fließtextfläche die Schriftelemente $x, x$ Mio. $€$ und $0,0 € / Z \mathrm{~km}$ durch Fettdruck markiert. Die jeweiligen Fließtextflächen sind näher an einer Überschrift angeordnet, die sich über der Schriftfläche befindet, als an einer Überschrift, die unter einer Textfläche positioniert ist. Der Abstand nach jeder Überschrift beträgt in AUSSCHREIBUNG 1 und 2 jeweils 6 pt. Dagegen enthalten die Vorschläge von Ausschreibung 3 keine Überschriften wie in den Textsortenexemplaren aus Ausschreibung 1 und 2.

Die Überschriften werden nicht nur durch die ,Form‘ des Fettdrucks, sondern auch durch ihre ,Größe'v von der Schriftgröße der Fließtextfläche abgehoben, wobei die Schriftgröße der Überschriften größer ist als die der Textflächen. Die Gesamtüberschrift ist in der größten Schriftgröße gegenüber den Fließtextflächen und den übrigen Unterüberschriften gehalten. Der ,Graustufenkontrast ${ }^{\star}$ unterscheidet die Überschriften und die Fließtextkörper dagegen nicht, sondern gestaltet beide Elementgruppen einheitlich. Dagegen wirkt die rote Färbung des Logos durch die übrige, ausschließlich schwarze Schrift des OV und durch den weißen Hintergrund visuell salient. Neben dem Fettdruck wird in einer mittleren Fließtextfläche die Kursive als ,Form‘ der Schriftelemente eingesetzt.

Entsprechend dem ,Gesetz der Nähe“ werden die Textflächen mit den näheren Überschriften als (Sinn-)Einheit wahrnehmbar. Eine Hierarchisierung der 
Schriftelemente wird einerseits durch Kontrastierung, andererseits durch Einheitlichkeit (,Similarität') erzeugt: Der Kontrast zwischen der Form des Fettdrucks und der größeren Schriftgrößen von Überschriften gegenüber der Schriftgestaltung der Fließtextflächen grenzt beide Schriftelementgruppen voneinander ab. Die einheitliche Gestaltung von Überschriften gegenüber der einheitlichen Gestaltung von mehrzeiligen Textflächen ermöglicht es dagegen, die jeweiligen Schriftelemente diesen beiden Gestaltungsgruppen zuzuordnen. Beide Gestaltungsgruppen semantisch als hierarchische Ebenen aufzufassen, wird durch die größeren Schriftgröße der Überschriften, deren Anordnung über den Textflächen und die Form des Fettdrucks möglich.

Des Weiteren legt erstens die größte Schriftgröße der Überschrift eine weitere Hierarchieebene gegenüber den weiteren Überschriften in kleinerer Schriftgröße nahe. Zweitens resultiert diese Annahme aus der Positionierung dieser Überschrift im Dokument oben, unmittelbar unterhalb der Linie der Kopfzeile. Diese Interpretation stützt auch die Von-links-oben-nach-rechts-unten-Chronologie, eine Konvention für lateinische Schriftsysteme (s. Einleitung), weil die oberste Überschrift als wichtigste Information als Erstes rezipiert wird. Durchbrochen wird diese Chronologie durch die Kopfzeile, die sich über der Überschrift der höchsten Hierarchieebene befindet. Die Logo-Farbe wirkt gegenüber den ,Graukontrasten' der Überschriften und Textflächen salient. Sie repräsentiert die Bedeutungssubstanz des Unternehmens. ${ }^{147}$

Die einheitliche Gestaltung der Kopf- und Fußzeilen zwischen den jeweiligen Optimierungsvorschlägen einer Ausschreibung erzeugt Kohäsion und macht sie als ein zusammenhängendes Dokument wahrnehmbar. Die Nummerierung der OV einer Ausschreibung erzeugt eine Chronologie und wirkt ebenfalls kohäsionsstiftend. Kursive haben in den OV dabei die Funktion, Zitate aus den Verdingungsunterlagen kenntlich zu machen.

147 Das Logo, Identifikationsfarben und geschützte Design-Elemente sind Teil der Ausdrucksseite eines Unternehmens (KASTENS/LUX, 2014, S. 64). Die Marken-, Leistungs- und Branchenebene bestimmen die Bedeutungssubstanz als Inhaltsseite des Unternehmens (ebd., S. 58). 


\section{Optimierungsvorschläge Ausschreibung $X$}

Optimierungsvorschlag Nr. X

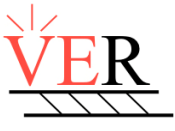

Lorem ipsum dolor sit amet, consetetur sadipscing elitr, sed diam nonumy

\section{Erläuterung}

Lorem ipsum dolor sit amet, consetetur sadipscing elitr, sed diam nonumy eirmod tempor invidunt ut labore et dolore magna aliquyam erat, sed diam voluptua. At vero eos et accusam et justo duo dolores et ea rebum. Stet clita kasd gubergren, no sea takimata sanctus est Lorem ipsum dolor sit amet. Lorem ipsum dolor sit amet, consetetur sadipscing elitr, sed diam nonumy eirmod tempor invidunt ut labore et dolore magna aliquyam erat, sed diam voluptua. At vero eos et accusam et justo duo dolores et ea rebum. Stet clita kasd gubergren, no sea takimata sanctus est Lorem ipsum dolor sit amet.

\section{Optimierung}

Wir schlagen die Anpassung Lorem ipsum dolor sit amet, consetetur sadipscing elitr, sed diam nonumy eirmod tempor invidunt ut labore et dolore magna aliquyam erat, sed diam voluptua. vor. . At vero eos et accusam et justo duo dolores et ea rebum. Stet clita kasd gubergren, no sea takimata sanctus est.

\section{Anzupassende Unterlagen}

Änderung der Anforderung an Stet clita kasd gubergren, no sea takimata sanctus est Lorem ipsum dolor sit amet. Lorem ipsum dolor sit amet, consetetur sadipscing elitr im Teil X. Anlage X.X Lorem (siehe Anlage): consetetur sadipscing elitr, sed diam nonumy eirmod tempor invidunt ut labore et dolore magna aliquyam erat, sed diam voluptua. At vero eos et accusam.

\section{Preiseffekt}

Durch diesen Vorschlag ergibt sich ein Einsparpotenzial von ca. X,X Mio. $€$ über die gesamte Vertragslaufzeit (entspricht ca. $X, X \in / Z \mathbf{k m}$ ).

\section{Abbildung 5-1: ${ }^{148}$ Beispiel eines prototypischen OV (eigene Darstellung basierend auf OV 2).}


Abweichungen von der Prototypik in Abbildung 5-1 stellen die Verwendung von a) Stichpunkten, b) Tabellen und c) abbildenden Diagrammen dar:

a) Beispielsweise nutzt OV 1 Stichpunkte, die in der Mitte des Blatts als Textfläche arrangiert sind. Diese Textfläche ist im Verhältnis zu den darüber und darunter angeordneten Fließtextflächen eingerückt. Die Schriftelemente zu einem Stichpunkt sind durch einen Tabulatorenstopp jeweils gleich weit vom jeweiligen Stichpunkt und in Blocksatz gesetzt, sodass der Eindruck einer Textfläche erzeugt wird. Auch die Stichpunkte sind jeweils durch einen Tabulatorenstopp gleich weit von den Schriftelementen der jeweiligen Zeile entfernt, sodass die Stichpunkte in der Vertikalen das ,Muster' einer imaginären Linie bilden. Die Schriftelemente sind in derselben Schriftart, -größe und -graustufe (,Form', ,Größe', ,Kontrast') wie die übrigen Fließtextflächen gehalten (,Similarität ${ }^{\circ}$ ), sodass lediglich die Positionierung der Textfläche gegenüber der imaginären Linie salient ist.

Diese einheitliche visuelle Anordnung von Stichpunkten erzeugt den Eindruck von gleichwertigen Elementen einer Liste, deren Kohärenz sich daraus ergibt, dass sie unter ein Kriterium subsumiert werden können. ${ }^{149}$ Diese Anordnung spiegelt die Kohärenz der einzelnen Stichpunkte wider, die sich unter das Thema, $\ddot{A} n$ derungen von Stellen in den Verdingungsunterlagen“ subsumieren lassen. Listen sind in Form von Spalten auch in Tabellen enthalten, ${ }^{150}$ die als zweite abweichende Darstellungsform zum prototypischen Optimierungsvorschlag analysiert werden.

b) Beispielsweise enthält OV 10 eine Tabelle mit Angaben zu Öffnungszeiten an bestimmten Standorten. Über der Tabelle ist die Beschriftung bzw. Überschrift Öffnungszeiten 2013 in Fettdruck angebracht. Die Leitzeile und -spalte sind mit einem ,Graukontrast` eingefärbt, während die übrigen Tabellenfächer im Weiß des Hintergrunds gehalten sind und sich von diesem nicht abheben. Die Tabellenfächer bilden Linien, die im selben Schwarz wie die Schriftelemente innerhalb

148 Die Beispiele dieser Arbeit sind anonymisiert. Das enthaltene Logo und der Firmenname werden als Beispiel genutzt. Es stammt vom Bieter mit dem größten Marktanteil.

149 ,[E]ine Auflistung [...] stellt unter einem geltenden Kriterium eine eindimensionale Ordnungsstiftung zur Verfügung.“ (KALVERKÄMPER, 1998d, S. 79)

150 Tabellen sind „mehrdimensionale Kombinationen von Listenformen“ (STEINSEIFER, 2013, S. 30). 
der Fächer gestaltet sind. Ziffern, Gedankenstriche und Buchstaben repräsentieren Uhrzeiten, Wochentage, Zeitsummen und Ortsnamen. Dabei sind die Ortsnamen in der Leitspalte angegeben, und Wochentage sind in der Leitzeile mit den drei Tabellenfächern Öffnungszeiten wochentags, samstags und sonntags dargestellt. Diese Schriftelemente sind entsprechend meiner Aufzählungschronologie von links nach rechts angeordnet. Im äußersten Tabellenfach der Leitzeile rechts findet sich die Angabe Öffnungszeiten je Woche. Die Schriftelemente der Leitzeile und -spalte sind in Fettdruck gestaltet. Uhrzeiten und Summenangaben in Ziffern sind nur in den Fächern zwischen Leitzeile und -spalte positioniert. Angaben innerhalb der Fächer werden in der Regel in einer Zeile und nur zum Teil über zwei Zeilen angegeben.

Diese Tabelle ermöglicht einen selektiven Rezeptionsprozess nach Orten in der Leitspalte oder Wochentagen in der Leitzeile. Denn solche Darstellungsformen dienen grundsätzlich dazu, Textlinearität aufzulösen und selektiv zu rezipieren. ${ }^{151}$ Die Leistung einer Tabelle ist es also, zwei Informationen aufeinander zu beziehen ${ }^{152}$ - im Beispiel (OV 10) Ortsangaben auf Uhrzeiten. Letztlich zielt diese Tabelle darauf, die Anzahl der jeweiligen Öffnungszeiten pro Standort in der Spalte rechts außen aufzusummieren. Nicht aufgelöst wird die Textlinearität in der Vonlinks-nach-rechts-Chronologie des Schriftsystems, der die Anordnung der Wochentage entsprechend dem Wochenverlauf von links nach rechts folgt.

Der ,Graukontrast“ des Hintergrunds von Leitzeile sowie -spalte und der Fettdruck der darin enthaltenen Schriftelemente wirkt salient gegenüber den übrigen Tabellenfächern. Dadurch werden die Angaben der Leitspalte und -zeile als übergeordnete Angaben von detaillierten Angaben der übrigen Tabellenfächer abgehoben. Der ,Graukontrast ${ }^{\star}$ des Hintergrunds und der Fettdruck der Schrift

151 „Jedes Feld einer Tabelle ist eindeutig nach zwei Ordnungskriterien bestimmt, das eine in der Horizontalen, das andere in der Vertikalen. Eine Tabelle potenziert also zum einen den Informationsgehalt, zum anderen die Zugriffsmöglichkeiten durch den Rezipienten. Beides wird, [...], wiederum deutlich, wenn man die simultan präsente und sichtbar geordnete Information, die in einer Tabelle steckt, verbal linearisiert. Die Übersichtlichkeit und die Vergleichbarkeit von Positionen gehen dabei in einem langen linearen Text völlig verloren.“ (RAIBLE, 1991, S. 15 f.)

152 ,[E]ine Tabelle ermöglicht es, Informationen zweidimensional aufeinander zu beziehen“ (KALVERKÄMPER, 1998d, S. 79; Kursive im Original). 
erzeugen also eine Hierarchisierung der Informationen in Leitzeile und -spalte gegenüber den Informationen der übrigen Tabellenfächer.

Die Tabellen der Anhänge zu den jeweiligen OV in Ausschreibung 2 (OV 1 - 7) nehmen dagegen das gesamte Blatt ein. Der Hintergrund der Leitzeile und -spalte ist hier nicht durch Graustufen hervorgehoben, und lediglich die Elemente der Leitzeile sind in Fettdruck gesetzt. Sämtliche Schriftelemente sind in kleinerer Schriftgröße gehalten als die Schriftelemente der Optimierungsvorschläge.

Die Tabelle nutzt drei Spalten. Die linke Spalte (Leitspalte) mit der Beschriftung Fundstelle enthält Schriftelemente, die in den Tabellenfächern mit Ziffern und Buchstaben auf die jeweilige Stelle der Verdingungsunterlagen (z. B. die Leistungsbeschreibung) verweisen. Das Leitzeilenfach der mittleren Spalte enthält die Schriftelemente Vorgabe laut Verdingungsunterlagen und die übrigen Tabellenfächer dieser Spalte enthalten ausschließlich Schriftelemente und wenige Ziffern mit Streckenlängen von Material, Fahrtzeiten etc. Außergewöhnlich wirkt darin die Angabe einer vollständigen Tabelle als Zitat aus der Leistungsbeschreibung. Auch die Fächer der rechten Spalte mit der Beschriftung Formulierungsvorschlag zur Umsetzung des Optimierungsvorschlags im Leitzeilenfach enthalten Schriftelemente.

Durch die Anordnung der zitierten Textstellen in der mittleren Spalte, also der aktuellen Version der Verdingungsunterlagen, und der vorgeschlagenen Änderungen, also der gewünschten zukünftigen Version der Verdingungsunterlagen, deckt sich die Von-links-nach-recht-Chronologie der Leserichtung mit der zeitlichen Chronologie der (erhofften) Unterlagenversionen. Die Schriftgröße sämtlicher Schriftelemente des tabellarischen Anhangs, die gegenüber den Schriftgrößen in den Optimierungsvorschlägen kleiner ist, stuft den Informationswert des Anhangs gegenüber den eigentlichen Optimierungsvorschlägen ab; der Fettdruck in der Leitzeile der Tabellen hierarchisiert die Information dieser Zeile gegenüber den Schriftelementen der übrigen Fächer. 
c) Lediglich OV 7 enthält zwei Säulendiagramme (s. Abbildung 5-2; Abbildung $5-3),{ }^{153}$ die mehrere Farben nutzen. Die Diagramme sind mit roten Linien gerahmt und separat auf zwei aufeinanderfolgenden Blättern, jeweils mittig über die Breite der Seite positioniert. Darüber und darunter sind Fließtextflächen angeordnet. Die Diagramme sind mit den Überschriften Entwicklung und Verteilung Fahrgelder - Risikoszenario EVU (s. Abbildung 5-2) und Entwicklung und Verteilung Fahrgelder-Optimistisches Szenario (s. Abbildung 5-3) in Fettdruck beschriftet. Die jeweils zwölf Säulen beider Diagramme sind zu mindestens Zweidrittel - und zwar bis auf den oberen Teil - in Blau eingefärbt. Darüber sind je nach Säule größere oder kleinere Flächen in Grün angeordnet, die maximal ein Viertel der Gesamtsäule einnehmen. Über diesen grünen Flächen sind nur bei einigen Säulen sehr kleine rote Flächen, beinahe schon Striche positioniert. In Abbildung 5-2 sind alternativ zu den roten Flächen an einigen Säulen grau schraffierte Flächen in den Säulen gestapelt. In Abbildung 5-3 (dem optimistischen Szenario) nimmt die Größe der grünen Flächen mit jeder Säule von links nach rechts zu, während die darüber positionierten roten Flächen annähernd gleich groß bleiben. In Abbildung 5-2 (dem Risikoszenario) nimmt die Größe der grünen Flächen in ähnlicher

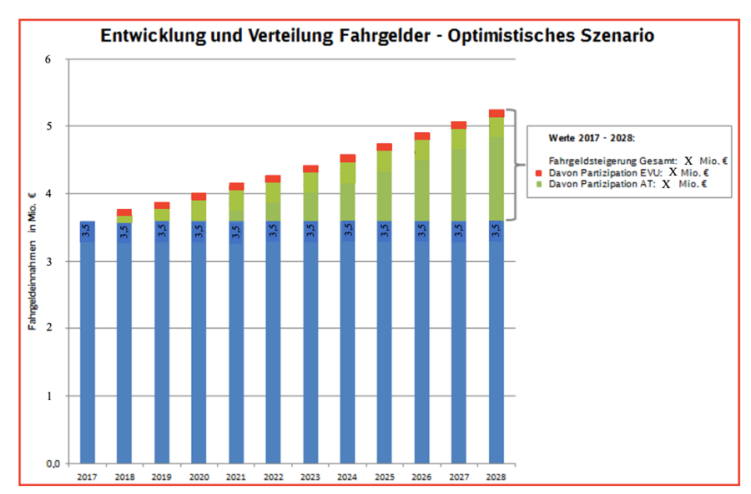

Abbildung 5-3: Diagramm 1 (OV 7).

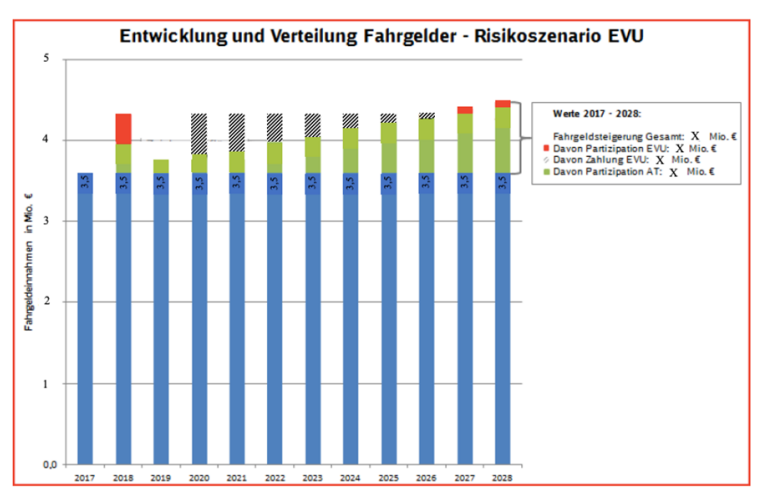

Abbildung 5-2: Diagramm 2 (OV 7).

Weise, aber weniger gleichmäßig zu. Auffällig ist, dass die grüne Fläche in der zweiten Säule von links (Jahr 2018) zu groß ist, um die Flächenzunahme über die zwölf Säulen als proportional wahrzunehmen. Des Weiteren sind nur an dieser Säule und an den beiden rechten Säulen (Jahr 2027 und 2028) rote Flächen gestapelt. In den dazwischen liegenden Säulen sind über den grünen Flächen nur

153 Die Beispiele dieser Arbeit sind anonymisiert. Es werden marktübliche Geldbeträge angegeben. 
grau schraffierte Flächen angebracht, die dafür sorgen, dass alle Säulen auf der gleichen Höhe der y-Achse enden.

Beschriftet sind die jeweiligen Säulen von links nach rechts jeweils mit einer Jahreszahl von 2017 bis 2028 auf der horizontalen x-Achse. Auf der vertikalen y-Achse ist parallel zum vertikalen Verlauf der Säulen die Wortgruppe Fahrgeldeinnahmen in Mio. $€$ in Fettdruck angebracht.

Hinter den Säulen ist das Koordinatensystem durch fünf hellgraue Hilfslinien in der Horizontalen angebracht, die auf der y-Achse in 5er-Schritten mit der Beschriftung 0,0 bis 6,0 abgetragen werden. Innerhalb der Säulen finden sich zu den jeweils gestapelten Teilflächen einer Säule am oberen Ende ebenfalls Ziffern, die die Säulenwerte bis zur ersten Nachkommastelle anzeigen, beispielsweise 1,8 in der blauen Fläche der Säule zum Jahr 2018. Rechts neben dem Koordinatensystem ist innerhalb des roten Gesamtrahmens ein grauer Kasten durch graue Linien abgetrennt, in dem oben die Überschrift Werte 2017 - 2028 angeordnet ist. Darunter sind innerhalb des Rahmens auf der linken Seite Rechtecke mit den jeweiligen Farben des Diagramms angebracht. $\mathrm{Zu}$ jedem farbigen Rechteck ist innerhalb der jeweiligen Zeile auf der rechten Seite ein Schriftelement positioniert, das mit Ziffern und dem Symbol $\ell$ endet.

Im grauen Kasten erläutert die Legende die Bedeutung der Farbfläche und fasst am Ende einer Zeile Summenbeträge in $€$ zusammen, die die blauen Flächen der zwölf Säulen repräsentieren. Dies gilt auch für Repräsentation der Summe von den jeweils andersfarbigen Flächen. Der Kasten hat damit auch die Funktion, einen Überblick zu geben. ${ }^{154}$

Die beiden Abbildungen kontrastieren zwei unterschiedliche Prognosen. Welche Annahmen diesen Prognosen zugrunde liegen, wird bedingt im Fließtext der Fließtextflächen um die Säulendiagramme herum erläutert. Unabhängig davon, ob alle Annahmen im Fließtext explizit gemacht werden oder angegeben sind, und unabhängig davon, ob der Rezipient diese Annahmen teilt, können diese Diagramme den Rezipienten in seiner Bewertung der Szenarien lenken. Denn die Diagramme stellen zwei komplexe Szenarien dar, deren Komplexität sie durch ihre Darstellungsform reduzieren. Die schriftsprachliche Darstellung in den umge-

154 Kapitel 5.1.4 erfasst diese Funktion als logisch-semantische Relation. 
benden Fließtextflächen wirkt dagegen noch äußerst komplex. Grundsätzlich kondensieren abbildende Diagramme den schriftsprachlichen Textinhalt und lenken dadurch die Aufmerksamkeit der Rezipienten auf das, was er als essentiell wahrnehmen soll. ${ }^{155}$ Die Beispieldiagramme können durch ihre präzisen quantitativen Angaben die Aufmerksamkeit der Rezipienten von den zugrunde liegenden Annahmen und der Komplexität des Sachverhalts wegführen und den Eindruck vermitteln, dass es sich bei den quantitativen Angaben um real existierende Fakten und nicht um Prognosen handelt.

Die Säulen der Diagramme sind nicht durch einheitliche Anteile roter und grauer Flächen gestaltet: Ohne die Achsen als Bestimmung von Zeit in Form von Kalenderjahren und monetären Mitteln in Form von Mio. € erkennen zu müssen, wird in Abbildung 5-2 deutlich, dass der obere rote Anteil der Säule zum Jahr 2018 in einem Missverhältnis sowohl gegenüber den übrigen Säulen dieses Diagramms als auch gegenüber den Säulen in Abbildung 5-3 steht: Während beim optimistischen Szenario ein kontinuierlicher Zuwachs der roten Flächen sichtbar wird, ist dies beim Risikoszenario nicht der Fall, sondern macht die grau schraffierten Flächen innerhalb der jeweiligen Säule notwendig. Die Legende ordnet die graue Schraffur den Zuschüssen des Bieters $(E V U)$, die Farbe Rot den Erträgen des Bieters und Grün den Erträgen des Auftraggebers $(A T)$ zu. Dementsprechend machen beide Diagramme auf das Risiko aufmerksam, dass der Auftraggeber die ausgeschriebenen Leistungen bezuschussen muss, wenn sich die Fahrgeldeinahmen entsprechend dem Risikoszenario entwickeln.

Einen Vergleich der beiden Diagramme legt die visuelle Darstellung dadurch nahe, dass die Diagramme beinahe identisch gestaltet sind und dementsprechend die Abweichungen salient werden. So besteht ,Similarität' in Bezug auf die roten Rahmen, die jeweils ein ,Panel` bilden, durch die identische Nutzung von ,Farbe“ für die Säulen, das ,Muster` der Koordinatensysteme, die ,Positionierung` der Legende, die ,Form‘ des Fettdrucks und Positionierung der Überschriften sowie die identischen Beschriftungen der Achsen und Säulen. Die materielle Positionierung

155 Diagramme sind „Ausdruck eines Autor-Interesses, das auf Verdeutlichung und Essentialisierung von Information Wert legt; dies belegt somit eine prinzipiell didaktisch motivierte Grundhaltung: der Rezipient soll ökonomisch und auf das Wesentliche reduziert dem Informationsanliegen folgen können“ (KALVERKÄMPER, 1998d, S. 76; Kursive im Original). 
der beiden Diagramme auf zwei aufeinanderfolgenden und nummerierten Seiten lässt den Schluss zu, dass das optimistische Szenario (s. Abbildung 5-3) vor dem Risikoszenario (s. Abbildung 5-2) rezipiert wird. Das als optimistisches Szenario bezeichnete Diagramm gibt die Annahmen wieder, die die Verdingungsunterlagen vor der Änderung enthielten. Das als Risikoszenario bezeichnete Diagramm beschreibt die Annahme des Bieters, also die von ihm gewünschte, zukünftige Version der Verdingungsunterlagen. Damit deckt sich die Chronologie der Diagramme, die durch die Positionierung auf zwei aufeinanderfolgenden Materialträgern entsteht, mit der gewünschten Chronologie der Versionen, in der sich die Verdingungsunterlagen befinden. D. h., die Diagrammanordnung zielt darauf ab, die Auftraggeber dazu zu ermutigen, den Optimierungsvorschlag anzunehmen und die dargestellten Annahmen für ein Risikoszenario in die Verdingungsunterlagen aufzunehmen. Die Gestaltung der Diagramme deutet bereits an, dass visuell saliente Elemente auch Module der Funktionsstruktur sein können.

\subsubsection{Funktionsstruktur}

Die Analyse der Funktionsstruktur orientiert sich am integrierten Analyseraster interfachlicher Sprache-Bild-Textsorten (s. Tabelle 3-1). Da sich die Textfunktion durch die kontextuell-situative Einbindung ergibt, wird diese im Folgenden anhand von Interviewaussagen und Situationsbeschreibungen dargestellt. Diese Darstellung bildet die Grundlage für die anschließende Bestimmung der Grundfunktion und weiterer Nebenfunktionen.

Interviewaussagen mit Bezug auf die Verdingungsordnung für Leistungen, die die Ausschreibungsverfahren regeln, und Textstellen aus den Verdingungsunterlagen belegen, dass OV die - im allgemeinsprachlichen Sinne - Funktion haben, den Preis der Bieter bei gleichbleibender Qualität zu senken, ohne einen beteiligten Bieter zu diskriminieren. Dies stellt AUfTRAGGEBER 1 heraus:

„[AT 1] Bei der Entscheidung für oder gegen die Aufnahme eines OV in die VDU spielt es aber keine Rolle, ob die EVU [Eisenbahnverkehrsunternehmen; AH] einen wortwörtlichen Vorschlag machen. Entscheidend ist die Überlegung, was den Preis senkt, die Qualität der zu erbringenden Leistung dabei nicht wesentlich mindert und vergaberechtlich zulässig ist.“ (2013, S. 7 f.)

Entsprechend formuliert Auftraggeber 2 die wesentliche Funktion von OV, wobei er betont, dass keine Optimierung der Leistungsqualität angestrebt wird: 
„[AT 2] Der Optimierungsvorschlag hat den Zweck, Geld zu sparen; einige meiner Kollegen aus dem Qualitätsmanagement würden das vielleicht anders sehen. Ein noch besseres Angebot für den Kunden fokussieren wir nicht, weil die Mindestanforderungen bereits ein angemessenes bis gutes Angebot für den Kunden sicherstellen.“"(2010a; S. 4)

Dass der Preis das ausschlaggebende Bewertungskriterium ist, belegen die Bewerbungsbedingungen (2013; S. 27) von Ausschreibung 1: „Der Zuschlag wird auf das unter Berücksichtigung aller Umstände wirtschaftlichste Angebot ( $\$ 25$ Nr. 3 VOL/A) erteilt, einziges Wertungskriterium hierbei ist der Wertungspreis.“

Das exklusive Wissen eines Bieters gegenüber dem Auftraggeber und anderen Bietern ist für AufTRAGGEBER 2 der Grund, OV in Ausschreibungsverfahren zu verwenden:

„[AT 2] Beispielweise hat in einer zurückliegenden Ausschreibung ein EVU [...] darauf aufmerksam gemacht, dass die Kosten erheblich gesenkt werden können, wenn wir den Zielwert für die Pünktlichkeit um einen Prozentpunkt von $96 \%$ auf $95 \%$ senken. Diesen Vorschlag haben wir dann aufgenommen. Die EVU wissen am besten, an welchen Stellen sie etwas optimieren können." (2010a; S. 2)

Demzufolge haben OV für Auftraggeber 2 die Funktion, die Expertise der Bieter derart in die Anforderungen einzubinden, dass Bieter die ausgeschriebene Leistung zu einem geringeren Preis anbieten können, ohne dabei die Qualität des Angebots wesentlich zu verändern und ohne dabei das Vergaberecht zu verletzen. Die Einhaltung des Vergaberechts ist relevant, weil beispielsweise schon die Zulassung von Gebrauchtfahrzeugen in den Verdingungsunterlagen Bieter diskriminieren kann, die über keinen eigenen Fuhrpark verfügen. Denn Bieter, die dagegen über einen eigenen Fuhrpark an Gebrauchtfahrzeugen verfügen, konnten angeschaffte Fahrzeuge bereits in vergangenen, abgeschlossenen Ausschreibungen amortisieren. Diese Bieter können ein Angebot mit einem geringeren Preis machen als Bieter ohne Fuhrpark: Die Kosten für eine Instandsetzung (Redesign) von Gebrauchtfahrzeugen und Unterhalt des Fuhrparks sind in der Regel niedriger als eine Fahrzeugneuanschaffung.

Ziele der Auftraggeber sind demnach eine Preissenkung, Transparenz und Diskriminierungsfreiheit in den Ausschreibungsverfahren. Diese Ziele können von den Zielen der Bieter als Wettbewerber abweichen. Beispielsweise kann ein Bieter die Eingabe von OV unterlassen, aus denen Veränderungen der Verdingungsunterlagen resultieren, die ihn gegenüber Konkurrenten benachteiligen, aber zu einer Senkung des Angebotspreises bei annähernd gleicher Qualität führen würden. Ein 
Bieter kann auch die OV als werbendes Mittel verstehen, was ebenfalls keinem der drei Auftraggeberziele entspricht. Die werbende Funktion belegt die Aussage des Wettbewerbsleiters vom untersuchten Bieter, Angebotstexte als Visitenkarte des Unternehmens anzusehen (s. Kapitel 4.3.1).

Die Überzeugung der Auftraggeber, dass eine bestimmte Veränderung der Verdingungsunterlagen eine Preissenkung bei gleichbleibender Qualität ermöglicht, ist demnach die Voraussetzung für die Veränderung der Verdingungsunterlagen. Eine solche Veränderung, die sich aus einem OV ergibt, stellt das ,perlokutionäre Nachspiel' bzw. die Textwirkung dar, während das ,illokutionäre Ziel' darin besteht, den Auftraggeber von der Auswirkung einer Unterlagenmodifikation zu überzeugen. Die Textwirkung und das ,illokutionäre Ziel` ergeben sich aus der/den konventionalisierten ,Grund- und Nebenfunktionen' der Textsorte.

Entsprechend diesem Verhältnis von Textfunktion und Textwirkung resultiert als Grundfunktion von OV auf der ersten der Drei-Ebenen-Hierarchie (s. Tabelle 31) als ,Handlungsziel“ (illocutionary point) eine direktive Textfunktion. Denn der Bieter weist den Auftraggeber an, die Verdingungsunterlagen zu verändern. Gleichzeitig kann der Bieter die Nebenfunktion verfolgen, durch die Gestaltung der OV für die Leistungsfähigkeit des eigenen Unternehmens zu werben. Denn auch Textsorten der Werbung - für Fachmann-Fachmann-Kommunikation als seducción bezeichnet (s. Kapitel 3.2.2) - werden als direktive Textfunktion klassifiziert (s. Kapitel 3.2.2). Auf der mittleren Ebene des ,Durchsetzungsmodus“ (mode of achievement) sind OV ,nicht-bindend“, weil der Auftraggeber nicht daran gebunden ist, einen Vorschlag eines Bieters anzunehmen und er die Verdingungsunterlagen nicht verändern muss. Auf der untersten Ebene der Textsortenfunktionsklassifikation der, vorliegenden Bedingungen' (preparatory point) wirkt die Textsorte OV ,reduzierend‘. Denn ein Vorschlag reduziert das Problem eines zu hohen Angebotspreises in Form einer quantitativen Einschätzung. Diesbezüglich erscheinen OV mit den Textsorten ,Alternativentwurf', ,Rat' oder ,Referentenentwurf ${ }^{\star}$ vergleichbar. ${ }^{156}$ Diese Zuordnung in der Textsortenklassifikation stützt die systematische Verwendung der Prädikatform [Der Bieter] schlägt

156 Diese Textsorten führt RolF (1993, S. 257) als Beispiele für Funktionsunterkategorie DIR 19 auf. 
vor ... als Einleitung des Themenmoduls Erläuterung (AusschreiBung 2, z. B. OV 1) oder die Form Wir schlagen vor ... als Einleitung des Moduls Optimierung (AusschreIBung 1; z. B. ebd., S. 414). OV können daher entsprechend ihrer Grundfunktion als problemreduzierende, nicht-bindende direktive Textsorte klassifiziert werden.

Im Anschluss an diese Bestimmung der Grundfunktion von OV werden die Unterund Nebenfunktionen der Funktionsstruktur am prototypischen Beispiel (basierend auf OV 2) diskutiert, das der Beschreibung des Textdesigns dient (s. Abbildung 5-1). Es visualisiert folgende Funktionsmodule in Grün der Optimierungsvorschläge in Ausschreibung 1, die sich mit den Themenmodulen decken: $3 \mathrm{An}$ zupassende Unterlagen, 4 Preiseffekt, 1 Erläuterung sowie 2 Optimierung; in Ausschreibung 2 werden die letzten beiden Funktionsmodule im Themenmodul 1 Erläuterung repräsentiert, weil die OV von Ausschreibung 2 keine Überschrift 2 Optimierung enthalten. Des Weiteren werden das Logo, die Gesamtüberschrift und die Beschriftung der Kopfzeile als Funktionsmodule bestimmt. An die Begründung für diese Gliederung im prototypischen Beispiel schließen Ausführungen zu Abweichungen bzw. Besonderheiten in anderen OV an.

Die folgende Beschreibung der Funktionsmodule dient dazu, die Funktionsstruktur zu analysieren. Diese Module konstituieren die oben behandelte Grundfunktion der Textsorte OV. Das Logo erhält durch das Corporate Design eine ästhetische Funktion. Denn die Farbe und Form sprechen den Rezipienten als einzige Elemente des OV auf diesen Ebenen des Textdesigns an. Diese ästhetische Funktion kann unter der Bedingung als sekundäre Funktion klassifiziert werden, dass das Logo primär indirekt als direktives Modul bestimmt wird. Für diese Interpretation spricht die Argumentation des Wettbewerbsleiters, OV als Visitenkarte des Unternehmens zu verstehen. 


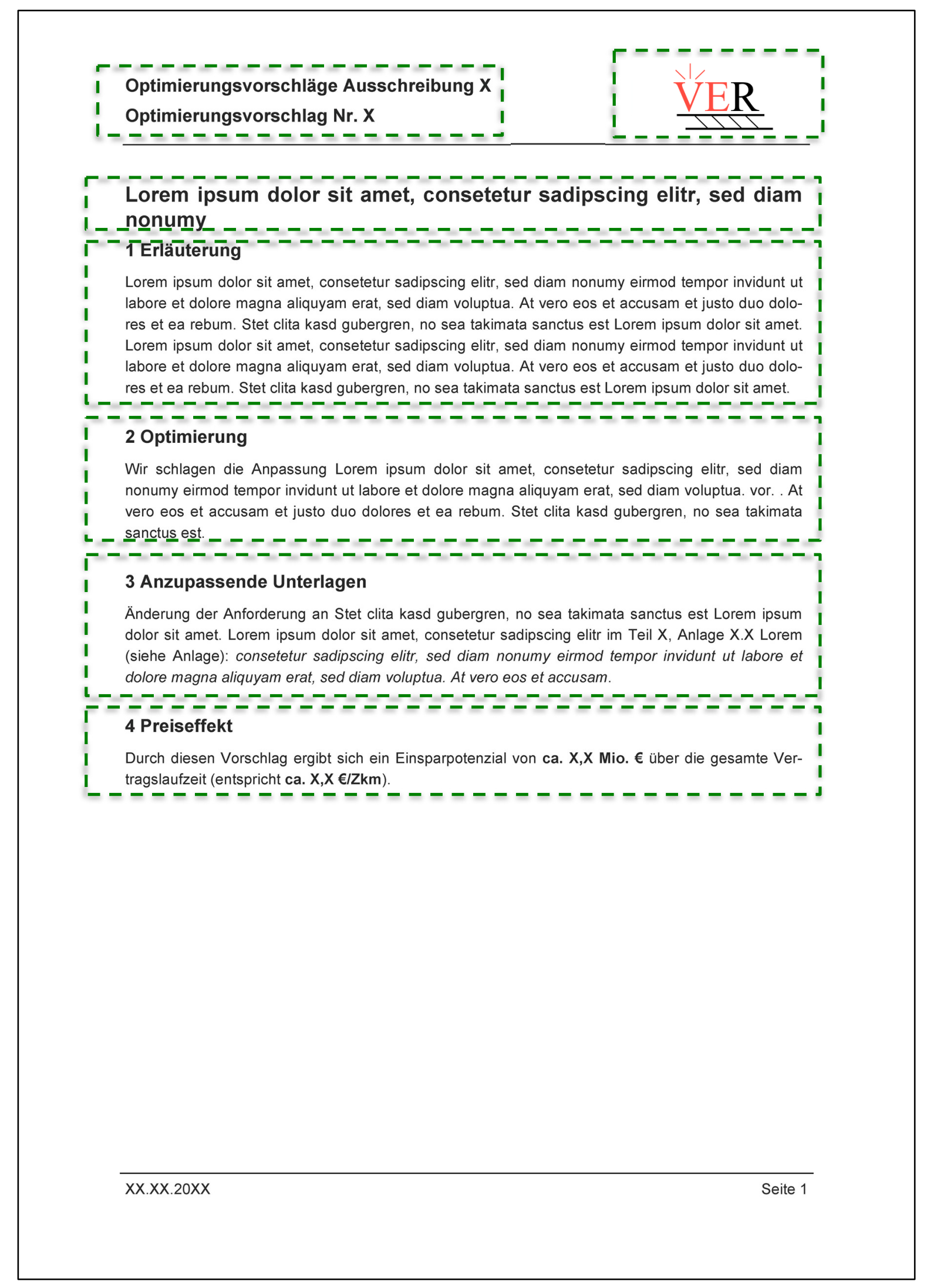

Abbildung 5-4:157 Struktur der Funktionsmodule (in Grün). 
Dadurch bekommt das Logo eine identitätsstiftende Funktion, die auf ein positives Image des Unternehmens zielt und damit eine indirekte werbende Funktion übernimmt. ${ }^{158}$

Das Funktionsmodul ,Beschriftung der Kopfzeile' informiert den Rezipienten darüber, zu welcher Ausschreibung dieser OV gehört. Durch die Angabe der Nummer des OV (beispielsweise $O V 2$ ) wird er darüber informiert, welche Position dieser OV innerhalb der Chronologie aller OV hat. Daher wird die Kopfzeilenbeschriftung als assertives Funktionsmodul klassifiziert.

Die ,Gesamtüberschrift‘, die unterhalb der Kopfzeile in der größten Schriftgröße angebracht ist, hat die Funktion, den Gesamtinhalt des OV zusammenzufassen, und informiert den Rezipienten dementsprechend. Die weiteren Unterüberschriften fassen zwar auch die Inhalte der darunter angebrachten Fließtextflächen zusammen, repräsentieren aber gleichzeitig die Funktion dieser Teilmodule. Dementsprechend wird nur die Gesamtüberschrift als assertives Funktionsmodul erfasst.

Das Funktionsmodul Erläuterung informiert den Rezipienten im ersten Satz über den Inhalt einer Anforderung aus den Verdingungsunterlagen und nennt meist (z. B. OV 1, 2), aber nicht in allen OV (z. B. OV 3), die Bezugsstelle. Im zweiten Teilsatz bzw. im zweiten Satz werden Bedingungen genannt, die die genannte Anforderung der Verdingungsunterlagen derart modifizieren, dass es möglich wird, die ausgeschriebene Leistung zu einem geringeren Preis anzubieten. Weil alle Sätze dieses Funktionsmoduls beschreibend bleiben, wird auch dieses Funktionsmodul als assertives zugeordnet.

Das Themenmodul Optimierung wird als direktives Funktionsmodul klassifiziert, weil es den Rezipienten indirekt auffordert, die betreffende Anforderung in den Verdingungsunterlagen zu ändern. Dies wird durch die bereits oben aufgeführten Formulierungen Wir schlagen vor (Ausschreibung 1; z. B. OV 1) bzw. [Der

157 Die Beispiele dieser Arbeit sind anonymisiert. Das enthaltene Logo und der Firmenname werden als Beispiel genutzt. Es stammt vom Bieter mit dem größten Marktanteil.

158 Marken- und Leistungsebene, die durch das Logo ausgedrückt werden, interagieren, was dazu führe, dass ,durch das gute Image einer Marke automatisch auch einzelne Produkteigenschaften besser eingeschätzt werden“ (KASTENS/LuX, 2014, S. 58). Werbung zielt auf diesen Effekt, um eine Kaufhandlung zu erzeugen. 
Bieter] schlägt vor als Einleitung des Themenmoduls Erläuterung (Ausschreibung 2; z. B. OV 1) ausgedrückt. Dieses Funktionsmodul expliziert die Grundfunktion der Textsorte.

Das Funktionsmodul Anzupassende Unterlagen gibt in AussChreIBung 1 die konkrete Bezugsstelle der Verdingungsunterlagen an, die zu ändern ist, und meist eine alternative Formulierung für diese Textstelle. In AusSCHREIBUNG 2 verweist dieses Kapitel auf den tabellarischen Anhang, in welchem in der linken Spalte die Bezugsstelle, in der mittleren die aktuelle Formulierung der Anforderung in den Verdingungsunterlagen und in der rechten Spalte die alternative, geänderte Formulierung aufgeführt werden (z. B. OV 1). Während die Nennung der Textstelle den Rezipienten informiert, zielt die alternative, geänderte Formulierung darauf ab, den Rezipienten von der Notwendigkeit dieser Änderung zu überzeugen und die Änderung möglichst zu übernehmen. Es handelt sich also um eine indirekte Aufforderung, das Funktionsmodul wird daher als direktives klassifiziert.

Das abschließende Funktionsmodul 4 Preiseffekt wird als assertives Funktionsmodul analysiert, weil es über die Preisauswirkung informiert. Da der OV bei Zuschlagserteilung Teil des Verkehrsvertrags wird (s. Kapitel 4.2.2), verpflichtet sich der Bieter als Verfasser des OV in diesem Modul mit der Angabe des Preiseffekts dazu, die Leistung bei Zuschlagerteilung zu diesem Preis zu erbringen. Dementsprechend handelt es sich primär indirekt um ein kommissives Funktionsmodul.

Die oben analysierten Funktionsmodule konstituieren die Funktionsstruktur des OV und dessen Grundfunktionen. Sie können entsprechend ihrer Salienz (s. Kapitel 5.1.1) in einer anderen Reihenfolge als in der Von-links-oben-nach-rechtsunten-Chronologie rezipiert werden. Zudem sind nicht alle Elemente nummeriert (das Logo und die Kopfzeile), sodass auch die Nummerierung ${ }^{159}$ für den Rezeptionspfad nicht ausschlaggebend sein kann.

„Die Sequenzsignale: Darunter sind Lexeme zu verstehen, die die funktionale Reihenfolge in der Textprogression zum Ausdruck bringen. Eine wichtige Untergruppe sind die Signale der Enumeration. Hierbei werden arabische und römische Ordinal- und Kardinalzahlen, laufende Buchstaben des Alphabets zur Kennzeichnung der inhaltlich-logischen Struktur des Textes sowie Kommandostriche systematisch verwendet. Sequenzsignale wirken anaphorisch.“ (BAUMANN, 1998b, S. 412; Kursive im Original) 
Über die Analyse dieses Prototypen gehen die OV hinaus, die bereits das Kapitel 5.1 zum Textdesign als Ausnahmen behandelt: OV 7 weicht von jenem Prototypen durch die Nutzung der Säulendiagramme ab. Beide Diagramme werden als selbstständige Funktionsmodule in der Funktionsstruktur aufgefasst, weil ihre visuelle Salienz ihnen eine eigene Position im Textdesign zuweist. Wie Kapitel 5.1.1 aufzeigt, macht der Vergleich der Überschriften Optimistisches Szenario und Risikoszenario, der farblichen Gestaltung von gestapelten Flächen innerhalb der Säulendiagramme und die Summenbildung in den beiden Diagrammlegenden auf das Risiko aufmerksam, dass der Auftraggeber die ausgeschriebenen Leistungen bezuschussen muss, wenn sich die Fahrgeldeinahmen entsprechend dem Risikoszenario entwickeln. Damit informieren sie grundsätzlich über das Risiko, werden also sekundär als assertives Themenmodul klassifiziert. Es handelt sich bei den quantitativen Angaben aber nicht um Fakten, sondern um Prognosen, denen Annahmen zugrunde liegen, die der Rezipient nicht teilen muss. Dementsprechend können diese Prognosen auch darauf angelegt sein, den Rezipienten darin zu beeinflussen, die zugrundeliegenden Annahmen zu teilen und das Eintreten der Prognosen als wahrscheinlich einzuschätzen. Infolgedessen beeinflussen die Diagramme den Rezipienten darin, die Verdingungsunterlagen verändern zu wollen. Daher werden die beiden Diagramme in der Funktionsstruktur primär indirekt als direktive Funktionsmodule eingeordnet. Während die Analyse der Funktionsstruktur letztlich auf die Analyse von Textfunktionen - basierend auf Illokutionen der Sprechakttheorie - zielt, entfaltet OV 7 (ebd., S. 422 ff.) nachweislich eine Textwirkung: Dieses perlokutionäre Nachspiel belegt die Änderung der in OV 7 angegebenen Stelle in den Verdingungsunterlagen entsprechend dem Änderungsvorschlag in OV 7. So wird in der Leistungsbeschreibung (S. 89) die Ergänzung deutlich, dass der Bieter in einem Vertragsjahr auf Mehrerlöse verzichten kann und der Auftraggeber im Gegenzug auf die Mindesteinnahmen verzichtet. ${ }^{160}$ Die Beschreibung der Funktionsstruktur bezieht sich bereits auf Themenmodule und verweist damit auf das Verhältnis zur Themenstruktur.

160 Die Änderung erfolgt in der endgültigen Version der Leistungsbeschreibung, also nach Einarbeitung relevanter Optimierungsvorschläge. Die Änderung ist durch die entsprechende WORD-Funktion als rote, unterstrichene Schrift erkennbar. 


\subsubsection{Themenstruktur}

Die Analyse der Themenstruktur gliedert sich entsprechend den Kriterien zur Themenstruktur aus dem integrierten Analyseraster zu interfachlichen SpracheBild-Textsorten (s. Tabelle 3-2). Im Folgenden wird eine Übersicht über die Themen aller OV durch die Analyse von Aussagen der Auftraggeber und Angaben in den Verdingungsunterlagen gegeben (s. Tabelle 5-1). Darauf aufbauend wird das prototypische Themenentfaltungsmuster von OV des Korpus analysiert (s. Abbildung 5-5). Darüber hinaus wird aufgezeigt, inwieweit OV unterschiedlicher Ausschreibungen von dieser Prototypik abweichen. Im Anschluss daran wird die horizontale Themenstruktur einzelner OV analysiert. Diese Struktur unterscheidet sich zwischen den OV wesentlich. Dies ist davon abhängig, welchen Organisationsbereichen (Fahrzeug, Rechtliches, Finanzierung, ...; s. Abbildung 4-1) die OV zugehören; beispielsweise sind raumdeiktische Mittel nur für OV relevant, die Themen der Bereiche ,Fahrzeugtechnik' und ,Betriebsplanung' behandeln.

Das Thema eines OV ist in der Überschrift erfasst und bezieht sich auf ein Teilthema der Verdingungsunterlagen. Dass diese thematische Bezugnahme nur für ausgewählte Bereiche sinnvoll ist, geben AUfTRAGGEBER 1 im Interview und die Verdingungsunterlagen an:

„Wir sehen die größten Chancen für eine Optimierung und eine Preissenkung in den Themenbereichen Fahrplan, Fahrzeuge und Fahrzeugfinanzierung; da spielt die Musik. Diese Bereiche führen wir in den VDU auch auf, setzen aber die Formulierung insbesondere davor, damit es den EVU möglich ist, in den OV auch andere Bereiche zu behandeln. Grundsätzlich ist auch eine Diskussion über andere Punkte als die angegebenen möglich.“(2013; S. 10; Fettdruck AH; Kursive im Original)

Eine ähnliche Aussage trifft auch AufTRAGGEBER 2: „Die Änderungen gehen vor allem in die Textteile ,Fahrzeuge' und ,Betriebsprogramm“ ein.“ (2010a; S. 2) Tabelle 5-1 zeigt, welchem Organisationsbereich die OV der drei Ausschreibungen entsprechend ihrem Thema zuzuordnen sind. Deutlich wird in Ausschreibung 1, dass sich einige OV nicht einem, sondern mehreren Bereichen zuordnen lassen (OV 3, OV 8, OV 9). Des Weiteren beinhalten die meisten Vorschläge Teilthemen des Bereichs ,Fahrzeuge'. In Ausschreibung 2 behandelt nur OV 6 Rechtliches. Dass OV 1 bis OV 4 in Ausschreibung 2 die Betriebsplanung und Fahrzeuge thematisieren, ist in der Zulassung bestimmter Fahrzeugtypen begrün- 
det. Diese Zulassung wirkt sich auf die Berechnung des Fahrplans aus, falls sich die Sitzplatzanzahl pro Fahrzeug oder die fahrbare Geschwindigkeit verändern.

\begin{tabular}{|c|c|c|c|}
\hline $\begin{array}{l}\text { Thema des } \\
\text { Organisationbereichs }\end{array}$ & $\begin{array}{l}\text { OV in Aus- } \\
\text { schreibung } 1\end{array}$ & $\begin{array}{l}\text { OV in Aus- } \\
\text { schreibung } 2\end{array}$ & $\begin{array}{l}\text { OV in Aus- } \\
\text { schreibung } 2\end{array}$ \\
\hline Fahrzeuge & $\begin{array}{l}\text { OV 1, OV } 3, \\
\text { OV 4, OV } 9\end{array}$ & $\begin{array}{l}\text { OV } 1, \text { OV } 2, \\
\text { OV } 3, \text { OV } 4\end{array}$ & $\begin{array}{l}\text { OV } 3, \text { OV } 4, \\
\text { OV } 6\end{array}$ \\
\hline $\begin{array}{l}\text { Fahrplan }{ }^{161 /} \\
\text { Betriebsplanung }\end{array}$ & $\begin{array}{l}\text { OV } 2, \text { OV } 3, \\
\text { OV } 11\end{array}$ & $\begin{array}{l}\text { OV } 1, \text { OV } 2, \\
\text { OV } 3, \text { OV } 4, \\
\text { OV } 5, \text { OV } 7\end{array}$ & $\begin{array}{l}\text { OV } 1, \text { OV } 2, \\
\text { OV } 5 \text {, OV } 6, \\
\text { OV } 7\end{array}$ \\
\hline Marketing/ Vertrieb & OV 9, OV 10 & / & / \\
\hline Fahrzeugfinanzierung & OV 6 & / & l \\
\hline $\begin{array}{l}\text { Kalkulation } \\
\text { allgemein }\end{array}$ & OV 6, OV 7 & l & I \\
\hline Controlling & OV 8 & / & / \\
\hline $\begin{array}{l}\text { Vertraglich-Rechtli- } \\
\text { ches }\end{array}$ & OV 5, OV 8 & OV 6 & OV 2 \\
\hline
\end{tabular}

Tabelle 5-1: Übersicht über OV-Themen und deren Zuordnung zu Organisationsbereichen (eigene Darstellung).

Um das , Themenentfaltungsmuster' zu bestimmen, wird im Folgenden die prototypische Themenstruktur von OV anhand der vier Themenmodule Erläuterung, Optimierung, Anzupassende Unterlagen und Preiseffekt analysiert (s. Abbildung $5-5) .{ }^{162}$

161 Die Betriebsplanung umfasst neben dem Fahrplan auch Themen zum Umgang mit Betriebsausfällen, Strafen/Pönalen bei Abweichung vom Fahrplan, Wartungszeiten etc.

Teilweise existiert ein thematischer Zusammenhang zwischen OV einer Ausschreibung, der über die einzelnen Textsortenexemplare hinausgeht. Beispielsweise ergibt sich ein OV 2 erst aus der Annahme von OV 1: „Voraussetzung für diesen Optimierungsvorschlag ist die Annahme des Optimierungsvorschlags 1.“(OV 2) Auch in Ausschreibung 2 besteht ein entsprechender Zusammenhang (OV 1; OV 2), der im Gegensatz zu Ausschreibung 1 nicht explizit gemacht wird. Dieser thematische Zusammenhang zwischen den OV einer Ausschreibung besteht neben der kohäsionsstiftenden Einheitlichkeit des Textdesigns und der Nummerierung aller OV einer Ausschreibung. 
Die OV aus Ausschreibung 2 weichen von dieser Modularisierung nur sehr bedingt ab, weil das Themenmodul Optimierung nicht durch eine Unterüberschrift gekennzeichnet, aber Teil des Moduls Erläuterung ist. Des Weiteren werden alternative Formulierungen, die in Ausschreibung 1 zum Modul Anzupassende Unterlagen gehören, in allen OV von Ausschreibung 2 in einen Anhang ausgelagert. Dieser Anhang stellt die Modifikation der aktuellen Formulierung in tabellarischer Form gegenüber und nennt die Bezugsstelle in den Verdingungsunterlagen. Die OV aus Ausschreibung 3 sind mit der thematischen Modularisierung aus Ausschreibung 1 vergleichbar, gliedern diese aber nicht explizit durch Unterüberschriften.

Der Grund dafür liegt im Zeitpunkt, zu dem diese Textsorte in Ausschreibungsverfahren eingeführt wurde: Erstmals werden sie in Ausschreibung 3 verwendet. ${ }^{163}$ Entsprechend konnten die Exemplare dieser Ausschreibung nur weniger konventionalisiert sein als die OV aus Ausschreibung 1 und 2. Daher dient die Systematik der OV aus Ausschreibung 1 und Ausschreibung 2 als Bezugspunkt für die Analyse des Themenentfaltungsmusters.

163 Erstmalig führt AUFTRAGGEBER $2 \mathrm{OV}$ in Ausschreibung 3 in ein Ausschreibungsverfahren ein und forderte vorher ca. 100-seitige Angebotstexte, die die Verdingungsunterlagen weitgehend spiegelten. So antwortet AUFTRAGGEBER 2 auf die Frage, ob es in Ausschreibungen keine Angebotstexte, sondern wie erstmals im Jahr 2010 in Ausschreibung 3 OV geben sollte: „Teilweise müssen wir uns mit Aufgabenträgern anderer Bundesländer abstimmen und derzeit eventuell noch einen Angebotstext fordern. Die zukünftigen Verfahren sollen aber so einfach gestaltet werden wie das zur [Ausschreibung 3; AH] “" (AUFTRAGGEBER 2, 2010b, S. 2) 


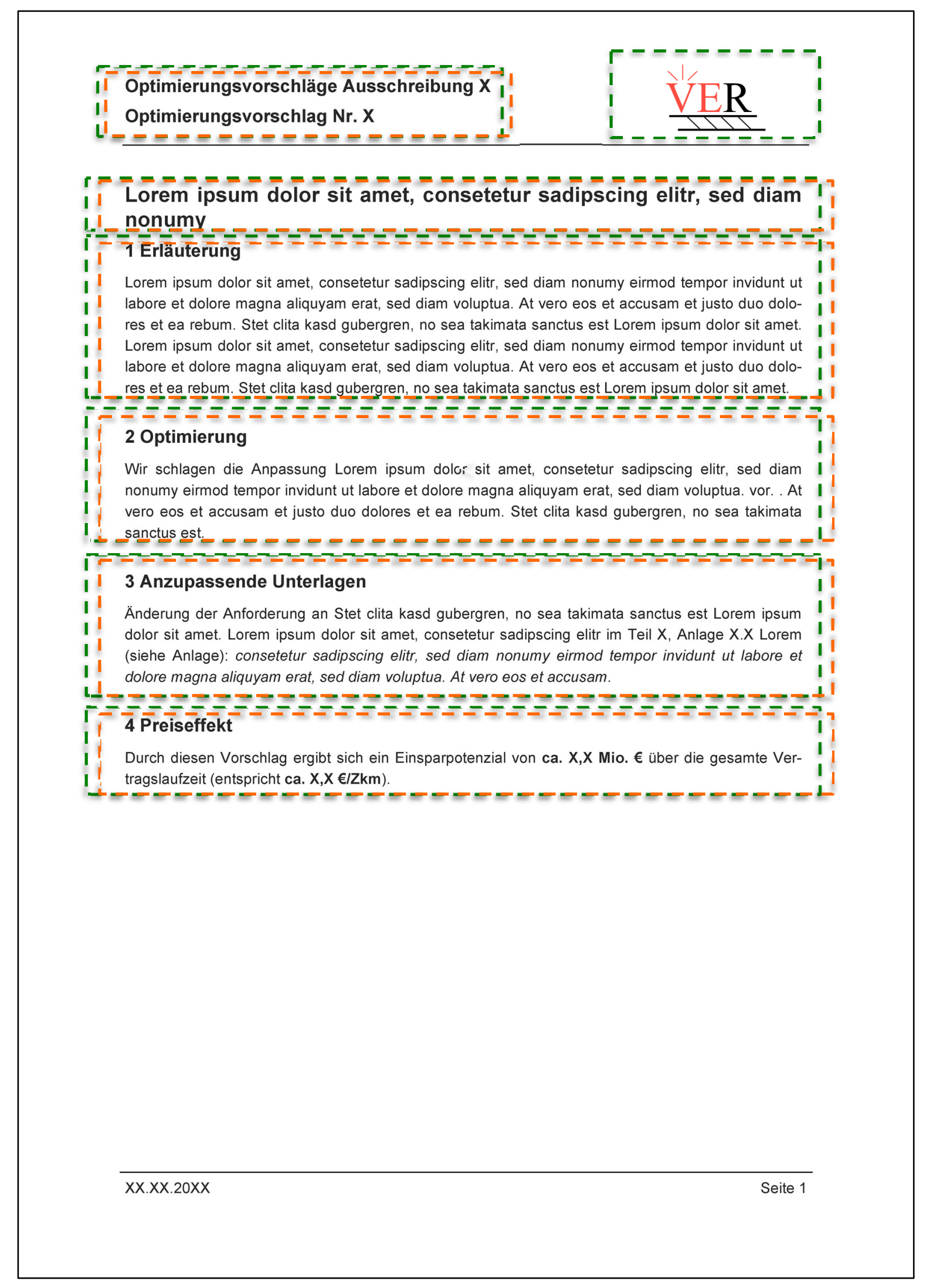

\footnotetext{
Abbildung 5-5:164 Themenstruktur mit Themenmodulen (Orange) im Verhältnis zur Funktionsstruktur (Grün; eigene Darstellung).
} 
Die Gliederungen der verschiedenen OV variieren in den Themenmodulen Erläuterung und Optimierung in Abhängigkeit vom jeweiligen Thema der Verdingungsunterlagen und können einem der Organisationsbereiche zugeordnet werden. Dabei weicht diese Zuordnung zwischen den verschiedenen OV voneinander ab. Dagegen umfasst das Modul Anzupassende Unterlagen lediglich einen intertextuellen Verweis und zum Teil einen alternativen Formulierungsvorschlag für die Bezugsstelle in den Verdingungsunterlagen. Deswegen erscheint dieser Textabschnitt als Themenmodul vernachlässigbar. Unabhängig von der unterschiedlichen thematischen Bezugnahme auf die Verdingungsunterlagen sind alle OV untereinander in Bezug auf das Themenmodul Preiseffekt identisch. D. h., der thematische Bezug auf den Themenbereich ,Kalkulation“ liegt bei allen OV unabhängig vom thematischen Bezug der weiteren Themenmodule vor. (Diese Themenmodule sind in Abbildung 5-5 als orange Rahmen dargestellt.)

Das Themenentfaltungsmuster des prototypischen OV folgt dem Schema, im Themenmodul Erläuterung einen Mangel oder Verbesserungspotenzial in den Verdingungsunterlagen aufzuzeigen, der/das nahelegt, dass die ausgeschriebene Leistung nur zu einem zu hohen Angebotspreis angeboten werden kann. Für die Behebung dieses Mangels folgt ein Lösungsvorschlag im Themenmodul Optimierung. Im abschließenden Themenmodul Preiseffekt wird die spezifizierte Auswirkung auf den Preis aufgezeigt (z. B. in OV 1). Diese vier Themenmodule folgen - entsprechend dem Analyseraster (s. Abbildung 3-7) - einem argumentativen Themenentfaltungsmuster (s. Abbildung 5-5). ${ }^{165}$

Denn das Themenmodul Erläuterung umfasst die Schema-Elemente ,Einbettung', ,Hypothese' und ,Argument‘, während das Themenmodul Optimierung die ,Schlussfolgerung' beinhaltet. Das Themenmodul Preiseffekt liefert eine, weitere Stützung'. In den Fällen, in denen das Themenmodul Anzupassende Unterlagen alternative Formulierungen aufführt, gehören diese zur ,Schlussfolgerung', die

164 Die Beispiele dieser Arbeit sind anonymisiert. Das enthaltene Logo und der Firmenname werden als Beispiel genutzt. Es stammt vom Bieter mit dem größten Marktanteil.

165 Andere Entfaltungsmuster scheiden für OV aus. Denn die (Teil-)Themenmodule der Textsortenexemplare lassen sich weder als Explanans oder Explanandum einer explikativen Themenentfaltung (s. Kapitel 3.3.3) zuordnen noch als Teil-Ganzes-Relationen eines Gegenstands (s. ebd.) oder als Gliederung eines Prozesses einer deskriptiven Themenentfaltung. 
Verdingungsunterlagen zu modifizieren. Auch die rechte Spalte der Anhänge zu OV in AussChreIBung 2, die alternative Formulierungen vorschlägt, stellt entsprechend eine ,Schlussfolgerung' dar.

Veranschaulichen lässt sich dies an der Zuordnung von Modulelementen in OV 6 zum Schema eines argumentativen Entfaltungsmusters (s. Abbildung 5-6). Die Elemente aus OV 6 sind dabei in Kursiven dargestellt. Lediglich die Bedeutung des Schema-Elements ,gemeinsame Wertebasis‘ wird nicht durch das Beispiel erklärt und wird daher kurz ausgeführt: Dass die ,gemeinsame Wertebasis` die Senkung des Preises bei geforderter Qualität des Angebots bildet, legt die oben zitierte Antwort von Auftraggeber 2 (2010a; S. 4) zur Funktion der OV nahe.

Dafür, die Preissenkung als ,gemeinsame Wertebasis' anzunehmen, spricht auch, dass der Bieter versuchen kann, den Preis auf eine Art und Weise zu senken, die die konkurrierenden Bieter nicht im selben Umfang leisten können, wie er es vermag. Einzuschränken ist die Gültigkeit dieser gemeinsamen Wertbasis demnach dadurch, dass ein Bieter keine Preissenkung als Optimierung vorschlagen würde, die nur ein Konkurrent leisten kann. Da die OV in AusschreIBung 2 im Themenmodul Anzupassende Unterlagen auf den jeweiligen Anhang verweisen, ist die für Ausschreibung 1 aufgezeigte Struktur auch in den OV in Ausschreibung $2 \mathrm{zu}$ finden. Wie bereits beschrieben wurde, finden sich die entsprechenden Teilthemen ohne Überschriften auch in OV von Ausschreibung 3.

Abweichungen bzw. Variationen von dieser Zuordnung zum Schema finden sich in mehreren OV aller drei Ausschreibungen: Beispielsweise ist eine ,Hypothese“ in OV 1 und OV 4 nicht explizit erkennbar. Anstelle eines Bezugs auf die Verdingungsunterlagen bildet in OV 2 der Bezug auf OV 1 den Ausgangspunkt der ,Einbettung'. Auch der Bezugspunkt wird in OV 3 nur thematisch oder in OV 4 als Bezugsstelle in den Verdingungsunterlagen genannt. Darüber hinaus ist in OV 4 kein ,Argument" erkennbar und im Themenmodul Optimierung befindet sich kein Element, das als Schema-Element ,Schlussfolgerung' klassifiziert werden kann. Eine besondere Abweichung stellt in OV 7 die Einbindung der Diagramme in das Themenmodul Erläuterung dar: So erscheint das Säulendiagramm mit der Überschrift Optimistisches Szenario (s. Abbildung 5-3) als Teil der ,Einbettung', während das Säulendiagramm (s. Abbildung 5-2) mit der Risikoprognose die ,Hypothese“ einerseits durch Flächen- und Farbrelationen, andererseits durch 
Ziffern darstellt. Schriftsprachlich werden in OV 7 die Inhalte des Diagramms mit der Risikoprognose durch den letzten Absatz unter diesem Diagramm wiederholt. Festzuhalten ist, dass die ,Themenentfaltung ' in den vorliegenden OV weitgehend, aber nicht vollständig einheitlich ist und diesbezüglich innerhalb einer Ausschreibung und auch über die Ausschreibungen hinweg minimal variieren kann. Innerhalb der einzelnen Themenmodule werden Mittel der horizontalen Themenstruktur (s. Abbildung 3-7) durch Sprache und durch Bild eingesetzt. Zu den sprachlichen Mitteln der thematischen Verknüpfung gehören als strukturell-grammatische Mittel ,Enumeration', ,Proformen' sowie ,anaphorische und kataphorische Formen`. Als semantisch-strukturelle Mittel finden sich ,Rekurrenz', ,KoReferenten', ,partielle Synonyme' bzw. ,paradigmatische Relationen' des Fachtextwortschatzes und ,Metaphern'. Oppositionspaare entwickeln eine ,implizite Wiederaufnahmestruktur'. Die semantisch-strukturellen Mittel konstituieren überwiegend die horizontale Themenstruktur eines Themenmoduls.

Konkret lassen sich Textsortenexemplar übergreifend folgende Merkmale feststellen:

Bestimmte Artikel werden als anaphorische Verweise in beinahe allen Themenmodulen aller OV in Ausschreibung 1 verwendet: des Wertungsaufschlags (OV 1); der Abdeckung (OV 3); die Entscheidung (OV 6); die Forderung (OV 10). Als kataphorische Verweise werden unbestimmte Artikel eingesetzt: einen Wertungsaufschlag (OV 1); eine [...] Steigerung (OV 3); ein hohes Risiko (OV 7); eines Dienstleistungsabends (OV 10). In OV 1, OV 3, OV 6 wird das letzte Themenmodul Preiseffekt durch die Nominalphrase durch diesen Vorschlag eingeleitet, sodass das attributiv verwendete Pronomen diesen anaphorisch Bezug auf die übrigen Themenmodule nimmt. ${ }^{166}$ Variiert wird diese Bezugnahme durch den bestimmten Artikel der Nominalphrase Der Vorschlag, die sich in der ersten Zeile des Themenmoduls Preiseffekt findet (OV 7). Vergleichbare Beispiele nutzen auch OV von Ausschreibung 2.

166 Da sich das Pronomen diesen attributiv zum Nominalkern Vorschlag verhält, handelt es sich nicht um einen Ko-Referenten, der wie der Terminus Vorschlag bzw. Optimierungsvorschlag $I$ auf die in diesem Textsortenexemplar enthaltene Vorstellung als Referenzobjekt verweist. 
Das Konjunktionaladverb daher des Teilsatzes Daher schlagen wir vor, ... verknüpft das Themenmodul Optimierung (OV 6) anaphorisch mit dem vorherigen Themenmodul Erläuterung. Dieser Konnektor markiert auf semantisch-struktureller Ebene das Themenmodul als Schlussfolgerung innerhalb der Themenentfaltung (s. Abbildung 5-6).

Ko-Referenten kommen ebenfalls Textsortenexemplar übergreifend vor, die in das Themenmodul Erläuterung einführen und im Modul Anzupassende Unterlagen aufgegriffen werden. Bewerbungsbedingungen, Anlage Fahrzeuge und Leistungsbeschreibung bilden Ko-Referenten, die auf die Verdingungsunterlagen verweisen. Auch folgende Ko-Referenten stellen jeweils in einem OV Kohyponyme für Teilthemen der Verdingungsunterlagen dar: die Nominalphrase Teil C, (Anlage) B.2 Fahrzeuge (OV 1, OV 3), Bewerbungsbedingungen (OV 6) und Verdingungsunterlagen Teil A, Leistungsbeschreibung, 2.5.2 Vertrieb (OV 10).

Das Nomen Einsparpotenzial und dessen Spezifizierung durch Währungs-, Zeitoder Weg-Einheiten werden im Themenmodul Preiseffekt aller OV von Ausschreibung 1, 2 und zum Teil von Ausschreibung 3 als ,partielles Synonym“ eingesetzt; z. B. in Form der Nominalphrase ca. XX Mio. $€$ über die Vertragslaufzeit oder durch entspricht ca. $X, X X € / Z \mathrm{~km}$. Das Nomen Einsparpotenzial ist demnach ein ,Abstraktum', die preislichen Spezifikationen, beispielsweise 1,15 $€ / Z k m$. (OV 1), sind dagegen ,Konkreta‘. Partiell synonym sind diese Nomen bzw. Nominalphrasen, weil sie unterschiedliche Teilaspekte fokussieren und entweder eine Perspektive der Zeit oder der räumlichen Distanz ermöglichen. Relevant sind diese beiden Perspektiven insoweit, als sie die Grundlage für unterschiedliche Berechnungswege der Entgelte bzw. der Kosten darstellen. Das Themenmodul Optimierung verwendet als weitere partielle Synonyme das Personalpronomen wir, die Abkürzung durch die initialen Segmente $E V U$ und das Logo (z. B. OV 2).

Diese Textsortenexemplar übergreifenden Phänomene zeigen, dass die analysierten sprachlichen Mittel nicht an die Verwendung durch einen Bereich der Organisation, zum Teil aber an Themenmodule gebunden sind. Denn die ausgewählten Beispielexemplare stammen aus dem Bereich Fahrzeuge (OV 1), Betriebsplanung (OV 3), Kalkulation (OV 6, OV 7) und Vertrieb/Marketing (OV 10). 


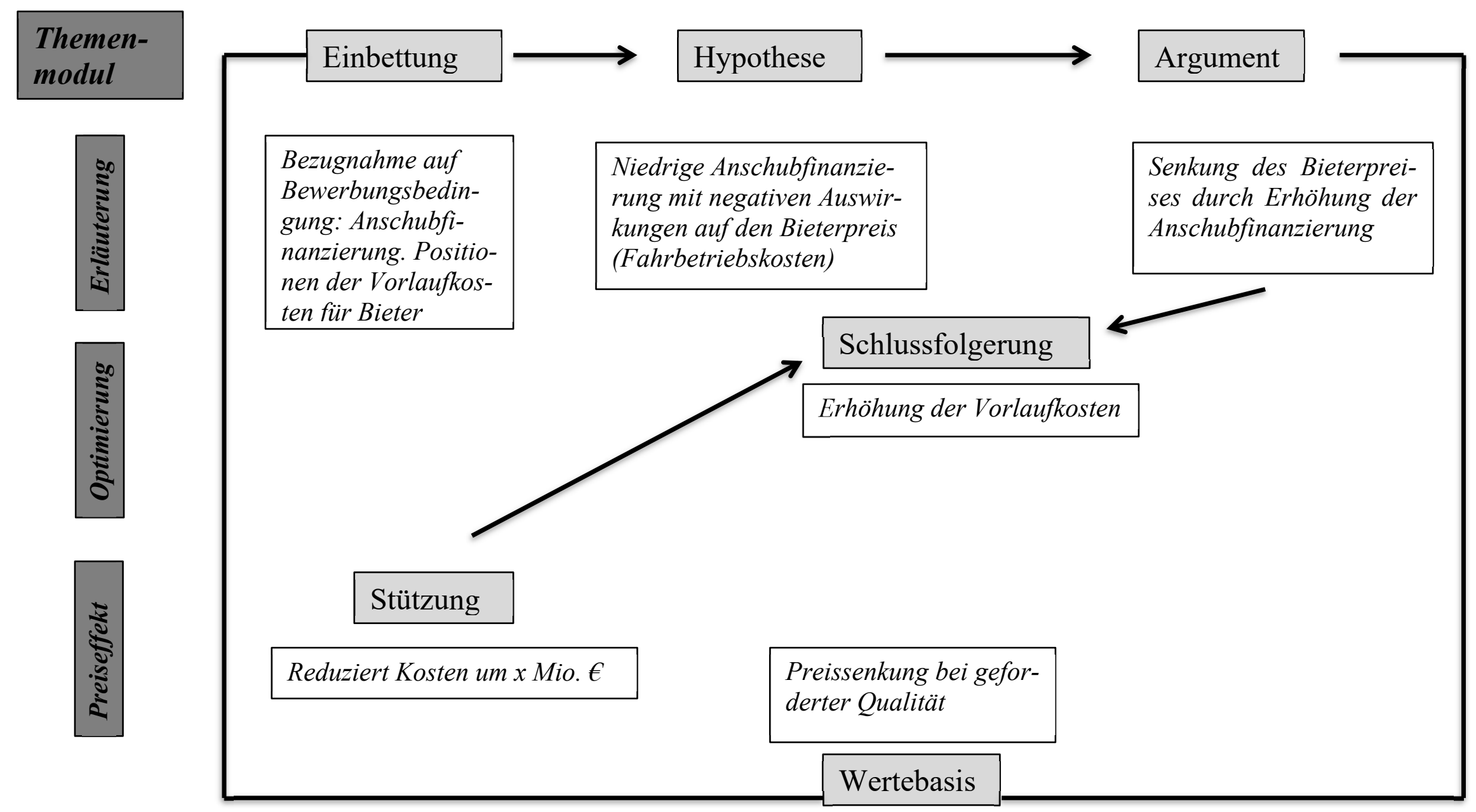

Abbildung 5-6: Analyse von OV 6 (Aus 1) entsprechend dem Schema argumentativer Themenentfaltung (eigene Darstellung). 
Die Verwendung der ,lexikalischen Mittel` als Teil der horizontalen Themenstruktur innerhalb eines Moduls oder Modul übergreifend hängt dagegen thematisch vom Organisationsbereich ab, der ein Textsortenexemplar produziert. Dies wird am Beispiel von OV 1 (ebd., S. 414 f.) veranschaulicht. In diesem OV des Bereichs ,Fahrzeuge“ werden keine anaphorischen Mittel verwendet, die über die oben aufgezeigten, bereichsunabhängigen Mittel hinausgehen. Als einziges kataphorisches Mittel dient die Vergleichspartikel-Gruppe wie folgt als Pre-Organizer innerhalb des Themenmoduls Anzupassende Unterlagen. Auffällig ist an der $\mathrm{Zu}-$ ordnung zu diesem Themenmodul, dass dieser Organizer Bestandteil der Argumentation ist, die in den übrigen OV im Themenmodul Erläuterung positioniert ist. Er gehört zur dritten Überschriftenebene ${ }^{167}$ Änderung der Berechnung des Wertungsaufschlags, die das Themenmodul Anzupassende Unterlagen gemeinsam mit den beiden weiteren Unterüberschriften Änderungen der Fahrzeuganforderungen und der Anforderungen an die Kapazitätsvorgaben untergliedert. Diese Untergliederung des Themenmoduls weicht von den anderen Exemplaren ab.

Rekurrenz erzeugt in OV 1 eine horizontale Themenstruktur teilweise innerhalb eines Themenmoduls, teilweise über die Module hinweg. So verknüpft der Gebrauch der Nomen Gebrauchtfahrzeuge und Anforderung(-en) sowohl im Modul Erläuterung als auch in Anzupassende Unterlagen diese beiden Module, während sich die Nominalphrase Los 1 in allen Modulen wiederfindet. Das Nomen Wertungsaufschlag wird ausschließlich im Teilthemenmodul Änderung der Berechnung des Wertungsaufschlags genutzt. Im Teilthemenmodul Wertungsaufschlag wird Rekurrenz durch die Wiederholung des Nomens Fahrzeugalter erzeugt, während im selben Teilthemenmodul Ko-Referenz ${ }^{168}$ durch die Verwendung der Komposita Fahrzeugalter und Durchschnittsalter entsteht. Die beiden Termini Fahrzeugalter und Durchschnittsalter bilden Ko-Referenten. Als Ko-Referenten erscheinen des Weiteren die folgenden Komposita in den Teilthemenmodulen

167 Die erste Ebene bildet in OV 1 (Ausschreibung 1) dessen Gesamtüberschrift Anpassungen im Bereich Fahrzeuge im Los 1, die zweite Ebene eine der vier Unterüberschriften, hier 3 Anzupassende Unterlagen, und die ausschließlich in letzterem Themenmodul befindliche dritte Ebene, hier: Änderung der Berechnung des Wertungsaufschlags.

168 Ko-Referenz und Synonyme unterscheidet, dass Synonyme Teil des (mentalen) Lexikons sind, während Ko-Referenten Weltwissen durch den Text aktualisieren (SCHWARZ-FRIESEL/CHUR, ${ }^{6} 2014$, S. 103). 
Änderungen der Fahrzeuganforderungen und Änderungen der Kapazitätsanforderungen: Sitzanordnung, Sitzgruppenteiler, Klappsitzanteil, Sitzplatzkapazitäten. Diese beinhalten als Erstglied bzw. (Teil-)Bestimmungswort das Nomen Sitz-, während das Grundwort variiert. Aufgrund dieser Variation stellen beide Komposita keine Kohyponyme dar.

Als partielle Synonyme konstituieren in OV 1 folgende Nominalphrasen eine horizontale Themenstruktur: Das Kompositum Bestandsfahrzeuge (Themenmodul Optimierung) stimmt mit dem partiellen Synonym Gebrauchtfahrzeuge in der Eigenschaft überein, kein Neufahrzeug zu sein, und variiert in der Eigenschaft, dass Letzteres Teil des Schienenfahrzeugmarktes sein kann. Das Bestandsfahrzeug kann dies dagegen nicht sein, da es Teil eines Unternehmensfuhrparks ist. Diese Unterscheidung ist für den gesamten Vorschlag relevant, weil sie den Ausgangspunkt für das Angebot bildet: Dem Auftraggeber werden Fahrzeuge angeboten, die auf dem Markt nicht verfügbar sind. Synonyme sind dagegen die Nomen Vorgabe und Anforderung: Beide konstituieren synonyme Komposita, die zur Terminologie der Verdingungsunterlagen gehören, und sind als Teil des Fachtextwortschatzes nicht eineindeutig: Beispielsweise werden in der Leistungsbeschreibung zu AusschreiBung 1 die Kapazitätsanforderung (S. 7) und Fahrzeuganforderung (S. 29) auch durch die Nutzung der Termini Kapazitätsvorgaben (ebd., S. 7; S. 26) und Mindestvorgaben (ebd., S. 17; S. 25) variiert.

Die synonyme Verwendung der beiden Nomen in OV 1 basiert dementsprechend auf der mangelnden Eineindeutigkeit der Terminologie in den Verdingungsunterlagen und belegt, dass der Fachtextwortschatz der Textsorte OV von den Verdingungsunterlagen abhängt. Die Ursache für diese Abhängigkeit erläutert AUFTRAGGEBER 2:

„Es ist problematisch, wenn ein Begriff im Angebot anders genutzt wird als in den Mindestanforderungen. Im Zweifelsfall würden wir den Bieter dann zu einem Aufklärungsgespräch bitten, weil durch die abweichende Terminologie ein Streit im Vertragsleben möglich würde. Grundsätzlich stechen aber die Mindestanforderungen das Angebotsschreiben bzw. Optimierungsvorschläge.

Im Extremfall könnte die abweichende Terminologie den Ausschluss aus dem Vergabeverfahren zur Folge haben, vorher würden wir aber wie gesagt zu einem Klärungsgespräch bitten.“(2010a; S. 3)

Dass Terminologie-Konflikte in der Textsorte Pflichtenheft aufgrund mangelnder Harmonisierung von TSI-PRM- und BAG-SPNV-Normen auftreten, zeigen die 
Analyse des Fachtextwortschatzes und die Beschreibung der zugehörigen Textüberarbeitungsprozesse (s. Kapitel 6.1).

Raumdeiktische Mittel und paradigmatische Relationen des Fachtextwortschatzes sind an der Konstitution einer horizontalen Themenstruktur beteiligt: Raumdeixis wird durch quantitative Angaben zum Ausmaß eines physikalischen

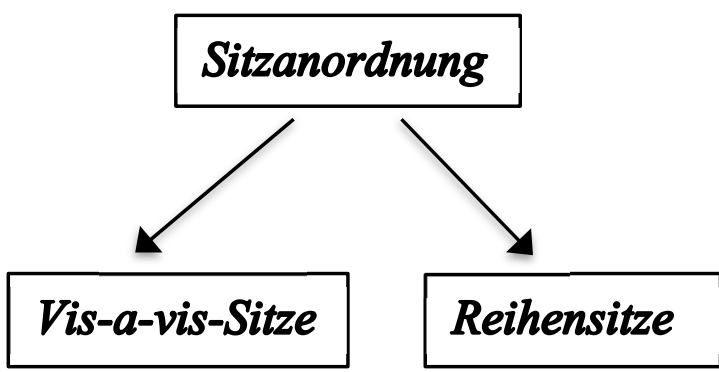

Abbildung 5-7: Hyponym-HyperonymRelationen im Fachtextwortschatz (eigene Darstellung).

Objekts entsprechend dem genormten Maßstab der Maßeinheiten $\mathrm{km} / \mathrm{h}, \mathrm{mm}$ (OV 1) angegeben. Diese Angaben drücken kardinale Raumdeixis aus, weil ihnen ein absoluter Maßstab zugrunde liegt. Auch das Kompositum Sitzanordnung (ebd.) drückt Raumdeixis aus und wird durch die Komposita vis-a-vis Sitze [sic] und Reihensitze (ebd.) präzisiert. Denn beide Komposita implizieren mögliche Anordnungen von Sitzen aus der Perspektive der Sitze. D. h., beide Komposita lassen sowohl auf eine intrinsische als auch eine deiktische sekundäre Perspektive schließen. Gleichzeitig bilden sie als paradigmatische Relation Kohyponyme zum Hyperonym Sitzanordnung (s. Abbildung 5-7). Des Weiteren können Vis-á-visSitze über die Raumachse und Reihensitze über eine Objektachse beschrieben werden.

Die Hyponym-Hyperonym-Relation zwischen Fahrzeugflotte (Teilthemenmodul Wertungsaufschlag) und Bestandsfahrzeugen (Themenmodul Optimierung) zählt ebenfalls zu den paradigmatischen Relationen im Fachtextwortschatz. Eine logisch-begrifflich implizite Wiederaufnahmestruktur bilden über die Module hinweg die Oppositionspaare Neufahrzeuge (Themenmodul Preiseffekt) - Gebrauchtfahrzeuge (Themenmodul Erläuterung) bzw. Bestandsfahrzeuge (Themenmodul Optimierung). ${ }^{169}$

Das Kompositum Spaltüberbrückung (ebd.) beinhaltet das Nomen Brücke, das insoweit als ,Metapher' verwendet wird, als es die Eigenschaft der Verbindung

169 Gegenüber den übrigen Textsortenexemplaren erscheint die Verwendung des Anredepronomens Sie (Teilthemenmodul Wertungsaufschlag) als markiert, da direkte Anrede in den übrigen Exemplaren vermieden wird. 
zweier begehbarer, aber getrennter Positionen am Boden aus dem Bereich des Straßen-/Wegebaus auf den Fahrzeugbau überträgt. Diese Verbindung dient dem Zweck, ein Objekt wie eine Schlucht, einen Fluss etc. in die jeweils eine oder andere Richtung zu überqueren, die/der die beiden Ansatzpunkte der Brücke trennt. Je nach Nutzungsrichtung des Fahrgasts beim Einsteigen in oder beim Aussteigen aus dem Fahrzeug impliziert diese Metapher einen Richtungsvektor vom Fahrzeug zur Bahnsteigkante bzw. vice versa. Dabei ist der Fahrgast deagentiviert, was der textkondensierenden Eigenschaft des OV geschuldet ist. Diese Deagentivierung verdeutlicht die Ersetzung des Kondensats Spaltüberbrückung durch Beispielsatz 5-1:

\begin{tabular}{|c|l|}
\hline $\begin{array}{c}\text { Beispielsatz } \\
\mathbf{5 - 1}\end{array}$ & $\begin{array}{l}\text { Eine Platte/eine Stufe überbrückt den Spalt zwischen Fahrzeug } \\
\text { und Bahnsteigkante, damit der Fahrgast gefahrlos in das Fahrzeug } \\
\text { einsteigen und aus dem Fahrzeug aussteigen kann. }\end{array}$ \\
\hline
\end{tabular}

Diese funktionale Perspektive der Nutzer bleibt bei der Verwendung des sie kondensierenden Kompositums Spaltüberbrückung in den OV und in den Pflichtenheften bestehen.

Die ,implizite Wiederaufnahme، als Teil der horizontalen Themenstruktur veranschaulicht die Analyse von OV 7 durch drei Oppositionspaare Chancen Risiken, EVU - Bahn und Bruttoausschreibung - Nettoausschreibung: ${ }^{170}$

Über die drei Themenmodule Erläuterung, Optimierung und Preiseffekt hinweg prägt das Oppositionspaar Chancen - Risiken als logisch-begrifflich implizite Wiederaufnahmestruktur dieses Textsortenexemplar. So wird dieses Oppositionspaar im Themenmodul ,Erläuterung' variiert: a) in der Nominalphrase Verteilung von Chancen und Risiken; b) durch die Synonyme optimistischer Fall und pessimistischer, aber plausibler Fall jeweils in den Textteilen, die zu den Diagrammen hinführen; c) in den Diagramm-Überschriften als optimistisches Szenario und Risikoszenario. Durch diese Überschriften erscheinen die Diagramme als Teilthemenmodule des Themenmoduls Erläuterung. Durch beide Diagramme bzw. deren Gestaltung entsteht eine weitere Ko-Referenz zum Oppositionspaar Chancen

170 Die Oppositionspaare pessimistisches Szenario und Risikoszenario sowie Chancen(-szenario) und optimistisches Szenario können aber nicht nur als Teil der Wiederaufnahmestruktur, sondern auch als Ko-Referenten klassifiziert werden. 
- Risiken: Insbesondere die Flächenverhältnisse und Farbrelationen repräsentieren präzise Angaben zu Chancen und Risiken.

Die implizite Wiederaufnahmestruktur wird weitergesponnen, indem das Oppositionspaar Chancen - Risiken mit dem entsprechenden Paar beider beteiligter Kommunikanten EVU - Aufgabenträger verknüpft wird (s. dazu die Analyse der Säulendiagramme als Teil der Funktionsstruktur und des Textdesigns). Letzteres Paar lässt sich insoweit als (mikro-)kulturelle implizite Wiederaufnahme wie das Beispiel Schaffner - Straßenbahn ${ }^{171}$ diskutieren, als die Termini Organisationen bezeichnen, die notwendig sind, damit Ausschreibungsverfahren stattfinden können. So gestaltet die Zuordnung von Chancen und Risiken zu EVU und Aufgabenträger die weiteren Themenmodule von OV 7.

Eine weitere (mikro-)kulturelle implizite Wiederaufnahme bildet in diesem OV die Gegenüberstellung der Nomen Bruttoausschreibung und Nettoausschreibung, die das Teilthemenmodul Optimierung wesentlich prägen (ebd., S. 424). So bezeichnet der Bruttovertrag einen Bieter-Auftraggeber-Vertrag, „bei dem das wirtschaftliche Risiko des Verkehrsangebots nicht allein vom Unternehmen getragen wird“'172 (WIEDEMANN, ${ }^{3} 2006$, S. 50), weil der Bieter einen festen Preis erhält. Dadurch trägt der Bieter das Kostenrisiko, wird aber nicht an Einnahmesteigerungen durch Fahrgastzuwächse beteiligt (ebd.). Der Auftraggeber trägt bei Bruttoverträgen das Einnahmerisiko. Bei einem Nettovertrag trägt der Bieter dagegen das Kosten- und Einnahmerisiko, schöpft aber auch Gewinne bei Einnahmezuwächsen ab (ebd., S. 133). Abgesehen von Anaphorika und Kataphorika setzen die beschriebenen Mittel der horizontalen Themenstruktur keine lineare Rezeption voraus. Als multimodale Verknüpfung wurde bereits der Zusammenhang zwischen Säulendiagrammen und dem Fließtext diskutiert.

\subsubsection{Logisch-semantische Sprache-Bild-Relationen}

Die Analyse der logisch-semantischen Sprache-Bild-Relationen gliedert sich nach den Kriterien des integrierten Analyserasters zu interfachlichen SpracheBild-Textsorten zur multimodalen Verknüpfung (s. Abbildung 3-10). Als

171 Dieses Beispiel geben BRINKER/CÖLFEN/PAPPERT ( ${ }^{9} 2018$, S. 38).

172 Der Begriff Unternehmen wird aus dieser Perspektive synonym zu Bieter verwendet. 
logisch-semantische Sprache-Bild-Relationen lassen sich in den vorliegenden OV aus Ausschreibung 1, Ausschreibung 2 und Ausschreibung 3 nur wenige Relationen diskutieren, da die Vorschläge keine ikonisch-materiellen Bilder, sondern lediglich abbildende Diagramme und ein Logo enthalten. Somit bezieht die folgende Analyse logisch-semantische Sprache-Bild-Relationen auf den Zusammenhang zwischen diesen Elementen und Schriftelementen des jeweiligen Textsortenexemplars.

Die Relation des Logos zu seinen Ko-Referenten wir und $E V U$, aber auch zu weiteren schriftsprachlichen Elementen wird für alle Textsortenexemplare beschrieben, weil alle OV entsprechend gestaltet sind. Tabellen stellen eine besondere Form als Gestaltungsform für die Anhänge in Ausschreibung 2 dar. Da die Tabellen aber nicht im selben Dokument wie die auf sie verweisenden Schriftelemente positioniert sind, kann lediglich der schriftsprachliche Verweis des jeweiligen OV auf seinen tabellarischen Anhang betrachtet werden. Weil es sich dabei um keine Sprache-Bild-Relation, sondern um einen intertextuellen Verweis handelt, wird diese Relation nicht weiter diskutiert. Im Gegensatz dazu werden Sprache-BildRelationen innerhalb der Diagramme 1 und 2 (OV 7) und zwischen diesen Diagrammen und den Fließtextflächen betrachtet, die sie umgeben.

Das Logo (s. Abbildung 5-1) kann als ikonisches, symbolisches und rekonfigurierend-diagrammatisches Zeichen verstanden werden: ${ }^{173}$ Symbolisch ist die Phonem-Graphem-Beziehung der beiden roten Grapheme $V E$ und das schwarze Graphem $R$. Weil es sich aber um eine Abkürzung initialer Segmente ${ }^{174}$ vom Unternehmensnamen VulkanEifelRail ${ }^{175}$ handelt, kann der Unternehmensname weitgehend durch eine Phonem-Graphem-Beziehung gelesen werden. Die Schienen als ikonisches Elemente unterhalb von VER verweisen wie auch das Wort Rail bzw. dessen initiales Segment $R$ auf Schienen als Interpretant. Die drei roten Striche

173 Ein Logo, das als Ausdrucksseite eines Unternehmens auf das gesellschaftliche Wissen über das Unternehmen als Inhaltsseite verweist (KASTENS/LUX, 2014, S. 58 ff.), kann als PEIRCEsches Ikon eingeordnet werden, weil es auf ein konkretes Unternehmen als ,tatsächlich vorhandenes, singuläres Objekt" (GALLERT, 1998, S. 119) referiert. Dem Wegweiser als Element des Systems Ort entspricht das Logo als Teil des Systems Unternehmen (ebd.) und soll ,im hinweisenden oder anweisenden Sinne Signalwirkung“ (ebd.) haben.

174 Diese Bezeichnung orientiert sich an der Beschreibung in EINS ( ${ }^{5} 2016$, S. 2).

175 Man möge mir diesen fiktiven Namen nachsehen, der aus meiner Begeisterung für die Vulkaneifel resultiert. 
oberhalb des Buchstaben $V$ verweisen wie auch der Buchstabe $V$ auf einen Vulkan; ihre Positionierung über der Öffnung des Buchstaben $V$ lässt den Buchstaben als Vulkanöffnung und damit als Teil eines Ikons erscheinen. Lediglich die initialen Segmente $V E$ verweisen nicht nur auf einen Vulkan, sondern auch auf die Eifel, was die drei Striche über dem $V$ nicht leisten können. Die ikonischen und symbolischen Elemente des Logos fügen sich somit zu einem diagrammatischen Element zusammen (s. Abbildung 5-1).

Die logisch-semantische Beziehung zwischen dem Logo und der Abkürzung EVU oder dem Personalpronomen wir wird als ,Similarität' (extension/similarity) klassifiziert (s. Abbildung 3-10). Denn alle drei Elemente verweisen gleichermaßen als Ko-Referenten auf das Unternehmen als Objekt.

Logisch-semantische Relationen bestehen zwischen den abbildenden Diagrammen zum optimistischen Szenario (s. Abbildung 5-3) und zum Risikoszenario (s. Abbildung 5-2) mit: a) der jeweiligen Überschrift des Diagramms; b) den Säulen und der Diagramm-Legende sowie der Legende und dem Fließtext; c) dem Fließtext, der zum jeweiligen Diagramm hinführt; d) dem Fließtext, der die Inhalte des Diagramms im Anschluss verarbeitet. Im Einzelnen stellen sich diese Relationen wie folgt dar:

a) Die Überschriften und die Säulen gehen drei Relationen ein.

a1) Die farbigen Flächen der Säulen, die auf der x-Achse als Zeitdimension der Diagramme abgetragen werden, gehen mit der jeweiligen Überschrift Entwicklung und Verteilung Fahrgelder in Verbindung mit der jeweils unter einer Säule positionierten Jahreszahl in beiden Diagrammen die Relation, verbesserte Zeitangabe' (enhancement/time) ein. Denn die Anzahl der Säulen spezifiziert die Anzahl der Jahre, über die sich die Entwicklung erstreckt. Die Verwendung von zwölf Säulen repräsentiert die Verteilung der Gelder auf die jeweiligen Jahre.

a2) Die Überschrift, die Flächen und unterschiedliche Farben der Säulen, die auf der y-Achse als Gelddimension abgetragen werden, sind in Verbindung mit der Nominalphrase Fahrgeldeinnahmen in Mio. $€$ als, verbesserte Angabe der Art und Weise' (enhancement/manner) verknüpft. Denn die Position auf der yAchse, auf der die jeweilige Säule endet, repräsentiert die Höhe der Einnahme, 
die für das jeweilige Jahr prognostiziert wird. Ein Vergleich der unterschiedlichen Säulenlängen entlang der y-Achse und der unterschiedlichen Verteilung von Farbflächen innerhalb der Säulen ermöglichen es, die Veränderungen der Einnahmen zu erkennen.

a3) Die Relation zwischen den Überschriften Entwicklung und Verteilung Fahrgelder-Optimistisches Szenario und den Säulen von Diagramm 1 (s. Abbildung 5-3) wie auch die Relation zwischen der Überschrift Entwicklung und Verteilung Fahrgelder - Risikoszenario EVU und den Säulen von Diagramm 2 (s. Abbildung 5-2) werden als ,Exemplifikation“ (elaboration/exemplification) bestimmt. Denn die beiden unterschiedlichen Szenarien machen deutlich, dass es sich bei den Prognosen jeweils um ein Beispiel handelt. So könnten neben diesen beiden durch Diagramm 1 und Diagramm 2 repräsentierten Szenarien auch Diagramme erstellt werden, die auf anderen möglichen Szenarien basieren - beispielsweise eine Prognose, die sich zwischen optimistisch und Risiko bewegt.

b) Als , augmentative Komplementarität' (complement/augmentation) wird die Relation zwischen den Beschriftungen der Legende in Diagramm 1/Diagramm 2, beispielsweise Davon Partizipation EVU: $[x]$ Mio. $€$, und den Säulen von Diagramm 1/Diagramm 2 erfasst. Denn die Schriftelemente in der Legende ergänzen die bildliche Darstellung der Säulen konsistent, indem sie quantitative Angaben der Säulenflächen zusammenfassen.

c) Zwei Sätze, die zu den Diagrammen hinführen, gehen logisch-semantische Relationen mit den Diagrammen 1 und 2 ein.

c1) Eine ,verbesserte Angabe der Art und Weise' (enhancement/manner) und der Zeit (enhancement/time) ermöglichen die Relationen zwischen Diagramm 1 (s. Abbildung 5-3) und dem folgenden Satz von OV 7: Szenario 1 bildet dabei den optimistischen Fall einer kontinuierlichen Steigerung der Einnahmen um jährlich $[X] \% a b$. Denn die Flächengrößen und -farben von Diagramm 1 werden durch das attributiv verwendete Adjektiv kontinuierlich in ihrer Art und Weise präzisiert. Das Attribut um jährlich $[X] \%$ präzisiert die Höhe der Steigerung für das jeweilige Jahr, also in Bezug auf den zeitlichen Verlauf. 
c2) Die Nominalphrase in OV 7 Steigerung der Fahrgeldeinnahmen in 2018 (bspw. durch eine besonders gute Saison oder ein sportliches Großereignis) als Hinführung zu Diagramm 2, insbesondere zur Säule für das Jahr 2018 (s. Abbildung 5-2), stellt eine, verbesserte Angabe des Grunds' (enhancement/cause) dar. Denn die Nominalphrase sportliches Großereignis erläutert die ungewöhnliche Höhe von Säule 2018, die die proportionale Steigerung der Einnahmehöhen aus Diagramm 1 durchbricht.

d) Zwischen Schriftelementen unter den Diagrammen und diesen Diagrammen finden sich drei logisch-semantische Relationen:

d1) Eine ,augmentative Komplementarität' (complement/augmentation) gehen die Flächengrößen und -formen aus Diagramm 1 (s. Abbildung 5-3) mit folgenden zwei Sätze aus OV 7 ein, die an Diagramm 1 anschließen (OV 7): Kumuliert ergeben sich Fahrgeldsteigerungen i. H. v. $[x]$ Mio. $€$. Hiervon erhält das EVU in Summe $[X]$ Mio. $€([X] \%$ bzw. $[X] \%$ und $[X] \%$ der einmaligen Steigerung) Denn die Partizip-II-Form kumuliert erfasst die Summe der Einnahmen, die die Farbflächen der Säulen repräsentieren. Diese Relation entspricht der Relation zwischen Diagrammen und der Nominalphrase Davon Partizipation EVU: [x] Mio. $€$ in der Legende entsprechend obiger Analyse unter Punkt b). ${ }^{176}$

d2) Eine ebenfalls ,augmentative Komplementarität' (complement/augmentation) besteht zwischen den roten Flächen zur Säule 2018 in Diagramm 2 und folgendem Satz (ebd.) unter Diagramm 2: In diesem Fall liegen die Fahrgeldsteigerungen bei $[x]$ Mio. $€$. Das EVU erhält hiervon $[x]$ Mio. $€$. Denn auch dieser Satz fasst die Summe der Einnahmen zusammen, die die Farbflächen der Säulen repräsentieren.

d3) Eine ,verbesserte Angabe der Art und Weise' (enhancement/manner) ergibt sich aus der Relation zwischen den grauen Flächen in Diagramm 2 (s. Abbildung 5-2) und dem folgenden Satz (OV 7) unter Diagramm 2: Durch die für

176 Die Wiederholung von Schriftelementen aus der Legende und im Fließtext unter den Diagrammen konstituieren als Rekurrenz neben anderen Mitteln die horizontale Themenstruktur und werden daher nicht weiter in diesem Teilkapitel zu Sprache-Bild-Relationen behandelt. 
die Jahre 2019 ff. geltende, vom Einmaleffekt in 2018 bestimmte Mindesteinnahme muss das EVU jedoch einen wirtschaftlichen Verlust i. H. v. $[x]$ Mio. $€$ tragen. Denn die Nominalgruppe wirtschaftlicher Verlust präzisiert die Bedeutung der grauen Flächen, wie es auch die Nominalphrase Davon Zahlung $E V U$ in der Legende (ebd.) leistet.

Inwieweit diese Mittel der textuellen Gestaltung situativ-kontextuell eingebunden sind, ist bei der Analyse der Funktionsstruktur angeschnitten worden und wird im Folgenden ausführlich behandelt.

\subsubsection{Verknüpfungen zwischen Textgestaltung und Kontext}

Die Analyse der Textgestalt-Kontext-Verknüpfungen gliedert sich entsprechend den betreffenden Kriterien des integrierten Analyserasters zu interfachlichen Sprache-Bild-Textsorten (s. Tabelle 3-4). Die ,Bündelung von Fachsprachen“ spiegelt sich darin wider, dass die Themenmodule Erläuterung und Optimierung durch Mittel verschiedener Fachsprachen wie Schienenfahrzeugtechnik, Betriebsplanung und Vertrieb gestaltet sind. Dagegen ist das Themenmodul Preiseffekt weitgehend von diesen Fachsprachen abweichend durch die Fachsprache der Betriebswirtschaft gestaltet. Die ,Interfachlichkeit der Domäne' spiegelt sich daher in themenstrukturellen Elementen verschiedener Fachsprachen wider.

Unabhängig von der jeweiligen ,Beteiligung einer Fachsprache“ an einem Textsortenexemplar sind die Optimierungsvorschläge in identische Themenmodule und vergleichbare Funktionsstruktur eingeteilt. D. h., die Themen- und Funktionsstruktur der untersuchten Textsortenexemplare aus ,verschiedenen Organisationsbereichen' ist durch identische bzw. sehr ähnliche Muster gestaltet. Auch das Textdesign der untersuchten Textsortenexemplare ist weitgehend identisch. Demnach handeln die Kommunikanten der Domäne entsprechend, interfachlicher Textsortenkonventionen', die sich auf das Textdesign sowie die Themen- und Funktionsstruktur beziehen. Diesen Bezug stellen sie in Abhängigkeit von allen Fächern her, die an der Projektkommunikation beteiligt sind.

Die Textwirkung, den Auftraggeber nicht nur von Änderungen der Anforderungen zu überzeugen, sondern auch zu einer Änderung zu bewegen, erreicht der Bieter nur in OV 7: Die Verdingungsunterlagen werden entsprechend OV 7 geändert. Weil der Zusammenhang zwischen Textsortenfunktion und Textwirkung 
nicht konventionalisiert ist, kann aus einer Textwirkung aber nicht auf die Effizienz der Funktionsstruktur oder des Textdesigns geschlossen werden. Diese Wirkung wird daher nicht weiter untersucht.

Die interfachliche ,Diskursgemeinschaft" nimmt wie oben dargestellt nur sehr bedingt Einfluss auf das Themenentfaltungsmuster, weil es über die Textsortenexemplare verschiedener Organisationsbereiche hinweg unverändert bleibt. Dagegen wird der Textgegenstand durch die jeweilige Diskursgemeinschaft der einzelnen Organisationsbereiche insoweit beeinflusst, als die Gegenstände der Optimierung in den Themenmodulen Erläuterung und Optimierung je nach Beteiligung eines Organisationsbereichs voneinander abweichen, beispielsweise als Anpassung der Fahrzeuganforderungen (OV 1) oder der Anschubfinanzierungssumme (OV 6). Eine, Wissenssymmetrie' oder eine, Asymmetrie des zeichenmodalen Wissens' zwischen den Experten unterschiedlicher Organisationsbereiche kann aus den vorliegenden Textsortenexemplaren aus methodischen Gründen nicht interpretiert werden - diese Interpretation leistet erst die Analyse semiotischer Effizienz auf der Grundlage von Beobachtungen und Interviewaussagen. Die ,soziotechnische Aufgabe“ (Dedikation), den Preis bei gleichbleibender Qualität zu reduzieren und im Verfahren diskriminierungsfrei und transparent zu kommunizieren, spielt mit dem Textgegenstand zusammen: So werden Teilgegenstände der VDU - beispielsweise der Fahrzeuganforderungen oder des Finanzierungsmodells - im Themenmodul Erläuterung in Bezug auf ihre möglicherweise negative Auswirkung auf den Bieterpreis dargestellt. Das Themenmodul Optimierung und das Modul Anzupassende Unterlagen stellen eine alternative Konzeption des fachlichen Teiltextthemas vor, die in die VDU einfließen soll. Beispielsweise ergänzt - wie oben zur Textwirkung dargestellt - OV 7 die Bewerbungsbedingungen.

Diese soziotechnischen Aufgaben zeigen sich gleichzeitig in der folgenden Grundfunktion der Textsorte: Mit der direktiven Textfunktion zielt der Textproduzent als Fachmann darauf, den Rezipienten beim Fachmann zu einer Änderung der Verdingungsunterlagen zu bewegen. Dies entspricht der KALVERKÄMPERschen seduccion (s. Kapitel 3.2.2). Diese Grundfunktion wird in den untersuchten Textsortenexemplaren durch eine weitgehend identische Funktionsstruktur konstituiert: Die Grundfunktion der Textsorte wird entsprechend RoLFs (1993) 
3-Ebenen-Modell als Problem reduzierende, nicht-bindende direktive Textsorte bestimmt, die sich aus der Funktionsstruktur mit den verschiedenen Funktionsmodulen mit Unter- und Nebenfunktionen ergibt. Diese Grundfunktion ist in allen OV zu finden, auch wenn diese OV Themen unterschiedlicher Organisationsbereiche thematisieren.

Da die einzelnen Textsortenexemplare über eine relativ geringe zeichenmodale Komplexität verfügen, weichen die Exemplare in ihren Textdesigns und ihren logisch-semantischen Sprache-Bild-Relationen kaum voneinander ab, auch wenn sie aus verschiedenen Organisationsbereichen stammen. Der zeichenmodal komplexeste OV, OV 7, beinhaltet ein Thema aus dem Organisationsbereich ,Kalkulation" und stellt eine Ausnahme dar. Dass Vorschläge insbesondere aus diesem Bereich modal komplex sind, belegt der aus allen drei Ausschreibungen (alle OV) einzige weitere OV aus diesem Bereich, OV 6, nicht.

Die Themenstruktur weist der Textsorte eine ,Position im Textsortennetz‘ zu: Das Aufgreifen der jeweiligen thematischen Bereiche aus den VDU und die Modifikationen, die die OV für die VDU vorschlagen, verweisen darauf, dass die Exemplare der Textsorte OV zwischen der ersten Version der VDU und einer zweiten Version der VDU positioniert sind. ${ }^{177}$

Nicht nur diese zeitliche Verortung der Textsorte OV in der Chronologie der im Ausschreibungsverfahren aufeinander folgenden Textsorten, sondern vor allem die Grundfunktion der Textsorte ergibt sich durch ihre funktionale Relation im Textsortennetz: Die funktionale Text-Text-Relation MOD (Modifizieren der Leistungsbeschreibung, der Anhänge und/oder des Vertrags etc.) bedingt die direktive Grundfunktion, den Auftraggeber von einer Änderung der VDU zu überzeugen. Darauf deutet die Änderung der VDU durch OV 7 hin.

Der Wettbewerbsleiter hat den Anspruch, dass die OV als Visitenkarte des Unternehmens angesehen werden, indem die Qualität ihrer Gestaltung, also aller textuellen Bereiche, auf die Qualität des Angebots verweist. Dementsprechend können die Textsortenexemplare indirekt werben. Die Bedeutung dieser Ergebnisse für

177 Beispielsweise sind die OV in Ausschreibung 1 bis zum 25.02.2013 einzureichen und beziehen sich auf eine Version der Leistungsbeschreibung, die bis 19.04.2013 gültig war. OV 7 modifiziert eine Version der Leistungsbeschreibung, die ab dem 19.04.2013 gilt. 
die drei Forschungsthesen (s. Kapitel 2.1.3) erläutert das Zwischenfazit zur Textsortenanalyse, in dem die Ergebnisse zu OV mit denen zu Lasten- und Pflichtenheften sowie Fahrplanvarianten kontrastiert werden.

\subsection{Textsortenvarianten Lastenheftvordruck (LHV) und Pflichtenheft (PH)}

Eine Beschreibung von Lasten- und Pflichtenheften mithilfe der relevanten DIN-, VDI-Normen und wissenschaftlichen Quellen geht der Analyse dieser Textsortenvarianten voraus, weil die Bezeichnungen dieser beiden Varianten im Diskurs widersprüchlich verwendet werden. Die Verdingungsunterlagen der drei untersuchten Ausschreibungsverfahren enthalten aus juristischer Perspektive jeweils eine Leistungsbeschreibung, die aus technischer Perspektive auch als Lastenheft bezeichnet wird. Das Lastenheft spiegelt sich im Pflichtenheft wider:

„Pflichtenhefte sind üblicherweise die Vertragsgrundlage zwischen Auftraggeber und Auftragnehmer und dadurch besonders wichtige Dokumente in einem Projekt. Sie sind in ihrer Brückenfunktion zwischen Auftraggeber und Auftragnehmer [...].“ (LuTZ, 2015, S. 342)

Folgende Normen definieren, welcher Kommunikant Textproduzent von welcher der beiden Textsortenvarianten ist: ${ }^{178}$ So wird der Begriff ,Lastenheft ${ }^{\star}$ definiert als ,,vom Auftraggeber festgelegte Gesamtheit der Forderungen an die Lieferungen und Leistungen eines Auftragnehmers innerhalb eines (Projekt-)Auftrags" (DIN 69901-5, 2009, S. 9). Eine vergleichbare, aber detailliertere Definition des Begriffs Lastenheft mit seiner Funktion und entsprechender Zuweisung des Textproduzenten gibt VDI 2519-1 (2001):

„Im Lastenheft wird definiert [sic] WAS und WOFÜR zu lösen ist. Das Lastenheft wird vom Auftraggeber oder in dessen Auftrag erstellt. Es dient als Ausschreibungs-, Angebots- und Vertragsgrundlage.“ (ebd., S. 2; Fettdruck und Versalien im Original)

178 Normungsinstitutionen konventionalisieren vor allem durch DIN 69901-5 (2009), DIN 69901-2 (2009), VDI 2519-1 (2001), VDI 2632-2 (2013) und VDI 3694 (2013) den Prozess der Lasten- und Pflichtenhefterstellung. Im Bereich Requirements Engineering, das Anforderungen vor allem für Softwareprodukte und -dienstleistungen formuliert, finden sich vor allem Ratgeber (RUPP/DIE SOPHISTEN, 2014; EBERT, 2012; POHL, 22008; TEICH/KolBENSCHLAG/REINERS, 2008 u. a.). Die Fachzeitschrift „Requirements Engineering"widmet sich aktuellen Entwicklungen und dokumentiert die Ergebnisse der jährlichen Tagung zu RE, in deren Fokus Entwicklungen des Requirements Engineering zu Softwareanforderungen stehen. 
Die Funktion des Lastenhefts besteht darin, Inhalte und Ziele einer Ausschreibung festzulegen, was gleichzeitig vertragsrelevant ist. Diese Inhalte sind im Lastenheft als „Anforderungen aus Anwendersicht einschließlich aller Randbedingungen zu beschreiben“ (ebd., S. 2). ${ }^{179}$

Gespiegelt wird das Lastenheft im Pflichtenheft als „,vom Auftragnehmer erarbeitete Realisierungsvorgaben auf der Basis des vom Auftraggeber vorgegebenen Lastenheftes“ (DIN 69901-5, 2009, S. 10). Die Vertragsinhalte des Lastenhefts werden durch die „Umsetzung dieser Vertragsinhalte in entscheidungsreife Formulierungen (z. B. in Form eines Pflichtenhefts)“ (DIN 69901-2, 2009, S. 26) überführt. Entsprechend definiert VDI 2519-1 (2001) das Pflichtenheft gegenüber dem Was und Wofür des Lastenhefts folgendermaßen:

„Im Pflichtenheft wird definiert [sic] WIE und WOMIT die Anforderungen zu realisieren sind. Es wird eine definitive Aussage über die Realisierung des Materialfluss- bzw. Automatisierungssystems konkret ausgearbeitet.“ (ebd., S. 3; Fettdruck und Versalien im Original)

FAHNEY/HERRMANN (2013) differenzieren den Bezug des Was und des Wie im Lasten- und Pflichtenheft entsprechend der Perspektive der beteiligten Kommunikanten: „Für den Auftraggeber ist das Projektziel das ,was‘ [sic], das Lastenheft das ,wie' [sic]. Für den Auftragnehmer ist das Lastenheft das ,was' [sic], das Pflichtenheft das ,wie‘ [sic].“ (ebd., S. 12; Kursive im Original) Diese Untersuchung legt die Definitionen von Lasten- und Pflichtenheft aus VDI 2519 (2001) zugrunde, weil sie die folgende Analyse von Textsortenexemplaren stützt FAHNEY/HerRmanNs Projektziel des Auftraggebers ist nicht untersuchbar. Weil Lasten- und Pflichtenheft annähernd identische Funktionen aus unterschiedlichen Perspektiven übernehmen, identische Themen beinhalten und somit funktionalthematisch annähernd deckungsgleich sind, fasst diese Untersuchung sie als Textsortenvarianten auf.

Textproduzent des Pflichtenhefts ist demnach der Auftragnehmer, wobei die inhaltlich-funktionale Gestaltung durch die Vorgaben des Lastenhefts festgelegt ist (PoHL, ${ }^{2} 2008$, S. 234; EBERT, 2012, S. 92). Diese eindeutige Zuweisung der Textsortenvarianten zu den Kommunikanten ist insoweit einzuschränken, als das

179 Diese Anwendersicht wirkt sich auf die horizontale Themenstruktur des Pflichtenhefts aus (s. Kapitel 5.2.3). 
Pflichtenheft „falls erforderlich unter Mitwirkung des Auftraggebers“ (VDI 2519-1, 2001, S. 3) erstellt werden könnte.

Vielfach sind Lasten- und Pflichtenhefte als Formularvordruck und Formular gestaltet. ${ }^{180}$ So stellen in SPNV-Ausschreibungsverfahren Teile der Leistungsbeschreibung die ausformulierte Variante des Lastenhefts dar, während die Anlage ,Fahrzeuge ' bzw. der Lastenheftvordruck Grundlage des Pflichtenhefts sind. Das Pflichtenheft stellt die vom Bieter ausgefüllte Variante des Lastenheftvordrucks dar. Auch dieser Zusammenhang spricht dafür, die beiden Textsorten Lasten- und Pflichtenheft als Varianten aufzufassen. Aufgrund dieses Zusammenhangs zwischen den Textsortenvarianten sind Auftraggeber und -nehmer Prozipienten (s. Abbildung 2-12). Weil Lastenhefte als Vordrucke meist keine Bilder enthalten, aber fordern können, dass das zugehörige Pflichtenheft Bilder angibt, sind Pflichtenhefte meist modal komplexer gestaltet als Lastenhefte.

KÖSLER (2009) gibt in seinem Erfahrungsbereicht als Leiter des Praktiker-Workshops zur Erstellung von Pflichtenheften an, dass zwar „Fragen [von den Teilnehmenden, $\mathrm{AH}$ ], wie Texte und Abbildungen (Charts, Diagramme usw.) optimal gestaltet werden sollen, selten vor[kommen]“ (ebd., S. 77). LUTZ (2015) empfiehlt aber das „Verwenden von Beschreibungssprachen, die beide Seiten verstehen, je nach Anwendungsdomäne und Beschreibungstiefe z. B. Pläne, Diagramme, Visualisierungen, Szenarien, Use Cases, Personas oder UML “181 (ebd., S. 344). Die modale Komplexität der Lasten- und Pflichtenhefte des Korpus untersucht das Kapitel ,Textdesign‘.

180 Dies empfehlen beispielsweise TEICH/KolBEnsCHLAG/ReINERS (2008, S. 81) und veranschaulichen die Gestaltung eines Lastenhefts als digitales Formular durch das System ePAVOS (ebd., S. 141 ff.).

181 Unified Modeling Language (UML) verwendet ,[h]albformale Notationen mit einer definierten Syntax “(EBERT, 2012, S. 107) in Softwaresystemen und veranschaulicht komplexe Abläufe „,in Anforderungen durch Diagramme“ (ebd.) im Sinne von grafischer Veranschaulichung von Szenarien und Strukturen. Dass visuelle Formen wie UML einen wesentlichen Anteil an der Gestaltung von Lasten- und Pflichtenheften haben, belegt auch die Existenz der eigens dazu geschaffenen Norm VDI 2632-2 (2013) „Industrielle Bildverarbeitung. Leitfaden für die Erstellung eines Lastenhefts und eines Pflichtenhefts": Erst durch die Verwendung von Bildverarbeitungssystemen werden ,eine ständig fortschreitende Automatisierung und immer höhere Anforderungen an die Fertigungsqualität" (VDI 2632-2, 2013, S. 2) durch Lasten- und Pflichtenhefte möglich. 


\subsubsection{Textdesign}

Die Analyse der Kategorie ,Textdesign“ orientiert sich am integrierten Analyseraster interfachlicher Sprache-Bild-Textsorten (s. Abbildung 3-2). Das Textdesign von Lastenheftvordrucken und Pflichtenheften unterscheidet sich entsprechend ihrer unterschiedlichen modalen Komplexität. Exemplare dieser Textsortenvarianten zu kontrastieren, ermöglicht es daher, die Charakteristika des jeweiligen Textsortenexemplars bzw. der jeweiligen Textsortenvariante herauszustellen. Verglichen werden dabei Textstellen, an denen das Pflichtenheft die Elemente des Lastenheftvordrucks wiederholt und der Bieter die Angaben des Auftraggebers ergänzt. Dieses Teilkapitel analysiert Lastenhefte zuerst, weil sie in der Chronologie des Textsortennetzes vor Pflichtenheften angeordnet sind. Der Prozipient ,Auftraggeber' erstellt im ersten Textproduktionsprozess den Lastenheftvordruck. Im Anschluss daran rezipiert der Prozipient ,Bieter' den Vordruck und füllt ihn aus, wodurch das Pflichtenheft entsteht. Im dritten Schritt liest der Auftraggeber dieses Pflichtenheft. Anders als in obiger Analyse der Optimierungsvorschläge werden Lastenheftvordrucke und Pflichtenhefte im Folgenden an Beispielseiten aus den drei Pflichtenheften des Korpus beschrieben und anschließend kontrastiert:

Fünf rechteckige Rahmen bilden im Lastenheftvordruck (LHV 1; s. Abbildung 5-8) Panels in gleicher ,Größe' und ,Form‘, die horizontal zu den Seitenrändern und vertikal zueinander in identischen Abständen ,positioniert` sind (,Similarität'; s. Abbildung 3-2). Diese Panels gleichen sich auch darin, die Wortgruppen Bild/Zeichnung und darunter ggf. separat beifügen anzuordnen. Dass die jeweils gleich großen, in Fettdruck gesetzten Schriftelemente Abb. $X$ : ... unmittelbar unter jedem Panel als deren Beschriftungen fungieren, erklärt das ,Gesetz der Nähe'.

In Lastenheftvordruck 1 (s. Abbildung 5-8) ist auf der linken Seite in der Vertikalen eine Bezifferung von Zeilen (sie erzeugt eine vertikale Ziffernleiste) angebracht. Schwarze Linien machen Zeilen nur in der Kopfzeile sichtbar. Diese Bezifferung in Lastenheftvordruck 1 und im ausgefüllten Vordruck, Pflichtenheft 1 (s. Abbildung 5-9), ist während der Textüberarbeitungen in der digitalen Schreibumgebung EXCEL am Bildschirm sichtbar und dient den Textüberarbeitenden als Orientierung. Die ausgedruckte Abgabeversion für den Auftraggeber, in der die übrigen Pflichtenhefte des Korpus gehalten sind ( $\mathrm{PH} \mathrm{2),} \mathrm{enthalten}$ 
dagegen keine Bezifferungen. Die ,Form` Fettdruck hebt die jeweilige Beschriftung der fünf Panels von der Zeilenbezifferung und der Beschriftung innerhalb der Panels ab. Dagegen sind alle Schriftelemente und Linien in der gleichen ,Graustufe' gehalten und nutzen keine ,Farbe'.

Lediglich der Formularkopf mit der Überschrift Bieter (LHV 1; s. Abbildung 5-8) ist gegenüber den übrigen Elementen auffällig. Dieser Kopf ist an der Stelle positioniert, an der sich üblicherweise die Überschrift eines Dokuments befindet. Er erzeugt dadurch Einheitlichkeit, dass seine Schriftelemente zwischen vier parallel angeordneten horizontalen Linien, also innerhalb von einer Zeile, angeordnet sind, über mehrere Zeilen Fettdruck und unterschiedliche Schriftgrößen gebrauchen. Diese Gestaltungsmittel erzeugen die Salienz des Formularkopfs gegenüber den beschriebenen fünf Panels, deren Beschriftungen und der vertikalen Ziffernleiste. Innerhalb des Formularkopfs wird dagegen das Analyse- bzw. Gestaltungskriterium ,Größe' auf einer vertikalen Achse genutzt, um dessen Schriftelemente voneinander abzugrenzen bzw. zu gruppieren: die Schriftgröße verringert sich zwischen den Elementen Bieter (14 pt) in der obersten Zeile, Zeile 1, zum Schriftelement Fahrzeugtyp Zeile (12 pt) in der Zeile 2 hin zu Anzahl ... (10 pt) in Zeile 4 und davon Reserve (10 pt) in der untersten Zeile (Zeile 5). Die Wortgruppe (bei Waggonzügen je Waggontyp auszufüllen) in Zeile 2 hinter dem Nomen Fahrzeugtyp und die Gruppe (bei Triebwagenzügen Anzahl der Segmente) in Zeile 3 durchbrechen diese über die fünf Zeilen abnehmende Schriftgrößenskalierung (von 14 pt zu 10 pt) durch ihre Positionierung in Zeile 2 und 3 mit ihrer Schriftgröße 8 pt. Darüber hinaus nutzen sie als einzige Schriftelemente die ,Form‘ Kursive.

Neben der horizontalen Von-oben-nach-unten-Skalierung der Schriftgröße werden Elemente der Zeilen in der Vertikalen unterschiedlich positioniert: Während die Schriftelemente der Zeilen 1 bis 3 linksbündig ausgerichtet sind, schließen die Elemente in den Zeilen 4 und 5 rechtsbündig ab. Dabei endet der rechtsbündige Abschluss in der Mitte der Zeile. In der gesamten rechten Hälfte des Formularkopfs sind dagegen keine Schriftelemente positioniert. 


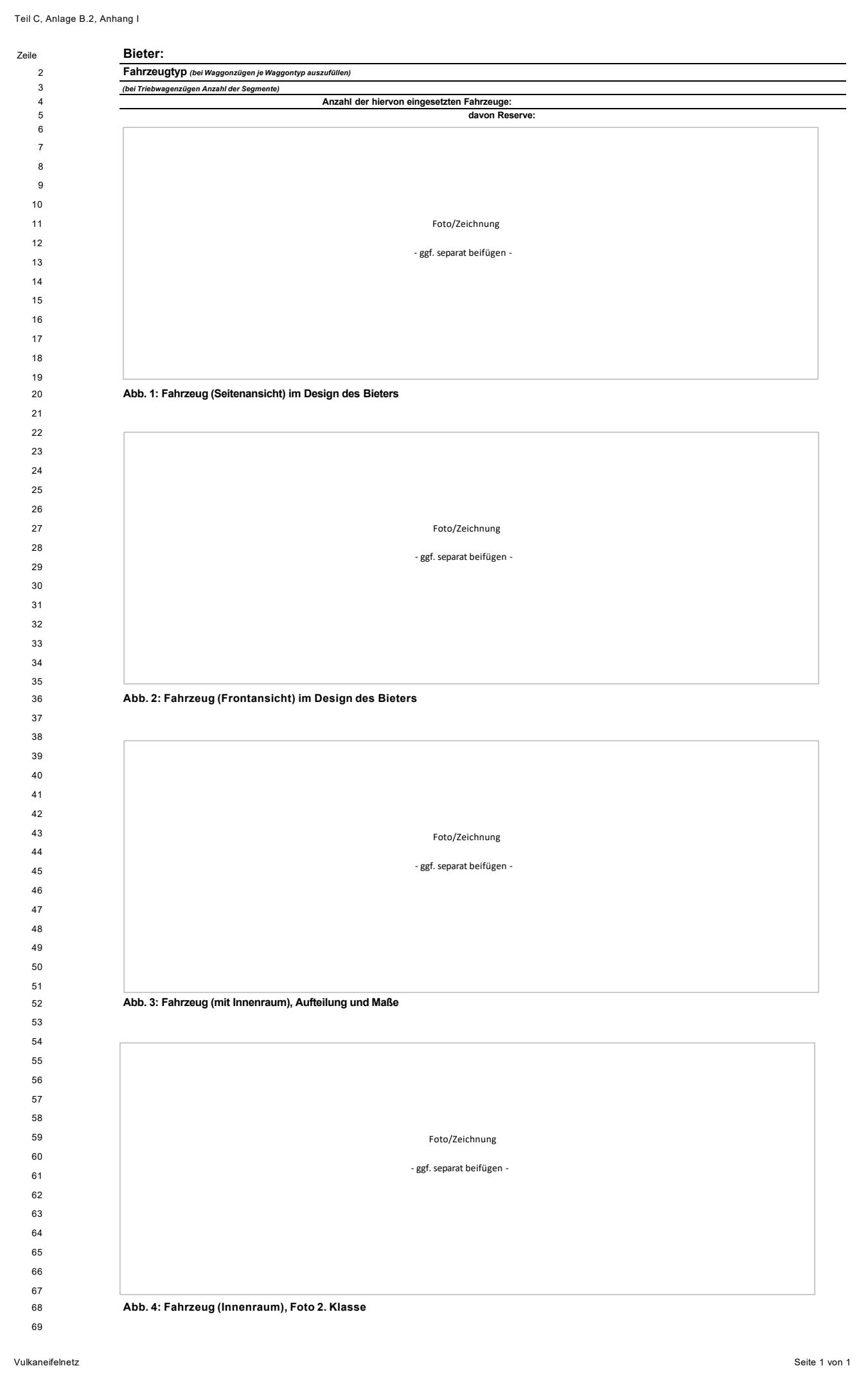

Abbildung 5-8: Erste Seite von Lastenheftvordruck 1 in Ansicht der digitalen Schreibumgebung des Bieters. 


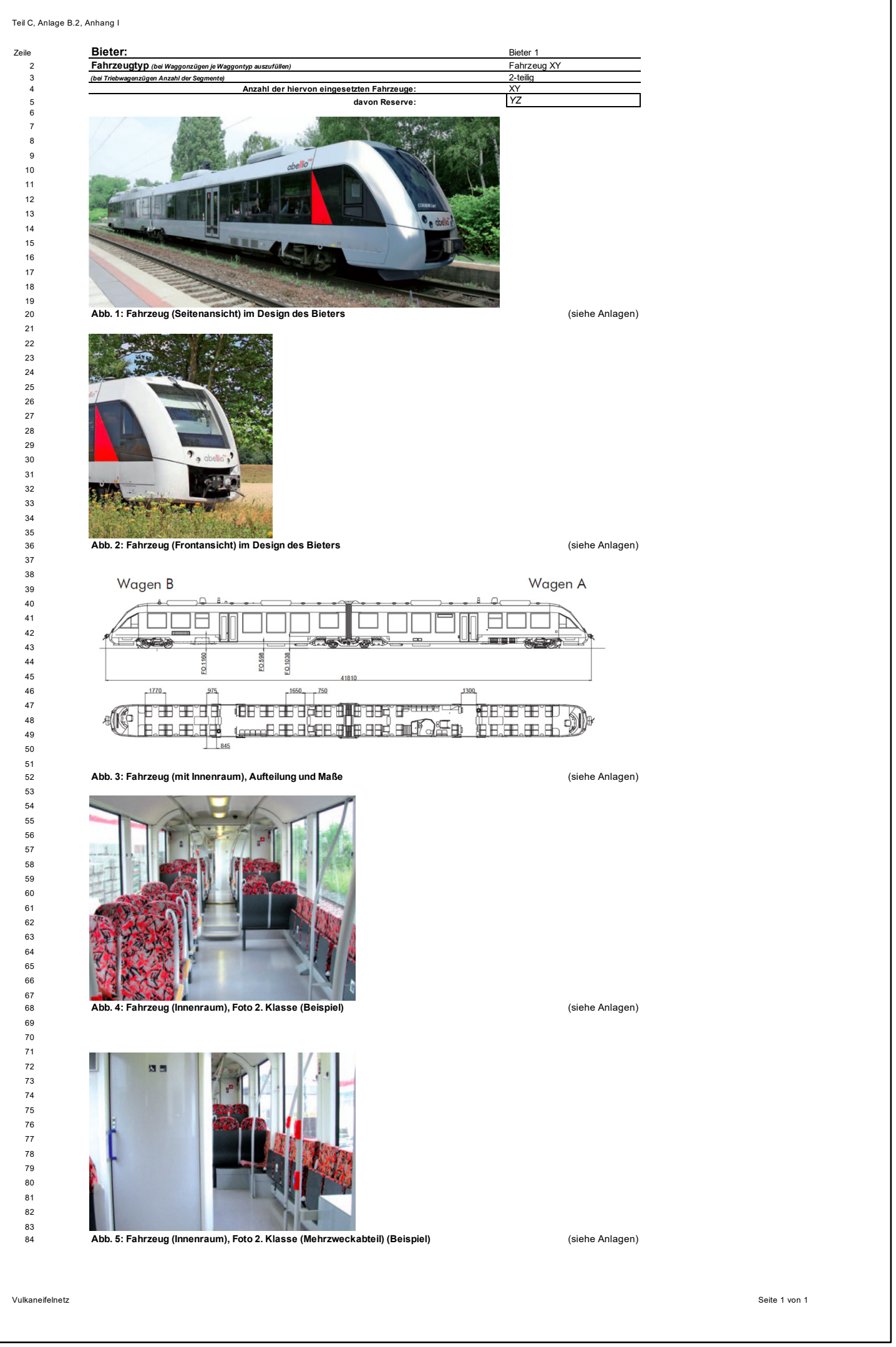

Abbildung 5-9: ${ }^{182}$ Anonymisierte erste Seite von Pflichtenheft 1 in Ansicht der digitalen Schreibumgebung für die Textüberarbeitung durch den Bieter (verfremdet mithilfe von ABELLIO, 2012; S. 24 ff.). 
Im Formularkopf werden die Kriterien ,Größe' und ,Positionierung' genutzt, um die Schriftelemente zu hierarchisieren und zu gruppieren: Die wichtigsten Elemente werden in der größten Schriftgröße (14 pt) in den oberen Zeilen positioniert, während die weniger wichtigen Elemente in kleinerer Schriftgröße (12 pt, $10 \mathrm{pt}, 8 \mathrm{pt}$ ) gehalten sind und in den unteren Zeilen angebracht sind. Letztere Elemente werden wiederum durch ihre identische Größe und ihre Positionierung in den benachbarten Zeilen 4 und 5 entsprechend dem ,Gesetz der Nähe' als Einheit erkennbar. Diese Abstufung der Relevanz nach Schriftgröße und nach Positionierung in der Horizontalen wird durch die Positionierung in der Vertikalen unterstützt - diese Interpretation legt die Von-links-oben-nach-rechts-untenChronologie nahe, wonach das Nomen Bieter links in der obersten Zeile zuerst und die Nominalgruppe davon Reserve rechts in der untersten Zeile zuletzt rezipiert werden.

Die Kursive wird als Mittel genutzt, um die Schriftelemente in ihrer Relevanz innerhalb des Formularkopfs abzustufen: Diese Schriftelemente repräsentieren Informationen, die für bestimmte Fahrzeug-Arten bzw. -Typen (z. B. bei Waggonzügen bzw. bei Triebwagenzügen) relevant sind und zu denen der Bieter nur Informationen geben muss, wenn es sich um den entsprechenden Fahrzeugtypen handelt - beispielsweise die Angabe 2-teilig in Zeile 3 (s. Abbildung 5-9). Gleichzeitig dienen diese Informationen als Anleitung, wie Bieter weitere Angaben im LHV außerhalb des Formularkopfs zu machen haben: So vervielfacht bzw. vermindert sich die im Pflichtenheft anzugebende Anzahl an Türen bei diesen Fahrzeugtypen. ${ }^{183}$

182 Einige Elemente rechts oben sind im Gegensatz zum Exemplar des Anhangs geschwärzt bzw. geweißt, um den Fahrzeughersteller und den Bieter zu anonymisieren. Technische Zeichnungen und Abbildungen finden sich in den frei zugänglichen Broschüren (z. B. ABELLIO, 2012).

183 Beispielsweise vermindert sich bei Fahrzeug 1, das sich aus mehreren Waggons zusammensetzt, die pro Waggon anzugebende Anzahl der Türen in Höhe von 2 Türen (PH 1) gegenüber der Türanzahl von Fahrzeug 2. Dieses ist 1-teilig, nutzt also keine separaten Waggons und verfügt über 7 Türen (PH 2). Beide Fahrzeugtypen müssen die gleiche Sitzplatzanzahl umfassen. Terminologisch unscharf ist die Unterscheidung von Fahrzeugseite und Zugseite in PH 1, weil Zug kein Terminus der Fahrzeugtechnik, sondern der Betriebsplanung ist und auf die Fahrtrichtung bzw. die Fahrbarkeit zielt. 
Dass die rechte Hälfte des Formularkopfs im Lastenheft ohne Schriftelemente gestaltet ist und im zugehörigen Pflichtenheft Schriftelemente enthält, deutet auf die Kommunikationsform Formular hin. D. h., sie wird durch die ,Positionierung ‘ in der Horizontalen visuell repräsentiert: Im Formularkopf des Lastenheftvordrucks sind alle schriftsprachlichen Elemente, die der Auftraggeber angibt, auf der linken Seite angeordnet (LHV 1; s. Abbildung 5-8). Im zugehörigen Pflichtenheft (PH 1; s. Abbildung 5-9) sind dagegen die Angaben des Bieters auf der rechten Seite zu finden. Die verschriftlichte Sprecherspur des Auftraggebers ist als Frageform links positioniert, also auf der Seite, die nach der konventionalisierten Von-links-nach-rechts-Rezeptionschronologie zuerst gelesen wird. ${ }^{184}$ Die Antworten des Bieters sind entsprechend der Frage-Antwort-Chronologie auf der rechten Seite positioniert. Diese Interpretation untermauert die Beschreibung des Formulars (s. Abbildung 5-10), das der Dienstleister NeDTRAIN nutzt: ${ }^{185}$

„Passend zum Erscheinungsbild wurde ein dezentes Formulardesign entwickelt, das Klarheit und Ordnung dadurch schafft, Fragen neben Antworten zu platzieren und diese deutlich zu gruppieren." (ABDUlLah/HenZe, 2007, S. 193)

Die Unterscheidung der Sprechspuren wird in den Pflichtenheften aber nicht nur durch die Links-rechts-Positionierung, sondern auch durch weitere Mittel visualisiert: Pflichtenheft 1 gestaltet seine Angaben nicht entsprechend dieser Vonoben-nach-unten-Skalierung der ,Schriftgröße“ in Lastenheftvordruck 1, sondern verwendet eine einheitliche Schriftgröße von 12 pt (ebd.). Die Schriftelemente im Formularkopf von PH 1 (ebd.) und PH 3 weichen durch die ,Form‘ Fettdruck ab, die sich im Formularkopf beider Pflichtenhefte nur auf der linken Seite finden, also Angaben des Auftraggebers sind. Während alle Schriftelemente des Formularkopfs in PH 1 und PH 3 identische ,Graustufenkontraste' nutzen, sind die Antworten des Bieters in Pflichtenheft 2 (s. Abbildung 5-11) in der Farbe Blau gehalten; die Schriftelemente in der linken Fragespalte des Auftraggebers dagegen in Graustufen. Die Mittel ,Positionierung', ,Form‘, ,Schriftgröße' und zum Teil ,Farbe' kennzeichnen demnach die Verschriftlichung des Dialogs in der

184 Ähnlicher dieser 2-gliedrigen Zeilenstruktur ist die 3-gliedrige Struktur der Zeilen in Schriftmodulen (s. Abbildung 5-14).

185 Der Links-rechts-Chronologie entspricht ein Großteil der Struktur im NedTrain-Formular; einige Elemente weichen davon ab, indem sie die Schriftelemente mit Fragen über den Antwortfeldern anordnen. 
Kommunikationsform Formular (s. Kapitel 2.4.3). Nur Schriftelemente ordnen die Sprecherspuren auf der linken bzw. der rechten Seite an.

Ikonisch-materielle Bilder oder Diagramme, mit denen der Bieter antwortet, werden in den Pflichtenheften in die Panels des Lastenheftvordrucks gesetzt. Dadurch ersetzen die Bilder in den Pflichtenheften die schriftsprachlichen Forderungen aus den Lastenheftvordrucken. Beispielsweise werden die Nomen Bild/Zeichnung und die darunter angebrachte Infinitivgruppe ggf. separat beifügen im Panel mit der Beschriftung Abb. 1 (LHV 1; s. Abbildung 5-8) im dazugehörigen Pflichtenheft durch

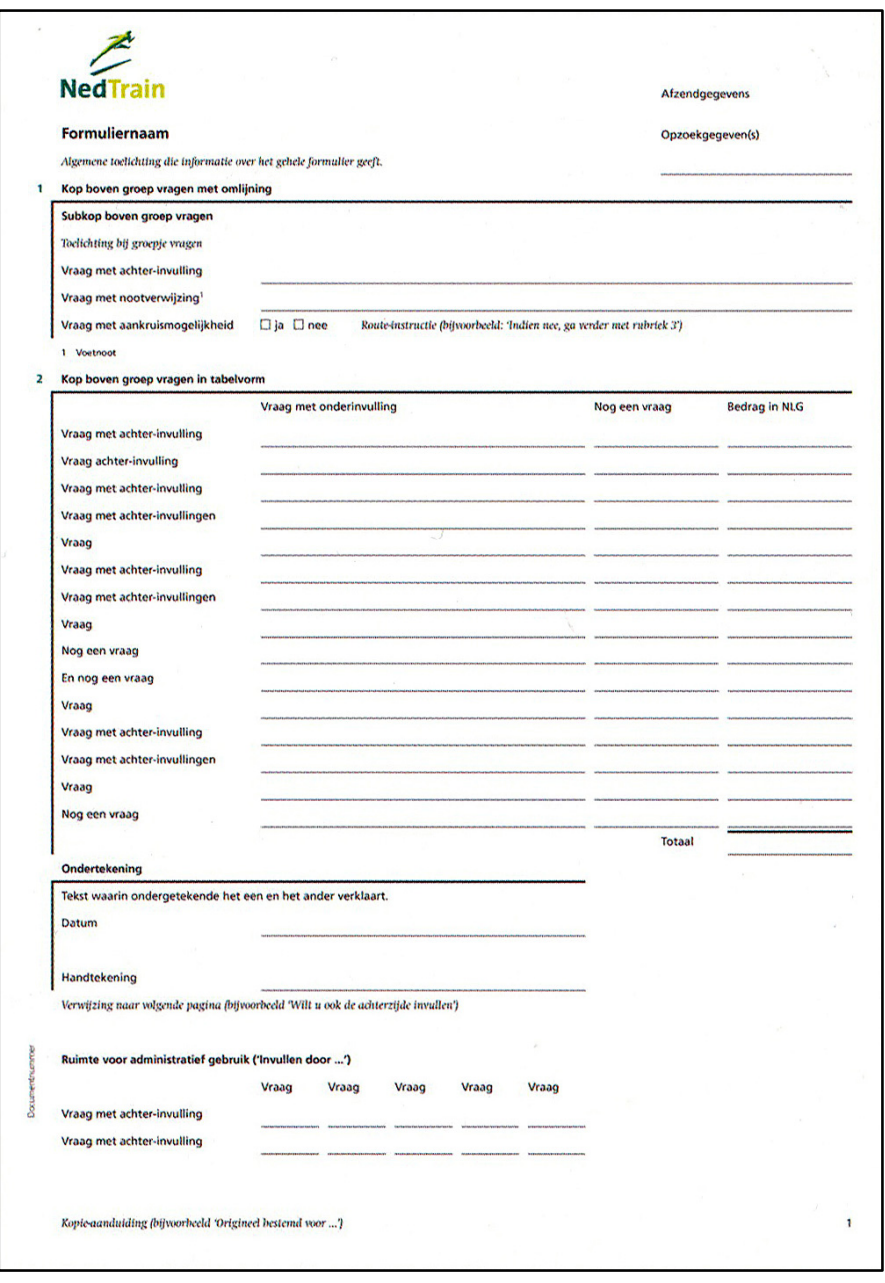

Abbildung 5-10: Modellformular NedTrain (ABDULLAH/ HENZE, 2007, S. 193). ein Foto von einem Fahrzeug in Seitenansicht ersetzt (PH 1; s. Abbildung 5-9). Lediglich in Pflichtenheft 2 bleiben einige schriftsprachliche Forderungen des Auftraggebers erhalten und werden durch Schriftelemente des Bieters ergänzt (s. Abbildung 5-11). Die Farbgestaltung oder der Graustufenkontrast unterscheidet die Schriftelemente des Auftraggebers und die des Bieters innerhalb eines solchen Panels: Die Schriftelemente des Auftraggebers nutzen dieselbe Graustufe wie die Beschriftungen, die Schriftelemente im Formularkopf und in den übrigen Schriftmodulen des gesamten Lastenheftvordrucks. Die Schriftelemente des Bieters innerhalb des Panels - s. beispielsweise Anhang la (ebd.) - sind wie die übrigen von ihm angegeben Schriftelemente in Blau gefärbt. Die ,Similarität‘ der ,Farbe‘ bzw. des ,Graustufenkontrasts' von Schriftelementen in den Bildpanels machen es möglich, die Elemente dem Auftraggeber oder dem Bieter zuzuordnen. 
Die Schriftelemente unter den Panels in den Pflichtenheften bleiben aus den Lastenheftvordrucken erhalten, während die Elemente innerhalb der Platzhalter ersetzt werden. Diese Tatsache erklärt die abweichende Semantik der schriftsprachlichen Elemente: Die Schriftelemente innerhalb der Panels machen in identischer Form Angaben zur zeichenmodalen Beschaffenheit und deren Positionierung von Bildern innerhalb des Pflichtenhefts. Dagegen bestehen zwischen den unterschiedlichen Beschriftungen unterhalb der Panels und den ikonisch-bildlichen bzw. diagrammatischen Realisaten des Bieters logisch-semantische Relationen (s. Kapitel 5.2.4).

Das Textdesign des Lastenheftvordrucks wird gestaltet durch: a) die Similarität verschiedener Bildpanels und Beschriftungen; b) die Proportionalität zwischen den schriftsprachlichen Elementen des Auftraggebers und Bieters; c) die Proportionalität ausschließlich zwischen den Elementen des Auftraggebers. Des Weiteren sind Kontrast bzw. Farbvariation, Form und zum Teil die Größe der Schriftelemente auf der ersten Seite eines Lasten- und zugehörigen Pflichtenhefts einheitlich (Unterkategorie ,Muster'; s. Abbildung 3-2). Dies gilt auch über die Textsortenexemplare hinweg, die das Korpus enthält.

Lastenheftvordruck und Pflichtenheft unterscheiden sich vor allem durch ihren Bildeinsatz. So sind die Seiten 1 bis 3 in Pflichtenheft 1, in Pflichtenheft 2 und in Pflichtenheft 3 stark durch ikonisch-bildliche Repräsentationen geprägt. Aufgrund ihrer Position am Anfang des Sprache-Bild-Textes und ihrer einführenden Funktion bzw. ihrer Überblicksfunktion für den Gesamttext (s. Kapitel 5.2.3) werden sie als Bilderabstract bezeichnet. Auch im Folgenden werden vorerst Seite 1 von PH 1 (s. Abbildung 5-9), PH 2 (s. Abbildung 5-11) und PH 3 analysiert.

In den Fotos mit der Beschriftung $A b b .1$ und $A b b .2$ auf Seite 1 von Pflichtenheft 1 (s. Abbildung 5-9) fallen Grau und Schwarz als ,Graustufen' und zum Teil die ,Farbe' Rot (speziell das rote Dreieck) in Flächen aller Abbildungen auf, die die Fahrzeugkarosserie darstellen. Rot und zum Teil Grau dominieren in den Abbildungen (Beschriftung Abb. 4 und Abb. 5), welche Sitze als Teil der Innenansicht repräsentieren. Die Graustufenvarianten nehmen in den beiden oberen Abbildungen den größten Teil der Bildfläche ein. Weil die Kombination der beiden Graustufen in beiden Abbildungen einheitlich ist und die beiden Abbildungen unmittelbar untereinander angeordnet sind (,Gesetz der Nähe'), werden diese als 
Gruppe wahrnehmbar. Entsprechend werden auch die beiden unteren Abbildungen durch die Dominanz der roten Farbe und durch ihre unmittelbare Positionierung untereinander als Gruppe wahrnehmbar.

Augenfällig wirkt in den oberen Abbildungen (Beschriftungen Abb. 1 und Abb. 2) der Kontrast zwischen den großen grau-schwarzen Flächen und dem kleinen roten Dreieck auf der Fahrzeugkarosserie. Dagegen fällt in den beiden unteren Abbildungen (Beschriftungen $A b b .4$ und $A b b .5$ ) auf, dass die rote Färbung der Sitzflächen die Graustufen des Bodens und der Decke im Fahrzeuginneren dominiert. Die symmetrische, gespiegelte Positionierung der beiden Bildergruppen auf zwei gegenüberliegenden Seitenhälften unterstützt diesen Kontrast. Die technische Zeichnung (ebd., Beschriftung Abb. 3) bringt diesen Kontrast weiter zur Geltung, weil der Graukontrast wiederum im Gegensatz zu den beiden Farbflächen steht und zudem zwischen den beiden Farbfotos positioniert ist.

Alle Abbildungen auf dieser ersten Seite von PH 1 (s. Abbildung 5-9) sind Fotos, also ikonisch-materielle Bilder von einem Fahrzeug. D. h., sie verweisen als Repräsentamen auf ein Fahrzeug als real existierenden physikalischen Gegenstand, also auf das zugeordnete Denotat. Dagegen verweisen CAD-Darstellungen wie im obersten Bild von PH 2 (s. Abbildung 5-11, Beschriftung Abb. 1) als Repräsentamen auf ein imaginäres Fahrzeug, also auf einen Interpretanten.

Die in der Analyse von PH 1 herausgearbeitete Verwendung von Farbe und deren symmetrische Verteilung auf Flächen auf den Blatt erfüllen eine ästhetische Funktion. Diese Funktion lässt sich nicht als Formularstruktur oder Hierarchisierung von Informationseinheiten wie in den oben analysierten Beispielen erklären. Daher unterstützen die Gestaltungsmittel des Bilderabstracts eine ästhetische Funktion des Pflichtenhefts (s. Kapitel 5.2.2).

Folgende Eigenschaften des Bilderabstracts von PH 1 (s. Abbildung 5-9) repräsentieren weitere Funktionen: Die Sitze auf dem Foto mit der Beschriftung Abb. 4 sind dem Betrachterstandpunkt im oberen Bild zugewandt, während sie im unteren Bild abgewandt sind. Die Zugewandtheit der Sitze ermöglicht es, sich den Nutzer des Fahrzeugs vorzustellen. D. h., die oben aus VDI 2519 (2001) zitierte Nutzerperspektive, die für Pflichtenhefte typisch ist, wird durch die Position der Sitze ausgedrückt. Auch die sprachlichen Mittel repräsentieren diese Perspektive, 
obwohl sie nicht durch Nominalgruppen wie Der Fahrgast sitzt etc., sondern durch Präpositionalgruppen etc. ausgedrückt wird (s. Kapitel 5.2.3).

,Similarität' besteht zwischen den ,Formen` des Fahrzeugs im oberen Längsschnitt der technischen Zeichnung (s. Abbildung 5-9; $A b b .3$ ) und des vollständigen Fahrzeugs in seitlicher Außenansicht ( $A b b$. 1). Sie verweisen als Interpretanten auf dasselbe Denotat. Dieser gemeinsame Verweis eröffnet den Vorstellungsraum für ein imaginäres Fahrzeug, dessen Eigenschaften durch die einzelnen Kapitel des Pflichtenhefts vorgestellt werden. ${ }^{186}$

Pflichtenheft 1 ist im Gegensatz zu Lastenheftvordruck 1 durch ,Farben“, ,Formen' und ,Positionierungen' bestimmt. Zu prüfen bleibt, inwieweit aus der Analyse von Pflichtenheft 2 ähnliche oder identische Ergebnisse hervorgehen.

Auch im Bilderabstract von Pflichtenheft 2 (s. Abbildung 5-11) sind die seitliche Fahrzeugaußenansicht ( $\mathrm{PH} 2 ; A b b .1)$ und eine darunter angeordnete SeitenFront-Ansicht eines Zuges (ebd.; Abb. 2) enthalten. Beim oberen Bild handelt es sich um eine CAD-Darstellung, während das in der Mitte angeordnete Bild ein Foto ist. Entsprechend der Interpretation des Bilderabstracts von PH 1 (s. o.) verweisen die verschiedenen Abbildungsarten als Repräsentamen zum einen auf einen imaginären Interpretanten (CAD-Darstellung) und zum anderen auf ein realen physikalischen Gegenstand als Denotat (Foto). Insbesondere die CAD-Darstellung ist durch ästhetische Ausdrucksmittel geprägt und erfüllt eine ästhetische Funktion, wie eine ausführliche Analyse zeigt (s. Kapitel 5.2.2, insbesondere zu Abbildung 5-16). Daher greift auch für diese Farbgestaltung in Pflichtenheft 2 keine der Interpretationen wie Repräsentation der Formularform etc., sodass der Farbgestaltung und weiteren Darstellungsmitteln eine ästhetische Funktion zugeschrieben wird (s. obige Interpretation von PH 1)

Die Panels aus Lastenheftvordruck 2 bleiben im Bilderabstract von Pflichtenheft 2 als schwarze Linien des Rahmens erhalten (s. Abbildung 5-11). In den ersten beiden Panels von Seite 1 aus Pflichtenheft 2 sind neben den Bildern jeweils die Nominalgruppen Beispielgrafik - ... als Schriftelemente enthalten, die wieder

186 Der Grundriss verweist dagegen als Quasi-Inhaltsverzeichnis durch eingezeichnete Elemente wie PRM-Sitze präziser auf die Schriftmodule, die sich im Pflichtenheft anschließen (s. Kapitel 5.2.3). 
durch einen kleineren Rahmen innerhalb des Panels ( $A b b$. 2) bzw. über das Panel hinausragend ( $A b b .1)$ positioniert sind. Diese kleineren Rahmen nutzen dabei eine andere Graustufe als die größeren Rahmen, von denen sie umgeben sind: Letztere stammen aus Lastenheftvordruck 2.

Durch den ,Graukontrast ' wird deutlich, welche Rahmen aus dem Lastenheftvordruck stammen und welche der Bieter im Pflichtenheft hinzufügt. Durch die ,Positionierung' der Schriftelemente und des Bildes innerhalb eines Panels und durch das ,Gesetz der Nähe‘ werden beide Elemente als Einheit erkennbar.

Das obige Analyseergebnis zu Lastenheftvordruck 1, die drei Panels aufgrund ihrer gleichen Größe und Form als Einheit (,Similarität‘) wahrzunehmen, kann wegen der identischen Gestaltung auf Lastenheftvordruck 2 übertragen werden. Diese Gestaltung von Formularvordruck 2 bleibt im ausgefüllten Exemplar, also Pflichtenheft 2, erhalten. Daher werden alle drei Panels auf Seite 1 von PH 2 (s. Abbildung 5-11) als Einheit wahrnehmbar. Dies gilt, auch wenn die ersten beiden Panels mit den Beschriftungen Abb. 1, Abb. 2 ikonisch-materielle Bilder und Schriftelemente enthalten, das Panel mit der Beschriftung dagegen aber nur Schriftelemente. Die augenfällige Farbgestaltung der Schriftelemente des Bieters in Blau gegenüber dem, Graukontrast ' der Elemente vom Auftraggeber behandelt ebenfalls obige Analyse zu Formularköpfen (sie bezieht sich bereits auf PH 2). Übertragbar ist auch das obige Ergebnis zum Abgleich, wie Bildpanels aus dem Lastenheftvordruck 1 in das zugehörigen Pflichtenheft 1 übernommen werden. Darüber hinaus gelten die weiteren Analyseergebnisse zum Formularkopf von Pflichtenheft 1 auch für Pflichtenheft 2. Anders als auf Seite 1 des Bilderabstracts von PH 1 ist im Bilderabstract von PH 2 keine technische Zeichnung enthalten. Stattdessen verweist die Nominalgruppe siehe Anhang la auf den Anhang. Dadurch fehlt in PH 2 der unmittelbar auf einer Seite sichtbare Kontrast zwischen Fotos bzw. CAD-Darstellungen gegenüber einer technischen Zeichnung, wie er in PH 1 enthalten ist. Entsprechend kann keine technische Zeichnung auf Seite 1 von PH 2 positioniert sein. Seite 1 von PH 2 kann also nicht wie in PH 1 aufgeteilt sein. 


\begin{tabular}{|c|c|}
\hline Fahrzeugtyp (bei Waggonzügen je Waggontyp auszufüllen) & Fahrzeug $X Y$ \\
\hline (bei Triebwagenzügen Anzahl der Segmente) & 5-teilig \\
\hline Anzahl der hiervon eingesetzten Fahrzeuge: & $\mathrm{XY}$ \\
\hline
\end{tabular}

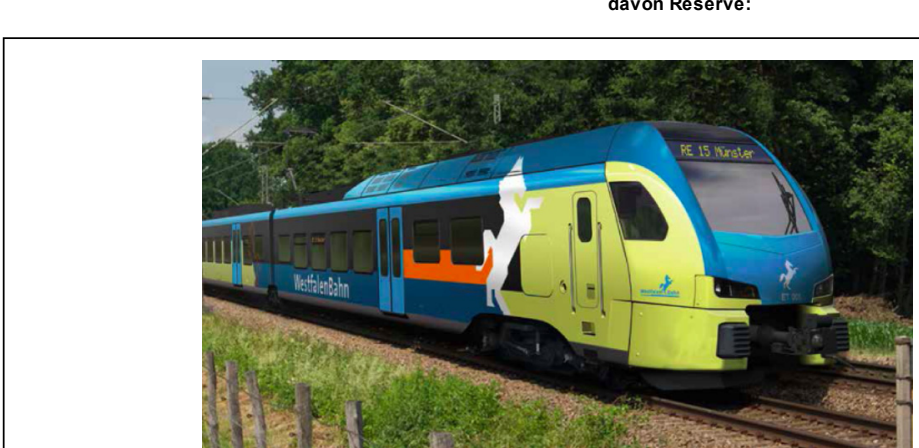

$\mathrm{YZ}$

Abb. 1: Fahrzeug (Seitenansicht) im Design des Bieters

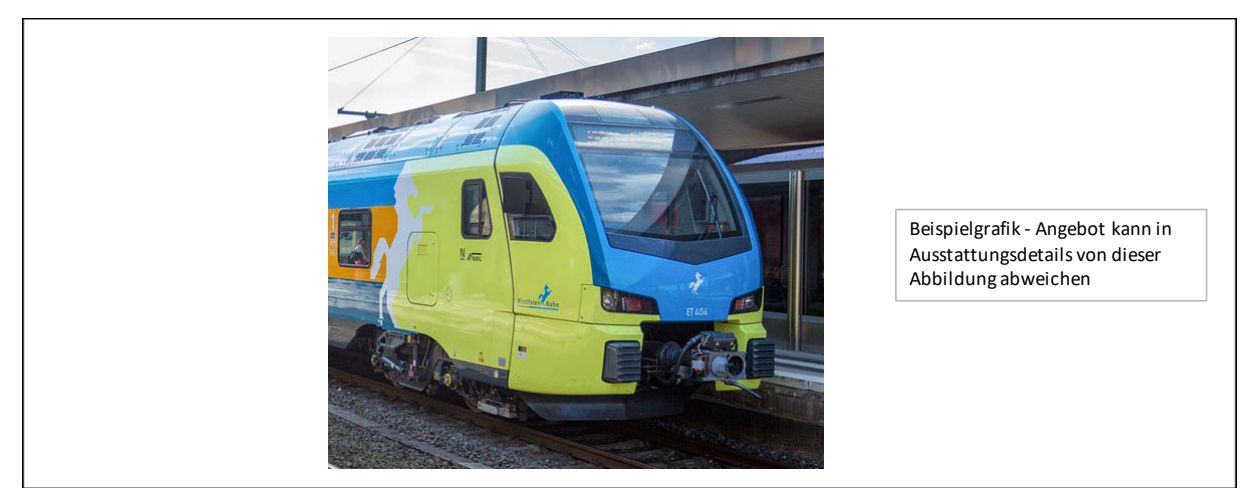

Abb. 2: Fahrzeug (Frontansicht) im Design des Bieters

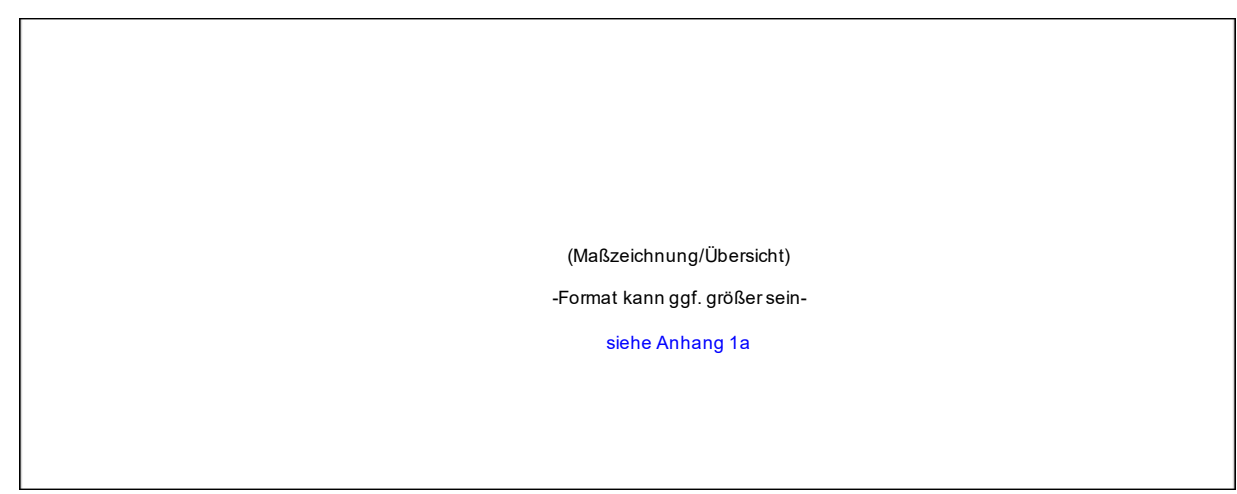

Abb. 3: Fahrzeug (mit Innenraum), Aufteilung und Maße

Abbildung 5-11: Anonymisiertes Pflichtenheft 2 in der ausgedruckten Ansicht (verfremdet mithilfe von STADLER, o. J.c, S. 1; STADLER 2019, URL). 
Relevant für das Textdesign sind in Pflichtenheft 1, 2 und $3^{187}$ erstens die ,Positionierung' a) von zeichenmodal komplexen Panels, die in ,Form' und ,Größe identisch sind, in der Mitte der Textseite, b) des Formularkopfs sowie c) der schriftbildlichen Elemente in Kopf- und Fußzeile. Dies gilt zweitens auch für den Informationswert, der durch die ,Positionierung' von zeichenmodal komplexen Einheiten in der Mitte der Textseite gegenüber zeichenmodal weniger komplexen Modulen wie dem Formularkopf sowie der Kopf- und Fußzeile in der Peripherie der Textseite erzeugt wird. Drittens konstituieren diese Einheiten das ,Gesetz der Nähe ' und die ,Positionierung' in durch Linien begrenzte Panels, sodass ikonischmaterielle Bilder und Schriftelemente innerhalb eines Panels sowie deren darunter angeordnete Beschriftung als Einheit wahrnehmbar werden. Die Gestaltung der ,Farbflächen' in ikonisch-materiellen Bildern erfüllt eine ästhetische Funktion. Die graue Gestaltung und linksseitige Positionierung von Schriftelementen des Auftraggebers gegenüber der blauen Färbung und rechtsseitigen Positionierung von Schriftelementen des Bieters im Formularkopf repräsentieren auch in Pflichtenheft 2 die Frage-Antwort-Chronologie der Formularkommunikation. Lediglich die genannte Farbvariation, nicht die Positionierung innerhalb der Bildpanels, repräsentiert diese Frage-Antwort-Struktur in Letzteren. Die Zusammenhänge zwischen Beschriftung und Bildern bzw. zwischen Schriftelementen und einem Bild innerhalb eines Panels werden als logisch-semantische Sprache-Bild-Relationen diskutiert (s. Kapitel 5.2.4).

Pflichtenheft 1, 2 und 3 enthalten nach dem Bilderabstract Panels mit schriftsprachlichen Elementen unterschiedlicher ,Größe', ,(Graustufen-)Kontraste ' und ,Positionierung'. Diese Panels werden im Folgenden als Schriftmodule bezeichnet, während Panels mit ikonisch-materiellen Bildern, abbildenden oder rekonfigurierenden Diagrammen (konkret Fotos, CAD-Darstellungen, Diagramme und technische Zeichnungen) Bildmodule genannt werden. Nur auf wenigen Textseiten der Pflichtenhefte sind sowohl Bild- als auch Schriftmodule angeordnet, sodass die weiteren Seiten der Pflichtenhefte fast ausschließlich durch Schriftmodule geprägt sind. Im Folgenden werden das Schriftmodul Toilettenräume (s. Abbildung 5-12) aus Lastenheftvordruck 1 und das dazugehörige ausgefüllte Modul

187 Auch wenn PH 3 nicht ausführlich analysiert wird, basieren die folgenden Aussagen ebenfalls auf seiner Analyse, die der Prüfungsausschuss am PH 3 nachvollzog. 
Toilettenräume (s. Abbildung 5-13) aus Pflichtenheft 1 analysiert, deren Textdesign für die übrigen Schriftmodule exemplarisch ist. Denn diese Module nutzen sämtliche Gestaltungsmöglichkeiten wie Einrückungen, Schriftgrößen, Fettdruck, Graustufenkontrast etc.

Bei der Untersuchung des Schriftmoduls können die Analysekriterien ,Textdesign' und ,Themenstruktur' nicht getrennt werden, weil das Zusammenspiel von Semantik und Grammatik dieser schriftsprachlichen Elemente erklärt, warum sie auf eine bestimmte Art und Weise gestaltet oder an einer bestimmten Stelle positioniert sind. Dieser Schluss folgt auch aus dem Konzept der Schwundgrammatik, demzufolge Design und Layout schriftsprachliche Grammatik ersetzen können. ${ }^{188}$ Aufgrund identischer Größe, Proportion und vertikal identischer Anordnung werden die Tabellenfächer des Schriftmoduls aus Lastenheftvordruck 1 (s. Abbildung 5-12) und aus Pflichtenheft 1 (s. Abbildung 5-13) in drei Spalten aufgeteilt.

\begin{tabular}{|c|c|c|}
\hline Toilettenräume & & \\
\hline Merkmal & Kriterien & Angabe Bieter \\
\hline Anzahl Toiletten & Anzahl & \\
\hline davon behindertengerecht & Anzahl & \\
\hline $\begin{array}{l}\text { davon vom Einstieg mit Rampe/Lift u. allen Rollstuhlplätzen } \\
\text { barrierefrei erreichbare behindertengerechte Toilette }\end{array}$ & Anzahl & \\
\hline Bei 2. Toilette: 2. Toilette grenzt an 1. Toilette & ja/nein & \\
\hline Notrufeinrichtung mit Wechselsprecheinrichtung & ja/nein & \\
\hline Notruftaster vom WC aus sowie vom Boden liegend erreichbar & ja/nein & \\
\hline Türverriegelung nur von innen möglich & ja/nein & \\
\hline Zugangstüren mit Rückfallebene bei Ausfall der Türschließautomatik & ja/nein & \\
\hline $\begin{array}{l}\text { defekter Türschließmechanismus führt nicht zur automatischen Sperrung } \\
\text { der Toilette }\end{array}$ & ja/nein & \\
\hline Anzeige zum Fahrgastraum: WC defekt & Anzahl Anzeigen/wC & \\
\hline $\begin{array}{l}\text { Geschlossenes Toilettensystem (mit witterungs-/temperaturunabhängiger } \\
\text { Ver-/Entsorgung) }\end{array}$ & ja/nein biolog/chem. System & \\
\hline Funktionale Toilettenausstattung & Angabe & \\
\hline per Fuß bedienbarer Toilettendeckel & ja/nein & \\
\hline automatische Deckelreinigung & ja/nein & \\
\hline klappbarer Wickeltisch in behintergerechter Toilette & ja/nein & \\
\hline Art der Handtrocknung & Papier/Gebläse & \\
\hline Rauchmelder & ja/nein & \\
\hline
\end{tabular}

\section{Abbildung 5-12: Lastenheftvordruck, Schriftmodul Toilettenräume (LHV 1).}

Während alle Tabellenfächer der linken Spalte Schriftelemente beinhalten, die linksbündig ausgerichtet sind, positioniert die mittlere Spalte alle Schriftelemente mittig. Dagegen prägen die Tabellenfächer der rechten Spalte ausschließlich

188 Die Analysekapitel Funktions- und Themenstruktur berücksichtigen ebenfalls Textdesign. 
weiße Flächen; sie enthalten also keine Schriftelemente. Das zugehörige Schriftmodul des Pflichtenhefts (s. Abbildung 5-13) unterscheidet sich lediglich dadurch, dass in den Fächern der rechten Spalte Schrift-elemente positioniert sind, was darauf hinweist, dass das Pflichtenheft die vorgegebenen Felder des Lastenheftvordrucks ausfüllt.

\begin{tabular}{|c|c|c|}
\hline Toilettenräume & & \\
\hline Merkmal & Kriterien & Angabe Bieter \\
\hline Anzahl Toiletten & Anzahl & 1 \\
\hline davon behindertengerecht & Anzahl & 1 Behindertenfreundliche \\
\hline $\begin{array}{l}\text { davon vom Einstieg mit Rampe/Lift u. allen Rollstuhlplätzen } \\
\text { barrierefrei erreichbare behindertengerechte Toilette }\end{array}$ & Anzahl & 1 Behindertenfreundliche \\
\hline Bei 2. Toilette: 2. Toilette grenzt an 1. Toilette & ja/nein & entfällt \\
\hline Notrufeinrichtung mit Wechselsprecheinrichtung & ja/nein & ja \\
\hline Notruftaster vom WC aus sowie vom Boden liegend erreichbar & ja/nein & ja \\
\hline Türverriegelung nur von innen möglich & ja/nein & $\begin{array}{l}\text { nein, im Notfall mit Vierkant von } \\
\text { außen }\end{array}$ \\
\hline Zugangstüren mit Rückfallebene bei Ausfall der Türschließautomatik & ja/nein & keine Türschließautomatik \\
\hline $\begin{array}{l}\text { defekter Türschließmechanismus führt nicht zur automatischen Sperrung } \\
\text { der Toilette }\end{array}$ & ja/nein & ja \\
\hline Anzeige zum Fahrgastraum: WC defekt & Anzahl AnzeigenwC & $1 / \mathrm{WC}$ \\
\hline $\begin{array}{l}\text { Geschlossenes Toilettensystem (mit witterungs-/temperaturunabhängiger } \\
\text { Ver-/Entsorgung) }\end{array}$ & ja/nein biolog./chem. System & ja \\
\hline Funktionale Toilettenausstattung & Angabe & $\begin{array}{l}\text { WC mit Handwaschbecken, } \\
\text { Spiegel, Seifenspender, } \\
\text { Papierhandtuchspender, } \\
\text { Toilettenpapierhaltung und einem } \\
\text { Abfallbehälter } \\
\end{array}$ \\
\hline per Fuß bedienbarer Toilettendeckel & ja/nein & nein \\
\hline automatische Deckelreinigung & ja/nein & nein \\
\hline klappbarer Wickeltisch in behintergerechter Toilette & ja/nein & ja \\
\hline Art der Handtrocknung & Papier/Geblãse & Papierhanftücher \\
\hline Rauchmelder & ja/nein & ja \\
\hline
\end{tabular}

\section{Abbildung 5-13: Pflichtenheft, Schriftmodul Toilettenräume (PH 1).}

Das Schriftmodul des Pflichtenhefts (s. Abbildung 5-13) ordnet die Frage des Auftraggebers in der linken Spalte, die vom Auftraggeber vorgegebenen Antwortmöglichkeit in der mittleren Spalte und die Antworten des Bieters in der rechten Spalte an. D. h., die Abfolge der Wortbeiträge des verschriftlichten Formulardialogs repräsentiert die visuelle Anordnung der Schriftelemente entsprechend der konventionalisierten Von-links-nach-rechts-Rezeptionsrichtung (in Grün). Der Einsatz von Bildern (in Gelb) durchbricht diese Dialogrichtung (s. Abbildung 5-14): 


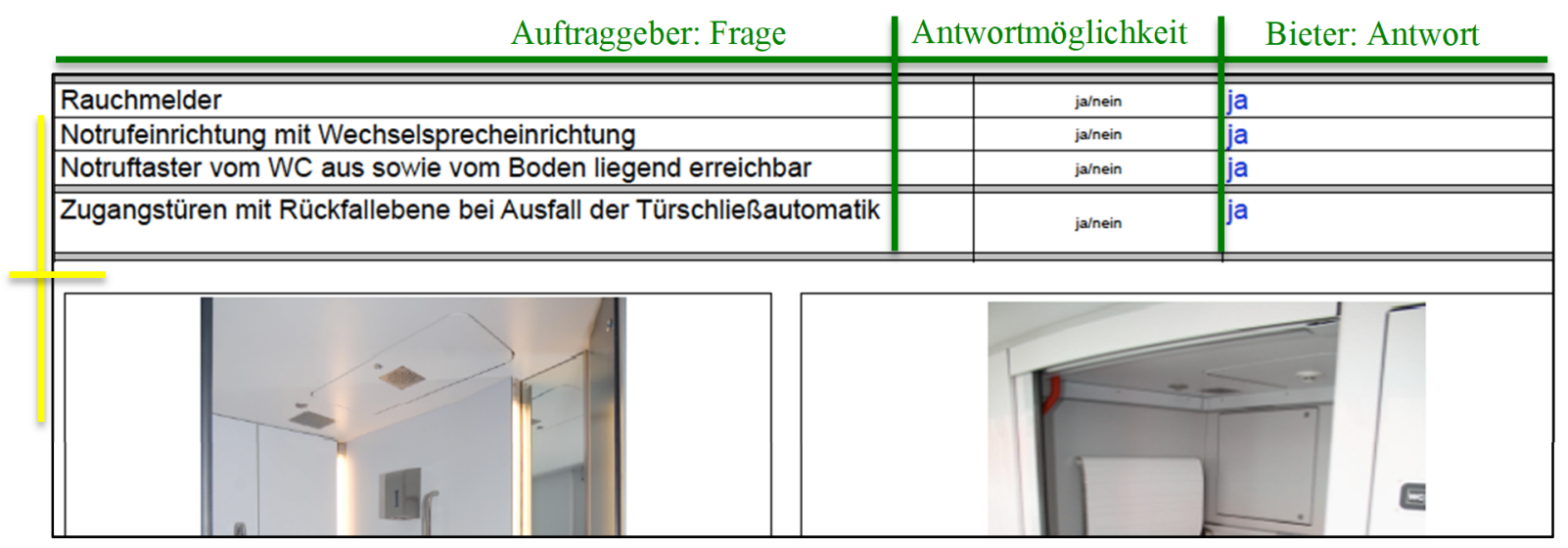

\begin{abstract}
Abbildung 5-14: Vertikale Bildmodul-Gliederung (in Gelb), horizontale FormularGliederung mit Frage-Antwortmöglichkeit-Antwort-Struktur (in Grün) im Themenmodul Toilettenräume (verfremdetes PH 2).
\end{abstract}

Diese 3-spaltige Anordnung wird unter funktionalen Aspekten als horizontal angeordneter Teil der Funktionsstruktur (s. Kapitel 5.2.2) analysiert. Auch in der ausgefüllten rechten Spalte des Pflichtenhefts fällt auf, dass die Schriftelemente mittig ausgerichtet sind, wenn die Antwortmöglichkeiten aus der mittleren Spalte wiederholt werden, die ebenfalls mittig ausgerichtet sind. Wenn die mittlere Spalte keine konkreten Antworten vorgibt und beispielsweise durch das Nomen Angabe darauf hinweist, dass der Bieter einen Freitext eingeben muss, sind die Schriftelemente der Bieter-Antworten linksbündig ausgerichtet (beispielsweise WC mit Handwaschbecken, Spiegel, ...; s. Abbildung 5-13). In der rechten Spalte sind auch die Antworten linksbündig ausgerichtet, die von den Antwortvorgaben abweichen, beispielsweise keine Türschließautomatik zu den Antwortmöglichkeiten ja/nein (ebd.). Die Ausrichtung der Schriftelemente in der rechten Antwort-Spalte weist demnach darauf hin, ob der Bieter als Antwort ein vorgegebenes Element des Lastenheftvordrucks übernimmt oder Schriftelemente einfügt, die er frei formuliert.

Auffällig ist an der ,Positionierung' einiger Elemente der linken Spalte, die untereinander angeordnet werden, dass die unteren Elemente durch einen einheitlichen Tabulatoren-Abstand vom linken Seitenrand eingerückt werden - beispielsweise zum darüber angeordneten Element Anzahl Toiletten das Schriftelement davon behindertengerecht in der ersten Zeile darunter und im gleichen Abstand vom Seitenrand das Element davon vom Einstieg ... in der zweiten Zeile (s. Abbildung 5-13). Alle eingerückten Elemente werden durch ihre ,Positionierung' als Gruppe wahrnehmbar. 
In den Pflichtenheften existieren auch Schriftmodule, in denen die vertikal untereinander angeordneten Elemente durch zwei Tabulatoren-Stopps mit weiterem Abstand vom linken Seitenrand horizontal eingerückt werden, wie beispielsweise in Abbildung 5-15. Nominalphrasen, die innerhalb des Formulars eingerückt sind, werden den Nominalphrasen in der darüber befindlichen Zeile subordiniert. Daher verwenden die Schriftmodule auch kaum Subjunktionen bzw. subordinierende Schriftelemente, wie das Beispiel in Abbildung 5-15 zeigt. ${ }^{189}$ Dementsprechend substituieren Positionierungen als strukturell-visuelle Gestaltungsmöglichkeiten in der Formularform vollständige Satzstrukturen.

\begin{tabular}{|l|}
\hline Sitzreihenabstand \\
\hline Merkmal \\
\hline 1. Klasse \\
\hline Vis-à-vis-Bestuhlung \\
\hline Reihenbestuhlung \\
\hline Fußraum jeweils unter den Vordersitzen nutzbar \\
\hline
\end{tabular}

\section{Abbildung 5-15: Beispiel für zwei Subordinationsebenen (PH 1).}

D. h., die mit zwei Tabulatoren-Abständen eingerückte Wortgruppe Fußraum jeweils unter den Vordersitzen nutzbar (s. Abbildung 5-15) ist dem darüber positionierten und nur mit einem Tabulator-Abstand eingerückten Nomen Reihenbestuhlung subordiniert. Letzteres ist wiederum dem Nomen 1. Klasse untergeordnet. Gleichzeitig werden die Nomen Vis-á-vis-Bestuhlung und Reihenbestuhlung (ebd.) durch die einheitliche Einrückung (gegenüber den genannten subordinierten Elementen) zu koordinierten Elementen.

Darüber hinaus sind der ,Graustufenkontrast' der Tabellenfächer in der Leitzeile und die ,Form“ Fettdruck der schriftbildlichen Elemente in der Leitzeile im Schriftmodul (s. Abbildung 5-13) salient. So betonen die graue Unterlegung der Tabellenfächer und der Fettdruck in der Leitzeile die semantische Überordnung der enthaltenen Nomen gegenüber den Wortgruppen in den darunter angeordneten Tabellenfächern. Im Gegensatz zu den untersuchten Exemplaren der Textsorte Optimierungsvorschlag wirkt die Überschrift aber nicht durch eine Variation der

189 Eine Ausnahme von dieser Regel stellt das Adverb davon aus der eingerückten AdjektivGruppe davon behindertengerecht im Beispiel Abbildung 5-13 dar. 
Schriftgröße auffällig, sondern ist einheitlich in Schriftgröße 12 pt gehalten. Dies lässt sich damit begründen, dass das Schriftmodulbeispiel Toilettenräume ein Modul der Themenstruktur bildet, das als Meronym ${ }^{190}$ unter das Holonym Innenausstattung geordnet ist; letzteres ist eine übergeordnete Überschrift (PH 1). Auch die Textdesign-Kriterien ,Größe' und ,Form` drücken diese Subsumption aus, indem die Überschrift Innenausstattung in Fettdruck und in der Schriftgröße 16 pt gestaltet ist, während die Unterüberschrift des untergeordneten Moduls Toilettenräume in Fettdruck und 12 pt gehalten ist. Die einheitliche Gestaltung dieser Unterüberschriften in Fettdruck und 12 pt drückt aus, dass die weiteren Unterüberschriften zu den Schriftmodulen Sitze, Sitzreihenabstand, Gepäckunterbringung etc. (ebd.) aus semantischer Sicht wie das Schriftmodul Toilettenräume Meronyme zum Holonym Innenausstattung bilden.

Die Gestaltung der Überschriften macht diese Holonym-Meronym-Beziehung als (semantisch) einheitliche Struktur sichtbar: Die unterschiedliche Schriftgröße von Überschrift und Unterüberschriften repräsentiert dieses Holonym-Meronym-Verhältnis. Der Graustufenkontrast, der eingesetzt wird, um alle Überschriftenebenen zu hinterlegen, und der Fettdruck heben die Überschriftenebenen visuell von den übrigen Schriftelementen ab, die in Schriftmodulen enthalten sind.

Auffällig ist auch die Graukontrastierung zwischen einigen vertikalen Doppellinien, die Tabellenfächer mit Schriftelementen voneinander abgrenzen und so Teilschriftmodule erzeugen (s. Abbildung 5-13). Letztere ersetzen ein nicht vorhandenes schriftsprachliches Element, das ein Homonym zu den darunter angeordneten Meronymen bilden würde. Beispielsweise ließen sich die Nominalphrase (ebd.) Notrufeinrichtung (mit Wechselsprecheinrichtung) und Notruftaster (vom WC aus ...), die in zwei aufeinanderfolgenden Zeilen jeweils oberhalb und unterhalb durch eine graukontrastierte Linie von den übrigen Zeilen abgegrenzt werden, als Meronyme unter das nicht genannte Holonym Notruf fassen. Auch die beiden graukontrastierten Linien über und unter den drei Zeilen mit den

190 Meronymie wird als ,[1] exikal. Teil-von-Beziehung“ (REHBOcK, ${ }^{5}$ 2016, S. 426) definiert. Diese Teil-Ganzes-Relation unterscheidet sich von Hyponymie (ebd.) dadurch, dass es „eher ein Reflex ausserspr. Gegebenheiten als eine genuin semant. Relation“ (ebd., S. 427) darstellt. Das Holonym als übergeordnetes Lexem setzt sich aus den Meronymen als Elementen zusammen (ebd.). 
Nominalphrasen Türverriegelung ... (1. Zeile), ... Türschließautomatik (2. Zeile) und Türschließmechanismus ... (3. Zeile) bilden ein Teilmodul. Sie ließen sich ebenfalls als Meronyme unter das ungenannte Holonym Türverschluss subsumieren. D. h., die themenstrukturelle Holonym-Meronym-Beziehung wird visuell durch die Graukontrastierung repräsentiert. Diese nicht aufgeführten Holonyme (z. B. Türverschluss und Notruf) stehen zu den genannten Überschriften der jeweiligen Teilmodule wiederum als Meronyme im Verhältnis. Beispielsweise sind die ungenannten Holonyme Türverschluss, Notruf etc. Meronyme, wenn sie ins Verhältnis zur Überschrift Toilettenräume (s. Abbildung 5-13) als Holonym gesetzt werden.

Somit ergibt sich eine Themenhierarchie, die innerhalb der Schriftmodule durch die visuellen Variablen ,Positionierung' (Einrückungen, identische Ausrichtung von Schriftelementen an einer Vertikalen), ,Form‘ (Schriftelemente in Fettdruck), ,Graukontrast‘ (Unterlegung, Doppellinie) sowie zwischen den Schriftmodulen und der Überschrift Innenausstattung durch die visuelle Variable ,Größe“ (Schriftgröße) gestaltet sind. Diese visuelle Struktur unterstützt Holonym-Meronym-Relationen, die in Schriftmodulen und zwischen Schriftmodulen und Kapitelüberschriften bestehen (z. B. die Modulüberschriften Toilettenräume und Gepäckunterbringung als Meronyme zur Kapitelüberschrift Innenausstattung als Holonym). Darüber hinaus wird Pflichtenheft 2, in dem das Blau der Schriftelemente in der rechten (Bieter-)Spalte von den übrigen Schriftelementen der Schriftmodule abhebt, durch die Variable ,Farbvariation` gekennzeichnet.

Über die beschriebenen Schriftmodule und das Bilderabstract hinausgehend sticht im Textdesign der Pflichtenhefte als weiteres Element das Zugkraft-Geschwindigkeits-Diagramm (PH 2; PH 3) hervor. Es wird hier analysiert, weil es zum einen als eigenes Modul zu einem Teil der Funktions- und Themenstruktur wird und zum anderen bei den Textüberarbeitungsprozessen ausführlich diskutiert wird. Als Interpretant verweist das Zugkraft-Geschwindigkeits-Diagramm auf die gemessenen physikalischen Größen als sein Denotat. Diese Größen repräsentiert es durch die ,Farbvariation“ der Linien und deren Anordnung im x-y-Diagramm, also der Positionierung in der ,Fläche‘. Die blaue Farbe der oberen Linie repräsentiert die Zugkraft in Kilo-Newton $(\mathrm{kN})$, während die rote Farbe der unteren Linie den Fahrtwiderstand ebenfalls in $\mathrm{kN}$ darstellt. Das Diagramm stellt 
gleichzeitig ein Koordinatensystem dar, woraus sich ergibt, dass die Positionierung eines Punktes auf dieser Linie den gemessenen Fahrtwiderstand (y-Achse) und die Geschwindigkeit als Zustand (x-Achse) zu einem bestimmten Zeitpunkt der Messung relationiert. Der Vorteil des Diagramms besteht darin, markante Werte, sogenannte Ausreißer, derart zu visualisieren, dass sie auf den ersten Blick erkennbar werden. Dagegen sind solche Ausreißer in einer Tabelle, wie sie beispielsweise PH 1 anstelle eines Diagramms einsetzt, nicht auf den ersten Blick erkennbar. ${ }^{191}$ Inwieweit Tabellen oder Diagramme im Pflichtenheft zu bevorzugen sind, diskutieren die Textüberarbeitenden (s. Kapitel 6.1).

Diesem Diskussionspunkt ging ich durch die Befragung der Fahrzeughersteller nach, die diese Diagramme erstellten. Ich fragte, ob sich eher eine Tabelle oder ein Zugkraft-Geschwindigkeits-Diagramm (z-V-Diagramm) eignet, um die Betriebsplanung mit einem bestimmten Fahrzeug zu überprüfen. FAHRZEUGHERSTELLER 2 (2014, S. 4) antwortet, dass beide Darstellungsformen ungeeignet seien, und weist auf den Netzbetreiber DB Netz AG hin. Denn inwieweit

\begin{abstract}
„ein Fahrzeug auf dem ausgeschrieben [sic] Netz einsetzbar ist und die Fahrplanvorgaben einhalten kann, wird i.d.R. durch DB Netz ermittelt. Dazu wird speziell für das hier angebotene Fahrzeug ein zugeschnittenes fahrdynamisches Datenblatt erstellt. Das Ausfüllen dieses Datenblattes geschieht nach dem Anforderungsprofil der DB Netz AG. Neben den tabellarischen Angaben der Zugkraft zur jeweiligen Geschwindigkeit, sind dort weitere Werte wie z. B. Fahrzenggewicht, -widerstand, Leistung und Höchstgeschwindigkeit einzutragen. Aus einem Zusammen-spiel all dieser Daten kann eine netzbezogene Fahrdynamik ermittelt werden. Die Darstellung nur eines ZV-Diagramms in der FCL trägt somit recht wenig zur Ermittlung der Fahrbarkeit dar.“ (FAHRZEUGHERSTELLER 2, 2014, S. 4; Kursive im Original)
\end{abstract}

D. h., der Bieter muss das Formular „Anforderungsprofil für Fahrdynamische Triebfahrzeugdaten“ (2012) des Infrastrukturbetreibers DB Netz AG bei diesem ausgefüllt einreichen, um das Testat zu erhalten, das mit dem Angebot im Ausschreibungsverfahren abzugeben ist (s. Tabelle 4-3). So entsteht der Eindruck, dass die Angaben in Pflichtenheft und Testat redundant und somit im Pflichtenheft weglassbar sind. Es ist aber notwendig, ein z-V-Diagramm bzw. eine Tabelle einzubinden, um die Qualität der Angaben zu prüfen, die dem Testat zugrunde

191 Diese Tabelle ist dem Formular „Anforderungsprofil für Fahrdynamische Triebfahrzeugdaten“ der DB Netz AG entnommen. Aus diesem Formular der DB Netz AG leitet sich die Forderung der Auftraggeber nach diesem Diagramm in den Lastenheftvordrucken (LHV 1) ab. 
liegen. Dies geht aus den Empfehlungen der BAG SPNV (22010, S. 14) hervor, auf der die Lastenhefte basieren: „Diesem Testat müssen sämtliche technischen und fahrdynamischen Daten des Fahrzeugs wie z. B. Zugkraft-/Geschwindigkeitsdiagramm nachweislich zugrunde liegen. "(ebd.; Kursive im Original) Die Frage, ob Tabellen oder Diagramme als Darstellungsmittel im Pflichtenheft eher geeignet sind, lässt sich demnach nicht auf der Grundlage ihrer Leistungsfähigkeit als Darstellungsmittel entscheiden. Für diese Entscheidung ist vielmehr die Frage relevant, ob eher der Einsatz eines Diagramms oder der einer Tabelle in den Pflichtenheften für diese Textsorte als konventionell gilt. Diese Aussagen der beiden Fahrzeughersteller weisen bereits auf eine Unterfunktionen der Textsorte Pflichtenheft hin.

\subsubsection{Funktionsstruktur}

Die Analyse der Funktionsstruktur orientiert sich am integrierten Analyseraster interfachlicher Sprache-Bild-Textsorten (s. Tabelle 3-1). Die Analyse des Textdesigns von Lasten- und Pflichtenheften rückt bereits die Formularstruktur des verschriftlichten Dialogs mit den Fragen und vorgegebenen Antwortmöglichkeiten des Auftraggebers im Lastenheftvordruck und den Antworten des Bieters im Pflichtenheft ins Zentrum. Diese Struktur weist bereits auf die Grundfunktionen der beiden Textsorten hin. Die Darstellung von SPNV-Ausschreibungsverfahren in Kapitel 4.2 wird dabei mehrfach als Kontext herangezogen, aus dem sich die Textsortenfunktion und Unterfunktionen ergeben. Die Analyse dieser Struktur bezieht sich an mehreren Stellen auf Textsortenbeispiele aus RoLfs (1993) 3-Ebenen-Klassifikation von Textsortenfunktionen. Die Beschreibung dieser Beispiele wird herangezogen, wenn sie sich eignet, um ebenfalls Lasten- und Pflichtenhefte in ihrer Grundfunktion zu bestimmen. Unter- und Nebenfunktionen der Funktionsstruktur, die einzelne Module der Textsortenexemplare repräsentieren, konstituieren diese Grundfunktion. RoLFs (1993) Beispiele zu Textsortenfunktionen, die sich auf die Grundfunktion beziehen, werden auch herangezogen, um diese Unter- und Nebenfunktionen von Funktionsmodulen der Lasten- und Pflichtenhefte zu analysieren.

Die Analyse der funktionalen Text-Text-Relationen im Ausschreibungsverfahren (s. Tabelle 4-3) bestimmt das Verhältnis zwischen Lasten- und Pflichtenheften als perspektivische Gegenstücke der Formularkommunikation: Die funktionale 
Relation Subsumption (SUB) gibt an, dass das Pflichtenheft die Lebensrealität der Kommunikanten unter die Kategorien des Formulars als Ziel gelenkter Kommunikation ordnet. Die funktionale Relation Lenkung (LENK) bezeichnet das Verhältnis, das es dem Auftraggeber ermöglicht, mit dem Lastenheftvordruck den Ausfüllprozess des Bieters zu lenken.

Im Anschluss an diese funktionale Relation des Textsortennetzes werden Lastenheftvordrucke in ihrer Grundfunktion als direktive Textsorte bestimmt. Lastenhefte können darüber hinaus anhand der Beschreibung folgender Textsorte in ihrer Grundfunktion präzisiert werden: Die Textsorte ,Ausschreibung ${ }^{\text {` }}$ - und weitere Textsorten, die dieser Klasse zugeordnet sind - zeichnet aus, dass „deren Ausführung nicht nur im Interesse des jeweiligen Textproduzenten liegt, sondern auch in dem des Adressaten" (Rolf, 1993, S. 250). Daher besteht ein komplementäres bzw. beiderseitiges Interesse an der Kommunikation (ebd.). Gleichzeitig seien Ausschreibungen und weitere Textsorten dieser Klasse nicht-bindende Aufforderungen, weil eine Rückmeldung durch den Adressaten nicht obligatorisch, sondern fakultativ ist (ebd., S. 251). Bezogen auf SPNV-Ausschreibungsverfahren ist es zwar korrekt, dass die Auftraggeber die ,Bekanntmachung' veröffentlichen und ein Exemplar der Textsorte ,Aufforderung zur Angebotsabgabe' an interessierte Bieter senden (s. Tabelle 4-3). Auf Exemplare dieser beiden Textsorten können Bieter reagieren, sie müssen es aber nicht. Hat sich ein Bieter verpflichtet, am Verfahren teilzunehmen, ist er dagegen verpflichtet, den Aufforderung des Auftraggebers nachzukommen, Antworten auf die Fragen im Lastenheftvordruck zu geben. Denn mit der Abgabe eines unvollständig ausgefüllten Pflichtenhefts schließt sich ein Bieter aus dem Verfahren aus (s. Kapitel 4.2.2). Zwar kann ein Bieter sich aus einem Verfahren zurückziehen. Die Bieter haben aber ein Interesse daran, die Ausschreibung zu gewinnen, weil sie sich beinahe ausschließlich aus den Einnahmen dieser Verfahren finanzieren. Erfolg im Verfahren zu haben, ist für einen Bieter nur möglich, wenn er sich den kommunikativen Regeln des Verfahrens unterwirft, die in den Bewerbungsbedingungen angegeben sind. Im Gegensatz zur Textsorte ,Aufforderung zur Angebotsabgabe“ ist das Antworten auf die Fragen, die der Lastenheftvordruck stellt, daher wesentlich bindender als die Zusage des Bieters, am Ausschreibungsverfahren teilzunehmen. Deswe- 
gen werden Lastenheftvordrucke in ihrer Grundfunktion als bindend-direktive Textsorte mit beiderseitigem Interesse klassifiziert. ${ }^{192}$

Die Antworten der Bieter stellen dagegen ein Angebot dar, weil sie sich mit ihren Antworten verpflichten, die Leistung entsprechend dem Pflichtenheft zu erbringen bzw. das Fahrzeug in der angegeben Ausstattung zu liefern. Verbindlich werden diese Angaben dadurch, dass der Bieter nach gewonnener Ausschreibung den Verkehrsvertrag unterschreibt. Die Pflichtenhefte werden nach Zuschlagerteilung Bestandteil dieses Vertrags (s. Kapitel 4.2.2). D. h., die Geltung dieser Verpflichtung mit dem Pflichtenheft ergibt sich aus dem Textsortennetz. Im Anschluss daran werden Pflichtenhefte in ihrer Grundfunktion als kommissive Textsorte charakterisiert.

Folgende Schilderung zur Textsorte ,Angebot' trifft auch auf Pflichtenhefte zu. Der Bietenden legt sich mit seinem verpflichtenden ,Angebot' ${ }^{\star}$ zwar fest, wobei sich die Qualität des Angebots erst entfaltet, wenn es angenommen wird (RoLF, 1993, S. 265). Dann sei der Anbieter auf sein Angebot festgelegt. Diese Eigenschaft gilt auch für Pflichtenhefte, wie die Ausführung oben aufzeigt: Die Zuschlagserteilung stellt im SPNV-Ausschreibungsverfahren die Annahme dar. D. h., der Bieter legt sich in der Kommunikationssituation in Abhängigkeit von der Annahme in seinem Angebot fest. Diese Verpflichtung bestehe demnach bedingt einseitig - nach RoLF (ebd.) bestehe sie , bedingt unilateral'. Daher werden Pflichtenhefte in ihrer Grundfunktion als bedingt einseitig-kommissive Textsorten klassifiziert.

Die folgende Analyse der Funktionsstruktur von Lasten- und Pflichtenheften berücksichtigt, wie die verschiedenen Funktionsmodule die jeweilige Grundfunktion konstituieren.

Die Schriftelemente, die sich in der linken Spalte befinden, und ein Teil der Schriftelemente in den Bildpanels der Lastenheftvordrucke fordern den Bieter zu einer Handlung a

192 Diese Verortung im 3-Unterebenen-Funktionsmodell ermöglicht es, die Funktion präziser zu analysieren als mit BRINKERs 5-Funktionen-Modell. Gleichzeitig sind die Unterklassifikationen von ersterem Modell mit BRINKER kompatibel. 
Die linksseitig positionierten Schriftelemente stellen Fragen dar, die die oben beschriebene direktive Grundfunktion widerspiegeln, indem sie zu einer Antwort auffordern. Auch das Schriftelement ggf. separat beifügen (LHV 1) innerhalb der Bildpanels der Lastenheftvordrucke fordert die Bieter zu einer Antwort auf. Dabei legt der Auftraggeber auch fest, in welcher Modalität der Bieter seine Antwort geben soll: als Schriftelement in den Spalten, als Bild, Zeichnung oder Diagramm in den Bildpanels. Einzuschränken ist, dass der Verweis auf den Anhang - z. B. s. Anhang $1 a$ in PH 2 (s. Abbildung 5-11) - es ermöglicht, unmittelbar mit einem Schriftelement zu antworten, das auf die technische Zeichnung verweist. Unter den Bildpanels befinden sich Beschriftungen, beispielsweise Abb. 1: Fahrzeug (Seitenansicht) im Design des Bieters (LHV 1, S. 169). Diese elliptische Nominalphrase (s. Kapitel 5.2.3) lässt sich situativ-funktional ebenfalls als folgende Frage interpretieren: Wie sieht das Fahrzeug in Seitenansicht im Design des Bieters aus? Die Beschriftungen unterstützen die direktive Grundfunktion der Lastenhefte, weil auch sie präzisieren, mit welchem Bildinhalt der Bieter antworten soll. Das Panel und die Schriftelemente in und unter dem Panel konstituieren daher ein direktives Funktionsmodul.

Dass die Spalten Schriftelemente fordern, wird vor allem dadurch deutlich, dass die mittlere Spalte schriftsprachliche Antwortmöglichkeiten vorgibt. Diese Antwortmöglichkeiten erzeugen ,direkt-assertive' Funktionsmodule, weil sie den Bieter über Möglichkeiten informieren, wie er die Antwort gestalten kann.

Solche Antwortmöglichkeiten können gleichzeitig als ,indirekt-direktive‘ Funktionsmodule klassifiziert werden, weil sie den Bieter - im Gegensatz zu den elliptischen Fragen der linken Spalte - indirekt zu einer Antwort auffordern.

Die Funktionen der Schriftelemente sind in der mittleren Spalte und innerhalb der Panels identisch. Zu Letzteren gehören beispielsweise Foto/Zeichnung (LHV 1). D. h., sie sind ,direkt-assertiv', aber ,indirekt-direktiv', sodass die Bildpanels des Lastenheftvordrucks nach wie vor direktive Funktionsmodule darstellen.

Das Bildpanel (z. B. LHV 1; s. Abbildung 5-8) des Lastenheftvordrucks als ,direkt-assertives' und gleichzeitig, indirekt-direktives Funktionsmodul' spiegelt das Pflichtenheft durch die Angabe eines Fotos oder einer Zeichnung wider (PH 1; s. Abbildung 5-9). So fügen die drei Pflichtenheftexemplare Bilder, Zeichnungen und zum Teil Diagramme in die Bildpanels der ersten Seiten des Lasten- 
heftvordrucks ein. Diese ausgefüllten Bildpanels der ersten Seiten bilden das Bilderabstract (s. Kapitel 5.2.1). Zwar bleiben die Beschriftungen wie Abb. 1: Fahrzeug (Seitenansicht) im Design des Bieters ( $\mathrm{PH} 1$ ) erhalten und repräsentieren die ,assertive Grundfunktion“ des Pflichtenhefts. Denn es informiert den Auftraggeber über den dargestellten Bildinhalt und fügt keine Informationen hinzu, die nicht bereits im Lastenheftvordruck vorhanden sind. Das Foto oder die technischen Zeichnung informiert den Auftraggeber auch über das Aussehen des Fahrzeugs oder die Anordnung und Größe von Elementen des Fahrzeugs. Somit handelt es sich beim Bildpanel des Pflichtenhefts um ein ,direkt-assertives Funktionsmodul'. Gleichzeitig drückt dieses Bildpanel die ,indirekt-kommissive Grundfunktion“ des Pflichtenhefts aus, weil sich der Bieter mit dem Foto verpflichtet, das Fahrzeug in dieser Gestaltung (in der Außenansicht der Fahrzeugkarosserie) bzw. mit dieser Ausstattung (in der Innenansicht des Fahrzeugraums) zu liefern. Dies gilt unter der Bedingung, dass der Auftraggeber das Angebot des Bieters annimmt. So könnte der Auftraggeber sich im Zweifelsfall auf das Foto berufen, wenn es zur Auseinandersetzung zwischen Bieter und Auftraggeber darüber käme, aus welchem Material der Sitzbezug gestaltet sein muss.

Die kommissive Funktion schränkt die Version von Pflichtenheft 1 nicht ein (s. Abbildung 5-9), die die Textüberarbeitenden in der EXCEL-Umgebung nutzen. Dagegen verhindert die Nominalphrase Beispielgrafik - Angebot kann in Ausstattungsdetails von dieser Abbildung abweichen zu sämtlichen Abbildungen in Pflichtenheft 2 (s. Abbildung 5-11), dass die Bildmodule als indirekt-kommissive Funktionsmodule interpretiert werden können. Auch in der Vorversion von Pflichtenheft 3, die während der Textüberarbeitung genutzt wurde, wird die kommissive Funktion noch nicht eingeschränkt. Dagegen verhindert auch der folgende Satz in der Abgabeversion von Pflichtenheft 3, dass der Rezipient den Bildern eine kommissive Funktion zuweist: Alle Abbildungen: Die dargestellte Ausstattung entspricht nicht in allen Belangen der angebotenen Ausstattung. Maßgeblich ist der Inhalt der Tabelle. (ebd.)

Darüber hinaus kann den Fotos des Bilderabstracts - im Gegensatz zu den technischen Zeichnungen - auch eine werbende Funktion zugesprochen werden. Dies wird möglich, weil in der Experte-Experte-Kommunikation zwischen Auftraggeber und Bieter geworben wird (seduccion). Dies belegt die Analyse der Funktio- 
nen von Optimierungsvorschlägen (s. Kapitel 5.1.2): Dort bezieht sich diese Analyse des Kontextes auf die Aussage des Wettbewerbsleiters, dass er die Texte des Angebots, also auch Optimierungsvorschläge und Pflichtenhefte, als Visitenkarte des Unternehmens verstehe. Dass der Aufbau eines positiven Image von einem Unternehmen eine indirekte werbende Funktion übernimmt, führt dieses Kapitel ebenfalls aus.

ROLFs (1993) oben aufgeführte Beschreibung von Anzeigen, die als direktive Textsorte klassifiziert werden, bezieht RoLF (1993, S. 251) auch auf die Textsorte ,Werbeanzeige‘. Konkret können Bilder in Werbeanzeigen durch indirekte Aufforderungen eine werbende Funktion übernehmen. ${ }^{193}$ Entsprechende Aufforderungen realisieren die Bildmodule des Bilderabstracts nicht. Wie die Analyse des Textdesigns zeigt, erfüllt das Bilderabstract aber eine ästhetische Funktion. Werbung nutzt ästhetisierende Darstellungen häufig, um ihre kommunikative Funktion zu erfüllen. ${ }^{194} \mathrm{Im}$ Folgenden wird daher an einem Beispiel diskutiert, auf welche Art und Weise die CAD-Darstellung eines Schienenfahrzeugs ästhetisiert wird, um das Schienenfahrzeug als angebotenes Produkt aufzuwerten.

Abbildung 5-16 entspricht in Darstellung, Funktion und Inhalt der CAD-Darstellung in Seitenansicht aus Pflichtenheft 2 (s. Abbildung 5-11). Um nicht nur das Corporate Design bzw. das Fahrzeugdesign eines Bieters zu beschreiben, die in PH 1, PH 2 und PH 3 dargestellt sind, wird Abbildung 5-16 für die folgende Analyse herangezogen. Denn aus dem Corporate Design des dargestellten Fahrzeugs ließe sich auf das anonymisierte EVU schließen.

193 Indirekte Aufforderungshandlungen von Werbeanzeigen beschreiben BRINKER/CÖLFEN/PAPPERT ( ${ }^{9} 2018$, S. 113) unter anderem durch Einstellungsbekundungen in Form von Ich-Aussagen eines Agens mit Vorbildfunktion. In der Beispielanalyse realisiert diese indirekte Aufforderung ein Bild (ebd., S. 115 f.). Zudem weist die Untersuchung von Werbekommunikation Bildern meist eine werbende Funktion zu (JANICH, ${ }^{5} 2010$, S. 76 ff.).

SCHMITZ (2011b) stellt den Zusammenhang zwischen ästhetischer Darstellung und werbender Funktion in der Analyse einer Zeitungsanzeige aus der Automobilbranche als ,eher ästhetisierende, also imagebildende Werbung“ (ebd., S. 82) her. 


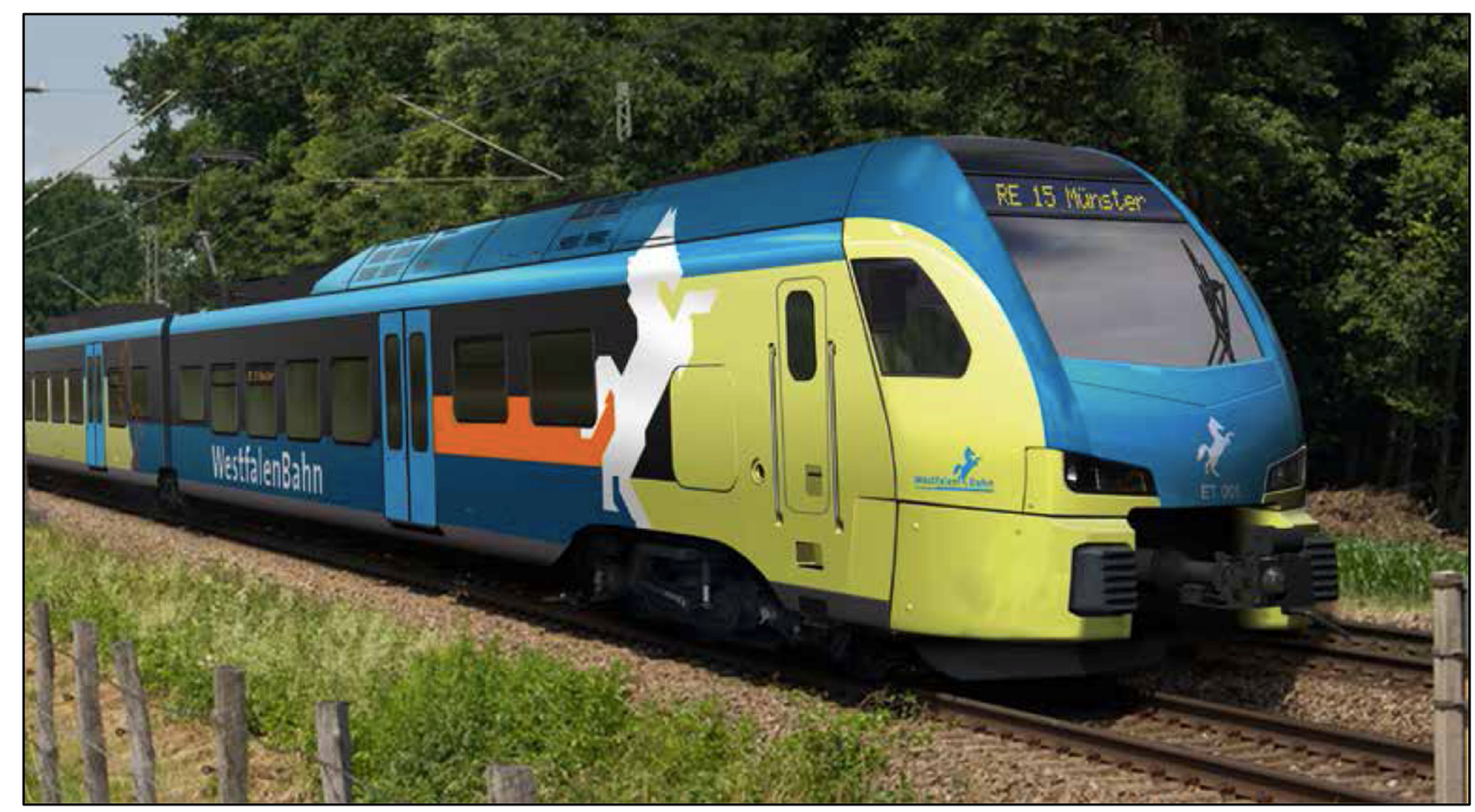

Abbildung 5-16: CAD-Seitenansicht aus STADLER (o. J.c, S. 1).

Die Darstellung zeigt die Seitenansicht eines Schienenfahrzeugs in einer grünen Wald- und Weidenlandschaft. Das Gleisbett, das vor und neben dem Schienenfahrzeug zu sehen ist, trennt dicht beieinanderstehende Bäume auf der rechten Seite - in der Seitenansicht der Hintergrund - von einer Weide am unteren linken Bildrand. Die Weide wird durch einen einfachen, alten Zaun aus verwitterten Holzpfählen und Stacheldraht vom Gleisbett abgegrenzt. Zwischen dem braunen Gleisbett und dem Zaun ist ein grün-brauner Wiesenstreifen positioniert, wie Wiesen in heißen Sommern gefärbt sind. In der linken oberen Ecke ist blauer Himmel erkennbar.

Das Schienenfahrzeug ist in der Bildmitte positioniert und ragt bis in die Mitte des linken Bildrands. Über dem Fahrzeug sind Seile einer Oberleitung erkennbar. Das Fahrzeug selbst ist überwiegend in Gelb und Blau gefärbt. Über diesen Farben ist an der vorderen Fahrzeugseite die Silhouette eines sich aufbäumenden Pferdes in Weiß angebracht. Auf der blauen Dachseite und der blauen Fahrzeugfront sind leichte Lichtreflexionen angedeutet. Aufgrund einer solchen Reflexion ist auch nicht erkennbar, was sich hinter der Frontscheibe befindet. Über der Frontscheibe ist in der elektronischen Anzeige in gelber Schrift die Nominalphrase RE 15 Münster angebracht, unter der Scheibe wiederholt sich eine kleinere weiße Pferdesilhouette, die wiederum darunter mit ET001 beschriftet ist. In der linken Bildhälfte ist auf die Fahrzeugseite unter den Fenstern in Weiß der 
Name Westfalenbahn positioniert. In der Bildmitte am Ende der Fahrzeugseite, an die die Fahrzeugfront anschließt, unterbricht die Pferdesilhouette diesen Schriftzug in die Bestandteile Westfalen und bahn.

Dieses Bild arbeitet assoziativ ${ }^{195}$ und ermöglicht so mehrere Interpretationen, von denen hier zwei ausgeführt werden:

Erstens fällt auf, dass die Umgebung des Fahrzeugs idealisiert wird, weil der Wiesenstreifen im Zustand dargestellt wird, in dem er sich meist im Sommer befindet - wie die Farben erkennen lassen. Das Bild stellt die Gegenstände in hellem Licht dar, wie es in einer idealtypischen Vorstellung von Sommer als Sonnenschein vorkommt. Nimmt der Rezipient Sommerwetter als etwas Positives wahr, stellt das Bild das Fahrzeug und die Landschaft bei idealen Wetterbedingungen dar. Das Besondere an der Weide, die durch den Zaun als Koppel fungieren kann, besteht darin, dass sie mit dem Fahrzeug verschmilzt. Möglich wird dies dadurch, dass das Pferd nicht auf der Koppel steht, sondern als Silhouette auf das Schienenfahrzeug montiert ist. Die Idealisierung des Wetters und die Verschmelzung von Natur und Fahrzeug erlauben die Assoziation, dass Schienenpersonennahverkehr gegenüber individuellem Autoverkehr umweltfreundlicher ist. Dass die Weide beim Bau der Bahnstrecke verkleinert, der Wald vermutlich gerodet wurde und Pferde von häufig vorbeifahrenden Zügen irritiert sein dürften, spielt bei dieser Assoziation keine Rolle.

Zweitens kann das Bild den Rezipienten an sommerliche Kurzurlaube ins Münsterland erinnern, bei denen sie tagelang von Gasthof zu Biergarten radelten und zwischendurch erschöpft den Regionalexpress nutzten, um wieder zum Ausgangsort zu gelangen. Weitere Assoziationen sind natürlich möglich. Weil das Bild in seiner Bedeutung offen ist, kann und soll hier nicht entschieden werden, welche die plausibelste ist.

Festzuhalten bleibt aber, dass die Darstellung dadurch ästhetisiert wird, dass sie als Bildinhalt sommerliches Wetter und sommerliche Umgebung zeigt. Des Weiteren ästhetisieren die Lichtreflexionen das Fahrzeug, weil es besonders sauber

195 STÖCKL (2016) grenzt nicht nur Geräusche aufgrund ihrer assoziativen Wirkungen von Sprache ab: „Bilder erlauben aber auch assoziative und inferierende gedankliche Operationen, die zu weiteren Deutungen führen (energetisch).“(ebd., S. 13) 
und neu wirkt (in einer verschmutzten Fahrzeugkarosserie spiegelt sich die Sonne nicht). Die Positionierung der Pferdesilhouette auf dem Zug verknüpft den Zug und die (Pferde-)Koppel. Dieses Spiel ästhetisiert die Darstellung des Fahrzeugs ebenfalls. Die gleiche Funktion ermöglicht die Verwendung des Logos der Westfalenbahn - die Pferdesilhouette - und der Farben des Corporate Designs, das die Westfalenbahn nutzt. ${ }^{196}$ Im Vergleich dazu stellen die Bilder aus Pflichtenheft 2 (s. Abbildung 5-11) das gleiche Fahrzeug im Corporate Design des Bieters dar. Denn die Lastenheftvordrucke fordern die Darstellung im Corporate Design (ebd.). Demzufolge können die Bilder von Fahrzeugaußendarstellungen der Pflichtenhefte ästhetisieren und entsprechend der obigen Diskussion eine werbende Funktion übernehmen. D. h., die Bildmodule, die ästhetisieren, können auch als ,indirekt-direktive Funktionsmodule‘ interpretiert werden.

Dagegen ist die technische Zeichnung zur Beschriftung Abb. 3 aller drei Pflichtenhefte (PH 1; PH 2; PH 3) als, darstellend-assertives Funktionsmodul' einzuordnen: Denn diese diagrammatische Darstellung ist in der Darstellung durch DIN-Normen konventionalisiert und kann keine Mittel des Corporate Designs durch Oberflächengestaltung wie Corporate-Design-Farben des Unternehmens oder dessen Logo nutzen. ${ }^{197}$ Darüber hinaus abstrahieren technische Zeichnungen von Licht- und Wetterverhältnissen etc., sodass sie die Fahrzeugdarstellung nicht ästhetisieren können. Auch die Zugkraft-Geschwindigkeits-Diagramme bzw. -Tabellen (PH 1; PH 2; PH 3) nutzen als abbildende Diagramme keine ästhetisierenden Mittel und werden daher auch als ,darstellend-assertive Funktionsmodule eingeordnet. Wie die Fotos können aber auch technische Zeichnungen und abbildende Diagramme als ,indirekt-kommissive' Funktionsmodule kategorisiert werden, weil der Bieter sich auch mit ihnen gegenüber dem Auftraggeber verpflichtet, das Fahrzeug entsprechend den Angaben zu liefern, die Zeichnungen und Diagramme machen.

Die Antworten der Bieter innerhalb der rechten Spalte der Schriftmodule und die Bilder innerhalb der Bildpanels bestimmen die Funktion der Pflichtenhefte, weil die Bieter ausschließlich diese Elemente einfügen. Die Schriftelemente in der

196 Dies zeigt auch die Gestaltung der Homepage der WeSTFALENBAHN (2018, o. S.).

197 Lediglich PH 3 geht durch Einfärbungen über die Konventionen der DIN-Normen hinaus (s. Kapitel 5.2.4). 
mittleren und rechten Spalte bilden direkt-assertive Funktionsmodule: Quantitative Angaben erfassen Maßangaben wie ca. 265 cm (PH 1); Gewichtsangaben wie $70 t$ (ebd.) als Zustände; physikalische Kräfte wie 9 kW/t (ebd.); Geschwindigkeiten 120 [km/h] (ebd.) etc. als Abläufe; Materialangaben wie Stahl (ebd.); Raumangaben wie komplett eben (ebd.), aber auch zugelassen (ebd.) oder besondere Crasheigenschaften - nicht zutreffend (ebd.) als Beschaffenheit. Auch die technischen Zeichnungen und Fotos stellen Zustände bzw. Formen von Beschaffenheit dar (Weiteres s. Kapitel 5.2.3, Bilderabstract).

Diese Angaben in den Schriftmodulen konstituieren aber ebenfalls die indirektkommissive Grundfunktion der Textsorte, weil die Bieter sich verpflichten, das Fahrzeug mit diesen Eigenschafen zu liefern. Dass die Schriftelemente der rechten Spalte auch eine werbende Funktion wie die CAD-Darstellungen und Fotos übernehmen können, indem sie Werbesprache verwenden, lässt sich nicht belegen. ${ }^{198}$

Die Grundfunktion der Textsortenvarianten Lastenheftvordruck und Pflichtenheft unterscheidet sich wie folgt: Die Funktionsmodule der Lastenheftvordrucke konstituieren eine Grundfunktion, die ,direkt-assertiv' und ,indirekt-direktiv' ist. Dies betrifft sowohl die Schriftelemente der linken und mittleren Spalten von Schriftmodulen als auch die Beschriftungen unter und in Bildpanels. In Pflichtenheften bilden Fotos, CAD-Darstellungen, technische Zeichnungen, abbildende Diagramme bzw. Tabellen sowie die rechte Spalte der Schriftmodule ,direkt-assertive' und gleichzeitig, indirekt-kommissive' Funktionsmodule. Ausschließlich

198 Nach JANICH ( ${ }^{5} 2010$, S. 169 ff.) nutzt Werbesprache a) Hochwertwörter, die ein positives Denotat wie ideal, vollendet etc., b) Schlüsselwörter, die ,individuelle und emotionale Imaginationen und Assoziationen an[ ]regen“ (ebd., S. 171) und die die Argumentation steuern, sowie c) Plastikwörter, die trotz einer vagen Inhaltsseite ,den Eindruck wissenschaftlicher Qualität und Fundiertheit [verstärken]“" (ebd.), sich letztlich aber als Luftblasen entpuppten - beispielsweise Fortschritt, Entwicklung oder Sicherheit. Weder werden in der rechten Spalte der Pflichtenhefte ungewöhnliche Wortbildungen wie Neologismen bzw. Ad-hoc-Bildungen wie unkaputtbar etc. verwendet, die Originalität erzeugen sollen (ebd., S. 152 f.). Die Pflichtenhefte nutzen auch keine Anglizismen (ebd., S. 156 f.), die Scheinentlehnungen auf der Ebene der Lexik (Dressman, Showmaster) sind, oder die Ebene der Morphologie (Teenie, Twen) betreffen oder eine Bedeutungsveränderung von der Ausgangs- gegenüber der Zielsprache (Flirt, Oldtimer) darstellen. So ist das Wort Crash-Absorber Teil der Fachsprache. Auch die Werbestrategie, die Verwendung einer Fachsprache zu inszenieren (ebd., S. 216 ff.), ist nicht möglich, weil die Pflichtenheftexemplare in Fachkommunikation eingebettet sind. 
Bilder und CAD-Darstellungen können in Pflichtenheften auch dann als indirektdirektive Funktionsmodule klassifiziert werden, wenn sie ästhetisierende Darstellungen verwenden, die eine werbende Funktion übernehmen. Die Analyse der Funktionsstruktur bezieht sich bereits auf Themenmodule, wodurch Überschneidungen beider Strukturen deutlich werden.

\subsubsection{Themenstruktur}

Die Analyse der Themenstruktur gliedert sich entsprechend den Kriterien des integrierten Analyserasters zu interfachlichen Sprache-Bild-Textsorten (s. Tabelle 3-2). Im Folgenden wird die Überschriftenstruktur der Lastenheftvordrucke 1, 2 und 3 verglichen (s. Tabelle 5-2), um auf dieser Grundlage das Themenentfaltungsmuster der Textsorte zu bestimmen. Der Abgleich mit Überschriftenstrukturen aus LHV 1, 2 und 3 mit der Überschriftenstruktur der BAG-SPNVEmpfehlungen dient dazu, die Aussage von AUfTRAGGEBER 1 zu überprüfen, dass „die BAG-SPNV-Empfehlungen [...] auch vollständig ein[fließen], damit wir eine Standardisierung erreichen“ (2013, S. 6). 


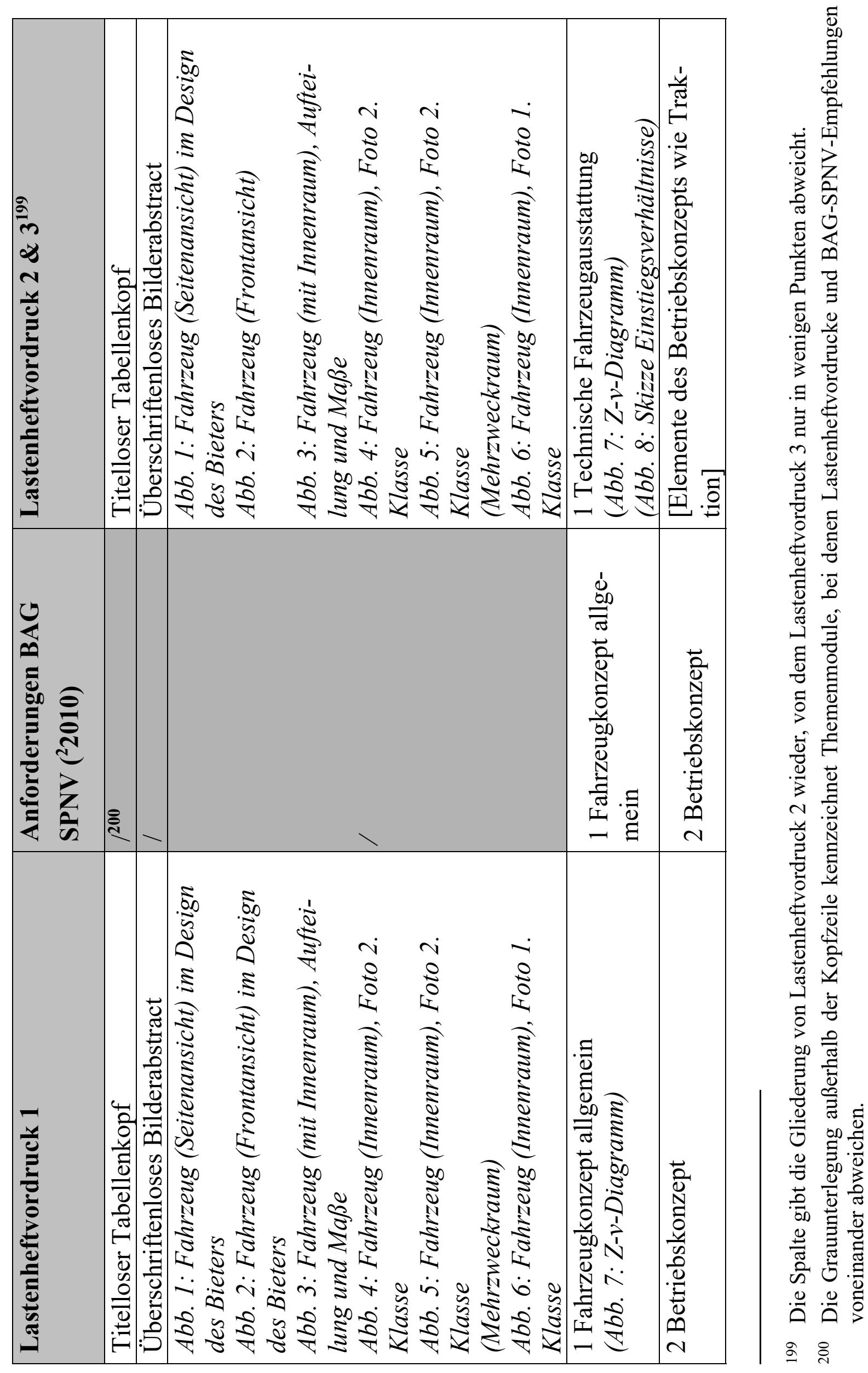




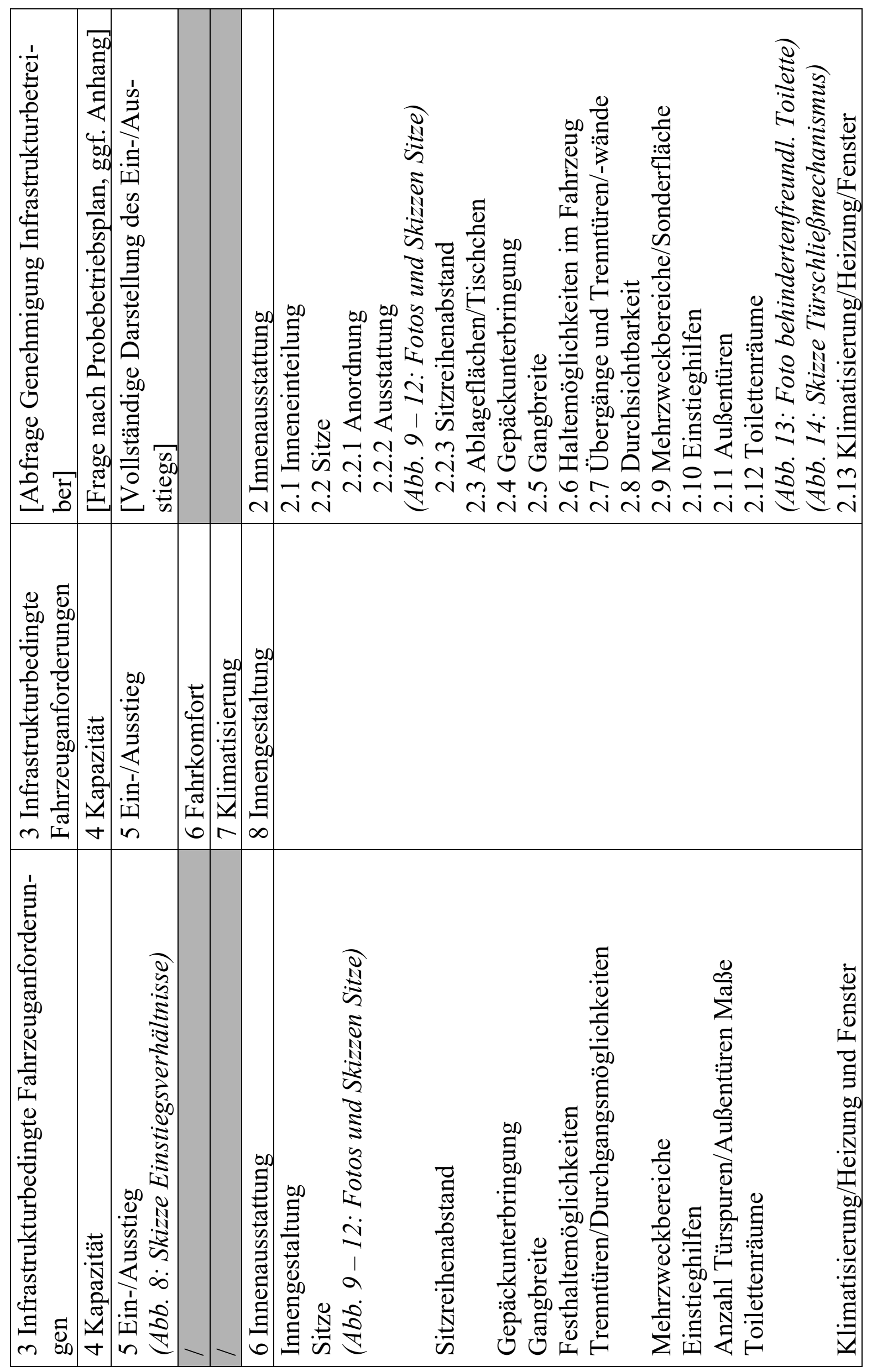




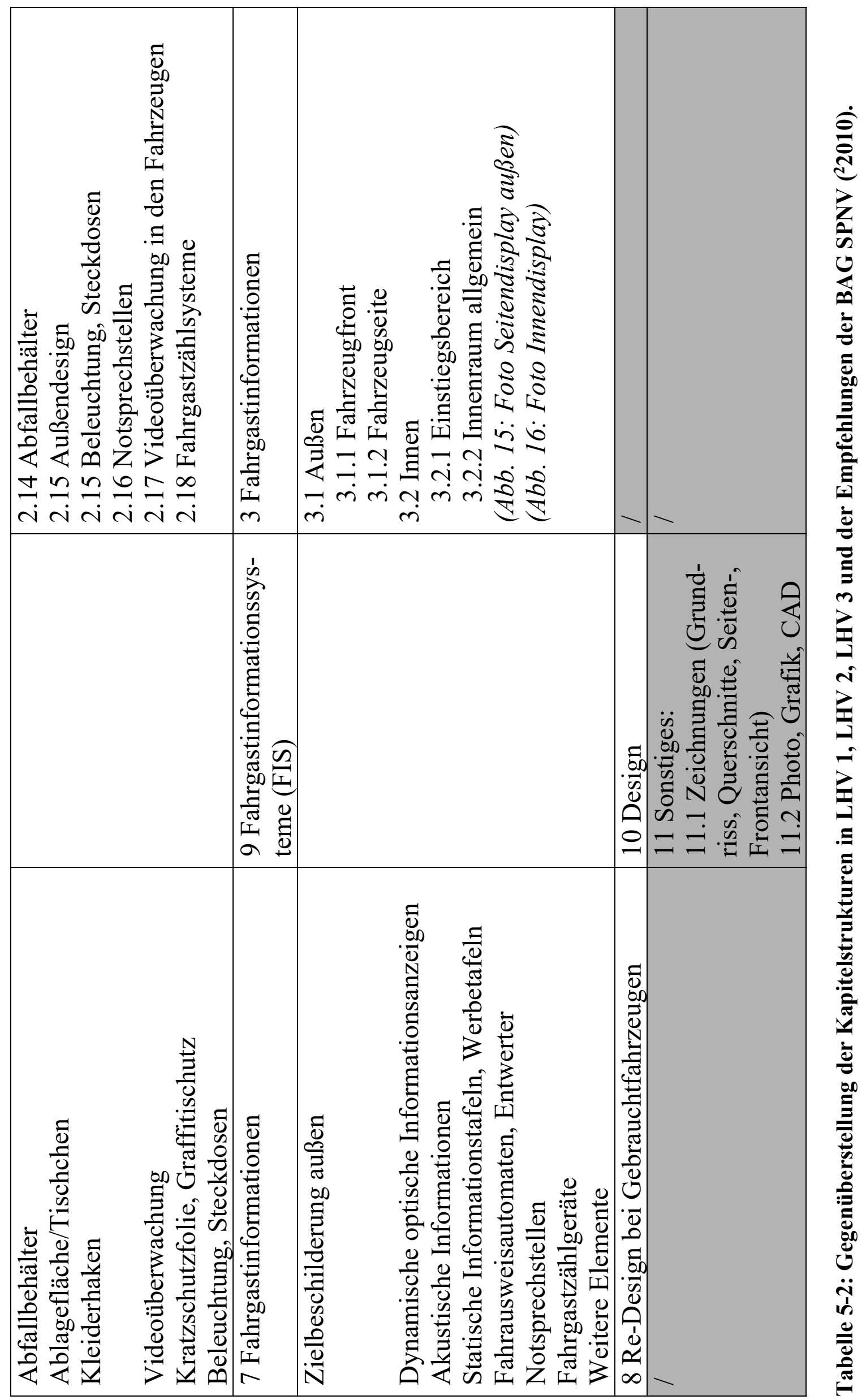


Eine Übereinstimmung zwischen den Überschriftenstrukturen würde vor dem Hintergrund der Aussage von AufTRAGgeBer 1 darauf hindeuten, dass die BAGSPNV-Empfehlungen die vorliegenden Pflichtenhefte und die Textsorte für diese Domäne thematisch-strukturell konventionalisieren. Darauf deutet die obige Gegenüberstellung hin, was im Einzelnen auszuführen ist: ${ }^{201}$ Die LASTENHEFTVORDRUCKE 1 und 2 repräsentieren Themenelemente gegenüber den BAG-SPNVEmpfehlungen auch durch Bildpanels, die die zugehörigen Pflichtenhefte 1 und 2 mit Bildern und Diagrammen füllen. D. h., in den Pflichtenheften werden Themenmodule durch Bilder, Diagramme und Schriftelemente, in den BAG-SPNVEmpfehlungen dagegen ausschließlich schriftsprachlich realisiert. Diese Empfehlungen leiten die Auftraggeber aber an, die Bieter durch die Lastenheftvordrucke dazu aufzufordern, dass sie Bilder und Diagramme abgeben und welcher einzureichen sind. Anzugeben ist der

„Grundriss (mit Maßen wie Außenlänge, Außen-/Innenbreite, Gangbreite, lichte Weite [sic] Innen-/Aussentüren, Sitzabstände, Ausmaße der Toilettenkabine und Angabe 1. Klasse-Bereich sowie Angabe der Sitzplätze insgesamt, der 1. Klasse insgesamt, der 2. Klasse insgesamt sowie gesondert der in der 2. Klasse befindlichen Klappsitze)“ (BAG SPNV, ${ }^{2} 2010$, S. 57).

Diesen Grundriss fordert LASTENHEFTVORDRUCK 1 durch die Beschriftung Abb. 3: Fahrzeug (Innenraum), Aufteilung und Maße und die Angabe (Maßzeichnung/ Übersicht) - Format kann ggf. größer sein - (ebd.) innerhalb des Panels (s. Abbildung 5-8). In identischer Form fordern die Beschriftungen von LASTENHEFT-

201 In Lastenheftvordruck 2 (aus dem Jahr 2013) und Vordruck 3 (aus dem Jahr 2010), die derselbe Auftraggeber verwendet hat, findet sich zwar eine weniger differenzierte Nummerierung gegenüber Lastenheftvordruck 1 wie auch gegenüber den BAG-SPNV-Empfehlungen. Aber an dieser Abweichung wird deutlich, dass die (Unter-)Überschriftenstruktur einen Hinweis auf die Themenstruktur gibt. So müssen insbesondere im Abgleich der verschiedenen Exemplare auch schriftsprachliche Elemente berücksichtigt werden, die nicht Teil der (Unter-)Überschriftenstruktur sind. Beispielsweise ersetzt der folgende Satz aus Lastenheftvordruck 2 und 3 die Überschrift Infrastrukturbedingte Fahrzeuganforderungen aus Lastenheftvordruck 1 und aus den BAG-SPNV-Empfehlungen: Fahrzeug entspricht allen gängigen technischen und gesetzlichen Anforderungen (PH 2). Die Überschrift $\mathrm{Ka}$ pazität aus Lastenheftvordruck 1 und den Empfehlungen substituiert folgende Nominalphrase eines Tabellenfachs der linken Spalte: Zeitplanung für die Fahrzeugbeschaffung (Regel- und Reservefahrzeuge) und Planung des Probebetriebs (ebd.). Die dazugehörige mittlere Spalte stellt folgende Antwortmöglichkeiten zur Auswahl: gesondert angefügt: ja/nein (ebd.). Abweichungen zwischen Lastenheftvordruck 1 und 2 bestehen bei den Zuordnungen folgender Teilthemenmodule zu Themenmodulen: Einstiegverhältnisse, Außendesign, Notsprechstellen, Fahrgastzählsysteme, Fahrausweisautomaten, Re-Design, weitere Elemente und in der Darstellung der Informationsanzeigen. 
VORDRUCK 2 und LASTENHEFTVORDRUCK 3 diesen Grundriss. PfLichtenheFt 1 setzt in das zugehörige Bildpanel von LASTENHEFTVORDRUCK 1 eine technische Zeichnung ein, die den detaillierten BAG-SPNV-Anforderungen entspricht (s. Abbildung 5-9). Dies trifft auch zu auf PFLICHTENHEFT 2 im Verhältnis zu LASTENHEFTVORDRUCK 2 und auf PFLICHTENHEFT 3 im Verhältnis zu LASTENHEFTVORDRUCK 3.

Die BAG-SPNV-Empfehlungen schlagen gegenüber der Forderung nach technischen Zeichnungen die Forderung von Fotos lediglich vor:

„Ergänzend zu den technischen Zeichnungen (dort Kap. 11.1) können Photos oder Graphiken bzw. 3D-Computeranimationen (Innenraum 1. und 2. Klasse, Mehrzweckraum, Toilette, etwaige Besonderheiten, Außenaufnahmen von der Seite und von vorne) des exakten angebotenen Fahrzeugs oder ggf., falls das Fahrzeug insgesamt oder nur in dieser Konfiguration noch nicht im Einsatz sein sollte, des Fahrzeugtyps angefordert werden.“ (BAG SPNV, ${ }^{2} 2010$, S. 57)

AUfTRAGGEBER 1 übernimmt diesen durch die Beschriftungen der Bildpanels in LASTENHEFTVORDRUCK 1, sodass sich entsprechende Fotos zu Front- und Seitenaußenansichten, von der 1. und 2. Klasse des Innenraums, des Mehrzweckbereichs, des Toilettenraums und der Sitze in der 1. und 2. Klasse in allen Pflichtenheften finden (PH 1). Die Beschriftungen $A b b .15: \ldots$ und $A b b .16: \ldots$ in PfLICHTENHEFT 2 fordern zusätzlich Abbildungen vom Seiten- und Innendisplay (ebd.). Die Empfehlungen der BAG SPNV (2010, S. 14) schlagen ebenfalls vor, das Zugkraft-Geschwindigkeits-Diagramm neben den dazugehörigen Testaten zu fordern. Dementsprechend bilden Überschriften und Bildpanels die Themenstruktur, deren Themenentfaltungsmuster analysiert wird.

Lastenheftvordrucke und Pflichtenhefte behandeln das Thema ,Fahrzeugangebot', bei dem das physikalische Objekt ,Fahrzeug' in Bezug auf seine Eigenschaften repräsentiert wird, die für das Angebot relevant sind: die Objekte werden in ihren Funktionen dargestellt. D. h., Objekte werden durch funktionale Anforderungen beschrieben, die neben Qualitätsanforderungen und Rahmenbedingungen in Pflichtenheften (KÖSLER, 2009, S. 66) eine Perspektive auf das Textthema bilden. So werden Funktionen zum einen als technische Funktionen spezifiziert. ${ }^{202}$

202 Beispielsweise die mechanische Beweglichkeit (klappbarer Wickeltisch; LHV 1), räumliche Anordnungen (Rampenneigung; LHV 1) oder die Kraftwirkung (Zugkraft-Geschwindigkeits-Diagramm; ebd.) etc. 
Zum anderen explizieren die Lasten-/Pflichtenhefte die rechtlich-gesellschaftliche Relevanz dieser physikalischen (Teil-)Objekte. ${ }^{203}$

Entsprechend der Bestimmung von technisch-rechtlichen Funktionen physikalischer Gegenstände, deren Teilen und Relationen lässt sich die Themenentfaltung als deskriptives Muster erfassen (s. Kapitel 3.3.3). Die semantische Struktur zwischen den Themenmodulen, aber auch innerhalb von ihnen lässt sich als TeilGanzes-Relation charakterisieren, bei denen die Textstruktur der Hierarchie von Objektteilen folgt (s. Kapitel 3.3.3). Im Folgenden werden die Teil-Ganzes-Relationen als Nebeneinander von ikonisch-bildlichen und schriftsprachlichen Einheiten innerhalb der jeweiligen Themenmodule bzw. als Nebeneinander der Themenmodule eines Pflichtenheftexemplars systematisiert (s. Abbildung 5-17).

Entsprechend diesem Themenentfaltungsmuster (s. Abbildung 5-17) wird in allen drei Pflichtenheften Folgendes dargestellt (PH 1; s. Abbildung 5-9; PH 2; s. Abbildung 5-11; PH 3): das gesamte Fahrzeug von außen in Abb. 1, eine Vorderansicht von außen als spezifizierender Ausschnitt des gesamten Fahrzeugs in Abb. 2 und Ausschnitte des Innenraums in $A b b .4$ und $A b b .5$. Die Grundrisszeichnung zu $A b b .3$ bildet einen Übergang von der Darstellung des Fahrzeugäußeren zum Fahrzeuginneren. Die Anordnung des Grundrisses passt sich demnach zwar in das semantisch-strukturelle Muster von außen nach innen ein, aber nicht in das Muster vom Allgemeinen zum Speziellen. Denn Abb. 2 stellt bereits einen Ausschnitt dar.

203 Die Klappbarkeit des Wickeltischs wird durch die „Technische Spezifikation für die Interoperabilität bezüglich ,eingeschränkt mobiler Personen“" (Technical specifications for interoperability relating to accessibility of the Union's rail system for persons with disabilities and persons with reduced mobility/TSI PRM) der EU gefordert, um mobil eingeschränkte Personen in der Nutzung des Schienenfahrzeugs nicht zu benachteiligen, beispielsweise mit den Anforderungen für einen Wickeltisch (TSI PRM, 2008, S. 99) oder mit der Neigung von Einstiegsrampen, die Rollstuhlfahrer nutzen (ebd., S. 106). Dementsprechend bilden die Generalklauseln den elementaren Ausgangspunkt bei der Themenbestimmung, ob das Fahrzeug ,allen gängigen technischen und gesetzlichen Anforderungen“" (LHV 3; LHV 2) bzw. den ,jeweils geltenden einschlägigen gesetzlichen Vorgaben“ (LHV 1) entspricht und ob die „TSI PRM [...] erfüllt [wird]“ (LHV 2). 

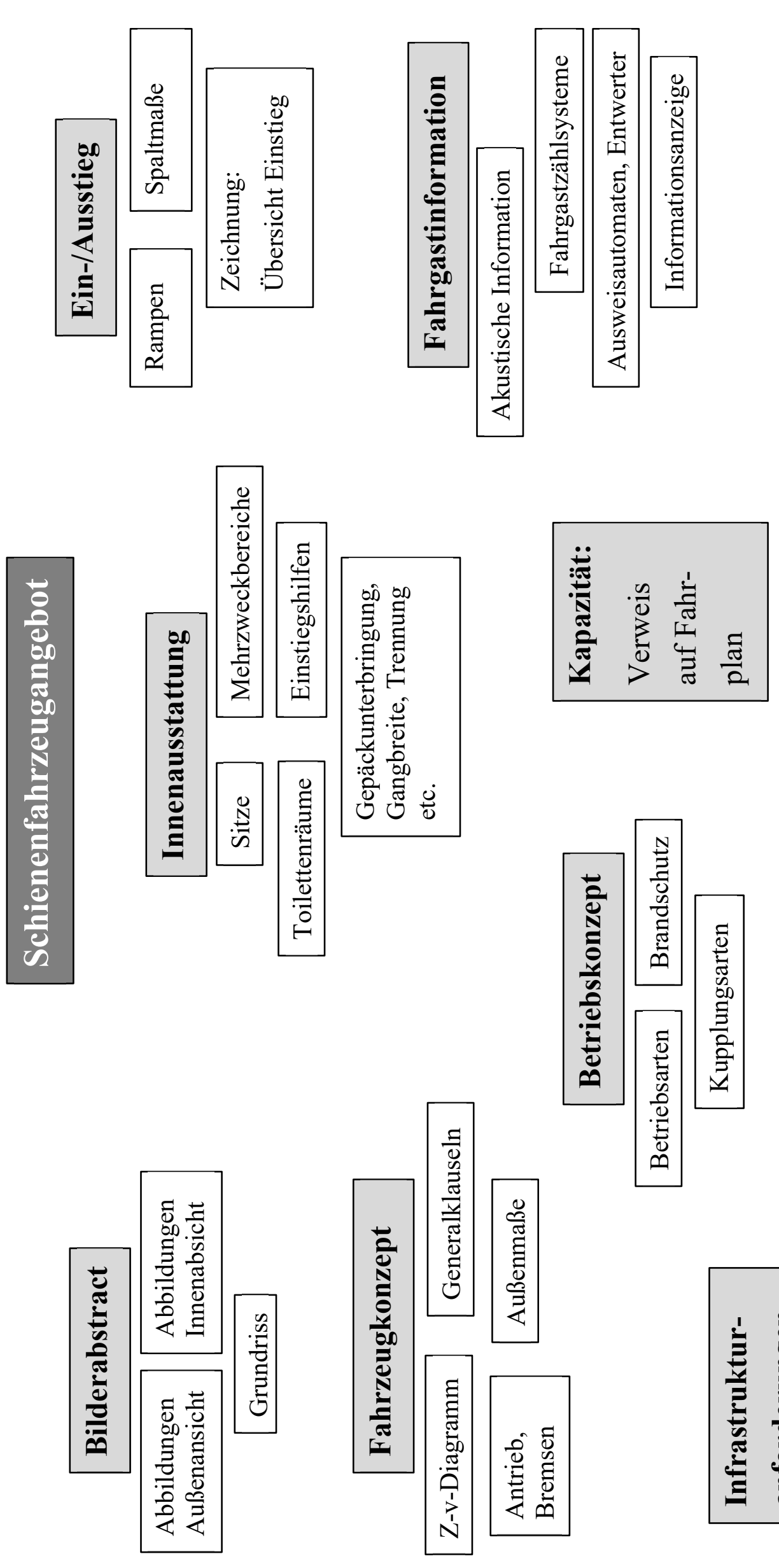

กิ่

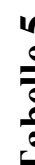


Die Positionierung des Grundrisses zwischen den Fotos lässt sich durch seine mögliche Funktion als Quasi-Inhaltsverzeichnis (s. unten) erklären: Rezipienten, denen die Themenmodule des Pflichtenhefts als Teil der Textsortenkonvention bekannt sind, möglicherweise aber auch nichtfachliche Rezipienten können die Grundrisszeichnung als delinearisiertes Verzeichnis der Themenmodule im Pflichtenheft nutzen. Denn die im Grundriss eingezeichneten Bestandteile des Fahrzeugs verweisen auf sämtliche Themenmodule des Pflichtenhefts, die physikalische Gegenstände des Innenraums behandeln. Beispielsweise verweist das partielle Synonym PRM-Sitze 204 im Grundriss von PFLICHTENHEFT 3 (s. Abbildung 5-18) auf das Themenmodul Sitze. Die schriftsprachlichen Elemente Kameraabdeckung, Display, Entwerter und $W C$ aus dem Grundriss in Pflichtenheft 1 greifen folgenden Themenmodule des Pflichtenhefts auf: a) das Themenmodul Videoüberwachung (ebd.), b) das Modul $d y$ namische optische Informationsanzeigen (ebd.), c) das Modul Fahrausweisautomaten, Entwerter (ebd.) sowie d) das Themenmodul Toilettenräume (ebd.). Diese Bezüge stellen logisch-semantische Sprache-Bild-Relationen dar und werden ausführlich in Kapitel 5.2.4 analysiert. Die Nominalphrase Behindertengerechtes $W C$ im Grundriss von PFLICHTENHEFT 3 (s. Abbildung 5-18) leitet als Bild-Bild-Relation zum spezifizierenden Foto mit der Beschriftung Behindertenfreundliche Toilette und zur technischen Zeichnung mit der Beschriftung Türschließmechanismus (PH 3) weiter. Die im Grundriss von PFLICHTENHEFT 2 eingezeichneten Klappsitze, Fahrrad- und Rollstuhlplätze weisen auf die Themenmodule Ausstattung (inkl. Klappsitze; PH 3) und Mehrzweckbereiche/Sonderflächen (ebd.) hin.

Diese Beispiele verdeutlichen, dass die Textelemente des deskriptiven Themenentfaltungsmusters nicht nur in einer linearen Von-links-oben-nach-rechtsunten-Chronologie und entsprechend der Seitennummerierung, sondern auch delinear rezipiert werden können - beispielsweise kann an die Rezeption des Grundrisses (PH 3) diejenige der technischen Zeichnung zum Türschließmechanismus (ebd.) angeschlossen werden.

204 Beim Terminus PRM-Plätze handelt es sich um Jargon, weil das Initialwort PRM das Grundwort Plätze in diesem Kompositum präzisiert. PRM verweist auf die technische Norm TSI PRM (s. oben). 


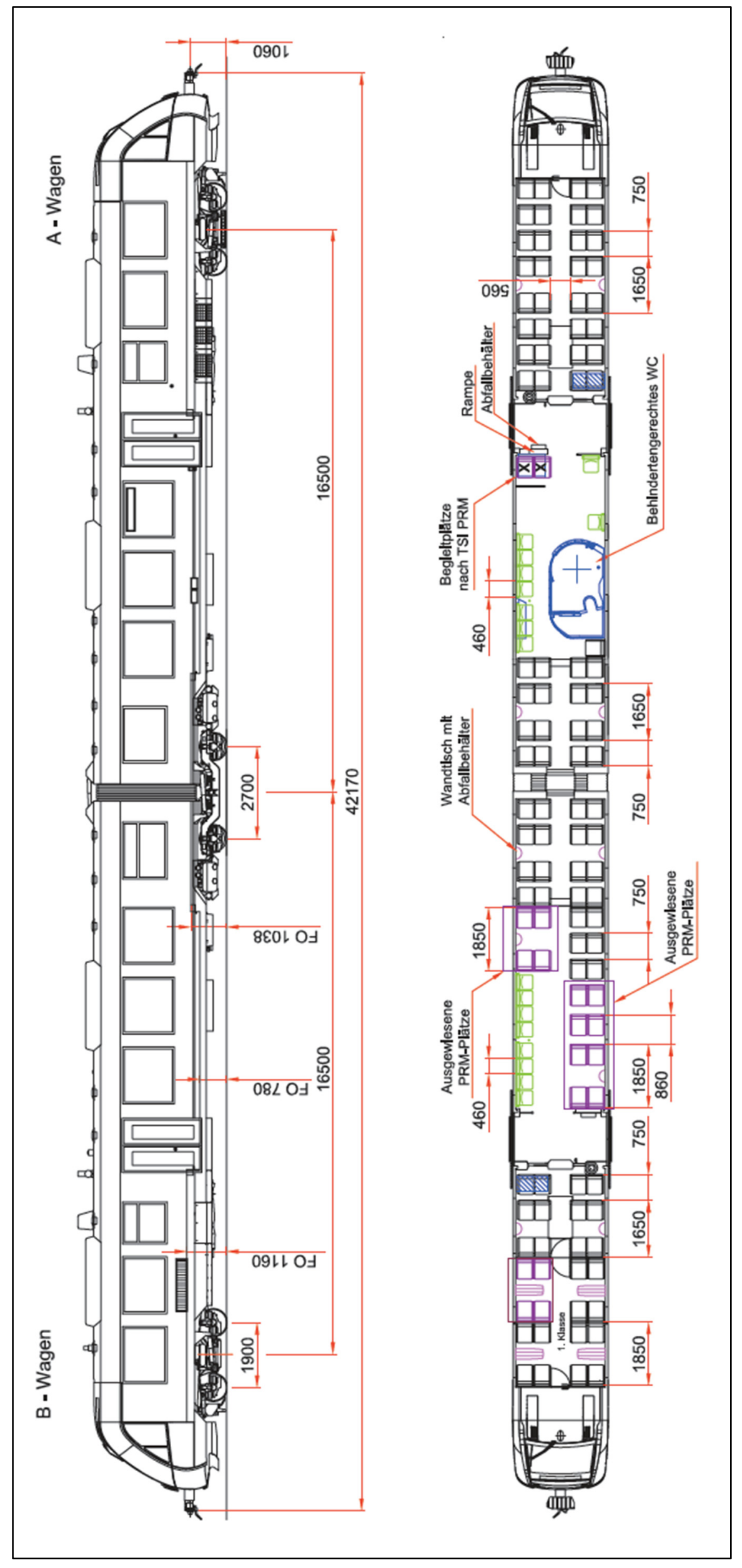

อิ

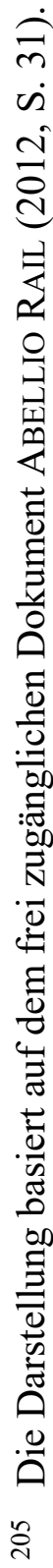


Die genannten Themenmodule, die der Grundriss ankündigt, stellen Schriftmodule dar. Wie bereits das Kapitel ,Textdesign“ ausführt (s. Abbildung 5-14), können die Ellipsen der drei Spalten als verschriftlichter Formulardialog interpretiert werden: Auftraggeberfragen - Antwortvorgaben - Bieterantworten. ${ }^{206}$ Diese Formen sind stark schwundgrammatisch, weil lexikalisches Material durch Mittel des Textdesigns ersetzt wird (s. Kapitel 5.2.1). So ist die semantische Struktur der schriftsprachlichen Elemente in den Schriftmodulzeilen von Pflichtenheften stark elliptisch. Grundsätzlich werden Frage-AntwortFolgen wie Wer hat einen Steinadler gekauft? - Mein Bruder (hat einen Steinadler gekauft.) als Ellipsen beschrieben. ${ }^{207}$ Der situativ-funktionale Kontext der Formularkommunikation und die Repräsentation der Schriftelemente durch das Textdesign (s. Abbildung 5-14) ermöglichen es, auch eine Zeile mit Schriftelementen in den Pflichtenheften als Frage-Antwort-Folge aufzufassen. Diese wird im Formular um die für sie typischen Vorgaben von Antwortmöglichkeiten ergänzt, wie Tabelle 5-3 zeigt:

206 Nur die Anordnung von schriftsprachlichen Elementen wie Foto/Zeichnung, ggf. separat beifügen (LHV 1) innerhalb der Panels, die Bilder fordern, durchbrechen in den Lastenheftvordrucken die Systematik zu diesen Elementen der Formularkommunikation.

Unterschieden wird zum einen die reduktionistische Perspektive auf Ellipsen, derzufolge Ellipsen als elliptische Äußerungen in Ergänzung um den ausgelassenen Äußerungsteil auf einen vollständigen Satz zurückzuführen sind (STAFFELDT, ${ }^{5} 2016$, S.173). Zum anderen werden Ellipsen als ,kommunikativ selbstständige Einheiten ohne Satzwert" (ebd.) aufgefasst. Dabei wird die Unterscheidung beider Perspektiven auf Ellipsen mit der Unterscheidung von kontextkontrollierten und nicht-kontextkontrollierten Ellipsen verknüpft (ebd.): Bei Ersteren verdeutlicht der sprachliche Kontext die ausgelassenen Äußerungsteile; bei Letzteren sind „Sprechsituation und Kontext erforderlich“ (ebd.), um deren Bedeutung zu erfassen, beispielsweise die eines Hilferufs. Aus kontextkontrollierter Perspektive wird bei lexikalisch-/phonologisch-reduzierten (p-reduzierten) Ellipsen ,lediglich ein Teil der gesamten lexikalischen Information — die phonologische - unter bestimmten Umständen nicht explizit gemacht" (KLEIN, 1993, S. 790). Als Beispiel wird die Ellipse Deine vor anstelle der lexikalisch vollständigen Konstruktion Deine Uhr geht vor gegeben, die als p-reduzierte Ellipse sprachlichen Kontext benötige. Insbesondere Frage-Antwort-Paare bieten den sprachlichen Kontext für diese Form der p-Reduktionen (ebd.). Bei Fragesätzen mit Kopfstellung des Prädikats wie Hat dein Bruder einen Steinadler gekauft? - Ja. wird ,lediglich der ,Geltungsanspruch“ als Fokus markiert: gilt der Satzinhalt oder gilt er nicht? Um dies zu spezifizieren, gibt es in der Antwort keine eigene Konstituente: der Fokusausdruck ist in diesem Fall im finiten Verb verborgen, kann aber nicht isoliert werden. Wenn man in der Antwort nur den Fokus allein ausdrücken will, muß man ein eigenes Wort (ja oder nein) verwenden." (ebd., S. 791; Kursive im Original) 


\begin{tabular}{|l|l|l|}
\hline Breite des Fahrzeugs (außen) & cm & 288 \\
\hline
\end{tabular}

Tabelle 5-3: Zeile aus dem Themenmodul Technische Fahrzeugausstattung (PH 2).

In Tabelle 5-3 kann die Nominalphrase Breite des Fahrzeugs (außen) als satzwertige Ellipse für den Fragesatz Wie breit ist das (angebotene) Fahrzeug? verstanden werden. Zusammengenommen mit der Antwortvorgabe $\mathrm{cm}$ der mittleren Spalte kann die Frage zu Wie viele cm Breite umfasst das Fahrzeug außen? erweitert werden. Die Antwort 288 in der rechten Spalte könnte zum Satz Das angebotene Fahrzeug ist $288 \mathrm{~cm}$ breit. ausformuliert werden. Um diese Konstruktion zu analysieren, wird das Konzept der Fokus-Topik-Gliederung $^{208}$ bei W-Phrasen herangezogen. Im Anschluss daran entspricht die Antwort 288 dem Fokusausdruck, der durch die elliptische Frage der linken Spalte erbeten wird, während die übrigen Satzbestandteile Das angebotene Fahrzeug ist cm breit dem Topikausdruck entsprechen. D. h., die Ellipsen in den Formularzeilen geben lediglich den Fokusausdruck an, kürzen aber den Topikausdruck.

Die Antwortvorgaben der mittleren Spalte sind für die Möglichkeit des Bieters relevant, seine Antworten, also diese Fokusausdrücke, zu gestalten: Schriftelemente wie ja/nein, cm, Anzahl oder Angabe (PH 1) verfügen über einen hohen semantischen Gehalt, über wenig graphemisch-lexikalisches Material und sind in hohem Maße an die textuelle Umgebung gebunden. Nur wenige Antwortmöglichkeiten sind in geringerem Maße an die textuelle Umgebung der Ellipsen gebunden wie Sommer/Winter (in \%) (PH 1), Anzahl Sitzplätze mit Sitzreihenabstand in $\mathrm{cm}$ (PH 1). ${ }^{209}$ Die drei Pflichtenhefte enthalten jeweils mehr als 100-mal ja/nein-Konstruktionen als vorgegebene Antwortmöglichkeiten und kommen damit am häufigsten vor. Ihre Konstruktion veranschaulicht beispielsweise Tabelle 5-4:

208 „Fokusausdruck der Antwort ist jener Teil, der der W-Phrase (oder den W-Phrasen) entspricht, Topikausdruck ist der Rest; die Topik (und oft, aber nicht immer auch der Topikausdruck) wird aus der Frage beibehalten." (KLEIN, 1993, S. 791)

209 Eine Ausnahme bildet die Antwortmöglichkeit Angabe [sic] welche Tür ausgenommen werden kann (PH 1), die unabhängig von der linken Spalte verstanden werden kann. 


\begin{tabular}{|l|l|l|}
\hline Mehrzweckraum & $\begin{array}{l}\text { ja/nein, An- } \\
\text { zahl }\end{array}$ & ja, 7 \\
\hline
\end{tabular}

Tabelle 5-4: Zeile aus dem Themenmodul Mehrzweckraum (PH 2).

In der linken Spalte der Pflichtenhefte kommen meist Formen vor, die elliptisch sind wie das Nomen Mehrzweckraum. Antwortmöglichkeiten können auch kombiniert sein, wie die Partikeln ja/nein und das Nomen Anzahl in der mittleren Spalte zeigen. Die Antwortmöglichkeiten ja/nein sowie Anzahl oder auch $\mathrm{cm}$ in Tabelle 5-3 repräsentieren dabei einen hohen semantischen Gehalt mit wenig graphemisch-lexikalischem Material und sind stark an den Aussagesatz - also die textuelle Einbettung - gebunden. Selbiges gilt für die Bieter-Antwort $J a$ und 7.

Auffällig ist dagegen die vollständige Syntax in der linken Spalte von Tabelle 5-5, der auch weitere Darstellungen juristischer Themen in den Pflichtenheften entsprechen:

\begin{tabular}{|l|l|l|}
\hline $\begin{array}{l}\text { Fahrzeug entspricht allen gängigen techni- } \\
\text { schen und gesetzlichen Anforderungen }\end{array}$ & Ja \\
\hline
\end{tabular}

Tabelle 5-5: Zeile aus dem Teilthemenmodul Generalklausel (PH 2).

Der Aussagesatz in der linken Spalte kann einerseits durch die Kommunikationssituation, andererseits durch die Anordnung in der linken Spalte als Frage und Aufforderung zu einer Antwort verstanden werden. Die Analyse der mittleren und rechten Spalte zum Beispiel aus Tabelle 5-4 lässt sich auch auf die entsprechenden Spalten von Tabelle 5-5 übertragen. Die zweithäufigsten Schriftelemente der mittleren Spalte sind nach ja/nein-Antwortmöglichkeiten Maßeinheiten wie $\mathrm{cm}$, $t$ etc. Ihre häufiges Vorkommen hat zur Folge, dass die rechte Spalte der Bieterantworten häufig quantitative Angaben in Form von Ziffern enthält, wie beispielsweise in Tabelle 5-3.

Der größere Teil der Lexik innerhalb der mittleren Spalte kann weder einem beteiligten Organisationsbereich noch einem Themenmodul zugeordnet werden, sondern ist vielmehr auf die Kommunikationsform Formular zurückzuführen (s. Abbildung 5-19). Beispiele für die Zuordnung bilden Angabe, Anzahl, 
Merkmal, Kriterien, Bezeichnung, die Antwortmöglichkeiten ja/nein usw. in weitgehend allen Themenmodulen der Pflichtenhefte 1, 2 und 3.

Ausnahmen in der Lexik der mittleren Spalte stellen Nomen dar, die als Jargon erscheinen wie das onomatopoetische Nomen Gong (PH 2; ebd., S. 471) oder das polyseme, metaphorisch verwendete Nomen Laufband (PH 2; ebd., S. 475). Augenfällig ist auch die Metaphorizität folgender Nomen, die in den Pflichtenheften verwendet werden, gegenüber dem weiteren Fachtextwortschatz dieser Textsortenexemplare: Durch die Metapher Kopfstützen mit Öhrchen/2 kleine Öhrchen (PH 1) in der linken bzw. rechten Spalte werden Form und Position der Kopfstützen vom Ausgangsbereich der Metapher (dem menschlichen Körper, speziell dem menschlichen Ohr) übertragen auf den Zielbereich der Schienenfahrzeugtechnik, speziell auf den technisch-physikalischen Gegenstand Kopfstütze eines Sitzes. Die Diminutiv-Endung - chen deutet zudem an, dass es sich um kleine Aussparungen an der Sitzoberseite handeln muss. Die Metapher Spenderfahrzeuge (ebd.) in der linken Spalte stellt eine Eigenschaft der Realtechnik sprachlich analog zu menschlichem Verhalten als intelligent und/oder fürsorglich dar: ${ }^{210}$ So wird das menschliche Verhalten, Blut, ein Organ oder Knochenmark zu spenden, sprachlich analog zu Fahrzeugumbau, dem sogenannten Re-Design gebildet. Dabei wird im gebrauchten Fahrzeug Material eingebaut, damit es den technischen und gesetzlichen Anforderungen entspricht. Die Verwendung dieser Metapher ermöglicht es, die Bedeutung des Terminus Re-Design (PH 1) bzw. Re-Design-Fahrzeuge nachvollziehen zu können.

Nur einige mittlere Spalten enthalten lexikalische Formen, die derart fachsprachlich sind, dass sie einem der beteiligten Organisationsbereiche zugeordnet werden können (s. Abbildung 5-19): beispielsweise dem Bereich Schienenfahrzeugtechnik Angabe [sic] an welchen Drehstellen (PH 2), Höhe (cm) über SOK, Anzahl Stufen/Breite Spaltmass [sic] (cm) (PH 3); dem Bereich Recht zugelassen/zulassungsfähig (PH 1). Die thematische Zuordnung der Lexik, die die mittleren Spalte enthält, ist teilweise auf ein Themenmodul beschränkt -

210 Diese Beschreibung verwendet JAKOB (1991, S. 64), um das Mensch-Metaphern-Modell zu bestimmen, der sich die Metapher Spenderfahrzeug zuordnen lässt. 
beispielsweise Höhe (cm) über SOK, Anzahl Stufen/Breite Spaltmass [sic] zum Themenmodul Einstieg(-sverhältnisse) (PH 1, S. 3; PH 2, S. 45 PH 3, S. 5 f.). Bereits die Analyse des Textdesigns veranschaulicht Meronym-Holonym-Relationen zwischen der Kapitelüberschrift Innenausstattung und den untergeordneten Schriftmodulen Sitze, Sitzreihenabstand, Gepäckunterbringung. Auch der größte Teil des Fachtextwortschatzes aus dem Bereich ,Schienenfahrzeugtechnik' steht in einem Meronym-Holonym-Verhältnis. So stellen die meisten Nomen ein Meronym zum Holonym Fahrzeug dar.

Diese Meronyme erzeugen mehrere Themenmodule: So kann das Fahrzeug grundsätzlich in die Meronyme Antrieb, Bremsen und Außenmaße eingeteilt werden, die ein Themenmodul bilden. Von diesen Meronymen abzugrenzen ist das Meronym Wagenkasten bzw. Wageninneres, das das umfangreichste Themenmodul mit Teilthemenmodulen wie Sitze, Mehrzweckbereich, Toilette etc. bildet (s. Abbildung 5-19). Die Nummerierung der Seiten, Kapitel und Abbildungen ordnet die Themenmodule im Textsortenexemplar von Antrieb/Bremsen/Außenmaße als Fahrzeugäußeres hin zum Wagenkasten als Fahrzeuginneres an.

Aufgrund fehlender Referenzkorpora aus den Fächern, die an der Projektkommunikation beteiligt sind, wird die Zuordnung von Fachtextwortschatzgruppen zu Organisationsbereichen interpretiert: Der Fachtextwortschatz setzt sich aus fahrzeugtechnischer, juristischer, betriebsplanerischer Lexik - zum Teil Terminologie $\mathrm{e}^{211}$ - und formularbedingter Lexik zusammen. Letztere behandelt bereits obige Analyse der elliptischen Frage-Antwort-Strukturen. Die Lexik der meisten Themenmodule ist dem Organisationsbereich Fahrzeugtechnik zuzuordnen.

211 Viele lexikalische Einheiten sind nicht definiert, beispielsweise Öhrchen, und können daher nicht als fachsprachliche Terminologie (ARNTZ/PICHT/SCHMITZ, ${ }^{7} 2014$, S. 118 f.) im engeren Sinne gelten. 


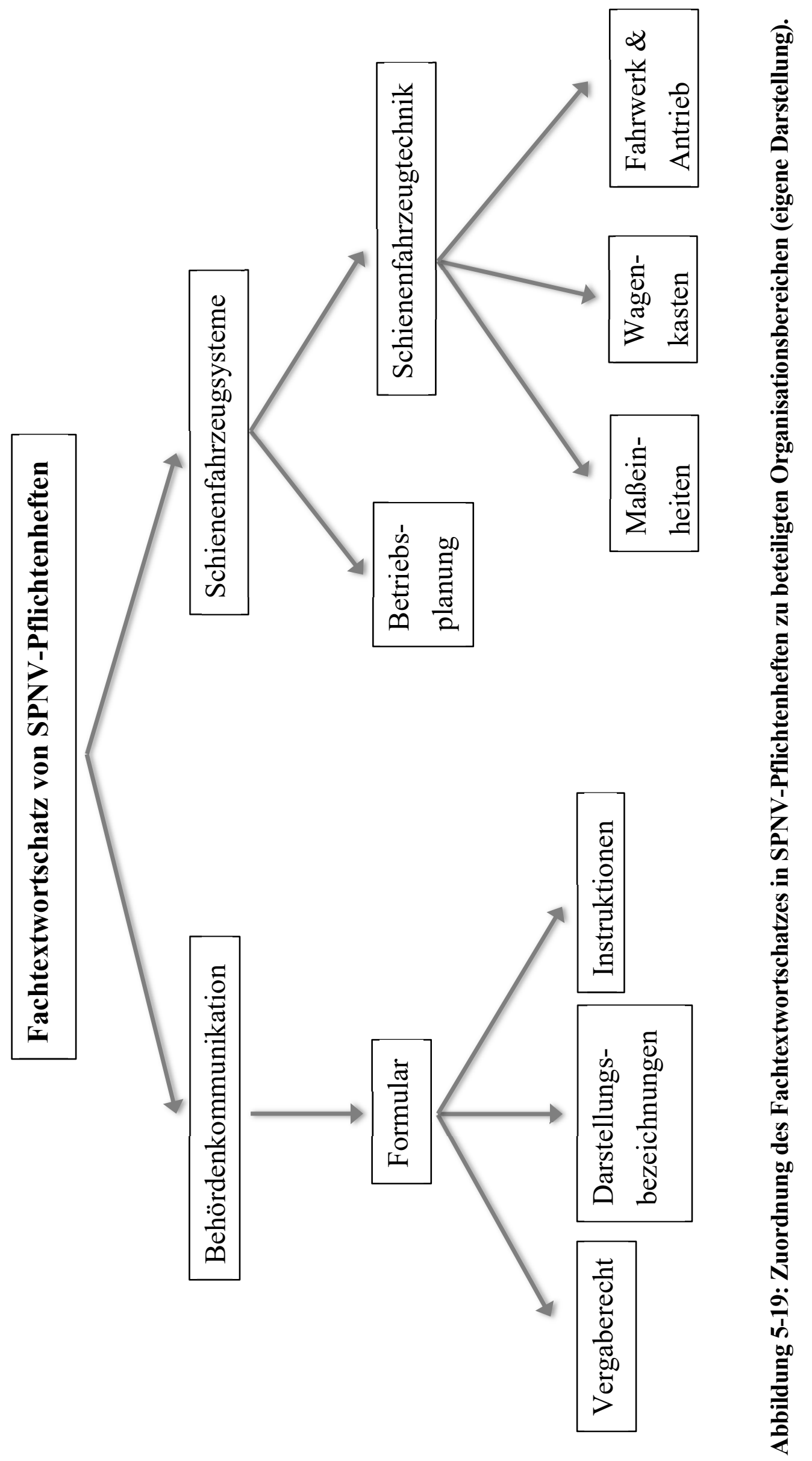


Eine Ausnahme stellen lediglich folgende Module dar: das Teilthemenmodul Generalklauseln durch juristische Lexik, das Themenmodul Betriebskonzept (PH 1) durch Lexik der Betriebsplanung wie Höchstgeschwindigkeit, Kupplungen etc. (ebd.) und das Bilderabstract durch die überwiegende Verwendung ikonisch-materieller Bilder (s. Abbildung 5-19). An einigen Stellen durchmischt sich die juristische und technische Terminologie als doppelte Fachsprachlichkeit der interfachlichen Kommunikation wie in Brandschutzklasse/-stufe (PH 1) oder PRMPlätze (PH 3), die beide durch die Definition in der angegebenen DIN-Norm bzw. der TSI PRM als Terminus des Rechts und der Technik gelten können.

Die Analyse der elliptischen Frage-Antwort-Strukturen hält bereits fest, dass die weitgehend vollständige Syntax ${ }^{212}$ der Generalklauseln (z. B. PH 1) strukturell augenfällig ist und kaum auf Mittel des Textdesigns wie Subordination durch Einrückungen zurückgreift (s. Kapitel 5.2.1). Auch kondensierende Formen wie Genitivattribute, weitere Attribute oder elliptische Formen werden nicht mehrfach gebraucht. Vielfach gebrauchen Tabellenfächer der linken Spalte Nomen als Ellipsen für einen vollständigen Satz (z. B. Mehrzweckraum; s. Tabelle 5-4), wodurch die Bedeutung dieser Nomen abhängig von der textuellen Einbettung werden. Demgegenüber ermöglicht die vollständige Syntax der Generalklauseln dadurch, dass sie unabhängig von der textuellen Umgebung verstanden werden können, juristisch eindeutig zu sein. Denn das Pflichtenheft wird bei Zuschlagerteilung Teil des Verkehrsvertrags (s. Kapitel 4.2.2), sodass die enthaltenen Angaben juristisch verbindlich werden.

Auf semantischer Ebene ist der Fachtextwortschatz der Generalklauseln weitgehend als juristische Lexik bestimmt, die dem Organisationsbereich Recht zugehört. Dies wird am Beispiel der drei Generalklauseln aus Pflichtenheft $1^{213}$ zum Fahrzeuginnenraum und -antrieb veranschaulicht:

212 Einzuschränken ist, dass Nominalphasen wie Fahrzeug entspricht (s. Beispielsatz 5-2) und Fahrzeug ist (s. Beispielsatz 5-3) Nullartikel verwenden. In Beispielsatz 5-7 fehlt eine flektierte Form des Hilfsverbs sein.

213 Strukturell und semantisch identische Formulierungen finden sich in Pflichtenheft 2 und Pflichtenheft 3 (PH 2; PH 3). 
Fahrzeug entspricht demn [sic] jeweils geltenden einschlägigen gesetzlichen Vorgaben.

\section{Beispielsatz 5-2}

Fahrzeug ist nach näherer Maßgabe des Kap. 1.5 zugelassen oder zulassungsfähig.

\section{Beispielsatz 5-3}

Das Fahrzeug erfüllt uneingeschränkt alle in der Leistungsbeschreibung definierten Mindestanforderungen und mit ihm ist die Durchführung des vorgegebenen Betriebsprogramms gewährleistet.

\section{Beispielsatz 5-4}

Die Lexik der drei weiteren Generalklauseln des Themenmoduls Infrastrukturbedingte Fahrzeuganforderungen gehören im Gegensatz zu den ersten drei Klauseln nicht nur zur Rechtssprache, sondern auch zur Lexik der Betriebsplanung - Sie beziehen sich also darauf, ob ein bestimmter Fahrplan mit diesem Fahrzeug umgesetzt werden kann:

Anforderungen des Infrastrukturbetreibers sind erfüllt.

\section{Beispielsatz 5-5}

Technische Netzzugangskriterien des befahrenen Streckennetzes werden erfüllt.

\section{Beispielsatz 5-6}

Fahrzeuge netzweit im ausgeschriebenen Netz zugelassen.

\section{Beispielsatz 5-7}

Um juristische Terminologie handelt es sich beim Partizip I geltenden (s. Beispielsatz 5-2) und bei den Verbformen erfüllt s. Beispielsatz 5-4, 5-5, 5-6) sowie gewährleistet (s. Beispielsatz 5-3). Diese Verbformen stellen Konversionen der Nomen Erfüllung und Gewährleistung dar, deren Bedeutung in ihrer Verwendung beispielweise das BGB festlegt (§ 365). Die Lexeme Erfüllung und Gewährleistung können als Terminologie des BGB keiner juristischen Teildisziplin zugeordnet werden. Dagegen definiert die „Verdingungsordnung für Leistung - Teil A“ (VOL - A) die Bedeutung der folgenden Nomen aus Beispielsatz 5-4, sodass 
diese der Terminologie der juristischen Teildisziplin Vergaberecht zuzuordnen sind: Leistungsbeschreibung ( $(8 \mathrm{VOL}-\mathrm{A})$ und Mindestanforderungen/Anforderungen ( 9 , Abs. 2 VOL - A). Lediglich das Nomen Fahrzeug als Subjekt der Beispielsätze 5-2, 5-3 und 5-4 entstammt nicht dem Organisationsbereich Recht, sondern der Fahrzeugtechnik bzw. der Allgemeinsprache.

Das Nomen Generalklauseln und die Nominalphrase Infrastrukturbedingte Fahrzeuganforderungen nutzen darüber hinaus lexikalische Mittel der Verweistechniken, die für Rechtstexte typisch sind. ${ }^{214}$ Teil dieser Verweistechnik sind die Präpositionalgruppen nach Maßgabe des Kap. 1.5 (s. Beispielsatz 5-3) und in der Leistungsbeschreibung (s. Beispielsatz 5-4), während die Nominalphrase geltenden einschlägigen gesetzlichen Vorgaben (s. Beispielsatz 5-2) wesentlich unspezifischer und allgemeingültiger auf Gesetze verweist.

Die vollständige Syntax der Kommentierung von Abbildungen, die die kommissive Funktion von Bildern (s. Kapitel 5.2.2) ausschließt, deutet auf den Organisationsbereich Recht: Alle Abbildungen: Die dargestellte Ausstattung entspricht nicht in allen Belangen der angebotenen Ausstattung. Maßgeblich ist der Inhalt der Tabelle. (PH 3, S. 1; ähnlich in PH 2, S. 1 f.) Gegenüber diesem strukturellen Merkmal, das im Pflichtenheft auffällig ist, kann die Lexik der Kommentierung wie entspricht oder maßgeblich nicht eindeutig als juristisch klassifiziert werden.

Folgende Mittel der horizontalen Themenstruktur prägen die Verwendung des Fachtextwortschatzes in Lasten- und Pflichtenheften. Die untersuchten Textsortenexemplare der Optimierungsvorschläge nutzen nicht nur ein anderes Themenentfaltungsmuster (s. Kapitel 5.1.3), sondern auch andere Mittel der horizontalen Themenstruktur als die drei Pflichtenheftexemplare. Dieser Unterschied ist weitgehend auf deren unvollständige Syntax zurückzuführen. Die linke Spalte der Pflichtenhefte substituiert vollständige Syntax schwundgrammatisch durch Textdesign (s. Kapitel 5.2.1) und folgende Mittel der horizontalen Themenstruktur:

214 In Verträgen wirkt eine „hochentwickelte Verweistechnik [...] mit dem Blick auf andere Texte (Intertextualität), z. B. $\S \S 325,326$ BGB; Urkunde des Notars [...] vom [...] UR Nr. [...]" (HofFMANN, 1998, S. 537; Kursive im Original). 
- Genitivattribute wie Anzahl der Fahrzeuge

- Präpositionalgruppen wie in Sitznähe

- attributive und prädikative Verwendung von Adjektiven wie klappbarer Sitz bzw. Sitz klappbar, die Prädikate kondensieren

- Nominalisierungen, die Prädikate kondensieren wie Aufhängung

- Holonym-Meronym-Relationen bzw. Meronym-Meronym-Relationen wie das Holonym Sitze zu den Meronymen Vis-á-Vis-Bestuhlung und Reihenbestuhlung, die teilweise Prädikate ersetzen

- weitere Konnektoren wie sofern

Die Genitivattribute treten überwiegend als (nachgestellte) possessive Genitivattribute, speziell als Genitivus subiectivus (DUDEN, ${ }^{8} 2009$, S. 825) auf. ${ }^{215}$ Die obige Beschreibung der Nominalphrase Breite des Fahrzeugs und Interpretation als Ellipse des Fragesatzes Wie breit ist das Fahrzeug? veranschaulichen auch, dass das Genitivattribut des Fahrzeugs eine vollständige Syntax kondensiert. Grundsätzlich bestimmen qualifizierende Adjektive semantische Eigenschaften wie Farbe, Geschmack, aber auch die Form wie die Adjektive oval, breit, lang etc. (DUDEN, ${ }^{8} 2009$, S. 339). Dementsprechend determiniert das Prädikativ breit die Eigenschaft des Subjekts Das Fahrzeug. Übertragen auf das Beispiel der Nominalphrase mit Genitivattribut - Breite des Fahrzeugs - bestimmt der Nominalphrasenkern Breite demnach eine Eigenschaft des Genitivattributs des Fahrzeugs. Entsprechende Konstruktionen nutzt auch PfLichTENHEFT 1, beispielsweise: Art der Spaltüberbrückung (PH 1), Material der Gepäckablageflächen (ebd.), Lage der Türöffner (ebd.), Art der Handtrocknung (ebd.), Art der Deckenbeleuchtung (ebd., S. 8). Und auch Pflichtenheft 2 bindet diese Konstruktion in die horizontale Themenstruktur ein, beispielsweise: Alter der Fahrzeuge (PH 2), Lichte Breite der Türspuren (ebd.), Länge des Fahrzeugs (ebd.), Breite des Fahrzeugs (ebd.), Bereich der Toilette (ebd.), Anzahl der Klappsitze (ebd.).

215 Der Genitivus subiectivus wird im Gegensatz zu weiteren Genitivattributformen nicht durch die Lexik, sondern strukturell durch eine Umstellprobe und die Einordnung als Satzglied bestimmt: Die Nominalphrase Die Freundlichkeit der Kellnerin (ebd., S. 825) kann derart umgestellt werden, dass das Genitivattribut zum Subjekt und der Phrasenkern durch Konversion (ebd., S. 667) zum Prädikat des Satzes wird: Die Kellnerin war freundlich. Weitere Genitivattributformen sind der Genitivus qualitatis wie Ein Mensch guten Willens (DUDEN, ${ }^{8} 2009$, S. 830) oder der Genitivus explicativus wie das Rechtsmittel des Einspruchs (ebd., S. 831). 
Zur Gruppe dieser Konstruktionen zählen auch variierte Formen wie Bezeichnung der verwendeten Kupplungen (ebd.). Denn die attributiv gebrauchte Partizip-IIForm verwendeten versprachlicht keine wertenden Eigenschaften wie in der Phrase Ein Mensch guten Willens oder anderen Formen des Genitivus qualitatis (s. Fußnote 215).

Einige Konstruktionen kondensieren diese Nominalphrasen mit Genitivattributen, indem sie den bestimmten Artikel des Attributs tilgen, z. B.: Anteil Vis-á-Vis Sitzplätze [sic] (PH 1), Anzahl Türspuren (ebd.), Anzahl Notsitze (PH 2), Typ Sitzaufhängung (ebd.), Anzahl Rollstuhl-/Kinderwagenplätze (ebd.). Auch hier sind variierte Formen wie Anzahl gewertete Sitzplätze (PH 2) der Analysekategorie zuzuordnen, weil das attributiv verwendete Partizip II gewertete keine wertenden Eigenschaften versprachlicht wie Formen des Genitivus qualitatis (guten Willens). Auffällig ist an diesen Konstruktionen, dass sie weitgehend im Themenmodul Sitzplätze platziert werden. Genitivattributkonstruktionen und ihre gekürzten Formen tragen dazu bei, die sprachlichen Mittel der Textsortenexemplar extrem zu verdichten.

Die horizontale Themenstruktur der Lasten- und Pflichtenhefte konstituieren des Weiteren Präpositionalgruppen, die Teil von Nominalphrasen sind und dem Phrasenkern nachgestellt werden. Beinahe alle Präpositionen werden in den Pflichtenheften als Teil von Präpositionalphrasen mit Nominalkern verwendet. Grundsätzlich sind lokale, temporale, kausale Präpositionen ${ }^{216} \mathrm{zu}$ unterscheiden (DUDEN, ${ }^{8} 2009$, S. 604 ff.), die alle in den Textsortenexemplaren vorkommen. Im Folgenden werden die Präpositionalgruppen entsprechend dieser Differenzierung zusammengefasst und in ihrer Funktion analysiert. ${ }^{217}$

In den Pflichtenheften ${ }^{218}$ sind als größte Gruppe lokale Präpositionen zu differenzieren, die

216 Die ersten beiden Kategorien dieser Unterscheidung sind auf eine Ich-jetzt-hier-Origo (ebd., S. 1215) zurückzuführen.

217 Reihungen von Präpositionalphrasen wie Gepäckablage in Kopfhöhe in Sitznähe von jedem festen Sitzplatz (PH 1) werden innerhalb dieser Kategorien ggf. mehreren der drei Kategorien zugeordnet.

218 Weitgehend identische Beispiele finden sich in Pflichtenheft 2 und Pflichtenheft 3. 
- Gegenstände im Fahrzeuginneren verorten wie Armlehnen am Fenster (PH 1), Armlehnen zum Gang (ebd.), Haltegriffen [sic] an allen Sitzen zum Gang (ebd.), bei Türen im Übergang (ebd.), an allen Außentüren (ebd.), Hinweisaufkleber im Fahrzeug (ebd.),

- zwei Gegenstände innerhalb des Fahrzeuginnenraums relationieren oder verorten wie zwischen den Einzelsitzen (ebd.), Sitze in Längsrichtung (ebd.), unter den Vordersitzen (ebd.), Gepäckablage über allen Klappsitzen (ebd.), Haltegriffen [sic] an allen Sitzen zum Gang (ebd.), Gepäckablage [...] in Sitznähe (ebd.),

- das Fahrzeug aus der Perspektive eines nicht explizit genannten Fahrzeugnutzers beschreiben, der durch den Fahrzeuginnenraum geht wie barrierefreier Zugang vom Einstiegsbereich zum Rollstuhlstellplatz (ebd.),

- einen Gegenstand mit Betrachterstandpunkt dieses Fahrzeugnutzers relationieren wie Gepäckablagen in Kopfhöhe (ebd.), Notruftaster vom WC aus sowie vom Boden liegend erreichbar (ebd.), nur von innen möglich (ebd.), Verbindung zum Fahrer durch optische Anzeige (ebd.),

- Raumdeixis im Sinne von räumlichen Maßen des Fahrzeugäußeren realisieren wie über Puffer (ebd.), über gesamte Fahrzeugbreite (ebd.),

- den Fahrzeugübergang raumdeiktisch beschreiben wie Spaltmaß an $76 \mathrm{~cm}$ (ebd.), Spaltüberbrückung bei 76 cm (ebd.), Einstiegsverhältnisse mit Höhen-/ Spaltmaß (ebd.),

- geographisch verorten wie Fahrzeuge netzweit im ausgeschriebenen Netz (ebd.),

- Abstrakta wie Mindestanforderungen in der Textstruktur der Verdingungsunterlagen verorten, z. B. alle in der Leistungsbeschreibung definierten Mindestanforderungen (ebd.) und

- Gegenstände in der Textstruktur des Lasten-/Pflichtenhefts zuordnen wie Haltestangen [...] in der Zeichnung (ebd.).

Eine weitere große Gruppe bilden kausale Präpositionen im weiteren Sinne (DUDEN, 2009, S. 605 f.), die

- den Geltungsbereich des Nominalkerns durch die Präpositionalphrase beim Gegenstand Fahrzeug einschränken wie bei Gebrauchtfahrzeugen (PH 1), mit ihm [dem Fahrzeug] (ebd.), bei gegenüberliegenden Türen (ebd.), mit Rampe 
(ebd.), Festsitze mit klappbarer Sitzfläche (ebd.), Sitzplätze mit Sitzreihenabstand (ebd.), 1. Klasse mit transparenten Trenntüren (ebd.), Überfahrrampe für Elektrorollstühle (ebd.),f.[ür] Funktionsbereiche (ebd.), Aushangmöglichkeiten für Aufgabenträger (ebd.), max. Belastung je Steckdose (ebd.), bei unbesetzten Klappsitzen (ebd.), und in der markierten Form Hinweisaufkleber [...] bezügl. Abfallbehälter (ebd.),

- Bedingungen der Nutzung für bzw. durch den deagentivierten Nutzer aufführen wie Informationen zum eigenen Zug (ebd.), per Fuß bedienbarer Toilettendeckel (ebd.), Bei Freigabe grün und nach Betätigung bis Türöffnung rot (ebd.),

- das Agens einer Handlung beschreiben wie durch TF [Triebfahrzeugführer] (ebd.), Notbelüftung durch (abschließbare) Kippfenster (ebd.) und

- Bedingungen durch intertextuelle Verweise präzisieren wie manuelle Klapprampe nach Vorgaben der TSI PRM (ebd.), Klimatisierung entsprechend EN Norm 14750-1 (ebd.), nach näherer Maßgabe des Kap. 1.5 (ebd.).

Temporale Präpositionen wie vor der voraussichtlichen Ist-Ankunft (ebd.) verwenden die Lasten- und Pflichtenhefte kaum. Festzuhalten ist, dass Präpositionen eine wesentliche Rolle bei der Konstitution der horizontalen Themenstruktur spielen, insbesondere bei der Konstitution von Raumdeixis. Augenfällig ist die Gruppe der Präpositionalgruppen, die syntaktische Konstruktionen mit explizit genanntem Agens substituieren.

Diese Präpositionalgruppen drücken die Darstellung eines physikalischen Gegenstandes aus funktionaler Perspektive aus, die für die Textsorte ,Pflichtenheft ${ }^{\text {* }}$ (KÖSLER, 2009, S. 66) in Verbindung mit einer Benutzerperspektive (ebd., S. 69) prototypisch ist. Folgende sprachliche Konstruktion drücken die funktionale Benutzerperspektive aus: die genannten Präpositionalgruppen, Adjektive in prädikativem Gebrauch mit der Endung -bar, elliptische Funktionsverbgefüge mit dem Adjektiv möglich, attributive Verwendungen verschiedener Adjektivformen und von Partizip-II-Gruppen und Nominalisierungen. Wie oben bereits ausgeführt wird, erklärt das Konzept der Schwundgrammatik diese elliptische Gestaltung. Das Textdesign des Formulars und der situative Kontext einer institutionell asymmetrischen Kommunikation machen es möglich, die Bedeutung und Funktion dieser sprachlichen Konstruktionen zu verstehen. 
Insbesondere Adjektive in prädikativem Gebrauch (DUDEN, ${ }^{8} 2009$, S. 352 ff.) gehören zu weiteren elliptischen Konstruktionen, die die funktionale Benutzerperspektive ausdrücken. Prädikative schaffen einerseits satzwertige semantische Einheiten, andererseits generieren sie eine konsistente Perspektive auf den Textgegenstand. Wie die bereits genannten verkürzten Sprachformen dieser Textsortenexemplare werden auch die Prädikative elliptisch gebraucht, indem die flektierte Form des Hilfsverbs sein ausgelassen wird. Durch die Endung -bar zeigen die Adjektive die Möglichkeit an, einen Vorgang auszuführen. So kann der elliptische Dialog der linken und mittleren Spalte (s. Beispielsatz 5-8) ausformuliert werden zu Beispielsatz 5-8

Sitztiefe/Lehnenneigung verstellbar - ja/nein (PH 1)

\section{Beispielsatz 5-8}

Sind die Sitztiefe und die Lehnenneigung verstellbar?

Ja, Sitztiefe und die Lehnenneigung sind verstellbar. Oder:

Nein, Sitztiefe und die Lehnenneigung sind nicht verstellbar.

\section{Beispielsatz 5-9}

Da die Lehne nur durch einen Nutzer verstellt werden kann, impliziert diese Frage eine Person, die den physikalischen Gegenstand nutzt. Als weitere Adjektive in prädikativem Gebrauch nutzt z. B. Pflichtenheft 1 folgende elliptische Dialoge:

(a) Art der Spaltüberbrückung - fest/ausfahr-/ausklappbar (PH 1),

(b) Mittelarmlehne 1. Klasse-Angabe fest/klappbar (ebd.),

(c) Fußraum jeweils unter den Vordersitzen nutzbar - ja/nein (ebd.),

(d) [Überfahrrampe für Elektrorollstühle] nutzbar bei Bahnsteighöhe - von bis (cm) (ebd.)

(e) Türöffner taktiv erkennbar - ja/nein (ebd., S. 6), Notruftaster [...] vom Boden liegend erreichbar (ebd.).

Wie Adjektive mit der Endung -bar in prädikativem Gebrauch drücken auch Komposita die Nutzerperspektive indirekt aus, die mit einer Adjektiv gebildet werden - beispielsweise [Anzahl Toiletten] davon behindertengerecht (ebd.). 
Neben Adjektiven, die auf -bar enden, wird das Adjektiv möglich elliptisch prädikativ gebraucht, um die Nutzerperspektive indirekt auszudrücken, beispielsweise Türverriegelung nur von innen möglich (ebd.). Diese Nominalphrase kann als Ellipse für das abstrahierte Funktionsverbgefüge Eine Verriegelung ist nur von innen möglich. interpretiert werden. Die Pflichtenhefte nutzen mehrere dieser Konstruktionen - beispielsweise Wendezugbetrieb möglich (ebd.); Traktionsbildung möglich mit Fahrzeugtypen (ebd.); Zweirichtungsbetrieb - möglich: ja/nein (ebd.), zentrale Überwachung/Aufzeichnung auch bei gekuppelten Fahrzeugen möglich-ja/nein (ebd.).

Auch die attributive Verwendung von Adjektiven (DUDEN, ${ }^{8} 2009$, S. 341 f.) mit der Endung -bar unterstützt die Darstellung des Gegenstands aus Anwendersicht. Diese Attribute ersetzen den Gebrauch von Prädikaten: So kann die Nominalphrase klappbarer Wickeltisch (PH 1) ausformuliert werden zum vollständigen Satz Der Wickeltisch kann auf-/zugeklappt werden. Pflichtenheft 1 nutzt folgende identische Konstruktionen: verschiebbare Haken (ebd.), automatisch klappbare Türtrittstufe im Fz [Fahrzeug] (ebd.), Festsitze mit klappbarer Sitzfläche (ebd.). Diese Funktion erfüllen auch Konstruktion mit: a) Partizip-II-Formen wie luftgefederte Drehgestelle (ebd.); b) Adjektiven auf die Endung -frei wie barrierefreier Zugang (ebd.); c) Adjektiven auf die Endung -ive wie Bereichselektive Türöffnung (ebd.) usw.

Auch Nominalisierungen drücken diese funktionale Anwendersicht aus. Denn sie basieren auf Adjektiven oder Verben, die Handlungen eines Anwenders darstellen. Beispielsweise nutzt Pflichtenheft 1 Komposita mit dem Grundwort -möglichkeit, das das Adjektiv möglich nominalisiert: ${ }^{219}$ Kopfstützen m.[it] Durchsichtmöglichkeit (ebd.), Festhaltemöglichkeiten (ebd.), Durchgangsmöglichkeiten (ebd.), Aushangmöglichkeiten (ebd.). Folgende Konstruktionen nominalisieren Prädikate mit einer Anwenderperspektive: Türöffnung (ebd.), Türschließkontrolle (ebd.), Gepäckablage (ebd.), Schwenklift (ebd.), Anforderungstaste (ebd.) usw. Diese Nominalisierungen kommen in wenigen Fällen auch

219 Ähnlich setzen die Lasten- und Pflichtenhefte die oben beschriebenen prädikativen Konstruktionen mit möglich ein. 
außerhalb eines Kompositums vor: Automatisches Öffnen/Schließen der Außentüren (ebd.), Einstieg mit Rampe (ebd.).

Die beschriebenen schriftsprachlichen Kommentare zu Fotos und die Verweise des Grundrisses auf Schriftmodule betreffen bereits logisch-semantische SchriftBild-Relationen.

\subsubsection{Logisch-semantische Sprache-Bild-Relationen}

Die Analyse der logisch-semantischen Sprache-Bild-Relationen gliedert sich entsprechend den Kriterien des integrierten Analyserasters zu interfachlichen Sprache-Bild-Textsorten (s. Abbildung 3-10). Zum Teil werden auch Merkmale des ,Textdesigns“ (s. Abbildung 3-2) berücksichtigt. Sie ermöglichen neben der Rezeption entsprechend den Enumerationsmitteln (Kapitel-, Seiten- und Abbildungsnummerierungen) auch weitere Rezeptionsabfolgen.

Wie das Kapitel ,Themenstruktur ${ }^{6}$ bereits aufzeigt, verweisen die im Grundriss eingezeichneten physikalischen Gegenstände des Fahrzeuginnenraums aller drei Pflichtenhefte (z. B. PH 1; Abb. 3) auf die entsprechenden Schriftmodule, die diese Gegenstände näher darstellen. Seine Einfärbungen und Beschriftungen machen die vier Grundrisse aus der Zeichnung von Pflichtenheft 3 gegenüber den Grundrissen der anderen Pflichtenhefte (PH 1; PH 2; PH 3) auffällig. Die in ihm enthaltenen Sprache-Bild-Relationen werden im Folgenden genauer analysiert (PH 3):

Im untersten Grundriss der Zeichnung färben orange Flächen viele rechteckige Flächen, die Sitze repräsentieren. Die Einfärbung ist mit dem Element Gepäckablagen beschriftet, das im selben Orangeton gehalten ist und unmittelbar oberhalb einer dieser Flächen positioniert ist. Durch diese Beschriftung wird die Bedeutung der Farbflächen deutlich. D. h., die ,Textdesign'-Kategorien ,Farbe‘ und das ,Gesetz der Nähe‘ verknüpfen ein Sprache- und ein Bild-Element. Die ,Farbe‘ des Schriftelements Gepäckablagen nimmt zudem Einfluss auf dessen Schriftbildlichkeit. Ohne das Schriftelement wäre die Bedeutung der orangefarbenen Flächen unklar, während die Bedeutung des Schriftelements auch ohne die Farbfläche verstanden werden kann. Zwischen dem Schriftelement Gepäckablagen und der Farbfläche besteht also augmentative Komplementarität (augmentation complement). Diese Beziehung gehen alle Schriftelemente des Grundrisses in 
PH 3 mit den ihnen zugeordneten bildlichen Elementen ein. Des Weiteren ist zwar das Schriftelement Gepäckablagen unabhängig von den Farbflächen verständlich. Die Farbflächen präzisieren aber die Bedeutung des Schriftelements um die Angabe der räumlichen Lage und Anordnung (enhancement - place). Dieses Verhältnis besteht ebenfalls zwischen allen Elementen der Zeichnungen, die physikalische Gegenstände des Fahrzeuginnenraums darstellen und beschriftet sind. Somit können zwei logisch-semantische Relationen zwischen Schriftelement und positionierten Farbflächen bestimmt werden.

Die beiden Relationen augmentative Komplementarität und Verbesserung der Angabe von räumlicher Lage und Anordnung besteht darüber hinaus in den Grundrissen von PH 3 zwischen: ${ }^{220}$ a) dem Schriftelement Videoüberwachung und den blau-, rot- und lilafarbenen Kuchenstückformen; ${ }^{221}$ b) den drei identischen Schriftelementen Ausgewiesene PRM-Plätze und den lilafarbenen Flächen oder Rechtecken; c) dem Schriftelement Begleitplätze nach TSI PRM und den lilafarbenen Rechtecken (die Farbe wird daher verschiedenen Schriftelementen zugeordnet, sodass der Bezug nicht mehr eineindeutig ist); d) dem Schriftelement Behindertengerechtes $W C$ und dem blauen Rechteck mit einem Halbkreis an der rechten Seite; e) dem Schriftelement Rampe und einer grauen Linie; f) dem Schriftelement Abfallbehälter und einem grauen Rechteck. ${ }^{222}$

Folgende Relationen bestehen zwischen diesen sechs diagrammatischen SchriftBild-Elementen der technischen Zeichnung in PH 3 und mehreren Schriftmodulen, die auf den Folgeseiten in PH 3 an diese Zeichnung anschließen. Dabei entsteht die Sprache-Bild-Relation durch eine schriftsprachliche Rekurrenz zwischen dem Schriftelement des Schriftmoduls und dem Schriftelement von einem der

220 Im Gegensatz zum vorangehenden Beispiel Gepäckablagen werden die Schriftelemente alle in Schwarz gehalten, nehmen also nicht die Farben der Fläche/Rechtecke an, auf die sie verweisen. Darüber hinaus expliziert jeweils eine rote Linie grafisch den Bezug des Schriftelements zum Bildelement.

221 Im Gegensatz zu den Gepäckablagen stellen diese Flächen aber keine physikalischen Gegenstände, sondern den Bereich dar, den die Videokameras aufzeichnen können. So bilden die Spitzen der acht kuchenstückförmigen Flächen jeweils den Punkt, an dem eine Kamera installiert ist. Dadurch erklärt sich auch, warum die Flächen über die Begrenzungslinien des Fahrzeugs hinausragen.

222 Die Schriftelemente Rampe und Abfallbehälter könnten aufgrund des ,Gesetzes der Nähe‘ fälschlicherweise als semantische Einheit wahrgenommen werden. 
sechs oben aufgeführten diagrammatischen Elemente (z. B. Gepäckunterbringung):

1. Das Schriftmodul Gepäckunterbringung (PH 3), insbesondere die Nominalphrase in Kopfhöhe als Teil der Nominalphrase Gepäckablagen in Kopfhöhe in Sitznähe von jedem festen Sitzplatz (ebd.), spezifiziert die räumliche Lage des diagrammatischen Schrift-Bild-Elements Gepäckablagen mit orangefarbenen Flächen. Denn die Höhe der Ablagen wird aus der technischen Zeichnung nicht ersichtlich. Die Präpositionalphrase in Sitznähe von jedem festen Sitzplatz (ebd.) desselben Schriftmoduls präzisiert die Angabe der Art und Weise der eingezeichneten Sitze: Alle Sitze, über die in der Zeichnung eine orangefarbene Fläche gelegt ist, sind folglich feste Sitze.

2. Das diagrammatische Videoüberwachung mit verschiedenfarbigen Kuchenstückformen steht zum Schriftmodul Videoüberwachung in den Fahrzeugen, speziell der Nominalphrase Anzahl Kameras - 8 (PH 3), in einem augmentativkomplementären Verhältnis. Denn die schriftsprachliche Angabe der Anzahl an Videokameras (8) fasst die Darstellung der acht Spitzen von der jeweiligen Kuchenstückform als Positionierung der Kameras zusammen (augmentation - complement). Diese kuchenstückförmigen Flächen präzisieren die Bedeutung des Nomens Kameras aus diesem Schriftmodul um ihre Position im Fahrzeug (augmentation-complement). ${ }^{223}$

3. Das diagrammatische Schrift-Bild-Element Behindertengerechtes $W C$ mit blauem Rechteck verweist auf das Schrift-Bild-Modul Toilettenräume (PH 3), konkret auf die Nominalphrase Anzahl Toiletten mit den Unterkategorien davon vom Einstieg mit Rampe [...] barrierefrei erreichbare behindertengerechte Toilette sowie Bedienungsfreundlich gem. TSI PRM. Der weiße Untergrund, der sich zwischen der schematischen Darstellung und den Sitzen/dem Ausgang befindet,

223 Vergleichbar sind die logisch-semantischen Relationen zwischen den Sprache-Bild-Elementen des Grundrisses (PH 1) und den jeweiligen Schriftmodulen in Pflichtenheft 1 (ebd.). Anstelle von Farben wie in Pflichtenheft 3 nutzen die Grundrisse zur Beschriftung $A b b .3$ in Pflichtenheft 1 für die Darstellung der Überwachungskameras aber keine vollständig transparenten Flächen, die durch farbige Linien umgrenzt werden. Stattdessen setzt Pflichtenheft 1 Schraffuren ein. Die Schriftelemente werden an den ikonisch-bildlichen Elementen des Grundrisses ebenfalls durch Verweislinien verortet. Pflichtenheft 1 verzichtet in der Zeichnung zur Beschriftung $A b b .3$ aber auf die Einfärbung der ikonisch-schematischen Gegenstände wie bei Gepäckablagen in PH 3. 
stellt den Weg zum Toilettenraum dar. Die im Schriftmodul enthaltene Nominalphrase barrierefrei erreichbare Toilette präzisiert diesen weißen Untergrund in Bezug auf die Art und Weise (enhancement-manner), barrierefrei zu sein. Die Nominalphrase Bedienungsfreundlich gem. TSI PRM präzisiert die Nominalphrase Behindertengerechtes WC in der Art und Weise (enhancement-manner), in der der Toilettenraum behindertengerecht ist: Es muss den genauen Angaben entsprechen, die in der Norm TSI PRM vorgeschrieben werden.

4. Das diagrammatische Schrift-Bild-Element Behindertengerechtes WC mit blauem Rechteck (PH 3; Grundriss) verweist auf das Schrift-Bild-Modul Toilettenräume (PH 3), konkret auf die Zeichnung und das Foto zur Beschriftung Abb. 13. Als Bild-Bild-Relation konkretisiert das Foto des Moduls Toilettenräume das diagrammatische Schrift-Bild-Element Behindertengerechtes WC mit blauem Rechteck (ebd.; Grundriss) in der Art und Weise, wie die Oberflächen beschaffen, z. B. gefärbt, sind. Die technische Zeichnung aus dem Schrift-Bild-Modul Toilettenräume (PH 3) spezifiziert das diagrammatische Schrift-Bild-Element Behindertengerechtes WC mit blauem Rechteck ( $\mathrm{PH} 3$; Grundriss) darin, dass ein Türschließmechanismus vorhanden ist (also in der Art und Weise), und darin, wo dieser Türschließmechanismus positioniert ist (Angabe der räumlichen Lage).

5. Das im Grundriss enthaltene Schrift-Bild-Element Rampe mit grauer Linie verweist auf das Schrift-Bild-Modul Einstiegsverhältnisse (PH 3). Letzteres enthält sowohl Schriftelemente wie Angaben zur Einstiegshöhe/Spaltmaß etc. (ebd.) als auch eine technische Zeichnung zur Beschriftung Abb. 8 (ebd.), die mehrere Rampenneigungen zu verschiedenen Bahnsteighöhen darstellt. Die Angaben der Einstiegshöhen in der technischen Zeichnung mit der Beschriftung Abb. 8 und die schriftsprachliche Angabe im Tabellenfach des Moduls Einstiegsverhältnisse präzisieren das Schrift-Bild-Element Rampe mit grauer Linie (PH 3; Grundriss) darin, dass die Rampe für mehrere Einstiegshöhen geeignet ist (also in der Art und Weise).

6. Das Schrift-Bild-Element Rampe mit grauer Linie des Grundrisses ist des Weiteren mit dem Schriftmodul Einstiegshilfen (ebd.), konkret Überfahrrampe für Rollstühle (ebd.) verknüpft. Letztere Nominalgruppe konkretisiert die Zeichnung in der Art und Weise, um was für eine Art von Rampe es sich handelt. 
7. Das Schrift-Bild-Element Rampe mit grauer Linie im Grundriss (ebd.) präzisiert die Nominalgruppe Einstiegsbereich Wagen A aus dem Schriftmodul Einstiegshilfen (ebd.) durch die Angabe der räumlichen Lage.

8. Auch das Schrift-Bild-Element Abfallbehälter mit grauem Rechteck (Grundriss, PH 3, S. 2) verbessert die Bedeutung des Nomens Abfallbehälter aus dem gleichnamigen Themenmodul (ebd., S. 13) durch die Angabe der räumlichen Lage. Die Zeile Abfallbehälter je Eingangsbereich - Anzahl/Länge x Breite (cm)/Größe (Liter) - 1/35 x 32 / 14,5 aus demselben Modul verhält sich zum Grundriss augmentativ-komplementär, weil es die Anzahl der Abfallbehälter nennt. Die Angabe der Größe präzisiert den Grundriss dagegen als Angabe zum räumlichen Ausmaß (diese Relation erfasst am ehesten die Kategorie enhancement-place). ${ }^{224}$

9. Die Nominalphrase Begleitplätze nach TSI PRM und die Nominalphrase Ausgewiesene PRM-Plätze werden dagegen nicht explizit von einem Themenmodul aufgegriffen, verweisen aber implizit auf die Generalklausel Fahrzeug entspricht allen gängigen technischen und gesetzlichen Anforderungen (ebd.) ${ }^{225}$ und auf das Schriftmodul Sitze (ebd.). Dass diese logisch-semantische Sprache-BildRelation implizit zwischen dem Grundriss und dem Schriftmodul Sitze bzw. der Generalklausel besteht, stellt einen Sonderfall in dieser Textsorte dar. Daher wird im Folgenden der fachliche Hintergrund kurz erläutert, um den Verweis nachvollziehbar zu machen:

Die Norm TSI PRM gehört zu den geltenden technischen und gesetzlichen Regelungen, deren Einhaltung die Generalklauseln (s. Beispielsätze 5-2 und 5-3) in

224 Der Grundriss in Pflichtenheft 2 verbindet das Schrift-Bild-Element Wagen C mit schematischem Grundriss erstens mit dem Schriftmodul Mehrzweckbereiche/Sonderflächen (PH 2) und zweitens mit dem Modul Einstiegshilfen (ebd.). So verortet das Schrift-BildElement Wagen $C$ mit schematischem Grundriss räumlich, wo sich der im Schriftmodul durch das Initialwort MZR $C$ [Mehrzweckraum $C$ ] repräsentierte Wagen $C$ befindet. Diese Relation besteht für sämtliche Initialwörter dieses Schriftmoduls $(M R Z A, B, C, \ldots)$. Die Initialwörter und entsprechenden Quadratmeterangaben im Schriftmodul (ebd.) $M Z R$ [sic] $A$, $B$, D je 1 á 2,8; MZR C: 1 á 10,8; MZR E: 3 á 2,8 (ebd.) fassen diese räumlichen Angaben des Grundrisses (ebd.) zusammen, sodass auch zwischen diesen Elementen ein augmentativ-komplementäres Verhältnis besteht.

$225 \mathrm{Zu}$ äquivalenten Generalklauseln in den anderen Pflichtenheften s. Beispielsätze 5-2 und 5-3. 
den Pflichtenheften fordern. Die Empfehlungen der BAG SPNV, die wie oben beschrieben nach AUFTRAGGEBER 1 vollständig in die Lastenheftvordrucke einfließen (2013, S. 9), führen explizit die Anforderungen der TSI PRM zu Sitzplätzen aus, die für Personen mit eingeschränkter Mobilität (PRM) als Fahrgast notwendig sind (2010, S. 23). Konkret sind aus der TSI PRM drei Punkte für die Sprache-Bild-Relationen in den Pflichtenheften relevant. Der TSI PRM zufolge ist zu beachten, dass a), ,[m]indestens $10 \%$ der Sitzplätze je Triebzug oder Reisezugwagen sowie je Klasse [...] als Behindertensitze für PRM zu kennzeichnen [sind]“" (TSI PRM, 2008, S. 111); b) „die Armlehnen von Behindertensitzen beweglich sein [müssen]“ (ebd.); c) ,[d]ie gesamte nutzbare Sitzfläche des Behindertensitzes [...] mindestens $450 \mathrm{~mm}$ breit sein [ muss]“ (ebd.).

Die implizite Relation besteht demnach zwischen der Generalklausel (PH 3), dem Schriftmodul Sitze und dem Grundriss. Dieser Zusammenhang ergibt sich wie folgt: Das Schriftmodul Sitze, konkret das Untermodul Ausstattung, gibt als Anzahl gewertete Sitzplätze (1.+2.Klasse; inkl. Klappsitze) (PH 3) 130 Sitzplätze an. $10 \%$ von dieser Gesamtsitzplatzanzahl an PRM-Sitzen, wie die TSI PRM vorschreibt, sind damit mindestens 13 PRM-Plätze. Dass mit der Anzahl von 16 PRM-Plätzen diese Mindestanzahl übertroffen wird, weisen die 16 lilafarbenen Rechtecke und deren Beschriftung PRM-Plätze im Grundriss nach (PH 3). Der Grundriss veranschaulicht (elaboration - exemplification) dementsprechend, dass die Generalklausel eingehalten wird. Die Generalklausel stellt dagegen die Bedingung (enhancement - condition) dafür dar, dass die Schrift-Bild-Elemente $P R M$-Elemente im Grundriss von PH 3 enthalten sein müssen. Dieses Analyseergebnis stellt heraus, dass die Generalklausel in logisch-semantischen SpracheBild-Relationen der Pflichtenhefte eine übergeordnete Rolle spielt.

Die zweite Anforderung der TSI PRM, bewegliche Armlehnen bei PRM-Sitzen zu verwenden, erfüllt die Zeile Armlehnen zum Gang - klappbar/fest-fest (klappbar nur PRM) im Schriftmodul Ausstattung (PH 3). Diese schriftsprachliche Zeile konkretisiert das Sprache-Bild-Element Ausgewiesene PRM-Plätze mit lilafarbenen Flächen/Rechtecken (PH 3; Grundriss) in der Art und Weise (enhancementmanner), dass nur die Armlehnen von PRM-Elementen beweglich sind. Alle übrigen Rechtecke identischer Größe repräsentieren Sitzplätze mit festen Armlehnen. Das Sprache-Bild-Element Ausgewiesene PRM-Plätze mit lila Farbflächen 
präzisiert dagegen im Umkehrschluss die Schriftzeile Armlehnen zum Gang durch die Angabe, wo diese Armlehnen räumlich angeordnet sind (enhancement place).

Logisch-semantische Relationen lassen sich in den drei Pflichtenheftexemplaren viele weitere finden. Die bisherige Analyse zeigt aber bereits, dass die Bilder und diagrammatischen Elemente den Inhalt von schriftsprachlichen Elementen nicht nur räumlich verorten, sondern auch veranschaulichen. Schriftelemente zeigen Bedingungen für diagrammatische Bildelemente oder Bilder.

Dabei können diese Relationen implizit sein und auf Fachwissen beruhen. Bildoder Schriftelemente können in einer konkreten Relation eines Sprache-BildTextsortenexemplars der anderen Zeichenmodalität logisch-semantisch über-/untergeordnet sein. Dass Generalklauseln der Organisationsabteilung ,Recht' entstammen, während Grundrisse dem Bereich ,Fahrzeugtechnik‘ zuzuordnen sind, weist darauf hin, dass die Konstitution logisch-semantischer Relationen auch mit dem situativen Kontext verknüpft sind.

\subsubsection{Verknüpfungen zwischen Textgestaltung und Kontext}

Die Analyse der Textgestalt-Kontext-Verknüpfungen gliedert sich entsprechend dem integrierten Analyseraster zu interfachlichen Sprache-Bild-Textsorten (s. Tabelle 3-4). Der situative Kontext in Form der Organisationsbereiche ist mit der Themenstruktur insoweit verknüpft, als sich einzelne Themenmodule einem Organisationsbereich zuordnen lassen. Beispielsweise können das Teilthemenmodul Generalklauseln dem Organisationsbereich ,Recht" und die Themenmodule Infrastrukturanforderungen, Betriebskonzept und Kapazität dem Organisationsbereich ,Betriebsplanung ' zugeordnet werden. Der größte Teil der übrigen Themenmodule ist dem Organisationsbereich ,Fahrzeugtechnik' zuzurechnen, weil das Themenentfaltungsmuster einer Teil-Ganzes-Relation des Textgegenstands Fahrzeugangebot folgt. Nur die Lexik der Formularkommunikation wie Angabe, ja/nein etc. nimmt sonst einen wesentlichen Teil im Fachtextwortschatz ein. Sie ist meist Teil der Struktur aus Frage - Antwortmöglichkeit - Antwort (z. B. Mehrzweckraum - ja/nein, Anzahl-ja, 7; s. Tabelle 5-4) einer Tabellenzeile. In dieser Anordnung spiegelt sich die institutionelle Asymmetrie zwischen Auftraggeber 
und Bieter wider. An dieser Stelle sind die thematisch-strukturelle Textgestaltung und gleichzeitig das Textdesign mit dem situativen Kontext verknüpft.

Diese Frage-Antwort-Struktur verknüpft gleichzeitig den situativen Kontext in Form der institutionellen Asymmetrie mit der Funktionsstruktur, indem die Schriftelemente der linken Spalte (z. B. Mehrzweckraum) eine ,direktive Funktion' in Form einer elliptischen Frage repräsentieren, die Antwortvorgaben eine ,direkt-assertive' und ,indirekt-direktive Funktion' erfüllen und die Antworten der rechten Spalte die ,direkt-assertive' und ,indirekt-kommissive Grundfunktion' der Pflichtenhefte ausdrücken.

Die weitgehende Ersetzung vollständiger Syntax durch elliptische Nominalphrasen mit Genitiv- und Präpositionalattributen, durch Präpositionalphrasen in prädikativer Verwendung usw. ist auf die Ersetzung von Syntax durch Textdesign in den Pflichtenheften zurückzuführen. Ohne das Wissen über die Funktion der Lastenheftvordrucke, das Angebot des Bieters anzufragen, wären diese Ellipsen nicht unmittelbar verständlich. Daher sind auch diese strukturell-thematischen Phänomene der horizontalen Themenstruktur mit dem situativen Kontext der Institutionenasymmetrien verknüpft.

Diese strukturell-thematische Gestaltung der Generalklauseln wird hier vom situativen Kontext in Form des Organisationsbereichs ,Recht' beeinflusst. In ähnlicher Weise ist die zeichenmodale Komplexität des Bilderabstracts augenfällig, dessen technische Zeichnungen und Abbildungen des angebotenen Fahrzeugs dem Bereich ,Fahrzeugtechnik` entstammen. An dieser Stelle ist der situative Kontext des Organisationsbereichs mit dem Textdesign verbunden. Die beiden Dichotomien ,Ellipsen - vollständige Syntax“ sowie ,Schriftelemente - Bildelemente" deuten in besonderer Weise darauf hin, wie sehr die Gestaltung verschiedener Textteile von den ihnen zugehörigen Organisationsbereichen abhängt.

Auch der Zusammenhang zwischen Organisationsbereichen und logisch-semantischen Sprache-Bild-Relationen lässt sich belegen: Relationen zwischen Grundriss und Schriftmodulen präzisieren meist die räumliche Lage (place), die Art und Weise (manner), wie ein Bildelement geprägt ist, oder sind augmentativ-komplementär, indem Schriftelemente Eigenschaften mehrerer Bildelemente zusammenfassen (z. B. die Anzahl der eingebauten Kameras). Diese Relationen prägen Textteile, die dem Organisationsbereich ,Fahrzeugtechnik` zugehören. Auch die 
Funktion des Grundrisses als Quasi-Inhaltsverzeichnis für Gegenstände des Fahrzeuginnenraums beziehen sich beinahe ausschließlich auf den Organisationsbereich ,Fahrzeugtechnik‘. Darüber hinaus entstehen implizite Sprache-Bild-Relationen durch das Hintergrundwissen zu den Generalklauseln, die dem Organisationsbereich ,Recht' zuzurechnen sind (13 PRM-Sitzplätze entsprechend der Norm TSI PRM).

Das Schriftmodul Kapazität in PfLICHTENHEFT 1 beinhaltet ausschließlich den Verweis auf den entsprechenden Anhang, in dem Fahrplanvarianten angegeben sind. Dagegen verweisen Pflichtenheft 2 und 3 nicht explizit darauf. Letztlich können die Fahrpläne als ein Teil der Pflichtenhefte aufgefasst werden; sie bilden aber eine selbstständige Textsorte, weil sie auch ohne die Pflichtenhefte funktional in den situativen Kontext eingebunden sind.

\section{3 Überblick über Varianten der Textsorte Fahrplan}

Die Beschreibung dieser Textsorte orientiert sich am integrierten Analyseraster interfachlicher Sprache-Bild-Textsorten zum Textdesign (s. Abbildung 3-2), zur Funktionsstruktur (s. Tabelle 3-1), zur Themenstruktur ( s. Tabelle 3-2), zu multimodalen Verknüpfungen (s. Abbildung 3-10) und zu Textgestalt-Kontext-Verknüpfungen (s. Tabelle 3-4). Die Beschreibung dieser Textsorte dient dazu, eine Diskussion unter den Textüberarbeitenden (s. Kapitel 6.1) nachvollziehbar zu machen, die ohne eine kurze Erläuterung der Bedeutung von Linien Anordnungen und Farben nicht nachvollziehbar wäre. Daher stehen vor allem das Textdesign und die Bedeutung, die es abbildet, im Vordergrund dieser Beschreibung. Die Diskussion der Textüberarbeitenden ist besonders relevant, weil sie die Wissensasymmetrie zwischen den Textüberarbeitenden in Bezug auf Zeichensysteme verdeutlicht, die das Textsortennetz enthält. Weil aber keine weiteren Textstellen in den Protokollen zu den Textüberarbeitungen Bezug auf diese Textsortenvarianten nehmen, wird die Textsorte nur im Überblick dargestellt.

In der Textsorte ,Fahrplan“ des Organisationsbereichs ,Betriebsplanung' sind die drei Textsortenvarianten ,tabellarischer Fahrplan' sowie die abbildenden Diagramme ,Bildfahrplan“ und ,Fahrzeugumlaufplan` zu unterscheiden. Vor allem ihr Textdesign grenzt diese drei Varianten voneinander ab: Zwar stellen alle drei Varianten den Fahrbetrieb in Abhängigkeit von den Dimensionen ,Zeit‘ (Uhrzeit) 
und ,Ort' (Bahnhöfe) dar. Die Fahrplanvarianten differieren aber in der Art, wie sie die Inhalte entsprechend ihrer Textfunktion und ggf. ihrer Textwirkung relationieren:

Durch den Bildfahrplan soll der Infrastrukturbetreiber davon überzeugt werden, dass der geplante Betrieb des Zuges mit dem Betrieb kompatibel ist, der auf den

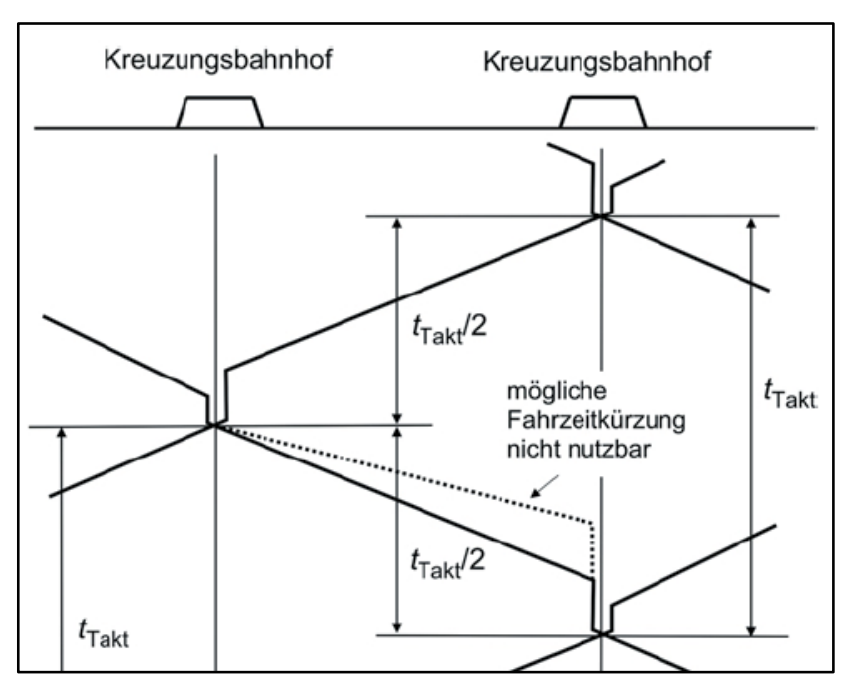

Abbildung 5-20: Zwangspunkte für die
Konstruktion eines Taktfahrplans
(PACHL, ${ }^{72013, ~ S . ~ 198) . ~}$
Teilstrecken des ausgeschriebenen Streckennetzes bereits gefahren wird. Dazu werden die Fahrpläne für die Ausschreibung mit dem sogenannten integralen Fahrplan (ITF) ${ }^{226}$ (PACHL, 2013, S. 197 ff.) abgeglichen, um zu prüfen, ob der geplante Zugbetrieb fahrbar ist. Ziel ist es, dass der Infrastrukturbetreiber dem Bieter die sogenannte Fahrbarkeit des Fahrplans testiert. Der Fahrzeugumlaufplan hat die Funktion zu belegen, dass die geplanten Schienenfahrzeuge und deren Anzahl geeignet sind, um die geplante Zugtaktung auf der Strecke zu fahren - auch unter Berücksichtigung möglicher Ausfälle. Durch den Umlaufplan können Ruhezeiten wie auch Instandsetzungs- und Pufferzeiten überprüft werden, die für den Betrieb relevant sind.

Das Textdesign des ,Bildfahrplans' ist durch ein x-y-Koordinatensystem geprägt, in dem die x-Achse die Bahnhöfe (Dimension Raum/Ort) und die y-Achse die Abfahrtzeiten (Dimension Zeit) darstellt (s. Abbildung 5-20). Die Orte und Uhrzeiten werden dabei an der jeweiligen Achse abgetragen. Zwischen diesen Achsen wird der Betrieb eines Zuges durch eine diagonalverlaufende Linie mit der Steigung repräsentiert, die die benötigte Zeit des Zugbetriebs zwischen zwei Bahnhöfen wiedergibt (ebd.). Die Linienschnittpunkte zeigen sogenannte Kreuzungs-

226 Der ITF fordert, Haltebahnhöfe einer geplanten Linie als sogenannte ITF-Knoten einzuzeichnen (s. Abbildung 5-20), um mehrere Bahnlinien aufeinander abzustimmen (PACHL, ${ }^{7}$ 2013, S. 197). Damit ermöglicht der ITF-Standard, ,dass während des Haltes in einem ITF-Knoten zwischen allen Linien gleichzeitig umgestiegen werden kann“" (ebd.). 
bahnhöfe, die so benannt sind, weil sich an diesen Bahnhöfen die Linien mehrerer Züge kreuzen. Dies ermöglicht, dass die Fahrgäste von einem in den anderen Zug umsteigen können. Auf Letzteres zielt der ITF, wodurch der Knotenbahnhof auch ein ITF-Knoten ist.

Auffällig ist am Textdesign des Bildfahrplans, dass die schriftsprachlichen Formen schwundgrammatisch sind, indem sie Kreuzungsbahnhöfe durch Kurzwörter kondensieren: ${ }^{227}$ Beispielsweise kürzt die Beschriftung NO.NK in Bildfahrplan 1 (s. Anhang, S. 1) den Haltestellennamen Narvik C(entral) ab, der als Ausgangspunkt der Fahrt dient. Die Beschriftung NO.SNS kondensiert den Namen Staumsnes als den nächst größeren Kreuzungsbahnhof. Dass diese Kurzwörter die entsprechenden Kreuzungsbahnhöfe bezeichnen, wird durch den Abgleich mit dem Tabellenfahrplan zu dieser Strecke deutlich, in dem Narvik C(entral) den Ausgangspunkt und Staumsnes den nächst größeren Kreuzungsbahnhof bilden (ebd.). Demnach werden die Kurzwörter durch Buchstaben des Kreuzungsbahnhofs, einen trennenden Punkt und die vorangestellten Buchstaben NO gebildet. Sie repräsentieren Norwegen als das Land, in dem diese Orte liegen.

Des Weiteren ist es „im Bildfahrplan [...] tatsächlich so, dass die Längen auf der Ortslinie proportional dargestellt werden" (PACHL, E-Mail vom 29.10.2014). Somit besteht eine Similarität zwischen Repräsentamen als Linienlänge und dem Denotat als außertextuelle Streckenlänge. Beispielsweise ist in Bildfahrplan 1 (s. Anhang, S. 1) die Strecke zwischen den Kreuzungsbahnhöfen Narvik C (NO.NK C) und Staumsnes (NO.SNS) größer als zwischen Staumsnes und Rombak (NO.ROM). Darüber hinaus überwiegen im Bildfahrplan Ziffern als Schriftelemente, die Uhrzeiten bzw. Zugnummern abbilden. So wird auf der y-Achse jeweils die volle Stunde eingezeichnet. Beispielsweise fährt der Zug in Bildfahrplan 1 (s. Anhang, S. 2) um 9:35 Uhr ab, was ersichtlich wird erstens aus dem Ansatzpunkt der hellblauen Linie links mittig zwischen der horizontalen roten Linie mit der Beschriftung 9 für die volle Stunde 9 Uhr; zweitens aus den blau eingefärbten Ziffern 35 unter der blauen Linie, die sich diagonal von links oben nach rechts unten bewegt. Sie endet mit der Beschriftung 55 oberhalb dieser blauen

227 Das Institut für Regional- und Fernverkehrsplanung stellte die folgenden Beispiele freundlicherweise zur Verfügung, um zu verhindern, dass aus Ortsnamen der ursprünglichen Ausschreibungsfahrpläne auf die zuständigen Auftraggeber geschlossen wird. 
Linie auf der Folgeseite (s. Anhang, S. 3) auf der rechten Seite. Die blaue Linie endet an der vertikalen roten Linie, die oberhalb mit NO.KRA bzw. Kiruna C(entral) beschriftet ist. Diese Linie zeigt die Fahrt des Zuges IC 100095 an, was durch die Positionierung der Buchstaben-Ziffern-Kombination IC 100095 deutlich wird. Diese Kombination stellt die Zugnummer dar, die nur einmal täglich für einen Zug vergeben wird. Diese Zugnummer und Fahrt sind auch im Tabellenfahrplan (s. Anhang, S. 5) eingetragen.

$\mathrm{Zu}$ beachten ist bei Bildfahrplänen, dass sie nicht nur von links nach rechts, sondern auch von rechts nach links gelesen werden: So ist beispielsweise in Bildfahrplan 1 (s. Anhang, S. 2) die dunkelblaue Linie mit der Beschriftung durch die Ziffer 2 unterhalb der horizontalen 9-Uhr-Linie nicht als Abfahrtszeit, sondern als Ankunftszeit zu lesen. Denn diese Linie verläuft nicht diagonal von links oben nach rechts unten, sondern diagonal von rechts oben nach links unten. Demnach wird die dunkelblaue Linie vom Haltestellennamen Kiruna C(entral) auf derselben Seite rechts oben gelesen, die mit den Ziffern 17 unterhalb der roten Linie in Fettdruck beschriftet ist. Diese rote Horizontallinie repräsentiert die volle Stunde 6 Uhr. Die Linie endet am Kreuzungsbahnhof Narvik $C$ mit der Beschriftung 2 unterhalb der roten 9-Uhr-Linie. Das bedeutet: Der Zug fährt um 6:17 Uhr in Kiruna Central ab und kommt um 09:02 Uhr in Narvik Central an. Die Zugnummer dieser Fahrt wird durch die Beschriftung Reg 90 rechts oben dargestellt, wobei auch diese Fahrt im Tabellenfahrplan dargestellt ist (s. Anhang. S. 5).

Das Textdesign der Fahrzeugumlaufpläne bildet mit der horizontalen Anordnung von Rechtecken eine zeitliche Dimension ab; die räumliche Nähe von Schriftelementen als Beschriftung zeigt die räumliche Dimension (s. Anhang. S. 6): Im Gegensatz zu den Bildfahrplänen stellt die horizontale Linie nicht die Streckenlängen des außertextuellen Denotats dar, sondern die Dauer eines Tages in Form von 24 Stunden, wobei jede Stunde auf der Horizontalen abgetragen und beschriftet wird (ebd.). Somit besteht zwischen Repräsentamen und Denotat Similarität, wie dies auch beim Bildfahrplan der Fall ist. Der Unterschied zum Similaritätsverhältnis im Bildfahrplan besteht darin, dass nicht die Streckenlänge, sondern die Tagesdauer als Denotat fungiert. Die Anordnung der Rechtecke in einer der Zeilen und die Beschriftung der Zeilen, beispielsweise So 6 No.NK C (ebd.), ordnen die Fahrt eines Zuges (ein sogenannter Zugumlauf) mehreren Umläufen einem 
Wochentag zu. Lokaldeiktisch werden die Rechtecke durch die Kurzwörter für den jeweiligen Haltestellenpunkt verortet, beispielsweise durch $K M B$ für den Haltepunkt Kiruna Malmbanegard (nach Angabe des Bildfahrplanherstellers Institut für Regional- und Fernverkehrsplanung, E-Mail vom 11.9.2019, konnte diese Linie aus Platzgründen nicht beschriftet werden). Der Umlauf beginnt am Vortrag vor Mitternacht in NO.NK C, also in Narvik Central. Dabei werden die Ankunft, die Wartung und die Abfahrt des Zugumlaufs eingetragen, sodass die Haltepunkte Kiruna und Narvik mehrmals aufgeführt sind (ebd.).

Die Rechtecke selbst sind Symbole, weil ihre unterschiedliche Bedeutung durch eine rote Färbung (Fahrtbetrieb) bzw. eine fehlende Färbung mit grauer Strichelung (kein Fahrtbetrieb, also Wartung, Reserve etc.) dargestellt wird (ebd.). Die vertikale Anordnung der Rechtecke verweist dementsprechend temporaldeiktisch auf den geplanten Ablauf, Fahrzeuge einzusetzen. Die Flächenpositionierungen und Färbungen von Rechtecken in einem Koordinatensystem drücken also Lokalund Temporaldeixis aus. Weil erst die Schriftelemente des Koordinatensystems die Deiktika als Benennung von Orten und Zeiten ermöglichen, besteht zwischen diesen Linien und Schriftelementen als logisch-semantischen Sprache-Bild-Relationen beinahe ausschließlich augmentative Komplementarität (augmentation - complement). Gleichzeitig verorten die Linien die Schriftelemente räumlich und zeitlich (enhancement - place \& time).

Der Tabellenfahrplan in Ausschreibung 1 (s. Anhang, S. 5) ist zeichenmodal dagegen weniger komplex: Zwar löst die Tabellenstruktur die Linearität des Textes auf (s. Fußnote 151). Es repräsentieren aber keine Linien die lokale und zeitliche Präsenz eines Zuges, sondern Uhrzeitangaben in Ziffern und Ortsnamen. Der Bildfahrplan ist gegenüber dem tabellarischen insoweit kondensiert, als der Bildfahrplan die Ankunfts- und Abfahrtzeiten von Zügen mit verschiedenen Fahrtrichtungen zeigt. Diese Informationen können dagegen nur zwei Fahrpläne darstellen, weil jeder Fahrplan jeweils nur zu einer Fahrtrichtung erstellt wird (ebd.). Alle drei Fahrplanvarianten machen Orts- und Zeitangaben, die mit dem integralen Taktfahrplan harmonisiert sind. Die Fahrplanvarianten lassen sich auch nicht wie bei den Textsorten Optimierungsvorschlag sowie Lasten- und Pflichtenheft in Funktionsmodule mit verschiedenen Unterfunktionen zergliedern. Vielmehr konstituieren alle Elemente der Exemplare die Grundfunktion der Textsorte. Die 
Darstellung von Orts- und Zeitangaben drücken eine ,direkt-assertive Grundfunktion` aus. Diese Interpretation stützt auch die Beschreibung der Textsorte ,Fahrplan“ in Rolf (1993), die „die Auskunft geben, was wann (und von wem) gemacht werden soll bzw. was wann (und durch wen) geschehen wird“ (ebd., S. 209; Kursive im Original). Gleichzeitig unterstellt RoLF (1993) ihnen eine ,assertive Grundfunktion“, weil sie der „Durchführung eines bestimmten Vorhabens“ (ebd., S. 213) dienen, deren schriftliche Fixierung für Letzteres notwendig ist (ebd.). Diese Fokussierung auf ein Vorhaben spricht bei den beschriebenen drei Fahrplanvarianten vielmehr dafür, ihnen eine, indirekt-direktive Grundfunktion` zuzuschreiben. Denn die Fahrpläne dienen zum einen dazu, den Netzbetreiber davon zu überzeugen, dass der geplante Fahrbetrieb für die ausgeschriebene Strecken mit dem weiteren ITF konform geht. Ziel des Bieters ist es, vom Netzbetreiber eine Testierung der Betriebsplanung zu erhalten (Textwirkung). ${ }^{228}$ Zum anderen soll der Auftraggeber im Ausschreibungsverfahren zusätzlich zum Testat durch die geforderten Fahrpläne davon überzeugt werden, dass die Betriebsplanung zuverlässig ist, um den Zuschlag bei der Ausschreibung zu erhalten (Textwirkung). Gleichzeitig verpflichtet sich der Bieter, den Fahrbetrieb entsprechend umzusetzen - eine ,indirekt-kommissive Funktion".

Wie bei der Funktionsstruktur konstituieren sämtliche Elemente der Textsortenexemplare eine Themenstruktur, ohne dass einzelne Themenmodule ausgemacht werden können. Bemerkenswert ist für diese Fahrpläne, dass das Textdesign in Form der Anordnung von Elementen in der Fläche die schriftsprachliche Themenstruktur ersetzt.

Die Analyse der semiotischen Effizienz wird zeigen, dass nur wenige Beteiligte der interfachlichen Projektkommunikation die Darstellungsmittel von Bild- und Umlauffahrplänen verstehen können (s. Kapitel 6.1 und 6.2). Diese stellt eine Form der Text-Kontext-Verknüpfung dar. Die Mitarbeitenden der Organisationsabteilung ,Betriebsplanung‘ erläutern bei der Textüberarbeitung grundlegend, wie Elemente des Fahrplans zu lesen sind (ebd.). Während die Redakteure im Interview angeben, betriebsinterne Schulungen zum Rezipieren der Fahrpläne

228 Dessen Berücksichtigung deutet die Leistungsbeschreibung (Ausschreibung 1, S. 13) an und nennt konkrete Bahnstationen des ITF, die Bieter in ihrer Fahrplanung zu berücksichtigen haben (ebd., S. 8). 
besucht zu haben, kommentieren lediglich die Mitarbeitenden des Bereichs ,Fahrzeuge‘ während der gemeinsamen Überarbeitung einzelne Fahrplanexemplare, was auf eine fachliche Nähe der Bereiche ,Fahrzeuge' und ,Betriebsplanung ' hindeutet. Die Analyseergebnisse zu den drei Textsorten werden im Folgenden für die Anwendung meines Effizienz-Modells (s. Kapitel 6) zusammengefasst.

\subsection{Zwischenfazit zur Textsortenanalyse}

Ein Fazit für die drei Textsorten Optimierungsvorschlag, den Lastenheftvordruck und das Pflichtenheft ziehen jeweils die Unterkapitel zu Textgestalt-Kontext-Verknüpfungen (s. Kapitel 5.1.5; 5.2.5; 6.3). Diese Zusammenfassungen setzen die Ergebnisse aber nur vereinzelt in Verbindung zueinander. Daher werden die Ergebnisse zu den Einzeltextsorten im Folgenden systematisch aufeinander bezogen.

\subsubsection{Intertextualität}

Bereits der Überblick zum Textsortennetz in Tabelle 4-3 fasst die funktionalen Text-Text- und Text-Verfahrens-Relationen für die Domäne von SPNV-Ausschreibungsverfahren zusammen. Dieser Überblick bezieht die wesentlichen Ergebnisse zu den Text-Text-Relationen im Textsortennetz auch für die drei analysierten Textsorten aufeinander. Im Folgenden werden diese Darstellungen aus Tabelle 4-3 kurz ausgeführt.

Die Textsorte Optimierungsvorschlag zielt darauf, die Verdingungsunterlagen zu modifizieren (Text-Text-Relationen MOD/Modifizieren). Dagegen verfolgen Lastenheftvordrucke im Textsortennetz das Ziel, den Ausfüllprozess und die Angaben der Bieter im Pflichtenheft zu lenken (Text-Text-Relation LENK) und ihn dazu zu bewegen, seine Lebensrealität in Form von Angaben zu verfügbaren Fahrzeugvarianten etc. unter die Kategorien des Formulars zu subsumieren (TextText-Relation SUB). Dabei bildet das Pflichtenheft das perspektivische Gegenstück zum Lastenheft. Die Fahrplanvarianten spezifizieren die Leistungsbeschreibung (Text-Text-Relation SPEZ).

Komplexe Text-Verfahrens-Relationen, konkret zwischen Texten des Ausschreibungsverfahrens und weiteren Interaktionsfeldern, bestehen beim Pflichtenheft und den Fahrplanvarianten. Denn das Z-v-Diagramm verweist auf das Fahrzeug- 
zulassungsverfahren, indem Pflichtenheft 1 die Tabelle aus dem „Anforderungsprofil Triebfahrzeugdaten" nutzt, das im Zulassungsverfahren einzureichen ist. Auch die Fahrplanvarianten sind in ein Testierungsverfahren eingebunden, um mit dem Angebot im Ausschreibungsverfahren neben den Fahrplänen auch das Testat des Fahrplans einreichen zu können. Letztlich interagieren auch die Pflichtenhefte mit dem Interaktionsfeld der Vertragsdurchführung, die an die $\mathrm{Zu}-$ schlagserteilung anschließt. Denn die Pflichtenhefte werden Teil des Verkehrsvertrags. Bei der Durchführung handelt es sich um ein eigenes Verfahren, in dem der Auftraggeber Grenzwerte wie Pünktlichkeit prüft, Marketingaktionen koordiniert, die Gewinnbeteiligung des Auftragnehmers berechnet, bei Vertragsbruch eine Pönale fordern kann usw.

\subsubsection{Textdesign}

Der Vergleich der Analyseergebnisse zu Lastenheftvordrucken und Pflichtenheften legt eine Art Streich- bzw. Weglassprobe für ikonisch-materielle Bilder nahe: Die Lastenheftvordrucke enthalten keine ikonisch-materiellen Bilder, sondern Linien, die eine Formularstruktur visualisieren, und Schriftelemente, deren Schriftbildlichkeit für das Textdesign relevant ist. Die Pflichtenheftexemplare nutzen Schriftelemente des jeweiligen Lastenheftvordrucks und zusätzlich ikonisch-bildliche sowie diagrammatische Elemente. Die Schriftelemente der Lastenheftvordrucke werden durch folgende Textdesignmittel gestaltet: Die (Schrift-)Größe, Form (Fettdruck) und Kursive gestalten die Schriftbildlichkeit, d. h. die Typographie, um die Schriftelemente des Textexemplars zueinander in Relation zu setzen.

Die Flächenpositionierung wird dagegen genutzt, um syntaktisch-semantische Strukturen wie lexikalisch ausgedrückte Subordinationen durch Einrückungen in einer Zeile zu ersetzen. Elemente verschiedener Zeilen werden aber auch durch einen identischen Abstand der Einrückung oder durch das einheitliche Weglassen einer Einrückung - im Gegensatz zur Subordination - koordiniert. Darüber hinaus repräsentiert die Flächenpositionierung die situativ-funktionale Formularkommunikation und die damit verbundene institutionelle Asymmetrie zwischen Auftraggeber und Bieter. So werden die Schriftelemente des Auftraggebers in der linken und mittleren Spalte bzw. unter und in den Bildpanels angeordnet, während der weiße Untergrund in der rechten Spalte und in/unter Bildpanels der Pflichtenhefte 
durch Schriftelemente und ikonisch-bildliche sowie diagrammatische Elemente des Bieters ersetzt wird. Demzufolge ist an dieser Repräsentation der Institutionenasymmetrie auch das Rahmungsmittel Panel beteiligt. Die Anordnung von Schriftelementen in der Kopf- und Fußzeile wird ebenfalls der Flächenpositionierung zugeordnet.

Auch das Textdesign von Optimierungsvorschlägen drückt sich vor allem in der Schriftbildlichkeit und der Positionierung von Schriftelementen aus, weil diese Textsorte ebenfalls keine ikonisch-materiellen Bilder beinhaltet: Der Fettdruck und die Schriftgröße machen Schriftelemente als Überschrift erkennbar. Demgegenüber zeigt eine kleinere Schriftgröße der Unterüberschriften eine Hierarchisierung von Überschriftenebenen auf. Die Anordnung von Schriftelementen in Kopf- und Fußzeile der Optimierungsvorschläge entspricht des Weiteren dem Textdesign der Lastenheftvordrucke. Auf Einrückungen, Spalten und Panels verzichten Optimierungsvorschläge allerdings, weil sie nicht der Kommunikationsform Formular unterworfen sind.

Als einzige für das Textdesign relevante Elemente, die über Schriftbildlichkeit und Linienanordnungen hinausgehen, nehmen symbolische und rekonfiguriernde sowie abbildende Diagramme Einfluss auf das Textdesign: Das Logo des Unternehmens wirkt durch seine rote Färbung gegenüber den Graustufenkontrasten der übrigen Schriftelemente und durch seine Beschaffenheit auffällig. Neben dem Logo ist das abbildende Diagramm von OptIMIERUNGSVORSCHLAG 7 aufgrund seiner Formen, Farben und Anordnung in der Mitte einer Textseite augenfällig. Die Verwendung dieses Diagramms wirkt sich auf die logisch-semantischen Relationen in Optimierungsvorschlägen aus, wobei sein Vorkommen in dieser Textsorte eine Ausnahme darstellt. Die Schriftelemente in Optimierungsvorschlägen unterscheiden sich von denen in Pflichtenheften darin, dass die Schriftflächen in Ersteren wesentlich länger und durch Absatzstrukturen geprägt sind. Die Schriftelemente in Pflichtenheften sind dagegen wesentlich kürzer, weil sie schwundgrammatisch geprägt sind.

Das Textdesign von Optimierungsvorschlägen und Pflichtenheften prägt ihre Schriftbildlichkeit und Flächenpositionierung. Für das Textdesign von Pflichtenheften sind darüber hinaus ikonisch-bildliche und diagrammatische Elemente wichtig. Diese ikonisch-materiellen und ikonisch-schematischen Bilder der 
Pflichtenhefte gestalten das Textdesign vor allem durch Farbvariation, weil Farben in dieser Textsorte ins Verhältnis zueinander gesetzt werden oder Farben einen Kontrast zu Graustufen erzeugen. Des Weiteren erfüllt die Flächenpositionierung dieser Farbelemente eine ästhetische Funktion. Demnach ist die Farbgestaltung von ikonisch-bildlichen Elementen und deren Positionierung in der Fläche wesentlich am Textdesign von Pflichtenheften beteiligt.

Gegenüber einer Rezeption, die sich an Seiten-, Kapitel- und Abbildungsnummerierungen orientiert, ermöglicht der Grundriss des Fahrzeugs als Quasi-Inhaltsverzeichnis auf Seite 1 (PH 1, PH 2) bzw. Seite 2 (PH 3), im Anschluss an den Grundriss Schriftmodule zu rezipieren, die sich am Ende des Pflichtenhefts befinden, beispielsweise Angaben zu Sitzen.

Während Optimierungsvorschläge und Lastenheftvordrucke aufgrund fehlender ikonisch-materieller Bilder oder Diagramme kaum logisch-semantische SpracheBild-Relationen eingehen, ${ }^{229}$ finden sich diese vielfach in Pflichtenheften, weil Letztere ikonisch-materielle und ikonisch-schematische Bilder enthalten.

Obwohl Tabellenfahrpläne keine ikonisch-materiellen Bilder beinhalten, weisen sie mehrere logisch-semantische Sprache-Bild-Relationen auf, indem sie als rekonfigurierende Ort-Zeit-Diagramme Kurzwörter und Linien aufeinander beziehen. Auch Fahrzeugumlaufpläne nutzen als diagrammatische Darstellungsformen Farben, Formen (Rechtecke), Ziffern und Kurzwörter als Beschriftungen, um Orts- und Zeitdeixis zu realisieren. Fahrzeugumlaufpläne symbolisieren auch Zugzustände (z. B. mehrere Waggons) durch unterschiedliche Schraffuren der Rechtecke. Die Mittel des Textdesigns, das Bildfahrpläne verwenden, nutzen weitgehend auch Umlaufpläne; lediglich die Schraffuren der symbolischen Rechtecke gehen über die Bildfahrpläne hinaus. Die Darstellungsmittel von Fahrzeugumlaufplänen sind im Gegensatz zu Bildfahrplänen aber nicht standardisiert. Denn der Abgleich des Bildfahrplans mit anderen Bildfahrplänen im integralen Fahrplan (ITF) macht es notwendig, den Bildfahrplan entsprechend den Vorgaben des Infrastrukturbetreibers als Knotennetz darzustellen.

229 Ausgenommen sind die aufgeführten Beispiele der abbildenden Diagramme und des Logos. 
Die Funktions- und Themenstruktur überschneiden sich sowohl in Optimierungsvorschlägen als auch in Lasten- und Pflichtenheften an vielen Stellen. D. h., die Einteilung der Funktions- und Themenmodule ist annähernd deckungsgleich. Weil Fahrpläne keine Module unterteilen, wie dies bei Optimierungsvorschlägen und Lasten- und Pflichtenheften sichtbar ist, kann eine Überschneidung dieser Strukturen bei Fahrplänen nicht geprüft werden.

\subsubsection{Themenstruktur}

Die Ergebnisse zum Einsatz von Mitteln der horizontalen Themenstruktur, zu der vor allem raumdeiktische Mittel gehören, und des Themenentfaltungsmusters innerhalb der drei Text-sorten werden im Folgenden gegenübergestellt. An der Konstitution dieser beiden Ebenen der Themenstruktur sind wie bei der Funktionsstruktur Sprache- und Bildmodule beteiligt.

Dass raumdeiktische Mittel Einfluss auf die Textsemantik in den Pflichtenheften nehmen, belegt die lokaldeiktische Verwendung der vielen Präpositionen in Präpositionalphrasen, die Gegenstände des Fahrzeuginnenraums und eine implizite funktionale Benutzerperspektive ausdrücken. ${ }^{230}$ Als weiteres Mittel der Raumdeixis werden technische Zeichnungen gebraucht, die Gegenstände im Fahrzeuginneren verorten, Gegenstände im Fahrzeuginneren zueinander oder zum Bahnsteig in Verbindung setzen und das Fahrzeug sowie seine Bestandteile proportional durch Größe und Bemaßungen relationieren. Als drittes raumdeiktisches Mittel präzisieren logisch-semantische Verknüpfungen die Angabe des Ortes (enhancement - place). In Exemplaren der Textsorte Optimierungsvorschläge spielen raumdeiktische Mittel nur sehr bedingt eine Rolle - beispielsweise durch Ortsnamen in Optimierungsvorschlägen des Bereichs ,Vertrieb' oder ,Betriebsplanung ${ }^{6}$-, sodass raumdeiktische Mittel im Verhältnis zu Pflichtenheftexemplaren kaum an der Erzeugung von Textualität der Optimierungsvorschläge beteiligt sind. Dagegen dominieren raum- und zeitdeiktische Mittel die Fahrplanvarianten. Während in Pflichtenheften und Optimierungsvorschlägen verschiedene Themenmodule die Themenstruktur bilden, existieren in Fahrplanvarianten keine

230 Präpositionen werden aber nicht nur lokaldeiktisch verwendet, sodass neben weiteren Verwendungsweisen die kausale Präpositionen im weiteren Sinne (s. o.) eine weitere große Gruppe bilden. 
Themenmodule. Die Themenstruktur ergibt sich in ihnen aus dem Verhältnis von Linien, Ziffern und Kurzwörtern im x-y-Koordinatensystem des Bildfahrplans bzw. der Rechtecke und Kurzwörter sowie Ziffern im Fahrzeugumlaufplan. Der Fahrzeugumlaufplan erzeugt Raumdeixis durch die Zuordnung der Rechtecke in den Zeilen des Plans. Die Bildfahrpläne erzeugen Raum-Zeit-Deixis durch die Anordnung der Linien, die Beschriftungen durch Ziffern für Uhrzeiten und Kurzwörter für Bahnhöfe und vor allem durch die Steigung der Linien.

Der Fachtextwortschatz von Lasten- und Pflichtenheften bezieht sich weitgehend auf Themen der Fahrzeugtechnik, aber auch auf Formularkommunikation und nur an wenigen Stellen auf Themen der Organisationsbereiche ,Recht' und der ,Betriebsplanung'. Häufig werden Holonym-Meronym- und auch HyponymHyperonym-Relationen der Fahrzeugtechnik verwendet. Augenfällig ist am Fachtextwortschatz der Lasten- und Pflichtenheftexemplare der Einsatz von zwei Nomen als Metaphern (Kopfstützen mit Öhrchen und Spenderfahrzeuge). Der Fachtextwortschatz der Optimierungsvorschläge ist dagegen weder durch Mittel der Formularkommunikation geprägt, noch bezieht er sich überwiegend auf den Bereich ,Fahrzeugtechnik', sondern auch auf Themen der Bereiche ,Recht', ,Betriebsplanung' und ,Marketing'. Metaphern fallen in Optimierungsvorschlägen nicht auf, aber die genannten paradigmatischen Relationen der Lasten- und Pflichtenhefte kommen in ihnen ebenfalls vor. Der Fachtextwortschatz der Fahrpläne ist durch Ortsangaben und - soweit dies dem Wortschatz überhaupt zuzurechnen ist - Ziffern bestimmt, die Zeitangaben wiedergeben. Metaphern und die genannten paradigmatischen Relationen lassen sich in den Fahrplänen nicht ausmachen.

In Lasten- und Pflichtenheften werden als strukturell-thematische Mittel vor allem satzwertige Ellipsen wie Genitivattribute, Präpositionalgruppen, HolonymMeronym-Relationen usw. eingesetzt. Dies gilt auch für Fahrplanvarianten, die die Schriftsprache noch weiter kondensieren als Lasten- und Pflichtenhefte. Dies geschieht, indem Fahrpläne nur Nomen und Ziffern einsetzen, wobei Bildfahrpläne und Fahrzeugumlaufpläne diese Nomen weiter durch Kurzwörter kondensieren. In Lasten- und Pflichtenheften wird im Gegensatz zum Gebrauch dieser elliptischen Formen die vollständige Syntax der wenigen Generalklauseln des Organisationsbereichs ,Recht` auffällig. Optimierungsvorschläge verwenden - abgesehen von Sprachelementen in Stichpunkten und zum Teil in Tabellen des 
Anhangs - vollständige Syntax. Dieser Unterschied im Einsatz von Ellipsen und Textkondensaten auf der strukturell-thematischen Ebene der drei Textsorten korreliert mit dem Grad, in dem die jeweilige Textsorte von ihrem Textdesign bestimmt wird: Der hohe Grad an eingesetzten Ellipsen kommt meist mit dem Einsatz vieler Mittel des Textdesigns vor. Dies veranschaulicht, dass Lasten- und Pflichtenhefte, aber auch Fahrpläne schwundgrammatisch gestaltet sind.

Exemplare der Pflichtenhefte folgen ausschließlich dem deskriptiven Entfaltungsmuster und Optimierungsvorschläge weitgehend dem argumentativen Entfaltungsmuster. Für die Fahrplanvarianten wird aufgrund fehlender Themenmodule kein Entfaltungsmuster interpretiert, weil bei Fahrplänen vielmehr das Textdesign die Themenstruktur erzeugt. Das argumentative Themenentfaltungsmuster legt eine Von-links-oben-nach-rechts-unten-Rezeption der Themenmodule fest, weil ein Themenmodul Voraussetzung für das Verständnis des nächsten Moduls ist. Dagegen ermöglicht in Pflichtenheften die Darstellung der Teil-Ganzes-Relation als deskriptives Entfaltungsmuster, von dieser Linearität abzuweichen. Dies veranschaulicht die Möglichkeit, den Fahrzeuggrundriss als Quasi-Inhaltsverzeichnis zu nutzen.

\subsubsection{Funktionsstruktur}

Sowohl Schrift- als auch Bildelemente repräsentieren als Funktionsmodule Unterbzw. Nebenfunktionen der Funktionsstruktur einer Textsorte und konstituieren die Grundfunktion der jeweiligen Textsorte. Dabei drücken sowohl Bild- als auch Schriftmodule direkte und indirekte Textfunktionen aus.

Die Frage-Antwort-Struktur bestimmt diese Struktur der Lasten- und Pflichtenhefte wesentlich: Schriftelemente der linken Spalte (z. B. Mehrzweckraum) bilden eine ,direktive Funktion“ in Form einer elliptischen Frage ab. Die Antwortvorgaben erfüllen eine ,direkt-assertive' und die, indirekt-direktive' Funktion. Nur in Pflichtenheften drücken die Antworten der rechten Spalte die ,direkt-assertive“ und ,indirekt-kommissive' Grundfunktion aus. Bildpanels sind in Lastenheftvordrucken ein ,direkt-assertives' und gleichzeitig ,indirekt-direktives' Funktionsmodul. Werden diese leeren Bildpanels der Lastenheftvordrucke in Pflichtenheften durch technische Zeichnungen, abbildende Diagramme, Fotos oder CAD-Darstellungen ausgefüllt, repräsentieren die Bildmodule eine ,darstellend-assertive“ 
und gleichzeitig ,indirekt-kommissive' Funktion. Lediglich Funktionsmodule, die Fotos oder CAD-Darstellungen beinhalten, deuten darüber hinaus auf ein werbende Funktion, also eine, indirekt-direktive' Funktion hin. Diese Direktiva belegen, dass entsprechend KALVERKÄMPERs seducción in der Fachmann-Fachmann-Kommunikation (arte) durchaus geworben werden kann.

Das werbende Logo realisiert in Optimierungsvorschlägen eine ,direktive' Funktion und die Gesamtüberschrift, Kopfzeilenbeschriftung sowie Fließtextflächen realisieren eine ,direkt-assertive' Funktion. Der Vorschlag erfüllt gleichzeitig eine ,indirekt-direktive' Funktion und beschreibt dadurch, wie die Verdingungsunterlagen angepasst werden könnten. Denn dieser Vorschlag fordert den Rezipienten dazu auf, die Verdingungsunterlagen zu ändern. Das Funktionsmodul Preiseffekt repräsentiert eine, indirekt-kommissive“ Funktion, weil sich der Bieter damit verpflichtet, diesen Preiseffekt bei Zuschlagerteilung umzusetzen. Damit haben Optimierungsvorschläge eine ,direkt-assertive“ und ,indirekt-direktive“ Grundfunktion.

Die Elemente der Fahrplanvarianten drücken - ohne eine Struktur aus mehreren Funktionsmodulen abzubilden - eine ,direkt-assertive" und ,indirekt-direktive" Grundfunktion aus, weil sie den Rezipienten über den geplanten Fahrbetrieb informieren, indirekt aber darauf zielen, vom Infrastrukturbetreiber ein Testat bzw. vom Bieter den Zuschlag zu erhalten.

Somit drücken alle drei Textsorten eine ,direkt-assertive' Grundfunktion aus und auch die indirekten Funktionen sind identisch: Fahrpläne, Optimierungsvorschläge und Pflichtenhefte sind, indirekt-direktiv', weil sie versuchen, den Auftraggeber zu beeinflussen. Gleichzeitig sind Pflichtenhefte und Fahrpläne ,indirekt-kommissiv', weil sich der Bieter verpflichtet, das Angebot entsprechend den Angaben in diesen Textsorten umzusetzen. In Optimierungsvorschlägen realisiert lediglich ein Funktionsmodul diese indirekte Funktion. Die Darstellung der kommissiven Funktion von Pflichtenheften, gesetzliche und technische Vorgaben wie die TSI PRM umzusetzen, ragen in den Bereich der logisch-semantischen Verknüpfungen hinein. 


\subsubsection{Logisch-semantische Sprache-Bild-Relationen}

Die obige Analyse stellt heraus, dass sich aus dem Textdesign an einigen Stellen logisch-semantische Verknüpfungen ergeben, beispielsweise bei Bildfahrplänen. Folgende Ergebnisse zu den drei Textsorten lassen sich kontrastieren:

Für Optimierungsvorschläge wurden aufgrund des geringen Vorkommens von ikonisch-bildlichen und diagrammatischen Elementen, die über Schriftbildlichkeit hinausgehen, nur sehr wenige logisch-semantische Relationen gefunden. In allen Textsortenexemplaren des Korpus erweitert (similarity - extension) das Logo einige Schriftelemente in den Fließtextflächen (wir, EVU). Die zwei abbildenden Geld-Zeit-Diagramme, deren Gebrauch für die Textsorte ungewöhnlich ist, präzisieren die Schriftelemente der Fließtextflächen durch zeitliche Angaben (enhancement - time) und durch räumliche Angaben (place), während diese Schriftelemente die Diagramme in der Angabe der Art und Weise (manner) und des Grundes (cause) konkretisieren. Die Zusammenfassung der Diagrammgrößen sowohl in der Fließtextfläche als auch in der Legende zu den Diagrammen verknüpft diese Elemente , augmentativ komplementär' (complement - augmentation). Die Überschriftenelemente Risikoszenario bzw. Optimistisches Szenario und auch die Diagramme exemplifizieren den Fließtext (elaboration - exemplification).

Im Bildfahrplan entsteht durch die Flächenpositionierung (das ,Gesetz der Nähe“ als Teil von Textdesign) von Linien, die die x- oder y-Achse oder auch Graphen zwischen den Achsen bilden, eine augmentativ-komplementäre Sprache-Bild-Relation (complement-augmentation). Denn erst durch diese Schriftelemente wird deutlich, was die Linien darstellen. Entsprechend sind Linien und Rechtecke sowie Schriftelemente im Fahrzeugumlaufplan verknüpft, unterscheiden sich vom Bildfahrplan aber durch den Symbolcharakter der schraffierten Rechtecke und deren Konventionalisierung. ${ }^{231}$

231 Der Symbol- und Ikon-Charakter der Rechtecke veranschaulicht für die Konzeption logisch-semantischer Sprache-Bild-Relationen, wie verschiedene Bildarten ausdifferenziert werden können, die eine Verbindung mit Schriftelementen eingehen. Optimierungsvorschläge haben den Bildbegriff auf das diagrammatische Logo bezogen. Pflichtenhefte schließen an diese Differenzierung an, indem sie Abbilder, schematische-rekonfigurierende Diagramme wie technische Zeichnungen und abbildende Diagramme einsetzen. 
Technische Zeichnungen (in Form von Grundrissen) spezifizieren in Pflichtenheften die meisten Elemente aus Schriftmodulen durch die Angabe der ,räumlichen Lage und Anordnung' (place). Die Zeichnungen erfüllen vor allem eine raumdeiktische Funktion. Die Schriftelemente sind insoweit ,augmentativ komplementär` (augmentation - complement), als sie die Flächengrößen oder die Anzahl von Abfalleimern aus dem Grundriss zusammenfassen. Die Schriftelemente innerhalb der Zeichnung konkretisieren auch die ,Art und Weise" (manner), wie Flächen des Grundrisses gestaltet sind (beispielsweise entsprechend der Norm TSI PRM). Die Elemente der technischen Zeichnungen sind dabei selbst diagrammatische Elemente, weil sie sich aus einem durch Farbe/Graustufenkontrast und Flächenpositionierung gestalteten Bildelement und einem (symbolischen) Schriftelement zusammensetzen. Das ,Gesetz der Nähe‘ und/oder eine Verbindungslinie macht sie als diagrammatische Einheit erkennbar. Meist rekurriert der schriftsprachliche Teil eines diagrammatischen Elements auf ein Element in einem Schriftmodul.

Eine logisch-semantische Sprache-Bild-Relation besteht implizit zwischen der schriftsprachlichen Generalklausel (sie verweist indirekt auf Hintergrundwissen wie auf die Inhalte der Norm TSI RPM), der schriftsprachlichen Angabe der Gesamtsitzplatzanzahl und den 16 diagrammatischen Elementen in der Zeichnung, die sich aus lila-umrahmten Rechtecken und der Beschriftung PRM-Sitze zusammensetzen. Die Generalklausel schafft im Pflichtenheft somit die ,Bedingung“ (enhancement - condition), dass die Zeichnung mindestens 13 dieser diagrammatischen Elemente enthält. An diesem Beispiel wird die übergeordnete Rolle der Generalklausel auch für logisch-semantische Sprache-Bild-Relationen deutlich. Der Grundriss fungiert als Quasi-Inhaltsverzeichnis für die anschließenden Schriftmodule, die physikalische Gegenstände des Fahrzeuginnenraums thematisieren. Diese Funktion der Generalklausel und des Grundrisses verdeutlichen, dass Schrift- oder Bildelemente anderen Zeichenmodalitäten innerhalb einer Textsorte über- oder untergeordnet sein können.

Somit stimmen Optimierungsvorschläge, Pflichtenhefte und Fahrpläne darin überein, als logisch-semantische Sprache-Bild-Relationen die Präzisierung der räumlichen und zeitlichen Angaben zu verwenden. Und auch das ,augmentativ komplementäre‘ Verhältnis von Schrift- zu Bildelementen besteht in allen drei 
Textsorten. Schriftelemente sowohl der Optimierungsvorschläge als auch der Pflichtenhefte konkretisieren darüber hinaus die Art und Weise eines Textgegenstands, den ein Bildelement darstellt (beispielsweise Barrierefreiheit oder Obenflächenbeschaffenheiten). Ansonsten weichen die logisch-semantischen Relationen zwischen den Textsorten ab. Dabei bestehen die meisten Relationen in Pflichtenheften. Die meisten unterschiedlichen Arten von logisch-semantischen Relationen enthalten aber Optimierungsvorschläge. Grundsätzlich können in einer Textsorte Sprache und Bild verknüpft sein, wogegen der Text immer funktional mit dem situativen Kontext verbunden ist.

\subsubsection{Verknüpfungen zwischen Textgestaltung und Kontext}

Die Ergebnisse zu Verknüpfungen der Textgestaltung mit dem situativen Kontext dieser Texte stellen die Teilkapitel zur jeweils untersuchten Textsorte dar (s. Kapitel 5.1.5; 5.2.5; 5.3). Diese Ergebnisse geben bereits eine Antwort auf den Teil meiner zentralen Forschungsfrage, der sich auf das Kommunikat bezieht. Weil erst das Verhältnis zwischen der Kapazität der Kommunikanten und der Kommunikatskomplexität die semiotische Effizienz interfachlicher Sprache-Bild-Textsorten untersucht, wird auf die drei Thesen, die die Forschungsfrage präzisieren (s. Kapitel 2.1.3), erst in Kapitel 6 und Kapitel 7 Bezug genommen.

Aufgrund fehlender Vergleichskorpora wird die Zuordnung des Fachtextwortschatzes (Teil der Themenstruktur) zu Organisationsabteilungen nur interpretiert. Diese Interpretation prüft den Zusammenhang zwischen dieser Unterkategorie der Themenstruktur und dem situativen Kontext als Zugehörigkeit zu einem Organisationsbereich. In Optimierungsvorschlägen enthalten die ersten drei von vier Themenmodulen - Erläuterung, Optimierung, Anzupassende Unterlagen Terminologie, die je nach Textsortenexemplar dem Organisationsbereich ,Fahrzeuge', ,Betriebsplanung' oder ,Controlling' zugerechnet werden kann. Dies gilt, wenn die Lexik in diesen Bereichen verwendet wird. Das vierte Themenmodul von Optimierungsvorschlägen, das Modul Preiseffekt, enthält dagegen überwiegend Lexik, die Textsortenexemplar übergreifend dem Bereich, Controlling' zugehört. Dies deutet darauf hin, dass der Diskurs des Finanzcontrollings die weiteren in dieser Textsorte behandelten Diskurse überlagert. In den Exemplaren der Textsorte Pflichtenheft überwiegt dagegen die Lexik des Organisationsbereichs ,Fahrzeugtechnik'. Die Lexik anderer Organisationsbereiche bestimmt nur weni- 
ge Themenmodule - insbesondere das Themenmodul Generalklauseln durch die Lexik des Bereichs ,Recht" und die Themenmodule Infrastrukturanforderungen und Betriebskonzept durch die Lexik des Organisationsbereichs ,Betriebsplanung'. Neben der Zuordnung von Lexik als Teil der Themenstruktur von Pflichtenheften ist die vollständige Syntax der Generalklausel als strukturell-thematisches Merkmal gegenüber den übrigen elliptischen Formulierungen augenfällig, die durch das Textdesign und den situativen Kontext verständlich werden. Somit sind in Pflichtenheften Fachtextwortschatz und strukturell-semantische Strukturen mit den Organisationsbereichen als situativem Kontext verquickt. Für die Fahrplanvarianten ergeben sich keine Textgestaltung-Kontext-Verknüp-fungen, die sich auf eine Themenstruktur beziehen. Denn in den Fahrplänen kann keine differenzierte Themenstruktur ausgemacht werden. Eine Zuordnung von Themenentfaltungsmustern zu Textsorten nimmt bereits Kapitel 5.4.2 vor. Eine Verknüpfung der Textsorte Optimierungsvorschläge mit einem Organisationsbereich ist nicht möglich, weil diese Vorschläge Themen unterschiedlicher Bereiche beinhalten. Diese Textsortenzuordnung ist auch für Fahrpläne nicht möglich, weil in ihnen keine Entfaltungsmuster erkennbar werden. Nur das Themenentfaltungsmuster in Pflichtenheften ist bedingt durch einen Organisationsbereich determiniert: Das deskriptive Entfaltungsmuster als Teil-Ganzes-Relation ergibt sich daraus, dass es sich an der Teil-Ganzes-Relation des physikalischen Gegenstandes Fahrzeug orientiert, das Pflichtenhefte anbieten. Weil Teil-Ganzes-Relationen des Fahrzeugs im Organisationsbereich ,Fahrzeugtechnik' behandelt werden, ist dieses Entfaltungsmuster der Textsorte mit diesem Bereich verknüpft.

Dagegen ist das Textdesign der Fahrpläne mit dem Organisationsbereich dahingehend verknüpft, dass nur die Mitglieder des Organisationsbereichs ,Betriebsplanung ' und bedingt die Mitarbeitenden des Bereichs, Fahrzeugtechnik die diagrammatische Linien-Kurzwort-Darstellung verstehen. Die CAD-Darstellungen, technischen Zeichnungen als rekonfigurierende Diagramme und auch die abbildenden Diagramme gehören tendenziell zum Bereich ,Fahrzeugtechnik‘. Das Textdesign, das sich aus ihnen ergibt, ist somit ebenfalls mit dem Organisationsbereich ,Fahrzeugtechnik` verbunden. Dagegen fällt bei Optimierungsvor- 
schlägen auf, dass sie weder Abbilder noch rekonfigurierende Diagramme ${ }^{232}$ nutzen. Diese zeichenmodale Besonderheit kann daher nicht einzelnen Organisationsbereichen zugeordnet werden.

Entsprechend sind die logisch-semantischen Relationen in Fahrplänen mit dem Organisationsbereich ,Betriebsplanung' verknüpft. Auch die logisch-semantischen Sprache-Bild-Relationen in Pflichtenheften sind mit dem Organisationsbereich ,Fahrzeugtechnik' verbunden, weil technische Zeichnungen Raumdeixis ausdrücken und Pflichtenhefte die Bedingungen, Gründe sowie die Art und Weise des Fahrzeugangebots darstellen. Die wenigen logisch-semantischen Relationen in Optimierungsvorschlägen können dagegen keinem Organisationsbereich zugewiesen werden.

Die Funktionsstruktur bzw. die Grundfunktionen von Optimierungsvorschlägen, Lasten- und Pflichtenheften sowie Fahrplänen sind an die Textsorte, nicht aber an einen der beteiligten Organisationsbereiche gebunden. Denn das Ausschreibungsverfahren bzw. das daraus resultierende Textsortennetz bestimmen die Grundfunktionen der Textsorten. Beispielsweise ist die Frage-Antwort-Struktur der Pflichtenhefte mit der institutionellen Asymmetrie zwischen Auftraggeber und Bietern verknüpft. Somit besteht zwischen den Funktionsstrukturen der drei Textsorten und dem situativen Kontext im Sinne des Ausschreibungsverfahrens ein enger Zusammenhang. Im Folgenden werden diese Ergebnisse zum Kommunikat entsprechend dem Modell semiotischer Effizienz (s. Tabelle 2-2) mit der Analyse der Kommunikantenkapazität zusammengebracht.

232 Das Logo ist von diesem weiten Rekonfigurationsbegriff ausgenommen. 



\section{Zu Aushandlungen semiotischer Effizienz bei Textüberarbeitungsprozessen}

These 1 (s. Kapitel 2.1.3) bezieht semiotische Effizienz auf Textsortenkonventionen, die das vorangegangene Kapitel 5 untersucht. Kapitel 5 widmet sich auch dem ersten Teil von These 3 (ebd.), indem es untersucht, inwieweit Textsorten aus naturwissenschaftlich-technischen Kommunikationsbereichen (also Pflichtenhefte und Fahrpläne aus den Organisationsbereichen ,Fahrzeugtechnik ‘ und ,Betriebsplanung') durch bildliche, schriftsprachliche und diagrammatische Mittel gestaltet sind. Kapitel 6 geht dagegen dem zweiten Teil von These 3 nach, ob die Fähigkeit, wie diese Elemente rezipiert werden, von einer unterschiedlichen mikrokulturellen Textkompetenz der einzelnen Kommunikanten abhängt. Kapitel 6 verfolgt auch das Ziel, These 2 (ebd.) darauf zu untersuchen, ob die Kommunikanten unterschiedlicher mikrokultureller Prägungen (Betriebswirte, Juristen, Ingenieure, ...) über Textwissen verfügen, das voneinander abweichende Textsortenkonventionen umfasst. Im Anschluss daran wären die Textsortenkonventionen in interfachlicher Projektkommunikation vom Standpunkt der unterschiedlichen Mikrokulturen auszuhandeln.

Diese Thesen bilden die Grundlage für das Modell semiotischer Effizienz (s. Tabelle 2-2), in dem die Komplexität des Kommunikats und die Kapazität der Kommunikanten ins Verhältnis zueinander gesetzt werden. Ergebnisse zur Kommunikatskomplexität liefert bereits Kapitel 5.4. Es fasst die Ergebnisse zusammen, die darauf fußen, dass das integrierte Analyseraster für interfachliche Sprache-BildTextsorten (s. Kapitel 3) auf Exemplare der drei Textsorten(varianten) Optimierungsvorschlag, Lasten- und Pflichtenheft sowie Fahrplan angewendet wird. Daher wird im Anschluss ausschließlich die Kapazität der Kommunikanten anhand von Beobachtungen etc. interpretiert (s. Kapitel 6.2), um diese mit den Ergebnissen zur Kommunikatskomplexität ins Verhältnis zueinander setzen zu können (s. Kapitel 6.3).

Wie die Definition von semiotischer Effizienz in Kapitel 2.5 bereits beschreibt, wird dieses Verhältnis nicht quantitativ, sondern dadurch bestimmt, inwieweit Kommunikanten über die Kompetenz verfügen, die Konventionalität und 
Funktionalität von Textsortenexemplaren zu erkennen, zu verstehen und entsprechend ihrem funktionalen Zweck in den situativen Kontext einzubinden. Somit steht die Aushandlung dieser Konventionen im Mittelpunkt der Untersuchung von semiotischer Effizienz.

Bereits Kapitel 2.1.3 macht darauf aufmerksam, dass von der Performanz nicht unmittelbar auf die Kompetenz eines Kommunikanten geschlossen werden kann. Es kann beispielsweise nicht unmittelbar von der Gestaltung eines Pflichtenhefts auf die Kompetenz des Fahrzeugtechnikers geschlossen werden, der es erstellt hat. Die empirische Analyse versucht aber, sich dem auf der Grundlage der Textsortenanalyse und der Beobachtung von Diskussionen während der Textüberarbeitungen ${ }^{233}$ durch eine Interpretation zu nähern. Letztere bezieht sich dabei auf die kreative und transsubjektive Kompetenz von Kommunikanten als Unterkategorien kommunikativer Effizienz. Diese Unterkategorien adaptiert das EffizienzModell (s. Tabelle 2-2) aus den Kategorien ENGBERG/JANICHs (2007), die Kapitel 2.2.2 beschreibt.

Im Folgenden werden 19 Beispiele $^{234}$ aus den umfangreichen Protokollen von Textüberarbeitungen (s. Kapitel 4.5.5) und Ausschnitte aus Interviews mit Auftraggebern (s. Kapitel 4.5.6), Fahrzeugherstellern (ebd.) und einzelnen Projektmitgliedern (ebd.) herangezogen, die an der Überarbeitung beteiligt waren. Diese Beispiele werden ausgewählt, weil sie am markantesten Antworten zur Forschungsfrage nach den Auswirkungen von Interfachlichkeit auf semiotische Effizienz von Sprache-Bild-Textsorten, insbesondere Pflichtenheften geben. Weitere Beispiele des Korpus zielen zwar auch, aber in weniger prägnanter Weise auf diese Frage. Darüber hinaus verhindert der Datenschutz von beobachteten und interviewten Personen (ebd.), unzählig viele Textstellen des Korpus zitieren und letztlich veröffentlichen zu können. Weil These 3 und die Forschungsfrage vor

233 Auch wenn der aus KLEINMANN (1993) entlehnte Terminus Review für die ,institutionell veranlassten Überarbeitungsschleifen“ (JAKOBS, 2005, S. 27) verwendet wird, nutze ich für diese beobachteten Prozesse den Terminus Textüberarbeitung. Denn der Terminus Review wird auch als Fachterminus für die Prüfung von wissenschaftlichen Artikeln etc. verwendet und ist daher weniger eindeutig als Überarbeitung.

Die Nummerierung der Beispiele gibt neben Überschriften, Absätzen, Abschnitten und weiteren lexikalischen Mitteln der Textorganisation eine Orientierung in der Struktur dieses Kapitels. 
allem auf Pflichtenhefte zielen, stehen deren Überarbeitungen im Fokus der Untersuchung. Kapitel 4.4 stellt bereits dar, dass nur zu Optimierungsvorschlägen mehrere Versionen eines Textsortenexemplars vorliegen. Die folgende Analyse kann sich daher nur an wenigen Stellen auf unterschiedliche Versionen eines Optimierungsvorschlags (im Anschluss an Beispiel 12), aber vor allem eines Pflichtenheftexemplars beziehen (z. B. in Beispiel 13), macht geschilderte Beobachtungen aber durch Verweise auf die Beobachtungsprotokolle und Textsortenexemplare (in der Regel auf die Endversion) überprüfbar.

\subsection{Die Kapazität der Kommunikanten}

Drei Kriterien charakterisieren im Modell semiotischer Effizienz (s. Tabelle 2-2) die Unterkategorie ,Kapazität':

1. Die Kommunikanten verfügen über Kenntnisse der Textsortenkonventionen und -funktionen, die auf reziproken Erwartenserwartungen basieren und aus denen wiederum reziproke Erwartenserwartungen resultieren.

2. Für den einzelnen Kommunikanten kann in der Textproduktion oder Überarbeitung ein Spannungsverhältnis zwischen dem Abweichen von Konventionen und dem Erfüllen von Konventionen bestehen. Um in der Gestaltung eines Textsortenexemplars von dessen konventioneller Gestaltung abzuweichen, können Kommunikanten ihre kreative Kompetenz nutzen, die Teil ihrer kommunikativen Kompetenz ist. Dieses Spannungsverhältnis wird in der gemeinsamen Textüberarbeitung an Diskussionen der Beteiligten zur Textgestaltung deutlich.

3. Bei der Aushandlung, wie einzelne Textsortenexemplare gestaltet werden, können die Mitglieder dieser interfachlichen Projektkommunikation auf ihre transsubjektive Kompetenz zurückgreifen, die ebenfalls Teil ihrer kommunikativen Kompetenz ist. Diese Teilkompetenz ermöglicht es, dass die Kommunikanten die Textgestaltung über die mikrokulturellen Konventionen der verschiedenen beteiligten Organisationsbereiche hinweg diskutieren.

Im Anschluss werden die Beispiele aus Fahrplänen und Optimierungsvorschlägen, vor allem aber aus Pflichtenheften beschrieben, um sich interpretativ der Kapazität der Kommunikanten anzunähern. 


\subsubsection{Beispiele zur Überarbeitung von Fahrplanvarianten}

Kapitel 5.3 weist darauf hin, dass die Überarbeitung der Fahrplanvarianten eine Wissensasymmetrie veranschaulicht, die sich auf die Lesbarkeit von Z-v-Diagrammen, Fahrzeugumlaufplänen und Bildfahrplänen bezieht. Auf diese Asymmetrie deuten die beobachteten Textüberarbeitungen durch das Projektteam des Bieters:

Die Wissensasymmetrie zwischen Mitarbeitenden des interfachlichen Projektteams des Bieters veranschaulicht das folgende Beispiel 1 zur Überarbeitung des Bildfahrplans 1 (Ausschreibung 1), in dem Betriebsplaner (Btp), Redaktionsmitglieder (Rdk) und Fahrzeugtechniker (Tec) auch über den Auftraggeber (AT) diskutieren:

„Btp 1: Erläutert allgemein, dass im Dokument die ankommenden und abfahrenden Fahrtzeiten dargestellt seien. Die separate Darstellung von Fahrtzeiten für die Wochentage Mo - Do und Fr in zwei Dokumenten sei vom AT gefordert. Bittet Btp 2, diese Angaben auszuführen.

Btp 2: Ergänzt die Angaben von Btp 1 an einigen Stellen.

Rdk 2: Gibt zu bedenken, dass das vorliegende Dokument eine PDF-Datei sei, der AT aber ein EXCEL-Dokument fordere.

Tec 2: Zeigt, wo es in diesem Linienfahrplan durch die Auswahl des Fahrzeugs zu Abweichungen im Musterfahrplan komme. Diese Abweichungen seien aber unproblematisch, da der AT bzw. die DB Netz AG diese genehmigt habe.

[WORD-Kommentar AH: Frage an Rdk1: Von welcher Institution zu genehmigen (EBA?)? Antwort Rdk 1: Vom AT genehmigt, Rückfrage wurde gestellt. Eine Testierung von DB Netz war erforderlich für die Zusage des AT. Abweichung als fahrbar testiert worden.]

Rdk 1: Kommentiert, dass das Lesen der Linienpläne ungewöhnlich sei und man sich in diese erst einfinden müsse.

[Nach dem QP gibt Rdk 1 an, dass Rdk 1 und Asm an einer Schulung zur Rezeption von Linienfahrplänen teilgenommen haben und dadurch in der Lage seien, diese zu verstehen.]

Rdk 2: Zustimmung.

Btp 1: Bittet um Anmerkungen, ob das Layout angemessen sei.

Alle: Zustimmung.“ (Holste, 2013b, S. 12)

Dass die beiden Mitarbeitenden des Organisationsbereichs ,Betriebsplanung ' den übrigen Projektmitgliedern aus den Bereichen ,Recht', ,Redaktion', ,Vertrieb', ,Controlling', aber auch der ,Leitung' den Bildfahrplan erläutern mussten, veranschaulicht die Wissensasymmetrie, die sich auf Wissen über das Zeichensystem bezieht. Dass die Mitglieder der übrigen Organisationsbereiche den Bildfahrplan in der Regel nicht lesen können, bestätigt Redaktionsmitglied 1 nach der gemeinsamen Überarbeitung: Sie gibt an, dass sowohl die Redaktion als auch die 
Ausschreibungsmanager , an einer Schulung zur Rezeption von Linienfahrplänen teilgenommen haben und dadurch in der Lage seien, diese zu verstehen“ (ebd.). Dass nur Fahrzeugtechniker 2 das Exemplar des Bildfahrplans kommentiert, deutet darauf hin, dass er über vergleichbares Wissen verfügt, weil der Organisationsbereich ,Fahrzeugtechnik' ähnliche Zeichensysteme verwendet und mit dem Bereich ,Betriebsplanung“ eng kooperiert. ${ }^{235}$ Dass die Betriebsplaner den anderen Projektmitgliedern den Bildfahrplan erläutern, verweist auf ihre transsubjektive Kompetenz, weil die Betriebsplaner das fehlende Fachwissen ihrer Projektkollegen durch ihre Erläuterungen im vertikalen Wissenstransfer zwischen sich als Experten und den Mitgliedern der anderen Organisationsabteilungen als Laien vermitteln. Dieselbe Asymmetrie deutet sich bei der Rezeption von Exemplaren der Textsortenvariante Fahrzeugumlaufplan an, die an die Erläuterung des Bildfahrplans anschließt und ebenfalls unkommentiert bleibt: „Btp 1: Erläutert das Dokument kurz und bittet um Anmerkungen. (Btp $1 \&$ Rdk 1 warten ab. Die TN [Teilnehmenden; AH] signalisieren, dass es keine Kritikpunkte gibt.)“ (HOLSTE, 2013b, S. 12)

In Bezug auf die Kommunikation zwischen dem Projektteam des Bieters und den hauptverantwortlich Rezipierenden des Auftraggebers (AT) geht FAHRZEUGTECHNIKER 1 des Bieters für die Rezeption eines abbildenden Diagramms ebenfalls von einer Wissensasymmetrie im Team des Auftraggebers aus, wie Beispiel 2 zeigt:

„AH: Inwieweit ist das Diagramm für den AT lesbar ist [sic] (so wie es in der Fahrzeugcheckliste auftaucht)?

[Tec1:] Ich kann mir nicht vorstellen, dass der AT alle Daten aus dem Diagramm lesen und bewerten kann. Er hat aber natürlich die Möglichkeit [sic] andere Stellen damit zu beauftragen." (E-Mail vom 9.4.2014)

Gleichzeitig geht der Fahrzeugtechniker aber davon aus, dass die hauptverantwortlich Rezipierenden ebenfalls durch ein interfachliches Projektteam unterstützt werden, um mögliche Wissensasymmetrien auszugleichen. Dass der Auftraggeber im interfachlichen Team arbeitet, bestätigt AufTRAGgeBER 1 in Beispiel 3 bei der Beantwortung einer Frage zur Fachterminologie in Optimierungsvorschlägen $(\mathrm{OV})$ :

235 Dies zeigt beispielsweise, dass für die Testierung des Fahrplans (also dessen Zulassung) detaillierte Angaben zum Fahrzeug zu machen sind. 
„Wie gehen Sie als federführend Zuständige beim Lesen der OV mit Verständnisfragen um, die sich aus unbekannter Fachsprachenterminologie ergeben?

Bei derartigen Fragen wenden wir uns an die jeweiligen Fachautoren im Hause. Gegebenenfalls klären wir Formulierungen, die unklar sind, im Bietergespräch.“ (AuftraggeBer 1, 2013, S. 9; Kursive im Original)

In Beispiel 4 bestätigt auch AuftRAGGeBer 2, dass er bei der Rezeption auch im interfachlichen Team arbeiten kann:

„Die Texte liest der jeweilige Projektleiter - das Wettbewerbsteam des [Auftraggebers 2] besteht aus 4 Mitarbeitern. Dieser Leiter kann bei Bedarf Rücksprache mit einzelnen Abteilungsleitern oder anderen Mitarbeitern vom [Auftraggeber 2] halten." (2010a, S. 1)

Diese Aussagen der hauptverantwortlich Lesenden deuten eine transsubjektive Kompetenz an: Beide antizipieren, möglicherweise Fachwissen beteiligter Bereiche zu benötigen, um Pflichtenhefte und Fahrplanvarianten rezipieren zu können.

Das Vorgehen der hauptverantwortlichen Lesenden als Laien auf wenigen Teilgebieten der beteiligten Organisationsbereiche, die Lexik als Fachterminologie oder Angaben als Verweis auf Hintergrundwissen zu identifizieren, zieht ein Problem nach sich: Ein juristischer Laie muss beispielsweise den Verweis der Generalklausel auf die Forderungen der Norm TSI PRM als Hintergrundwissen nicht zwingend erkennen (s. Kapitel 5.2.4). Im Anschluss daran könnte er die geforderte Mindestanzahl an PRM-Plätzen als $10 \%$ der Gesamtsitzplatzanzahl in der technischen Zeichnung nicht überprüfen (ebd.).

Demnach bestehen Wissensasymmetrien zwischen Mitgliedern verschiedener Organisationsbereiche einer Organisation, aber nicht zwischen den beiden Organisationen. D. h., die Prozipienten verfügen als Projektteam auf Bieter- und auch auf Auftraggeberseite über das Textwissen, das zur Produktion und Rezeption der Textsortenexemplare notwendig ist.

\subsubsection{Beispiele zur Überarbeitung von Optimierungsvorschlägen}

Die Frage in Beispiel 3 resultiert aus der Beobachtung des folgenden Beispiels 5 zur Überarbeitung des Optimierungsvorschlags Ferienfahrplan durch den Prüfer (Prüf), Redaktionsmitglied 1 und den Leiter (Leit):

„[Prüf] fragt, was ein werktäglicher Feiertag sei.

[Rdk 1] antwortet, dass dies im Bereich Planung ein bekanntes Wort sei.

[Prüf] behauptet, dass die Formulierung an Feiertagen eindeutiger sei.

[Leit] stimmt zu.“ (HoLSTE, 2010a, S. 3; Kursive im Original) 
Die Behauptung des Prüfers, dass das Lexem Feiertag mit hohem allgemeinsprachlichem Grad eindeutiger sei als die Nominalphrase werktägiger Feiertag mit hohem fachsprachlichem Grad, impliziert, dass allgemeinsprachliche Lexik an dieser Stelle eindeutiger sei als fachsprachliche Terminologie. Demnach unterstellt der Betriebsplaner, der diese Formulierung aus der Terminologie seines Organisationsbereichs in das Textsortenexemplar einbindet, dem Rezipienten, die Bedeutung des Fachterminus zu kennen. Die Kritik des Prüfers deutet darauf hin, dass er dem Rezipienten diese Kompetenz nicht zuspricht. Beispiel 5 verweist damit auf eine transsubjektive Kompetenz des Prüfers, der einen möglichen fachterminologischen Kenntnisstand des hauptverantwortlichen Rezipienten beim Auftraggeber antizipiert. Die Kritik des Prüfers weist gleichzeitig auch auf eine reziproke Erwartenserwartung hin: Er geht davon aus, dass der Rezipient beim Auftraggeber erwartet, keine betriebsplanerische Fachterminologie in den Optimierungsvorschlägen lesen zu müssen.

Auch die folgenden Beispiele verweisen auf die Vorwegnahme von Erwartungen an a) die Themen- und Funktionsstruktur der Vorschläge; b) die Notwendigkeit intertextueller Verweise zwischen einzelnen Optimierungsvorschlägen bzw. deren Rezeptionschronologie.

In Beispiel 6 (OV 9 aus Ausschreibung 1) diskutieren Techniker 1 (Tec 1), der Leiter (Leit) und Redaktionsmitglied 1 (Rdk 1) eine Vereinheitlichung der Themenstruktur:

„Tec 1: Schlägt eine Vereinheitlichung der OV bezüglich des ,Wordings“ vor: Ein [sic] einheitliche Angabe des Preises pro Zugkilometer sei für den Aufgabenträger übersichtlicher. Des Weiteren vermutet er, dass den Aufgabenträger vor allem der Preis interessiere.

Leit: Zustimmung, nach dem Gesamtpreis pro Jahr und nach Preis pro Zugkilometer zu differenzieren.

Rdk 1: Hält Aussage von Tec 1 entgegen, dass nicht nur der Preis entscheidend sei, sondern auch die Anpassung an die VDU. Erläutert die grundsätzliche Dreiteilung aller OV dieser Ausschreibung entsprechend der Vorlage der Redaktion für die Fachautoren zu:

1. Verweis auf die VDU

2. Inhaltliche Ausführung der Optimierung

3. Angabe des Preises.

Leit: Zustimmung.“ (Holste, 2013a, S. 5) 
Die Diskussion ${ }^{236}$ zwischen Techniker 1 und Redaktionsmitglied 1 entspinnt sich an den beiden Grundfunktionen von Optimierungsvorschlägen: Techniker 1 hat die Erwartung, dass der Auftraggeber die Angabe der Preisreduktion in Optimierungsvorschlägen erwartet. Diese Annahme untermauert folgende Aussage des hauptverantwortlich Lesenden von AUfTRAGGEBER 2 in Ausschreibung 3: „Der Optimierungsvorschlag hat den Zweck, Geld zu sparen.“ (2010a, S. 4) Und auch auf die Frage, wann ein Optimierungsvorschlag überzeugend ist, antwortet der hauptverantwortlich Lesende: „Der Preis überzeugt. Zu 100 \%.“ (ebd.) Gleichzeitig schränkt dieser Leser seine erste Aussage zur Funktion von Optimierungsvorschlägen ein, wie Beispiel 7 belegt:

„[E]inige meiner Kollegen aus dem Qualitätsmanagement würden das vielleicht anders sehen. Ein noch besseres Angebot für den Kunden fokussieren wir nicht, weil die Mindestanforderungen bereits ein angemessenes bis gutes Angebot für den Kunden sicherstellen.“ (ebd.)

Wie auch schon Kapitel 5.2.2 zeigt, besteht die textuelle Grundfunktion der Optimierungsvorschläge darin, den Auftraggeber von einer Änderung der Verdingungsunterlagen zu überzeugen, die den Angebotspreis senkt. Gleichzeitig müssen a) die Mindestanforderungen eingehalten werden, wie auch die in Kapitel 5.1.2 zitierte Aussage von Auftraggeber 1 (2013, S. 7 f.) belegt (Beispiel 8), b) eine Preissenkung verfolgt, c) vergaberechtliche Zulässigkeit und d) eine weitgehende Erhaltung der Qualität dessen garantiert sein, was angeboten wird.

Die in Beispiel 6 thematisierte Vereinheitlichung der Themenstruktur lässt auf die Erwartung von Redaktionsmitglied 1 schließen, der Auftraggeber erwarte, dass die Exemplare der Textsorte Optimierungsvorschlag einheitlich gestaltet sind. Diese angenommene Erwartenserwartung untermauert folgende Antwort von Auftraggeber 1 (Beispiel 9) auf die Frage, ob bestimmte inhaltliche Punkte in Optimierungsvorschlägen behandelt und in der Überschrift aufgeführt werden sollten:

236 Differenziert werden können die Angabe von Personenkilometern und die Angabe von Zugkilometern. Personenkilometer bezeichnen „das Produkt der Anzahl der beförderten Personen und der mittleren Fahrweite" (WiEDEMANN, ${ }^{32006, ~ S . ~ 141) . ~ Z u g k i l o m e t e r ~ b e-~}$ zeichnen „die Fahrleistung eines Zuges auf Streckenfahrt. Einheit ist die Fahrt von einem Zug über einen Kilometer" (ebd., S. 199). Für Ausschreibungen sind i. d. R. Zugkilometer relevant. Beispielsweise ist in Ausschreibung 1 ,,der Preis für jeden eingesetzten Fahrzeugtyp je Zugkilometer je Los anzugeben“ (Leistungsbeschreibung, S. 14). 
„Schön ist es, wenn alle OV eines EVU eine einheitliche Struktur haben, d. h., wenn eindeutige Gliederungspunkte in allen OV vorkommen. Das macht die Kommunikation intern und extern einfacher.“ (2013, S. 10)

Als Resultat der Diskussion in der gemeinsamen Überarbeitung wird die Struktur aller Exemplare der Textsorte ,Optimierungsvorschlag' in dieser Ausschreibung vereinheitlicht, wie unter anderem die Anpassung von OV 7 in Ausschreibung 1 während der gemeinsamen Überarbeitung zeigt (Beispiel 10): ,[Rdk 1 passt die Überschriften an die von OV 15 (Phase 3: OV 9) an: 1 Erläuterung 2 Optimierung 3 Anzupassende Unterlagen 4 Preiseffekt.]"237 (Holste, 2013a, S. 13) Dieser Strukturierungsvorschlag von Redaktionsmitglied 1 weist auf eine kreative Kompetenz hin. Im Gegensatz zum Einsatz kreativer Kompetenz, durch die die Kommunikanten in Beispiel 11 von einer Textsortenkonvention abweichen, muss Redaktionsmitglied 1 in Beispiel 10 kreativ werden, weil die Textsorte keine Vorgaben zur Textstruktur macht. Beispiel 10 zeigt aber, dass eine einheitliche Textstruktur notwendig ist, um die Rezeption der Optimierungsvorschläge - wie von AufTRAGGEBER 1 gewünscht - zu erleichtern.

Beispiel 11 aus der gemeinsamen Überarbeitung von OV 1 in Ausschreibung 1 weist auf die Erwartungen des Marketing-Mitarbeitenden 1 (Mkt 1) und Erwartungen von Techniker 1 (Tec 1) hin:

„Mkt 1: Bezweifelt, dass der AT die OV zu Beginn des Ausschreibungsprozesses vollständig liest.

Tec 1: Wiederholt, dass die OV das Bietergespräch vorbereiten und dass erst dort die Zusammenhänge zwischen den Inhalten von OV 1 und OV 10 [Phase 3: OV 8] detailliert dargestellt werden sollten. So würden die Probleme der Informationsaufteilung auf die OV und die der Darstellungschronologie umgangen werden.“ (Holste, 2013a, S. 8 f.)

Aufgrund der Erwartung, dass der Auftraggeber die Optierungsvorschläge nicht vollständig oder chronologisch lese, versucht Techniker 1 die Optimierung innerhalb des Textsortennetzes auf das anschließende Bietergespräch zu verschieben.

237 Die Benennung Optimierungsvorschlag Phase 3 bezeichnet die Abgabeversion, während Vorschläge mit der Bezeichnung Phase 2 die Version der gemeinsamen Überarbeitung bezeichnen. Zum Teil haben Leitung und Redaktion nach der gemeinsamen Überarbeitung Angaben und Gestaltung minimal verändert. Im Anhang finden sich ausschließlich Exemplare in Version 3. 
Dass diese Strategie zu einer Umsetzung des Vorschlags führt, widerspricht der Aussage von AuftraggeBer 1 (Beispiel 12):

„Die OV sollten möglichst selbsterklärend sein. Wenn das nicht der Fall ist, fragt man im Bietergespräch nach. Als Aufgabenträger möchten wir uns im Vorfeld orientieren und mit Kollegen anderer Aufgabenträger abstimmen [...]. Denn ohne unter den Aufgabenträgern eine Entscheidungstendenz zu einem Vorschlag und seinen Details festgelegt zu haben, können wir im Bietergespräch auf Anfragen keine Antwort geben. Der Ausschreibungsprozess würde sich dadurch unnötig verlängern.“ (2013, S. 11)

Ausgehend von dieser Ansicht des Auftraggebers würden Vorschläge, die nicht in Form der Textsorte Optimierungsvorschlag an der vorgesehene Stelle im Textsortennetz (s. Tabelle 4-3) gemacht werden, aber im anschließenden Bietergespräch thematisiert würden, die Erwartungen von Auftraggeber 1 enttäuschen. Optimierungsvorschlag 10 (Phase 2), an dem sich die Diskussion entzündet, verweist als Optimierungsvorschlag 8 in der Abgabeversion (Phase 3) nicht auf Optimierungsvorschlag 1, wie der Marketing-Mitarbeitende dies in Beispiel 11 vorschlägt. Sein Vorschlag weicht aber von der Konvention ab, Vorschläge zur Verbesserung der Anforderungen schriftlich als Exemplar der Textsorte Optimierungsvorschlag mitzuteilen. Daher deutet seine Idee auf kreative Kompetenz hin.

\subsubsection{Beispiele zur Überarbeitung von Pflichtenheften}

Im Folgenden werden Hinweise auf die Verwendung von kreativer und transsubjektiver Kompetenz sowie (reziproken Erwartens-)Erwartungen bei der Überarbeitung von Pflichtenheften untersucht. Dazu werden fünf Ausschnitte aus Gesprächen über Pflichtenhefte herangezogen, die sich beziehen auf: 1. die Eindeutigkeit der Rekurrenz zwischen einem Schriftelement und einem multimodalen Element in der Grundrisszeichnung; 2. die Relevanz der Generalklausel für alle Schriftelemente und einen daraus resultierenden Normkonflikt; 3. die kommissive Funktion aller Textsortenelemente bzw. deren Beschränkung für Abbilder; 4. die Erwartung einer Sanktionierung bei einer Veränderung der Unterlagen und 5. die Erwartung, für die Verwendung von Terminologie in der Pflichtenheftantwort, die vom Lastenheftvordruck abweicht, nicht sanktioniert zu werden.

1. Der erste Gesprächsausschnitt bezieht sich auf die Sprache-Bild-Relation bzw. Relation zwischen dem Fahrzeuggrundriss (s. Abbildung 5-18) und folgender Tabellenzeile eines Schriftmoduls (s. Tabelle 6-1): 


\begin{tabular}{|l|l|l|}
\hline $\begin{array}{l}\text { Anteil Sitzplatzrichtung (in betr. Seg- } \\
\text { menten) nach vorne/hinten }\end{array}$ & $\begin{array}{l}\text { Anteil } \\
\text { vorne/hin- } \\
\text { ten in \% }\end{array}$ & $\begin{array}{l}\text { 2. K1. HF B: } 50 \mathrm{zu} 50 \\
\text { 2. K1. NF B: } 33 \mathrm{zu} 66 \\
\end{array}$ \\
& $\begin{array}{l}\text { 2. K1. Übergang: } 50 \mathrm{zu} \\
50\end{array}$ \\
& 2. K1. NF A: $0 \mathrm{zu} 100$ \\
& 2. K1. HF A: $50 \mathrm{zu} 50$ \\
\hline
\end{tabular}

Tabelle 6-1: Zeile aus der Vorversion von Pflichtenheft 3 zur Verteilung der Anteile an Sitzplätzen nach deren Ausrichtung.

Dieses Modul rekurriert auf die Beschriftung A-Wagen im genannten Grundriss, das sich mit der schematischen Darstellung des Schienenfahrzeugs durch Linien als multimodales Element zusammenfügt. Bei der gemeinsamen Überarbeitung bezieht sich Techniker 1 (Beispiel 13) auf die Textstelle, die Tabelle 6-1 angibt: „TEC 1: Eindeutige Angaben für $A$ besser $A$-Wagen. “ (HoLSTE, 2010b, S. 6) ${ }^{238}$ In der Abgabeversion des Pflichtenheftexemplars findet sich eine entsprechende Änderung der Angaben (s. Tabelle 6-2):

\begin{tabular}{|c|c|c|}
\hline $\begin{array}{l}\text { Anteil Sitzplatzrichtung (in betr. Seg- } \\
\text { menten) nach vorne/hinten }\end{array}$ & $\begin{array}{l}\text { Anteil } \\
\text { vorne/hin- } \\
\text { ten in \% }\end{array}$ & $\begin{array}{l}\text { 1. K1. Hochflur B-Wa- } \\
\text { gen: } 50 \text { zu } 50 \\
\text { 2. K1. Hochflur B-Wa- } \\
\text { gen: } 33 \text { zu } 66 \\
\text { 2. K1. Niederflur B-Wa- } \\
\text { gen: } 22 \text { zu } 78 \\
\text { 2. K1. Übergang: } 50 \mathrm{zu} \\
\text { 50 } \\
\text { 2. K1. Niederflur A-Wa- } \\
\text { gen: } 0 \text { zu } 100 \\
\text { 2. K1. Hochflur A-Wa- } \\
\text { gen: } 50 \text { zu } 50\end{array}$ \\
\hline
\end{tabular}

Tabelle 6-2: Zeile aus Pflichtenheft 3 zu Sitzplatzanteilen nach deren Ausrichtung.

238 Vergleichbare Verweise kommen in Pflichtenheft 2 vor. 
Diese Überarbeitung deutet auf die Erwartung von Techniker 1 hin, dass der Auftraggeber den Versal $A$ nicht als Verweis auf die Zeichnung interpretiert. Dass der alternative Vorschlag lediglich aus A-Wagen besteht, deutet die Erwartung an, dass der Auftraggeber den Grundriss rezipiert, bevor er diese Angabe im Schriftmodul liest. Diese angenommene Erwartung von Techniker 1 ist demnach eine Erwartenserwartung: Er würde dem Auftraggeber unterstellen, im Pflichtenheft einen eindeutigen Verweis auf den Grundriss zu erwarten. Dieser Überarbeitungsvorschlag des Technikers lässt auf seine transsubjektive Kompetenz schließen.

2. Der zweite Gesprächsausschnitt bezieht sich auf folgende Textstelle (s. Tabelle 6-3):

\begin{tabular}{|l|l|l|}
\hline Überfahrrampe für Elektrorollstühle & $\begin{array}{l}\text { ja/nein, } \\
\text { Anzahl/Seite }\end{array}$ & Nein \\
\hline
\end{tabular}

Tabelle 6-3: Zeile aus Pflichtenheft 1 mit der Angabe zu Elektrorollstühlen.

Dieser Ausschnitt in Tabelle 6-7 verweist darauf, dass die Norm TSI PRM und die Empfehlungen der BAG SPNV nicht harmoniert wurden. Dieser NormenKonflikt wird durch die Verwendung abweichender Terminologie in Beispiel 14 deutlich:

„Rdk 1: Fragt, warum die Stelle Überfahrrampe für Elektrorollstühle markiert ist. Tec 2: Unklar sei, ob die Klapprampe aus der TSI PRM mit der hier angegebenen Überfahrrampe gleichzusetzen sei. [Bezug Z. 403]

Tec 1: Präzisiert, dass die in Z. 403 angegebene manuelle Rampe TSI-konform sei. Er stimmt Tec 2 zu, dass unklar sei, ob eine Überfahrrampe gleichzusetzen sei mit einer Klapprampe. Daher schlägt er vor, Folgendes anzugeben: Überfahrrampe nein (Klapprampe nach TSI).

Rdk 1: Kommentiert, dass der fachkundige Leser wisse, dass sich eine Klapprampe für Elektrorollstühle eigne.“"239 (HOLSTE, 2013b, S. 5; Kursive im Original)

Zwar wird die TSI PRM implizit durch die Generalklausel zu technischen und gesetzlichen Anforderungen genannt (s. Beispielsätze 5-2 und 5-3). Dass die Empfehlungen der BAG SPNV für die Erstellung von Lastenheftvordruck 1 und weitere Lastenheftvordrucke relevant ist, bestätigt AUFTRAGGEBER 1

239 Angaben wie Z. 403 beziehen sich auf die Nummerierung der Zeilen (Zeile 403). Angaben wie $C 277$ beschreiben die Position eines Tabellenfachs in einer Spalte (Spalte $C$ ) und einer Zeile (Zeile 277). 
(Beispiel 15) auf die Frage nach einfließenden Normen: „Bei uns liegen die Gesetze aus, die BAG-SPNV-Empfehlungen fließen auch vollständig ein, damit wir eine Standardisierung erreichen.“(2013, S. 6) Die folgende Textstelle aus den Empfehlungen der BAG SPNV, die den Terminus Überfahrrampe verwendet und dabei auf die Norm TSI PRM verweist, bildet den Ausgangspunkt für die Diskussion bei der gemeinsamen Überarbeitung:

„Die TSI PRM (dort Kap. 4.2.2.12.3.2) legt die Randbedingungen für die Verfügbarkeit von Einstiegshilfen für Rollstuhlfahrer fest. Davon unabhängig kann gefordert werden, dass je eingesetzter Wagengarnitur bzw. Triebzug an jeder Fahrzeugseite zu den Bahnsteigen mindestens eine Überfahrrampe oder ein Lift für den Einstieg von Elektrorollstühlen vorhanden sein muss.“" (BAG SPNV, ${ }^{2} 2010$, S. 31)

Durch den unscharfen Bezug des Korrelats davon ist unklar, ob die Anforderungen an die Überfahrrampe den Anforderungen der TSI PRM entsprechen müssen oder ob eine Überfahrrampe zusätzlich zu den TSI-PRM-Anforderungen auch den BAG-SPNV-Anforderungen entsprechen muss. Auch bei einem klaren Verweis auf die TSI PRM besteht ein terminologischer Konflikt, weil der Terminus Überfahrrampe in der gesamten TSI PRM (2008) nicht verwendet wird. An der entsprechenden Stelle der TSI PRM, also in Kapitel 4.2.2.12.3.2, wird stattdessen die Nominalphrase Einstiegshilfe für Rollstuhlfahrer (TSI PRM, 2008, S. 126 f.) verwendet. Der Terminus Einstiegshilfe fungiert als Hyperonym zu den Kohyponymen, die in der TSI PRM durch die Termini Überbrückungsplatte, Rampe und Hublift repräsentiert werden (s. Tabelle 6-4).

\begin{tabular}{|l|l|l|l|}
\hline Nutzung der Einstiegshilfe & \multicolumn{1}{|c|}{$\begin{array}{c}\text { Nicht für Rollstuhlfahrer } \\
\text { zugänglich }\end{array}$} & $\begin{array}{l}\text { Für Rollstuhlfahrer und } \\
\text { andere Personen } \\
\text { zugänglich }\end{array}$ & \multicolumn{1}{c|}{$\begin{array}{c}\text { Nur für Rollstuhlfahrer } \\
\text { zugänglich }\end{array}$} \\
\hline Art der Einstiegshilfe* & $\begin{array}{l}\text { Bewegliche Trittstufe } \\
\text { Andere Vorrichtungen }\end{array}$ & $\begin{array}{l}\text { Rampe } \\
\text { Überbrückungsplatte } \\
\text { Andere Vorrichtungen }\end{array}$ & $\begin{array}{l}\text { Hublift } \\
\text { Andere Vorrichtungen }\end{array}$ \\
\hline $\begin{array}{l}\text { Allgemeine } \\
\text { Anforderungen gemäß: }\end{array}$ & Kategorie A & $\begin{array}{l}\text { Kategorie A } \\
\text { Kategorie B }\end{array}$ & Kategorie B \\
\hline
\end{tabular}

Tabelle 6-4: Überblick über Anforderungen an Einstiegshilfen (TSI PRM, 2008, S. 126).

Der Terminus Klapprampe wird aber ebenso wenig in der TSI PRM verwendet wie der Terminus Überfahrbrücke (TSI PRM, 2008). Beim Gebrauch des Terminus Überfahrbrücke verweisen die BAG-SPNV-Empfehlungen ebenfalls auf die TSI PRM: „Die Ausgestaltung von Klapprampe oder Hublift und deren fahrzeug- 
seitige Unterbringung muss den Vorgaben der TSI PRM (dort Kap. 4.2.2.12.3) entsprechen.“ (BAG SPNV, ${ }^{2} 2010$, S. 32)

Die Antwort auf die Frage von Techniker 2 in Beispiel 14, ob eine Klapprampe aus der TSI PRM mit einer Überfahrrampe gleichzusetzen sei, ist demnach mit einem Nein zu beantworten, weil die TSI PRM keine Klapprampe definiert. Seine Frage unterstellt die Erwartung, dass der Auftraggeber von den Angaben des Bieters erwartet, sowohl die Norm TSI PRM als auch die Empfehlungen der BAG SPNV - auf die terminologisch verwiesen wird ${ }^{240}$ - zu erfüllen. Diese Erwartenserwartung teilt Redaktionsmitglied 1 dagegen nicht. Denn der Auftraggeber könne als Experte die Eignung der Klapprampe für Elektrorollstühle einschätzen, wie der Redakteur in Beispiel 14 annimmt. Letzteres Argument setzt sich durch, sodass nicht die Nominalphrase Überfahrrampe nein (Klapprampe nach TSI), sondern die Angabe Überfahrrampe für Elektrorollstühle - nein in Pflichtenheft 1 (PH 1) übernommen wird. Der Lösungsvorschlag von Techniker 1 für den terminologischen Normenkonflikt durch die Formulierung Überfahrrampe nein (Klapprampe nach TSI) spricht für einen hohen Grad an kreativer Kompetenz.

3. Der dritte Gesprächsausschnitt diskutiert zwei Textstellen in Pflichtenheft 1. Zum einen bezieht sich das Gespräch auf die folgende Zeile des Schriftmoduls (s. Tabelle 6-5):

\begin{tabular}{|l|l|l|}
\hline Kopfstützen mit Öhrchen zum Gang/Fenster & ja/nein & ja/ja \\
\hline
\end{tabular}

Tabelle 6-5: Zeile zu sogenannten Öhrchen an Kopfstützen (PH 1).

Zum anderen diskutieren die Textüberarbeitenden die Bildmodule mit den Beschriftungen Abb. 9 und Abb. 10 unterhalb dieses Schriftmoduls in Pflichtenheft 1, die Fotos von den Sitzen der 1. Klasse und 2. Klasse enthalten. Diese Textstelle aus Pflichtenheft 1 gibt bei der gemeinsamen Überarbeitung Anlass zu folgender Aushandlung in Beispiel 16 zwischen dem Prüfer (Prf), Techniker 1 (Tec 1) und Redaktionsmitglied 1 (Rdk 1):

240 Die Empfehlungen der BAG SPNV sind in der Domäne von SPNV-Ausschreibungsverfahren nicht nur den hauptverantwortlich Lesenden der Auftraggeber (AUFTRAGGEBER 1, 2013, S. 6), sondern meiner Erfahrung während der Tätigkeit beim Bieter nach den Fahrzeugtechnikern und auch Leitern von Ausschreibungsprojekten bekannt. 
„Prf: Kritisiert, dass das Bild eine Kopfstütze ohne Öhrchen wiedergebe, während die Tabelle [Bezug auf C277] angebe, Sitze mit Öhrchen anzubieten.

Tec 1: Rechtfertigt, dass keine Bilder mit Öhrchen vorhanden seien.

Prf: Hält dem entgegen, dass das Bild einen falschen Eindruck vermittle.

Tec 1: Gibt an, dass er versuche, ein passendes Bild zu beschaffen.

Rdk 1: Stimmt Tec 1 zu, dass dem Unternehmen entweder Bilder von Sitzen mit Armlehne oder von Sitzen mit Öhrchen vorliegen. Verweist auf einen Satz unter einem Foto in einer vergangenen Ausschreibung [sinngemäß]: Foto beispielhaft. Entspricht nicht in allen Details der Angabe in der Tabelle. Sagt zu, den genauen Wortlaut zu prüfen und in diejenigen Beschriftungen einzufügen, bei denen das Bild stark vom Text abweiche. Argumentiert, dass der AT wisse, dass dem Unternehmen zurzeit keine passenden Fotos vorliegen." (Holste, 2013b, S. 8; Kursive im Original)

Da nicht das Pflichtenheftexemplar mit diesem Fahrzeug, sondern zu einem anderen Fahrzeug eingereicht worden ist, hat die Redaktion die vorgeschlagene Bildkommentierung nach der gemeinsamen Überarbeitung nicht in dieses Exemplar eingearbeitet. Eine kommentierende Formulierung, die mit der vorgeschlagenen Formulierung weitgehend identisch ist, findet sich aber in PFLICHTENHEFT 2, wie bereits Kapitel 5.2.2 bespricht: „Beispielgrafik - Angebot kann in Ausstattungsdetails von dieser Abbildung abweichen“. (PH 2) ${ }^{241}$ Durch die Kommentierung wird ein mögliches Kommissiv als impliziter Bildakt vermieden, wie er für die Schriftelemente anzunehmen ist (s. Kapitel 5.2.2).

Der Einwand des Prüfers in Beispiel 16, dass Abbildung und Schriftelement der betreffenden Zeile nicht übereinstimmen, weist darauf hin, dass er die Erwartenserwartung hat, der Auftraggeber erwarte identische Inhalte in Schrift- und Bildelementen. Auf diese interpretierte Erwartenserwartung deutet die Aussage von Techniker 1 dagegen nicht hin. Denn der Techniker geht davon aus, dass der Auftraggeber über eine mangelnde Verfügbarkeit von geeigneten Fotos vonseiten der Fahrzeughersteller informiert sei. Es setzt sich zum Teil der Einwand des Prüfers durch, weil zwar die technischen Zeichnungen Sitze mit sogenannten Öhrchen darstellen (s. Kapitel 5.2.3), aber zumindest Fotos ohne Öhrchen eingefügt werden (ebd.). Der Vorschlag von Redaktionsmitglied 1 in Beispiel 16, sämtliche Bildelemente zu kommentieren, deren dargestellte Inhalte den Inhalten der entsprechenden Schriftelemente widersprechen, lässt einerseits den Einsatz von Kreativität vermuten. Denn ein entsprechender Kommentar ist in den Lastenheft-

241 Auch Pflichtenheft 3 verwendet eine entsprechende Kommentierung. 
vordrucken nicht vorgesehen, sodass der Bieter von der Formularvorgabe abweicht, ohne die Angaben des Vordrucks zu verändern. Andererseits wirkt das Einfügen dieser Anmerkungen konventionell, weil PfLichtenheft 2 und PFLICHTENHEFT 3 ebenfalls diese Kommentierungen enthalten. Damit erfindet Redaktionsmitglied 1 den Kommentar möglicherweise nicht neu, sondern könnte die Idee für den Vorschlag aus anderen Ausschreibungsverfahren übernehmen.

4. Der vierte Gesprächsausschnitt bezieht sich auf folgende Beschriftung eines Bildmoduls: „Abb. 5: Fahrzeug (Innenraum), Foto 2. Klasse (Mehrzweckabteil) (Beispiel)“(PH 1). Diese Textstelle gibt bei der gemeinsamen Überarbeitung Anlass zur Diskussion (Beispiel 17) zwischen dem Prüfer (Prf), Techniker 2 (Tec 2) und Redaktionsmitglied 1 (Rdk 1):

„Prf: Merkt an, dass zwei Klammern hintereinander nicht korrekt seien, schränkt dabei aber ein, dass es sich nur um einen formalen Fehler handele.

Rdk 1: Regt an, die Klammern um das Wort Beispiel zu löschen.

Tec 2: Gibt zu bedenken, dass diese Klammern vom AT vorgegeben seien. Verweist darauf, dass Rechtschreibfehler in den Vorgaben des AT nicht korrigiert werden dürften." (Holste, 2013b, S. 7; Kursive im Original)

Auch wenn das Regelwerk des Rats für deutsche Rechtschreibung keine Regel enthält (Amtliches Regelwerk Deutsche Rechtschreibung, 2018, S. 94 ff.), die die unmittelbar aneinander anschließende Verwendung von zwei Klammertermen ausschließt, ist diese Verwendung markiert. Der Einwand des Prüfers deutet auf die Erwartenserwartung hin, dass der Auftraggeber keine Veränderung des Lastenheftvordrucks erwarte, weil eine solche Veränderung durch den Ausschluss aus dem Verfahren sanktioniert werden kann (s. Kapitel 2.4.3). Dementsprechend ist davon auszugehen, dass der Prüfer eine entsprechende Sanktionierung erwartet, falls die Textüberarbeitenden des Bieters die Schriftelemente des Lastenheftvordrucks verändern.

5. Der fünfte Gesprächsausschnitt thematisiert wie auch Beispiel 14 die Abweichung von einer Vorgabe. Im Gegensatz zu Beispiel 14 resultiert die Abweichung aber nicht aus einem Normenkonflikt zwischen BAG-SPNV- und TSIPRM-Vorgaben. Vielmehr weicht der Bieter von der Terminologie der Verdingungsunterlagen zu dieser Ausschreibung ab. Ausgangspunkt der Diskussion bildet folgende Zeile aus einem Schriftmodul (s. Tabelle 6-6): 


\begin{tabular}{|l|l|l|}
\hline Anzahl Toiletten & Anzahl & 1 \\
\hline davon behindertengerecht & Anzahl & 1 Behindertenfreundliche \\
\hline
\end{tabular}

Tabelle 6-6: Zeile mit der Abweichung vom Terminus behindertengerecht durch behindertenfreundlich (PH 1).

Prüfer (Prf), Techniker 2 (Tec), Redaktionsmitglied 1 (Rdk 1) und Betriebsplaner (Btp) diskutieren in Beispiel 18 dazu Folgendes:

„Prf: Kritisiert, dass das Wort behindertenfreundlich und nicht das TSI-PRMkonforme Wort behindertengerecht verwendet werde.

Tec: Rechtfertigt die Wortwahl damit, dass die Toilette nicht den TSI-PRMAnforderungen für eine behindertengerechte Toilette entspreche.

Prf: $\quad$ Schlägt infolgedessen vor, als Anzahl 0 anzugeben.

Rdk 1: Zustimmung.

Tec 2: Vermittelt mit dem Vorschlag, 0 (aber behindertenfreundlich) anzugeben.

Rdk 1: Modifiziert die Angabe in 0 (1 behindertenfreundlich).

A464 u. A465

[A464] klappbarer Wickeltisch in behintergerechter [sic] Toilette-ja/nein -ja

[A465] Art der Handtrocknung - Papier/Gebläse - Papierhanftücher [sic]

Btp: [A465] Bittet um Änderung von Papierhanftücher [sic] in Papierhandtücher.

[A464] Gibt in Anlehnung an Besprechung von A446 zu bedenken, dass in A464 die Anzahl in einer behindertengerechten Toilette gefordert sei.

Fragt, ob nein angegeben werden müsse, da es eine behindertenfreundliche Toilette ist.

Rdk 1: Empfiehlt, einen Strich zu setzen.

Tec 2: Schlägt in Anlehnung an A464 vor, nein (aber 1 in behindertenfreundlicher) einzutragen.

Rdk 1: Zustimmung.

Tec 1: Argumentiert für die Formulierung ja (aber in behindertenfreundlicher Toilette)

Leit: $\quad$ Zustimmung zu Tec 1.“ (Holste, 2013b, S. 8 f.; Kursive im Original)

Die Anmerkung des Prüfers, dass der Terminus behindertengerecht mit der Norm TSI PRM (2008) konform wäre, lässt sich nicht bestätigen. Denn dieses Wort wird in der gesamten Norm nicht verwendet (ebd.). In Analogie zu Beispiel $14-$ der Verwendung von Überfahrrampe - nutzen nur die Empfehlungen der BAG SPNV diesen Terminus und verweisen auf die TSI PRM:

„Die Vorgaben der TSI PRM zur Gestaltung von Sitzplätzen für Menschen mit Behinderungen, Rollstuhlplätzen, behindertengerechtem WC, Spaltbreite, Rampen etc. sind in den nachfolgenden Anforderungen enthalten." (BAG SPNV, 22010 , S. 24; Kursive im Original; Fettdruck AH) 
In der TSI PRM (2008) werden weder der Terminus behindertenfreundlich noch der Terminus behindertengerecht verwendet. ${ }^{242}$ Letztere Norm nutzt lediglich Komposita als partielle Synonyme, die mit dem Grundwort -gerecht enden. $\mathrm{Zu}$ diesen gehören rollstuhlgerecht und PRM-gerecht. So wird rollstuhlgerecht verwendet in den Themenmodulen zu Toiletten in Bahnhöfen (ebd., S. 98), Einstiegshilfen (ebd., S. 105) etc. Das partielle Synonym PRM-gerecht kommt in den Themenmodulen Schlafgelegenheiten (ebd., S. 124), Parkmöglichkeiten (ebd., S. 96), Türen (ebd., S. 97) etc. vor. Auf Barrierefreiheit in Schienenfahrzeugen bezieht sich auch DIN EN 16585-1 (2017). Diese betitelt Anhang E als „Anleitung für rollstuhlgerechte Toiletten und bewährte Verfahrensweisen“ (ebd., S. 32). Auch DIN 32977-1 (1992), die die Gestaltung technischer Erzeugnisse behandelt, beinhaltet im Titel „Behinderungsgerechtes Gestalten“ den Terminus behindertengerecht. Partielle Synonyme, die auf -freundlich enden, kommen dagegen weder in der TSI PRM (2008) noch in DIN EN 16585-1 (2017) oder in DIN 32977-1 (1992) vor. Dieser Gebrauch des Grundworts -gerecht in Lexemen zum Themengebiet ,Barrierefreiheit‘ in DIN-Normen und der TSI PRM (2008) deuten auf die Konventionalität der Kompositabildung mit letzterem Grundwort hin.

Diese Bezeichnungen in den DIN-Normen und der TSI PRM stützen daher den Einwand des Prüfers in Beispiel 18. Der Vorschlag von Techniker 2, als Anzahl behindertengerechter Toiletten in das Tabellenfach die Ziffer 0 einzufügen, verweisen auf die Erwartenserwartung der Überarbeitenden, dass der Auftraggeber eine Mengenangabe entsprechend der vorgegebenen Terminologie des Lastenheftvordrucks erwarte. ${ }^{243}$ Gleichzeitig weichen Techniker 2 mit der Ergänzung (aber behindertenfreundlich) und Redaktionsmitglied 1 mit der Modifikation zu

242 Die Suche nach dem Teilwort behindert ergibt in der PDF-Datei der TSI PRM (2008) nur mehrfache Treffer zu den Komposita Sehbehinderte (ebd., z. B. S. 99), Behindertensitze (ebd., z. B. S. 111) und dem Nomen Behinderte (ebd., z. B. S. 2) etc.

243 Die Relevanz, ob der Terminus behindertengerecht oder behindertenfreundlich verwendet wird, belegt folgender Kommentar des Nutzers MATZEHBS im SPNV-Internetfachforum DREHSCHEIBE.DE, der die Vergabepraxis anzweifelt: „Keine Sorge, [der Aufgabenträger; $\mathrm{AH}$ ] wird schon dafür sorgen, dass es [den Zuschlag; $\mathrm{AH}$ ] [ein Bieter; $\mathrm{AH}$ ] nicht bekommt. Wenn dann aus Versehen [der Bieter; $\mathrm{AH}$ ] das günstigste Angebot abgibt, dann wird nachverhandelt, [sic] oder irgend eine [sic] fadenscheinige Begründung gefunden [sic] warum es wer anders bekommt. [...] Oder man findet das Salz in der Suppe [sic], wie z.B [sic] dass die Toiletten nicht, behindertengerecht' sondern nur ,behindetenfreundlich [sic] sind“.“ (DREHSCHEIBE, 2012; Fettdruck AH) 
dieser Ergänzung - 0 (1 behindertenfreundlich) - von der vorgegebenen Terminologie ab. Sie machen damit weder eine unwahre Angabe, noch verzichten sie auf die Angabe, dass die Toilette im Ansatz der Forderung entspricht. Dieser Lösungsvorschlag lässt auf einen hohen Grad an kreativer Kompetenz schließen.

\subsubsection{Zwischenfazit zur Interpretation von Kommunikantenkapazität}

Die vorangehende Diskussion erzielte folgende Interpretationen zur Kommunikantenkapazität im Sinne des Modells semiotischer Effizienz (s. Tabelle 2-2): Insbesondere an der Besprechung der Fahrplanvarianten (s. Beispiele 1 und 2) werden Wissensasymmetrien zwischen den Projektmitgliedern des Bieters als Teil der Textkompetenz deutlich, die sich auf Zeichensysteme beziehen. Diese Asymmetrien erfordern von den Experten eines beteiligten Projektbereichs eine transsubjektive Kompetenz, um diese Asymmetrie durch Erläuterungen innerhalb des Projekts zu überbrücken. Von dieser Kompetenz zeugen auch die Aussagen der hauptverantwortlichen Rezipienten auf der Seite der Auftraggeber, die angeben, sich bei Fragen zu den Optimierungsvorschlägen Unterstützung innerhalb des Projektteams zu holen (s. Beispiele 3 und 4). An dieser Asymmetrie und an der Ersetzung von Fachterminologie in Optimierungsvorschlägen (s. Beispiel 5) wird deutlich, dass Mitarbeitende des Bieters eine transsubjektive Kompetenz einsetzen. Denn sie halten es für möglich, dass der hauptverantwortliche Rezipient zwar nicht über das notwendige Wissen zu Zeichnungen oder Fachterminologie aller Organisationsbereiche verfügt, das für die Rezeption der Fahrpläne und Pflichtenhefte notwendig ist. Aber sie setzen voraus, dass er Unterstützung durch ein interfachliches Team erhält, das die interfachliche Struktur des Bieterteams widerspiegelt.

Die Vereinheitlichung der Themenstruktur von Optimierungsvorschlägen (s. Beispiele 6, 9 und 10) einer Ausschreibung deutet auf die Kreativität hin, die aufgrund einer kaum konventionalisierten, aber für das leichteres Rezipieren notwendige Themenstruktur verlangt ist. Im Gegensatz dazu setzen Projektmitglieder ihre Kreativität auch ein, um von einer Textsortenkonvention abzuweichen: Die Überarbeitung der Optimierungsvorschläge (s. Beispiel 11) veranschaulicht die unterschiedlichen Erwartungen der Projektmitglieder des Bieters, ob der Auftraggeber die Optimierungsvorschläge linear und vollständig rezipiert. Die Strategie wird vom Projektteam aufgegriffen, einen komplexen Zusammenhang zwischen 
Optimierungsvorschlägen durch einen Verweis nicht explizit zu machen, sondern den Auftraggebern erst im Bietergespräch zu erläutern (s. Beispiel 12). Dieser Vorschlag zeugt von Kreativität im Sinne einer Abweichung von der Konvention, Modifikationsvorschläge für die Verdingungsunterlagen mit dem Ziel der Preissenkung ausschließlich in der Textsorte Optimierungsvorschlag zu machen.

Bei der Überarbeitung der Pflichtenheftexemplare setzen die Überarbeitenden an mehreren Stellen kreative Kompetenz ein: a) bei der Lösung des terminologischen Normen-Konflikts (s. Beispiele 14 und 15) zwischen BAG-SPNV-Empfehlungen und TSI PRM durch die Angaben Überfahrrampe nein (Klapprampe nach TSI); b) bei der Angabe (s. Beispiel 18) behindertengerechte Toiletten 0 (1 behindertenfreundliche); c) beim Ausschluss kommissiver Bildakte durch entsprechende Beschriftungen (s. Beispiel 16). Auf die Erwartung der Textüberarbeitenden, dass der Auftraggeber eine Veränderung des Lastenheftvordrucks in Form des Verfahrensausschlusses sanktioniert, deutet Beispiel 17 hin. Auf eine transsubjektive Kompetenz verweist die Präzisierung des Kurzworts Wagen A (s. Beispiel 13). Im Folgenden werden die Kapazität der Kommunikanten und die beschriebene Komplexität der Kommunikate zueinander ins Verhältnis gesetzt.

\subsection{Semiotische Effizienz: Verhältnis zwischen Komplexität und Kapazität}

Bereits die Hinführung zu Kapitel 6.1 führt aus, dass das Verhältnis zwischen der Komplexität des Kommunikats und der Kapazität der Kommunikanten nicht quantifiziert, sondern durch qualitative Kriterien ${ }^{244}$ beschrieben werden kann. Dementsprechend wird im Modell semiotischer Effizienz (s. Tabelle 2-2) bestimmt, inwieweit Kommunikanten über die Kompetenz verfügen, die

244 Kommunikative Effizienz wird im Modell kommunikativer Effizienz durch die Ausgewogenheit der Kapazität der Kommunikanten und Komplexität des Kommunikats als quantitatives Verhältnis bestimmt (RoElcKe, 2002a, S. 67 f.). Diese Ausgewogenheit rückt HEIDRICH (2016) in das Zentrum ihrer qualitativen Modellierung von kommunikativer Optimierung, die Übersetzungsprozesse mit Ausgangs- und Zieltexten fokussiert: „Wenn ein solcher Text nun allen Qualitätsanforderungen entspricht (inklusive der Anpassung an die Eigenschaften des Rezipienten), stehen also die Verständlichkeit des Textes und das Wissen des Rezipienten in ausgewogenem Verhältnis zueinander. Das lässt die Schlussfolgerung zu, dass der Kommunikationsprozess des Rezipierens des Zieltextes durch den Rezipienten effizient verläuft.“( (ebd., S. 205) 
Konventionalität und Funktionalität von Textsortenexemplaren zu erkennen, zu verstehen und entsprechend ihrem funktionalen Zweck in den situativen Kontext einzubinden. Die Hinführung zu Kapitel 6.1 bezieht sich darüber hinaus auf These 3, die die Fähigkeit thematisiert, Textelemente abhängig von der mikrokulturellen Textkompetenz rezipieren bzw. nicht rezipieren zu können. Entsprechend These 2 zu unterschiedlichen Textsortenkonventionen, die auf der jeweiligen mikrokulturellen Prägung der beobachteten Betriebswirte, Juristen, Ingenieure etc. basierte, ergeben sich Aushandlungen in interfachlicher Projektkommunikation. Die Bestimmung semiotischer Effizienz soll diese beiden Thesen untermauern.

Methodisch ist zu berücksichtigen, dass durch die Beobachtung der Überarbeitungsprozesse, die das interfachliche Projektteam des Bieters durchführt, nur ein Ausschnitt dessen beobachtbar wird, was als effizient erfasst wird. Denn die Aufgabe der Überarbeitenden besteht darin, die Stellen in den Textsortenexemplaren zu überarbeiten, die ihnen nicht angemessen erscheinen in Bezug auf die Textsortenfunktion und deren Repräsentation durch Sprache-Bild-Mittel, d. h. in Bezug auf die Textsortenkonventionalität. Alle Textstellen, die weder diskutiert noch geändert werden, können damit aus Sicht der Überarbeitenden als konventionell gelten.

Für die Beschreibung semiotischer Effizienz werden die Ergebnisse aus Kapitel 5.4 und Kapitel 6.1 anhand von relevanten Textstellen ins Verhältnis gesetzt, konkret anhand der fünf Beispiele zu 1. der Bildfahrplanerläuterung; 2. der Strukturierung der Optimierungsvorschläge; 3. der einschränkenden Kommentierung von Fotos; 4. der Abweichung von der Terminologie des Auftraggebers; 5. der Rekurrenz des schriftsprachlichen und multimodalen Elements A-Wagen im Grundriss und dessen Relevanz als Quasi-Inhaltsverzeichnis:

1. Die Bildfahrplanerläuterung veranschaulicht, dass eine Asymmetrie bezüglich des zeichenmodalen Wissens innerhalb der interfachlichen Projektteams, aber keine Asymmetrie zwischen den beiden interfachlichen Projektteams von Auftraggeber und Bieter besteht (s. Kapitel 6.1.1). Vergleichbar erscheinen die Annahmen des Fahrzeugtechnikers beim Bieter über die Rezeptionsmöglichkeiten des Z-v-Diagramms durch das interfachliche Projektteam des Auftraggebers (ebd.). Die Kapazität bezieht sich dabei auf das zeichenmodale Wissen und das weitere Fachwissen zur Betriebsplanung. Das Beispiel zur Erläuterung des 
Bildfahrplans deutet auf eine transsubjektive Kompetenz des Betriebsplaners hin, der damit auf die Asymmetrie innerhalb des Projektteams reagiert und somit die Überarbeitung effizient gestaltet (ebd.).

Semiotisch effizient sind die Exemplare der Textsortenvarianten ,Bildfahrplan“ und ,Fahrzeugumlaufplan“ dadurch, dass sie der Kapazität vom jeweiligen Fachrezipienten aus dem Projektteam des Auftraggebers entsprechen. Dies belegen die Aussagen der Auftraggeber zur Unterstützung durch ein interfachliches Projektteam, das die interfachliche Struktur des Projektteams beim Bieter spiegelt (s. Kapitel 6.1.1). Dass sowohl die Exemplare der Textsorten ,Bildfahrplan“ und ,Umlaufplan` als auch die Diagramme in den Pflichtenheften (bezüglich des genannten Diagramms) nicht verändert werden, lässt sich des Weiteren als Anzeichen dafür deuten, dass die Exemplare bereits effizient gestaltet sind. Der Grund für eine ausbleibende Änderung liegt vermutlich im hohen Grad der Normung und Konventionalisierung dieser Textsorte (s. Kapitel 5.3).

2. Dagegen besteht bei den Optimierungsvorschlägen nur ein relativ geringer Grad an Konventionalität (s. Kapitel 6.1.2). Die interfachliche Überarbeitung vereinheitlicht die Textsortenexemplare aber in Bezug auf die Funktions- und Themenstruktur (s. Kapitel 5.1.2 und 5.1.3): So werden die Exemplare aller Organisationsbereiche in der Einteilung ihrer Themen- und Funktionsmodule identisch gestaltet. Innerhalb dieser Textstrukturen werden die ersten drei Module thematisch in Abhängigkeit von ihrem Organisationsbereich ausgestaltet - beispielsweise zu einem Thema aus dem Bereich ,Fahrzeugtechnik' oder, Vertrieb“. Das vierte Themenmodul gibt in allen Optimierungsvorschlägen eine Preisänderung an, da diese Angabe der Grundfunktion der Textsorte entspricht. Das Textdesign repräsentiert diese Funktions- und Themenstruktur durch schriftbildliche Elemente wie Schriftgröße und Fettdruck, aber auch durch die Anordnung in der Fläche - Eine Besonderheit stellt das werbende Logo und dessen Positionierung dar (s. Kapitel 5.1.1).

Die Vereinheitlichung der Themen- und Funktionsstruktur in Ausschreibung 1 und 2 weist auf die Erwartung der Textüberarbeitenden hin (s. Kapitel 6.1.2), dass der hauptverantwortlich Lesende des Auftraggebers eine einheitliche Textstruktur erwartet. Das Interview mit dem Lesenden bestätigt diese Annahme (ebd.) - mit der methodischen Einschränkung, dass Interviewantworten opportun sein können. 
Die Äußerungen der Textüberarbeitungen (s. Kapitel 6.1.1), diese Interviewantwort und die Gestaltung der Themenstruktur in den vorliegenden Optimierungsvorschlägen (s. Kapitel 5.1) implizieren, dass diese vereinheitlichte Themen- und Funktionsstruktur und deren Repräsentation durch Textdesign semiotisch effizient sind. Denn diese Vereinheitlichung ermöglicht, mehrere Textsortenexemplare schneller rezipieren zu können. Dies wird dadurch möglich, dass die Textstruktur nach der Rezeption des ersten Textsortenexemplars bekannt ist und im Anschluss die Orientierung in weiteren Textsortenexemplaren einfacher wird. Insbesondere die einheitliche Positionierung der Preisminderungsangabe am Ende jedes Exemplars und deren Hervorhebung durch Fettdruck unterstützt die Grundfunktion der Textsorte, den Rezipienten von der Änderung der Verdingungsunterlagen zu überzeugen.

3. Auf die indirekte Textsortenfunktion der Pflichtenhefte reagiert das interfachliche Projektteam bei der Überarbeitung durch das Einfügen des Kommentars unter Fotos, CAD-Darstellungen und zum Teil unter Zeichnungen (s. Kapitel 6.1.3): Denn die Funktionsstruktur der Textsorte Pflichtenheft prägt die direkt-assertive und indirekt-kommissive Grundfunktion (s. Kapitel 5.2.2). Eine Ausnahme bilden innerhalb der Funktionsstruktur Fotos und zum Teil CAD-Darstellungen. Diese repräsentieren nicht nur direkt-assertive, sondern auch indirekt-direktive Funktionsmodule, indem sie durch eine ästhetisierte Darstellung eine werbende Funktion andeuten. Wie dargestellt schließen die Schriftelemente aus, dass die ikonisch-materiellen Bilder als kommissives Funktionsmodul aufgefasst werden können (ebd.).

Die Überarbeitung deutet die Erwartenserwartung der Projektmitglieder an, dass der Auftraggeber ausschließlich Bild- und Schriftelemente mit kommissiver Funktion in Pflichtenheftexemplaren erwartet (s. Kapitel 6.1.3). So wird ein hohes Maß an Kreativität der Projektmitarbeitenden erkennbar, weil Letztere auf ein Problem reagieren, das nicht durch die stark normierte Kommunikationsform Formular gelöst, sondern vielmehr erzeugt wird. Die Pflichtenhefte wirken semiotisch effizient, weil a) die Anordnung von verschriftlichten Sprecherspuren als Frage-Antwort-Konstellation die Institutionenasymmetrie visuell wiedergibt; b) die Bilder für den Bieter eine werbende Funktion in der Experte-Experte-Kommunikation einnehmen; c) die schriftsprachliche Kommentierung ausschließt, die 
Bildmodule missverständlich als kommissive Funktionsmodule zu verstehen; c) die Angabe des Kommentars gleichzeitig der Erwartung des Auftraggebers entspricht, die Teile des Lastenheftvordrucks nicht zu verändern.

4. Die Verwendung der Nominalphrase behindertenfreundliche Toilette im Pflichtenheftexemplar anstelle der vorgegebenen Phrase behindertengerechte Toilette aus dem Lastenheftvordruck deutet auf die Erwartung des Überarbeitenden hin, dass der Auftraggeber wahrheitsgemäße Angaben und die Verwendung der Terminologie erwarte, die der Lastenheftvordruck vorgibt (s. Kapitel 6.1.3). Diese Erwartung bzw. Erwartenserwartung stützt die direkt-assertive und zugleich die indirekt-kommissive Grundfunktion der Textsorte ,Pflichtenheft" (s. Kapitel 5.2.2). Durch die Verwendung des Terminus behindertenfreundlich weichen die Überarbeitenden vom Terminus behindertengerecht ab, der im Lastenheftvordruck vorgegeben und in den Empfehlungen der BAG SPNV sowie DIN-Normen angegeben wird. Damit entsprechen die Überarbeitenden der Erwartung, wahrheitsgemäß zu antworten. Die Abweichung in der Terminologie weist auf die Kreativität hin. Denn der Auftraggeber erwartet, dass die verschiedenen Bieter die Eigenschaften ihres jeweils angebotenen Fahrzeugs darstellen, indem sie dazu die vorgegebenen Kategorien des Formularvordrucks nutzen. Dadurch sollen die Fahrzeugangebote verschiedener Anbieter vergleichbar werden. In einigen Fällen lassen es die Eigenschaften eines angebotenen Fahrzeugs aber nicht zu, dass Bieter diese unter die vorgegebenen Formularkategorien ordnen. Ein Bieter stellt eine bestimmte Form berufsbezogener Kreativität unter Beweis, indem er an diesen Stellen sprachliche und/oder ikonisch-bildliche Alternativen zu den vorgegebenen Antwortmöglichkeiten des Auftraggebers findet und diese an der vorgegebenen Stelle im Formular angibt. Dies gilt, obwohl diese Abweichung dem Konzept der Formularfunktion zuwiderläuft, vergleichbare Angebote von den Bietern zu erhalten.

Semiotisch effizient wirkt das Pflichtenheft aber an dieser Stelle, weil der Bieter die Formularkategorie umgeht, ohne den Lastenheftvordruck unzulässig zu verändern. Damit orientieren sich die Überarbeitenden an der Konventionalität der Textsorte. 
5. Die Substitution des Schriftelements $A$ durch das Nomen $A$-Wagen lässt sich als Ergebnis der Erwartung deuten, dass der Auftraggeber eine Wiederholung von Schriftelementen in Schriftmodulen erwartet, die als Beschriftungen in der Grundrisszeichnung vorkommen (s. Kapitel 6.1.3). Diese Erwartenserwartung verweist auf die Funktion des Grundrisses und seiner Beschriftungen als QuasiInhaltsverzeichnis (s. Kapitel 5.2.4). Semiotisch effizient wirkt der Grundriss, weil er Lesenden eines Pflichtenheftexemplars die Orientierung über die physikalischen Bestandteile des Fahrzeugs bietet, die im Pflichtenheft detailliert durch die anschließenden Schriftmodule thematisiert werden. Diese rekurrieren wiederum durch logisch-semantische Sprache-Bild-Relationen auf den Grundriss.

Die Implikationen dieser fünf Beispiele für Empfehlungen werden wie die Bedeutung für die Thesen im Schlussteil diskutiert (s. Kapitel 7). 



\section{Schluss}

Diese Untersuchung geht der Forschungsfrage nach, wie sich Interfachlichkeit auf die semiotische Effizienz von Sprache-Bild-Textsorten, insbesondere von Pflichtenheften, auswirkt. Die drei Thesen aus Kapitel 2.1.3 präzisieren diese Frage. Die Fragestellung und die Thesen resultieren aus der Problemstellung der Kommunikanten im Untersuchungsfeld: Für Bieter ergibt sich bei der Überarbeitung von Pflichtenheften das Problem, inwieweit ein hauptverantwortlich Lesender über die Kapazität verfügt, die Lexik, zum Teil auch die Terminologie und damit verbundene Begriffe und Zeichensysteme aller beteiligten Organisationsbereiche rezipieren zu können. Unklar ist, inwieweit der hauptverantwortliche Rezipient des Auftraggebers auf das Projektteam zugreift, d. h., inwieweit er den Text als fachlicher Laie oder Experte rezipiert. Kapitel 2 baut in der Auseinandersetzung mit dem Forschungsdiskurs eine Argumentation auf, warum diese Thesen wahr sein können. Vor dieser Argumentation stellen die Thesen streng genommen noch vorläufige Arbeitsthesen dar. Die Analyse der Textsortenexemplare und der Beobachtungen und Befragungen prüft diese Thesen empirisch. Die drei Thesen werden im Fazit (s. Kapitel 7.1) aufgegriffen.

Den Ausgangspunkt für diese Frage bilden zum einen die Problemstellung im untersuchten Berufsfeld und zum anderen die Forschungslücke, wie eine charakteristische Textgestaltung mit ihrer Verwendung durch Kommunikanten eines Fachs bzw. einer Domäne zusammenhängt. Das aus dem Forschungsdiskurs abgeleitete Desiderat, inwieweit dabei sprachliche und/oder nicht-sprachliche Mittel in Fachkommunikation zusammenspielen, steht am Anfang der Untersuchung von Textsortenexemplaren. Spezifisch Multimodalität und Textsortenvernetzung werden als Phänomene des Textsortenwandels thematisiert. Die Beschreibung von Formularkommunikation konkretisiert diese Arbeit durch das ProzipientenKonzept, um die Kommunikanten zu erfassen. Neben der Untersuchung dieser Schreibprodukte liefern die Beschreibung der Aushandlungsprozesse im interfachlichen Team und deren Interpretation, die auf der Textanalyse und auf der Auswertung von Interviewaussagen basiert, Erkenntnisse zu den Schreibprozessen. Für diese Schreibprozesse wird insbesondere der Bezug zur Kommunika- 
tionsoptimierung herausgestellt. Das wesentliche Ergebnis der Argumentation für die drei Thesen besteht in der Modellierung von semiotischer Effizienz (s. Tabelle 2-2), die auch das ,Kontextmodell zu B2G-Ausschreibungsverfahren“ einschließt (s. Abbildung 2-12), und in der Definition des Begriffs, semiotische Effizienz' (s. Kapitel 2.5). Die Beschreibung von den in der Linguistik weitgehend unbekannten Textsorten Lasten-/Pflichtenheft, Optimierungsvorschlag und Fahrplanvarianten sowie die Beschreibung der Text-Text-Relationen im Textsortennetz zu SPNV-Ausschreibungsverfahren sollen auf der Objektebene einen wesentlichen Beitrag zum Forschungsdiskurs leisten.

Die Zwischenfazits zur Textanalyse (s. Kapitel 5.4) und zur Effizienzanalyse (s. Kapitel 6) stellen bereits die Ergebnisse der empirischen Analyse bzw. die Erkenntnisse zusammen, die diese Arbeit bei der Bearbeitung der Forschungsfrage erzielte. Inwieweit eine Zusammenschau dieser Ergebnisse Emergenzen erzeugt, soll im Folgenden geprüft werden (s. Kapitel 7.1). Des Weiteren soll diskutiert werden, ob diese Ergebnisse auf weitere interfachliche Domänen und Textsorten übertragen werden können (s. Kapitel 7.3). Ansätze von Lösungsvorschlägen für die Problemstellung sollen einerseits für die Bieter, andererseits für Auftraggeber vorgestellt werden (s. Kapitel 7.3).

\subsection{Fazit}

Die drei Thesen (s. Kapitel 2.1.3) gliedern das Fazit, sodass die Ergebnisse zu den Thesen jeweils unter die Darstellung der jeweiligen These geordnet werden:

\subsubsection{These 1}

Das Verhältnis zwischen der Kapazität der Kommunikanten und der Komplexität des Kommunikats, das kommunikative Effizienz bestimmt, kann als Textsortenkonventionalität und -funktionalität erfasst werden.

Das Konzept semiotischer Effizienz ${ }^{245}$ (s. Tabelle 2-2) ist das Ergebnis der Argumentation für These 1, die in Kapitel 2 in Auseinandersetzung mit dem Diskurs

245 Hervorzuheben bleibt bei der Modellierung semiotischer Effizienz die Rolle des situativen Kontextes, die im ,Kontextmodell zu B2G-Ausschreibungsverfahren“ (s. Abbildung 2-12) systematisiert wird. Darin ermöglicht es die Modellierung der Kommunikanten als Lesen- 
zu multimodalen Textsorten und zu kommunikativer Effizienz entsteht. Die Definition des Begriffs semiotischer Effizienz (s. Kapitel 2.5) ist ebenso Ergebnis dieser Argumentation: Kommunikanten wählen Textdesign, -grammatik, -semantik und -funktionen derart, dass sie entsprechend ihrem kommunikativen Zweck in den situativen Kontext eingebunden sind. Dies schließt in Form einer kreativen Kompetenz auch Abweichungen von Konventionen ein (ebd.). Die empirische Untersuchung der Textsortenexemplare aus dem Korpus durch das integrierte Analyseraster interfachlicher Sprache-Bild-Textsorten (s. Kapitel 3) untermauert die These empirisch. Die Anwendung dieses Rasters auf einige Textsortenexemplare des Korpus untersucht daher Schreibprodukte, die auf der Grundlage von Aushandlungsprozessen von den Textproduzenten erstellt und von den Textüberarbeitenden in Bezug auf ihre Konventionalität und Funktionalität ausgehandelt wurden (s. Kapitel 5). Somit weisen diese Exemplare bereits auf die Konventionalität und Funktionalität der jeweiligen Textsorte hin, die im Modell semiotischer Effizienz auf der Kommunikatsseite bestimmt wird. ${ }^{246}$ Die Beschreibung und Interpretation der Aushandlungsprozesse zur Konventionalität und Funktionalität dieser Textsortenexemplare (s. Kapitel 6), in der die Textüberarbeitenden ihre Erwartenserwartungen in Bezug auf die Erwartungen des Rezipienten explizit machen, bilden den zweiten, notwendigen Bestandteil, um semiotische Effizienz als Kommunikats-Kapazitäts-Verhältnis bestimmen zu können. Daher untermauern das Zwischenfazit zur Textanalyse (s. Kapitel 5.4), das Zwischenfazit zur Kapazitätsanalyse (s. Kapitel 6.1.4) und die Bestimmung semiotischer Effizienz (s. Kapitel 6.2) These 1.

de und gleichzeitig Schreibende in Formularkommunikation, die Textsortenvarianten Lastenheftvordruck und Pflichtenheft gegenüberzustellen: Der Auftraggeber tritt beim Lastenheftvordruck als Textproduzent auf, während er beim ausgefüllten Lastenheftvordruck, also dem Pflichtenheft, in der Rolle des Rezipienten agiert. Entsprechend tritt der Bieter beim Pflichtenheft als Produzent auf, während er Rezipient des Lastenheftvordrucks ist.

246 Aufgrund der salienzbasierten Perspektive dieser Untersuchung steht die Analyse der Textsortenexemplare im Vordergrund. 


\subsubsection{These 2}

Diese Textsortenkonventionen sind domänenspezifisch und mikrokulturell geprägt. In interfachlicher Kommunikation muss ausgehandelt werden, welche Textgestaltung als konventionell und funktional gilt, weil sich die Erwartungen der Kommunikanten vor dem Hintergrund ihrer verschiedenen mikrokulturellen Prägungen unterscheiden.

Das Kontextmodell (s. Abbildung 2-12), das Interfachlichkeit durch die horizontale Skala interfachlicher Kommunikation aus dem Forschungsdiskurs adaptiert, ist ein Ergebnis der Argumentation für These 2. Diese Argumentation führt Kapitel 2 in Auseinandersetzung mit dem Diskurs zur fachlichen Prägung von Textsortenkonventionen. Die Ergebnisse aus der empirischen Textanalyse (s. Kapitel 5.4) stehen bereits implizit in Verbindung mit These 2. An dieser Stelle werden die Ergebnisse explizit auf These 2 bezogen. So werden im Anschluss die Ergebnisse zur Zuordnung von Textsortenelementen zu Organisationsbereichen als mikrokulturellem Hintergrund aufgeführt.

Die Gestaltung der Themenstruktur von Optimierungsvorschlägen deutet bedingt auf die Verbindung zwischen der Interfachlichkeit des Projektteams mit der Themen- und Funktionsstruktur sowie dem Textdesign der Textsortenexemplare hin: Textdesign und Themenstruktur aller Exemplare sind einheitlich, d. h. unabhängig vom jeweiligen Organisationsbereich, gestaltet, denen die Textthemen zuzuordnen sind. Die ersten drei Themenmodule wirken im Blick auf den Fachtextwortschatz mit den beteiligten Organisationsbereichen zusammen. Der Fachtextwortschatz des letzten Themenmoduls ist dagegen unabhängig von den Organisationsbereichen gestaltet, und auch als Funktionsmodul ist dieser Abschnitt durchgehend durch eine (werbende) indirekt-direktive Grundfunktion der Textsorte bestimmt. So soll der Auftraggeber als Rezipient davon überzeugt werden, dass eine Annahme des Vorschlags zu einer Preissenkung führt. Da diese Funktion auch durch die Darstellung der Teilthemen realisiert wird, ist zudem die Abhängigkeit der ersten drei Themenmodule von den Organisationsbereichen einzuschränken. Denn auch die Themenentfaltung, die am ehesten dem argumentativen Muster entspricht, wird unabhängig von der Zugehörigkeit zu Organisationsbereichen realisiert. 
In Pflichtenheften wird die Abhängigkeit der Textsortenelemente von den Konventionen der beteiligten Organisationsbereiche dagegen offensichtlicher: Die indirekt-kommissive Textsortenfunktion von Pflichtenheften schränkt die Überarbeitenden für Fotos, CAD-Darstellungen und zum Teil für Zeichnungen ein. An dieser Stelle reagiert die Perspektive des Organisationsbereichs Recht auf die Darstellung des Bereichs Fahrzeugtechnik, sodass die Perspektiven der beteiligten Organisationsbereiche mit den Textelementen zusammenspielen. Dass die inhaltlich dem Organisationsbereich Recht zuzuordnende Einschränkung schriftsprachlich realisiert wird, lässt sich kaum durch die Bindung letzteren Bereichs an Schriftsprache als Ausdrucksmittel begründen. Denn auch der Bereich ,Fahrzeugtechnik' nutzt die Schriftsprache in Form von Terminologie etc., sodass eine Verknüpfung von Mikrokultur und zeichenmodaler Gestaltung der Ausdrucksmittel nicht nachvollziehbar belegt werden kann.

Der Überarbeitungshinweis zur logisch-semantischen Relation zwischen dem Schriftelement $A$ bzw. A-Wagen und dem multimodalen Element des Grundrisses, der sich aus dem Schriftelement $A$-Wagen und dessen zeichnerischer Darstellung zusammensetzt, deutet dagegen auf den Zusammenhang zwischen mikrokultureller Zugehörigkeit und zeichenmodaler Gestaltung der Ausdrucksmittel hin. Denn diese Sprache-Bild-Relationen erscheinen sowohl in weiteren Überarbeitungsanmerkungen (s. Anhang; S. 548 ff.; ebd., S. 561 ff.) als auch in den Pflichtenheften als charakteristisch für den Organisationsbereich ,Fahrzeugtechnik‘.

Dass die Perspektiven der Mikrokulturen bzw. Organisationsbereiche nicht zwingend an die Aussagen von Mitarbeitenden der Bereiche gebunden sind, veranschaulicht die Diskussion zu den Termini behindertengerecht und behindertenfreundlich in zweierlei Hinsicht:

Erstens gleicht der Prüfer und nicht der Fahrzeugtechniker die Termini mit der Norm TSI PRM ab, die grundsätzlich dem Organisationsbereich und bedingt der Mikrokultur der Fahrzeugtechnik zuzuordnen ist. Der Einwurf des Prüfers wie auch weitere Anmerkungen weisen darauf hin, dass er über Anteile von Fachwissen in allen beteiligten Organisationsbereichen verfügt und somit eine Sonderstellung einnimmt. Vergleichbares ist für den hauptverantwortlich Lesenden der Auftraggeber anzunehmen. Zweitens veranschaulicht die Norm TSI PRM, dass eine eindeutige Zuordnung von schriftsprachlichen Elementen zu Mikrokulturen nicht 
möglich ist. Denn bereits diese Norm enthält sowohl juristische als auch technische Anteile. Der Fahrzeugtechniker verwendet das Adjektiv behindertenfreundlich als Angabe im Textsortenexemplar und rechtfertigt dies bei der Überarbeitung damit, dass die Toilette nicht behindertengerecht sei. Ob die Sorge vor juristischen Konsequenzen bei Falschangaben oder die Sorge vor mangelnder Eineindeutigkeit bei der Verwendung technischer Terminologie den Fahrzeugtechniker motiviert, das Adjektiv behindertenfreundlich zu verwenden, bleibt unklar. Deutlich wird an diesem Beispiel die Sonderstellung des Organisationsbereichs ,Prüfung', der keiner Mikrokultur eindeutig zuzuordnen ist. Dies verdeutlicht, dass ein Organisationsbereich im Untersuchungsfeld nicht immer mit einer Mikrokultur deckungsgleich ist.

Gegenüber diesen ikonisch-materiellen Bildern und weiteren diagrammatischen Elementen lässt sich die Zeichenmodalität Schriftsprache keinem der Organisationsbereiche bzw. Mikrokulturen pauschal zuordnen, da alle Bereiche letzteres Zeichensystem verwenden. Lediglich für den Bereich Recht lässt sich festhalten, dass er in den beobachteten Überarbeitungssituationen und Textsortenexemplaren ausschließlich mit Schriftsprache arbeitet. So ist letzteres Zeichensystem auf den verschiedenen Textebenen ,Fachtextwortschatz' bzw. ,Terminologie', ,horizontale Gliederungsmittel' etc. grundsätzlich nach den beteiligten Mikrokulturen differenzierbar. Die Differenzierung dieser Ebenen lässt daher bedingt eine Untersuchung von Textgestalt-Kontext-Verknüpfungen mit Interfachlichkeit zu. Wie aber die Diskussion um die Adjektive behindertenfreundlich und behindertengerecht gezeigt hat, sind die Möglichkeiten einer konkreten Zuordnung von Fachtextwortschatz zu einem Organisationsbereich begrenzt. Andere Beispiele haben dies auch für Mittel der horizontalen Themenstruktur veranschaulicht.

Lediglich die schwundgrammatische Gestaltung von schriftsprachlichen Elementen in Lastenheftvordrucken und Pflichtenheften wirkt mehr oder weniger eindeutig mit der Zugehörigkeit zu einer Mikrokultur zusammen: Zwar ist die Schwundgrammatik grundsätzlich der Kommunikationsform Formular geschuldet, die schriftsprachliche Elemente durch Textdesign, aber auch durch Bilder ersetzt. Da die Generalklauseln, die dem Organisationsbereich , Recht' ${ }^{\star}$ zuzuordnen sind, aber in vollständigen Sätzen gestaltet sind, erscheint die schwundgrammatische Ge- 
staltung von Schriftsprache in diesen Textsortenexemplaren auch als Zusammenspiel mit der mikrokulturellen Zugehörigkeit.

Die Textsortenvarianten zu Fahrplänen und deren Überarbeitungen durch das interfachliche Projektteam deuten auf Asymmetrien im Projektteam hin, sodass deren Ergebnisse bei der Behandlung von These 3 dargestellt werden. Ihre Gestaltung belegt zwar entsprechend These 2 die mikrokulturelle Prägung. Diese Gestaltung wird aufgrund der Asymmetrie aber nicht interfachlich ausgehandelt (s. These 3).

Die Ergebnisse der Textanalyse von Optimierungsvorschlägen, Pflichtenheften und Fahrplanvarianten stützen demnach These 2 in der Annahme, dass die Textsortenkonventionen interfachlichen ausgehandelt werden können. Die Textüberarbeitungen illustrieren zudem, dass die Erwartungen der Kommunikanten zum Teil von ihrem fachlichen Hintergrund abhängen. Das Beispiel des Prüfers zeigt aber auch, dass die Zuordnung nicht immer eindeutig möglich ist. Prüfer führen ausschließlich Textüberarbeitungen durch, während die Aufgaben der weiteren Organisationsmitglieder nur temporär in der Projektarbeit und hauptberuflich in ihrem jeweiligen Organisationsbereich liegen. Daraus ergibt sich die Annahme, dass mit der zunehmenden Anzahl betreuter Ausschreibungsverfahren der Grad abnimmt, in dem die Konventionalitätsvorstellungen eines Projektmitglieds durch den mikrokulturellen Hintergrund seines Organisationsbereichs geprägt ist.

\subsubsection{These 3}

Kommunikate sind in naturwissenschaftlich-technischen Kommunikationsbereichen multimodal gestaltet, nutzen also auf der textuellen Aufwandsseite bildliche, schriftsprachliche und diagrammatische Elemente, die durch Grammatik und Textdesign angeordnet bzw. gestaltet sind. Auf der textuellen Ergebnisseite können alle Elemente Textfunktionen und -semantik repräsentieren. Die Fähigkeit, wie diese Elemente rezipiert werden, wird durch die mikrokulturelle Textkompetenz der einzelnen Kommunikanten bestimmt.

Das Zwischenfazit zur Textanalyse stützt These 3 darin, dass naturwissenschaftlich-technische Textsorten multimodale Gestaltungsmittel nutzen. Denn Bildfahrpläne und Fahrzeugumlaufpläne, vor allem aber Pflichtenhefte, sind modal äußerst komplex gestaltet. Die Beschreibung und Interpretation der Textüberarbei- 
tungen deuten auf die Fähigkeiten der beteiligten Projektmitglieder hin, Elemente dieser Textsortenexemplare rezipieren und verstehen zu können:

Vor allem die Erläuterung der Bildfahrpläne und Fahrzeugumlaufpläne durch den Betriebsplaner gegenüber den anderen Projektmitgliedern und deren ausbleibenden Kommentierungen sind auffällig. Diese Beobachtung deutet auf eine Wissensasymmetrie in Bezug auf die Zeichenmodalitäten hin, die an den Organisationsbereich ,Betriebsplanung' gebunden sind. Dies korrespondiert mit der Interviewaussage, die der Fahrzeugtechniker des Bieters macht: Der Techniker erwartet vom hauptverantwortlich Lesenden des Auftraggebers nicht, das Z-v-Diagramm vollständig interpretieren zu können. Diese Einschätzung ergänzt die Aussage des Fahrzeugtechnikers und die gleichlautende Interviewaussage von Auftraggeber 1, dass dieser Lesende bei einem Projektteam Unterstützung suchen kann. Dabei kann sich die Unterstützung auch auf Fachwissen beziehen. Denn auch das Team des Bieters ist interfachlich zusammengesetzt. Diese Aussagen zeigen, dass innerhalb der Projektteams eine Asymmetrie sowohl in Bezug auf Wissen über Zeichensysteme (wie technische Zeichnungen, abbildende Diagramme oder Fahrplanvarianten) als auch bezüglich weiteren fachlichen Wissens besteht. Auch die Relevanz der Generalklausel für alle Schriftelemente streicht heraus, dass die Fähigkeit der beteiligten Projektmitglieder, Textelemente des Pflichtenhefts verstehen zu können, vom mikrokulturellen Hintergrund abhängt. So müssen juristische Laien - möglicherweise der hauptverantwortlich Lesende des Auftraggebers nicht zwingend den Verweis der Generalklausel auf die Forderungen der Norm TSI PRM als Hintergrundwissen erkennen (s. Kapitel 5.2.4). Zwischen den Projektteams der beiden Organisationen ,Bieter " und ,Auftraggeber ' besteht dagegen keine Wissensasymmetrie.

Die zeichenmodale Gestaltung der Textsortenexemplare wirkt mit Hinweisen auf unterschiedliche Fähigkeiten der Projektmitglieder verschiedener Organisationsbereiche zusammen, die sich auf fachspezifische Zeichensysteme beziehen. Zumindest deuten darauf die Beobachtungen und Interviewaussagen der Textüberarbeitenden und der Rezipienten hin. Die Realisate der diagrammatischen, materiell-bildlichen Zeichensysteme und auch der Schriftsprache, die sich in den Textsortenexemplaren befinden oder von Mitarbeitenden der Organisationsbereiche Betriebsplanung und Schienenfahrzeugtechnik vorgeschlagen werden, spielen 
mit der Mikrokultur bzw. dem Organisationsbereich zusammen. Somit stützen die Ergebnisse zu semiotischer Effizienz (s. Kapitel 6.2) auch These 3.

Alle drei Thesen werden weitgehend durch die Ergebnisse der empirischen Analyse untermauert, sodass sich die Forschungsfrage wie folgt beantworten lässt: Die mikrokulturelle Prägung der jeweiligen Mitglieder nimmt in einem interfachlichen Projektteam Einfluss auf den Konventionalisierungsprozess von Textsortenexemplaren. Wie sich dieser mikrokulturelle Hintergrund der Organisationsbereiche im Detail auf die Textüberarbeitungen auswirkt, zeigen die obigen Ausführungen zu den Thesen.

Da die Untersuchungsergebnisse keinen Anspruch auf Allgemeingültigkeit erheben, wird im Folgenden diskutiert, ob und in welcher Form sich die Ergebnisse auf andere Domänen übertragen lassen.

\subsection{Ausblick}

Aus dieser Untersuchung ergeben sich vier Desiderata: Es stellt sich erstens die Frage, ob die oben aufgeführten Ergebnisse zu Textgestaltung-Kontext-Verknüpfungen auf andere Domänen übertragen werden können. Zweitens ist zu diskutieren, inwieweit erhobenes Material, das nicht verarbeitet wurde, geeignet ist, um unter einer anderen Fragestellung an einen anderen Forschungsdiskurs als denjenigen der Kommunikationsoptimierung, Textgestalt-Kontext-Verknüpfung und Multimodalität anzuschließen. Drittens kann die Zusammenführung der Daten aus Textanalyse, Interviews und Beobachtung auf methodologischer Ebene diskutiert werden. Und viertens ist offen, inwieweit das Text- und das Effizienzanalyseraster geeignet sind, um Exemplare anderer Textsorten zu analysieren. Möglicherweise lassen sich mit Letzteren auch Textsorten analysieren, die einen geringen Fachsprachlichkeitsgrad haben wie Online-Zeitungsartikel oder Unternehmenshomepages.

Die Übertragbarkeit dieser Forschungsergebnisse kann in dreierlei Hinsicht ermittelt werden: Erstens ist zu überprüfen, inwieweit die Ergebnisse für staatliche Ausschreibungskommunikation relevant sind, die sich auf andere Produkte als Schienenfahrzeuge bezieht und der Erfüllung der Daseinsvorsorge dient. So finden sich beispielsweise bei staatlichen Krankenhäusern, Gesundheitsämtern etc. 
Ausschreibungen zu medizinisch-technischen Produkten wie zu Untersuchungsapparaten oder zu biologischen Produkten wie Impfstoffen. Zweitens ist die Relevanz der Ergebnisse für privatwirtschaftliche Ausschreibungskommunikation zu verschiedenen Produkten zu prüfen, beispielsweise zu Windrädern. Diese Ausschreibungsverfahren sind nicht an die gesetzlichen Rahmenbedingungen wie die Verdingungsordnung für Leistung etc. gebunden, sodass der Grad an Verfahrensbedingtheit bei dieser Ausschreibungskommunikation wesentlich geringer ist. Drittens ist die Anwendbarkeit der Ergebnisse auf Kommunikationsverfahren in interfachlichen Domänen zu prüfen, die nicht Teil von Ausschreibungsverfahren sind, aber von staatlichen Organisationen unter Berücksichtigung von Gesetzen, Verordnungen etc. durchgeführt werden. $\mathrm{Zu}$ diesen Kommunikationsverfahren gehören beispielsweise Patentanmeldungen (BRAMBILla, 2013; GÖPFERICH, 22006; GREWENDORF, 2002; SCHAMLU, 1985) oder Zulassungen von Beipackzetteln (VAERENBERGH, 2007) etc.

Zweitens erhob ich von Exemplaren der Textsorte Optimierungsvorschlag und zum Teil für die Textsorte Pflichtenheft Versionen in unterschiedlichen Textproduktions- bzw. Textüberarbeitungsstadien. Auf diese greift die Analyse der Textsortenexemplare und der Textüberarbeitungsprozesse nur sehr bedingt zurück, weil diese Versionen noch keine Hinweise ergeben, die sich als Kreativität oder transsubjektive Kompetenz der Überarbeitenden interpretieren lassen. Dies ermöglichen vielmehr die Interviews und Beobachtungen.

Erkenntnisse zu Textüberarbeitungsprozessen, die an Modelle der Textüberarbeitungen wie das Züricher Textanalyseraster (NUSSBAUMER, 1991) anknüpfen, ermöglichen eine Untersuchung dieser verschiedenen Versionen von Textsortenexemplaren. Nicht nur Anwendungen dieser Modelle auf (hoch-)schulische Schreibkontexte (BolAND, 2011; HeLD, 2006; LEHNEN, 2000), sondern auch auf Kontexte der Unternehmenskommunikation (HeINE, 2010; KRISCHKE 2004; BlomQvist, 2002; KLeINMANN, 1993 u. a.) sind denkbar. Die erhobenen Versionen der Textsortenexemplare könnten unter einer anderen Fragestellung auch an den Forschungsdiskurs zu Textüberarbeitungen anschließen.

Drittens triangulierte ich die Ergebnisse der Analysen von Textsortenexemplaren und von Interviews sowie Beobachtungen institutionell veranlasster, gemeinsamer Textüberarbeitungen. Auf methodologischer Ebene kann im Anschluss daran 
ausführlicher als im entsprechenden Kapitel 2.3.3 diskutiert werden, inwieweit die Interpretation von Eye-Tracking-Aufzeichnungen die Analyse von Interviews, Beobachtungen und Textsortenexemplaren ergänzen kann.

$\mathrm{Zu}$ prüfen bleibt viertens, inwieweit das Analyseraster auf andere Textsorten und Schreibprozesse angewendet werden kann. So könnte die Eignung der Raster ebenso an Exemplaren von Online-Zeitungen wie auch an Exemplaren von Berichten geprüft werden, in denen ikonisch-materielle Bilder und weitere diagrammatische Darstellungen die Kommunikate wesentlich bestimmen - beispielsweise Arbeiten aus dem Bereich Ingenieurwesen.

Vorerst soll aber skizziert werden, inwieweit die Forschungsergebnisse, die diese Untersuchung erzielt, eine Lösung der Problemstellung ermöglicht. Es sollen auch Anwendungsmöglichkeiten auf weitere Kommunikationsprozesse der Domäne angedeutet werden.

\subsection{Empfehlungen zu semiotischer Effizienz}

Auftraggeber können in Ausschreibungsverfahren entscheiden, welche Dienstleistungen

oder Produkte sie fordern und wie diese gestaltet sein sollen. Sie können sogar fordern, wie die verschiedenen Bieter ihr Angebot darstellen sollen und wie die Bieter mit ihnen kommunizieren dürfen: nur schriftlich, nur mit bestimmten Textsorten, nur in bestimmten Phasen der Ausschreibung usw.

D. h., Auftraggeber haben größtmöglichen bzw. - wenn sie die geltenden Vorschriften der Verdingungsordnung für Leistungen berücksichtigen - relativ großen Spielraum, ob sie die Kommunikation im Ausschreibungsprozess effizient gestalten. Auch die Bieter können in schriftlicher Kommunikation semiotisch effizient agieren. Beispielweise können sie für die unternehmensinterne Kommunikation Style Guides erarbeiten, Workshops mit den Projektmitarbeitenden durchführen usw. Dadurch wird es möglich, sich innerhalb eines Projektteams auf eine Leitlinie zu einigen und diese während der Überarbeitung nicht immer wieder am Einzelfall zu diskutieren. Dies gilt natürlich auch für das Projektteam beim Auftraggeber. 
Bieter wie auch Auftraggeber nutzen häufig Musterunterlagen, Unterlagen von Partnerorganisationen oder die letzte Version eines Textes und aktualisieren ihn für die anstehende Ausschreibung, wie die vorangegangene Untersuchung zeigt. Häufig schleichen sich bei der Aktualisierung aber Fehler ein, weil aus den Verdingungsunterlagen einer Partnerorganisation Forderungen (z. B. für Grenzfahrten in niederländisches Staatsgebiet) übersehen und damit übernommen wurden. In einem solchen Fall kann es z. B. passieren, dass Bieter in einem S-Bahn-Ausschreibungsverfahren in Berlin vor der Herausforderung stehen, sich zu erklären, warum der Auftraggeber fordert, dass der Berliner Schaffner auf einmal Niederländisch sprechen können muss usw.

Für die Seite der Auftraggeber dürften allerdings die Empfehlungen das größte Wirkungspotenzial haben, die auf die „Empfehlungen für Anforderungen an Fahrzeuge in Vergabeverfahren“ des Auftraggeberverbands BAG SPNV zielen. Denn der Verband nimmt durch Weitergabe von Know-how Einfluss darauf, wie der einzelne Auftraggeber die Verdingungsunterlagen gestaltet. Dementsprechend setzt die folgende Skizzierung meiner Hinweise an der Modifikation der BAGSPNV-Empfehlungen an (s. Kapitel 7.3.1), weil z. B. die beschriebenen terminologischen Normenkonflikte in der aktuellen Auflage (BAG SPNV, ${ }^{32016}$ ) nach wie vor enthalten sind..$^{247}$

Der Verband BAG SPNV könnte seinen Mitgliedern neben diesen Empfehlungen auch eine digitale Textbausteinsammlung zur Verfügung stellen, die aus den vorhandenen Verdingungsunterlagen (VDU) extrahiert wird (s. Kapitel 7.3.2). Zu diesem Ansatz hat mich die Aussage von Auftraggeber 1 angeregt, „dass die Autoren Textbausteine aus VDU vergangener Ausschreibungen verwenden können, die entweder sie selbst oder Kollegen betreut haben“ (AUfTRAGGEBER 1, 2013, S. 7). Als Vorlage für Verdingungsunterlagen dienen AufTRAGGEBER 1 , auch die von Kollegen anderer Aufgabenträger“ (ebd.). Eine Datenbank, die der Verband seinen Mitgliedern zur Verfügung stellt, hätte den Vorteil, einen schnelleren Zugriff und das Auffinden geeigneterer Textmodule durch die Systematisierung beispielsweise durch Verschlagwortung der Module zu erzielen.

247 Diese Auflage wurde publiziert, nachdem die drei untersuchten Ausschreibungsverfahren abgeschlossen waren. 


\subsubsection{Optimierungsansätze für die Empfehlungen der BAG SPNV}

Die Erfahrungen aus Ausschreibungen, die Auftraggeber als BAG-SPNV-Autoren bei der Aktualisierung der BAG-SPNV-Empfehlungen einfließen lassen, führen an einigen Stellen zu Problemen, die die Bieter im Ausschreibungsverfahren nur schlecht lösen können.

Wenn der Auftraggeber die Textstellen in den Empfehlungen belässt, die zu diesen Problemen für den Bieter führen, können daraus folgende Probleme für den Auftraggeber entstehen:

1. Der Bieter könnte Falschangaben machen, was eine Nachrüstung und vermutlich zeitweise Auswirkungen auf den Umfang der angebotenen Leistung haben könnte. Im Extremfall könnte eine Nachbesserung derart kostenintensiv sein, dass der Bieter, der den Zuschlag erhalten hat, die Leistung nicht erbringen kann. Eine Aufhebung des Vertrags und eine Neuausschreibung der Leistung sind grundsätzlich möglich. ${ }^{248}$ Dementsprechend könnte für den Zeitraum der Neuausschreibung die benötigte Leistung als Interimsvergabeverfahren ohne Teilnahmewettbewerb gemäß $§ 13$ Abs. 2 Nr. 4 SektVO zu einem höheren Preis von einem anderen Bieter ausgeführt werden.

2. Der Bieter könnte einem Auftraggeber eine Leistung aufgrund mangelnder Eineindeutigkeit der BAG-SPNV-Empfehlungen, denen Vergabeunterlagen eines Auftraggebers folgen, mit geringerer Qualität anbieten, als der Auftraggeber dies gehofft hatte. Der Grund dafür könnte darin liegen, dass die Vorstellungen des Auftraggebers nicht im Lastenheft fixiert sind. Möglich ist daher, dass ein Bieter eine Leistung nicht in der gewünschten Spezifik anbietet. Nicht nur mangelnde Konsistenz der Terminologie innerhalb der BAG-SPNV-Empfehlungen kann zu mangelnder Eineindeutigkeit und entsprechenden Auswirkungen auf die Leistungserbringung führen, sondern auch mangelnde Harmonisierung der BAGSPNV-Empfehlungen mit der Norm TSI PRM, auf die sich Erstere beziehen. Zudem fordern die BAG-SPNV-Empfehlungen, dass sämtliche Angebote der Bieter die TSI PRM berücksichtigen und erfüllen. Wird durch den Konflikt aus der Wortwahl in der TSI PRM und den Verdingungsunterlagen nicht deutlich, was

248 Ggf. macht sich der Auftraggeber bei einer Neuausschreibung bzw. einer vorausgehenden Aufhebung des Vertrags schadensersatzpflichtig gemäß $\S 28$ Abs. 1 und Abs. 2 SektVO bzw. $§ 31$ Abs. 1 und Abs. $2 \mathrm{VgV}$. 
durch welches Wort der Verdingungsunterlagen bezeichnet wird, kann das auch für ein juristisches Verfahren ${ }^{249}$ relevant sein - falls Bieter und Auftraggeber dies führen sollten. Das Beispiel zeigt, dass nicht nur das Fahrzeug als physikalischer Gegenstand genormt werden muss, sondern auch, dass die Darstellung des Fahrzeugs im Lasten- und Pflichtenheft durch Wörter, technische Zeichnungen, CADDarstellungen etc. zu standardisieren ist. Denn nicht nur eine mangelnde Vereinheitlichung des Fahrzeugs, sondern auch der Mangel in der Darstellung dieser Forderungen kann zum Kostentreiber werden.

Was führt in der aktuellen, 3. Auflage (BAG SPNV, ${ }^{32016)}$ der BAG-SPNVEmpfehlungen konkret zu Problemen?

Ich beziehe mich im Folgenden nur auf einige Beispiele, die sich aus den Beobachtungen der Textüberarbeitungen ergeben. Um Normkonflikte weitgehend auszuschließen, müssten die BAG-SPMV-Empfehlungen weiter gehend geprüft werden.

Den beobachteten Überarbeitungsprozessen lag die 2. Auflage der BAG-SPNVEmpfehlungen zugrunde, und die dritte Auflage räumt an einer Stelle einen Terminologiekonflikt aus. ${ }^{250}$ Die Gefahr, dass die beobachteten Konflikte (s. Kapitel 6.1) auch durch die Gestaltung in der 3. Auflage auftreten, bleibt für folgende zwei Fälle bestehen:

1. Die Nominalphrase behindertengerechtes $W C$ (BAG SPNV, ${ }^{32016, ~ S . ~ 33) ~ w i r d ~}$ bei der Beschreibung von Gangbreiten verwendet, die auf das Kapitel zu Toiletten verweist. In Letzterem werden dagegen die Termini Toilette, Universaltoilette und Standardtoilette (ebd., S. 55), aber nicht die Nominalphrase behindertengerechtes $W C$ verwendet. Das Kapitel zu Toiletten in den BAG-SPNV-Empfehlungen verweist unspezifisch auf die Norm TSI PRM und gibt die Definition aus Letzterer wieder:

249 S. beispielsweise Schadensersatzpflicht bei Vertragsaufhebung.

250 Terminologisch präzisiert die 3. Auflage beispielsweise die Begriffe Zugverband, Fahrzeug, Fahrzeugtyp, Spurweite und Höchstgeschwindigkeit, indem diese Auflage einen Auszug aus der „Technische[n] Spezifikation für die Interoperabilität des Teilsystems ,Fahrzeuge Lokomotiven und Personenwagen““ (TSI LOK\&PAS, 2014) aufnimmt (BAG SPNV, ${ }^{3} 2016$, S. 82 ff.). 
„Die TSI PRM unterschiedet [sic] zwischen sogenannten Universaltoiletten, die so ausgelegt sind, dass sie von allen Reisenden genutzt werden können [sic] und Standardtoiletten, die nicht von Rollstuhlfahrern genutzt werden können." (BAG SPNV, ${ }^{3} 2016$, S. 56; Kursive im Original)

Diese sinngemäße Wiedergabe der TSI-PRM-Definition in den BAG-SPNVEmpfehlungen entspricht den Definitionen der Begriffe ,Standardtoilette " und ,Universaltoilette' in der TSI PRM (2008, S. 118). Für Auftraggeber wäre für die Gestaltung von Verdingungsunterlagen darüber hinaus aber auch ein konkreter Verweis auf die entsprechende Textstelle in der TSI PRM hilfreich. Somit sind zwar die Normen TSI PRM und BAG-SPNV-Empfehlungen harmonisiert. Die Terminologie innerhalb Letzterer wird aber aufgrund der Synonyme Universaltoilette und behindertengerechtes $W C$ nicht konsistent verwendet.

2. Aus den BAG-SPNV-Empfehlungen (BAG SPNV, ${ }^{2} 2010$, S. 31) ist in Lastenheftvordruck 1 von Ausschreibung 1 vermutlich der Terminus Überfahrrampe übernommen worden, der den Überarbeitenden des Bieters eine Angabe erschwert hat und von ihnen diskutiert wurde (s. Kapitel 6.1). Dabei verweist die entsprechende Textstelle auf die Norm TSI PRM (BAG SPNV, ${ }^{2} 2010$, S. 31), obwohl diese den Terminus Überfahrrampe nicht nutzt. Die Normen TSI PRM und BAG-SPNV-Empfehlungen (BAG SPNV, ${ }^{2} 2010$ ) sind an dieser Stelle terminologisch nicht harmonisiert. Die betreffende Textstelle wird in der dritten Auflage nur mit der Abweichung verwendet, dass der konkrete Verweis auf die TSI PRM in der zweiten Auflage „TSI PRM (dort Kap. 4.2.2.12.3.2)“ (BAG SPNV, ${ }^{2} 2010$, S. 31) gelöscht wurde:

„Die TSI PRM legt die Randbedingungen für die Verfügbarkeit von Einstiegshilfen für Rollstuhlfahrer fest. Davon unabhängig kann gefordert werden, dass je eingesetzter Wagengarnitur bzw. Triebzug an jeder Fahrzeugseite zu den Bahnsteigen mindestens eine Überfahrrampe oder ein Lift für den Einstieg von Elektrorollstühlen vorhanden sein muss.“ (BAG SPNV, ${ }^{3} 2016$, S. 35; Fettdruck AH)

Diese beiden Beispiele belegen, dass die Terminologie der BAG-SPNV-Empfehlungen weder vollständig mit der TSI PRM harmoniert ist, noch die Terminologie innerhalb der BAG-SPNV-Empfehlungen konsistent verwendet wird.

Gegenüber dieser mangelnden Eindeutigkeit der Terminologie in der 3. Auflage spezifizieren Letztere die Anforderungen an technische Zeichnungen (BAG SPNV, ${ }^{3} 2016$, S. 80 f.), z. B. den Zusammenhang zwischen Zeichnungsinhalten und Perspektiven (z. B. Übersichtszeichnung Fahrzeuglayout beinhaltet die 
Seiten-, Stirnansicht). Gegenüber den Vorgaben der 2. Auflage (BAG SPNV, 22010, S. 57) stellen diese Anforderungen der 3. Auflage eine Präzisierung dar. Von den Bemühungen der BAG SPNV, in der 3. Auflage zulässige Darstellungsmittel und -weisen in Lastenheften zu SPNV-Ausschreibungen zu vereinheitlichen, zeugt ebenso, dass in der 3. Auflage der BAG-SPNV-Empfehlungen DINNormen herangezogen werden, die die Gestaltung von technischen Zeichnungen standardisieren. Wie gezeigt wurde (s. Kapitel 5.2.1; 5.2.4), sind einige Übersichtszeichnungen vage gehalten und entsprechen beispielsweise in Form von Einfärbungen von Gepäckablagen oder TSI-PRM-Plätzen keiner DIN-Norm. Entgegen dem Verweis auf Anlage 5 (BAG SPNV, ${ }^{3} 2016$, S. 80) existieren aber keine Beispiele für eine Übersichtszeichnung. Diese Übersichtszeichnungen entsprechen dem Überblicksgrundriss beispielsweise in Pflichtenheft 3 (s. Abbildung 518). Dass Letztere aber weniger sprachunabhängig sein können, als DIN ISO 1281 (2003, S. 10) dies fordert, legitimiert folgende Angabe in den BAG-SPNVEmpfehlungen: „Als weiterführende Information kann im Zeichnungsblatt eine Auflistung der angebotenen Inneneinrichtung dienen." (BAG SPNV, ${ }^{32016}$, S. 80)

Gegenüber diesen Präzisierungen der Anforderungen an technische Zeichnungen fehlen in der 3. Auflage der BAG-SPNV-Anforderungen Vorgaben zu Fotos und Sprache-Bild-Relationen. So lässt die 3. Auflage (BAG SPNV, ${ }^{32016, ~ S . ~} 80$ f.) Angaben zu Fotos aus der 2. Auflage weg, welche Teile des Fahrzeuginnenraums wie darzustellen sind (BAG SPNV, ${ }^{2} 2010$, S. 57).

Bei dieser Forderung, die in der 3. Auflage gelöscht wurde, bleibt unklar, aus welchem Grund Fotos gefordert werden können. Pflichtenhefte haben im Verfahren die grundsätzliche Funktion, sich mit den Angaben zu verpflichten, sie auch umzusetzen. Die Textüberarbeitenden des Bieters haben die Funktion für Fotos, CAD-Darstellungen und für Zeichnungen ausgeschlossen, indem sie diese wie folgt kommentiert haben (s. Kapitel 6.1): Verbindlich seien die schriftsprachlichen Angaben in den Schriftmodulen, aber nicht die Angaben durch Fotos. Die Forderung von Lastenheftvordrucken, in Pflichtenheften Angebotsbestandteile wie Öhrchen von Sitzen (s. Kapitel 6.1) in schriftbasierten Tabellen und Fotos einheitlich anzugeben, würde die Eindeutigkeit der Pflichtenhefte und damit die Eindeutigkeit des Angebots erhöhen. Auch ein Hinweis in den Lastenheftvor- 
drucken, dass lediglich die Angaben in den schriftbasierten Tabellen bindend sind, würde die Eindeutigkeit der Pflichtenhefte bzw. der Angebote verbessern und die Wahrscheinlichkeit verringern, dass es zu Folgekosten durch juristische Auseinandersetzungen kommt. Anstatt diese Forderung zu Fotos zu löschen, ist es deswegen notwendig, die oben genannte Passage aus der 2. Auflage (BAG SPNV, ${ }^{2} 2010$, S. 57) wieder in die nächste Auflage der BAG-SPNV-Empfehlungen aufzunehmen und um eine Anforderung zur Konsistenz der Angaben in Schrift und Bild zu ergänzen.

Die Überarbeitenden haben in einem Schriftmodul den Großbuchstaben $A$ durch die Wortzusammensetzung A-Wagen ersetzt (s. Kapitel 6.1), um durch Wiederholung in schriftbasierter Tabelle und technischer Zeichnung einen Bezug herzustellen (s. Kapitel 5.2.4). Das ist auch geschehen, um das Pflichtenheft eindeutiger zu machen. Dementsprechend könnten die BAG-SPNV-Anforderungen Verbindungen zwischen Schrift- und Bildelementen im Lastenheft thematisieren, um die Relationen präziser zu gestalten.

\subsubsection{Modularisierung von Lasten- und Pflichtenheften nach Funktionsdesign}

Die Analyse der Textsortenexemplare hat die Textbausteine einer Inhalts- und einer Funktionsstruktur für Optimierungsvorschläge (s. Kapitel 5.1.2; 5.1.3), Lastenheftvordrucke sowie Pflichtenhefte (s. Kapitel 5.2.2; 5.2.3) veranschaulicht. Diese Analyse wird im Folgenden herangezogen, um ansatzweise zu skizzieren, wie aus vorhandenen Textsortenexemplaren schriftsprachliche, bildliche bzw. multimodale Funktionsmodule extrahiert und zu einer verschlagworteten Datenbank systematisiert werden könnten. Datenbanken zu Bürger-Behörde-Kommunikation, die aus der Erforschung Letzterer resultieren (VON LUCKE, 2014; BLAHA, 2010), haben die Idee zu einer entsprechenden Datenbank für Ausschreibungskommunikation geliefert. Der Ansatz des Funktionsdesigns ${ }^{\circledR}$ entwickelt als Methode einen Standard (Muthig/SCHÄFLEIN-ARMBruster, ${ }^{2} 2014$, S. 53). ${ }^{251} \mathrm{Im}$ Gegensatz zum Funktionsdesign ${ }^{\circledR}$ schlage ich vor, die in der Analyse abgegren-

251 Diese Standards stammen ,inzwischen [von] eigenen professionellen Leistungsanbietern und einem entstehenden Sub-Markt im Rahmen der Fachkommunikation“" (KALVERKÄMPER, 2016b, S. 57). 
zten Inhaltsmodule aus den Textsortenexemplaren (s. Kapitel 5.1.3 und Kapitel 5.2.3) zu extrahieren, aufzubereiten und in einer Datenbank zu organisieren.

Aus der Sprechakttheorie nach SEARLE und der kommunikationsanalytischen Handlungstheorie entwickeln MUTHIG/SCHÄFLEIN-ARMBRUSTER ( $\left.{ }^{2} 2014\right)$ das Funktionsdesign ${ }^{\circledR}$, das neben einem Prozessmodell zur Implementierung des Funktionsdesigns ${ }^{\circledR}$ in einer Technischen Redaktion ein Ebenen-Modell umfasst. Dieses Modell setzt Texte als sogenannte Informationsprodukte aus mehreren Sequenzmustern zusammen: Auf der obersten Ebene sind Sequenzmuster festgelegt als „Strukturbausteine, aus denen Informationsprodukte aufgebaut sind. Zusammengesetzt sind die Sequenzmuster aus den Funktionalen Einheiten" (ebd., S. 50). Diese funktionalen Einheiten stehen im Zentrum der Konzeption (s. Abbildung 7-1):

„Der Anspruch, dass jeder Satz und Abschnitt eines Textes einer spezifischen kommunikativen Funktion zugeordnet werden kann und dass die geeigneten Regeln für Verwendung, Inhalt, Sequenzierung, Formulierung und Gestaltung der Elemente präzise definiert werden können, bildete den Ausgangspunkt der Idee zum Funktionsdesign.“ (Muthig/SCHÄFleIN-ARMBrUSTER, ${ }^{2} 2014$, S. 51; Fettdruck $\mathrm{AH})$

Inwieweit Textabschnitte als funktionale Einheiten extrahiert und vor allem entsprechend den sogenannten fünf Regeln dokumentiert werden, bleibt offen. Für funktionale Module werden folgende Beispiele gegeben: „Themenangabe, Zielund Teilzielangabe, Voraussetzung, Einführung, Erklärung, Bedingungsangabe, Maßnahme, Handlungsaufforderung, Resultat, Bildbenennung, Legende, Verweis“ (ebd.). Die Beispiele Maßnahme und Resultat verdeutlichen, dass funktionale Einheiten keine Funktionsmodule sind, die nach Illokutionen der Sprechakttheorie erfasst werden. ${ }^{252}$ Vielmehr sind diese beiden Beispiele inhaltlich-funktional bestimmt, wie dies bei Modulen als Teil der sogenanten Themenentfaltung (s. Kapitel 3.3.3), also der Anordnung von Textinhalten entsprechend einem gängigen Muster, der Fall ist. Die Beispiele Legende, Bildbenennung, Verweis bezeichnen dagegen strukturelle Merkmale eines Textes. D. h., funktionale Einheiten können auch entsprechend ihrer textinternen Funktion erfasst werden. Relevant ist für die Gegenüberstellung meines Modularisierungsansatzes aber, dass auch die optische Gestaltung funktionaler Einheiten berücksichtigt wird. Funktio-

252 Letzteres legt der Bezug auf SEARLEs sprechakttheoretischen Ansatz nahe. 
nale Einheiten werden durch „Gestaltungsmittel wie Listen oder Tabellen“ (ebd., S. 53) bestimmt, die aber „lediglich der optischen Aufbereitung“ (ebd.) dienen. Im Gegensatz zum Ansatz des Funktionsdesigns ${ }^{\circledR}$ berücksichtige ich auch technische Zeichnungen, Fotos, CAD-Darstellungen und Typographie.

\section{Festlegungskategorien für jede Funktionale Einheit}

Für jede einzelne Funktionale Einheit müssen bzw. können

Festlegungen getroffen werden, die man den folgenden

Kategorien zuordnen kann:

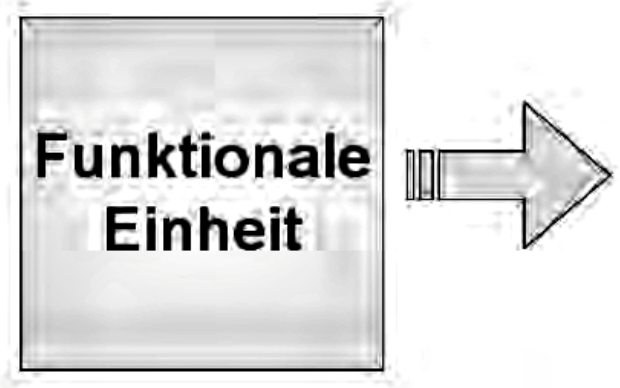

1. Verwendung

2. Inhalt

3. Sequenzierung

4. Formulierung/ syntaktisches Muster

5. Optische Gestaltung

6. Explizite Kennzeichnung

Abbildung 7-1: Festlegungskategorien für jede Funktionale Einheit (MUTHIG/SCHÄFLEIN-ARMBRUSTER, ${ }^{2}$ 2014, S. 51).

Kritisiert wird an der Methode Funktionsdesign ${ }^{\circledR}$ unter anderem, dass Sequenzmuster nicht definiert werden und dass die gegebenen Beispiele es nicht ermöglichen, Sequenzmuster wie Listen und Tabellen von funktionalen Einheiten zu unterscheiden (LEY, 2006, S. 52).

Das Funktionsdesign ${ }^{\circledR}$ wird durch seine Leistung charakterisiert, dass „bestimmte Informationsarten an bestimmten Stellen im Dokument ihren Platz finden“ (HEIDRICH, 2016, S. 133). Da die Funktion von bestimmten Informationsarten durch Funktionsdesign ${ }^{\circledR}$,,auf den ersten Blick erkennbar“ (ebd.) sein soll, könnten beispielsweise implizite Handlungsaufforderungen in Anwender-Dokumentationen wie Bedienungsanleitungen durch „die Formulierung einer Auffor- 
derung" (ebd.) ersetzt werden. Wie meine Analyse gezeigt hat, sind implizite Grundfunktionen von anderen Textsorten als Bedienungsanleitungen - hier: Optimierungsvorschlag und Pflichtenheft - aber nicht expliziert, sondern sie leiten sich aus dem Textsortennetz ab, also auch der Anordnung der Muster, in der die einzelnen Texte gestaltet sein sollen (erst der Optimierungsvorschlag, dann der Lastenheftvordruck, dann das Pflichtenheft). Da nicht klar ist, „[o]b das konventionell Vorgefundene tatsächlich optimal zur Erfüllung der jeweiligen kommunikativen Funktion beiträgt" (GÖPFERICH, 2000, S. 84), eignen sich die impliziten Textfunktionen der analysierten Exemplare zwar nicht, um zu einer anderen Beschreibung als der oben aufgeführten von HEIDRICH (2016) zu gelangen. Dass aber insbesondere direktive Funktionsmodule, konkret mit werbender Funktion, bewusst nicht explizit realisiert werden, ist bereits auf konzeptioneller Ebene dargestellt worden (s. Kapitel 3.2.2; BRINKER/CÖLFEN/PAPPERT, ${ }^{9} 2018$, S. 113). Daher hängt eine Erfassung der Funktion bei vielen Textsortenelementen von der Textsorte ab.

Meine Analyse der Textsortenexemplare hat bereits gezeigt, dass die Module der Inhaltsstruktur und die Module der Funktionsstruktur weitgehend deckungsgleich sind (s. Kapitel 5.1.3; 5.2.3). Dementsprechend erscheint die Zuordnung eines Moduls, wie es im Funktionsdesign ${ }^{\circledR}$ vorgesehen ist, sowohl zur Verwendung (Funktionsmodul) als auch zum Inhalt (Themenmodul) problematisch. Die Analyse der Funktionsstruktur von Optimierungsvorschlägen (s. Kapitel 5.1.2) und Pflichtenheften (s. Kapitel 5.2.2) hat darüber hinaus gezeigt, dass Module direkt erkennbare Funktionen und gleichzeitig - in Abhängigkeit von der Grundfunktion der Textsorte - abweichende indirekte Funktionen ausdrücken. Weil die Funktion eines Funktionsmoduls von der Textsorte abhängt, ließen sich die extrahierten Module ausschließlich dazu nutzen, Exemplare dieser Textsorte zu produzieren. Für die Textproduktion, die auf modularisierten Datenbanken basiert, wird aber vorgeschlagen, dass ,Superstrukturen ausgewählt werden, die für die jeweiligen Medien und Nutzungsanforderungen (z. B. für ein Softwareprodukt ein Handbuch im PDF-Format, eine Online-Hilfe und Videotutorials) geeignet sind“ (VILLIGER, 2014, S. 238). D. h., die Module, die aus Textsortenexemplaren extrahiert werden, sollen auch für die Produktion von Texten anderer Textsorten genutzt werden können (RothKeGEL, 2010, S. 198 f.). Daher könnten die indirekten Funktionen 
bei der Extraktion eines Moduls entweder nicht in den Metadaten des Moduls vermerkt werden oder diese Datenbank könnte ausschließlich für die Erstellung von Exemplaren dieser Textsorte genutzt werden.

Eine Lösungsmöglichkeit bei der Modularisierung der Textexemplare besteht darin, als grundlegende Kategorie der Extraktion Themenmodule heranzuziehen. Im Anschluss daran könnte ein extrahiertes Themenmodul mit den nachgeordneten Kategorien als Metadaten dokumentiert werden: ,Funktion(-en) ${ }^{\varsigma}$, , Gestaltung in Schrift und/oder Bild` etc. Bereits die obige Diskussion von funktionalen Einheiten des Funktionsdesigns ${ }^{\circledR}$ hat gezeigt, dass einige Beispiele thematisch-funktional bestimmt sind und daher Anknüpfungspunkte zur Modularisierung einer Themenstruktur bestehen. Auch Konzepte zu Inhaltsstrukturen bzw. zu Themenentfaltungsmustern sind funktional determiniert (s. Kapitel 3.3.3). Dies spricht für eine Modularisierung von Textsortenexemplaren, die sich nach der Gliederung der Inhaltsstruktur richtet. Dementsprechend können zu den extrahierten Themenmodulen folgende Kategorien dokumentiert werden, die einem thematisch-funktionalen Zugang nachgeordnet sind: ,Modulthema', ,Kommunikative Funktion(-en)', ,Zeichenmodale Gestaltung‘, ,Schriftbildlichkeit‘ und ,Zugehörigkeit zu Textsorte $X^{6}$.

Zwar bleibt auch bei diesem Vorgehen das Problem bestehen, dass die indirekte Funktion eines Moduls von der Textsorte abhängt und die Anwendbarkeit der Datenbank beschränkt. Da die Modularisierungssystematik aber nicht mehr hauptsächlich durch die Funktion bestimmt wird, ist es möglich, die indirekte Funktion als Metainformation bei der Dokumentation als bedingt gültig zu markieren.

Dass Textmodule der Datenbank auf die Produktion von Exemplaren verschiedener Textsorten ausgerichtet sein sollten, erscheint insoweit für die Domäne relevant, als sich Elemente aus Pflichtenheften in Artikeln auf Homepages von Bietern, aber auch von Auftraggebern finden. Beispielsweise führt EVU 2 technische Angaben auf deren Homepage auf, die mit denen in Pflichtenheft 3 vergleichbar sind.

Im Anschluss an die Extraktion und Dokumentation von Themenmodulen aus einem Textsortenexemplar ist zu prüfen, inwieweit dieses für die Verwendung in weiteren Textexemplaren bereinigt werden muss. So wäre beispielsweise die Löschung von Informationen notwendig, die aus der Spezifik einer Ausschreibung 
resultieren und von anderen Ausschreibungen grundlegend abweichen. Beispielsweise wird in Lastenheftvordruck 2 gefordert, dass das Fahrzeug auch in den Niederlanden zugelassen ist und der Fahrplan auch für die Niederlande testiert ist. Diese Forderung resultiert daraus, dass die zu bedienende Strecke sich sowohl auf deutschem als auch auf niederländischem Staatsgebiet befindet. Eine entsprechende Forderung ist für andere Ausschreibungen ungewöhnlich und müsste für die Datenbank getilgt werden. Zwar wird „die Vorgehensweise, dass durch die Wiederverwendung von Textbausteinen gleiche Sachverhalte immer gleich versprachlicht werden“ (GÖPFERICH, ${ }^{3} 2011$ a, S. 513), bereits als Standardisierung bezeichnet. Für den Aufbau einer Datenbank wird aber empfohlen, dass Textbausteine (also Textmodule) durch Nachbearbeitung (Post-Editing) in Wortschatz und Satzbau überarbeitet werden (ebd., S. 515). So sollen Synonymie und Doppelung von Textbausteinen vermieden werden (ebd., S. 514). Dieser Nachbereitungsschritt der maschinellen Übersetzung ist auch für die einsprachige Technische Redaktion relevant. Bei Sprache-Bild-Texten sind Terminologie, Syntax, Schriftbildlichkeit, diagrammatische und materiell-bildliche Elemente zu berücksichtigen. Entsprechende Forderungen bestehen für Optimierungsprozesse der Technischen Redaktion bezüglich der Verständlichkeit (GÖPFERICH, ${ }^{3} 2011 \mathrm{~b}$, S. 168 f.). Für die Textproduktion mit dem Ziel der maschinellen Übersetzbarkeit wird vorgeschlagen, das Kommunikationsziel eines Textes zu definieren, Textvarianten herzustellen und durch Adressaten testen zu lassen (GÖPFERICH, 2000, S. 95 ff.). $\mathrm{Zu}$ prüfen ist, ob sich dieses vorgeschlagene Vorgehen für die maschinelle Übersetzung bezüglich der Entität, Text ${ }^{`}$ auf die Technische Redaktion bezüglich der Entität, Textbaustein` übertragen lässt.

Die Umsetzung einer entsprechenden Datenbank erscheint vor allem für den Verband der Auftraggeber BAG SPNV relevant. Denn Letztere könnten ihren Mitgliedern einerseits eine Austauschplattform, andererseits ein Textproduktionstool an die Hand geben. Ein entsprechender Austausch könnte insoweit Synergien für die einzelnen Auftraggeber erzeugen, als nicht mehrere Auftraggeber weitgehend identische Themenmodule verfassen müssten. Diese Datenbank würde entsprechend der Analyse (s. Abbildung 5-5; 5-6; 5-17) neben Inhalten von Schriftsprache auch deren Typographie, Zeichnungen, Fotos und CAD-Darstellungen als eine Metainformation dokumentieren. 


\section{Literaturverzeichnis}

Abdullah, Rayan / Henze, Karsten (2007): Formulare. Von der Wiege bis zur Bahre ... Formulare im Corporate Design. München: Stiebner.

Adamzik, Kirsten (2016): Textlinguistik. Grundlagen, Kontroversen, Perspektiven. 2., völlig neu bearbeitete, aktualisierte und erweiterte Ausg. Berlin / Boston: De Gruyter.

Adamzik, Kirsten (2011): Textsortennetze. In: Habscheid, Stephan (Hg.): Textsorten, Handlungsmuster, Oberflächen. Linguistische Typologien der Kommunikation. Berlin: De Gruyter. S. 367 - 388.

Adamzik, Kirsten / Antos, Gerd / Jakobs, Eva-Maria (1997): Domänen- und kulturspezifisches Schreiben. Einleitung und Überblick. In: Dies. (Hg.): Domänen- und kulturspezifisches Schreiben. Textproduktion und Medien, Band 3. Frankfurt a. M.: Peter Lang. S. $1-6$.

Alvarez-Rodríguez, Jose María / Labra-Gayo, José Emilio / Rodríguez-González, Alejandro / Ordoñez De Pablos, Patricia (2013): Empowering the access to public procurement opportunities by means of linking controlled vocabularies. A case study of Product Scheme Classifications in the European e-Procurement sector. In: Computers in Human Behavior (30). S. $674-688$.

Ammon, Ulrich (52016): Normierung. In: Glück, Helmut / Rödel, Michael (Hg.): Metzler Lexikon Sprache. 5., aktualisierte und überarbeitete Auflage. Stuttgart: J. B. Metzler. S. $470-471$.

Antos, Gerd (2001): Transferwissenschaft. Chancen und Barrieren des Zugangs zu Wissen in Zeiten der Informationsflut und der Wissensexplosion. In: Antos, Gerd / Wichter, Sigurd (Hg.): Wissenstransfer zwischen Experten und Laien. Umriss einer Transferwissenschaft. Frankfurt a. M. u. a.: Peter Lang. S. 3 - 33.

Antos, Gerd/Hasler, Ursula / Perrin, Daniel (2011): Textoptimierung. In: Habscheid, Stephan (Hg.): Textsorten, Handlungsmuster, Oberflächen. Linguistische Typologien der Kommunikation. Berlin / New York: De Gruyter. S. $638-658$. 
Arntz, Reiner / Picht, Heribert / Schmitz, Klaus-Dirk ("2014): Einführung in die Terminologiearbeit. 7., vollständig überarbeitete und aktualisierte Auflage. Hildesheim / Zürich / New York: Georg Olms.

Austin, John (2007 [1972]): Zur Theorie der Sprechakte (How to do thing with Words). Bibliographisch ergänzte Auflage von 2002. Deutsche Bearbeitung von Eike von Savigny. Bearbeitung nach der englischen Ausgabe von 1962 und 1975. Universalbibliothek Nr. 9396. Stuttgart: Reclam.

Ballstaedt, Steffen-Peter (2016): Sprache im multikodalen Kontext als Parameter der Bildung. In: Felder, Ekkehard / Gardt, Andreas (Hg.): Handbuch Sprache in der Bildung. Handbücher Sprachwissen: Band 21. Berlin: De Gruyter. S. 141 - 159.

Ballstaedt, Steffen-Peter (2003): Technische Kommunikation mit Bildern. In: Hennig, Jörg / Tjarks-Sobhani, Marita (Hg.): Visualisierung in Technischer Kommunikation. Lübeck: Schmidt-Römhild. S. 11 - 31 .

Bateman, John (2014): Text and Image. A critical introduction to the visual / verbal divide. London / New York: Routledge.

Bateman, John (2008): Multimodality and Genre. A Foundation for the Systematic Analysis of Multimodal Documents. New York: Palgrave Macmillan. Bauer, Matthias / Ernst, Christoph (2010): Diagrammatik. Einführung in ein kultur- und medienwissenschaftliches Forschungsfeld. Bielefeld: transcript.

Baumann, Klaus-Dieter (2012): Ein Anlass - drei Komponenten - siebzehn Aspekte - zwei Bücher: Eine Vernetzung von Emotionen, Pragmatik und Fachanliegen. In: Ders. (Hg.): Fach - Translat - Kultur. Interdisziplinäre Aspekte der vernetzten Vielfalt. FFF, Band 98. Berlin: Frank \& Timme. S. $21-81$.

Baumann, Klaus-Dieter (1998a): Das Postulat der Exaktheit für den Fachsprachengebrauch. In: Hoffmann, Lothar / Kalverkämper, Hartwig / Wiegand, Herbert Ernst (Hg.): Fachsprachen/Languages for Special Purposes: ein internationales Handbuch zur Fachsprachenforschung und Terminologiewissenschaft. HSK, Band 14.1. Berlin / New York: De Gruyter. S. 373 - 377.

Baumann, Klaus-Dieter (1998b): Textuelle Eigenschaften von Fachsprachen. In: Hoffmann, Lothar / Kalverkämper, Hartwig / Wiegand, Herbert Ernst 
(Hg.): Fachsprachen/Languages for Special Purposes: ein internationales Handbuch zur Fachsprachenforschung und Terminologiewissenschaft. Berlin / New York: De Gruyter. HSK, Band 14.1. S. 408 - 416.

Baumann, Klaus-Dieter / Kalverkämper, Hartwig (1996): Curriculum vitae cursus scientiae - progressus linguisticae. Fachtextsorten als Thema: Einführung. Zugleich Würdigung des wissenschaftlichen Werks von Lothar Hoffmann (Leipzig) anläßlich seines 65. Geburtstags am 23. Oktober 1993. In: Dies. (Hg.): Fachliche Textsorten. Konponenten - Relationen - Strategien. FFF, Band 25. Tübingen: Gunter Narr. S. 13 - 34.

Beaugrande, Robert-Alain / Dressler, Wolfgang Ulrich (1981): Einführung in die Textlinguistik. Konzepte der Sprach- und Literaturwissenschaft, Band 28. Tübingen: Niemeyer.

Becker-Mrotzek, Michael / Scherner, Maximilian (2000): Textsorten der Verwaltung. In: Brinker, Klaus / Antos, Gerd / Heinemann, Wolfgang / Sager, Sven F. (Hg.): Text- und Gesprächslinguistik: ein internationales Handbuch zeitgenössischer Forschung. Berlin / New York: De Gruyter. S. $628-641$.

Becker-Mrotzek, Michael / Ehlich, Konrad / Fickermann, Ingeborg (1992): Bürger-Verwaltungs-Diskurse. In: Fiehler, Reinhard / Sucharowski, Wolfgang (Hg.): Kommunikationsberatung und Kommunikationstraining. Anwendungsfelder der Diskursforschung. Opladen: Westdeutscher Verlag. S. $234-253$.

Belke, Andreas (2012): Vergabepraxis für Auftragnehmer, Rechtliche Grundlagen - Angebot-Durchführung. Wiesbaden: Vieweg und Teubner; Springer.

Berruto, Gaetano (2004): Sprachvarietät - Sprache (Gesamtsprache, historische Sprache). In: Ammon, Ulrich / Dittmar, Norbert / Mattheier, Klaus J. / Trudgill, Peter (Hg.): Soziolinguistik. Ein internationales Handbuch zur Wissenschaft von Sprache und Gesellschaft. 2., vollständig neu bearbeitete und erweiterte Auflage. HSK Band 3.1. Berlin / New York: De Gruyter. S. $188-195$.

Bertin, Jacques (2010): Semiology of Graphics. Diagrams - networks - maps. Übersetzung von William J. Berg. Redslands: Esri Press. 
Blaha, Michaela (2010): Amtsdeutsch a. D.? Auf dem Weg zu einer verständlicheren Verwaltungssprache. In: Fluck, Hans-Rüdiger / Blaha, Michaela (Hg.): Amtsdeutsch a. D.? Europäische Wege zu einer modernen Verwaltungssprache. Arbeiten zur angewandten Linguistik, Band 4. Tübingen: Stauffenburg. S. $59-64$.

Blomqvist, Clarissa (2002): Über die allmähliche Veränderung der Nachricht beim Redigieren. Eine linguistische Analyse der Nachrichtenbearbeitung bei der Deutschen Presse-Agentur (dpa) und verschiedenen deutschen Tageszeitungen. Frankfurt a. M. / Berlin; Wien: Peter Lang.

Bock, Melanie (2010): Die Ausschreibungspflicht im Schienenpersonennahverkehr. Schriften zum Bau- und Vergaberecht, Band 7. Hamburg: Dr. Kovac.

Boland, Jan-Hendrik (2011): Vier Augen sehen mehr als zwei: Computergestütztes Peer-Feedback im Deutschunterricht. Duisburg: Universitätsverlag Rhein-Ruhr.

Brambilla, Marina (2013): Überlegungen $\mathrm{zu}$ den Patentschriften als Fachtextsorte in Deutschland und Österreich. In: Brambilla, Marina / Gerdes, Joachim / Messina, Chiara (Hg.): Diatopische Variation in der deutschen Rechtssprache. FFF, Band 113. Berlin: Frank \& Timme. S. $153-168$.

Bremerich-Vos, Albert (2009): Rhetorische Ratgeber für Beruf und Alltag. In: Fix, Ulla / Gardt, Andreas / Knape, Joachim (Hg.): Rhetorik und Stilistik. HSK 31.2. Berlin; New York: De Gruyter. S. 2320 - 2334.

Brinker, Klaus (1985): Linguistische Textanalyse. Eine Einführung in Grundbegriffe und Methoden. Grundlagen der Germanistik, Band 29. Berlin: Erich Schmidt.

Brinker, Klaus / Cölfen, Hermann / Pappert, Steffen ( $\left.{ }^{9} 2018\right)$ : Linguistische Textanalyse. Eine Einführung in Grundbegriffe und Methoden. 9., durchgesehene Auflage. Grundlagen der Germanistik, Band 29. Berlin: Erich Schmidt.

Bucher, Hans-Jürgen (2011): Multimodales Verstehen oder Rezeption als Interaktion. Theoretische und empirische Grundlagen einer systematischen Analyse der Multimodalität. In: Diekmannshenke, Hajo / Klemm, Michael / Stöckl, Hartmut (Hg.): Bildlinguistik. Theorien-Methoden-Fallbeispiele. 
Philologische Studien und Quellen, Band 228. Berlin: Erich Schmidt. S. $123-156$.

Bucher, Hans-Jürgen (2007): Textdesign und Multimodalität. Zur Semantik und Pragmatik medialer Gestaltungsformen. In: Roth, Sven / Spitzmüller, Jürgen (Hg.): Textdesign und Textwirkung in der massenmedialen Kommunikation. Konstanz: UVK. S. 49 - 76.

Bucher, Hans-Jürgen / Schumacher, Peter (2006): The relevance of attention for selecting news content. An eye-tracking study on attention patterns in the reception of print- and online media. In: Communications. The European Journal of Communications Research. Paper 31. S. 347 - 368.

Bühler, Karl ( $\left.{ }^{3} 1999\right):$ Sprachtheorie. Die Darstellungsfunktion der Sprache. Mit einem Geleitwort von Friedrich Kainz. UTB Band 1159. Stuttgart: Lucius \& Lucius (UTB).

Busch, Albert (2001): Wissenstransfer und Kommunikation in Gesundheitszirkeln. In: Antos, Gerd / Wichter, Sigurd (Hg.): Wissenstransfer zwischen Experten und Laien: Umriss einer Transferwissenschaft. Transferwissenschaften, Band 1. Frankfurt a. M. u. a.: Peter Lang. S. 85 - 103.

Busse, Dietrich (2000): Textsorten des Bereichs Rechtswesen und Justiz. In: Brinker, Klaus / Antos, Gerd / Heinemann, Wolfgang / Sager, Sven F. (Hg.): Text- und Gesprächslinguistik. Ein internationales Handbuch zeitgenössischer Forschung. HSK, Band 16.1. Berlin: De Gruyter. S. 658 - 675.

Coseriu, Eugenio ( $\left.{ }^{4} 2007 a\right)$ : Textlinguistik. Eine Einführung. 4., unveränderte Auflage. Herausgegeben und bearbeitet von Jörn Albrecht. Tübinger Beiträge zur Linguistik, Band 500. Tübingen: Narr Francke Attempto.

Coseriu, Eugenio (2007b): Sprachkompetenz. Grundzüge der Theorie des Sprechens. Tübinger Beiträge zur Linguistik, Band 508. Tübingen: Gunter Narr.

Coseriu, Eugenio ( $\left.{ }^{3} 1979\right)$ : System, Norm und ,Rede‘. In: Ders. (Hg.): Sprache: Strukturen und Funktionen. 3. Auflage. Tübingen: Narr. S. 45 - 60.

Dannerer, Monika (2008): Gute Kommunikation teuer? Zum Konzept der kommunikativen Effizienz in den Wirtschaftswissenschaften und der Linguistik. In: Müller, Andreas P. / Menz, Florian (Hg.): Organisationskommunikation. Grundlagen und Analysen der sprachlichen Inszenierung 
von Organisation. Managementkonzepte, Band 34. München / Mering: Rainer Hampp. S. 47 - 69.

Däschler, Eberhard ( $\left.{ }^{5} 2016\right)$ : Metonymie. In: Glück, Helmut / Rödel, Michael (Hg.): Metzler Lexikon Sprache. 5., aktualisierte und bearbeitete Auflage. Stuttgart: Metzler. S. 430.

Denzin, Norman K. ( $\left.{ }^{2} 1978\right):$ The Research Act. A Theoretical Introduction to Sociological Methods. 2. Auflage. New York: Mc Graw Hill.

Diatlova, Irina (2003): Unternehmenstexte: Textsorten, Textcluster, topische Muster. Europäische Hochschulschriften. Reihe I - Deutsche Sprache und Literatur, Band 1850. Frankfurt a. M. u. a.: Peter Lang.

Dick, Thorsten (2019): Fachlich kommunizieren mit sich selbst. Verständlichkeit und Optimierung von Recherchenotizen. FFF, Band 150. Berlin: Frank \& Timme.

Dietz, Gunther (1998): Titel in wissenschaftlichen Texten. Fachsprachen / Languages for Special Purposes: ein internationales Handbuch zur Fachsprachenforschung und Terminologiewissenschaft. HSK 14.1 Berlin / New York: De Gruyter. S. 617 - 624.

Doelker, Christian (1997): Ein Bild ist mehr als ein Bild. Visuelle Kompetenz in der Multimedia-Gesellschaft. Stuttgart: Klett-Cotta.

Domke, Christine (2011): Organisationale Kommunikationstypen. In: Habscheid, Stephan (Hg.): Textsorten, Handlungsmuster, Oberflächen. Berlin / New York: De Gruyter. S. 206 - 230.

Dovalil, Vít (2013): Soziales Kräftefeld einer Standardvarietät als methodologischer Impuls für die Debatte über die Standardnormen. In: SchneiderWiejowski, Karina / Kellermeier-Rehbein, Birte / Haselhuber, Jakob (Hg.): Vielfalt, Variation und die Stellung der deutschen Sprache. Berlin: Walter De Gruyter. S. 65- 78.

Drewer, Petra (2003): Die kognitive Metapher als Werkzeug des Denkens. Zur Rolle der Analogie bei der Gewinnung und Vermittlung wissenschaftlicher Erkenntnisse. FFF, Band 62. Tübingen: Gunter Narr.

Duchéne, Alexandre / Heller, Monica (2012): Language policy in the workplace. In: Spolsky, Bernhard (Ed.): The Cambidge Handbook of Language Policy. Cambridge: Cambridge University Press. S. 323 - 334. 
Duden ( $\left.{ }^{8} 2009\right)$ : Die Grammatik. 8., überarbeitete Auflage. Band. 4. Mannheim: Duden Verlag.

Dürr, Michael / Schlobinski, Peter ( $\left.{ }^{3} 2006\right)$ : Deskriptive Linguistik. Grundlagen und Methoden. 3., überarbeitete Auflage. Studienbücher zur Linguistik, Band 11. Göttingen: Vandenhoeck \& Ruprecht.

Dürscheid, Christa (2005): Medien, Kommunikationsformen, kommunikative Gattungen. In: Linguistik online. Band 22.

Ebert, Christof (2012): Systematisches Requirements Engineering. Anforderungen ermitteln, spezifizieren, analysieren und verwalten. 4., überarbeitete Auflage. Heidelberg: dpunkt.verlag.

Eco, Umberto ( $\left.{ }^{2} 1991\right)$ : Semiotik. Entwurf einer Theorie der Zeichen. 2., korrigierte Auflage. Supplemente Band 5. Übersetzt von Günther Memmert. München: Wilhelm Fink.

Ehlich, Konrad ( $\left.{ }^{3} 2010\right)$ : Funktionale Pragmatik - Terme, Themen und Methoden. In: Hoffmann, Ludger (Hg.): Sprachwissenschaft. Ein Reader. 3., aktualisierte und erweiterte Auflage. Berlin / New York: De Gruyter.

Ehlich, Konrad / Rehbein, Jochen ( $\left.{ }^{2} 1980\right)$ : Sprache in Institutionen. In: Althaus, Hans Peter / Henne, Helmut / Wiegand, Herbert Ernst (Hg.): Lexikon der Germanistischen Linguistik. 2., vollständig neu bearbeitete und erweiterte Auflage. Tübingen: Max Niemeyer. S. 338 - 345.

Ehrenheim, Andrea (2011): Das Textdesign der Stellenanzeige. Linguistisch und interdisziplinär. Arbeiten zu Diskurs und Stil, Band 11. Frankfurt a. M. u. a.: Peter Lang.

Eins, Wieland (52016): Abkürzung. In: Glück, Helmut / Rödel, Michael (Hg.): Metzler Lexikon Sprache. 5., aktualisierte und bearbeitete Auflage. Stuttgart: Metzler. S. 2 - 3.

Engberg, Jan (2011): Fachtextsorten und Wissenstransfer. In: Habscheid, Stephan (Hg.): Textsorten, Handlungsmuster, Oberflächen. Berlin / New York: De Gruyter. S. 190 - 205.

Engberg, Jan (1997): Konventionen von Fachtextsorten. Kontrastive Analyse zu deutschen und dänischen Gerichtsurteilen. FFF, Band 36. Tübingen: Gunter Narr.

Engberg, Jan / Janich, Nina (2007): Über die Komplexität fachkommunikativer Sprachkompetenz und ihrer Beschreibung. In: Heller, Dorothee / Ehlich, 
Konrad (Hg.): Studien zur Rechtskommunikation. Bern: Peter Lang. S. 209 -236 .

Fahney, Ralf / Herrmann, Andrea (2013): Grundlagen des professionellen Requirements Engineering und Management. In: Valentini, Uwe / Weißbach, Rüdiger / Fahney, Ralf (Hg.): Requirements Engineering und Projektmanagement. Berlin / Heidelberg: Springer. S. 9 - 16.

Fandrych, Christian / Thurmair, Maria (2011): Textsorten im Deutschen. Linguistische Analyse aus sprachdidaktischer Sicht. Stauffenburg Linguistik, Band 57. Tübingen: Stauffenburg.

Fielding, Nigel G. / Fielding, Jane L. (1986): Linking Data. Beverly Hills: Sage. Fisch, Rudolf / Marglies, Burkhard (Hg.; 2014): Bessere Verwaltungssprache. Grundlagen, Empirie, Handlungsmöglichkeiten. Berlin: Duncker \& Humblot.

Fix, Ulla (2014): Aktuelle Tendenzen des Textsortenwandels. In: Hauser, Stefan / Kleinberger, Ulla / Roth, Sven Kersten (Hg.): Musterwandel - Sortenwandel. Aktuelle Tendenzen der diachronen Text(sorten)linguistik. Sprache in Kommunikation und Medien, Band 3. Berlin u. a.: Peter Lang. S. $15-48$.

Flick, Uwe ( $\left.{ }^{8} 2017\right):$ Qualitative Sozialforschung. Eine Einführung. 8., völlig überarbeitete Neuauflage. Reinbek: Rowohlt.

Flick, Uwe ( $\left.{ }^{7} 2009\right)$ : Triangulation in der qualitativen Sozialforschung. In: Flick, Uwe / von Kardorff, Ernst / Steinke, Ines (Hg.): Qualitative Forschung. Ein Handbuch. Rororo, Band 55628. Reinbek: Rowohlt. S. 309 - 318.

Fluck, Hans-Rüdiger (1996): Fachsprachen. Einführung und Bibliographie. Fünfte, überarbeitete und erweiterte Auflage. Tübingen / Basel: Francke.

Fluck, Hans-Rüdiger / Blaha, Michaela (Hg.; 2010): Amtsdeutsch a. D.? Europäische Wege zu einer modernen Verwaltungssprache. Reihe AALArbeiten zur Angewandten Linguistik. Tübingen: Stauffenburg.

Frei, Viktor (2008): Was Styleguides der IT-Riesen regeln. In: Sprache und Datenverarbeitung. International Journal for Data Processing. No. 32 (2). S. $27-51$.

Friederici, Angela (1989): Raumreferenz unter extremen perzeptuellen Bedingungen: Perzeption, Repräsentationn und sprachliche Abbildung. In: Habel, Christopher / Herweg, Michael/ R ehkämper, Klaus (Hg.): Raumkon- 
zepte in Verstehensprozessen. Interdisziplinäre Beiträge zu Sprache und Raum. Linguistische Arbeiten, Band 233. Tübingen: Max Niemeyer. S. $17-36$.

Fries, Norbert (1987): Zu einer Randgrammatik des Deutschen. Zur Theorie randgrammatischer satzwertiger Konstruktionen. In: Meibauer, Jörg (Hg.): Satzmodus zwischen Grammatik und Pragmatik. Tübingen: Niemeyer. S. $75-95$.

Gallert, Klaus (1998): Markenzeichen - aus semiotischer Sicht-Analyse und Generierungsmöglichkeiten. Europäische Hochschulschriften - Reihe V, Volks- und Betriebswirtschaftslehre, Band 2226. Frankfurt a. M. u. a.: Peter Lang.

Gansel, Christina (2011): Textsortenlinguistik. UTB, Band 3459. Göttingen: Vandenhoeck \& Ruprecht.

Gerstenkorn, Alfred (2006): Zu Fahrzeugen und Zügen - Begriffsbeziehungen in Eisenbahnfachtexten. In: Gerstenkorn, Alfred / Hums, Lothar / Schmidt, Armin (Hg.): Die Sprache der Bahn. Zur deutschen Eisenbahnsprache im europäischen Kontext. Informationswissenschaft, Band 8. Frankfurt a. M.: Deutsche Gesellschaft für Informationswissenschaft und Informationspraxis. S. $235-262$.

Girnth, Heiko (1996): Texte im politischen Diskurs. Ein Vorschlag zur diskursorientierten Beschreibung von Textsorten. In: Muttersprache. Vierteljahresschrift für deutsche Sprache. No. 106. S. 66 - 80.

Gläser, Rosemarie (1990): Fachtextsorten im Englischen. FFF, Band 13. Tübingen: Gunter Narr.

Gloy, Klaus (2012): Empirie des Nichtempirischen. Sprachnormen im Dreieck von Beschreibung, Konstitution und Evaluation. In: Günthner, Susanne / Imo, Wolfgang / Meer, Dorothee / Schneider, Jan Georg (Hg.): Kommunikation und Öffentlichkeit. Sprachwissenschaftliche Potenziale zwischen Empirie und Norm. Berlin / Boston: De Gruyter. RGL 296. S. 23 - 40.

Gloy, Klaus (2004): Norm. In: Ammon, Ulrich / Dittmar, Norbert / Mattheier, Klaus J. / Trudgill, Peter (Hg.): Soziolinguistik. Ein internationales Handbuch zur Wissenschaft von Sprache und Gesellschaft. 2., vollständig neu bearbeitete und erweiterte Auflage. HSK, Band 3.1. Berlin / New York: De Gruyter. S. $392-399$. 
Gloy, Klaus (1975): Sprachnormen I. Linguistische und soziologische Analysen. Band I. Stuttgart / Bad Cannstatt: Frommann.

Glück, Helmut ( $\left.{ }^{5} 2016\right)$ : Logogramm. In: Glück, Helmut / Rödel, Michael (Hg.):

Metzler Lexikon Sprache. 5., aktualisierte und überarbeitete Auflage. Stuttgart: J. B. Metzler. S. 408.

Goodman, Nelson (1997): Sprachen der Kunst. Entwurf einer Symboltheorie.

Übersetzt von Bernd Philippi. Suhrkamp-Taschenbuch Wissenschaft, Band 1844. Frankfurt a. M.: Suhrkamp.

Göpferich, Susanne (2014): GAL: The German Association for Applied Linguistics. In: European Journal of Applied Linguistics. No. 2 (1). S. 145- 157. Göpferich, Susanne ( $\left.{ }^{3} 2011 a\right)$ : Standardisierung von Kommunikation. In: Knapp, Karlfried / Antos, Gerd / Becker-Mrotzek, Michael / Deppermann, Arnulf / Göpferich, Susanne / Grabowski, Joachim / Klemm, Michael / Villiger, Claudia (Hg.): Angewandte Linguistik. Ein Lehrbuch. 3., vollständig überarbeitete und erweiterte Auflage. UTB Sprachwissenschaft, Band 8275 Tübingen u. a.: Francke. S. 513 - 536.

Göpferich, Susanne ( $\left.{ }^{3} 2011 b\right)$ : Technische Kommunikation. In: Knapp, Karlfried / Antos, Gerd / Becker-Mrotzek, Michael / Deppermann, Arnulf / Göpferich, Susanne / Grabowski, Joachim / Klemm, Michael / Villiger, Claudia (Hg.): Angewandte Linguistik. Ein Lehrbuch. 3., vollständig überarbeitete und erweiterte Auflage. UTB Sprachwissenschaft, Band 8275. Tübingen u. a.: Francke. S. 149 - 171.

Göpferich, Susanne (2006): Patentschriften. In: Snell-Hornby, Mary / Hönig, Hans G. / Kußmaul, Paul / Schmitt, Peter A. (Hg.): Handbuch Translation. Unveränderter Nachdruck der 2. Auflage 1999. Tübingen: Stauffenburg. S. $222-225$.

Göpferich, Susanne (2002): Textproduktion im Zeitalter der Globalisierung. Entwicklung einer Didaktik des Wissenstransfers. Tübingen: Stauffenburg. Göpferich, Susanne (2000): Von der deskriptiven zur präskriptiven (proskriptiven) Fachtextsortenlinguistik. In: Baumann, Klaus-Dieter / Kalverkämper, Hartwig / Steinberg-Rahal, Kerstin (Hg.): Sprachen im Beruf. Stand Probleme - Perspektiven. FFF, Band 38. Tübingen: Gunter Narr. S. $83-103$. 
Göpferich, Susanne (1995): Textsorten in Naturwissenschaften und Technik. Pragmatische Typologie - Kontrastierung - Translation. FFF, Band 27. Tübingen: Gunter Narr.

Grewendorf, Günther (2002): „Kein Patent auf Leben!“ Zur Pragmatik des Patentrechts. In: Zeitschrift für Literaturwissenschaft und Linguistik. No. 128. S. $8-33$.

Grosse, Siegfried / Mentrup, Wolfgang (Hg.; 1980): Bürger - Formulare Behörde. Wissenschaftliche Arbeitstagung zum Kommunikationsmittel ,Formular‘. Mannheim, Oktober 1979. Tübingen: Gunter Narr.

Grosse, Siegfried (1981): Vorschläge zur Verbesserung der Verständlichkeit von Verwaltungstexten. In: Radtke, Ingulf (Hg.): Die Sprache des Rechts und der Verwaltung. Stuttgart: Klett-Cotta. S. $268-283$.

Große, Franziska (2011): Bild-Linguistik. Grundbegriffe und Methoden der linguistischen Bildanalyse in Text- und Diskursumgebungen. Germanistische Arbeiten zu Sprache und Kulturgeschichte, Band 50. Frankfurt a. M. u. a.: Peter Lang.

Grucza, Sambor / Alnajjar, Justyna / Grucza, Radomir (2014): Projektkommunikation bei Nearshoring-Kooperationen. Am Beispiel von polnischdeutschen Projektkooperationen bei REC Global. In: Gruzca, Sambor / Wierzbicka, Mariola / Alnajjar, Justyna / Bak, Pawel (Hg.): Polnisch-deutsche Unternehmenskommunikation. Ansätze zu ihrer linguistischen Erforschung. Warschauer Studien zur Germanistik und zur Angewandten Linguistik, Band 15. Frankfurt a. M.: Peter Lang. S. $153-170$.

Gülich, Elisabeth (1981): Formulare als Dialoge. In: Radtke, Ingulf (Hg.): Die Sprache des Rechts und der Verwaltung. Stuttgart: Klett-Cotta. S. $322-356$.

Gutermann, Barbara (1996): Die Raumdarstellung in deutschen und französischen technischen Texten. Sprachvergleichende Untersuchungen zur Frequenz der Darstellung räumlicher Relationen, zu ihrer sprachlichen Form und zu Inhalt-Form-Beziehungen. Europäische Hochschulschriften. Reihe XXI, Band 160. Frankfurt u. a.: Peter Lang.

Habscheid, Stephan (2003): Sprache in der Organisation. Sprachreflexive Verfahren im systemischen Beratungsgespräch. Linguistik - Impulse \& Tendenzen: Band 1. Berlin / New York: De Gruyter. 
Hagemann, Jörg (2007): Typographie und logisches Textdesign. In: Roth, Kersten Sven / Spitzmüller, Jürgen (Hg.): Textdesign und Textwirkung in der massenmedialen Kommunikation. Konstanz: UVK. S. 77 - 91.

Halliday, Michael A. K. (2004): The language of science. London: Continuum. Halliday, Michael A. K. / Hasan, Ruqaiya ( $\left.{ }^{2} 1989\right)$ : Language, context, and text: aspects of language in a social-semiotic perspective. 2nd edition. Oxford: Oxford University Press.

Haß, Ulrike (2018): Der verheißungsvolle Kontext und seine Leistungen bei der Erschließung von Wortbedeutungen. In: Zeitschrift für Angewandte Linguistik, No. 69. S. $33-68$.

Hausendorf, Heiko / Kesselheim, Wolfgang (2008): Textlinguistik fürs Examen. Linguistik fürs Examen, Band 5. Göttingen: Vandenhoeck \& Ruprecht.

Hauser, Stefan / Kleinberger, Ulla / Roth, Kersten Sven (2014): Textmuster und Textsorten im Wandel - Einführende Anmerkungen zu aktuellen Fragen der diachronen Textlinguistik. In: Dies. (Hg.): Musterwandel - Sortenwandel. Aktuelle Tendenzen der diachronen Text(sorten)linguistik. Sprache in Kommunikation und Medien, Band 3. Berlin u. a.: Peter Lang. S. 7 - 14.

Heidrich, Franziska (2016): Kommunikationsoptimierung im Fachübersetzungsprozess. TransÜD, Band 83. Berlin: Frank \& Timme.

Heidrich, Franziska (2013): Rezension Thorsten Roelcke: Kommunikative Effizienz - Eine Modellskizze. In: trans-kom. No. 6 (1). S. 241 - 259.

Heine, Carmen (2010): Modell zur Produktion von Online-Hilfen. FFF, Band 90. Berlin: Frank \& Timme.

Heine, Carmen / Schubert, Klaus (2013): Modellierung in der Fachkommunikation. In: Fachsprache. H. 3 - 4. S. 100 - 117.

Heinemann, Margot / Heinemann, Wolfgang (2002): Grundlagen der Textlinguistik. Interaktion - Text-Diskurs. RGL, Band 230. Tübingen: Niemeyer.

Heinemann, Wolfgang / Viehweger, Dieter (1991): Textlinguistik. Eine Einführung. RGL 115. Tübingen: Niemeyer.

Heinrich, Peter (2014): Verwaltungssprache als Element der Organisationskultur. In: Fisch, Rudolf / Margies, Burkhard (Hg.): Bessere Verwaltungssprache. Grundlagen, Empirie, Handlungsmöglichkeiten. Berlin: Duncker \& Humblot. S. $49-62$. 
Held, Ursula (2006): Textüberarbeitung in der Grundschule. Eine Untersuchung zur Entwicklung und Förderung grundlegender Revisionskompetenzen bei jungen Schreibern. Frankfurt a. M.: Peter Lang.

Helfferich, Cornelia (2009): Die Qualität qualitativer Interviews: Manual für die Durchführung qualitativer Interviews. 3., überarbeitete Auflage. Wiesbaden: VS Verlag für Sozialwissenschaften.

Hoffmann, Lothar (1998): Fachtextsorten der Institutionensprachen III: Verträge. In: Hoffmann, Lothar / Kalverkämper, Hartwig / Wiegand, Herbert Ernst (Hg.): Fachsprachen / Languages for Special Purposes: ein internationales Handbuch zur Fachsprachenforschung und Terminologiewissenschaft. HSK, Band 14.1. Berlin / New York: De Gruyter. S. $533-539$.

Hoffmann, Lothar (1993): Fachwissen und Fachkommunikation. Zur Dialektik von Systematik und Linearität in den Fachsprachen. In: Bungarten, Theo (Hg.): Fachsprachentheorie. Konzeptionen und theoretische Richtungen. Band 2. Tostedt: Attikon. S. 595 - 617.

Hoffmann, Lothar (1988): Vom Fachwort zum Fachtext. Beiträge zur Angewandten Linguistik. FFF, Band 5. Tübingen: Gunter Narr.

Holsanova, Jana / Holmqvist, Kenneth / Rahm, Hendrik (2006): Entry points and reading paths on newspaper spreads: comparing a semiotic analysis with eye-tracking measurements. In: Visual Communication. No. 5 (1). S. $65-93$.

Hopf, Christel (72009): Qualitative Interviews - Ein Überblick. In: Flick, Uwe / von Kardorff, Ernst / Steinke, Ines (Hg.): Qualitative Forschung. Ein Handbuch. Rororo, Band 55628. Reinbek: Rowohlt. S. 349 - 360.

Horn-Helf, Brigitte (2010): Konventionen technischer Kommunikation: Makro- und mikrokulturelle Kontraste in Anleitungen. FFF, Band 91. Berlin: Frank \& Timme.

Itten, Johannes (282003): Die Kunst der Farbe. Subjektives Erleben und objektives Erkennen als Wege zur Kunst. 28. Auflage. Gekürzte Studienausgabe. Stuttgart: Urania.

Jakob, Karlheinz (1991): Maschine, mentales Modell, Metapher. Studien zur Semantik und Geschichte der Techniksprache. RGL, Band 123. Tübingen: Niemeyer. 
Jakobs, Eva-Maria (2011a): Multimodale Fachkommunikation. In: Baumann, Klaus-Dieter (Hg.): Fach-Translat-Kultur. Interdisziplinäre Aspekte der vernetzten Welt. FFF, Band 98. Berlin: Franke \& Timme. S. 106 - 124.

Jakobs, Eva-Maria (2011b): Dynamische Textwelten. Forschungsfelder angewandter Textwissenschaften. In: Bonner, Witbold / Reuter, Ewald (Hg.): Umbrüche in der Germanistik. Ausgewählte Beiträge der finnischen Germanistentagung 2009. Frankfurt a. M. u. a.: Peter Lang. S. 77 - 94.

Jakobs, Eva-Maria (2005): Writing at Work. In: Jakobs, Eva-Maria / Lehnen, Katrin / Schindler, Kirsten (Hg.): Schreiben am Arbeitsplatz. Wiesbaden: VS Verlag für Sozialwissenschaften. S. $13-40$.

Jakobs, Eva-Maria / Spinuzzi, Clay (2014): Introduction: Domain perspectives in text production research. In: Jakobs, Eva-Maria / Perrin, Daniel (Hg.): Handbook of Writing and Text Production. Communication Competence, Volume 10. Berlin / Boston: De Gruyter Mouton. S. 325 - 332.

Jakobson, Roman (2007 [1960]): Linguistik und Poetik. In: Ders.: Poesie der Grammatik und Grammatik der Poesie. Sämtliche Gedichtanalysen. Kommentierte deutsche Auflage. Band I: Poetologische Schriften und Analysen zur Lyrik vom Mittelalter bis zur Aufklärung. Gemeinsam mit Sebastian Donat herausgegeben von Hendrik Birus. Übersetzt von Stephan Packard. Berlin u. a.: De Gruyter. S. 155 - 216.

Janich, Nina (52010): Werbesprache. Ein Arbeitsbuch. 5., überarbeitete und erweiterte Auflage. Tübingen: Narr Francke Attempto.

Janich, Nina (2009): Zur Analyse von Textsorten-in-Vernetzung. Eine Modelldiskussion an einem Fallbeispiel aus der Unternehmenskommunikation. Herausgeber: Linguistic Agency. Essen: Laud-Paper online. Band 734. URL: http://www.linse.uni-due.de/laud-downloadliste/articles/zur-analysevon-textsorten-in-vernetzung-eine-modelldiskussion-an-einem-fallbeispielaus-der-unternehmenskommunikation.html [abgerufen am 26.10.2018] Janich, Nina / Zakharova, Ekaterina (2014): Fiktion „gemeinsame Sprache“? Interdisziplinäre Aushandlungsprozesse auf der Inhalts-, der Verfahrensund der Beziehungsebene. In: Zeitschrift für Angewandte Linguistik. No. 61 (1). S. $3-25$. 
Janich, Nina / Zakharova, Ekaterina (2011): Wissensasymmetrien, Interaktionsrollen und die Frage der ,gemeinsamen“ Sprache in der interdisziplinären Projektkommunikation. In: Fachsprache. H. 3 - 4. S. 187 - 204.

Janicki, Jürgen / Reinhard, Horst (2013): Schienenfahrzeugtechnik. 3., überarbeitete Auflage. Heidelberg / Mainz: Bahn Fachverlag.

Jewitt, Carey (2014): Different approaches to multimodality. In: Dies. (Ed.): The Routledge Handbook of Multimodal Analysis. 2nd edition. London / New York: Routledge. S. $31-43$.

Jonas, Hans (2001): Homo Pictor: Von der Freiheit des Bildens. In: Boehm, Gottfried (Hg.): Was ist ein Bild? 3. Auflage. München: Fink. S. 105 - 124. Kalverkämper, Hartwig (2016a): Publikationsgeschichte als Wirkmächtigkeit einer Disziplin: Ein Forum für die Fachkommunikationsforschung. In: Ders. (Hg.): Fachkommunikationsforschung im Fokus - Paradigmen, Positionen, Perspektiven. FFF, Band 100. Berlin: Frank \& Timme. S. $229-331$.

Kalverkämper, Hartwig (2016b): Wissenschaft in Verbundenheit - KlausDieter Baumann zu Ehren. In: Ders. (Hg.): Fachkommunikation im Fokus - Paradigmen, Positionen, Perspektiven. FFF, Band 100. Berlin: Frank \& Timme. S. $15-84$.

Kalverkämper, Hartwig (2004): Arte - cuento - seducción: Fachliches Werben und werbende Fachlichkeit. In: Baumann, Klaus-Dieter / Kalverkämper, Hartwig (Hg.): Pluralität in der Fachsprachenforschung. FFF, Band 67. Tübingen: Gunter Narr. S. 129 - 190.

Kalverkämper, Hartwig (1998a): Fach und Fachwissen. In: Hoffmann, Lothar / Kalverkämper, Hartwig / Wiegand, Herbert Ernst (Hg.): Fachsprachen / Languages for Special Purposes: ein internationales Handbuch zur Fachsprachenforschung und Terminologiewissenschaft. HSK, Band 14.1. Berlin / New York: De Gruyter. S. 1 - 24.

Kalverkämper, Hartwig (1998b): Rahmenbedingungen für Fachkommunikation. In: Hoffmann, Lothar / Kalverkämper, Hartwig /Wiegand, Herbert Ernst (Hg.): Fachsprachen / Languages for Special Purposes: ein internationales Handbuch zur Fachsprachenforschung und Terminologiewissenschaft. HSK, Band 14.1. Berlin / New York: De Gruyter. S. 24 - 47. 
Kalverkämper, Hartwig (1998c): Bildsemiotik fachlicher Informationsanliegen - zugleich eine diachrone Argumentation für das narrative wissenschaftliche Bild. In: Dannneberg, Lutz / Niederhauser, Jörg (Hg.): Darstellungsformen der Wissenschaften im Kontrast. Aspekte der Methodik, Theorie und Empirie. FFF, Band 39. Tübingen: Gunter Narr. S. 349 - 412.

Kalverkämper, Hartwig (1998d): Darstellungsformen und Leistungen schriftlicher Fachkommunikation: diachrone und synchrone Aspekte. In: Hoffmann, Lothar / Kalverkämper, Hartwig / Wiegand, Herbert Ernst (Hg.): Fachsprachen / Languages for Special Purposes: ein internationales Handbuch zur Fachsprachenforschung und Terminologiewissenschaft. HSK, Band 14.1. Berlin / New York: De Gruyter. S. 60 - 92.

Kalverkämper, Hartwig (1993): Das fachliche Bild. Zeichenprozesse in der Darstellungsform wissenschaftlicher Ereignisse. In: Schröder, Hartmut (Hg.): Fachtextpragmatik. FFF, Band 19. Tübingen: Gunter Narr. S. $215-238$.

Kalverkämper, Hartwig (1989): Gemeinsprache und Fachsprachen - Plädoyer für eine integrierende Sicht. In: Stickel, Gerhard (Hg.): Deutsche Gegenwartssprache: Tendenzen und Perspektiven. Jahrbuch des Instituts für Deutsche Sprache. Berlin u. a.: De Gruyter. S. 88 - 133.

Kastens, Inga Ellen / Lux, Peter G. C. (2014): Das Aushandlungs-Paradigma der Marke. Den Bedeutungsreichtum der Marke nutzen. Wiesbaden: Springer Gabler.

Kesselheim, Wolfgang (2011): Sprachliche Oberflächen: Musterhinweise. In: Habscheid, Stephan (Hg.): Textsorten, Handlungsmuster, Oberflächen. Berlin / New York: De Gruyter. S. 337 - 366.

Kjørup, Søren (1978): Pictorial Speech Acts. In: Erkenntnis. No. 12. S. 55 - 71. Klammer, Katja (2017): Denkstile in der Fachkommunikation der Technik- und Sozialwissenschaft. FFF, Band 135. Berlin: Frank \& Timme.

Klärner, Andreas (2002): Rezension zu: Girtler, Roland (2002): Methoden der Feldforschung. Forum: Qualitative Social Research. Vol. 3 (4), URL: http://www.qualitative-research.net/index.php/fqs/article/view/783/1698. [abgerufen am 22.01.2018] 
Klein, Josef (2014a): Verfahren: Gesetzgebungsverfahren als Text(sorten)Geflecht. In: Ders. (Hg.): Grundlagen der Politolinguistik. Ausgewählte Aufsätze. Berlin: Frank \& Timme. S. 339 - 346.

Klein, Josef (2014b): Verwaltungssprache - Sprachästhetik und Funktionalität. In: Fisch, Rudolf / Margies, Burkhard (Hg.): Bessere Verwaltungssprache. Grundlagen, Empirie, Handlungsmöglichkeiten. Berlin: Duncker \& Humblot. S. $17-32$.

Klein, Josef (2007): Intertextualität, Geltungsmodus, Texthandlungsmuster. Drei vernachlässigte Kategorien der Textsortenforschung - exemplifiziert an politischen und medialen Textsorten. In: Adamzik, Kirsten (Hg.): Textsorten. Reflexionen und Analysen. Unveränderter Nachdruck der 1. Auflage 2000. Textsorten, Band 1. Tübingen: Stauffenburg. S. $31-44$.

Klein, Josef (1991): Politische Textsorten. In: Brinker, Klaus (Hg.): Aspekte der Textlinguistik. Hildesheim / Zürich / New York: Georg Olms. S. $245-278$.

Klein, Wolfgang (1993): Ellipsen. In: Jacobs, Joachim/von Stechow, Armin / Sternefeld, Wolfgang / Vennemann, Theo (Hg.): Syntax. Ein internationales Handbuch zeitgenössischer Forschung. HSK, Band 9.1. Berlin / New York: De Gruyter. S. 763 - 799.

Kleinmann, Rachel (1993): The Reciprocal Relationship of Workplace Culture and Review. In: Spilka, Rachel (Ed.): Writing in the Workplace. o. O.: Southern Illinois University. S. $56-71$.

Klug, Nina-Maria / Stöckl, Hartmut (2015): Sprache im multimodalen Kontext. In: Felder, Ekkehard / Gardt, Andreas (Hg.): Handbuch Sprache und Wissen. HSW, Band 1. Berlin / New York: De Gruyter. S. 242 - 264.

Koch, Peter / Oesterreicher, Wulf (1985): Sprache der Nähe - Sprache der Distanz. Mündlichkeit und Schriftlichkeit im Spannungsfeld von Sprachtheorie und Sprachgeschichte. In: Romanistisches Jahrbuch. 36. Jg. S. $15-43$.

Kösler, Bertram (2009): Lasten- und Pflichtenhefte. In: Hennig, Jörg / TjiarksSobani, Marita (Hg.): Arbeits- und Gestaltungsempfehlungen für Technische Dokumentation. Eine kritische Bestandsaufnahme. Lübeck: Schmidt-Römhild. S. $63-79$. 
Kolbe, Harald (2010): Empirischer Nachweis und ökonomische Implikationen von Sprachgemeinschaften.

URN: http://publikationen.ub.uni-frankfurt.de/frontdoor/index/index/ docId/19714 [abgerufen am 22.01.2018].

Krämer, Sybille ( $\left.{ }^{2} 2009\right)$ : „Schriftbildlichkeit“ oder: Über eine (fast) vergessene Dimension der Schrift. In: Krämer, Sybille / Bredekamp, Horst (Hg.): Bild - Schrift-Zahl. Reihe Kulturtechnik. 2., unveränderte Auflage. München: Fink. S. $157-176$.

Kress, Gunther / van Leeuwen, Theo (2006): Reading Images: The Grammar of Visual Design. 2nd edition. London / New York: Routledge.

Krisch, Jennifer / Houdek, Frank (2015): The Myth of Bad Passive Voice and Weak Words. An Empirical Investigation in the Automotive Industry. Conference Paper. DOI: 10.1109/RE.2015.7320451.

Krischke, Wolfgang (2004): PR-Texte für die Wissenschaft. Zur Produktion und Revision fachexterner Pressemitteilungen. In: Fachsprache. H. 3 - 4. S. $114-132$.

Lakoff, George / Johnson, Mark ( $\left.{ }^{6} 2008\right)$ : Leben in Metaphern. Konstruktion und Gebrauch von Sprachbildern. Übersetzt von Astrid Hildenbrand. Heidelberg: Carl-Auer.

Langer, Inhard / Schulz von Thun, Friedemann / Tausch, Reinhard ( $\left.{ }^{9} 2011\right):$ Sich verständlich ausdrücken. 9., neu gestaltete Auflage. München: Reinhardt.

Lehnen, Katrin (2000): Kooperative Textproduktion. Zur gemeinsamen Herstellung wissenschaftlicher Texte im Vergleich von ungeübten, fortgeschrittenen und sehr geübten SchreiberInnen.

URN: https://pub.uni-bielefeld.de/publication/2301399 [abgerufen am 22.01.2018]

Lehrndorffer, Anne / Reuther, Ursula (2008): Kontrollierte Sprache - standardisierende Sprache? In: Muthig, Jürgen (Hg.): Standardisierungsmethoden für die Technische Dokumentation. Lübeck: Schmidt-Römhild. S. 97 - 121. Lewis, David (1993): Die Sprachen und die Sprache. In: Meggle, Georg (Hg.): Handlung, Kommunikation, Bedeutung. Aus dem Englischen und Amerikanischen von Georg Meggle u. a. Suhrkamp-Taschenbuch Wissenschaft, Band 1083. Frankfurt a. M.: Suhrkamp. S. $197-240$. 
Ley, Martin (2006): Kontrollierte Textstrukturen: Ein (linguistisches) Informationsmodell für die technische Kommunikation. URL: http://geb.unigiessen.de/geb/volltexte/2006/ 2713/ [abgerufen am 22.01.2018]

Liebig, Martin (1999): Die Infografik. Konstanz: UVK Medien.

Linke, Benjamin (2010): Die Gewährleistung des Daseinsvorsorgeauftrags im öffentlichen Personenahverkehr. Schriften zum Wirtschaftsverwaltungsund Vergaberecht, Band 24. Baden-Baden: Nomos.

Lischeid, Thomas (2012): Diagrammatik und Mediensymbolik. Mulimodale Darstellungsformen am Beispiel der Inforgrafik. Duisburg: UVRR.

Liu, Yongdong (1992): Fachsprachliche Zeige- und Verweisstrukturen in Patentschriften. Studien Deutsch, Band 14. München: Iudicium.

Lücking, Andy / Pfeiffer, Thies (2012): Framing multimodal Technical Communication. With Focal Points in Speech-Gesture-Integration. In: Mehler, Alexander (Ed.): Handbook of technical communication. Berlin u. a.: De Gruyter / Mouton. S. $591-644$.

Lüders, Christian (72009): Beobachten im Feld und Ethnographie. In: Flick, Uwe / von Kardorff, Ernst / Steinke, Ines (Hg.): Qualitative Forschung. Ein Handbuch. Rororo, Band 55628. Reinbek: Rowohlt. S. 384 - 401.

Lüdtke, Hartmut (2004): Beobachtung. In: Ammon, Ulrich / Dittmar, Norbert / Mattheier, Klaus J. / Trudgill, Peter (Hg.): Soziolinguistik. Ein internationales Handbuch zur Wissenschaft von Sprache und Gesellschaft. 2., vollständig neu bearbeitete und erweiterte Auflage. HSK, Band 3.2. Berlin / New York: De Gruyter. S. 1033 - 1051.

Lukes, Rudolf (1981): Technik und Recht. In: Ropohl, Günter (Hg.): Interdisziplinäre Technikforschung. Beiträge zur Bewertung und Steuerung technischer Entwicklungen. Angewandte Innovationsforschung, Band 3. Berlin: Erich Schmidt. S. 185 - 194.

Lutz, Benedikt (2015): Verständlichkeitsforschung transdisziplinär. Plädoyer für eine anwenderfreundliche Wissensgesellschaft. Kommunikation im Fokus - Arbeiten zur Angewandten Linguistik, Band 6. Göttingen: Vienna University Press im Verlag V\&R unipress.

Mälzer, Nathalie (2015): Taxonomie von Bild-Text-Beziehungen im Comic. In: Dies. (Hg.): Comics - Übersetzungen und Adaption TransÜD, Band 76. Berlin: Frank \& Timme. S. $47-63$. 
Martin, James R. / Rose, David (2008): Genre Relations. Mapping Culture. London / Oakville: Equinox.

Martinec, Radan / Salway, Andrew (2005): A system for image-text relations in new (and old) media. In: $v$ is u a l c o m mu nic a t $i$ o n. 4. Jg. (3). S. $339-374$.

Mayer, Horst Otto (2012): Interview und schrifltiche Befragung. Grundlagen und Methoden empirischer Sozialforschung. 6., überarbeitete Auflage. München: Oldenbourg.

McCloud, Scott (1993): Understanding Comics. The Invisible Art. New York: Harper Perennial.

Metzger, Wolfgang $\left({ }^{3} 1975\right)$ : Gesetze des Sehens. 3., völlig neu bearbeitete Auflage. Frankfurt a. M.: Waldemar Kramer.

Meuser, Michael / Nagel, Ulrike (1991): ExpertInneninterviews - vielfach erprobt, wenig bedacht. Ein Beitrag zur qualitativen Methodendiskussion. In: Garz, Detlef / Raimer, Klaus (Hg.): Qualitativ-empirische Sozialforschung. Konzepte, Methoden, Analysen. Opladen: Westdeutscher Verlag. S. $441-471$.

Morris, Charles William (1988 [1938]): Grundlagen der Zeichentheorie. Ästhetik der Zeichentheorie. Aus dem Amerikanischen von Roland Posner unter Mitarbeit von Jochen Rehbein. Fischer Wissenschaft, Band 7406. Frankfurt a. M.: Fischer.

Müller, Andreas P. (2008): Aufgabenfelder einer Linguistik der Organisation. In: Müller, Andreas P. / Menz, Florian (Hg.): Organisationskommunikation. Grundlagen und Analysen der sprachlichen Inszenierung von Organisation. Managementkonzepte, Band 34. München / Mering: Rainer Hampp. S. $17-46$.

Mushchinina, Maria (2017): Sprachverwendung und Normvorstellung in der Fachkommunikation. FFF, Band 133. Berlin: Frank \& Timme.

Muthig, Jürgen / Schäflein-Armbruster, Robert (2014): Funktionsdesign (R) methodische Entwicklung des Standards. In: Muthig, Jürgen (Hg.): Standardisierungsmethoden für die Technische Dokumentation. 2., unveränderte Auflage. Lübeck: Schmidt-Römhild. S. 41 - 74. 
Nekvapil, Jirí (2006): On Language Management in Multinational Companies in the Czech Republic. In: Current issues in language planning. 7. Jg. (2). S. $307-327$.

Neubert, Christoph (2007): Leitkategorie: Soziale Kompetenz. Konsequenzen einer Analyse beruflicher Komplexität aus systemtheoretischer Perspektive. Reihe XI Pädagogik, Band 989. Frankfurt a. M. u. a.: Peter Lang.

Nickl, Markus (2006): Linguistische Gutachten für Patente. In: Hermes Journal of Linguistics. No. 36. S. $41-54$.

Nöth, Winfried ('2000): Handbuch der Semiotik. 2., vollständig neu bearbeitete und erweiterte Auflage mit 89 Abbildungen. Stuttgart / Weimar: Metzler.

Nussbaumer, Markus (1991): Was Texte sind und was sie sein sollen: Ansätze zu einer sprachwissenschaftlichen Begründung eines Kriterienrasters zur Beurteilung von schriftlichen Schülertexten. RGL, Band 119. Tübingen: Niemeyer.

Ostapenko, Valentyna (2009): Relationen zwischen den Textsorten im Textsortennetz. In: Kalverkämper, Hartwig / Schippel, Larissa (Hg.): Translation zwischen Text und Welt - Translationswissenschaft als historische Disziplin zwischen Moderne und Zukunft. TransÜD, Band 20. Berlin: Frank \& Timme. S. 227 - 240.

Ostapenko, Valentyna (2007): Vernetzung von Fachtextsorten. Textsorten der Normung in der technischen Harmonisierung. TransÜD, Band 15. Berlin: Frank \& Timme.

Pachl, Jörn (72013): Systemtechnik des Schienenverkehrs. Bahnbetrieb planen, steuern und sichern. 7., überarbeitete und erweiterte Auflage. Wiesbaden: Springer Vieweg.

Peirce, Charles Sanders (1998): The Essential Peirce. Selected Philosophical Writings. Volume 2. 1893 - 1913. Bloomington (Indianapolis): Indiana University Press.

Peirce, Carles Sanders (1982): Phänomen und Logik der Zeichen. Herausgegeben und übersetzt von Helmut Pape. Suhrkamp-Taschenbuch Wissenschaft, Band 425. Frankfurt a. M.: Suhrkamp.

Pelikan, Kristina (2019): Enhancing and analysing Project Communication. FFF, Band 151. Berlin: Frank \& Timme. 
Pelikan, Kristina (2015): Möglichkeiten der Optimierung internationaler Projektkommunikation. In: Grucza, Sambor / Alnajjar, Justyna (Hg.): Kommunikation in multikulturellen Projektteams. Warschauer Studien zur Germanistik und zur Angewandten Linguistik, Band 22. Frankfurt a. M. u. a.: Lang. S. $199-218$.

Peters, Tim (2008): Macht im Kommunikationsgefälle: der Arzt und der Patient. FFF, Band 82. Berlin: Frank \& Timme.

Petöfi, Janós (1983): Verbal-Semiotik, Texttheorie, Übersetzungstheorie. In: Ders. (Hg.): Texte und Sachverhalte. Aspekte der Wort- und Textbedeutung. Hamburg: Helmut Buske. S. 295 - 309.

Pfadenhauer, Michaela (2005): Auf gleicher Augenhöhe reden. Das Experteninterview - ein Gespräch zwischen Experte und Quasi-Experte. In: Bogner, Alexander / Littig, Beate / Menz, Wolfgang (Hg.): Das Experteninterview. Theorie, Methode, Anwendung. 2. Auflage. Wiesbaden: VS Verlag für Sozialwissenschaften. S. $113-130$.

Piitulainen, Maria-Leena / Reuter, Ewald / Tiittula, Liisa (2007): Einleitung. In: Dies. (Hg.): Die gemeinsame Konstitution professioneller Interaktion. FFF, Band 77. Tübingen: Gunter Narr. S. 9 - 24.

Pogner, Karl-Heinz (2012): A social perspective on writing in the workplace: Communities of Discourse (CD) and Communities of Practice (CoP). In: Rothkegel, Annely / Ruda, Sonja (Eds.): Communication on and via Technology. Text, Translation, Computational Processing, Vol. 10. Berlin / Boston: De Gruyter Mouton. S. 83 - 107.

Pogner, Karl-Heinz (2003): Writing and interacting in the discourse community of engineering. In: Journal of Pragmatics. No. 35. S. 855 - 867.

Pogner, Karl-Heinz (1999): Schreiben im Beruf als Handeln im Fach. FFF, Band 46. Tübingen: Gunter Narr.

Pohl, Klaus (2008): Requirements Engineering. Grundlagen, Prinzipien, Techniken. 2., korrigierte Auflage. Heidelberg: dpunkt.verlag.

Popitz, Heinrich (1980): Die normative Konstruktion von Gesellschaft. Tübingen.

Pünder, Hermann / Schellenberg, Martin (Hg.; 2011): Vergaberecht. Kommentar: $G W B-V g V-S e k t V O-V O L / A-V O B / A-V O F-$ Haushaltsrecht Öffentliches Preisrecht. Baden-Baden: Nomos. 
Radtke, Ingulf (Hg., 1981): Die Sprache des Rechts und der Verwaltung. Stuttgart: Klett.

Raible, Wolfgang (1991): Die Semiotik der Textgestalt. Erscheinungsformen und Folgen eines kulturellen Evolutionsprozesses. Abhandlungen der Heidelberger Akademie der Wissenschaften. Philosophisch-historische Klasse. 1. Abhandlung. Heidelberg: Carl Winter Universitätsverlag.

Rehbein, Jochen (1998): Die Verwendung von Institutionensprache in Ämtern und Behörden. In: Hoffmann, Lothar / Kalverkämper, Hartwig / Wiegand, Herbert Ernst (Hg.): Fachsprachen / Languages for Special Purposes: ein internationales Handbuch zur Fachsprachenforschung und Terminologiewissenschaft. HSK, Band 14.1. Berlin / New York: De Gruyter. S. $660-675$.

Rehbock, Helmut ( $\left.{ }^{5} 2016\right):$ Meronymie. In: Glück, Helmut / Rödel, Michael (Hg.): Metzler Lexikon Sprache. 5., aktualisierte und bearbeitete Auflage. Stuttgart: Metzler. S. 426 - 427.

Rehkämper, Klaus (2002): Bilder, Ähnlichkeit und Perspektive. Auf dem Weg zu einer neuen Theorie der bildhaften Repräsentation. Wiesbaden: Deutscher Universitäts-Verlag.

Roelcke, Thorsten (2014): Zur Gliederung von Fachsprache und Fachkommunikation. In: Fachsprache. H. 3 - 4. S. 154 - 178.

Roelcke, Thorsten (2013): Der Beitrag von graphischen Abbildungen zur Konstituierung von Fachwortschatz in der terminologischen Grundsatznorm DIN 2330 des Deutschen Instituts für Normung. In: Glottotheory. 4. Jg. (1), S. $5-35$.

Roelcke, Thorsten (2012): Der Beitrag von Text und Bild zur Konstituierung von Fachwortschatz. Eine exemplarische Studie zur terminologischen Grundsatznorm DIN 2330. In: Oomen-Welke, Ingelore / Staiger, Michael (Hg.): Bilder in Medien, Kunst, Literatur, Sprache, Didaktik. Festschrift für Adalbert Wichert. Freiburg: Fillibach. S. $231-248$.

Roelcke, Thorsten ( $\left.{ }^{3} 2010\right)$ : Fachsprachen. 3., neu bearbeitete Auflage. Grundlagen der Germanistik, Band 37. Berlin: Erich Schmidt Verlag.

Roelcke, Thorsten (2002a): Kommunikative Effizienz. Eine Modellskizze. Sprache - Literatur und Geschichte. Studien zur Linguistik / Germanistik, Band 23. Heidelberg: Universitätsverlag C. Winter. 
Roelcke, Thorsten (2002b): „Besser wäre z. B. ,JArbAmBMldg““، Überlegungen zur Konzeption von sprachlicher Ökonomie in der terminologischen Grundsatznormung. In: Fachsprache. H. 1 - 2. S. 36 - 49.

Roelcke, Thorsten (1994): Dramatische Kommunikation. Modell und Reflexion bei Dürrenmatt, Handke, Weiss. Quellen und Forschungen zur Sprach- und Kulturgeschichte der germanischen Völker, Band 231. Berlin / New York: De Gruyter.

Rolf, Eckhard (2008): Sprachtheorien. Von Saussure bis Millikan. Berlin u. a.: De Gruyter.

Rolf, Eckhard (2000): Textuelle Grundfunktionen. In: Brinker, Klaus / Heinemann, Wolfgang / Sager, Sven F. (Hg.): Text- und Gesprächslinguistik. ein internationales Handbuch zeitgenössischer Forschung. 1. Halbband. Berlin / New York: De Gruyter. S. 422 - 435.

Rolf, Eckhard (1993): Die Funktionen der Gebrauchstextsorten. Grundlagen der Kommunikation und Kognition. Berlin: De Gruyter.

Ropohl, Günter (2012): Allgemeine Systemtheorie. Einführung in transdisziplinäres Denken. Berlin: edition sigma.

Roßnagel, Alexander (2001): Rechtswissenschaft. In: Ropohl, Günter (Hg.): Erträge der Interdisziplinären Technikforschung. Eine Bilanz nach 20 Jahren. Berlin: Erich Schmidt. S. 195 - 214.

Roth, Sven / Spitzmüller, Jürgen (Hg.; 2007): Textdesign und Textwirkung in der massenmedialen Kommunikation. Konstanz: UVK.

Rothkegel, Annely (2010): Technikkommunikation. Produkte - Texte - Bilder. Konstanz: UVK.

Rothkegel, Annely (2008): Vom Wissen zum Text - Standardisierung und Kreativität. In: Sprache und Datenverarbeitung. International Journal for Language Data Processing. No. 32, H. 2. S. $65-83$.

Rothkegel, Annely (2005): Kowledge and text types. In: Dam, Helle / Engberg, Jan / Gerzymisch-Arbogast, Heidrun (Hg.): Knowledge systems and translation. Text, Translation, Computational Processing, Volume 7. Berlin u. a.: De Gruyter. S. 83 - 102.

Runde, Heinz ( $\left.{ }^{3} 2006\right)$ : Einleitung. In: Wiedemann, Torsten: Das Fachwort im Verkehr. Grundbegriffe des ÖPNV. Düsseldorf: Alba. S. 8 - 9 . 
Rupp, Chris / Die SOPHISTen (2014): Requirements-Engineering und -Management. Aus der Praxis von klassisch bis agil. 6., aktualisierte und erweiterte Auflage. München: Hanser.

Rusch, Gebhard (2011): (IT-)Projekt-Kommunikation - Kommunikation in Prozessen sozialer Strukturierung, soziotechnischen und multiplexen Systemen. In: Freitag, Matthias / Müller, Christiane / Rusch, Gebhard / Spreitzer, Thomas (Hg.): Projektkommunikation. Strategien für temporäre soziale Systeme. Wiesbaden: Verlag für Sozialwissenschaften. S. 49 - 86.

Satzger, Axel / Astapenko, Anna (2006): Technische Kommunikation als Gegenstand der Angewandten Linguistik. In: Fachsprache / International Journal of LSP. No. 28, H. 3 - 4. S. 123 - 147.

Schaeder, Burkhard (1998): Anwendungsmöglichkeiten und bisherige Anwendung von empirischen Erhebungsmethoden in der Fachsprachenforschung. In: Hoffmann, Lothar / Kalverkämper, Hartwig / Wiegand, Herbert Ernst (Hg.): Fachsprachen / Languages for Special Purposes: ein internationales Handbuch zur Fachsprachenfor-schung und Terminologiewissenschaft. HSK, Band 14.1 Berlin / New York: De Gruyter. S. 230 - 240.

Schamlu, Mariam (1985): Patentschriften - Patentwesen. Eine argumentationstheoretische Analyse. Studien Deutsch, Band I. München: Iudicium.

Scheel, Harald (1997): Zur Makrostruktur deutscher und französischer Patentschriften. In: Wotjak, Gerd (Hg.): Studien zum romanisch-deutschen und innerromanischen Sprachvergleich. Akten der II. internationalen Arbeitstagung zum romanisch-deutschen Sprachvergleich (Leipzig, 10.10.11.10.1995). Frankfurt a. M. u. a.: Peter Lang. S. 143 - 155.

Schmidt, Armin (2006): Die Eisenbahn - ihre Widerspiegelung in Sprache und Kunst. In: Gerstenkorn, Alfred / Hums, Lothar / Schmidt, Armin (Hg.): Die Sprache der Bahn. Zur deutschen Eisenbahnsprache im europäischen Kontext. Informationswissenschaft, Band 8. Frankfurt a. M.: Deutsche Gesellschaft für Informationswissenschaft und Informationspraxis. S. $263-284$.

Schmitz, Ulrich (2017): Randgrammatik und Design. In: Sprachreport. 33. Jg., H. 3. S. $8-17$. 
Schmitz, Ulrich (2016): Multimodale Texttypologie. In: Klug, Nina-Maria / Stöckl, Hartmut (Hg.): Handbuch Sprache im multimodalen Kontext. HSW, Band 7. Berlin / New York: De Gruyter. S. 327 - 347.

Schmitz, Ulrich (2014): Semiotic economy, growth of mass media discourse, and change of written language through multimodal techniques. The case of newspapers (printed and online) and web services. In: Androutsopoulos, Jannis (Ed.): Mediatization and Sociolinguistic Change. linguae \& litterae, Volume 36. Berlin / Boston: De Gruyter. S. 279 - 304.

Schmitz, Ulrich (2011a): Sehflächenforschung. Eine Einführung. In: Diekmannshenke, Hajo / Klemm, Michael / Stöckl, Hartmut (Hg.): Bildlinguistik. Theorien - Methoden - Fallbeispiele. Berlin: Erich Schmidt Verlag. S. $23-42$.

Schmitz, Ulrich (2011b): Blickfang und Mitteilung. Zur Arbeitsteilung von Design und Grammatik in der Werbekommunikation. In: Zeitschrift für Angewandte Linguistik. No. 54. S. 79 - 109.

Schmitz, Ulrich (2007): Bildakte? How to do things with pictures. In: Zeitschrift für Germanistische Linguistik. 35. Jg. S. 419 - 433.

Schmitz, Ulrich (2006a): Schriftbildschirme. In: Germanistische Linguistik. Neuere Entwicklungen in der linguistischen Internetforschung. H. $186-$ 187. S. $184-207$.

Schmitz, Ulrich (2006b): Tertiäre Schriftlichkeit im World Wide Web. In: Schlobinski, Peter (Hg.): Von *hdl* bis *cul8r*. Sprache und Kommunikation in Neuen Medien. Thema Deutsch, Band 7. Mannheim / Leipzig: Dudenverlag. S. $89-103$.

Schmitz, Ulrich (2005): Blind für Bilder. Warum sogar Sprachwissenschaftler auch Bilder betrachten müssen. In: Haueis, Eduard (Hg.): Paradigms lost. OBST, Band 69. S. $187-227$.

Schnieders, Ralf (2010): Die Delegation der öffentlichen Dienstleistung des Schienenpersonennahverkehrs. Ein deutsch-französischer Rechtsvergleich. Tübinger Schriften zum Staats- und Verwaltungsrecht, Band 82. Berlin: Duncker \& Humblot.

Schröder, Hartmut (1993): Semiotische Aspekte multimedialer Texte. In: Ders. (Hg.): Fachtextpragmatik. FFF, Band 19. Tübingen: Gunter Narr. S. $189-213$. 
Schubert, Klaus (2013): Bürgernahe Sprache. Überlegungen aus fachkommunikationswissenschaftlicher Sicht. In: Synaps. No. 29. S. 48 - 57.

Schubert, Klaus (2011): Optimierung als Kommuniaktionsziel: Bessere Sprachen. In: Baumann, Klaus-Dieter (Hg.): Fach - Translat - Kultur. Interdisziplinäre Aspekte der vernetzten Welt. FFF, Band 98. Berlin: Frank \& Timme. S. 363 - 392.

Schubert, Klaus (2009): Kommunikationsoptimierung: Vorüberlegungen zu einem fachkommunikativen Forschungsfeld. In: trans-kom. No. 2, H. 1. S. $109-150$.

Schubert, Klaus (2007): Wissen, Sprache, Medium, Arbeit. Ein integratives Modell der ein- und mehrsprachigen Fachkommunikation. FFF, Band 76. Tübingen: Gunter Narr.

Schubert, Klaus / Heidrich, Franziska (2014): Effiziente Optimierung messbar machen. In: Fritz, Michael / Gräfe, Elisabeth (Hg.): tekom-Jahrestagung und tcworld conference 2014 in Stuttgart. Zusammenfassungen der Referate. Stuttgart: tcworld GmbH. S. 87 - 89.

Schwarz-Friesel, Monika / Chur, Jeannette ('62014): Semantik. Ein Arbeitsbuch. 6., grundlegend überarbeitete und erweiterte Auflage. Narr Studienbücher. Tübingen: Narr Francke Attempto.

Schwesinger, Borries (2007): Formulare gestalten. Das Handbuch für alle, die das Leben einfacher machen wollen. Mainz: Hermann Schmidt.

Searle, John R. ( $\left.{ }^{12} 2013\right):$ Sprechakte. Ein sprachphilosophischer Essay. Suhrkamp Taschenbuch Wissenschaft, Band 458. Übersetzt von R. Wiggershaus. Frankfurt a. M.: Suhrkamp.

Searle, John R. (1982a): Zur Taxonomie illokutionärer Akte. In: Ders. (Hg.): Ausdruck und Bedeutung. Frankfurt: Suhrkamp. S. 17 - 50.

Searle, John R. (1982b): Indirekte Sprechakte. In: Ders. (Hg.): Ausdruck und Bedeutung Frankfurt: Suhrkamp. S. 51 - 79.

Searle, John R. / Vanderveken, Daniel (1985): Foundations of Illocutionary Logic. Cambridge: Cambridge University Press.

Soffritti, Marcello (2002): Die doppelte Fachsprachlichkeit in aktuellen Norm setzenden Texten. In: Gotti, Mauricio / Heller, Dorothee / Dossena, Marina (Hg.): Conflict and negotiation in specialized texts. Bern u. a.: Lang. S. $59-77$. 
Spillner, Bernhard (1982): Stilanalyse semiotisch komplexer Texte. Zum Verhältnis von sprachlicher und bildlicher Information in Werbeanzeigen. In: KODICAS / CODE. H. 4. S. 91 - 108.

Spitzmüller, Jürgen (2013): Graphische Variation als soziale Praxis. Eine soziolinguistische Theorie skripturaler >Sichtbarkeit . Linguistik - Impulse \& Tendenzen 56. Berlin u. a.: De Gruyter.

Spolsky, Bernhard (2009): Language Management. Cambridge: Cambridge University Press.

Staffeldt, Sven ( $\left.{ }^{5} 2016\right)$ : Ellipse. In: Glück, Helmut / Rödel, Michael (Hg.): Metzler Lexikon Sprache. 5., aktualisierte und bearbeitete Auflage. Stuttgart: Metzler. S. 173.

Steen, Gerhard J. / Drost, Aletta G. / Herrmann, J. Berenike / Kaal, Anna A. / Krennmayr, Tina (2010): Metaphor in usage. In: Cognitive Linguistics. No. 21 (4). S. $765-796$.

Steinke, Ines ( $\left.{ }^{7} 2009\right)$ : Gütekriterien qualitativer Sozialforschung. In: Flick, Uwe / von Kardorff, Ernst / Steinke, Ines (Hg.): Qualitative Forschung. Ein Handbuch. Rororo, Band 55628. Reinbek: Rowohlt. S. 319 - 331.

Steinseifer, Martin (2013): Texte sehen - Diagrammatologische Impulse für die Textlinguistik. In: Zeitschrift für Germanistische Linguistik. 41. Jg., H. 1. S. $8-39$.

Sternberger, Dolf (1981): Staatliche Zwangsgewalt und bürgerliche Kommunikation. Eine Notiz zum Generalthema. In: Radtke, Ingulf (Hg.): Die Sprache des Rechts und der Verwaltung. Stuttgart: Klett-Cotta. S. 16-19. Stickel, Gerhard (1981): Bei den kommunikativen Bedingungen und dem Sprachgebrauch der Behördenvordrucke nachgefaßt. In: Radtke, Ingulf (Hg.): Die Sprache des Rechts und der Verwaltung. Stuttgart: Klett-Cotta. S. $284-304$.

Stöckl, Hartmut (2016): Multimodalität - Semiotische und textlinguistische Grundlagen In: Klug, Nina-Maria / Stöckl, Hartmut (Hg.): Handbuch Sprache im multimodalen Kontext. HSW, Band 7. Berlin / New York: De Gruyter. S. 3 - 35.

Stöckl, Hartmut (2012): Finanzen visualisieren - Die Text-Bild-Sorte Infographik. In: Voßkamp, Patrick / Schmitz, Ulrich (Hg.): Sprache und Geld. 
Beiträge zur Pekunialinguistik. OBST, Band 81. Duisburg: UVRR. S. $177-200$.

Stöckl, Hartmut (2011): Sprache-Bild-Texte lesen. Bausteine zur Methodik einer Grundkompetenz. In: Diekmannshenke, Hajo / Klemm, Michael / Stöckl, Hartmut (Hg.): Bildlinguistik. Theorien-Methoden - Fallbeispiele. Philologische Studien und Quellen, Band 228. Berlin: Erich Schmidt. S. $45-70$.

Stöckl, Hartmut (2004): Die Sprache im Bild - Das Bild in der Sprache. Zur Verknüpfung von Sprache und Bild im massenmedialen Text. KonzepteTheorien - Analysemethoden. Linguistik - Impulse \& Tendenzen, Band 3. Berlin: De Gruyter.

Teich, Irene / Kolbenschlag, Walter / Reiners, Wilfried (2008): Der richtige Weg zur Softwareauswahl. Lastenheft, Pflichtenheft, Compliance, Erfolgskontrolle. Berlin / Heidelberg: Springer.

Unsworth, Len (2007): Image / Text Relations and Intersemiosis: Towards Multimodal Text Description for Multiliteracies Education. In: Proceedings of the 33rd International Systemic Functional Congress 2006. O. O.: o. V. S. $1165-1205$.

van Vaerenbergh, Leona (2007): Wissensvermittlung und Anweisungen im Beipackzettel. Zur Verständlichkeit und Textqualität in der ExpertenNichtexperten-Kommunikation. In: Villiger, Claudia / Gerzymisch-Arbogast, Heidrun (Hg.): Kommunikation in Bewegung multimedialer und multilingualer Wissenstransfer in der Experten-Laien-Kommu-nikation. Frankfurt a. M.: Peter Lang. S. 168 - 185.

van Leeuwen, Theo (2005a): Introducing Social Semiotics. London / New York: Routledge.

van Leeuwen, Theo (2005b): Multimodality, genre and design. In: Norris, Sigrid / Jones, Rodney H. (Eds.): Discourse in action. Introducing mediated discourse analysis. London / New York: Routledge. S. 73 - 94.

Villiger, Claudia (2014): Standardisierung von Sprache als Zugang zu barrierefreier Kommunikation? Ein praxisorientierter Ausblick auf Grundlage von Erfahrungen in der Technischen Kommunikation. In: Jekat, Susanne J. / Jüngst, Heike Elisabeth / Schubert, Klaus / Villiger, Claudia 
(Hg.): Sprache barrierefrei gestalten. Perspektiven aus der Angewandten Linguistik. TransÜD, Band 69. Berlin: Frank \& Timme. S. 221 - 265. von Lucke, Jörn (2014): Das „Stammtext- und Ergänzungs-Modell“ (SEM) Überlegungen zu einem Redaktionskonzept für Textbeiträge in Verwaltungsportalen. In: Fisch, Rudolf / Margies, Burkhard (Hg.): Bessere Verwaltungssprache. Grundlagen, Empirie, Handlungsmöglichkeiten. Berlin: Duncker \& Humblot. S. 159 - 176.

Wannenwetsch, Helmut (2005): Vernetztes Supply Chain Management. SCMIntegration über die gesamte Wertschöpfungskette. Berlin / Heidelberg: Springer.

Warnke, Ingo / Spitzmüller, Jürgen (2011): Diskurslinguistik. Eine Einführung in Theorien und Methoden der transtextuellen Sprachanalyse. Berlin / Boston: De Gruyter.

Wetzchewald, Marcus (2012): Junktoren zwischen Text und Bild-dargestellt anhand der Unternehmenskommunikation im Internet. Essener Schriften zur Sprach-, Kultur- und Literaturwissenschaft, Band 6. Duisburg: Universitätsverlag Rhein-Ruhr.

Wichter, Sigurd (2011): Kommunikationsreihen aus Gesprächen und Textkommunikaten: Zur Kommunikation in und zwischen Gesellschaften. RGL, Band 294. Berlin / Boston: De Gruyter.

Wiedemann, Torsten (32006): Das Fachwort im Verkehr. Betriebliche, verkehrswirtschaftliche und rechtliche Grundbegriffe des öffentlichen Personennahverkehrs. Düsseldorf: Alba.

Witzel, Andreas (2000): Das problemzentrierte Interview. In: Forum Qualitative Sozialforschung / Forum: Qualitative Social Research. No. 1, H. 1. Art. 22. o. S.

Witzel, Andreas / Reiter, Herwig (2012): The Problem-centered Interview. London / Los Angeles u. a.: Sage.

Wolff, Stephan ( $\left.{ }^{7} 2009\right)$ : Wege ins Feld und ihre Varianten. In: Flick, Uwe / von Kardorff, Ernst / Steinke, Ines (Hg.): Qualitative Forschung. Ein Handbuch. Rororo, Band 55628. Reinbek: Rowohlt. S. 334 - 349.

Zehrer, Christiane (2014): Wissenskommunikation in der technischen Redaktion. Die situierte Gestaltung adäquater Kommunikation. FFF, Band 114. Berlin: Frank \& Timme. 
Ziegler, Arne (2007): E-Mail - Textsorte oder Kommunikationsform? Eine linguistische Annäherung. In: Ziegler, Arne / Dürscheid, Christa (Hg.): Kommunikationsform E-Mail. Nachdruck der 1. Auflage 2002. Textsorten, Band 7. Tübingen: Stauffenburg. S. $9-32$. 


\section{Normen und Regelwerke}

BAG SPNV (32016): Empfehlungen für Anforderungen an Fahrzeuge in Vergabeverfahren. 3. Ausgabe. O. O.: o. V. URL: https://bag-spnv.de/files/ bagspnv/downloads/2016-02-23\%20Fahrzeuganforderungen $\% 20$ final $\%$ 20gesamt.pdf [abgerufen am 22.01.2018]

BAG SPNV (2010): Empfehlungen für Anforderungen an Fahrzeuge in Vergabeverfahren für Mitglieder der BAG-SPNV. O. O.: o. V.

DIN 128-24 (1999): Technische Zeichnungen. Allgemeine Grundlagen der Darstellung Teil 24: Linien in Zeichnungen der mechanischen Technik. Berlin: Beuth.

DIN 128-34 (2002): Technische Zeichnungen. Allgemeine Grundlagen der Darstellung Teil 34: Ansichten in Zeichnungen der mechanischen Technik. Berlin: Beuth.

DIN 406-10 (1992): Technische Zeichnungen. Maßeintragung - Begriffe, allgemeine Grundlagen. Berlin: Beuth.

DIN 820-1 (2013): Normungsarbeit - Teil 1: Grundsätze. Berlin: Beuth.

DIN 820-3 (2013): Normungsarbeit - Teil 3: Begriffe . Berlin: Beuth.

DIN 1421 (1983): Gliederung und Benummerung in Texten. Abschnitte, Absätze, Aufzählungen. O. O.: o. V.

DIN 2330 (2011): Begriffe und Benennungen - Allgemeine Grundsätze. Berlin: Beuth.

DIN 2342 (2011): Begriffe der Terminologielehre. Berlin: Beuth.

DIN 25003 (2001): Systematik der Schienenfahrzeuge. Berlin: Beuth.

DIN 32977-1 (1992): Behinderungsgerechtes Gestalten. Begriffe und allgemeine Leitsätze. Berlin: Beuth.

DIN 55301 (1978): Gestaltung statistischer Tabellen. Berlin: Beuth.

DIN 69901-2 (2009): Projektmanagement-Projektmanagementsysteme - Teil 2: Prozesse, Prozessmodell. Berlin: Beuth.

DIN 69901-5 (2009): Projektmanagement-Projektmanagementsysteme - Teil 5: Begriffe. Berlin: Beuth. 
DIN EN 16585-1 (2017): Bahnanwendungen - Gestaltung für die Nutzung durch PRM - Ausstattung und Bauteile in Schienenfahrzeugen - Teil 1: Toiletten . Berlin: Beuth.

DIN EN ISO 128-20 (2002): Technische Zeichnungen. Allgemeine Grundlagen der Darstellung - Teil 20: Linien, Grundregeln. Berlin: Beuth.

DIN EN ISO 5456-4 (2002): Projektionsmethoden Teil 4: Zentralprojektion. Berlin: Beuth.

DIN ISO 128-1 (2003): Technische Zeichnungen-Allgemeine Grundlagen der Darstellung Teil 1: Einleitung und Stichwortverzeichnis. Berlin: Beuth.

DIN ISO 128-22 (1999): Allgemeine Grundlagen der Darstellung Teil 22: Grund- und Anwendungsregeln für Hinweis- und Bezugslinien. Berlin: Beuth.

DIN ISO 128-40 (2001): Allgemeine Grundlagen der Darstellung Teil 40: Grundregeln für Schnittansichten und Schnitte. Berlin: Beuth.

DIN ISO 128-50 (2002): Technische Zeichnungen. Allgemeine Grundlagen der Darstel-lung - Teil 50: Grundregeln für Flächen in Schnitten und Schnittansichten. Berlin: Beuth.

DIN ISO 5456-2 (1998): Technische Zeichnungen. Projektionsmethoden Teil 2: Orthogo-nale Darstellungen. Berlin: Beuth.

TSI LOK\&PAS (2014): Verordnung Nr. 1302/2014 der Kommission über die technische Spezifikation für die Interoperabilität des Teilsystems „Fahrzeuge - Lokomotiven und Personenwagen“ des Eisenbahnsystems in der Europäischen Union. In der Fassung vom: 12.12.2014; EU-Amtsblatt. URL: https://eur-lex.europa.eu/legal-content/DE/

TXT/?uri=uriserv:OJ.L_.2014.356.01.0228.01.DEU\&toc=OJ:L:2014:356: TOC [abgerufen am 3.1.2019]

TSI PRM (2008): Verordnung Nr. 1300/2014 der Kommission über die technische Spezifkation für die Interoperabilität bezüglich , eingeschränkt mobiler Personen“. In der Fassung vom: 21.07.2007. URL: https://eurlex.europa.eu/LexUriServ/LexUriServ.

do?uri=OJ:L:2008:064:0072:0207:DE:PDF [abgerufen am 6.1.2019]

VDI 2519-1 (2001): Vorgehensweise bei der Erstellung von Lasten- / Pflichtenheften. Berlin: Beuth. 
VDI 2632-2 (2013): Industrielle Bildverarbeitung. Leitfaden für die Erstellung eines Lastenhefts und eines Pflichtenhefts. Berlin: Beuth.

VDI 3694 (2013): Lastenheft / Pflichtenheft für den Einsatz von Automatisierungssystemen. Berlin: Beuth. 


\section{Rechtsquellen}

Sektorenverordnung (SektVO): Ausfertigungsdatum: 12.04.2016; zuletzt geändert durch Art. 9 G v. 18.07.2017

Verordnung über die Vergabe öffentlicher Aufträge (Vergabeverordnung - V $\mathrm{gV}$ ): Ausfertigungsdatum: 09.01.2001; zuletzt geändert durch Art. 1 V v. 15.10.2013.

Verdingungsordnung für Leistungen - Teil A (VOL/A): o. O.: Bundesanzeiger.

Gesetz gegen Wettbewerbsbeschränkungen (GWB): Ausfertigungsdatum: 26.08.1998; zuletzt geändert durch Art. 2 Abs. 62 G v. 22.12.2011. 


\section{Weitere Quellen}

Abellio Rail NRW GmbH (2012): Programm zur Barrierefreiheit. URL: https://www.abellio.de/sites/default/files/downloads/Broschuere_Barrieref reiheit.pdf [abgerufen am 22.01.2018]

Amtliches Regelwerk - Deutsche Rechtschreibung (2018): Deutsche Rechtschreibung. Regeln und Wörterverzeichnis. Aktualisierte Fassung des amtliches Regelwerks entsprechend dem Empfehlungen des Rats für deutsche Rechtschreibung. URL: http://www.rechtschreibrat.com/regelnund-woerterverzeichnis/ [abgerufen am 24.01.2018]

BAG SPNV (2018): Wettbewerb \& Markt. URL: https://www.bagspnv.de/wettbewerb-markt (letzter Seitenabruf am 22.06.2018).

BAG SPNV (2015): Zahlen und Fakten. URL: http://bag-spnv.de/zahlenfakten [abgerufen am 24.03.2015]

DB Netz AG (2012): Anforderungsprofil für Fahrdynamische Triebfahrzeugdaten. Am 17.06.2014 verfügbar.

URL: http://fahrweg.dbnetze.com/fahrweg-de/start/produkte/trassen/trassen anmeldung/formulare_trasse/2359188/1formulare_netzfahrplan.html [am 22.01.2018 nicht mehr verfügbar]

Drehscheibe (2012): LNVG Ausschreibung DINSO (,ehemaliges Teillos 1“). URL: https://www.drehscheibe-online.de/foren/read.php?2,6207818, page $=$ all [abgerufen am 22.01.2018]

Emmelheinz, Johannes (2013): Hohe Verfügbarkeit der Züge entscheidend. Interview mit Johannes Emmelheinz, Leiter der Serviceeinheit Siemens Rail Systems. In: Nahverkehrs-praxis: Fachzeitschrift für moderne Mobilität. Dortmund: Arnold. S. 28 - 30.

Institut für Deutsche Sprache (IDS): Aufgaben und Ziele. URL: http://www1. ids-mannheim.de/org/aufgaben.html [abgerufen am 11.12.2018]

Stadler (o. J.a): Referenzen FLIRT $3>$ Zweckverband Verkehrsverbund RheinRuhr/Abellio Rail NRW GmbH. Am 08.04.2015 verfügbar. URL: http://www.stadlerrail.com/de/referenzen/zweckverband-verkehrsverbundrhein-ruhrabellio-rai/ [am 22.01.2018 nicht mehr verfügbar] 
Stadler (o. J.b): Referenzen FLIRT $3>D B$ Regio AG Haard-Achse. Am 08.04.2015 verfügbar. URL: http://www.stadlerrail.com/media/uploads/ STA-1432-039_FLIRT-Haard-Achse_D_web.pdf [am 22.01.2018 nicht mehr verfügbar]

Stadler (o. J.c): Referenzen FLIRT 3 > Alpha Trains, WestfalenBahn GmbH. Am 08.04.2015 verfügbar. URL: http://www.stadlerrail.com/de/referenzen/alpha-trains-westfalenbahn/ [am 22.01.2018 nicht mehr verfügbar]

Tenders Electronic Daily (TED; 2018): Supplement to the Official Journal of the EU. URL: https://ted.europa.eu/TED/main/HomePage.do. [abgerufen am 02.01.2019]

Westfalenbahn (2018): Startseite. URL: https://www.westfalenbahn.de/ [abgerufen am 16.1.2019]

Westfalenbahn (2019): Elektrischer Triebzug FLIRT.

URL: https://www.westfalenbahn.de/unternehmen/fahrzeuge/fahrzeugtypflirt/ [abgerufen am 3.9.2019]

ZEIT ONLINE (2018): Bund erwägt kostenlosen Nahverkehr. URL:

https://www.zeit.de/mobilitaet/2018-02/luftverschmutzung-kostenlosernahverkehr-bundesergierung [abgerufen am 22.06.2018].

Zughalt.de (2013): Interview: VRR und DB Regio zur Herstellerwartung. http://www.zughalt.de/2013/03/interview-vrr-und-db-regio-zurherstellerwartung-teil-1/ [abgerufen am 22.01.2018] 



\section{Anhang}

Der Anhang steht als Download auf der Verlagshomepage bereit: https://www.frank-timme.de/fileadmin/docs/Holste_Anhang.pdf

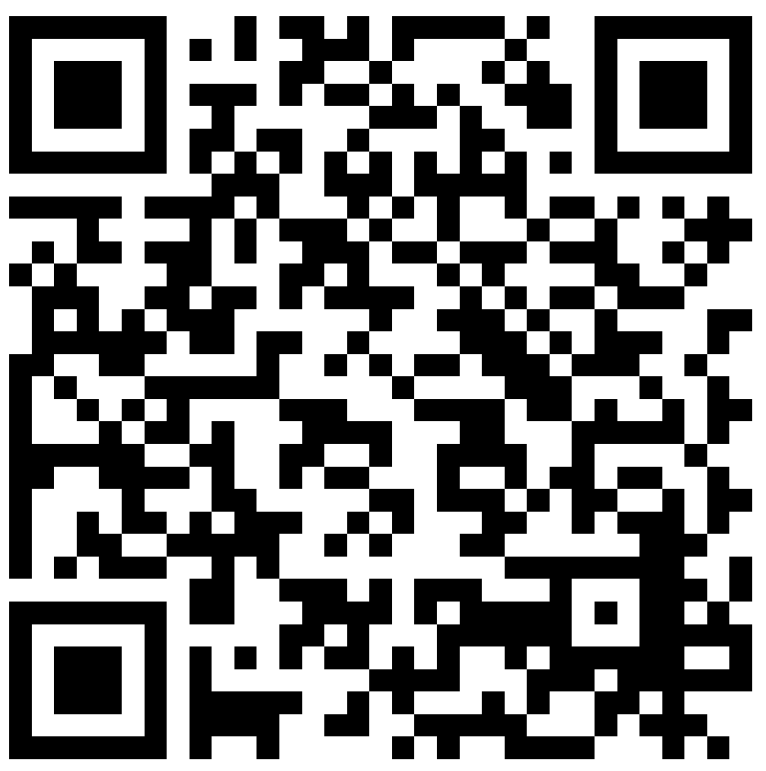

